DISSERTATION

\title{
Transfer of Nutrient and Harmful Elements from Soil to Rice and Health Risk Assessments for the Vietnamese Population
}

\author{
Dissertation \\ zur Erlangung des mathematisch-naturwissenschaftlichen Doktorgrades \\ "Doctor rerum naturalium" \\ der Georg-August Universität Göttingen \\ im Promotionsprogramm Geowissenschaften / Geographie \\ der Georg-August University School of Science (GAUSS)
}

vorgelegt von

\section{Thuy Phuong Nguyen}

aus Hue, Vietnam

Göttingen, 2019 
Betreuungsausschuss:

\section{Prof. Dr. Hans Ruppert}

Dept. Sedimentology/Environmental Geology, Geoscience Center, Georg-August-University Göttingen

\section{Dr. Benedikt Sauer}

Dept. Sedimentology/Environmental Geology, Geoscience Center, Georg-AugustUniversity Göttingen

Mitglieder der Prüfungskommission:

Referent: Prof. Dr. Hans Ruppert

Dept. Sedimentology/Environmental Geology, Geoscience Center, Georg-August-University Göttingen

Korreferent: Prof. Dr. Klaus Dittert

Dept. Plant Nutrition and Yield Physiology, Faculty of Crop Sciences, Georg-AugustUniversity Göttingen

Weitere Mitglieder der Prüfungskommission:

1. Prof. Dr. Daniela Sauer

2. Prof. Dr. Matthias Willbold

3. Dr. Benedikt Sauer

4. Dr. Jens Walter

Tag der mündlichen Prüfung: 16.09.2019 


\section{Dedication}

To my dearest parents,

who have given me the best things and sacrificed all their lives for my progress in study. 


\section{$\underline{\text { Abstract }}$}

\section{Thuy Phuong Nguyen}

"Transfer of nutrient and harmful elements from soil into rice and health risk assessments for Vietnamese population"

Main and trace element concentrations in paddy soils and corresponding rice plants collected along some transnational-river systems in Vietnam including Red River in the north and Mekong River in the south, and Huong River in the center were investigated to provide an insight into paddy soil characteristics and the element transfers into rice plant, and to assess chronic health risks by potentially harmful elements through rice consumption. The studied paddy soils have similar parent materials consisting of alluvial sediments deposited by inundation and irrigation. Most of the soils are not or only slightly affected by heavy metal(loid)s contamination from anthropogenic activities, except for $\mathrm{Cd}$ enrichment by the use of phosphate fertilizer. Elevated arsenic concentrations exceeding the allowable limit of agricultural soil $\left(15 \mathrm{mg} \mathrm{kg}^{-1}\right)$, are found mostly in the northern and the central paddy soils $(80 \%)$, but at fewer soils in the south $(11 \%)$. These high concentrations are the result of natural processes related to redox reactions of As-rich sulfide and Fe-oxides/hydroxide phases. Some

specific sites close to the river bank and near a fertilizer and chemical factory show a strong enrichment of heavy metals, resulting from industrial wastewater application.

Due to similar concentrations of elements in the parent material not polluted by human activities, many trace elements show extremely sharp correlations with each other, which can be arranged into groups. The correlations are mainly caused by variable concentrations of dilution by quartz, bio-opal and organic matter in the soil. These correlations can be used to assess if a soil sample is polluted by a certain element.

Soil parameters play an important role in the transferability of elements from soil to rice plant causing a large spread of transfer factors. Although the background concentrations of elements in areas are hardly distinguishable, differences in soil $\mathrm{pH}$-value, the content of organic matter, Fe- and Mn-oxides/hydroxides and clay minerals as well as the fertilizer input are the main reasons for contrasting element concentrations in the rice grains of the three research areas. Particularly, the translocation of the potentially harmful elements As, Cd, and Mn shows intermediate to high transfer factors. In general, concentrations of most elements in the plant parts decrease in the order: shoot >> husk > grain. Exceptions are $\mathrm{Ni}, \mathrm{Mg}, \mathrm{Zn}, \mathrm{S}, \mathrm{Cu}$, 
Mo, and $\mathrm{P}$, which are more easily transported to the grains due to their electrostatic repulsion at the negative cell wall charges or to their formation of soluble organic complexes.

Health risks of harmful elements intake from rice consumption are estimated by applying four approaches: (1) Tolerable Upper Intake Level (UL) of total daily consumption data available for $\mathrm{As}, \mathrm{Cd}, \mathrm{Co}, \mathrm{Mn}, \mathrm{Mo}, \mathrm{Ni}, \mathrm{Pb}, \mathrm{Sb}$, and $\mathrm{U}$; (2) allowable Maximum Concentration (MC) of rice - data for $\mathrm{As}, \mathrm{Cd}$, and $\mathrm{Pb}$; (3) non-cancer risks (HI) - data for $\mathrm{As}$, $\mathrm{Cd}, \mathrm{Co}, \mathrm{Cu}, \mathrm{Mn}, \mathrm{Mo}, \mathrm{Ni}$, and $\mathrm{Pb}$; and (4) cancer risk ( $\left.\sum \mathrm{ILCR}\right)$ - data for As and $\mathrm{Pb}$. The mentioned elements are the riskiest pollutants in rice for the Vietnamese population. For the UL-guidelines, $14 \%$ of the total studied samples cause health risks of exposure to As, $32 \%$ to $\mathrm{Cd}$, and $21 \%$ to $\mathrm{Pb}$. In comparison with the MC-values, $4 \%, 3 \%$, and $19 \%$ of the rice samples exceed these levels of $\mathrm{As}, \mathrm{Cd}$, and $\mathrm{Pb}$ respectively. Results of non-cancer risks and cancer risks exhibit that all rice grains have the HI-values and $\sum$ ILCR-values surpassing their safe and acceptable thresholds. Manganese occupies the highest portion of HI-index and As is the most potential oral carcinogenic factor. People in the three studied areas are facing the different levels of intoxication risk by these elements. People living in the Red River and Huong River area suffer from higher hazard of $\mathrm{As}$ and $\mathrm{Cd}$, but not of $\mathrm{Pb}$. People in the Mekong area are additionally exposed to $\mathrm{Pb}$ in rice, 10-times more than in the other areas. To mitigate these health risks, controlling the soil $\mathrm{pH}$-value is a simple way that needs to be considered first. 


\section{Acknowledgements}

To come to the completion of my doctoral journey, in this precious moment I would like to express heartfelt thanks to wonderful people who have helped and supported me during the great years of my life in Germany.

This whole research would not have been executed if there had not been the financial support from the Vietnamese Overseas Scholarship Program Project No. 911, Vietnamese Ministry of Education and Training, grants from Geo-Gender-Chancenfonds of Faculty of Geoscience and Geography, and from University Federation (Unibund) of Georg-AugustUniversity Göttingen. I would like to acknowledge these organizations for their support.

My research at Department of Sedimentology/Environmental Geology, Faculty of Geoscience and Geography, Georg-August-University was under the supervision of Prof. Dr. Hans Ruppert. From the bottom of my heart, I would like to express my sincere gratitude to my professor, who thoroughly helped, guided, and supported me from day one. He is really an embodiment of kindness. More importantly, he is always extremely patient, encourages, and motivates me to get through the hard times of my research. He gave me a new approach to knowledge. There are so many lessons that I have learnt from my mentor. Also, I would like to thank his wife Ms. Susanne for her contribution to improving English of my papers, as well as her kind heart. To say I am deeply touched by them will be an understatement.

I express my deep gratitude to my second supervisor, Dr. Benedikt Sauer, who provided and put forward sensible ideas in the research process. Many thanks go to my colleagues, Tino Pasold and Wiebke Fahlbusch, for enthusiastic helps during lab-analysis processes and programming with $\mathrm{R}$, and for constructive discussion.

In my doctoral research, I am greatly indebted to Department of Sedimentology \& Environmental Geology for providing all instruments and chemicals for my analytical work. I was lucky to receive many warm assistances of colleagues in the Department. Let me send my most honest thanks to all of them. I am also grateful to Cuu Long Delta Rice Research Institute, especially those provided favorable conditions for me in the course of collecting and treating samples in Mekong River delta. Also thanks go to many Vietnamese friends in Göttingen.

The last and most important, I would like to express my gratefulness to my beloved parents and family, who always encourage and lift me up whenever I was at a standstill and feel down. Their sacrifice gave me all the motivations to stay on track all the way and accomplish my work.

Thank you all!

Thuy Phuong Nguyen 


\section{Contents}

1 General introduction ................................................................................................................1

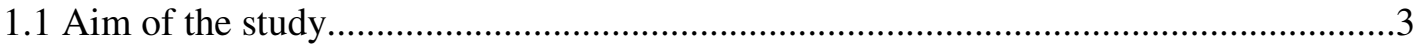

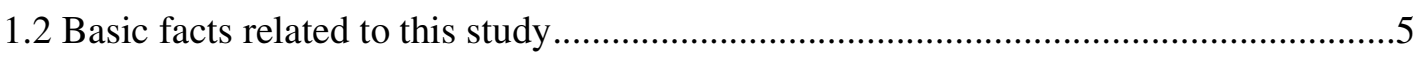

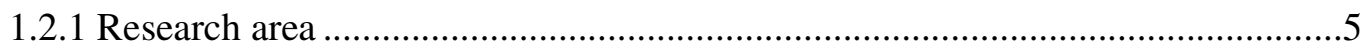

1.2.2 Previous research on harmful element concentration

in Vietnamese soils and groundwater .........................................................

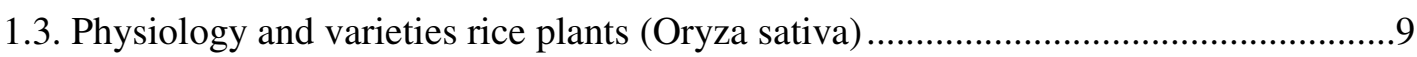

1.4 Nutrient and harmful elements concentrations in rice ............................................10

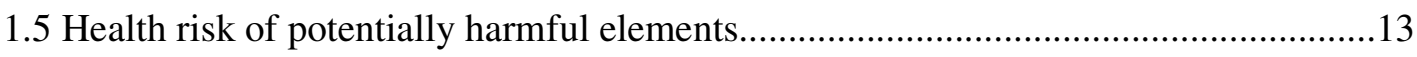

1.6 Measures to lower the uptake of toxic element by rice .........................................15

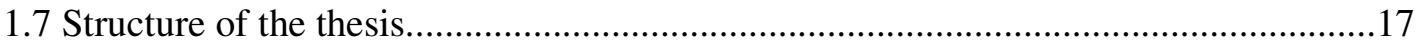

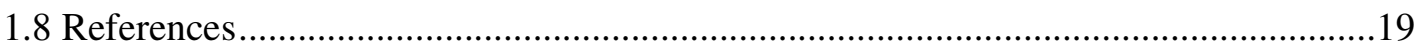

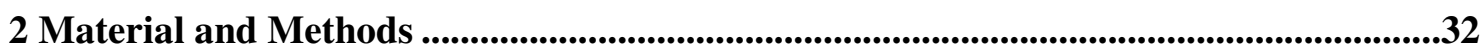

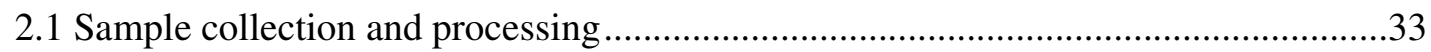

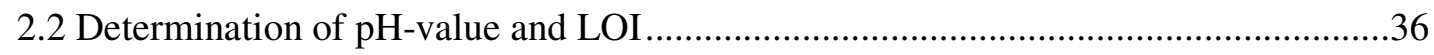

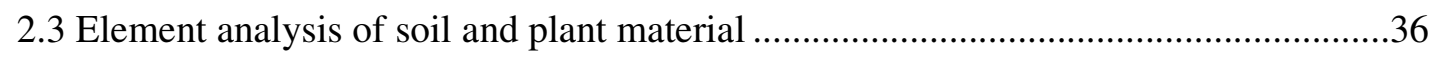

2.4 Calculation of physiological concentration and transfer factors of elements ...............37

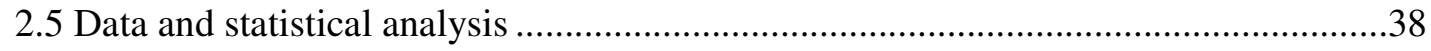

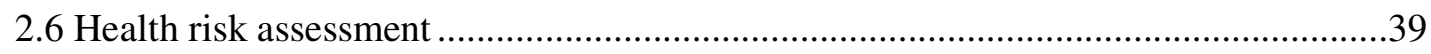

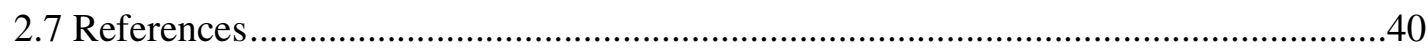

3 Harmful and nutrient elements in paddy soils and their transfer into rice grains (Oryza sativa) along two river systems in northern and central Vietnam ......................42

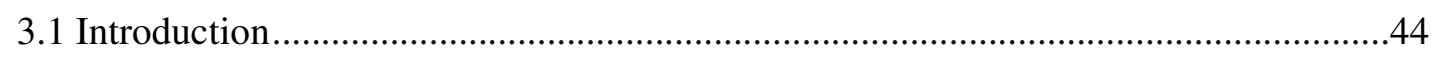

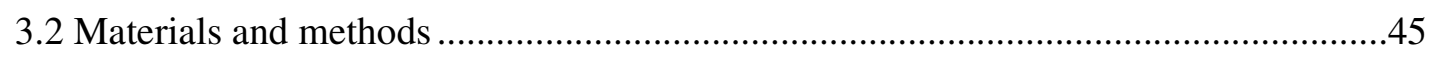

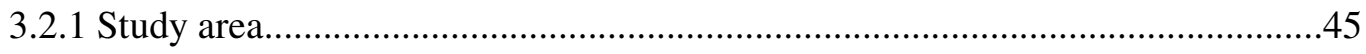

3.2.2 Sampling, preparation, analysis and calculation ...........................................46

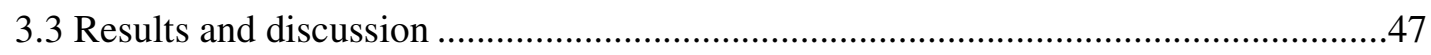

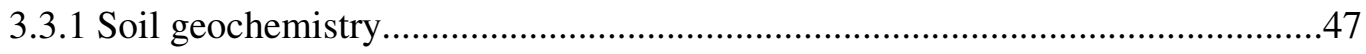

3.3.2 Transfer of elements from soil into unpolished rice .........................................54

3.3.3 Intake of nutrient and harmful elements by eating rice ..................................58

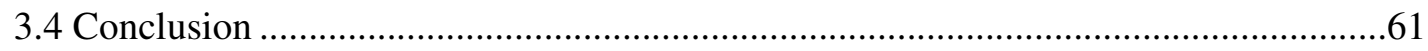

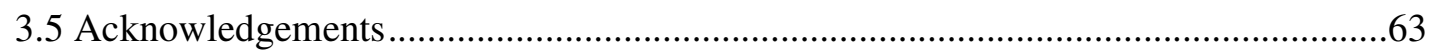

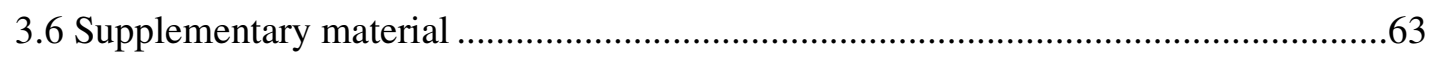

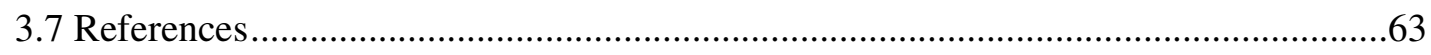

4 Paddy soil geochemistry, uptake of trace elements by rice grains

(Oryza sativa) and resulting health risks in the Mekong River Delta, Vietnam............68

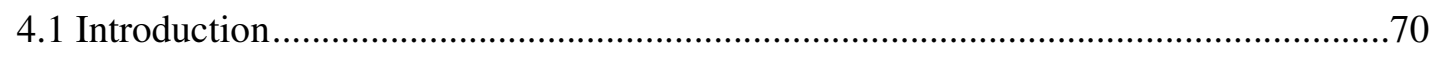




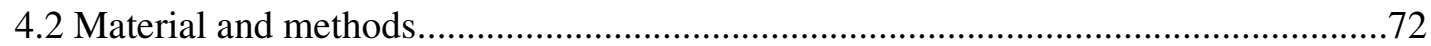

4.2.1 Sampling, sample preparation, analysis, and quality control............................72

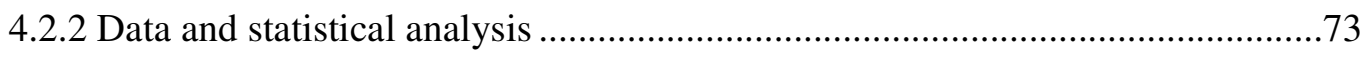

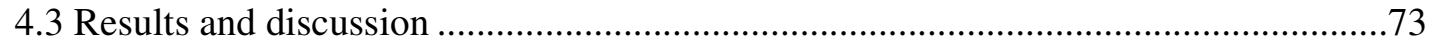

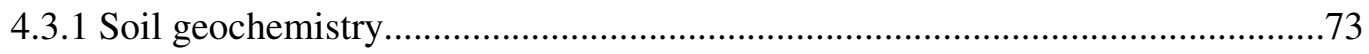

4.3.2 Transfer of nutrient and trace elements into rice grains ....................................8 80

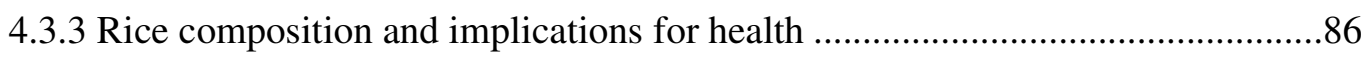

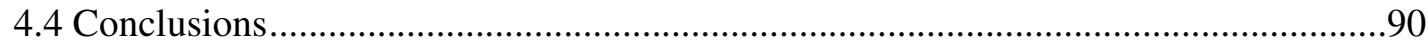

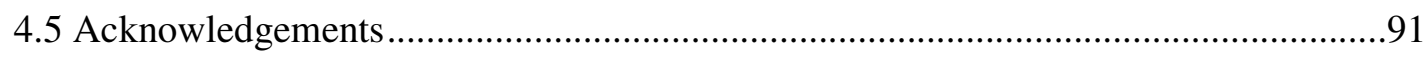

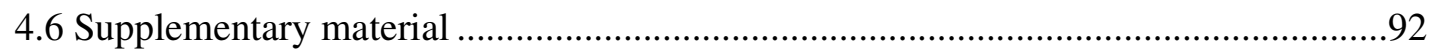

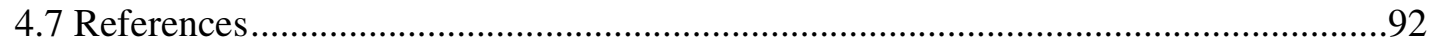

\section{Transfer of nutrient and toxic elements from paddy soils into different parts of rice} plants (Oryza Sativa) in Vietnam and resulting in health risks for the population .....99

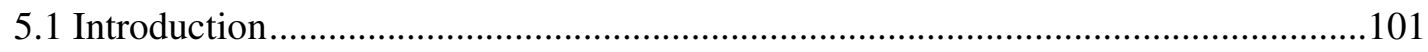

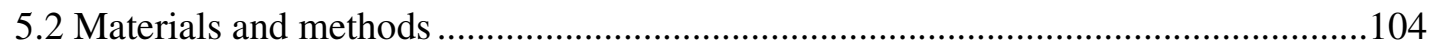

5.2.1 Sampling, digestion, analysis and quality control .........................................104

5.2.2 Correction for adhering particles, calculation of transfer factors .....................105

5.2.3 Exposure and health risk calculations ...........................................................106

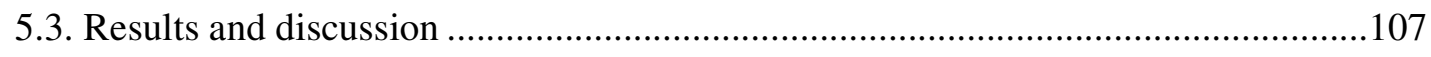

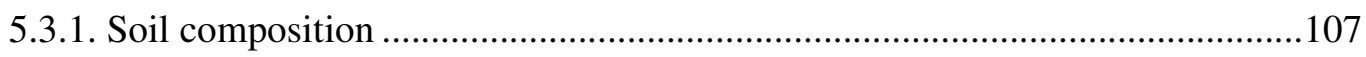

5.3.2. Element distribution in parts of rice plants ....................................................111

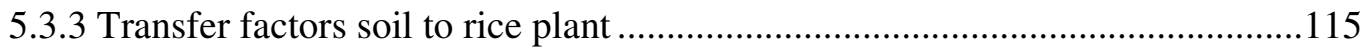

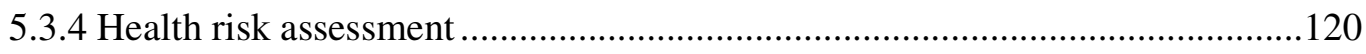

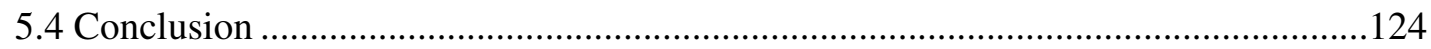

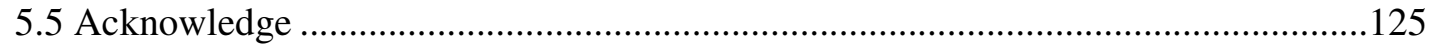

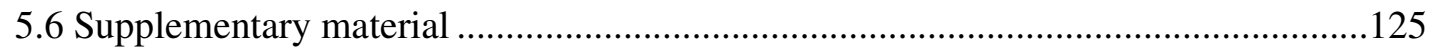

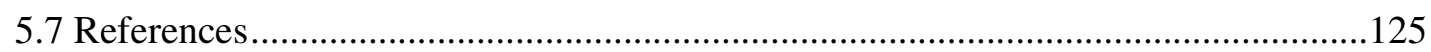

6 General conclusions and perspectives.......................................................................................133

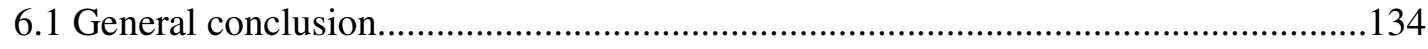

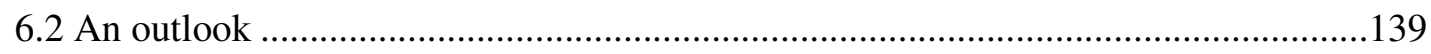

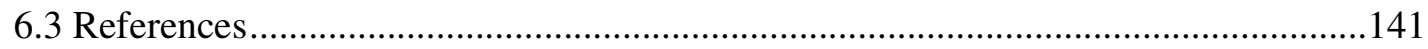

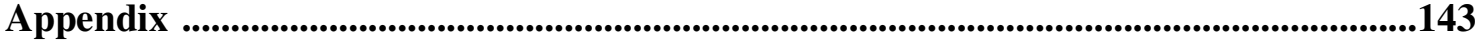

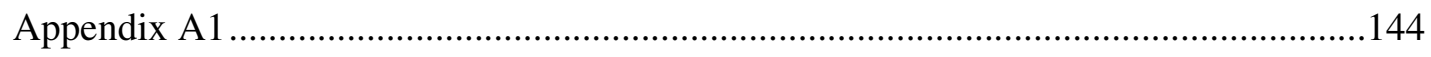

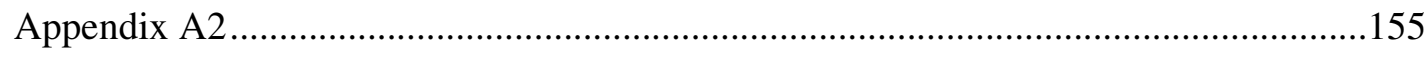

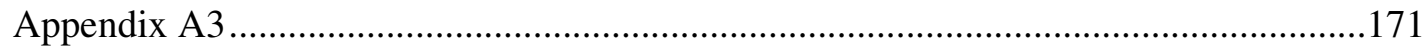

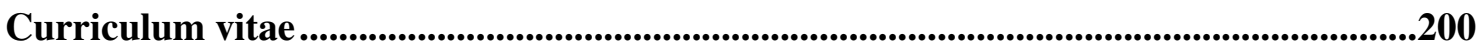




\section{$\underline{\text { List of Figures }}$}

\section{Figures in Text}

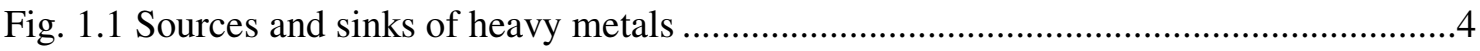

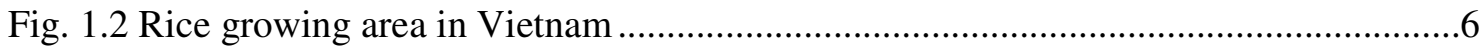

Fig. 1.3 Arsenic concentration in groundwater in Red River delta, Vietnam..........................8

Fig. 1.4 Arsenic concentration in groundwater in Mekong River delta, Vietnam....................8

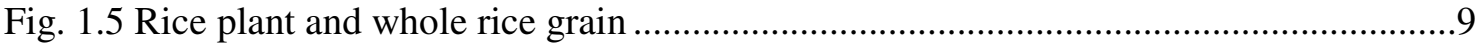

Fig. 2.1 Sample locations in the three investigated river areas in Vietnam...........................34

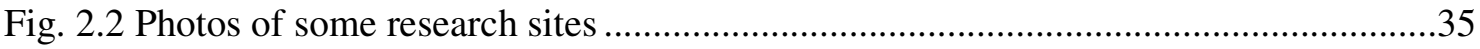

Fig. 2.3 Acid Sample Digestion System DAS 30 and dilution process ..................................37

Fig. 3.1 Map of sample locations in central and northern Vietnam......................................46

Fig. 3.2 Correlation matrix of soil element concentrations with no

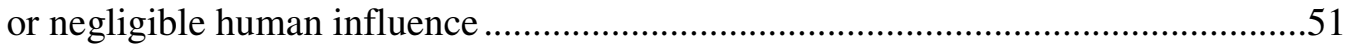

Fig. 3.3 Correlation plots of trace element concentrations in soils .....................................52

Fig. 3.4 Transfer factors of some elements from soil into rice grain....................................56

Fig. 3.5 Correlation plots of the soil parameters $\mathrm{pH}, \mathrm{LOI}, \mathrm{Al}, \mathrm{Fe}$, and $\mathrm{Mn}$ with transfer factors of potentially toxic elements ...............................................57

Fig. 4.1 Map of sample locations in the Mekong River Delta area, Vietnam ........................72

Fig. 4.4 Transfer factors of selected elements from soil to rice grain

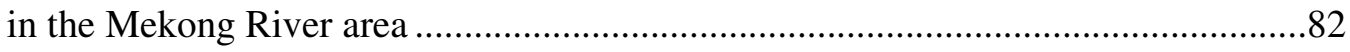

Fig. 4.5 Scattergram and correlation matrix for TFs of trace elements in the Mekong River area

Fig. 4.6 Map of As, $\mathrm{Cd}$, and $\mathrm{Pb}$ concentrations in rice grain in the Mekong River Delta and their allowable maximum levels

Fig. 5.1 Element concentrations in shoot, husk, grain, and whole aboveground rice plant...112 Fig. 5.2 Mass portions of elements in plant parts in relation to the aboveground rice plant.114 Fig. 5.3 Transfer factors from soil to plant for the Red River and Huong River areas..........118

Fig. 5.4 Target hazard index for non-cancer risk and cumulative carcinogenic risk .............123

\section{Figures in Appendix}

Fig. A1.1 Correlation matrix of $\mathrm{K}, \mathrm{Mg}$, and $\mathrm{P}$ concentrations in unpolished rice grains .......154

Fig. A2.1 Scattergram of measured contents versus modeled contents of selected trace elements in soils in the Mekong River

Fig. A2.2 Scattergram and correlation matrix for nutrient concentrations in rice grains in the Mekong River delta area 168

Fig. A2.3 Scattergram and correlation matrix of trace element concentrations in rice grains of the Mekong River Delta area........................................................................169 
Fig. A2.4 Scattergrams of element concentrations in soils versus concentrations in corresponding grains in the Mekong River Delta area

Fig. A3.1 Correlation matrix of the soil parameters pH, LOI, Al, Fe, and Mn in the different

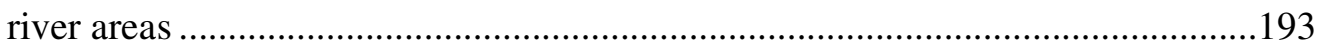

Fig. A3.2 Correlation plots of plant element concentrations $\left(\mathrm{mg} \mathrm{kg}^{-1}\right)$ and plant transfer factors versus their soil concentrations 194

Fig. A3.3 Correlation plots between element concentrations in grain, husk and shoot.........196

Fig. A3.4 Correlation plot matrix between plant element concentrations .............................198

Fig. A3.5 Correlation plot matrix between plant transfer factors and soil parameters ..........199 


\section{$\underline{\text { List of Tables }}$}

\section{Tables in Text}

Table 3.1 Statistics on selected element concentrations in the studied soils in comparison with average shale, Earth crust, and maximum allowable limit in agricultural soil

Table 3.2 Concentrations and transfer factors of selected elements in unpolished rice

Table 3.3 Daily element intake for a Vietnamese adult by eating rice

Table 4.1 Statistics of main and trace element concentrations in soils in Mekong River area....

Table 4.2 Regression models to estimate some trace element concentrations in soils in the Mekong River Delta based on soil parameters and $\mathrm{pH}$.

Table 4.3 Element concentrations in rice grains and transfer factors of the Mekong River area

Table 4.4 Ratios of maximum to minimum element concentrations in unpolished rice grains and soils as well as ratios of TF in Mekong River area....

Table 4.5 Daily element uptake by eating rice for a Vietnamese adult in Mekong River area

Table 5.1 Average element concentrations in soils and rice plant parts

Table 5.2 Average ratios of element concentrations in rice plant parts for the different areas

Table 5.3 Mean concentrations of selected elements in soils and rice plant parts in Vietnam compared to other Asian countries

Table 5.4 Average transfer factors for elements in shoot, husk, grain, and in the whole aboveground rice plant in the three different river areas

Table 5.5 Influences of soil parameters and soil element concentrations and $\mathrm{pH}$-value on transfer factors for aboveground rice plants from the Red River and Huong River areas

Table 5.6 Indexes for health risk assessment for potentially harmful elements including non-cancer risk and cancer risk

\section{Tables in Appendix}

Table A1.1 Compilation of wavelengths used by ICP-OES and masses by ICP-MS

Table A1.2 Concentrations of elements in studied soils along Red River and Huong River

Table A1.3 Concentrations of elements in unpolished rice 148 
Table A1.4 Transfer factors of selected elements from soil to unpolished rice

Table A2.1 Coordinates of sampling locations in the Mekong River Delta area, $\mathrm{pH}$-values and concentrations of main elements and LOI in paddy soils

Table A2.2 Concentrations of trace elements in paddy soils

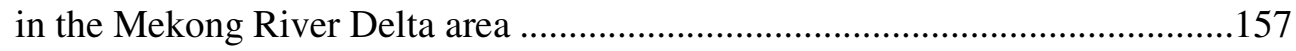

Table A2.3 Concentrations of elements in rice grains in the Mekong River Delta area .......159

Table A2.4 Transfer factors of elements from soils into rice grains in the Mekong River Delta area 163

Table A3.1 Coordinates of sample positions and mass ratios of plant parts to the plant ......171

Table A3.2 Measured element concentrations in husk and shoot......................................172

Table A3.3 Physiological element concentrations in shoot and their transfer factors...........175

Table A3.4 Physiological element concentrations in husk and their transfer factors ............178

Table A3.5 Physiological element concentrations in whole aboveground plants and their transfer factors.

Table A3.6 Indexes of non-cancer risk (HI) and cancer risk ( $\left.\sum \mathrm{ILCR}\right)$ assessment in the river areas 


\section{$\underline{\text { List of Abbreviation }}$}

$\begin{array}{ll}\text { AWD } & \text { : Alternate wetting and drying } \\ \text { DMA } & \text { : Dimethylarsinic acid } \\ \text { EFSA } & \text { : European Food Safety Authority } \\ \text { FAO } & \text { : Food and Agriculture Organization } \\ \text { ha } & : \text { hectares } \\ \text { HI } & : \text { chronic Hazard Index } \\ \text { IARC } & : \text { International Agency for Research on Cancer } \\ \text { ICP-MS } & : \text { Inductively Coupled Plasma - Mass Spectrometry } \\ \text { ICP-OES } & : \text { Inductively Coupled Plasma - Optical Emission Spectrometry } \\ \text { ILCR } & : \text { Incremental Lifetime Cancer Risk } \\ \sum \text { ILCR } & : \text { Cumulative Cancer Risk } \\ \text { LOI } & : \text { Loss on Ignition } \\ \text { MC } & : \text { Maximum Concentration } \\ \text { MMA } & : \text { Monomethylarsonic acid } \\ \text { OM } & : \text { Organic matter } \\ \text { RDA } & : \text { Daily Recommended Dietary Allowances } \\ \text { ROL } & : \text { Radical Oxygen Loss } \\ \text { TF } & : \text { Transfer factor } \\ \text { THQ } & : \text { Target Hazard Quotient } \\ \text { UL } & : \text { Tolerable Upper Intake Level } \\ \text { USEPA } & : \text { United States Environmental Protection Agency } \\ \text { WHO } & : \text { World Health Organization } \\ \text { b.w. } & : \text { body weight } \\ \text { iAs } & : \text { inorganic arsenic } \\ \text { tAs } & : \text { total arsenic } \\ \end{array}$


Chapter 1

\section{General introduction}




\section{General Introduction}

Rice is the primary staple food for more than half the world's population, with Asia representing the largest rice producing and consuming region (FAO 2018, 2019). Since some years, it is known that rice may contain health relevant concentrations of As and Cd. To put this information into a scientific context, a systematic environmental geochemistry study has been performed for Vietnam. The purposes are to get the information about the concentrations of numerous elements in paddy soils and corresponding rice plants as well as to get an estimate of the intake of potentially harmful elements and their health relevance from rice consumption. Soil and corresponding rice samples were collected in the two largest rice-growing areas in Vietnam including Red River delta in the north and Mekong River delta in the south, in addition to a few samples at Huong River in the central area. Abundant water for irrigation and fertile alluvial sediments deposited in the large transboundary river systems of the Red River and Mekong River deliver nutrients for rice agriculture, but the irrigation water and annual inundations may also bring some harmful elements like $\mathrm{As}, \mathrm{Cd}, \mathrm{Pb}$, and $\mathrm{Mn}$ into the rice fields. The Red River flows from Yunnan in Southwest China through northern Vietnam into the Gulf of Tonkin (South China Sea). Parent materials of paddy soils in this delta are mainly alluvial sediments of the Yunnan Plateau and the surrounding hills. The Mekong River originates in the Tibetan plateau, and flows through Myanmar, Laos, Thailand, Cambodia, and finally Vietnam before it disembogues into the South China Sea. Paddy soil materials in Mekong River area are composed of alluvial delta sediments delivered from the Tibetan Plateau and lower mountains along the river course. The parent material of the few investigated samples from the Huong River derives from Annamite Range of eastern Indochina or called Truong Son mountain chain, Vietnam. The river flows through Hue City before it discharges into the South China Sea.

Sources of contaminants in paddy fields can be anthropogenic inputs from mining and industrial activities in upstream areas, but also the local application of fertilizers (especially phosphates), agrochemicals (pesticides and herbicides), compost, sewage sludge, and manure leading to increasing levels of toxic elements in soils and plants. To determine the accumulation of contaminants through these sources, paddy soil and corresponding rice plant samples were collected in the three river areas. In addition, to assess the spatial and temporal effects of industrial activities, samples close to a brick factory, a fertilizer and chemical factory, and adjacent to the river outside dykes in the Red River area were analyzed. 
Three publications of the most important results were planned: one paper is already published, two of them are under review:

- Paper 1: Nguyen T. P., Ruppert H., Pasold T., Sauer B. (2019). Harmful and nutrient elements in paddy soils and their transfer into rice grains (Oryza sativa) along two river systems in northern and central Vietnam. Environ Geochem Health, https://doi.org/10.1007/s10653019-00333-3

- Paper 2: Nguyen T. P., Ruppert H., Pasold T., Sauer B. (2019). Paddy soil geochemistry, uptake of trace elements by rice grains (Oryza sativa) and resulting health risks in the Mekong River Delta, Vietnam. Environ Geochem Health. (Submitted manuscript)

- Paper 3: Nguyen T. P., Ruppert H., Pasold T., Sauer B. (2019). Transfer of nutrient and toxic elements from paddy soils into different parts of rice plants (Oryza Sativa) in Vietnam and resulting health risks for the population. Environ Sci Pollut Res. (Submitted manuscript)

\subsection{Aim of the study}

Some previous studies just evaluated local contamination of paddy soils and rice caused by mining, industrial and domestic activities in Vietnam (Huong et al. 2008; Phuong et al. 2010; Chu 2011; Vinh et al. 2012). There has not been a systematic research on paddy soil geochemistry for the main rice-producing areas in Vietnam and the element concentrations in corresponding rice plants. In addition, health risk assessment from rice consumption is very important for the population of Vietnam. Such studies are very relevant, because Vietnam is the world's fifth largest rice producer (after China, India, Indonesia, and Bangladesh) and the third largest rice exporter (after India and Thailand) (FAO 2018, 2019).

The rice quality can be especially affected by potentially harmful elements, which are in dissolved and solid forms contained in irrigation water (Li et al. 2010; Perera et al. 2016; Nogawa et al. 2017). In addition, redox mechanisms in the soil pore water of paddy soils may lead to the release As and other critical elements into soil solution, facilitating their uptake into rice plant. Paddy soils using water sources from corresponding transboundary river systems for irrigation demand have the potential to be enriched by many various outputs. All headwater activities may become a toxic element contamination/enrichment source for downstream soils, plants, and animals through river-transported materials that this was reported around the world (Garbarino et al 1995; Li et al. 2010; Perera et al. 2016; Nogawa et al. 2017; Singh et al. 2017, Bonotto et al. 2018). In addition, exhaust gases and wastewater from industrial actions, agrochemicals from agricultural practices can be disseminated and accumulated in paddy soils. 


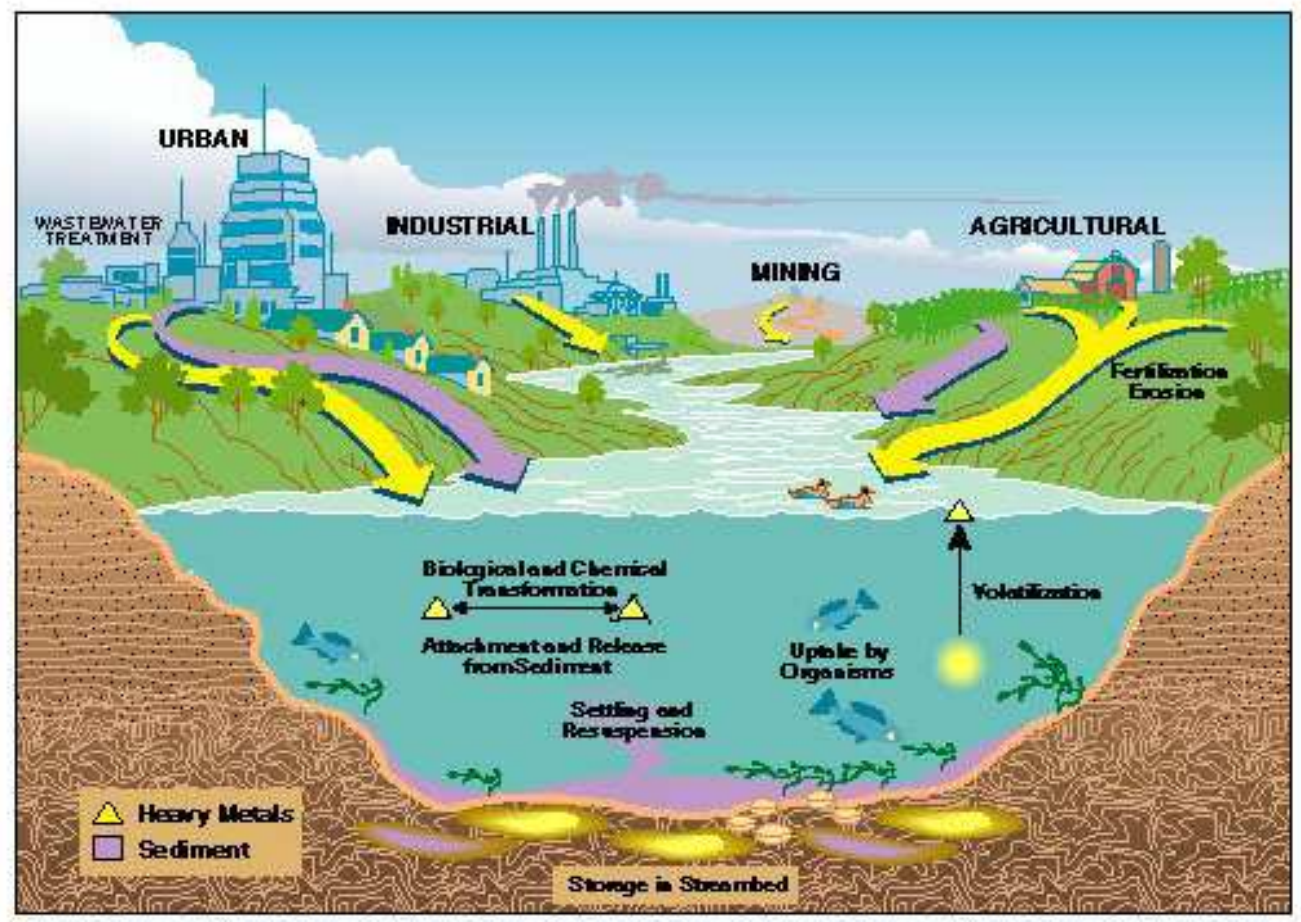

Fig. 1.1 Sources and sinks of heavy metals (Garbarino et al. 1995)

Allowable threshold values for the intake of some harmful elements are proposed by the World Health Organization and the Food and Agriculture Organization (WHO/FAO) and European Food Safety Authority (EFSA) organization. The intake of these elements by eating rice is calculated and compared with threshold values to estimate latent health risks posed to society. The daily intake of harmful element only by rice consumption may surpass the tolerable upper intake level of harmful element regulated for all sources (food and drinking water). However, the various approaches to Vietnamese health risk estimations lead to some discrepancies which are discussed in the three papers of this study. They accentuate the need for coherent and consistent guidelines on rice consumption relating to the community health risks.

To summarize, the main aims of this study are:

- to quantify paddy soil geochemistry for large rice-growing deltas in Vietnam,

- to estimate the enrichment of harmful elements in paddy fields by rivertransported pollutants and local inputs, 
- to calculate the physiological element concentrations which are corrected for adhering particles, and their transfer factors to rice grains and other plant parts like shoot, husk, and the total above-ground rice plant,

- to get information on the influence of main soil factors like $\mathrm{pH}$, organic matter, clay minerals, Fe- and Mn-oxides/hydroxides on the element concentration and transferability from soil into rice plant,

- to assess the daily and chronic health risks of the local population by potentially harmful elements from rice consumption.

\subsection{Basic facts related to this study}

\subsubsection{Research area}

Located on the Indochina peninsula in Southeast Asia, Vietnam is an agricultural country with 94.6 million people in 2018 , sharing $1.26 \%$ of the world population (Vietnam Government 2018). About $34.9 \%$ of the population live in urban areas and $65.1 \%$ in rural areas where many people depend on agricultural production.

Vietnam spans over nearly $15^{\circ}$ of latitude. It is located in the center of two main tropical monsoon areas (South-West Asian and East Asian monsoons) with seasonal reversals in atmospheric circulation and precipitation associated with the thermal contrast of land-sea heating (Nguyen et al. 2014). Vietnam's climate varies significantly between the regions and seasons. In summer (April/May to October/November), the climate is dominated by the SouthWest monsoon, which is hot and wet especially in the southern part of Vietnam. In winter (November to March), the climate is affected by the East Asian monsoon which is cold and dry especially in the northern and the central areas. The average yearly precipitation is $1820 \mathrm{~mm}$, varying from average an average 1600 to 2200 in the midlands and plains and 2000 to 2500 in the mountainous areas with an all over spread between 650 and $4760 \mathrm{~mm}$ (FAO 2012). The rainy season contributes to more than $80 \%$ of yearly rainfall (Nguyen et al. 2014). In Ho Chi Minh City in southern Vietnam, the temperature is nearly stable at a yearly average of around $27^{\circ} \mathrm{C}$, with average maximum temperature of $35^{\circ} \mathrm{C}$ in April (Climate-Data.org 2019). In the city of Hue in central Vietnam, the average winter temperature is $21{ }^{\circ} \mathrm{C}$ in January and the average summer temperature in June to August is $30^{\circ} \mathrm{C}$, reaching average maximum temperatures of $34^{\circ} \mathrm{C}$. In Hanoi in northern Vietnam, the lowest average temperature is $17^{\circ} \mathrm{C}$ in January and February and average temperature in June until August is $29^{\circ} \mathrm{C}$ with an average 
maximum at $33^{\circ} \mathrm{C}$ (Climate-Data.org 2019). The discrepancies in temperature, the amount of rainfall, and flooding season impact the agricultural practices in the various areas.

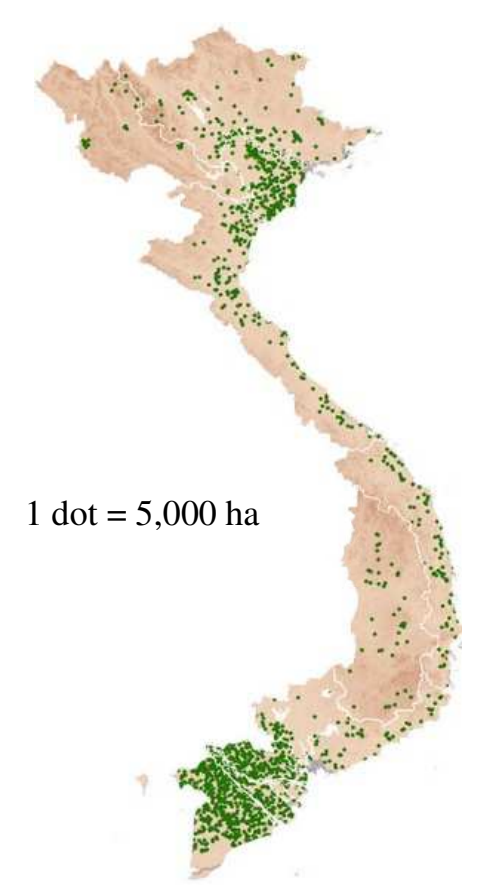

Fig. 1.2 Rice growing area in Vietnam (IRRI 2015)

Rice is the most important food crop in Vietnam. According to the report of FAO (April 2018), Vietnam produced 42.8 million tons of rice corresponding to 27.8 million tons on milled basis and exported 6.3 million tons milled rice in 2017. The main cropped area remained largely unvaried at 3.1 million hectares and the total cultivated area of three crops each year were approximately 7.7 million hectares (Ricepedia 2012). The average yearly yield per ha is 5.9 tons rough rice or 3.7 tons milled rice.

The Mekong and Red River deltas are two largest rice-granaries in Vietnam. About 18 million people lived in the Mekong Delta (Vietnam Government 2018), but 20.2 million in the Red River Delta (GSO 2012). The Mekong Delta area comprises 4050000 ha, the Red River Delta only 2100000 ha. In 2014, $52 \%$ of the Vietnamese rice was produced in the Mekong area and $18 \%$ in the Red River area (IRRI 2015). One reason is that three crops per year can be harvested in the Mekong area: WinterSpring (November -March), Summer-Autumn (May - September) and the Rainy Season (July - January) (Ricepedia 2012; Liew et al. 2014; Clauss et al. 2018; USDA Foreign Agricultural Service 2019). In 2018, winter rice was cultivated on 180000 ha, spring rice on 1595000 ha, and autumn rice on 2300000 ha. In the Red River Delta only 573900 ha are used for rice production (GSO 2012). There are only two main rice-cropping seasons in the Red River delta: a spring season and a summer season (Duy et al. 2015). Although the rice-growing area of the Mekong River delta comprises $30 \%$ of the gross national rice area, this delta contributes to $57 \%$ of the country's rice production (after data from USDA Foreign Agricultural Service 2019). More than $90 \%$ of Vietnam's rice exports come from the Mekong River Delta.

The Mekong River is a plentiful source of water for irrigation. The annual inundation also supplements large amounts of suspended sediment of about 160 million tons per year (Hung 2011). Water and sediments deliver nutrients for the paddy soils and rice plants, leading to higher rice productivity. On the other side, the Mekong delta is a low-level plain with many 
areas not more than 3 meters above sea level and criss-crossed by a complex system of channels and rivers (Ninh 2008). The delta may more and more affected by climate change related disasters such as increase of numbers and intensity of tropical storms, floods, inundation, and sea level rise that cause land loss, salt water intrusion as well as deterioration of soils and aquifers by salinization along the coast and the river channels (Ninh 2008). A similar situation exists for the low-level plain of the Red River Delta (Yen et al. 2017). Forecast models by FAO (2011) for the northern mountain regions in Vietnam indicated that rice production may drop under the influence of climate change by $12.5 \%$ in 2050 and $16.5 \%$ in 2070 due to floods, droughts, landslides, and fire.

In many zones, rice is grown in rotation with other crops especially in areas with restricted irrigation or in rain-fed areas. These cropping methods are differentially applied depending on climate (precipitation, temperature), soil parameters, season and individual and local nutrition preferences, market prices etc. In the Red River delta, maize and potato are planted alternately to rice. In the central region, a rice-subsidiary (mungbean, sesame, sweet potato, maize, groundnut, etc.) rotation system is widely practiced. In the Mekong Delta, ricevegetable rotations are popular (FAO 2002).

\subsubsection{Previous researches on harmful element concentration in Vietnamese soils and groundwater}

Chu (2011) analyzed paddy soils adjacent to mine waste dumps. The results showed that $\mathrm{Pb}$ concentrations of 1271 - $3953 \mathrm{mg} \mathrm{kg}^{-1}$ in Tan Long, Thai Nguyen Province and 250 $770 \mathrm{mg} \mathrm{kg}^{-1}$ in Chi Dao, Hung Yen Province in northern Vietnam, exceeding 3-56 times the Vietnamese allowable $\mathrm{Pb}$ level of $70 \mathrm{mg} \mathrm{kg}^{-1}$. Phuong et al. (2010) identified $\mathrm{Cu}, \mathrm{Pb}$, and $\mathrm{Zn}$ enrichments in soils close to a copper-casting handicraft village in Hung Yen Province. The results analyzed paddy soils of Lam Thao, Phu Tho Province in the north irrigated with industrial wastewater (Vinh et al. 2012) indicated high concentrations of $\mathrm{Cu}\left(204 \mathrm{mg} \mathrm{kg}^{-1}\right), \mathrm{Zn}$ (714 $\left.\mathrm{mg} \mathrm{kg}^{-1}\right)$, and $\mathrm{Pb}\left(140 \mathrm{mg} \mathrm{kg}^{-1}\right)$, surpassing the Vietnamese permissible limits of 50, 200, and $70 \mathrm{mg} \mathrm{kg}^{-1}$, respectively. Huong et al. (2008) pronounced mean concentrations of $\mathrm{Cd}$ (4 $\left.\mathrm{mg} \mathrm{kg}{ }^{-1}\right), \mathrm{Cu}\left(202 \mathrm{mg} \mathrm{kg}^{-1}\right), \mathrm{Pb}\left(159 \mathrm{mg} \mathrm{kg}^{-1}\right)$, and $\mathrm{Zn}\left(192 \mathrm{mg} \mathrm{kg}^{-1}\right)$ in waste water-irrigated paddies along To Lich and Kim Nguu Rivers close to Ha Noi, what is by far higher than their allowable soil limits.

Dissolved trace elements in water are the preferred forms for plant uptake. For example, the highly mobile As(III)-species which prevail in groundwater has a high bioavailability. 


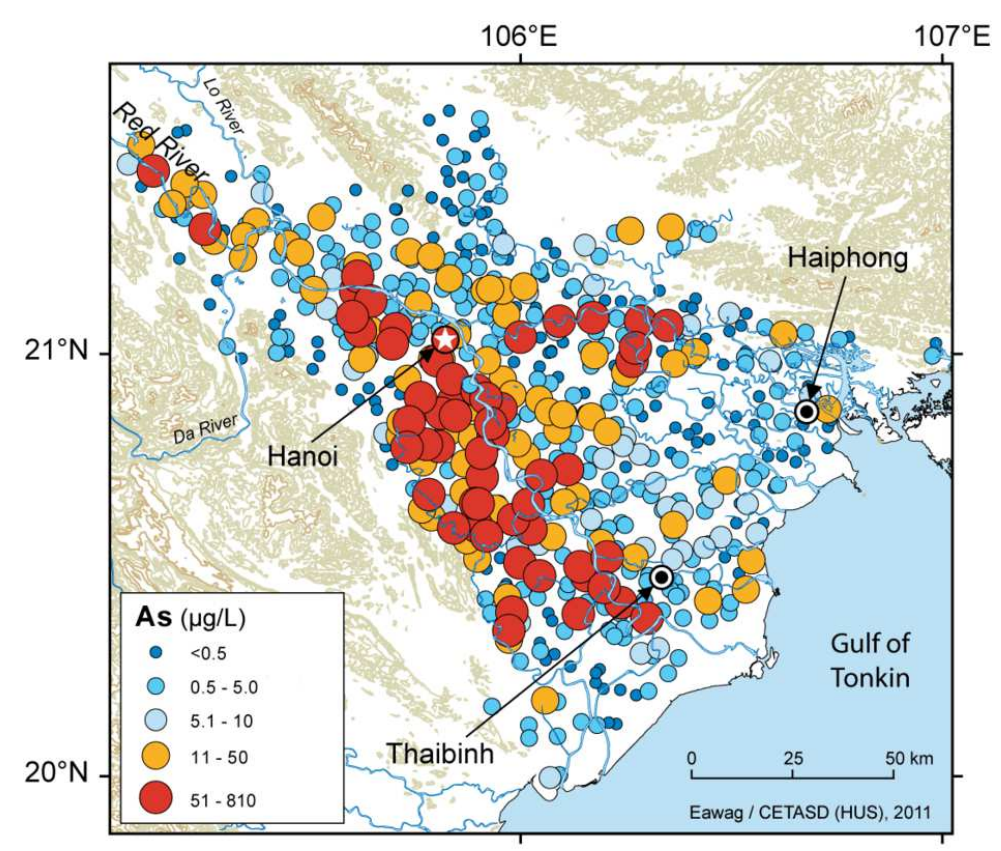

Fig. 1.3 Arsenic concentration in groundwater in Red River delta, Vietnam (Winkel et al. 2011)
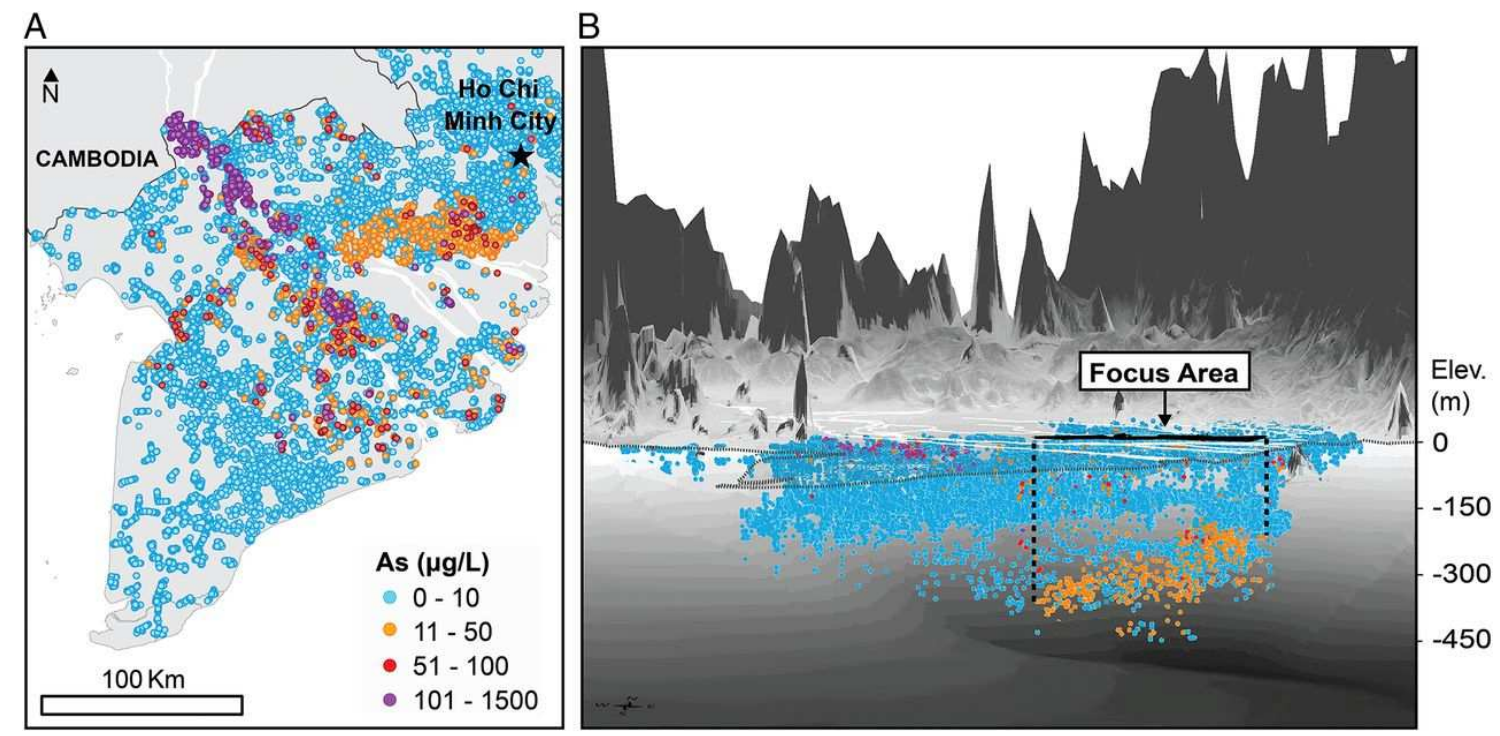

Fig. 1.4 Arsenic concentration in groundwater in Mekong River delta, Vietnam

(Erban et al. 2013)

Therefore, studies on trace elements in the water are of interest for this work. Some publications showed that the exceedance of standard guidelines for arsenic concentration in drinking water given by WHO $\left(10 \mu \mathrm{g} \mathrm{L}^{-1}\right)$ were found in $86 \%$ of the studied groundwater samples in Red River delta (Jessen 2009; Sø et al. 2018; Viet et al. 2019). In Mekong River delta, $26 \%$ of the groundwater samples contain higher As concentrations than drinking water guideline value of $10 \mu \mathrm{g} \mathrm{L}^{-1}$ ruled by USEPA, $74 \%$ have the Mn concentration higher than the guideline of 0.05 
$\mathrm{mg} \mathrm{L}^{-1}$, and $50 \%$ surpass the guideline of $0.3 \mathrm{mg} \mathrm{L}^{-1}$ for Fe (Hoang et al. 2010). Similarly, $27 \%, 91 \%$, and $27 \%$ of the shallow well-water samples in Tien Giang and Dong Thap provinces in the Mekong River delta exceed the WHO guidelines for As, Mn, and Ba respectively (Shinkai et al. 2007). High As concentration in Mekong delta groundwater are also recognized by Stanger et al. (2005), Erban et al. (2013), and Merola et al. (2015). In general, the distributions of high arsenic groundwater in two areas Red River and Mekong River deltas are not uniform and also depend on the sampling depth in the aquifer as shown in Fig. 1.3 and 1.4 respectively.

\subsection{Physiology and varieties rice plants (Oryza sativa)}

Rice (Oryza sativa) is a graminoid species of plant in the family true grasses (EOL 2004). Rice can be grown in the wide range of terrains from mountainous lands to low land delta areas under tropical, subtropical and moderate climate (Vijay and Roy 2013).
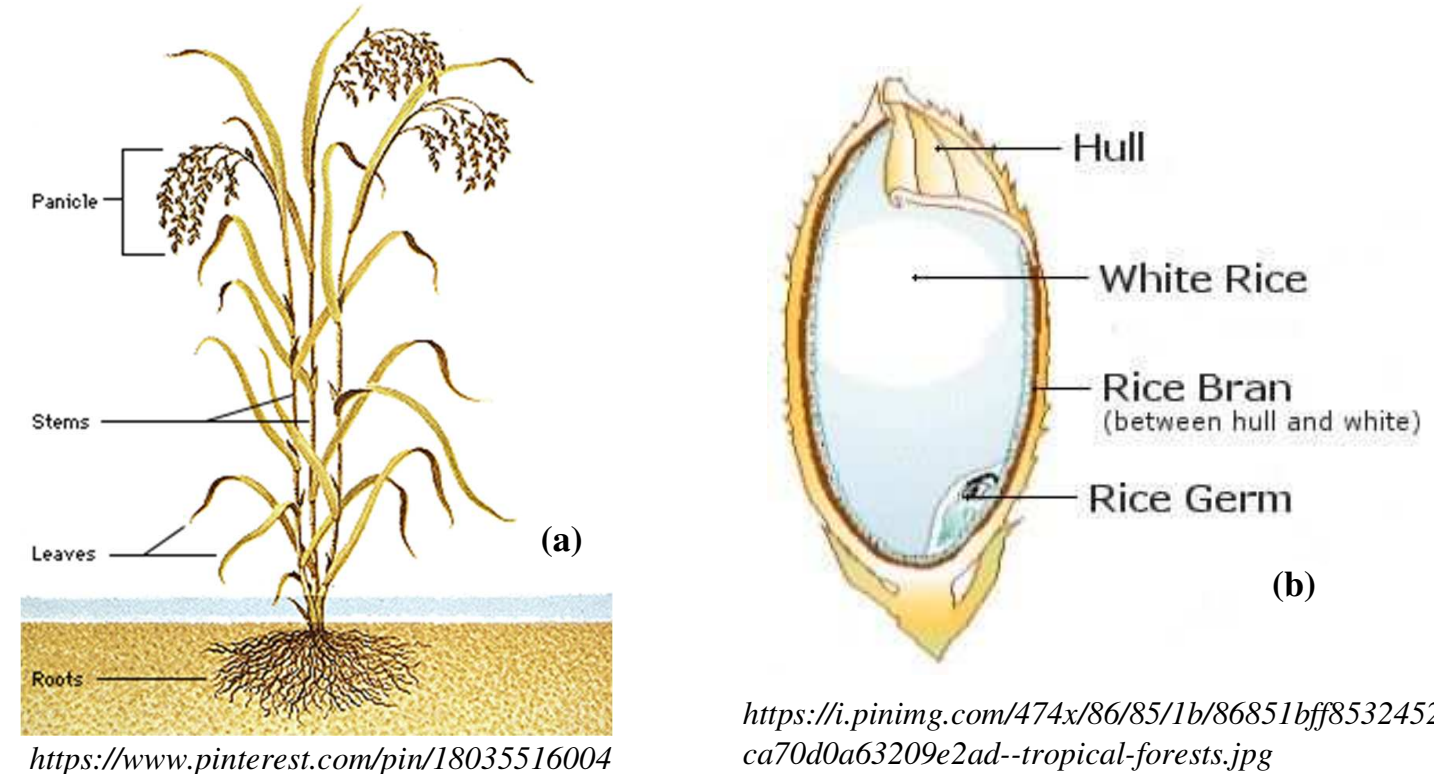

https://i.pinimg.com/474x/86/85/1b/86851bff8532452d ca70d0a63209e2ad--tropical-forests.jpg

Fig. 1.5 (a) Rice plant and (b) whole rice grain

In Vietnam, rice is harvested by cutting the whole aboveground rice plant (from 5 - 10 $\mathrm{cm}$ above the soil surface). Roots and stubbles are always left in the fields. The whole aboveground rice plant includes stems, leaves, and panicle as seen in Fig 1.5a. Whole rice grains are normally separated from the plant by using a threshing machine. After harvesting, stubbles and straw are sometimes burnt in situ, what prevents the accumulation of organic matter in the paddy fields. The whole rice grain (Fig. 1.5b) comprises the husk (or hull) and 
unpolished rice grain. These two compounds are then separated by a rice hulling machine. The structure of unpolished rice is composed of starchy endosperm, bran, and germ as illustrated in Fig 1.5b.

Shoot and husk of rice may now be applied for the various purposes. For a long time, shoot is utilized as animal bedding, cooking fuel, reclaiming soil, or organic fertilizers. In some areas, shoot is directly burnt in situ. Nowadays, husk is applied in many fields: producing heat/electric power (electricity), generating activated carbon, use as fertilizer and substrate, separating crystalline silica for brick and ceramic production (Kumar et al. 2013). Furthermore, husk ash is also exerted as an absorbent with a large surface area (Bazargan et al. 2014; Prasara and Gheewala 2017).

According to the FAO's data (FAO 2002), there are 24 rice cultivars that have been planted in the north and north central regions of Vietnam, 44 cultivars in southern and southcentral regions, 12 cultivars in irrigated and rainfed lowland regions, and 7 cultivars in upland areas. The rice cultivars are typically chosen according to the climate condition, the availability of water, and soil conditions in a certain area.

\subsection{Nutrient and harmful element concentrations in rice}

Rice is the food major staple of nearly $40 \%$ of the world population. $90 \%$ of the rice are cultivated and consumed in Asia (Vijay and Roy 2013). Rice is a main food in Vietnam as well as in southern and eastern Asia. Rice and rice-based products are present in breakfast, lunch, and dinner meals of Vietnamese adults. They cover almost all daily needs on carbohydrates providing energy. Vietnamese eating habits can be dissimilar among areas having a great natural diversity of dishes and ingredients. In 2018, the yearly amount of milled rice consumed per capita in Vietnam was average $153 \mathrm{~kg}$, only behind the residents of Bangladesh $(180 \mathrm{~kg})$, Myanmar (194 kg) and possibly Cambodia (159 kg) (FAO 2019). For comparison, European Union people consumed averagely $5.7 \mathrm{~kg}$ rice per year.

The main rice compounds are starchy carbohydrates, accounting for up to $90 \%$ of the total dry weight and $87 \%$ of the total caloric content (Arnarson 2017). Rice just supplies a very small amount of proteins $(2.4 \%)$ and virtually no fat. In addition, rice also contains other essential compounds such as thiamine, riboflavin, niacin, vitamin E, zinc, potassium, iron, and fiber (Schenker 2012).

A link between high carbohydrate intakes and a risk of chronic diseases like obesity, diabetes II, metabolic syndrome, and cardiovascular disease is assumed (Schenker 2012). 
Other hazardous health effects that Asian communities are facing are a chronic intake of toxic elements by rice consumption. Rice is considered to be a major intake sources for As and Cd (Tsukahara et al. 2003; Arunakumara et al. 2013; Chaney et al. 2016; Shraim 2017) for people consuming daily a large amount of rice. Furthermore, other potentially harmful elements like $\mathrm{Pb}, \mathrm{Cr}$, and $\mathrm{Mn}$ may also be enriched in rice grains in some areas (Norton et al. 2014; Shraim 2017).

Some authors investigated the As intake from rice consumption. Sigrist et al. (2016) analyzed high total As (tAs) concentrations in rice $\left(0.09-0.32 \mathrm{mg} \mathrm{kg}^{-1}\right)$ and rice products $(0.05$ - $0.20 \mathrm{mg} \mathrm{kg}^{-1}$ ) in Argentina. Wheat products accounted for $53 \%$ and rice products for $17 \%$ of the inorganic As (iAs) intake. The tAs concentrations in some studied rice grains in Italy fluctuated from 0.11 to $0.28 \mathrm{mg} \mathrm{kg}^{-1}$ (Sommella et al. 2013), corresponding to only $1.1 \%$ - 2.8 $\%$ of the tolerable upper intake As level $\left(2.1 \mu \mathrm{g} \mathrm{kg}^{-1} \mathrm{~b} . \mathrm{w}\right.$.) if rice consumption is $5.38 \mathrm{~kg}$ year${ }^{1}$ and average Italian body weight (b.w.) of $70 \mathrm{~kg}$ (after data from Walpole et al. 2012). Similar low risks of As intake by rice were also estimated for France where the daily tAs intake varies between 0.002 and $0.184 \mu \mathrm{g} \mathrm{kg}^{-1}$ b.w. by rice corresponding to $0.1 \%-8.8 \%$ of the permissible As level (Jitaru et al. 2016). In Pakistan, wheat and rice contributed $5 \%$ and $1 \%$ of the total daily intake of iAs perspectively while 74\% was from water (Rasheed et al. 2018). In some contaminated areas in Korea, local habitants ingested by eating rice $50 \%$ of the tAs threshold (2.1 $\mu \mathrm{g} \mathrm{kg}^{-1}$ b.w.) and and $80 \%$ of the Cd threshold (0.36 $\mu \mathrm{g} \mathrm{kg}^{-1}$ b.w.) (Kwon et al. 2017). For Hong Kong people, rice consumption leads to $10 \%$ - $18 \%$ iAs of the permissible As limit (Wong et al. 2013). Notably, Chinese people ingest $71 \%$ - 171\% of the permissible maximum As level from rice consumption (Lei et al. 2013; Liao et al. 2018). A study in the major arseniccontaminated area in Nadia district, West Bengal (India) revealed that the mean tAs concentration was the highest in rice $\left(0.451 \mathrm{mg} \mathrm{kg}^{-1}\right)$ in comparison with wheat, common vegetables, and pulses (Bhattacharya et al. 2010). It exceeds the permissible maximum

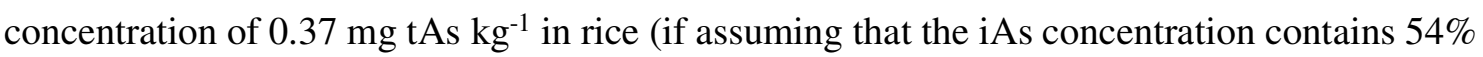
of the tAs concentration in rice according to Suriyagoda et al. 2018. Similarly, Arunakumara et al. (2013) reported the extremely high total As concentrations in rice grains collected in Nadia district, West Bengal, India (0.25 - $\left.0.72 \mathrm{mg} \mathrm{kg}^{-1}\right)$. These authors cited data from other countries, revealing also high As concentrations in rice from the Xingyi region in Southwest China and some regions in Bangladesh.

Xie et al. (2017) found that $15.5 \%$ and $4.6 \%$ of the 110 leading Chinese rice cultivars had $\mathrm{Cd}$ and $\mathrm{Pb}$ concentrations exceeding the allowable maximum concentration of $0.2 \mathrm{mg} \mathrm{kg}-$ 
${ }^{1}$ for each element in rice. An earlier study by Fang et al. (2014) also indicated that $\mathrm{Pb}$ and $\mathrm{Cd}$ concentrations in rice from the main rice growing areas in China surpassed their allowable concentrations in $4.3 \%$ and $3.3 \%$ of 92 samples respectively. In Japan, two heavily Cdcontaminated zones are the Jinzu River basin and Kakehashi River basin, where the Itai-Itai disease was detected in 1968. The Cd concentrations in rice range from $0.02-1.06 \mathrm{mg} \mathrm{kg}^{-1}$ and $0.11-0.67 \mathrm{mg} \mathrm{kg}^{-1}$ respectively (Nogawa et al. 2004). Uraguchi and Fujiwara (2012) reported that the average Cd intake of Japanese people was $0.43 \mu \mathrm{g} \mathrm{kg}^{-1} \mathrm{~b} . \mathrm{w}$. day ${ }^{-1}$, higher than the tolerable upper Cd intake level of $0.36 \mu \mathrm{g} \mathrm{kg}^{-1}$ b.w. day-1. According to Satpathy et al. (2014), rice samples from the East Coast of India contain $0.01-1 \mathrm{mg} \mathrm{kg}^{-1} \mathrm{~Pb}$ and $0.1-0.6 \mathrm{mg}$ $\mathrm{kg}^{-1} \mathrm{Cr}$ exceeding partially their permissible concentrations of $0.2 \mathrm{mg} \mathrm{kg}^{-1}$ for each element.

Despite being one of world' leading rice producing and consuming country, Vietnam shows still a strong deficiency of a systematic comprehensive research on the element uptake of rice plants from the soil and a lack of appraisals of human's health risks from rice eating. There are a few studies at some locally contaminated regions. The concentrations of As, Cd, and $\mathrm{Pb}$ in studied rice in Lam Thao, Phu Tho Province exceeded 2 - 4 times the allowable concentration of $0.2 \mathrm{mg} \mathrm{kg}^{-1}$ for each element (Vinh et al. 2012). Rice grown close to To Lich and Kim Nguu Rivers in Ha Noi Province reached $\mathrm{Pb}$ concentration of $2.1 \mathrm{mg} \mathrm{kg}^{-1}, 10$-time higher than its allowable concentration (Huong et al. 2008). The elevated $\mathrm{As}$ and $\mathrm{Pb}$ concentrations in rice are assumed to primarily caused by geogenic sources (Ma et al. 2017).

Different to the much less toxic organic As compounds such as arsenobetaine and arsenosugars which are most prevalent forms in fish and seafood, the overwhelming inorganic arsenic and single methylated arsenic species (monomethylarsonic acid - MMA and dimethylarsinic acid - DMA) in terrestrial foods can lead to serious health problems (EFSA 2015; Cubadda et al. 2017). Therefore, most of current risk assessments of daily arsenic exposure are based on the inorganic forms. In rice, the ratios of inorganic As change considerably depending on its speciation in soils and on the variety of rice. An evaluation of different species studies in different countries by Suriyagoda et al. (2018) showed that iAs concentration comprises $54 \%$ of tAs concentration in rice grain (data were compiled from different countries and market data). Alternatively, this percentage in China rice is $67 \%$ (Lei et al. 2013) while in S and SE Asian rice is 80 - 91\% (Rahman and Hasegawa 2011). Some researchers identified As ${ }^{\mathrm{III}}$-species as the dominant compound in rice (Seyfferth et al. 2011; Patel et al. 2016; Ma et al. 2017). 


\subsection{Health risk of potentially harmful elements}

\section{Arsenic}

Arsenic is a naturally occurring metalloid and ubiquitously found in the environment (groundwater, food, soil, and air) in both inorganic and organic forms (Singh et al. 2011). In the environment, its universal oxidation states are trivalent arsenite ( $\mathrm{As}^{\mathrm{III}}$ ) and pentavalent arsenate $\left(\mathrm{As}^{\mathrm{V}}\right)$ forms. Arsenic in groundwater and soil primarily exists as inorganic oxy-anions $\left(\mathrm{AsO}_{2}{ }^{-}, \mathrm{AsO}_{4}{ }^{3-}, \mathrm{HAsO}_{4}{ }^{2-}, \mathrm{H}_{2} \mathrm{AsO}_{4}{ }^{-}\right.$, etc.). Arsenic is considered as a hazardous element positioned first in the list of toxicants which elicit the seriously potential threat to human health. It is called the "king of poisons" and causes serious health threats on a worldwide scale (Hughes et al. 2011; Singh et al. 2011; Tyler and Allan 2014). According to EFSA (2014a), the International Agency for Research on Cancer (IARC) classified As and inorganic arsenic (iAs) compounds as Group 1 carcinogen to human. An estimated 100 million people worldwide is confronted with As concentrations in drinking water surpassing the WHO provisional guideline

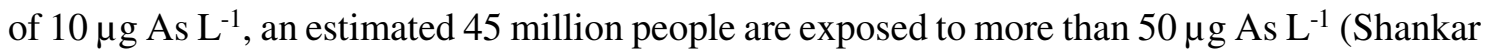
et al. 2014; Tyler and Allan 2014). As mentioned by Shankar et al. (2014) about 150 million people around the world are estimated to be affected with an increasing prospect as new affected areas are continuously discovered.

The toxicity of arsenic depends on its species. Inorganic arsenic forms are generally more widespread and are assumed to be more toxic than organic forms, although in some cases monomethylarsonous acid (MMA ${ }^{\mathrm{III}}$ ) may be more toxic than inorganic $\mathrm{As}^{\mathrm{III}}$, the species with the highest toxicity (Shankar et al. 2014). Excessive and prolonged exposure to As may result in arsenicosis to skin, brain, and internal organs. Arsenic poisoning causes skin disorders; cancers of bladder, kidney, and lung; diseases of the blood vessels of the legs and feet, diabetes mellitus, increased blood pressure, cardiovascular abnormalities, and reproductive disorders (EFSA 2009a; Singh et al. 2011; Shankar et al. 2014). Besides, arsenic impairs neurological functions leading to memory deficit and mood disorder even at low As concentration, particularly in children (Tyler et al. 2014).

\section{Cadmium}

Similar to arsenic, cadmium is classified as Group 1 - human carcinogen by the IARC. Acute $\mathrm{Cd}$ exposures can lead to severe health problems like cancer of the lung, prostate, kidney, endometrium, bladder, or breast (Bertin and Averbeck 2006; EFSA 2009b). In addition, Cd may also damage internal organs resulting in renal dysfunction, bone demineralization and 
disorder, immuno-suppression, and eventually to renal failure (Bertin and Averbeck 2006; EFSA 2009b). On cellular level, Cd may cause cell proliferation, differentiation and finally apoptosis (Bertin and Averbeck 2006). For the non-smoking population, foodstuffs are the major contributor of $\mathrm{Cd}$ exposure. Compared to inhalation exposure, $\mathrm{Cd}$ is relatively low absorbed through dietary pathways and contributes only to 3 - $5 \%$ of the total oral and inhalational Cd intake. Yet, it is efficiently and persistently stored in kidney with a biological half-life from 10 to 30 years (EFSA 2009b). Cadmium exist in the environment mainly as inorganic species although it may be bound to proteins and organic compounds.

\section{Lead}

Lead is enriched in the environment by anthropogenic activities. It is broadly used in industrial activities, as lead shot, formerly in gasoline and house paint, plumbing pipes, pewter pitchers, storage batteries, toys and taps (EFSA 2012; Jaishankar et al. 2014). In the past, it was emitted into the air and water bodies together with other heavy metals by smelting nonferrous metal ores beginning already before the Middle Ages (Deicke et al. 2006), later additionally by coal burning. Beside air, drinking water, industrial processes, and domestic sources, food can be a main factor contributing to Pb exposure (EFSA 2012), resulting in varying exposure to people. Inorganic $\mathrm{Pb}$ forms is predominantly accumulated in bone with a half-life of 10 - 30 years, and may slightly enriched in blood with a half-life of about 30 days (EFSA 2012). Pb can provoke hematological, gastrointestinal, and neurological dysfunctions (Stohs and Bagchi 1995; EFSA 2012).

\section{Manganese}

Manganese is as a component of a number of metalloenzymes an essential dietary element (EFSA 2013). Deficiencies may cause adverse effects of health. Thus, EFSA's report just focused on Adequate Intake for different age groups, but the toxicity of an increased Mn exposure is less considered. Increased Mn intake via inhalation, drinking water, and food may lead to neurotoxic reactions of adult and particularly children and may decline child intellectual functions (Wasserman et al. 2006).

\section{Some other harmful elements}

Chromium and nickel can be enriched in food and drinking water. Both elements are classified as human carcinogens by the IARC (EFSA 2014b; Casalegno et al. 2015; EFSA 2015; Nordberg 2015). 
Nickel and its compounds may increase the risk of cancer of the lung, the nasal cavity, and paranasal sinuses by inhalation exposures. However, no tumors have been found in oral pathway studies. Thus, the CONTAM Panel assumed that dietary Ni intake is unlikely to provoke cancers (EFSA 2015). However, acute Ni oral-exposure is responsible for noncarcinogenic health risks in the gastrointestinal, haematological, neurological and immune system.

Chromium toxicity depends on its oxidation state and speciation. $\mathrm{Cr}^{\mathrm{III}}$ compounds are less toxic than $\mathrm{Cr}^{\mathrm{VI}}$ compounds in general. $\mathrm{Cr}^{\mathrm{III}}$ organic compounds show unobvious adverse effects during oral exposure whilst $\mathrm{Cr}^{\mathrm{VI}}$ compounds increase the risk of intestinal tumors (EFSA 2014b; Casalegno et al. 2015).

\subsection{Measures to lower the uptake of toxic element by rice}

The uptake level of toxic metals and metalloids may influence the growth and yields of rice plants (Fahad et al. 2019; Pandey and Dubey 2019). More importantly, their uptake may cause adverse impacts for the human health. Researches about the mechanism of element uptake into rice plant and translocation within plant tissues were published with a main focus on the very relevant toxic elements As and Cd. Such investigations may help to find solutions in order to alleviate the uptake of these harmful elements, but may also deliver a more comprehensive explanation for the element transfer from soil into the rice plant as presented in this dissertation.

Suriyagoda et al. (2018) stated that the translocation of As from soil into rice plant was strongly dependent on the As quantity and speciation in the rhizosphere. In anaerobic soils, arsenate $\left[\mathrm{As}^{\mathrm{V}} \mathrm{O}_{4}\right]^{3-}$ is reduced to arsenite $\left[\mathrm{As}^{\mathrm{III}} \mathrm{O}_{3}\right]^{3-}$ which is less sorbed by root Fe-plaques. The enrichment of the highly mobile arsenite in the soil solution facilitates its transfer into the plant. Arsenite is taken up by a subclass of aquaporins (water channels consisting of integral membrane proteins), and then enters the stele following mainly the Si-uptake pathway. In aerobic soils, the $\mathrm{As}^{\mathrm{V}}$-species presents the main bioavailable form. Due to the structural analogy between arsenate $\left(\mathrm{AsO}_{4}{ }^{3-}\right)$ and phosphate $\left(\mathrm{PO}_{4}{ }^{3-}\right)$, this species shows strong similarities to the phosphate uptake. The typical organic As species, MMA and DMA, are transported at a much lower rate than inorganic forms into the plant. Some efficient methods are proposed to limit the As uptake. Panthri and Gupta (2019), Suriyagoda et al. (2018), and Shakoor et al. (2019) proposed some strategies to reduce the accumulation of As in rice as follows:

- Rice cultivation should be under changing anaerobic/aerobic, intermittent flooding or alternate wetting and drying (AWD) soil conditions, rather than permanently in 
submerged soils. The efficiency of AWD for decreasing the As uptake was reported earlier by Hu et al. (2013), Yang et al. (2017), and Carrijo et al. (2018).

- Application of biochar, sulfur, or remnants from rice polishing to soil;

- Use of adequate doses of P, Fe, and $\mathrm{Si}$;

- Use of irrigation water with low As concentration;

- Use of rice genotypes with low As uptake by the grains;

- Use of cooking water with low As concentrations.

Many authors (cited by Li et al. 2019) reported that the addition of reactive $\mathrm{Si}$ into the paddy soils reduces the As uptake by rice. However, Li et al. (2019) experienced that in an Ascontaminated soil the As concentration in shoot and root of the rice cultivar Nanjing 44 increased with the reactive $\mathrm{Si}$ (sodium silicate) concentration, whereas the rice cultivar Zhendao 10 was not significantly affected. They refer that the kind of added reactive Si the type of cultivar, but also the formation of Fe-plaque at the root of rice have a strong influence on the As-uptake. Wu et al. (2016) investigated the As uptake and speciation in indica and hybrid rice genotypes with different radial oxygen losses (ROL) in the root area, whereby the indica genotypes with higher ROL accumulated less inorganic As in grains. Reason is the more pronounced formation of Fe-rich plaque in the high ROL genotypes, what may be additionally enforced by reactive Si addition.

Rice primarily takes up $\mathrm{Cd}$ as $\mathrm{Cd}^{2+}$-species. The uptake ability is dependent on cultivar and growth conditions (Rizwan et al. 2016). Wang et al. (2015) evaluated that $\mathrm{Cd}^{2+}$ and $\mathrm{Ca}^{2+}$ have a similar uptake route. Some of the aforementioned As strategies may also hamper the Cd-uptake: AWD (Hu et al. 2013), application of nutrients, lime, reactive silica, compost, and biochar lower the Cd uptake (Rizwan et al. 2016; Babu and Nagabovanalli 2017; Kosolsaksakul et al. 2018; Yang et al. 2018).

In general, the extend of Fe-rich plaque formation, higher concentrations of reactive $\mathrm{Si}$, and AWD conditions may decrease the transfer of As (Panthri and Gupta 2018; Suriyagoda et al. 2018; Seyfferth et al. 2018), Cd (Cheng et al. 2014; Rizwan et al. 2016), and Pb (Liu et al. 2011; Cheng et al., 2014; Lai et al. 2018). Lai et al. (2018) refer additionally to the strong role of $\mathrm{Pb}$ sequestration by iron oxides in rhizosphere soils rather than by the plaques at the root surfaces.

Another parameter important for a safer rice production is the $\mathrm{pH}$-value. Kim et al. (2016) demonstrated that a pH-change induced by immobilizing agents such as dolomite, steel 
slag, and agricultural lime is a feasible approach to lower the $\mathrm{Cd}$ and $\mathrm{Pb}$ uptake in contaminated paddy soils.

In future studies, the interaction of the combined interacting parameters must be investigated in much more details to get a better basis for improving practical cultivation and management measures in order to mitigate the accumulation of potentially toxic elements in rice. These parameters are: AWD, role of soil conditioners, redox conditions, $\mathrm{pH}$-value, pore water geochemistry, the concentration of reactive $\mathrm{Si}$ and phosphate, influence of cultivars, ROL, formation and composition of plaque, Fe and organic matter phases in the rhizosphere soil etc. This kind of research should be complemented by systematic physiological, microbiological, biochemical, and species investigations, elucidating the mechanisms behind the transfer of toxic elements from the soil to the rice plant and within the plant - as shown by Kumarathilaka et al. (2018), Wang et al. (2019) and Panthri and Gupta (2019) for As, and by Fahad et al. (2019), Pandey and Dubey (2019), and Roychowdhury et al. (2019) for additional critical elements. Further research is needed to understand the interactions between different elements, the role of pore water chemistry, microbial processes, and speciation of the elements, as well as the plant uptake and accumulation mechanisms especially in rice grains. The new knowledge may help to mitigate the impact of harmful elements on the population, but also to understand much better their transfer mechanisms in the soil-water-plant system.

For area with high toxic elements concentrations in rice grains, it should be surveyed if other crops with a lower uptake of critical elements should be alternatively cultivated. In addition, to restrict exposure to harmful elements, local people should consume polished rice instead of unpolished rice. Some studies indicated that although the bran layer in unpolished rice is a storage to supply nutrients like K, Zn, and Ca (Seyfferth et al. 2011), but it also leads to higher risks of As and Cd. Eating polished rice could decrease level of inorganic As by $10 \%$ (Meharg et al. 2008; Naito et al. 2015) and of Cd by 3\% (Moriyama et al. 2003).

\subsection{Structure of the thesis}

Chapter 1 represents the background and framework of this thesis. An overall view of research area including facts on weather and climate, population, water sources, and on rice harvesting in three studied areas are described. Some previous investigations on trace element concentrations in paddy soils and rice are summarized. Structure, variety and composition of rice plants are summarized. In addition, potential health risks and possible adverse effects through rice consumption are assessed. 
In Chapter 2, all materials and methods used in this work are described in detail. Collecting and the preprocessing of samples in Vietnam, the pretreatment and digestion processes of samples in the geosciences laboratories are carefully described. The applied analytical techniques ICP-MS and ICP-OES for the quantification of main, minor, trace and ultratrace elements are presented together with an evaluation of the precision and accuracy of measurements.

Chapter 3 comprises the soil geochemistry and the element transfer into rice grain in the Red River delta in the north and Huong River in the center of Vietnam. Because of lacking geochemical data for the parent materials, the soil data are compared with average values of the upper Earth crust and average global shale to find out if the soil samples are contaminated or enriched. Groups of elements with high positive correlation coefficients are classified. The element concentration data are additionally used to get more information about the soil characteristics, especially concerning the role of oxide/hydroxides of Fe, $\mathrm{Al}$ and $\mathrm{Mn}$, but also to get an approximate indication for the presence of clay minerals. These phases together with the $\mathrm{pH}$-value and the organic matter in the soil help to understand the fixation or release mechanisms of potentially toxic elements and their contributions to the element bioavailability. The concentrations of potentially harmful elements in unpolished rice grains are used to calculate the amounts of single elements taken up by eating rice. The potential health risk for the local population can be deduced by comparing these amounts with the tolerable upper intake level or the permissible maximum concentration in rice grains.

In Chapter 4 paddy soil geochemistry and the transfer of elements into rice grain in Mekong River delta in the south are described and interpreted similar to the preceding chapter and again a health risk assessment has been performed. In addition, regression models on basis of the SPSS statistical analysis are calculated for single harmful elements in soil to predict their concentration on main soil factors such as reactive phases and $\mathrm{pH}$-values. Depending on the main soil compositions, concentrations of trace elements can be computed with low errors by multivariable statistical analysis for uncontaminated soils. A comparison for all three investigated areas is performed.

In Chapter 5 the selective transfer of elements from soil into single parts of rice plant (whole aboveground plant, shoot, husk, and unpolished rice) is evaluated. It elucidates the different translocation and uptake patterns within the plant again in dependency of soil factors. In addition to chapter 3 and 4, chronic non-carcinogen and carcinogenic health risk assessments for the three areas are performed by rice consumption. 
Chapter 6 summarizes the most important results of this study and shows perspectives for the future research.

\subsection{References}

Arnarson, A. (2017). Rice 101: Nutrition facts and health effects. https://www.medicalnewstoday.com/articles/318699.php. Accessed 1 July 2019.

Arunakumara, K. K. I. U., Walpola, B. C., \& Yoon, M.-H. (2013). Current status of heavy metal contamination in Asia's rice lands. Reviews in Environmental Science and Bio/Technology, 12:355-377. https://doi.org/10.1007/s11157-013-9323-1.

Babu, T., \& Nagabovanalli, P. (2017). Effect of silicon amendment on soil-cadmium availability and uptake in rice grown in different moisture regimes. Journal of Plant Nutrition, 40:2440-2457. https://doi.org/10.1080/01904167.2017.1346683.

Bazargan, A., Tan, J., Hui, C. W., \& McKay, G. (2014). Utilization of rice husks for the production of oil sorbent materials. Cellulose, 21:1679-1688. https://doi.org/10.1007/s10570-014-0203-9.

Bertin, G., \& Averbeck, D. (2006). Cadmium: cellular effects, modifications of biomolecules, modulation of DNA repair and genotoxic consequences (a review). Biochimie, 88:15491559. https://doi.org/10.1016/j.biochi.2006.10.001.

Bhattacharya, P., Samal, A. C., Majumdar, J., \& Santra, S. C. (2010). Arsenic Contamination in Rice, Wheat, Pulses, and Vegetables: A Study in an Arsenic Affected Area of West Bengal, India. Water, Air, \& Soil Pollution, 213:3-13. https://doi.org/10.1007/s11270010-0361-9.

Bonotto, D. M., Wijesiri, B., Vergotti, M., da Silveira, E. G., \& Goonetilleke, A. (2018). Assessing mercury pollution in Amazon River tributaries using a Bayesian Network approach. Ecotoxicology and Environmental Safety, 166:354-358. doi:https://doi.org/10.1016/j.ecoenv.2018.09.099.

Casalegno, C., Schifanella, O., Zennaro, E., Marroncelli, S., \& Briant, R. (2015). Collate literature data on toxicity of Chromium $(\mathrm{Cr})$ and $\mathrm{Nickel}(\mathrm{Ni})$ in experimental animals and humans. EFSA Supporting Publications, 12:478E. https://doi.org/10.2903/sp.efsa.2015.EN-478.

Carrijo, D. R., Akbar, N., Reis, A. F. B., Li, C., Gaudin, A. C. M., Parikh, S. J., et al. (2018). Impacts of variable soil drying in alternate wetting and drying rice systems on yields, 
grain arsenic concentration and soil moisture dynamics. Field Crops Research, 222:101-110. https://doi.org/10.1016/j.fcr.2018.02.026.

Chaney, R. L., Kim, W. 1., Kunhikrishnan, A., Yang, J. E., \& Ok, Y. S. (2016). Integrated management strategies for arsenic and cadmium in rice paddy environments.

Geoderma, 270:1-2. https://doi.org/10.1016/j.geoderma.2016.03.001.

Cheng, H., Wang, M., Wong, M.H., \& Ye, Y. (2014). Does radial oxygen loss and iron plaque formation on roots alter $\mathrm{Cd}$ and $\mathrm{Pb}$ uptake and distribution in rice plant tissues? Plant and Soil, 375(1-2):137-148. https://doi.org/10.1007/s11104-013-1945-0.

Chu, H. (2011). Survey on heavy metals contaminated soils in Thai Nguyen and Hung Yen provinces in Northern Vietnam. Journal of Vietnamese Environment, 1(1):34-39. https://doi.org/10.13141/jve.vol1.no1.pp34-39

Clauss, K., Ottinger, M., Leinenkugel, P., \& Kuenzer, C. (2018). Estimating rice production in the Mekong Delta, Vietnam, utilizing time series of Sentinel-1 SAR data. International Journal of Applied Earth Observation and Geoinformation, 73:574-585. https://doi.org/10.1016/j.jag.2018.07.022.

Climate-data.org (2019). Climate: Vietnam. https://en.climate-data.org/asia/vietnam-60/. Accessed 9 July 2019.

Cubadda, F., Jackson, B. P., Cottingham, K. L., Van Horne, Y. O., \& Kurzius-Spencer, M. (2017). Human exposure to dietary inorganic arsenic and other arsenic species: State of knowledge, gaps and uncertainties. Science of the Total Environment, 579:1228-1239. https://doi.org/10.1016/j.scitotenv.2016.11.108.

Deicke, M., Ruppert, H. \& Schneider, J. (2006): Mining and smelting in the Harz Mountains (Germany) - A never-ending environmental story. Schriftenreihe der Deutschen Gesellschaft für Geowissenschaften 45, pp. 237-256.

Duy, N., Wagner, W., Naeimi, V., \& Cao, S. (2015). Rice-planted area extraction by time series analysis of envisat asar ws data using a phenology-based classification approach: A case study for red river delta, Vietnam. Paper presented at the 36th International Symposium on Remote Sensing of Environment, Berlin, Germany, 11-15 May 2015. EFSA - European Food Safety Authority (2009a). Scientific Opinion on Arsenic in Food. EFSA Journal, 7:1351. https://doi.org/10.2903/j.efsa.2009.1351. 
EFSA - European Food Safety Authority (2009b). Cadmium in food - Scientific opinion of the Panel on Contaminants in the Food Chain. EFSA Journal, 7:980. https://doi.org/10.2903/j.efsa.2009.980.

EFSA - European Food Safety Authority (2012). Lead dietary exposure in the European population. EFSA Journal, 10:2831. https://doi.org/10.2903/j.efsa.2012.2831.

EFSA Panel on Dietetic Products Nutrition Allergies (2013). Scientific Opinion on Dietary Reference Values for manganese. EFSA Journal, 11:3419. https://doi.org/10.2903/j.efsa.2013.3419.

EFSA - European Food Safety Authority (2014a). Dietary exposure to inorganic arsenic in the European population. EFSA Journal, 12:3597. https://doi.org/10.2903/j.efsa.2014.3597.

EFSA - Panel on Dietetic Products Nutrition Allergies (2014b). Scientific Opinion on Dietary Reference Values for chromium. EFSA Journal, 12:3845. https://doi.org/10.2903/j.efsa.2014.3845.

EFSA - Panel on Contaminants in the Food Chain (2015). Scientific Opinion on the risks to public health related to the presence of nickel in food and drinking water. EFSA Journal, 13:4002. https://doi.org/10.2903/j.efsa.2015.4002.

EOL - Encyclopedia of Life (2004). Oryza sativa L. https://eol.org/pages/1115098. Accessed 26 June 2019.

Erban, L. E., Gorelick, S. M., Zebker, H. A., \& Fendorf, S. (2013). Release of arsenic to deep groundwater in the Mekong Delta, Vietnam, linked to pumping-induced land subsidence. Proceedings of the National Academy of Sciences, 110:13751-13756. https://doi.org/10.1073/pnas.1300503110.

Fahad, S., Rehman, A., Shahzad, B., Tanveer, M., Saud, S., Kamran, M., Ihtisham, M., Khan, S. U., Turan, V., \& ur Rahman, M. H. (2019). Rice responses and tolerance to metal/metalloid toxicity. In Hasanuzzaman, M., Fujita, M., Nahar, K., \& Biswas, J. K. (Eds.), Advances in Rice Research for Abiotic Stress Tolerance (pp. 299-312). Woodhead Publisher, Elsevier. https://doi.org/10.1016/B978-0-12-814332-2.00014-9.

Fang, Y., Sun, X., Yang, W., Ma, N., Xin, Z., Fu, J., et al. (2014). Concentrations and health risks of lead, cadmium, arsenic, and mercury in rice and edible mushrooms in China. Food Chemistry, 147:147-151. https://doi.org/10.1016/j.foodchem.2013.09.116. 
FAO - Food and Agriculture Organization (2002). FAO Rice Information - Vietnam, Roma,

Italy, Vol. 3. http://www.fao.org/3/Y4347E/y4347e1u.htm\#bm66. Accessed 9 July 2019.

FAO - Food and Agriculture Organization (2011). Strengthening Capacities to Enhance

Coordinated and Integrated Disaster Risk Reduction Actions and Adaptation to Climate

Change in Agriculture in the Northern Mountain Regions of Viet Nam.

http://www.fao.org/climatechange/34068-0d42acdf5fb7c4d80f3013c038ab92ce6.pdf.

Accessed 6 June 2019.

FAO - Food and Agriculture Organization (2012). Viet Nam - Geography, climate and population. 15 pp. Aquastat Water Report 37.

http://www.fao.org/nr/water/aquastat/countries_regions/VNM/VNM-CP_eng.pdf.

Accessed 6 June 2019.

FAO - Food and Agriculture Organization (2018). Rice Market Monitor. XXI (1): April

2018, pp. 38. http://www.fao.org/3/I9243EN/i9243en.pdf. Accessed 6 June 2019.

FAO - Food and Agriculture Organization (2019). Food Outlook - Biannual Report on Global

Food Markets, pp. 164. http://www.fao.org/3/ca4526en/ca4526en.pdf. Accessed 6 June 2019.

Garbarino, J. R., Hayes, H. C., Roth, D. A., Antweiler, R. C., Brinton, T. I., \& Taylor, H. E. (1995). Heavy metals in the Mississippi river. In R. H. Meade (Ed.), Contaminants in the Mississippi River. Reston, Virginia: U.S. Geological Survey Circular 1133.

GSO - General Statistics Office (2011). Statistical Yearbook of Vietnam 2011. Ha Noi, Vietnam.

https://www.gso.gov.vn/default_en.aspx?tabid=515\&idmid=5\&ItemID=12576.

Accessed 8 June 2019.

GSO - General Statistics Office (2012). Statistical Yearbook of Vietnam 2012. Ha Noi,

Vietnam.

https://www.gso.gov.vn/default_en.aspx?tabid=515\&idmid=5\&ItemID=13762.

Accessed 8 June 2019.

Hoang, T. H., Bang, S., Kim, K.-W., Nguyen, M. H., \& Dang, D. M. (2010). Arsenic in groundwater and sediment in the Mekong River delta, Vietnam. Environ Pollut, 158:2648-2658. https://doi.org/10.1016/j.envpol.2010.05.001.

Hu, P., Huang, J., Ouyang, Y., Wu, L., Song, J., Wang, S., et al. (2013). Water management affects arsenic and cadmium accumulation in different rice cultivars. Environ Geochem Health, 35:767-778. https://doi.org/10.1007/s10653-013-9533-z. 
Hughes, M. F., Beck, B. D., Chen, Y., Lewis, A. S., \& Thomas, D. J. (2011). Arsenic exposure and toxicology: a historical perspective. Toxicological sciences: an official journal of the Society of Toxicology, 123:305-332. https://doi.org/10.1093/toxsci/kfr184.

Hung, N. N. (2011). Sediment dynamics in the floodplain of the Mekong Delta, Vietnam. University of Stuttgart, Germany, The University of Stuttgart, Germany. http://doi.org/10.18419/opus-409.

Huong, N. T. L., Ohtsubo, M., Li, L., Higashi, T., Kanayama, M., \& Nakano, A. (2008). Heavy metal contamination of soil and rice in wastewater-irrigated paddy field in a suburban area of Hanoi, Vietnam. Clay Science, 13:205-215. https://doi.org/10.11362/jcssjclayscience1960.13.205.

IRRI - International Rice Research Institute (2015). GHG Mitigation in Rice. http://ghgmitigation.irri.org/our-work/vietnam. Accessed 15 June 2019.

Jaishankar, M., Tseten, T., Anbalagan, N., Mathew, B. B., \& Beeregowda, K. N. (2014). Toxicity, mechanism and health effects of some heavy metals. Interdisciplinary Toxicology, 7:60-72. https://doi.org/10.2478/intox-2014-0009.

Jessen, S. (2009). Groundwater arsenic in the Red River delta, Vietnam: Regional distribution, release, mobility and mitigation options. Technical University of Denmark, Denmark. https://orbit.dtu.dk/ws/files/5034320/ENV2009-208.pdf. Accessed 15 June 2019

Jitaru, P., Millour, S., Roman, M., El Koulali, K., Noël, L., \& Guérin, T. (2016). Exposure assessment of arsenic speciation in different rice types depending on the cooking mode. Journal of Food Composition and Analysis, 54:37-47. https://doi.org/10.1016/j.jfca.2016.09.007.

Kim, S.-C., Kim, H.S., Seo, B.-H., Owens, G., \& Kim, K.-R. (2016). Phytoavailability control based management for paddy soil contaminated with $\mathrm{Cd}$ and $\mathrm{Pb}$ : Implications for safer rice production. Geoderma, 270:83-88. https://doi.org/10.1016/j.geoderma.2015.11.031.

Kosolsaksakul, P., Oliver, I. W., \& Graham, M. C. (2018). Evaluating cadmium bioavailability in contaminated rice paddy soils and assessing potential for contaminant immobilisation with biochar. Journal of Environmental Management, 215:49-56. https://doi.org/10.1016/j.jenvman.2018.03.044. 
Kumar, S., Sangwan, P., Dhankhar, R., Mor, V., \& Bidra, S. (2013). Utilization of Rice Husk and Their Ash: A Review. Research Journal of Chemical and Environmental Sciences, 1:126-129. https://doi.org/10.19026/rjaset.9.2606.

Kumarathilaka, P., Seneweera, S., Meharg, A., \& Bundschuh, J. (2018). Arsenic accumulation in rice (Oryza sativa L.) is influenced by environment and genetic factors. Science of The Total Environment, 642: 485-496.

https://doi.org/10.1016/j.scitotenv.2018.06.030.

Kwon, J. C., Nejad, Z. D., \& Jung, M. C. (2017). Arsenic and heavy metals in paddy soil and polished rice contaminated by mining activities in Korea. Catena, 148:92-100. https://doi.org/10.1016/j.catena.2016.01.005.

Lai, Y.-C., Syu, C.-H., Wang, P.-J., Lee, D.-Y., Fan, C., \& Juang, K.-W. (2018). Field experiment for determining lead accumulation in rice grains of different genotypes and correlation with iron oxides deposited on rhizosphere soil. Science of The Total Environment, 610-611: 845-853. https://doi.org/10.1016/j.scitotenv.2017.08.034.

Lei, M., Tie, B., Zeng, M., Qing, P., Song, Z., Williams, P. N., et al. (2013). An arseniccontaminated field trial to assess the uptake and translocation of arsenic by genotypes of rice. Environ Geochem Health, 35:379-390. https://doi.org/10.1007/s10653-012-9501-z.

Li, P., Feng, X., \& Qiu, G. (2010). Methylmercury exposure and health effects from rice and fish consumption: A review. Int J Environ Res Public Health, 7:2666-2691. https://doi.org/10.3390/ijerph7062666.

Li, R., Zhou, Z., Xu, X., Xie, X., Zhang, Q., \& Liu, Y. (2019). Effects of silicon application on uptake of arsenic and phosphorus and formation of iron plaque in rice seedlings grown in an arsenic-contaminated soil. Bulletin of Environmental Contamination and Toxicology, 103:133-139. https://doi.org/10.1007/s00128-019-02552-x.

Liao, N., Seto, E., Eskenazi, B., Wang, M., Li, Y., \& Hua, J. (2018). A Comprehensive Review of Arsenic Exposure and Risk from Rice and a Risk Assessment among a Cohort of Adolescents in Kunming, China. Int J Environ Res Public Health, 15:2191. https://doi.org/10.3390/ijerph15102191.

Liew, S. C., Kam, S. P., Tuong, T.-P., Minh, V.-Q., Balababa, L., \& Lim, H. (2014).

Delineation of Rice Cropping Systems in the Mekong River Delta using Multitemporal ERS Synthetic Aperture Radar. https://earth.esa.int/workshops/ers97/papers/liew/index2.html. Accessed 20 June 2019. 
Liu, J., Leng, X., Wang, M., Zhu, Z., \& Dai, Q. (2011). Iron plaque formation on roots of different rice cultivars and the relation with lead uptake. Ecotoxicology and Environmental Safety, 74(5): 1304-1309. https://doi.org/10.1016/j.ecoenv.2011.01.017.

Ma, L., Wang, L., Jia, Y., \& Yang, Z. (2017). Accumulation, translocation and conversion of six arsenic species in rice plants grown near a mine impacted city. Chemosphere, 183:44-52. https://doi.org/10.1016/j.chemosphere.2017.05.089.

Meharg, A. A., Lombi, E., Williams, P. N., Scheckel, K. G., Feldmann, J., Raab, A., et al. (2008). Speciation and Localization of Arsenic in White and Brown Rice Grains. Environ. Sci. Technol, 42:1051-1057. https://doi.org/10.1021/es702212p.

Merola, R. B., Hien, T. T., Quyen, D. T. T., \& Vengosh, A. (2015). Arsenic exposure to drinking water in the Mekong Delta. Science of the Total Environment, 511:544-552. https://doi.org/10.1016/j.scitotenv.2014.12.091.

Moriyama, T., Shindoh, K., Taguchi, Y., Watanable, H., Yasui, A., \& Joh, T. 2003. Changes in the Cadmium Content of Rice during the Milling Process. Journal of the Food Hygienic Society of Japan, 44(3): 145-9. https://doi.org/10.3358/shokueishi.44.145.

Naito, S., Matsumoto, E., Shindoh, K., \& Nishimura, T. (2015). Effects of polishing, cooking, and storing on total arsenic and arsenic species concentrations in rice cultivated in Japan. Food Chemistry, 168:294-301. https://doi.org/10.1016/j.foodchem.2014.07.060.

Nguyen, D.-Q., Renwick, J., \& McGregor, J. (2014). Variations of surface temperature and rainfall in Vietnam from 1971 to 2010. International Journal of Climatology, 34: 249264. https://doi.org/10.1002/joc.3684.

Ninh, N. H. (2008). Flooding in Mekong River Delta, Viet Nam. UNDP Human Development Report 2007/2008. Office, pp. 24. http://hdr.undp.org/sites/default/files/nguyen_huu_ninh.pdf. Accessed 21 June 2019.

Nogawa, K., Kobayashi, E., Okubo, Y., \& Suwazono, Y. (2004). Environmental cadmium exposure, adverse effects and preventive measures in Japan. Biometals, 17:581-587. https://doi.org/10.1023/B:BIOM.0000045742.81440.9c.

Nogawa, K., Sakurai, M., Ishizaki, M., Kido, T., Nakagawa, H., and Suwazono, Y. (2017). Threshold limit values of the cadmium concentration in rice in the development of itaiitai disease using benchmark dose analysis. J. Appl. Toxicol., 37: 962- 966. https://doi.org/10.1002/jat.3444. 
Nordberg, G. F., Gerhardsson, L., Mumtaz, M. M., Ruiz, P., \& Fowler, B. A. (2015). Interactions and Mixtures in Metal Toxicology. In G. F. Nordberg, B. A. Fowler, \& M. Nordberg (Eds.), Handbook on the Toxicology of Metals (pp. 213-238). UK: Elsevier.

Norton, G. J., Williams, P. N., Adomako, E. E., Price, A. H., Zhu, Y., Zhao, F.-J., et al. (2014). Lead in rice: Analysis of baseline lead levels in market and field collected rice grains. Science of the Total Environment, 485-486:428-434.

https://doi.org/10.1016/j.scitotenv.2014.03.090.

Pandey, P. \& Dubey, R.S. (2019). Metal toxicity in rice and strategies for improving stress tolerance. In Hasanuzzaman, M., Fujita, M., Nahar, K., \& Biswas, J.K. (Eds.): Advances in Rice Research for Abiotic Stress Tolerance (pp. 313-339). Woodhead Publisher, Elsevier. https://doi.org/10.1016/B978-0-12-814332-2.00015-0.

Panthri, M. \& Gupta, M. (2019). Plausible strategies to reduce arsenic accumulation in rice. In Hasanuzzaman, M., Fujita, M., Nahar, K., \& Biswas, J.K. (Eds.): Advances in Rice Research for Abiotic Stress Tolerance (pp. 371-384). Woodhead Publisher, Elsevier. https://doi.org/10.1016/B978-0-12-814332-2.00017-4.

Patel, K. S., Sahu, B. L., Ramteke, S., \& Bontempi, E. (2016). Contamination of Paddy Soil and Rice with Arsenic. Journal of Environmental Protection, 7(05):10. https://doi.org/10.4236/jep.2016.75061.

Perera, P. A. C. T., Sundarabarathy, T. V., Sivananthawerl, T., Kodithuwakku, S. P., \& Edirisinghe, U. (2016). Arsenic and Cadmium Contamination in Water, Sediments and Fish is a Consequence of Paddy Cultivation: Evidence of River Pollution in Sri Lanka. Achievements in the Life Sciences, 10:144-160.

https://doi.org/10.1016/j.als.2016.11.002.

Phuong, N. M., Kang, Y., Sakurai, K., Iwasaki, K., Kien, C. N., Noi, N. V., et al. (2010). Levels and Chemical Forms of Heavy Metals in Soils from Red River Delta, Vietnam. Water, Air, \& Soil Pollution, 207:319-332. https://doi.org/10.1007/s11270-009-0139-0.

Prasara-A, J., \& Gheewala, S. H. (2017). Sustainable utilization of rice husk ash from power plants: A review. Journal of Cleaner Production, 167:1020-1028. https://doi.org/10.1016/j.jclepro.2016.11.042.

Rahimi, G., Kolahchi, Z., \& Charkhabi, A. (2017). Uptake and Translocation of Some Heavy Metals by Rice Crop (Oryza sativa) in Paddy Soils. Agriculture, 63(4):163-175. https://doi.org/10.1515/agri-2017-0016. 
Rahman, M. A., \& Hasegawa, H. (2011). High levels of inorganic arsenic in rice in areas where arsenic-contaminated water is used for irrigation and cooking. Science of the Total Environment, 409:4645-4655. https://doi.org/10.1016/j.scitotenv.2011.07.068.

Rasheed, H., Kay, P., Slack, R., \& Gong, Y. Y. (2018). Arsenic species in wheat, raw and cooked rice: Exposure and associated health implications. Science of the Total Environment, 634:366-373. https://doi.org/10.1016/j.scitotenv.2018.03.339.

Ricepedia (2012). Vietnam Basic Statistics. http://ricepedia.org/vietnam. Accessed 25 June 2019

Rizwan, M., Ali, S., Adrees, M., Rizvi, H., Zia-ur-Rehman, M., Hannan, F., et al. (2016). Cadmium stress in rice: toxic effects, tolerance mechanisms, and management: a critical review. Environmental Science and Pollution Research, 23:17859-17879. https://doi.org/10.1007/s11356-016-6436-4.

Roychowdhury, R., Khan, M.H., \&Choudhury, S. (2019). Physiological and molecular responses for metalloid stress in rice - a comprehensive overview. In Hasanuzzaman, M., Fujita, M., Nahar, K., \& Biswas, J.K. (Eds.): Advances in Rice Research for Abiotic Stress Tolerance (pp. 341-369). Woodhead Publisher, Elsevier. https://doi.org/10.1016/B978-0-12-814332-2.00016-2.

Satpathy, D., Reddy, M. V., \& Dhal, S. P. (2014). Risk assessment of heavy metals contamination in paddy soil, plants, and grains (Oryza sativa L.) at the East Coast of India. BioMed research international, 2014:545473-545473. https://doi.org/10.1155/2014/545473.

Schenker, S. (2012). An overview of the role of rice in the UK diet. Nutrition Bulletin, 37:309-323. https://doi.org/10.1111/j.1467-3010.2012.02002.x.

Seyfferth, A. L., Webb, S. M., Andrews, J. C., \& Fendorf, S. (2011). Defining the distribution of arsenic species and plant nutrients in rice (Oryza sativa L.) from the root to the grain. Geochimica et Cosmochimica Acta, 75:6655-6671. https://doi.org/10.1016/j.gca.2011.06.029.

Seyfferth, A. L., Limmer, M. A., \& Dykes G. E. (2018). Chapter Two - On the Use of Silicon as an Agronomic Mitigation Strategy to Decrease Arsenic Uptake by Rice. Advances in Agronomy, 149:49-91. https://doi.org/10.1016/bs.agron.2018.01.002.

Shakoor, M. B., Riaz, M., Niazi, N. K., Ali, S., Rizwan, M., Arif, M. S., \& Arif, M. (2019). Recent advances in arsenic accumulation in rice. In Hasanuzzaman, M., Fujita, M., 
Nahar, K., \& Biswas, J.K. (Eds.): Advances in Rice Research for Abiotic Stress

Tolerance (pp. 385-398). Woodhead Publisher, Elsevier. https://doi.org/10.1016/B978-

0-12-814332-2.00018-6.

Shankar, S., Shanker, U., \& Shikha (2014). Arsenic contamination of groundwater: A review of sources, prevalence, health risks, and strategies for mitigation. The Scientific World Journal, 2014:18. http://doi.org/10.1155/2014/304524.

Shinkai, Y., Truc, D. V., Sumi, D., Canh, D., \& Kumagai, Y. (2007). Arsenic and Other Metal Contamination of Groundwater in the Mekong River Delta, Vietnam. Journal of Health Science, 53:344-346. http://doi.org/10.1248/jhs.53.344.

Shraim, A. M. (2017). Rice is a potential dietary source of not only arsenic but also other toxic elements like lead and chromium. Arabian Journal of Chemistry, 10:S3434S3443. https://doi.org/10.1016/j.arabjc.2014.02.004.

Sigrist, M., Hilbe, N., Brusa, L., Campagnoli, D., \& Beldoménico, H. (2016). Total arsenic in selected food samples from Argentina: Estimation of their contribution to inorganic arsenic dietary intake. Food Chemistry, 210:96-101. https://doi.org/10.1016/j.foodchem.2016.04.072.

Singh, A. P., Goel, R. K., \& Kaur, T. (2011). Mechanisms pertaining to arsenic toxicity. Toxicology international, 18:87-93. http://doi.org/10.4103/0971-6580.84258.

Singh, H., Pandey, R., Singh, S. K., \& Shukla, D. N. (2017). Assessment of heavy metal contamination in the sediment of the River Ghaghara, a major tributary of the River Ganga in Northern India. Applied Water Science, 7:4133-4149. http://doi.org/10.1007/s13201-017-0572-y.

Sø, H. U., Postma, D., Vi, M. L., Pham, T. K. T., Kazmierczak, J., Dao, V. N., et al. (2018). Arsenic in Holocene aquifers of the Red River floodplain, Vietnam: Effects of sediment-water interactions, sediment burial age and groundwater residence time. Geochimica et Cosmochimica Acta, 225:192-209. https://doi.org/10.1016/j.gca.2018.01.010.

Sommella, A., Deacon, C., Norton, G., Pigna, M., Violante, A., \& Meharg, A. A. (2013). Total arsenic, inorganic arsenic, and other elements concentrations in Italian rice grain varies with origin and type. Environ Pollut, 181:38-43. https://doi.org/10.1016/j.envpol.2013.05.045. 
Stanger, G., Truong, T. V., Ngoc, K. S. L. T. M., Luyen, T. V., \& Thanh, T. T. (2005). Arsenic in groundwater of the Lower Mekong. Environ Geochem Health, 27:341-357. http://doi.org/10.1007/s10653-005-3991-X.

Stohs, S. J., \& Bagchi, D. (1995). Oxidative mechanisms in the toxicity of metal ions. Free Radical Biology and Medicine, 18:321-336. https://doi.org/10.1016/08915849(94)00159-H.

Suriyagoda, L. D. B., Dittert, K., \& Lambers, H. (2018). Mechanism of arsenic uptake, translocation and plant resistance to accumulate arsenic in rice grains. Agriculture, Ecosystems \& Environment, 253:23-37. http://doi.org/10.1016/j.agee.2017.10.017.

Tsukahara, T., Ezaki, T., Moriguchi, J., Furuki, K., Shimbo, S., Matsuda-Inoguchi, N., et al. (2003). Rice as the most influential source of cadmium intake among general Japanese population. Science of the Total Environment, 305:41-51. https://doi.org/10.1016/S0048-9697(02)00475-8.

Tyler, C. R., \& Allan, A. M. (2014). The effects of arsenic exposure on neurological and cognitive dysfunction in human and rodent studies: a review. Current environmental health reports, 1:132-147. http://doi.org/10.1007/s40572-014-0012-1.

Uraguchi, S., \& Fujiwara, T. (2012). Cadmium transport and tolerance in rice: perspectives for reducing grain cadmium accumulation. Rice, 5:5. http://doi.org/10.1186/1939-8433-5-5.

USDA Foreign Agricultural Service (2019). Vietnam - Grain and Feed Annual 2019. GAIN Report VM9014, pp. 25. https://gain.fas.usda.gov/Recent\%20GAIN\%20Publications/Grain\%20and\%20Feed\%20 Annual_Hanoi_Vietnam_4-8-2019.pdf. Accessed 26 June 2019.

Viet, P. H., Trang, P. T. M., \& Nga, D. V. (2019). Arsenic contamination in groundwater in the Red river delta, Vietnam - a review. Vietnam Journal of Science. Technology and Engineering, 60:23-27. https://doi.org/10.31276/VJSTE.60(1).23.

Vietnam Government (2018). Vietnam Geographic Information. http://chinhphu.vn/portal/page/portal/chinhphu/NuocCHXHCNVietNam/ThongTinTon gHop/dialy. Accessed 30 June 2019.

Vijay, D., \& Roy, B. (2013). Rice (Oryza sativa L.). In B. Roy, A. K. Basu, \& A. B. Mandal (Eds.), Breeding, Biotechnology and Seed Production of Field Crops (pp. 71). India: New India Publishing Agency New Delhi. 
Vinh, N. C., Oborn, I., Ha, P. Q., Minh, N. D., Hough, R. L., Khai, N. M., et al. (2012).

Potential Environment and Public Health Risk Due to Contamination of Heavy Metals from Industrial Waste Water in Lam Thao, Phu Tho, Vietnam. American Journal of Environmental Sciences, 8:71-78. https://doi.org/10.3844/ajessp.2012.71.78.

Walpole, S. C., Prieto-Merino, D., Edwards, P., Cleland, J., Stevens, G., \& Roberts, I. (2012). The weight of nations: an estimation of adult human biomass. BMC Public Health, 12:439. https://doi.org/10.1186/1471-2458-12-439.

Wang, F., Wang, M., Liu, Z., Shi, Y., Han, T., Ye, Y., et al. (2015). Different responses of low grain-Cd-accumulating and high grain-Cd-accumulating rice cultivars to $\mathrm{Cd}$ stress. Plant Physiology and Biochemistry, 96:261-269. https://doi.org/10.1016/j.plaphy.2015.08.001.

Wang, M., Tang, Z., Chen, X.-P., Wang, X., Zhou, W.-X., Tang, Z., Zhang, J., Zhao, F.-J. (2019). Water management impacts the soil microbial communities and total arsenic and methylated arsenicals in rice grains. Environmental Pollution, 247: 736-744. https://doi.org/10.1016/j.envpol.2019.01.043.

Wasserman, G. A., Liu, X., Parvez, F., Ahsan, H., Levy, D., Factor-Litvak, P., et al. (2006). Water Manganese Exposure and Children's Intellectual Function in Araihazar, Bangladesh. Environmental health perspectives, 114:124-129. https://doi.org/10.1289/ehp.8030.

Winkel, L. H. E., Trang, P. T. K., Lan, V. M., Stengel, C., Amini, M., Ha, N. T., et al. (2011). Arsenic pollution of groundwater in Vietnam exacerbated by deep aquifer exploitation for more than a century. Proceedings of the National Academy of Sciences, 108:12461251. https://doi.org/10.1073/pnas.1011915108.

Wong, W. W. K., Chung, S. W. C., Chan, B. T. P., Ho, Y. Y., \& Xiao, Y. (2013). Dietary exposure to inorganic arsenic of the Hong Kong population: Results of the first Hong Kong Total Diet Study. Food and Chemical Toxicology, 51:379-385. https://doi.org/10.1016/j.fct.2012.10.010.

Wu, C., Zou, Q., Xue, S.-G., Pan, W.-S., Huang, L., Hartley, W., Mo, J.-Y., Wong, M.H. (2016). The effect of silicon on iron plaque formation and arsenic accumulation in rice genotypes with different radial oxygen loss (ROL). Environmental Pollution, 212: 2733. https://doi.org/10.1016/j.envpol.2016.01.004. 
Xie, L. H., Tang, S. Q., Wei, X. J., Shao, G. N., Jiao, G. A., Sheng, Z. H., et al. (2017). The cadmium and lead content of the grain produced by leading Chinese rice cultivars. Food Chemistry, 217:217-224. https://doi.org/10.1016/j.foodchem.2016.08.099.

Yang, J., Zhou, Q., \& Zhang, J. (2017). Moderate wetting and drying increases rice yield and reduces water use, grain arsenic level, and methane emission. The Crop Journal, 5:151158. https://doi.org/10.1016/j.cj.2016.06.002.

Yang, Y., Chen, J., Huang, Q., Tang, S., Wang, J., Hu, P., et al. (2018). Can liming reduce cadmium $(\mathrm{Cd})$ accumulation in rice (Oryza sativa) in slightly acidic soils? Can liming reduce cadmium $(\mathrm{Cd})$ accumulation in rice (Oryza sativa) in slightly acidic soils. Chemosphere, 193:547-556. https://doi.org/10.1016/j.chemosphere.2017.11.061.

Yen, T. B. N., Kamoshita, A., Dinh, V. T. H., Matsuda, H., \& Kurokura, H. (2017). Salinity intrusion and rice production in Red River Delta under changing climate conditions. Paddy and Water Environment, 15:37-48. https://doi.org/10.1007/s10333-016-0526-2. 
Chapter 2

\section{Material and Methods}




\subsection{Sample collection and processing}

Rice and corresponding paddy soil samples were collected at 110 sites along three river systems: Mekong River in the south, Huong River in the center, and Red River in the north of Vietnam. At each sampling location, one representative complete rice plant was extracted along a path inside the rice field. The soil was taken directly from the extracted root within $0-10 \mathrm{~cm}$ depth. The corresponding rice plant samples were cut at approximately $5-10 \mathrm{~cm}$ above the soil called aboveground rice. Aboveground rice and soil samples at 30 positions were gathered in September 2015 in the Red River and Huong River areas. 80 sites were collected in April 2017 in the Mekong River delta. The sample collection took place within 10 days before the typical rice harvesting time. Maps of the sample locations are shown in Fig. 2.1

After collecting, all soil samples were air-dried at the room temperature for 2 - 3 days. Plant roots and gravels were removed from soil by hand. The soils were then sieved to particle sizes $<2 \mathrm{~mm}$. The plant samples were dried in sunlight at $40-50^{\circ} \mathrm{C}$ for 2 days. Then, all of the samples were transported to the laboratory of the Geoscience Center of Georg-AugustUniversity.

At the laboratory of the Geoscience Center, the soil samples were dried again at $105^{\circ} \mathrm{C}$ and the rice samples at $60^{\circ} \mathrm{C}$. The soil samples were pulverized into particle sizes $<63 \mu \mathrm{m}$ by an agate ball mill (Fritsch, Pulverisette 5). The 24 rice plants from north and central Vietnam were separated into shoot (stems and leaves), husk, and unpolished rice. The 78 whole rice grains from the Mekong area were split into husk and unpolished rice. The shoot and husk samples were pounded into particle sizes $<63 \mu \mathrm{m}$ by an agate ball mill (Fritsch, Pulverisette 19). The unpolished rice samples were milled by using an agate mortar. 


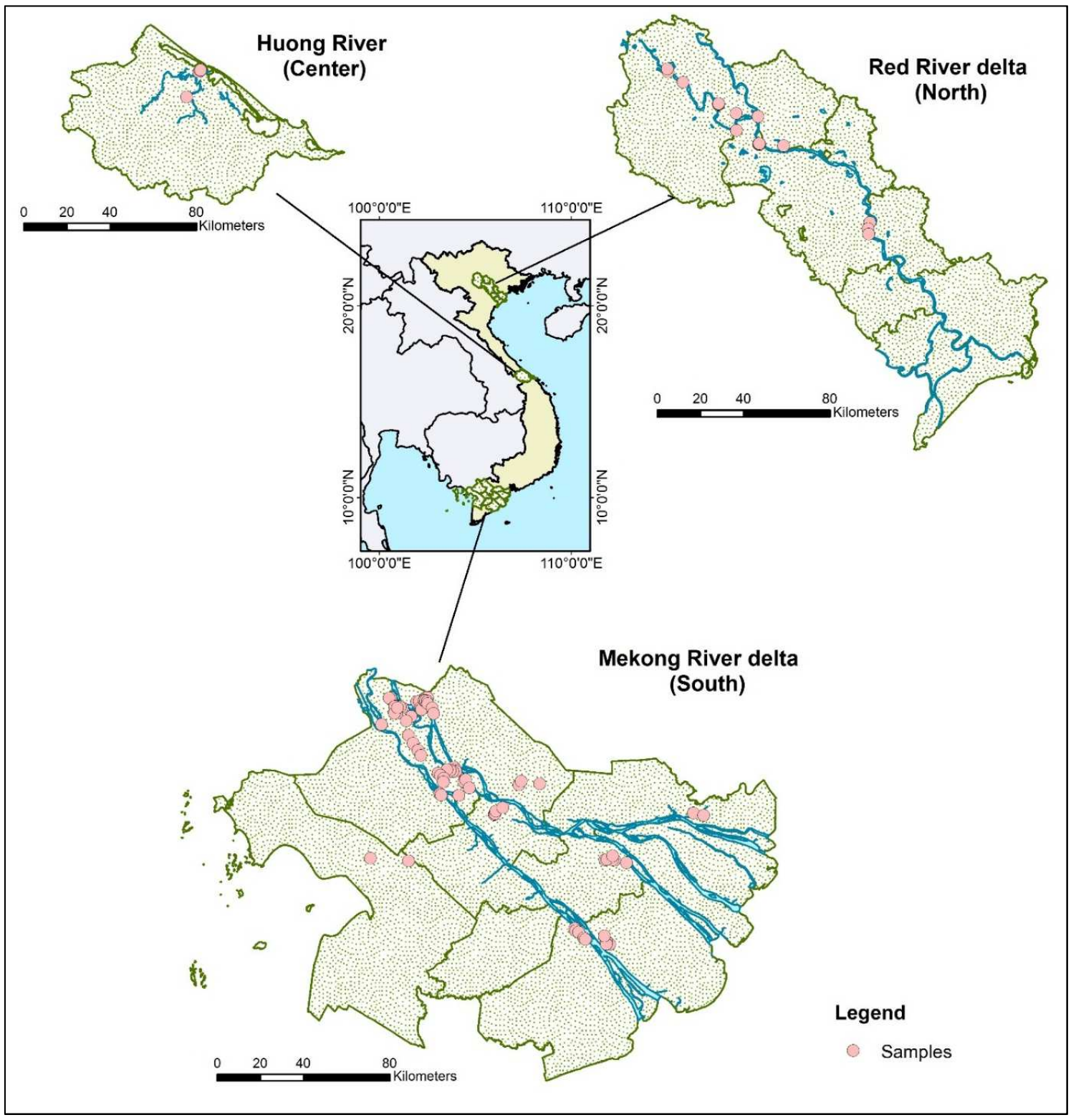

Fig. 2.1 Sample locations in the three investigated river areas in Vietnam 

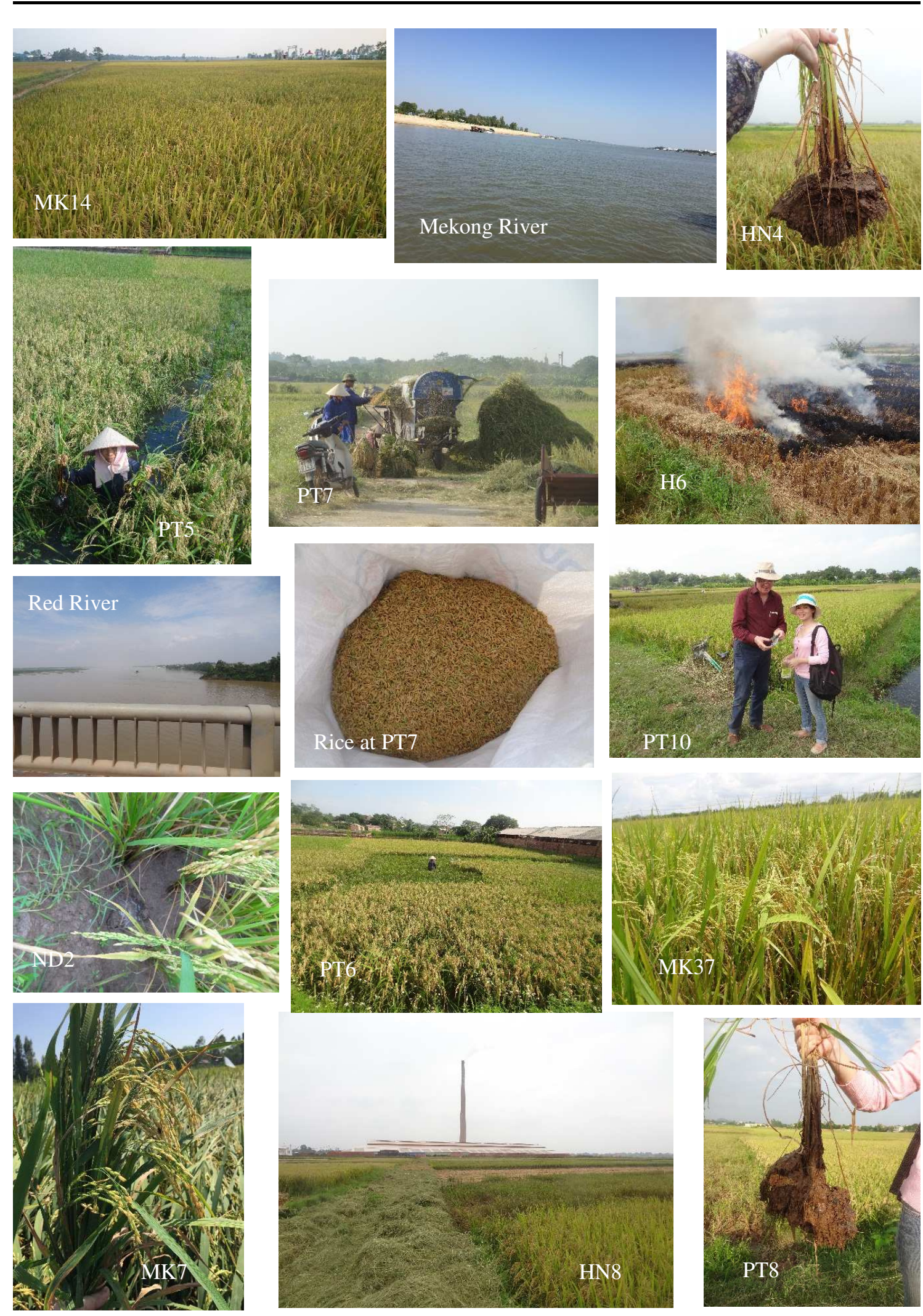

Fig. 2.2 Photos of some research sites 


\subsection{Determination of pH-value and LOI (loss on ignition) in soil samples}

\section{Soil pH-value}

A mixture of $10 \mathrm{~g}$ air-dried soil (particle sizes $<2 \mathrm{~mm}$ ) and $25 \mathrm{ml} 0.01 \mathrm{M} \mathrm{CaCl}_{2}$ solution was stirred for 10 minutes and then kept quiet for one hour. Then, the $\mathrm{pH}$-value in the liquid was measured by a glass electrode connected to the WTW ProfiLine $\mathrm{pH} / \mathrm{mV}$-Meter 197. The measurement was repeated in triplicate to get the mean soil-pH value.

\section{Loss on ignition (LOI)}

The LOI represents a proxy for the content of organic matter (OM) and of water in clay mineral and oxides/hydroxides. It was determined as follows: About $500 \mathrm{mg}$ of $105{ }^{\circ} \mathrm{C}$ dried, powdered soil (particle sizes $<63 \mu \mathrm{m}$ ) were placed into a small ceramic crucible and heated up to a temperature of $530^{\circ} \mathrm{C}$ for 2 hours. After that, the ceramic crucibles were cooled down in the desiccator to room temperature. The weight loss divided by the initial weight and multiplied by 100 to get the LOI content in percent.

\subsection{Element analysis of soil and plant material}

The digestion processes of soil and plant samples were executed according to the procedure stablished at the laboratory of the Geoscience Center: Approximately $150 \mathrm{mg}$ of soil or $700 \mathrm{mg}$ of plant powder (particle sizes $<63 \mu \mathrm{m}$ ) were completely digested by a mixture of ultra-pure concentrated $\mathrm{HNO}_{3}, \mathrm{HClO}_{4}$ and $\mathrm{HF}$ in a closed ultra-clean PTFE vessel (PicoTrace ${ }^{\circledR}$, Bovenden, Acid Sample Digestion System DAS 30). The digestion procedure consisted of 5 steps: 1. pre-reaction of the samples with the acid mixture for 5 hours increasing temperature up to $100^{\circ} \mathrm{C}$ in the loosely covered vessel; 2. pressure digestion in the closed vessels for 10 hours at $150^{\circ} \mathrm{C} ; 3$. evaporation of the acids nearly to dryness by using an evaporation plate at $180^{\circ} \mathrm{C}, \mathrm{CO}_{2}$ and $\mathrm{SiF}_{4}$ are also removed; 4. after cooling down, addition of $2 \mathrm{~mL}$ concentrated $\mathrm{HNO}_{3}$ and $0.5 \mathrm{~mL} \mathrm{HCl}$ and $10 \mathrm{ml}$ ultrapure water and heating for 2 hours at $150^{\circ} \mathrm{C}$ to completely dissolve the evaporation residue; 5 . transfer of the clear solution into a volumetric flask (100 $\mathrm{ml}$ for soil and $50 \mathrm{ml}$ for plant) and storage in precleaned PE-bottles. Each digestion series comprised 32 positions. Each series included two digestion blank samples (only the acids without sample material) and at least one international reference standard material in order to determine an eventual contamination (from handling and acids) during the digestion and to get information on precision, accuracy and international comparability of the measurements. The clear solutions were then quantified by Inductively Coupled Plasma - Optical Emission 
Spectrometry (ICP-OES, Agilent 5100 VDV) and - Mass Spectrometry (ICP-MS, Thermo Scientific iCAP Q), which were calibrated by a series of multi-element solutions containing the investigated elements in the expected concentration range of the unknown samples.

The detection limits for the single elements were calculated as 3-fold standard deviation of their concentrations in the blank samples from each set. The international reference samples comprised the following materials: lake sediment GSJ-JLk-1; bush branches and leaves NCS DC 73349; maize plant WEPAL-IPE-126; and the inhouse reference samples Wissenbach shale TW45. The finally selected element lines (ICP-OES) and masses (ICP-MS) were chosen based on the criteria (1) lowest detection limits and (2) best agreement with reference samples (see the listing in Table A1.1 in Appendix A1). In general, the accuracies of measurements for main elements were mostly better than $5 \%$ while those for trace elements fluctuated from $5 \%$ to $10 \%$, except for $\mathrm{Zr}$ which with results were $20 \%$ lower than the certified values (reason: incomplete dissolution of the mineral zircon).
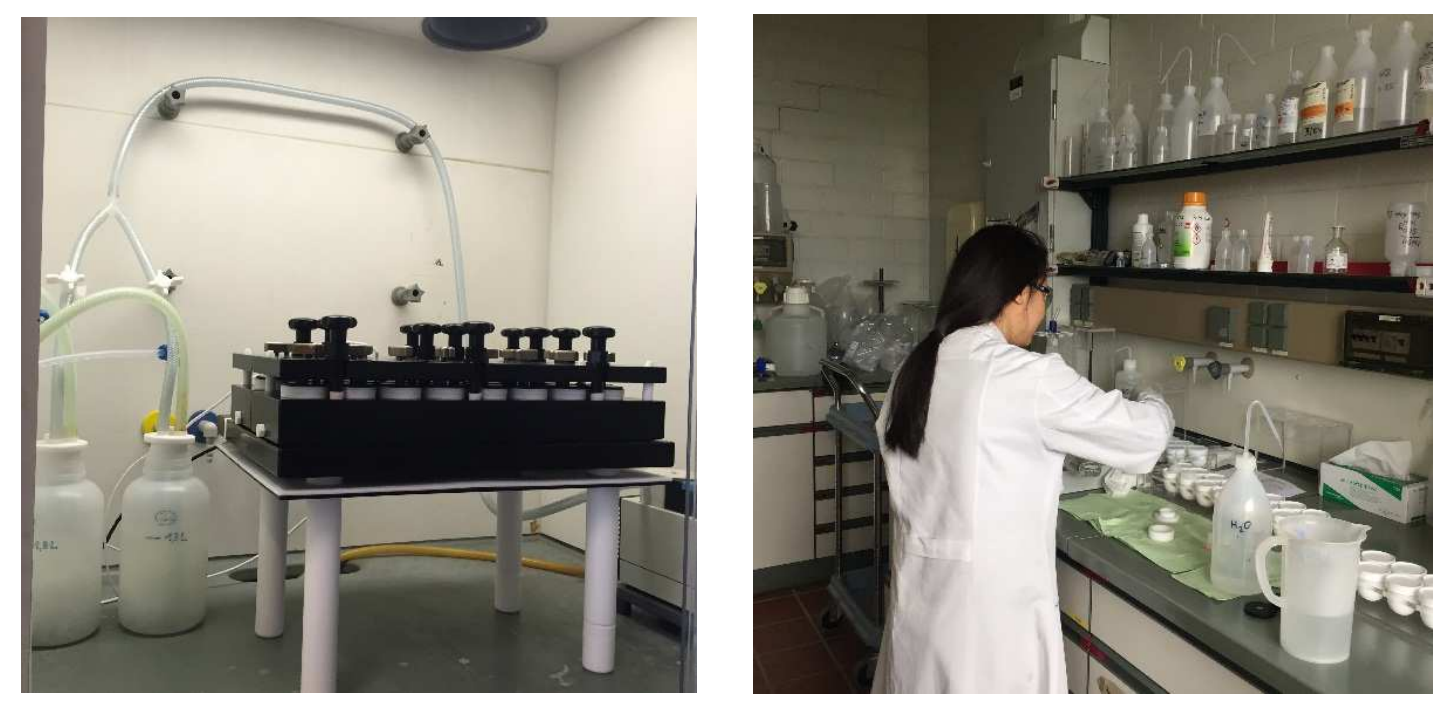

Fig. 2.3 Acid Sample Digestion System DAS 30 from PicoTrace ${ }^{\circledR}$ and dilution process

\subsection{Calculation of physiological concentration and transfer factors of elements}

\section{Physiological concentration in rice plants}

Washing plant samples before analysis is sometimes applied with the aim to remove adhering soil materials and air dust. This washing, however, may not completely eliminate the adhering particles and may partially remove elements contained in the plant tissue. In this study, the plant samples were directly analyzed without a washing step and then 
mathematically corrected for adhering material. This is the basis to calculate the physiological element concentrations in the plant. The physiological concentration represents the concentration of an element that enters the plant through the root (and to a very small extend through the aboveground plant parts like leaves or stalk). The calculation to correct for adhering particles in this work is based on three assumptions: (1) Adhering material can be represented by the local soil particles (this is a acceptable compromise even though a major portion of atmospheric dust consists of soil particle; unfortunately, a detailed sampling and analysis of the local atmospheric dust was not possible during this work); (2) There is only a negligible uptake of elements from the air; (3) Titanium can be used as an indicator element for adhering dust ( $\mathrm{Ti}$ is considered not to be taken up by rice plants). Correction procedures for adhering dust and their limits are presented in detail by Pospiech et al. (2017). The calculation formulas for the physiological concentrations are presented in the section "Materials and methods" of Chapter 5. This calculation is only applied for plant, shoot, and husk concentrations. For the rice grain samples, a particle correction was not necessary, because of their generally very low Ti-concentrations (mostly below detection limit). The husks surrounding the grains prevent that atmospheric or soil particles advance to the grains.

\section{Transfer factors (TFs)}

Transfer factors (TFs) from soils to plant parts are calculated as the ratio of concentration of an element in plant/shoot/husk/unpolished-rice to its concentration in the corresponding soil as seen in "Material and methods" of Chapter 3. The transfer factor represents the ability of an element in the soil to enter the plant. To calculate this translocation ability, physiological concentration in the plant tissues must be applied.

\subsection{Data and statistical analysis}

This research applied the software IBM SPSS statistics 20 (1) to evaluate the influence of the main soil factors such as the concentrations of Fe, Mn, and Al (proxies for oxide/hydroxide and clay minerals) on the concentration of potentially harmful elements in soils, (2) to predict trace element concentrations in soils from soil factors. The procedure is described in section "Material and methods" of Chapter 4. 


\subsection{Health risk assessment}

Health risk assessments of element exposure by rice consumption applied in this thesis include: (1) a comparison of the daily intake amount of an element by eating rice for a typical Vietnamese with the daily Tolerable Upper Intake Level; (2) a comparison between element concentration in rice grain with the permissible Maximum Concentration; (3) calculation of the chronic non-carcinogenic risks from selected harmful elements; and (4) calculation of chronic carcinogenic risks.

(1) Tolerable Upper Intake Level (UL)

Tolerable upper intake level (UL) is the permissible maximum level of total chronic daily intake of an element from all sources including food, supplements and drinking water. This threshold is judged to be unlikely to pose a risk of adverse health effects to humans and are regulated by the European Food Safety Authority (EFSA) and World Health Organization/ Food and Agriculture Organization of the United Nations (WHO/FAO). The ULs may be established for various life age groups. The ULs are not only applied to harmful elements but also to nutrients. An UL exceedance may cause an enhanced risk of adverse reactions. There are still insufficient UL data for some critical elements. In this work, the ULs (mg day ${ }^{-1}$ ) have been calculated for Vietnamese adults with average body weight of $45 \mathrm{~kg}$ for a female and 58 $\mathrm{kg}$ for a male.

In addition, the intake of nutrients is compared with Daily Recommended Dietary Allowances (RDA). The RDA is the average intake level to respond the daily nutrient requirements of the human body (NIH 2015).

(2) Permissible Maximum Concentration in rice grain (MC)

Permissible maximum concentrations (MC) of some potentially harmful elements in rice products are regulated by European Union (2006). The MCs of inorganic As (iAs), Cd, and $\mathrm{Pb}$ in rice grains are $0.2 \mathrm{mg} \mathrm{kg}^{-1}$ for each element. These regulations have been applicable for the European Union whose population consumed 2017 a very low amount of rice of on average of $15.6 \mathrm{~g}$ per day and capita (FAO 2019), 27 times less than Vietnamese people.

(3) Non-carcinogenic risk assessment

Chronic harmful element exposure causes non-carcinogenic adverse effects for human health. The Chronic Hazard Index (HI) helps to estimate the total non-cancer risks of harmful elements for human lifetime exposure. The HI integrates the exposure level and the related 
toxicity into just a value (USEPA 1989; Nordberg 2015). The HI is calculated by the sum of individual non-cancer risk of an element called Target Hazard Quotient (THQ). The calculation for these indexes are indicated in Materials and methods section in Chapter 5.

The HI approach is suitable to compare the toxicity level of foodstuffs or mixtures with each other. Nordberg (2015) noted that this index should be interpreted carefully. It can be used to compare the hazard risk levels among foodstuffs/mixtures. For example, it is feasible to collate the health risk level between rice and wheat to a local community.

(4) Carcinogenic risk assessment

The chronic cancer risks over a lifetime can be judged for individual carcinogenic factor by index Incremental Lifetime Cancer Risk (ILCR) and for total carcinogenic factors by the index Cumulative Cancer Risk ( $\sum$ ILCR) (USEPA 1989). The healthy safe level proposed by USEPA (1989) should be below $10^{-6}$ and the acceptable level is in the range of $10^{-6}$ to $10^{-4}$.

In this approach, two most important carcinogens $\mathrm{As}$ and $\mathrm{Pb}$ are adjusted for rice. Although $\mathrm{Cd}$ is a ubiquitous dangerous carcinogen, its carcinogenic risk comes primarily from inhalation exposure rather than from dietary exposure, so slope factor parameter of oral $\mathrm{Cd}$ exposure cannot be used here. Similar to non-carcinogenic risk index HI, the incremental carcinogenic risk index $\sum \mathrm{ILCR}$ is appropriate to compare foodstuffs/mixtures with each other. The formulas for these indices are exhibited in the Materials and methods section of Chapter 5.

\subsection{References}

European Union (2006). Commission regulation (EC) No 1881/2006 of 19 December 2006 setting the maximum levels for certain contaminants in foodstuffs. Journal of the European Union 32006R1881, Vol. 1881/2006. European Commission: EUR-Lex.

FAO - Food and Agriculture Organization (2019). Food Outlook - Biannual Report on Global Food Markets, pp. 164. http://www.fao.org/3/ca4526en/ca4526en.pdf. Accessed 23 June 2019.

FAO/WHO (2014). Joint FAO/WHO food standards programme codex alimentarius commission. (Vol. REP14/CF). Geneva, Switzerland: FAO/WHO.

NIH - National Institutes of Health (2015). Nutrient Recommendations: Dietary Reference Intakes (DRI). https://ods.od.nih.gov/Health_Information/Dietary_Reference_Intakes.aspx. Accessed 25 June 2019. 
Nordberg, G. F., Gerhardsson, L., Mumtaz, M. M., Ruiz, P., \& Fowler, B. A. (2015).

Interactions and Mixtures in Metal Toxicology. In G. F. Nordberg, B. A. Fowler, \& M. Nordberg (Eds.), Handbook on the Toxicology of Metals (pp. 213-238). UK: Elsevier.

Pospiech, S., Fahlbusch, W., Sauer, B., Pasold, T., \& Ruppert, H. (2017). Alteration of trace element concentrations in plants by adhering particles - Methods of correction.

Chemosphere, 182:501-508. https://doi.org/10.13140/RG.2.2.14457.36961.

USEPA - United States Environmental Protection Agency (1989). Risk Assessment Guide for Superfund (RAGS): volume I, Human Health Evaluation Manual-Part A, baseline risk assessment. https://www.epa.gov/sites/production/files/2015-

09/documents/rags_a.pdf. Accessed 19 March 2019. 


\title{
Chapter 3
}

\section{Harmful and nutrient elements in paddy soils and their transfer into rice grains (Oryza sativa) along two river systems in northern and central Vietnam}

\author{
Thuy Phuong Nguyen ${ }^{1,2}$. Hans Ruppert ${ }^{1}$. Benedikt Sauer ${ }^{1}$. Tino Pasold ${ }^{1}$
}

\section{Citation:}

Nguyen, T. P., Ruppert, H., Sauer, B., \& Pasold, T. (2019). Harmful and nutrient elements in paddy soils and their transfer into rice grains (Oryza sativa) along two river systems in northern and central Vietnam. Environmental Geochemistry and Health, 1-17.

https://doi.org/10.1007/s10653-019-00333-3.

Supplementary material: https://static-content.springer.com/esm/art\%3A10.1007\%2Fs10653019-00333-3/MediaObjects/10653_2019_333_MOESM1_ESM.pdf

\footnotetext{
${ }^{1}$ Department of Sedimentology and Environmental Geology, Faculty of Geoscience and Geography, Georg-August-University Go“ttingen, Goldschmidtstr. 3, 37077 Göttingen, Germany

${ }^{2}$ Department of Environment and Resources Management, Faculty of Land Resources and Agricultural Environment, Hue University of Agriculture and Forestry, 102 Phung Hung Street, Hue City, Vietnam
} 


\section{Abstract}

Thirty soil samples and 24 corresponding unpolished rice samples along the Red and Huong Rivers in northern and central Vietnam respectively, were analyzed in order to evaluate (a) soil geochemistry, (b) factors that determine the transfer of harmful and nutrient elements from soils into rice grains, (c) health risk to the local population through rice consumption. The concentrations of $\mathrm{As}, \mathrm{Bi}$, and $\mathrm{U}$ in the soils of this area are higher relative to those of average shale probably due to natural redox-related processes. Also, $\mathrm{Zn}, \mathrm{Ce}, \mathrm{Th}, \mathrm{La}, \mathrm{Sn}, \mathrm{Pb}$, and $\mathrm{Cd}$ are accumulated in some soils because of mining activities or industrial wastewater application. Arsenic concentrations exceed the Vietnamese allowable limit of $15 \mathrm{mg} \mathrm{kg}^{-1}$ in $80 \%$ of the tested soils. Twelve percent of the unpolished rice grains surpass the permissible maximum concentration of $0.2 \mathrm{mg} \mathrm{Cd} \mathrm{kg}^{-1}$ grain dry matter by FAO/WHO and European Union, and all samples are below the $\mathrm{Pb}$ limit. The daily intake of As is within the range of the tolerable intake levels proposed by the European Food Safety Authority. Influences of soil parameters such as $\mathrm{pH}$ value, contents of soil organic matter, oxides/hydroxides of $\mathrm{Al}, \mathrm{Fe}$, and $\mathrm{Mn}$ cause a broad spread of transfer factors from soil to grains. Positive trends exist between the transfer factors within the groups (a) As, $\mathrm{Sb}$, and $\mathrm{U}$, (b) $\mathrm{Co}, \mathrm{Cu}, \mathrm{Ni}$, and $\mathrm{Zn}$, (c) $\mathrm{Cd}$ and $\mathrm{Mn}$ which indicate similar influences of soil parameters on their uptake. We propose that the allowable $\mathrm{Cd}$ maximum concentration for rice should be set to less than $0.2 \mathrm{mg} \mathrm{kg}^{-1}$. The analysis of As and $\mathrm{Cd}$ concentrations in soils and corresponding rice grains as well as the soil $\mathrm{pH}$ value should be made obligatory in order to prevent intoxication. In addition, critical elements from nonferrous metal mining and industrial areas should also be evaluated.

Keywords Harmful elements $\bullet$ Nutrients $\bullet$ Paddy soils $\bullet$ Unpolished rice $\bullet$ Human health $\bullet$ Vietnam 


\subsection{Introduction}

Paddy soils along rivers receive suspended materials that are deposited through inundation and/or irrigation. In addition, anthropogenic inputs of potentially harmful elements from air pollution, fertilizers (especially phosphates), agrochemicals, compost, sewage sludge, and manure occur in many areas. Industrial waste, mining, traffic, and energy production contribute to harmful levels of potentially toxic elements in soils, plants, food, fodder and water, and consequently impair human.

Health risks that are associated with the exposure to harmful concentrations of trace elements have been widely investigated. Such risks are dependent on quantity, level of exposure and chemical form of the element, as well as age and gender of the consumer (Vinh et al. 2012). Singh and Kalamdhad (2011) described inorganic As, Cd, and Cr(VI) compounds as carcinogens, which can cause cancer of skin, kidney, lung, liver, or bladder, and boneweakness. Additionally, these elements can damage flora and fauna, cause weight and yield loss, diminish reproduction rates and increase mortality rates of organisms (Alloway 2013). Synergistic or antagonistic effects of these elements may intensify or reduce the impact.

Rice is Asia's major staple food crop. More than $90 \%$ of the world's rice is produced here (Arunakumara et al. 2013). In countries with preferential rice diet, the composition of rice determines the transfer of beneficial and harmful elements such as $\mathrm{Cd}$ and As into the human body (Chaney et al. 2016). An early study by Kobayashi (1978) showed that the Cd contamination around a $\mathrm{Zn}-\mathrm{Pb}$ mine in Toyama (Japan) caused the Itai-Itai disease of the local population due to intoxication from drinking water and rice consumption. In Hunan Province, China, the mean As concentration in brown rice grains growing near mining areas was found to be $0.52 \mathrm{mg} \mathrm{kg}^{-1}$, which is 2.6 times higher than the FAO/WHO permissible inorganic As level of $0.2 \mathrm{mg} \mathrm{kg}^{-1}$ (Fan et al. 2017). In a study in Thailand, $62.5 \%$ of white jasmine rice samples and 51.7\% of brown jasmine rice samples surpassed the inorganic As limits for rice (Hensawang and Chanpiwat 2017). In most cases, rural communities living in contaminated regions and eating their own rice are exposed to the greatest health risks.

In Vietnam, the Red River area in the north is the second largest rice-cultivating region behind the Mekong River Delta in the south. In 2016, Vietnam produced 43.6 million tons of rice (28.3 million tons of milled rice) on 7.8 million hectares (FAO 2017). The intensification of rice cultivation is likely to lead to a higher concentration of contaminants in rice and soil through increasing use of fertilizers and pesticides (Ahmed et al. 2008). In addition, some 
agricultural soils close to industrial areas and active mines in Vietnam are highly contaminated. Paddy soils adjacent to mine waste dumps show Pb concentrations of 1271 - 3953 mg kg-1 in Tan Long, Thai Nguyen Province and 250 - $770 \mathrm{mg} \mathrm{kg}^{-1}$ dry soil in Chi Dao, Hung Yen Province in northern Vietnam (Chu 2011). In these areas, the Vietnamese allowable Pb level of $70 \mathrm{mg} \mathrm{kg}^{-1}$ was exceeded 3 - 56 times. Phuong et al. (2010) identified $\mathrm{Cu}, \mathrm{Pb}$, and $\mathrm{Zn}$ enrichments in soils close to a copper-casting handicraft village in Hung Yen Province. In Lam Thao, Phu Tho Province in the north, soils irrigated with wastewater also showed high concentrations of $\mathrm{Cu}\left(204 \mathrm{mg} \mathrm{kg}^{-1}\right), \mathrm{Zn}\left(714 \mathrm{mg} \mathrm{kg}^{-1}\right)$, and $\mathrm{Pb}\left(140 \mathrm{mg} \mathrm{kg}^{-1}\right)$ while their Vietnamese permissible limits are 50, 200, and $70 \mathrm{mg} \mathrm{kg}^{-1}$ respectively (Vinh et al. 2012). The mean concentrations of $\mathrm{As}, \mathrm{Cd}$, and $\mathrm{Pb}$ in unpolished rice at these sites surpassed 2 - 4 times the allowable limit of $0.2 \mathrm{mg} \mathrm{kg}^{-1}$ of each element. In paddy fields along To Lich and Kim Nguu Rivers in Ha Noi Province, the mean concentrations of Cd (4 mg kg-1), Cu (202 mg kg$\left.{ }^{1}\right), \mathrm{Pb}\left(159 \mathrm{mg} \mathrm{kg}^{-1}\right)$, and $\mathrm{Zn}\left(192 \mathrm{mg} \mathrm{kg}^{-1}\right)$ were higher than the allowable soil limits of 2, 50, 70, and $200 \mathrm{mg} \mathrm{kg}^{-1}$ respectively (Huong et al. 2008). The mean content of Cr (3.1 $\left.\mathrm{mg} \mathrm{kg}^{-1}\right)$ and $\mathrm{Pb}\left(2.1 \mathrm{mg} \mathrm{kg}^{-1}\right)$ in rice grains of these fields exceed the permissible limit of 1 and $0.2 \mathrm{mg}$ $\mathrm{kg}^{-1}$ respectively.

The goal of this study is to evaluate (1) the soil composition and enrichment of potentially harmful elements in paddy soils in relation to geogenic background values, (2) the influence of soil factors on the transfer of elements from soil into the rice grain, (3) the daily intake of elements through rice consumption in relation to the daily demand for nutrient elements and the tolerable upper intake levels for potentially toxic elements.

\subsection{Materials and methods}

\subsubsection{Study area}

Paddy soils and corresponding rice samples were collected in September 2015 along the Huong River in central Vietnam and the Red River in northern Vietnam (Fig. 3.1). Five locations were chosen along the Huong River, where the impact of industrial and mining activities is low. The remaining 25 locations were along the lower Red River, which showed some anthropogenic influences. For instance, the samples HN5 to HN9 were taken in the surroundings of a brick factory, PT5 to PT9 near a fertilizer and chemical factory, PT2 and PT4 at the Red River bank. 


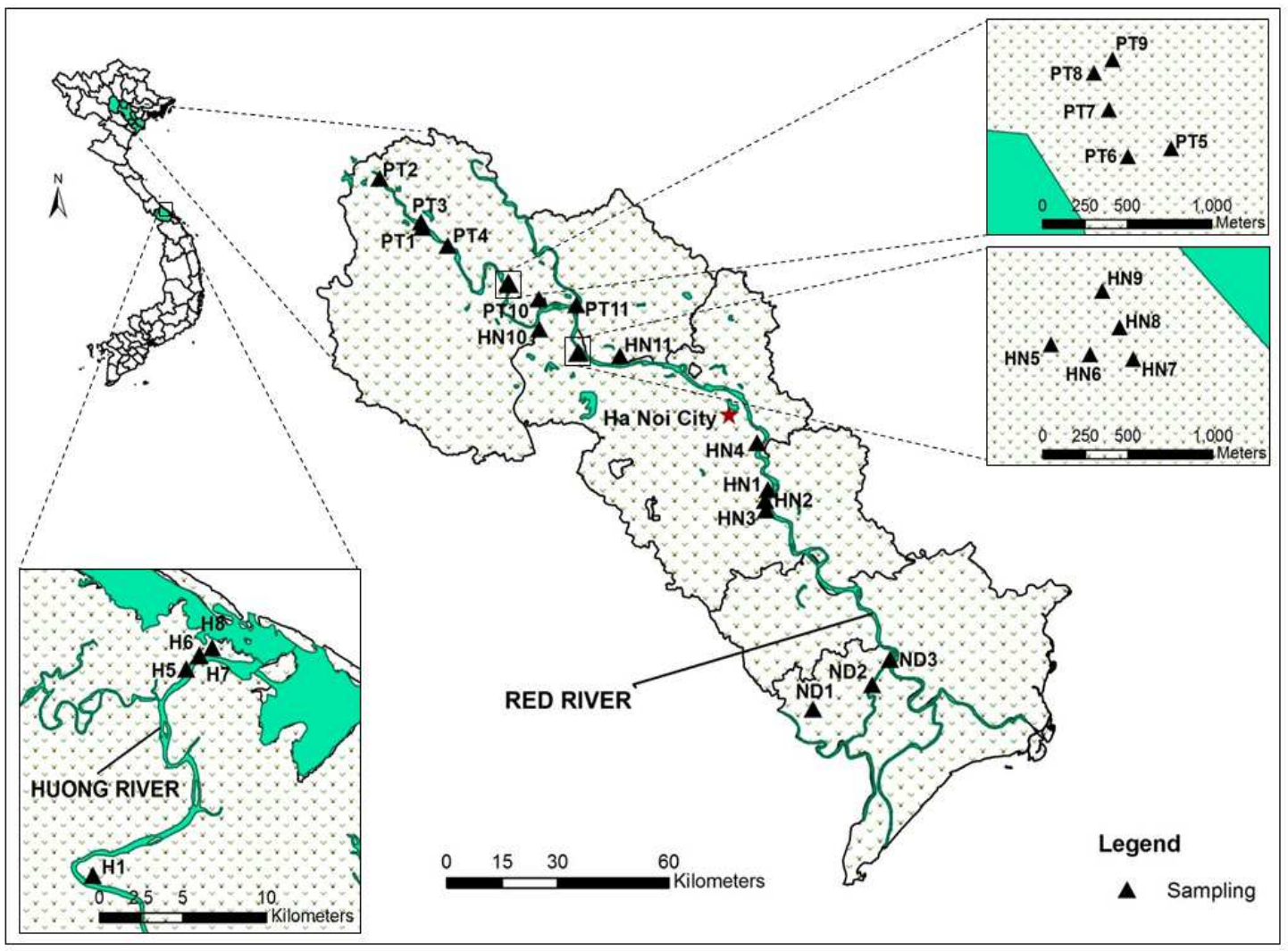

Fig. 3.1 Map of sample locations in central and northern Vietnam

\subsubsection{Sampling, preparation, analysis and calculation}

The soil samples were collected in the rooting zone of the rice plants, which is at $0-10$ $\mathrm{cm}$ depth. All soil and rice samples were taken within ten days before the typical rice harvesting time. The samples were air-dried and transported to Germany. Soil samples were dried at $105^{\circ} \mathrm{C}$, and rice samples at $60^{\circ} \mathrm{C}$ in the laboratory of the Geoscience Center of Göttingen University. All samples were pulverized to particle sizes $<63 \mu \mathrm{m}$ by an agate ball mill (Fritsch Pulverisette 5) and the grain samples were ground by hand with an agate mortar. Soil $\mathrm{pH}$ was measured in a 1:2.5 mixture of air-dried soil and $0.01 \mathrm{M} \mathrm{CaCl}_{2}$ solution by using a glass electrode WTW ProfiLine pH/mV-Meter 197. To quantify element concentrations in the soil and rice grain samples, $150 \mathrm{mg}$ of pulverized soil and $700 \mathrm{mg}$ of grain power were completely digested in a mixture of the ultrapure concentrated acids $\mathrm{HNO}_{3}, \mathrm{HF}$, and $\mathrm{HClO}_{4}$ in a closed ultra-clean PTFE vessel (PicoTrace®, Bovenden, Acid Sample Digestion System DAS 30). To dissolve precipitated aluminum and iron oxides/hydroxides, a small amount of $\mathrm{HCl}$ was added in the last step of the soil digestion procedure. The resulting clear solutions were diluted to 100 $\mathrm{ml}$ and $50 \mathrm{ml}$ for soil and plant samples respectively. In addition, blank (only acids without 
sample material) and reference samples were included into every digestion series. The elements in the solution were quantified by Inductively Coupled Plasma - Optical Emission Spectrometry (ICP-OES) Agilent 5100 VDV and by Inductively Coupled Plasma - Mass Spectrometry (ICP-MS) Thermo Scientific iCAP Q. The reproducibility and accuracy of measurements were checked by an in-house and international reference rock (Wissenbach slate TW45; lake sediment GSJ-JLk-1) and reference plant materials (Bush branches and leaves NCS DC 73349; maize plant WEPAL-IPE-126). The detailed results of the reference samples, and the selected wavelength (ICP-OES) and mass (ICP-MS) that were used for every element are listed in Tables A1.1 in Appendix A1. For most elements, the deviation from certified values was smaller than $5 \%$.

Loss on ignition (LOI) is used as a proxy for the content of organic matter and of water in clay mineral, and oxides/hydroxides in the soil. The LOI was determined as the weight loss by heating $500 \mathrm{mg}$ of the milled soil samples to $530^{\circ} \mathrm{C}$ for 2 hours. The approximate $\mathrm{SiO}_{2}$ concentration was calculated as follows:

$$
\mathrm{SiO}_{2}=[100-(\text { main element oxides }+ \text { minor element oxides }+\mathrm{LOI})] \quad(\text { wt. \%) }
$$

\subsection{Results and discussion}

\subsubsection{Soil geochemistry}

The parent materials of the analyzed paddy soil samples in the Red River area are mainly alluvial sediments of the Yunnan Plateau and of the surrounding highlands. The Huong River transports mainly eroded material from the Annamite Range. Descriptive statistics of the concentrations of selected elements in the analyzed paddy soils, the average shale and Earth crust are listed in Table 3.1. A single dataset of every sample is provided in Table A1.2 in Appendix A1.

The soils contain more water and organic matter compared to rock materials. The average LOI value for the soils is $6.6 \%$, which suggests that element concentrations on an LOIfree basis would be higher by a factor 1.066. However, this aspect is not considered in this study.

Because of the lack of geochemical data on the parent material in the drainage basins of the two rivers, the soil data are compared with the average composition of shale or Earth crust as reference. The ratios of the median element concentration in soil $\mathrm{El}_{\text {soil }}$ to the mean 
element concentration in shale $\mathrm{El}_{\text {shale }}$ are given in Table 3.1. The following trends of element depletion or enrichment are typical for the investigated soils from both areas:

- Depleted elements (decreasing depletion): $\mathrm{Ca}, \mathrm{S}, \mathrm{Mg}, \mathrm{Ni}, \mathrm{Li}, \mathrm{Sr}, \mathrm{Mn}, \mathrm{Na}, \mathrm{K}$, $\mathrm{Mo}, \mathrm{Cr}, \mathrm{Ba}, \mathrm{Hf}, \mathrm{Co}, \mathrm{V}, \mathrm{Zr}, \mathrm{Fe}, \mathrm{Sb}$

- Elements with changes less than 10\%: $\quad \mathrm{Cu}, \mathrm{Tl}, \mathrm{Sc}, \mathrm{Rb}, \mathrm{Al}, \mathrm{Ga}, \mathrm{Ti}, \mathrm{Si}$

- Enriched elements (increasing enrichment): P, Ce, Cs, Th, U, La, Nb, Sn, Pb, As, Cd, Bi.

Losses of $\mathrm{Ca}, \mathrm{Mg}$ and $\mathrm{Na}$ result from chemical weathering, soil acidification, and anthropogenic activities such as agricultural practices. Low soil $\mathrm{pH}$ and deficiency of $\mathrm{Ca}$ and $\mathrm{Mg}$ in soils do not only decrease crop yield, but also increase the susceptibility of plants to trace metal uptake (Gransee and Führs 2013). The soil pH values along the Huong River range from 4.2 to 4.7 , which are lower than those in the Red River soils with most $\mathrm{pH}$ values $>5.5$. Lower $\mathrm{pH}$ values coincide with the low concentrations of $\mathrm{Ca}, \mathrm{Na}$, and $\mathrm{Mg}$ in the Huong area. Thus, the soil pH-buffering and fertilizing elements are widely missing in the Huong area. The $\mathrm{SiO}_{2}$ concentration is high in this area because of the high presence of quartz.

The median concentrations of some elements are considerably higher than the average shale concentrations ( $\mathrm{Sn} 1.9$ times, $\mathrm{Pb}$ and $\mathrm{As} 2.0$ times, $\mathrm{Bi} 4.6$ times). The accumulation of $\mathrm{As}$ is caused by natural redox processes and can be explained by the following steps (Fendorf and Kocar 2009, Polizzotto et al. 2008):

- Uplifting, weathering, and erosion of rocks in the mountains and oxidation of $\mathrm{Fe}^{\mathrm{II}}$ and As ${ }^{\text {III-bearing sulfides }}$

- Oxidation of these Fe and As compounds, precipitation of Fe $\mathrm{Fe}^{\mathrm{III}}$ oxides/hydroxides and sorption of $\mathrm{As}^{\mathrm{V}}$

- Transportation and deposition of suspended material, including As-rich Fe-phases in river systems and paddy fields

- Reduction of the As-containing Fe-phases forming dissolved $\mathrm{Fe}^{\mathrm{II}}$ and $\mathrm{As}^{\mathrm{III}}$ in anaerobic soils of rice fields, facilitating the uptake of As by rice plants.

A similar natural enrichment mechanism might be applicable to $\mathrm{Bi}$. 
Table 3.1 Statistics on selected element concentrations in the studied soils $(n=30)$ in comparison with average shale, Earth crust, and maximum allowable limit in agricultural soil (main elements from LOI to $\mathrm{SiO}_{2}$ in wt. \%, and trace elements in $\mathrm{mg} \mathrm{kg}^{-1}$ dry matter)

\begin{tabular}{|c|c|c|c|c|c|c|c|c|c|c|c|}
\hline Element & Min & Q1 N & Median & Q3 & Max & Mean & Stdev & Shale & $\begin{array}{l}\text { Earth } \\
\text { crust }\end{array}$ & $\begin{array}{l}\mathrm{El}_{\text {soil }} / \\
\mathrm{El}_{\text {shale }}\end{array}$ & $\begin{array}{c}\text { Allowable } \\
\text { limits }\end{array}$ \\
\hline $\mathrm{pH}$ & 4.2 & 5.1 & 5.9 & 6.7 & 7.3 & 5.9 & 1.0 & - & - & & - \\
\hline LOI & 3.5 & 5.2 & 6.5 & 7.2 & 11.1 & 6.6 & 1.9 & - & - & & - \\
\hline $\mathrm{Al}_{2} \mathrm{O}_{3}$ & 7.4 & 12.4 & 15.1 & 16.3 & 18.3 & 14.4 & 2.7 & $15.1^{\mathrm{a}}$ & $15.4^{\mathrm{c}}$ & 1.00 & - \\
\hline $\mathrm{CaO}$ & 0.29 & 0.43 & 0.56 & 0.88 & 2.08 & 0.72 & 0.43 & $3.3^{\mathrm{b}}$ & $3.59^{c}$ & 0.17 & - \\
\hline $\mathrm{Fe}_{2} \mathrm{O}_{3}$ & 2.8 & 5.2 & 6.0 & 6.5 & 13.1 & 6.2 & 2.1 & $6.9^{\mathrm{d}}$ & $5.0^{c}$ & 0.87 & - \\
\hline $\mathrm{K}_{2} \mathrm{O}$ & 1.00 & 2.2 & 2.5 & 2.8 & 3.2 & 2.4 & 0.51 & $3.8^{\mathrm{b}}$ & $2.8^{\mathrm{c}}$ & 0.66 & - \\
\hline $\mathrm{MgO}$ & 0.54 & 1.00 & 1.35 & 1.61 & 1.93 & 1.28 & 0.39 & $2.7^{\mathrm{d}}$ & $2.5^{\mathrm{c}}$ & 0.51 & - \\
\hline $\mathrm{MnO}$ & 0.027 & 0.042 & 0.062 & 0.081 & 0.116 & 0.063 & 0.025 & $0.11^{\mathrm{d}}$ & $0.10^{c}$ & 0.56 & - \\
\hline $\mathrm{Na}_{2} \mathrm{O}$ & 0.27 & 0.43 & 0.66 & 0.73 & 1.51 & 0.65 & 0.26 & $1.01^{\mathrm{b}}$ & $3.3^{\mathrm{c}}$ & 0.65 & - \\
\hline $\mathrm{P}_{2} \mathrm{O}_{5}$ & 0.09 & 0.14 & 0.19 & 0.22 & 0.47 & 0.19 & 0.07 & $0.16^{\mathrm{a}}$ & $0.15^{\mathrm{c}}$ & 1.19 & - \\
\hline $\mathrm{S}$ & 0.016 & 0.030 & 0.045 & 0.061 & 0.87 & 0.090 & 0.176 & $0.24^{\mathrm{a}}$ & $0.056^{\mathrm{c}}$ & 0.19 & - \\
\hline $\mathrm{TiO}_{2}$ & 0.54 & 0.75 & 0.83 & 0.88 & 0.92 & 0.81 & 0.09 & $0.77^{\mathrm{d}}$ & $0.64^{\mathrm{c}}$ & 1.08 & - \\
\hline $\mathrm{SiO}_{2}$ & 56.0 & 62.0 & 66.6 & 69.0 & 81.2 & 66.6 & 6.1 & $60.5^{\mathrm{b}}$ & $66.6^{c}$ & 1.10 & - \\
\hline As & 9.5 & 15.9 & 19.8 & 24.2 & 49.7 & 21.9 & 10.0 & $10.0^{\mathrm{d}}$ & $4.8^{\mathrm{c}}$ & 1.98 & $15.0^{\mathrm{e}}$ \\
\hline $\mathrm{Ba}$ & 159 & 378 & 428 & 455 & 815 & 423 & 108 & $636^{\mathrm{b}}$ & $624^{c}$ & 0.67 & - \\
\hline $\mathrm{Bi}$ & 0.22 & 0.46 & 0.60 & 0.79 & 3.7 & 0.84 & 0.79 & $0.13^{\mathrm{d}}$ & $0.16^{\mathrm{c}}$ & 4.62 & - \\
\hline $\mathrm{Cd}$ & 0.17 & 0.30 & 0.34 & 0.45 & 6.5 & 0.56 & 1.12 & $0.13^{\mathrm{d}}$ & $0.09^{c}$ & 2.62 & $1.50^{\mathrm{f}}$ \\
\hline $\mathrm{Ce}$ & 55 & 79 & 89 & 97 & 184 & 91 & 26 & $67^{\mathrm{b}}$ & $63^{c}$ & 1.33 & - \\
\hline Co & 7.3 & 13.7 & 15.9 & 19.0 & 49.6 & 16.5 & 7.3 & $19.0^{\mathrm{d}}$ & $17.3^{\mathrm{c}}$ & 0.84 & $20-50^{\mathrm{e}}$ \\
\hline $\mathrm{Cr}$ & 30 & 48 & 60 & 77 & 128 & 64 & 24 & $90^{\mathrm{d}}$ & $92^{c}$ & 0.67 & $150^{f}$ \\
\hline Cs & 3.2 & 6.0 & 7.4 & 10.4 & 12.0 & 7.8 & 2.5 & $5.2^{\mathrm{b}}$ & $4.9^{c}$ & 1.42 & - \\
\hline $\mathrm{Cu}$ & 20 & 37 & 41 & 52 & 885 & 72 & 154 & $45^{\mathrm{d}}$ & $28^{c}$ & 0.91 & $100^{f}$ \\
\hline $\mathrm{Ga}$ & 10 & 17 & 20 & 23 & 27 & 20 & 4 & $19^{\mathrm{a}}$ & $17.5^{\mathrm{c}}$ & 1.05 & - \\
\hline $\mathrm{Hf}$ & 1.6 & 3.5 & 4.3 & 4.7 & 5.0 & 4.0 & 0.9 & $6.3^{\mathrm{b}}$ & $5.3^{\mathrm{c}}$ & 0.68 & - \\
\hline $\mathrm{La}$ & 27 & 38 & 45 & 47 & 90 & 44 & 11 & $31^{\mathrm{b}}$ & $31^{\mathrm{c}}$ & 1.45 & - \\
\hline $\mathrm{Li}$ & 18 & 30 & 36 & 47 & 56 & 38 & 12 & $66^{\mathrm{a}}$ & $21^{\mathrm{c}}$ & 0.55 & - \\
\hline Мо & 0.41 & 0.68 & 0.86 & 1.26 & 2.50 & 1.04 & 0.56 & $1.3^{\mathrm{d}}$ & $1.1^{\mathrm{c}}$ & 0.66 & $4-10^{\mathrm{e}}$ \\
\hline $\mathrm{Nb}$ & 13 & 18 & 21 & 23 & 38 & 21 & 5 & $11^{\mathrm{a}}$ & $12^{\mathrm{c}}$ & 1.91 & - \\
\hline $\mathrm{Ni}$ & 19 & 32 & 37 & 48 & 58 & 38 & 11 & $68^{\mathrm{d}}$ & $47^{c}$ & 0.54 & $20-60^{\mathrm{e}}$ \\
\hline $\mathrm{Pb}$ & 23 & 35 & 43 & 58 & 86 & 48 & 18 & $22^{\mathrm{d}}$ & $17^{\mathrm{c}}$ & 1.95 & $70^{f}$ \\
\hline $\mathrm{Rb}$ & 49 & 107 & 124 & 139 & 164 & 118 & 27 & $125^{\mathrm{b}}$ & $84^{\mathrm{c}}$ & 0.99 & - \\
\hline $\mathrm{Sb}$ & 1.0 & 1.6 & 1.9 & 2.2 & 3.5 & 2.0 & 0.6 & $2.1^{\mathrm{b}}$ & $0.4^{\mathrm{c}}$ & 0.90 & $10^{\mathrm{e}}$ \\
\hline $\mathrm{Sc}$ & 6.1 & 11.2 & 14.2 & 15.3 & 18.8 & 13.4 & 3.0 & $14.9^{\mathrm{b}}$ & $14^{\mathrm{c}}$ & 0.95 & \\
\hline Sn & 3.3 & 3.9 & 4.8 & 5.3 & 8.0 & 4.8 & 1.1 & $2.5^{\mathrm{d}}$ & $2.1^{\mathrm{c}}$ & 1.92 & $50^{e}$ \\
\hline $\mathrm{Sr}$ & 30 & 51 & 78 & 82 & 170 & 74 & 28 & $142^{\mathrm{b}}$ & $320^{c}$ & 0.55 & - \\
\hline Th & 9.1 & 16.0 & 17.6 & 19.3 & 29.9 & 17.8 & 3.6 & $12.3^{\mathrm{b}}$ & $10.5^{\mathrm{c}}$ & 1.43 & - \\
\hline $\mathrm{Tl}$ & 0.31 & 0.53 & 0.62 & 0.71 & 0.81 & 0.60 & 0.13 & $0.68^{\mathrm{d}}$ & $0.90^{c}$ & 0.91 & - \\
\hline $\mathrm{U}$ & 2.8 & 3.5 & 3.9 & 4.2 & 6.7 & 4.0 & 0.8 & $2.7^{\mathrm{b}}$ & $2.7^{\mathrm{c}}$ & 1.44 & - \\
\hline V & 55 & 92 & 110 & 123 & 165 & 109 & 25 & $130^{\mathrm{d}}$ & $97^{\mathrm{c}}$ & 0.85 & - \\
\hline $\mathrm{Zn}$ & 64 & 86 & 107 & 129 & 1725 & 160 & 297 & $95^{\mathrm{a}}$ & $67^{\mathrm{c}}$ & 1.13 & $200^{f}$ \\
\hline $\mathrm{Zr}$ & 47 & 109 & 136 & 148 & 154 & 125 & 29 & $160^{\mathrm{a}}$ & $193^{c}$ & 0.85 & \\
\hline
\end{tabular}


The presence of Fe oxides/hydroxides is shown in studies by Postma et al. $(2012,2016)$ and Sø et al. (2018), who analyzed various sediments that were deposited along the Red River. They identified in suboxic to anoxic sediments under inert $\mathrm{N}_{2}$ atmosphere, strongly varying $\mathrm{Fe}$ oxide concentrations between 1 and $77 \mu \mathrm{mol} / \mathrm{g}$ Fe (corresponding to 0.008 to 0.61 wt. \% $\mathrm{Fe}_{2} \mathrm{O}_{3}$ ), with the highest concentrations in the most recent sediments. The authors calculated that some of the $\mathrm{Fe}^{\mathrm{II}}$ might exist as siderite $\left(\mathrm{FeCO}_{3}\right)$. In the younger sediments the ratios As to Fe (bound as oxide) are fairly stable at $1.2 \mathrm{mmol} / \mathrm{mol}$, which corresponds to $1126 \mathrm{mg} \mathrm{As} \mathrm{kg}^{-1}$ $\mathrm{Fe}_{2} \mathrm{O}_{3}$. Similar solution precipitation dynamics are assumed for the paddy soils that are investigated in this paper.

The enrichment of $\mathrm{Pb}$ and $\mathrm{Cd}$ has different anthropogenic sources (emission and fertilizers). Both elements are deposited from the atmosphere and from contaminated river suspension in the irrigation water used. Cadmium may have been additionally accumulated through the application of phosphate fertilizer (Chen and Graedel 2015; Kratz et al. 2016). The paddy soils along Huong River in central Vietnam are less affected by anthropogenic activities compared to those along the Red River in the north. The Red River soils have higher Cd and $\mathrm{Pb}$ concentrations and slightly elevated contents of $\mathrm{As}, \mathrm{Bi}, \mathrm{Cr}, \mathrm{Cu}, \mathrm{Ni}, \mathrm{P}, \mathrm{Zn}, \mathrm{Mn}$, and $\mathrm{Fe}$ (see Table A1.2 in Appendix A1). Reasons might be the higher content of Fe- and Mnoxides/hydroxides enriched with these elements.

Some sites contain extraordinarily high concentrations of various elements (detailed data in Table A1.2 in Appendix A1):

- Soils sampled at PT2 and PT4, which were taken close to the Red River, show strong enrichments of $\mathrm{Ca}, \mathrm{Mg}, \mathrm{Na}, \mathrm{As}, \mathrm{Bi}, \mathrm{Cd}, \mathrm{Cu}, \mathrm{Mn}, \mathrm{Pb}, \mathrm{Sb}, \mathrm{Sn}, \mathrm{Zn}$, and of some rareearth elements like $\mathrm{La}$ and $\mathrm{Ce}$. These elements may be accumulated over time through river-transported materials. Considering that there are mining activities along the upper Red River, these enrichments might be caused by the exploitation of the Adebo monazite (Ce[PO4]) mine in Jinping (Xie et al. 2016), the Yuanjiang Gold Mine, Gejiu Tin Mine, and Laojinshan Gold Mine in the mountains south of Dali in China`s Yunnan Province (Yang et al. 2014). Soil contamination around these mines might deliver additional contamination via the Yuan River into the Red River.

- Soils sampled at PT5, PT6, and PT7 were taken within a radius of 700 meters around Lam Thao fertilizer and chemical factory. During sampling, the soil surfaces were covered by $50 \mathrm{~cm}$ of water, which was unusually high. PT5, PT6, and PT7 contain 
9.2, 13.1, and $11.4 \% \mathrm{Fe}_{2} \mathrm{O}_{3}$ respectively, which are nearly twice as much as the median value of the other soil samples. One reason for such elevated concentrations can be the discharge of iron-rich municipal wastewater on these sites (KabataPendias 2011). In these soils, Cr reaches extreme values of 109, 200, and $194 \mathrm{mg} \mathrm{kg}^{-}$ ${ }^{1}$ respectively. One reason can be the discharge of polluted municipal wastewater. In addition, PT5 is strongly enriched in $\mathrm{As}, \mathrm{Cd}, \mathrm{Cu}, \mathrm{Pb}, \mathrm{Zn}, \mathrm{Co}, \mathrm{Mo}, \mathrm{U}, \mathrm{LOI}$, and $\mathrm{S}$, what is possibly caused by the contaminated effluents from the factory. Portions of these elements (including $\mathrm{Fe}$ ) are probably bound as sulfides with the exception of $\mathrm{Ce}, \mathrm{La}$, and $\mathrm{U}$.

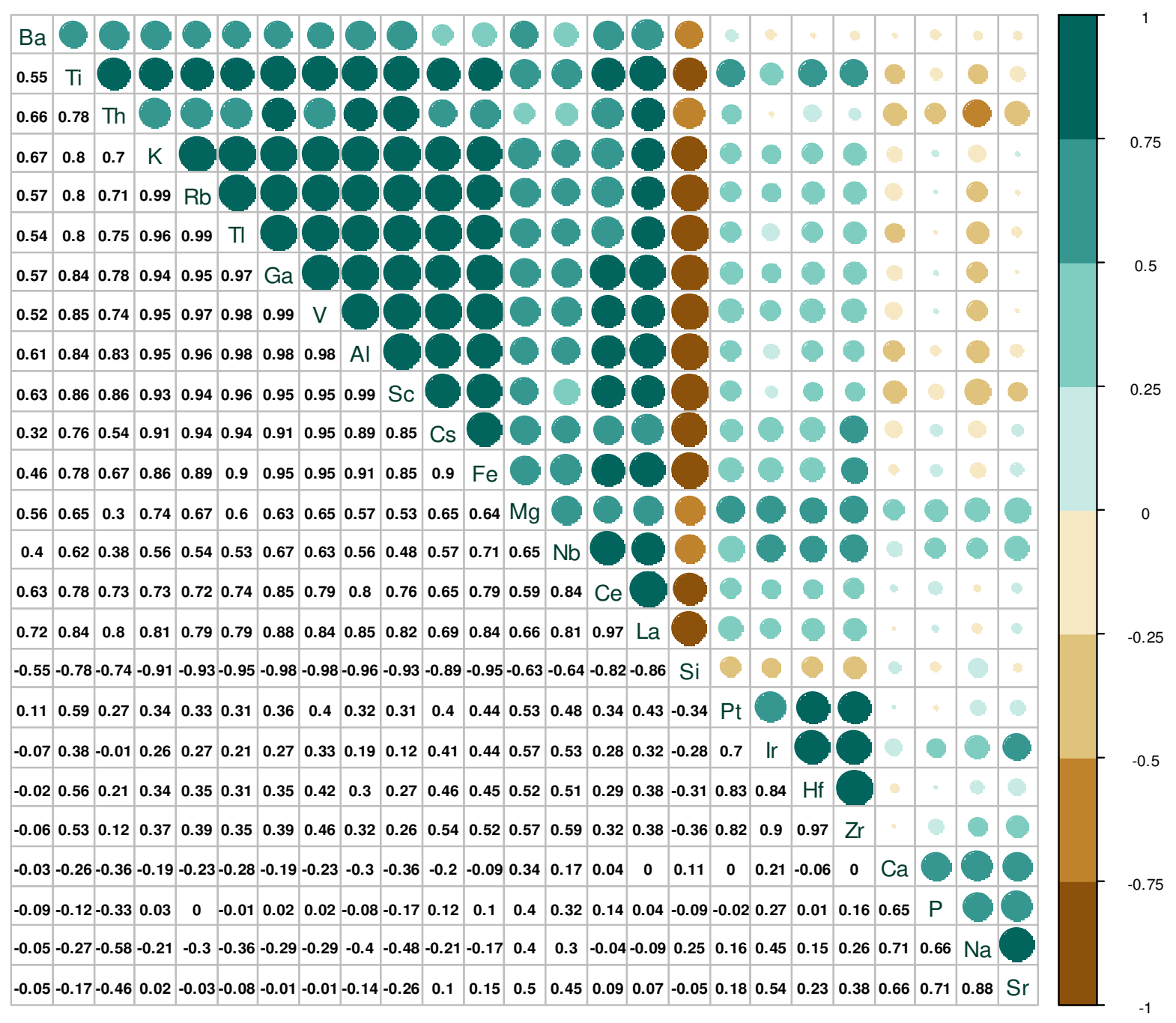

Fig. 3.2 Correlation matrix of soil element concentrations with no or negligible human influence. Diameter and color of the circles change with the value of the correlation coefficient 


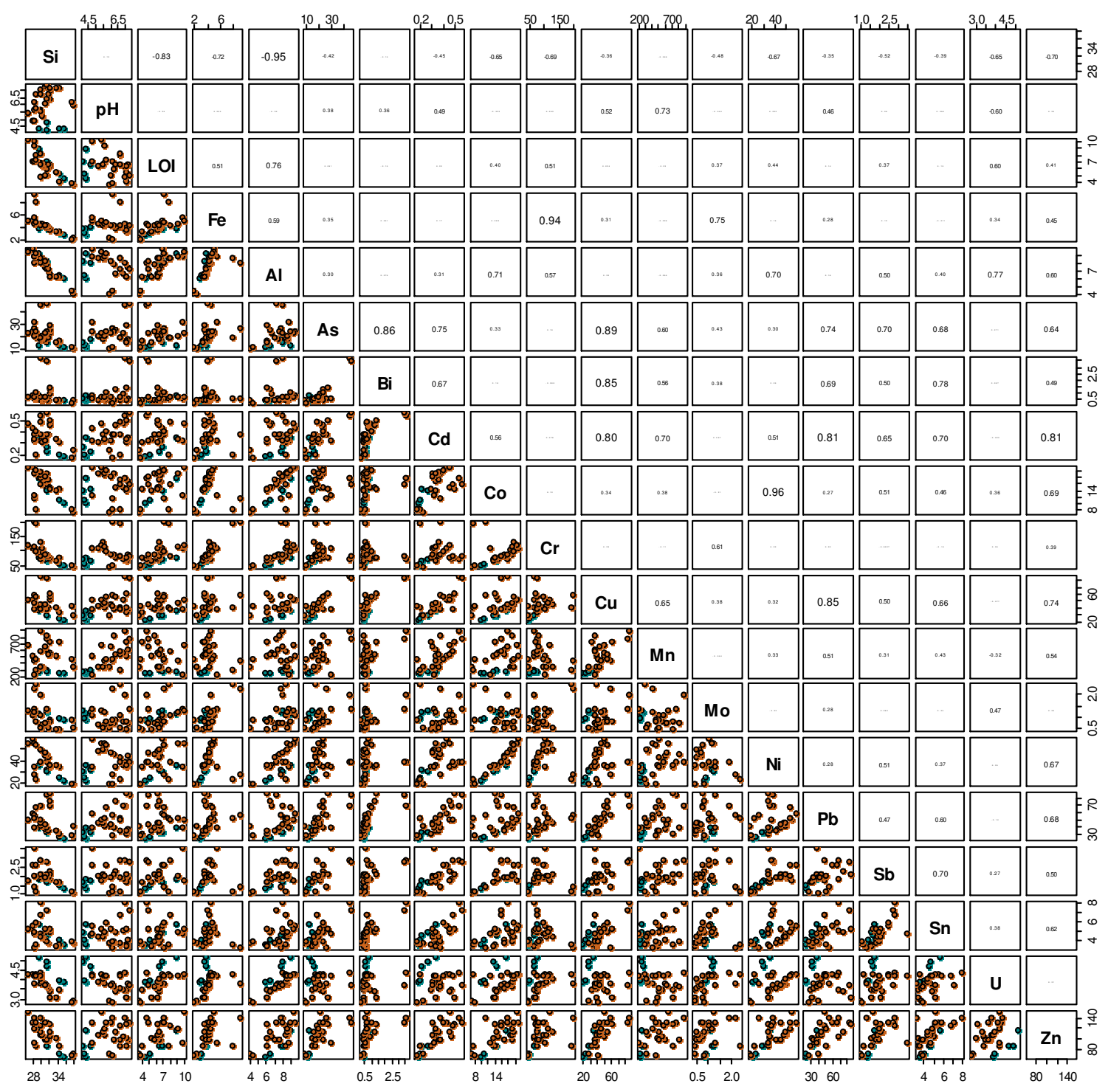

Fig. 3.3 Correlation plots of trace element concentrations in soils (site PT5 and sulfur in PT10 are excluded). Blue dots represent samples from the Huong River, red dots samples from the Red River

To get further information on the association of elements within soils, Pearson productmoment correlation coefficients for element concentration pairs are calculated. Elements, which are not or only slightly influenced by man, are visualized in Fig. 3.2. They are selected if the shale-normalized element ratio is less than or equal to 1 as shown in Table 3.1. There are four element groups with significant positive correlation coefficients:

- The first group comprises the elements Ba, Ti, Th, K, Rb, Tl, Ga, V, Al, Sc, Cs, Fe, $\mathrm{Mg}, \mathrm{Nb}, \mathrm{Ce}$, and La. All these elements are enriched in clay minerals and/or Fe 
oxides/hydroxides, which are often intimately associated in soils and sediments. Their negative correlation with $\mathrm{Si}$ is due to the increased concentrations of quartz $\left(\mathrm{SiO}_{2}\right)$ and bio-opal $\left(\mathrm{SiO}_{2} \cdot \mathrm{nH}_{2} \mathrm{O}\right)$. These phases dilute the other elements, which cause their positive correlations. The elements $\mathrm{K}, \mathrm{Rb}, \mathrm{Al}, \mathrm{Fe}, \mathrm{Sc}, \mathrm{La}, \mathrm{Ga}$, and $\mathrm{V}$ form a subgroup with very high correlation coefficients of $\mathrm{r}>0.8 \mathrm{Al}$ and $\mathrm{Fe}$ have a correlation coefficient of $r=0.91$, whereby the extreme Fe-rich samples PT5, PT6 and PT7 were excluded.

- The second group comprises Hf and $\mathrm{Zr}$ with $\mathrm{r}=0.97$. Their strong correlations can be explained by their comparable parent material, poor mobility in soil, and dilution with quartz. They are bound in their own weathering-resistant phases.

- The third group contains the highly correlated elements $\mathrm{Ca}, \mathrm{P}, \mathrm{Na}$, and Sr. These elements are fairly mobile during weathering, but they are also added by phosphate and lime fertilizers (except for $\mathrm{Na}$ ).

- LOI shows a positive correlation with $\mathrm{S}$ and to a certain degree with $\mathrm{Al}$ and Fe that have water bound phases. Sulfur is usually enriched in organic material or as sulfide in reducing environments (as assumed for the sites PT5 and PT10).

The elements $\mathrm{Co}, \mathrm{Cr}, \mathrm{Cu}, \mathrm{Mo}, \mathrm{Ni}$, and $\mathrm{Sb}$ are not enriched relative to shale. However, they are plotted in Fig. 3 because they belong to the potentially toxic elements group as listed by Alloway (2013). The correlations between the concentrations of these critical elements are plotted against each other in Fig. 3.3. Many of these elements such as $\mathrm{As}, \mathrm{Cd}, \mathrm{Co}, \mathrm{Cr}, \mathrm{Cu}, \mathrm{Mo}$, $\mathrm{Ni}, \mathrm{Pb}, \mathrm{Sb}, \mathrm{U}$, and $\mathrm{Zn}$ have positive correlations with $\mathrm{Al}$ and $\mathrm{Fe}$. Reasons are that the nearly amorphous Al- and Fe-rich weathering phases are able to accumulate these critical elements by sorption and co-precipitation (Lair et al. 2007; Young 2013). Manganese shows only slight correlations with the other trace elements. Presumably, oxidic Mn-phases are not present due to the low oxidation speed of $\mathrm{Mn}^{2+}$ during aeration of paddy soils. Excluding some specific samples with stronger enrichments, some elements show remarkable correlations with each other: group 1 - $\mathrm{Co}, \mathrm{Ni}, \mathrm{Cr}$; group 2 - As, $\mathrm{Bi}, \mathrm{Cu}, \mathrm{Pb}$; group 3 - Zn, Cd, Sb. The elements of group 1 may have similar concentration ratios in the parent material, and their geochemical behavior is similar. The elements in group 2 and 3 are additionally affected by the redox behavior of $\mathrm{Fe}$ in the paddy fields during the growing season (release of the elements during reduction of Fe-oxides/hydroxides and sorption/co-precipitation during oxidation events). 
Most element concentrations in the analyzed paddy soils are within the Vietnamese national technical regulation on the allowable limits of heavy metals in the soils (QCVN 2015) except for As. $80 \%$ of the samples exceed the As concentration limit of $15 \mathrm{mg} \mathrm{kg}^{-1}$ in; $13 \%$ surpass the limit by more than a factor of 2 . The median As concentration of $19.8 \mathrm{mg} \mathrm{kg}^{-1}$ is considerably higher than those of agricultural soils in the U.S. and Europe with 7.2 and $5.5 \mathrm{mg}$ $\mathrm{kg}^{-1}$ respectively (Kabata-Pendias 2011; Reimann et al. 2018). In addition, sample PT5 located near the fertilizer and chemical factory exceeds the allowable levels for Vietnamese agricultural soil for As by factor 3.3, Cd by 4.3, Cu by 8.9, Pb by 1.1, and $\mathrm{Zn}$ by 8.6.

\subsubsection{Transfer of elements from soil into unpolished rice}

Descriptive statistics of the concentrations and transfer factors of nutrients and potentially harmful elements in unpolished rice are shown in Table 3.2 (the detailed values are listed in Table A1.3 and A1.4 in Appendix A1). To evaluate the transport ability of elements from soil to rice grains, transfer factors (TF) are calculated (Table 2) according to:

$$
T F=E l_{\text {rice grain }} / E l_{\text {soil }}
$$

In which $\mathrm{El}_{\text {rice grain }}$ refers to element concentration in rice grains, $\mathrm{El}_{\text {soil }}$ to the corresponding soil concentration (Sauer \& Ruppert 2013).

Table 3.2 Concentrations and transfer factors of selected elements in unpolished rice $(n=24)$

\begin{tabular}{|c|c|c|c|c|c|c|c|c|c|}
\hline \multirow{2}{*}{ Elements } & \multicolumn{5}{|c|}{ Concentration $\left(\mathrm{mg} \mathrm{kg}^{-1}\right)$} & \multicolumn{4}{|c|}{ Transfer factors } \\
\hline & Min & Median & $\operatorname{Max}$ & Mean & Stdev & Min & Median & Max & Mean Stdev \\
\hline $\mathrm{Al}$ & $<4$ & $<4$ & 15.4 & $<4$ & 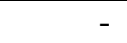 & $<0.00005$ & $<0.00005$ & 0.00020 & $<0.00005$ \\
\hline $\mathrm{Ca}$ & 106 & 135 & 163 & 135 & 14 & 0.008 & 0.029 & 0.073 & $\begin{array}{ll}0.035 & 0.018\end{array}$ \\
\hline $\mathrm{Fe}$ & 8.3 & 11.0 & 19.3 & 11.3 & 2.4 & 0.0001 & 0.0003 & 0.0005 & 0.00030 .0001 \\
\hline K & 2356 & 2966 & 3352 & 2916 & 263 & 0.10 & 0.15 & 0.36 & 0.16 \\
\hline $\mathrm{Mg}$ & 1104 & 1381 & 1591 & 1368 & 134 & 0.11 & 0.19 & 0.42 & 0.20 \\
\hline $\mathrm{Mn}$ & 12 & 22 & 45 & 22 & 6 & 0.015 & 0.042 & 0.22 & $\begin{array}{ll}0.059 & 0.043\end{array}$ \\
\hline $\mathrm{Na}$ & 2.7 & 3.9 & 8.4 & 4.4 & 1.5 & 0.0004 & 0.0010 & 0.0032 & 0.00120 .0008 \\
\hline $\mathrm{P}$ & 2656 & 3613 & 4167 & 3519 & 385 & 2.0 & 4.7 & 8.5 & 4.7 \\
\hline S & 884 & 1086 & 1330 & 1090 & 121 & 0.1 & 2.4 & 6.5 & 2.8 \\
\hline $\mathrm{Ti}$ & $<0.05$ & 0.06 & 0.86 & $<0.1$ & - & $<0.00001$ & 0.00001 & 0.0002 & $<0.00002$ \\
\hline As & 11 & 21 & 0.34 & 0.22 & 0.08 & 0.002 & 0.010 & 0.027 & $0.012 \quad 0.006$ \\
\hline $\mathrm{Ba}$ & 0.44 & 1.20 & 3.6 & 1.30 & 65 & 0.001 & 0.003 & 09 & $\begin{array}{ll}0.003 & 0.002\end{array}$ \\
\hline $\mathrm{Bi}$ & .0002 & 0.0002 & .0045 & 0.0005 & 0.0009 & $<0.0003$ & 0.0004 & 0.0057 & 0.00060 .0014 \\
\hline $\mathrm{Cd}$ & 02 & 42 & 0.96 & 11 & 99 & 0.005 & 0.124 & 2.99 & 0.35 \\
\hline $\mathrm{Ce}$ & $<0.0006$ & 0.0008 & 0.0144 & 0.0016 & 0.0029 & $<0.00001$ & 0.00001 & 0.00014 & 0.00002 \\
\hline $\mathrm{CO}$ & 04 & 20 & 33 & 0.028 & 0.029 & 0.0002 & .0010 & 0.0134 & 0.00200 .0028 \\
\hline $\mathrm{Cr}$ & & & $<0.1$ & $<0.1$ & & 001 & .001 & 0.003 & $<0.001$ \\
\hline Cs & 05 & 0.030 & 0.99 & 0.103 & 0.21 & 0.0005 & 0.0037 & 0.202 & $0.0192 \quad 0.043$ \\
\hline 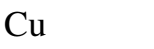 & & 0.5 & 8.5 & 3.4 & 1.61 & 0.003 & 0.086 & 0.23 & $\begin{array}{ll}0.085 & 0.051\end{array}$ \\
\hline Ht & 002 & $<0.0002$ & 015 & $<0.0004$ & - & .00005 & $<0.00005$ & 0.0003 & 0.0002 \\
\hline $\mathrm{La}$ & 003 & 0.0004 & .0079 & 0.0009 & 0.0016 & $<0.00001$ & 0.00001 & 0.00017 & 0.00002 \\
\hline $\mathrm{Li}$ & $<0.006$ & $<0.006$ & 0.03 & $<0.008$ & - & $<0.0001$ & $<0.0001$ & 0.001 & $<0.0002$ \\
\hline
\end{tabular}


Chapter 3. Northern and central paddy soils

\begin{tabular}{|c|c|c|c|c|c|c|c|c|c|c|}
\hline Mo & 0.18 & 0.57 & 1.29 & 0.63 & 0.32 & 0.09 & 0.92 & 3.1 & 0.90 & 0.69 \\
\hline $\mathrm{Nb}$ & $<0.034$ & $<0.034$ & $<0.034$ & $<0.034$ & - & $<0.002$ & $<0.002$ & $<0.002$ & $<0.002$ & \\
\hline $\mathrm{Ni}$ & 0.03 & 0.35 & 2.24 & 0.45 & 0.49 & 0.001 & 0.009 & 0.104 & 0.015 & 0.022 \\
\hline $\mathrm{Pb}$ & $<0.02$ & $<0.02$ & $<0.02$ & $<0.02$ & - & $<0.0005$ & $<0.0005$ & 0.0005 & $<0.0005$ & - \\
\hline $\mathrm{Rb}$ & 2.6 & 11.5 & 60.2 & 18.4 & 15.7 & 0.02 & 0.10 & 0.62 & 0.19 & 0.18 \\
\hline $\mathrm{Sb}$ & $<0.0006$ & $<0.0006$ & $<0.0006$ & $<0.0006$ & - & $<0.0003$ & $<0.0003$ & 0.0006 & $<0.0003$ & \\
\hline $\mathrm{Sc}$ & $<0.003$ & $<0.003$ & 0.005 & $<0.003$ & - & $<0.0003$ & $<0.0003$ & 0.0003 & $<0.0003$ & \\
\hline $\mathrm{Sn}$ & $<0.06$ & $<0.06$ & $<0.06$ & $<0.06$ & - & $<0.02$ & $<0.02$ & $<0.02$ & $<0.02$ & \\
\hline $\mathrm{Sr}$ & 0.18 & 0.38 & 0.53 & 0.38 & 0.09 & 0.002 & 0.005 & 0.015 & 0.006 & 0.004 \\
\hline Th & $<0.0002$ & $<0.0002$ & 0.0025 & $<0.0002$ & - & $<0.00001$ & $<0.00001$ & 0.00011 & $<0.00001$ & - \\
\hline $\mathrm{Tl}$ & $<0.0002$ & 0.0002 & 0.0004 & 0.0002 & 0.0001 & $<0.0003$ & 0.0004 & 0.0009 & 0.0004 & - \\
\hline $\mathrm{U}$ & $<0.0001$ & $<0.0001$ & 0.0017 & $<0.0001$ & - & $<0.00002$ & $<0.00002$ & 0.0003 & $<0.00005$ & \\
\hline $\mathrm{Zn}$ & 13.7 & 24.6 & 32.2 & 24.0 & 4.1 & 0.02 & 0.23 & 0.37 & 0.23 & 0.08 \\
\hline $\mathrm{Zr}$ & $<0.007$ & $<0.007$ & 0.066 & $<0.007$ & - & $<0.00006$ & $<0.00006$ & 0.0005 & $<0.00006$ & \\
\hline
\end{tabular}

Most of the element concentrations in unpolished rice are not or only slightly correlated with each other except for $\mathrm{K}, \mathrm{Mg}$, and $\mathrm{P}$ with correlation coefficients higher than 0.7 (Fig. A1.1 in Appendix). Mg and $\mathrm{P}$ concentrations in unpolished rice show an outstanding correlation:

$$
[\mathrm{P}]=2.7 *[\mathrm{Mg}]-172 \quad(\mathrm{r}=0.94)
$$

The concentrations of $\mathrm{As}, \mathrm{Bi}, \mathrm{Ca}, \mathrm{Cd}, \mathrm{Co}, \mathrm{Cu}, \mathrm{Fe}, \mathrm{Mn}, \mathrm{Na}, \mathrm{Ni}, \mathrm{P}, \mathrm{Sb}$, and $\mathrm{Zn}$ in most grain samples of the central area are higher compared to those in the northern area. This trend is opposite to the soil concentrations (compare Table A1.2 and Table A1.3 in Appendix A1). A master variable for element transfer into plants is the $\mathrm{pH}$ value of the soil. In the central area, soil $\mathrm{pH}$ values range from 4.2 to 4.7 , in the northern area from 4.8 to 7.3 . Soil $\mathrm{pH}$ affects element transfer by two mechanisms:

- Many cationic elements get soluble in acidic solution (desorption from surface sites at $\mathrm{pH}$ values $<5$ ) and insoluble under weakly acidic to slightly alkaline conditions (sorption maximum between $\mathrm{pH} 5$ and 8).

- Acidification increases the solubility of the sorbents Al-, Fe-, and Mnoxides/hydroxides, thus enforcing the release of elements into solution.

In addition, under low Eh conditions and absence of sulfur, most of the cationic heavy metals including $\mathrm{As}, \mathrm{Bi}$ and $\mathrm{Sb}$ could go into solution because Fe-oxides/hydroxides are dissolved. This release facilitates the uptake of these elements by the rice plant. On the other hand, sorption on organic material may lower the concentration of dissolved elements hindering their uptake.

The concentrations of elements in unpolished rice show no significant correlations with their corresponding soil concentrations except for phosphorus. To visualize the relative ability of the plant to mobilize and take up elements from the soil, transfer factors (TFs) are plotted in 
Fig. 3.4. Mean TFs are presented in a decreasing order (elements in brackets have median concentrations in grains below detection limit):

- TF 5 to 1: P, S

- TF 1 to 0.1: $\quad \mathrm{Mo}, \mathrm{Zn}, \mathrm{Mg}, \mathrm{K}, \mathrm{Cd}$

- TF 0.1 to 0.01: $\mathrm{Rb}, \mathrm{Cu}, \mathrm{Mn}, \mathrm{Ca},(\mathrm{Sn}), \mathrm{As}$

- TF 0.01 to 0.001: Ni, Sr, Cs, Ba, (Nb), Co

- TF <0.001: $\quad(\mathrm{Cr}), \mathrm{Na}, \mathrm{Bi}, \mathrm{Tl}, \mathrm{Fe},(\mathrm{Pb}),(\mathrm{Sb}),(\mathrm{Sc}),(\mathrm{Zr}),(\mathrm{Hf}),(\mathrm{U}), \mathrm{La}, \mathrm{Ce},(\mathrm{Li})$, $(\mathrm{Al}),(\mathrm{Ti}),(\mathrm{Th})$

There is a broad variation of TFs for some elements, which spans over 3 orders of magnitude for $\mathrm{Cd}$ (from 0.01 to 3), but only 1 order of magnitude for the nutrients $\mathrm{K}, \mathrm{Mg}, \mathrm{P}$, $\mathrm{Fe}$, and $\mathrm{Zn}$.

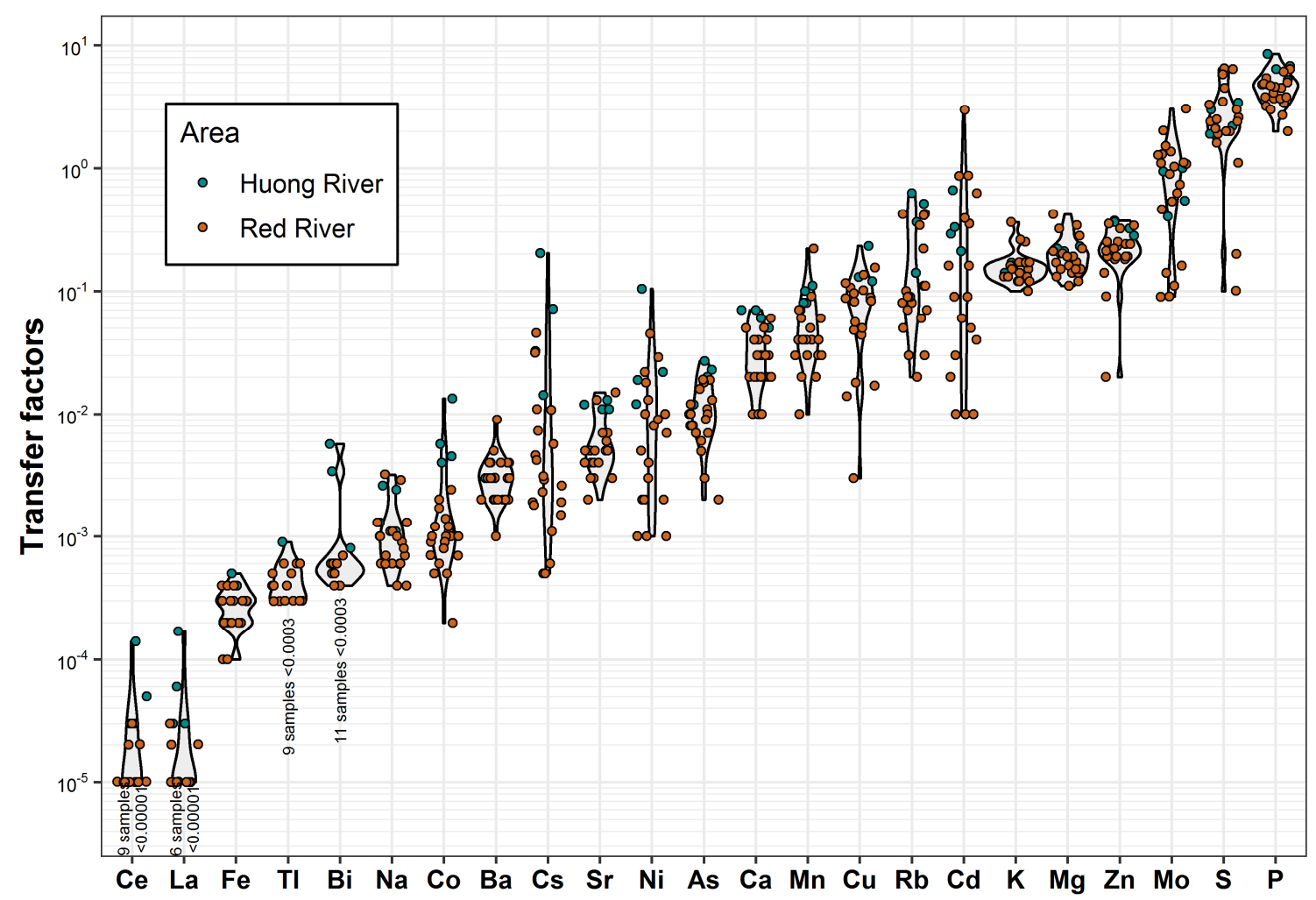

Fig. 3.4 Transfer factors of some elements from soil into rice grain. TFs of elements with concentrations below detection limit are not shown: Th, Ce, La, Al, U, Zr, V, Sb, Pb, Ti, Cr, Sn, Co 
Reasons for the broad TF variation and the lack of correlation between soil and plant concentrations are influences of various soil and plant factors. The most important soil factors are the $\mathrm{pH}-$ and Eh-value in the soil solution, the concentration of organic matter, $\mathrm{Al}$ - and $\mathrm{Fe}$ oxides/hydroxides, and clay minerals. These parameters influence binding, distribution, and availability of elements in soils. The concentration and species of an element in soil solution determine the element uptake by a plant root. Within plants, different element distribution and incorporation mechanisms lead to different concentrations in different parts of the plant (Greger 2004).

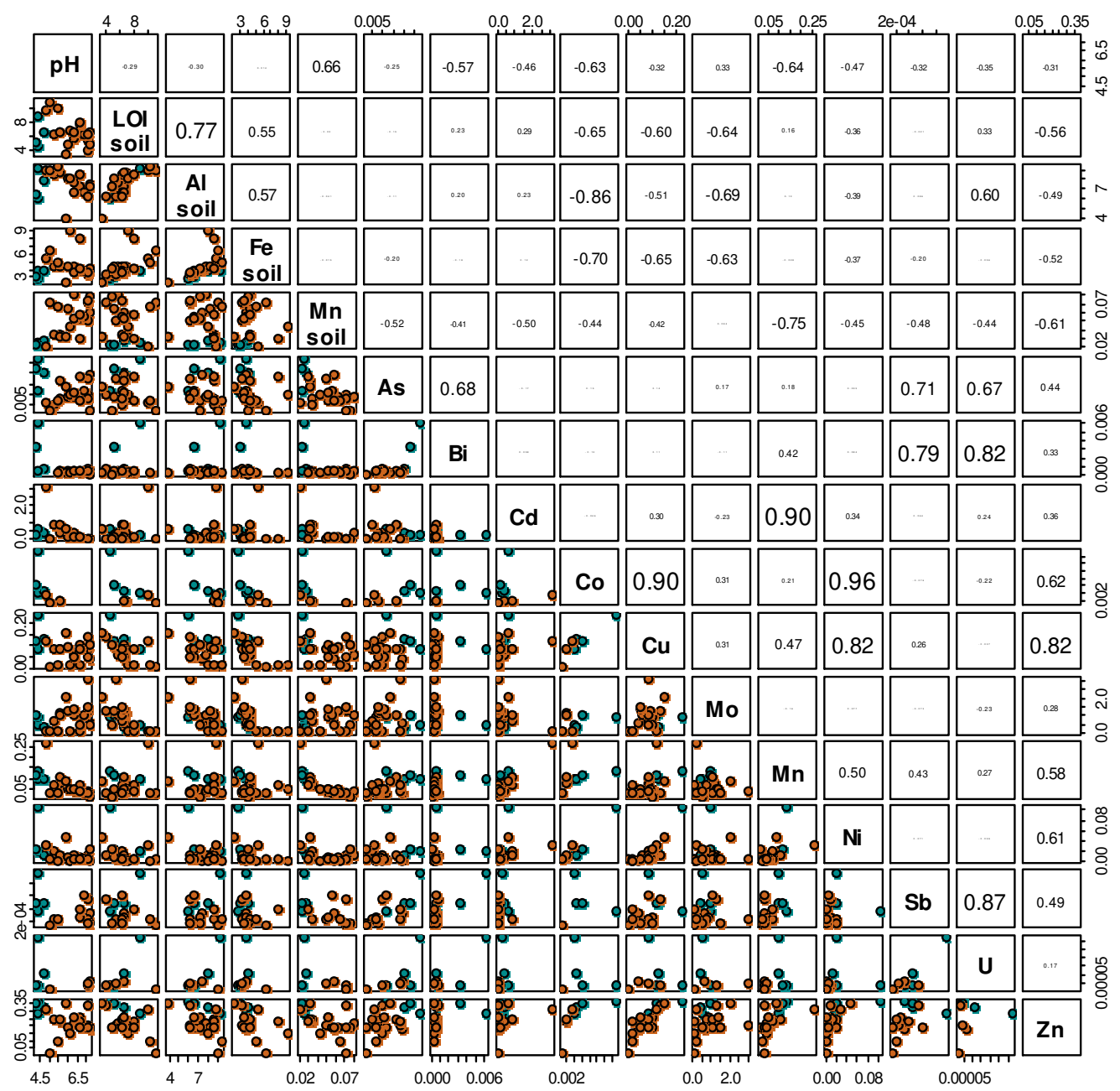

Fig. 3.5 Correlation plots of the soil parameters pH, LOI, Al, Fe, and Mn (wt. \%) with transfer factors of potentially toxic elements. Blue dots represent samples from the Huong River, red dots samples from the Red River 
In this context, the TFs of sample site PT5 are remarkable. As described above, various potentially toxic elements are strongly enriched in the soil. The rice grains, however, show element concentrations that are typical for uncontaminated sites. One reason for the little uptake at site PT5 may be the reducing environment within the soil, which is indicated by the outstanding concentrations of organic matter (LOI 11.1\%), $\mathrm{Fe}_{2} \mathrm{O}_{3}(9.2 \%), \mathrm{S}(0.87 \%)$, and $\mathrm{P}_{2} \mathrm{O}_{5}$ $(0.47 \%)$. In the stagnant anoxic interstitial water, sulfide ions may form insoluble compounds with most of the divalent cationic heavy metals as well as As, Sb, and Bi. Another mechanism could be the sorption of the elements on organic matter and the precipitation of cationic elements as insoluble phosphates. These fixation mechanisms may inhibit a trace element transfer into the rice plant.

In Fig. 3.5, TFs of different potentially toxic elements are plotted against each other, soil $\mathrm{pH}$ values, and concentrations of $\mathrm{LOI}, \mathrm{Al}, \mathrm{Fe}$, and $\mathrm{Mn}$. As expected, sites with low $\mathrm{pH}$ values between 4 and 5 tend to increased TFs of $\mathrm{As}, \mathrm{Bi}, \mathrm{Cd}, \mathrm{Co}, \mathrm{Mn}, \mathrm{Ni}, \mathrm{Sb}$ and $\mathrm{Zn}$, but sites with $\mathrm{pH}>5$ to lowered TFs. As, Mo, and Sb tend to higher TFs at $\mathrm{pH}>6$. In the presence of oxygen, these elements form oxy-anions. At higher $\mathrm{pH}$ values, $\mathrm{OH}$-ions may replace the oxyanions at the oxide/hydroxide interfaces and release them into solution for uptake by plants.

The TFs of As, $\mathrm{Co}, \mathrm{Cu}, \mathrm{Mo}, \mathrm{Mn}, \mathrm{Ni}, \mathrm{Sb}$, and $\mathrm{Zn}$ show slightly downward trends with increasing concentrations of LOI, Al-, Fe-oxides/hydroxides, and clay minerals in soils. These soil compounds hamper the plant's uptake of these elements. In contrast, the TF of U increases with rising concentrations of LOI and Al-phases. An explanation may be that $\mathrm{U}$ is loosely sorbed on clay minerals or organic matter from which it may be easily desorbed. Looking at the plots of TFs, similar uptake trends within three element groups become evident: group 1 - As, Sb, and U; group 2 - $\mathrm{Co}, \mathrm{Cu}, \mathrm{Ni}$, and $\mathrm{Zn}$; group 3 - $\mathrm{Cd}$ and $\mathrm{Mn}$.

\subsubsection{Intake of nutrient and harmful elements by eating rice}

Rice is the most important energy supplier for the Vietnamese population. Therefore, it is of great importance to get information on the amount of beneficial and harmful elements taken up by human through rice consumption. In rural areas of Vietnam, people older than 19 years eat on average $0.398 \mathrm{~kg}$ rice per day: female $0.35 \mathrm{~kg}_{\text {day }}{ }^{-1}$ and male $0.45 \mathrm{~kg} \mathrm{day}^{-1}$ (based on information from local population). The daily intake of nutrient and toxic elements is calculated by multiplying the daily amount of rice consumed $\left(\mathrm{kg} \mathrm{day}^{-1}\right)$ by the element concentration in rice $\left(\mathrm{mg} \mathrm{kg}^{-1}\right)$. Table 3.3 shows the intake quantities compared with the Daily Recommended Dietary Allowances (RDA) and Tolerable Upper Intake Levels (UL) for human 
issued by Food and Nutrient Board (FNB) of the U.S National Academies (Institute of Medicine 2001) and the European Food Safety Authority (EFSA various years).

The average element intake for some nutrient elements from rice is higher as compared to the total recommended dietary allowances: Mn 4.4 times, P 1.8 times, Mg 1.5 times, Mo 4.4 times, and $\mathrm{Cu} 1.3$ times. However, the values of these elements are far below the ULs of EFSA with the exception of $\mathrm{Mg}$, which is 1.4 times higher than UL, and Mn in some areas. In contrast, the $\mathrm{Ca}$ and Fe supply by rice consumption is far below people's daily requirement. The low supply of these elements must be complemented by other food products and water.

Table 3.3 Daily element intake for a Vietnamese adult by eating rice in comparison with the Daily Recommended Dietary Allowances (RDA) and the Daily Tolerable Upper Intake Levels (UL) for total consumption of food and drinking water in $\mathrm{mg} \mathrm{day}^{-1}$ (Institute of Medicine 2001 and other sources)

\begin{tabular}{|c|c|c|c|c|c|c|c|c|c|c|}
\hline \multirow{3}{*}{ Element } & \multicolumn{5}{|c|}{ Intake by Female } & \multicolumn{5}{|c|}{ Intake by Male } \\
\hline & \multicolumn{3}{|c|}{ Study area } & \multicolumn{2}{|c|}{ FNB } & \multicolumn{3}{|c|}{ Study area } & \multicolumn{2}{|c|}{ FNB } \\
\hline & Min & $\operatorname{Max}$ & Mean & RDA & UL & Min & $\operatorname{Max}$ & Mean & RDA & UL \\
\hline $\mathrm{Ca}$ & 37 & 57 & 47 & 1000 & 2500 & 47 & 73 & 60 & 1000 & 2500 \\
\hline $\mathrm{Fe}$ & 3 & 7 & 4 & 18 & 45 & 4 & 9 & 5 & 8 & 45 \\
\hline K & 825 & 1173 & 1020 & - & - & 1051 & 1495 & 1300 & - & - \\
\hline $\mathrm{Mg}$ & 386 & 557 & 479 & 310 & 350 & 492 & 710 & 610 & 400 & 350 \\
\hline $\mathrm{Na}$ & 0.9 & 2.9 & 1.6 & - & 2300 & 1.2 & 3.7 & 2.0 & - & 2300 \\
\hline $\mathrm{Zn}$ & 5 & 11 & 8 & 8 & 40 & 6 & 14 & 11 & 11 & 40 \\
\hline $\mathrm{P}$ & 930 & 1458 & 1232 & 700 & 4000 & 1184 & 1858 & 1569 & 700 & 4000 \\
\hline As & 0.04 & 0.12 & 0.08 & - & $0.096^{\mathrm{a}}$ & 0.05 & 0.15 & 0.10 & - & $0.124^{\mathrm{a}}$ \\
\hline $\mathrm{Cd}$ & 0.001 & 0.34 & 0.039 & - & $0.016^{\mathrm{a}}$ & 0.001 & 0.43 & 0.049 & - & $0.021^{\mathrm{a}}$ \\
\hline $\mathrm{Cr}$ & $<0.04$ & $<0.04$ & $<0.04$ & 0.025 & - & $<0.05$ & $<0.05$ & $<0.05$ & 0.035 & \\
\hline Co & 0.001 & 0.05 & 0.01 & - & $0.072^{\mathrm{a}}$ & 0.002 & 0.06 & 0.01 & & $0.093^{\mathrm{a}}$ \\
\hline $\mathrm{Cu}$ & 0.3 & 3.0 & 1.2 & 0.9 & 10 & 0.3 & 3.8 & 1.5 & 0.9 & 10 \\
\hline Mn & 4 & 16 & 8 & 1.8 & 11 & 5 & 20 & 10 & 2.3 & 11 \\
\hline Mo & 0.06 & 0.45 & 0.22 & 0.05 & 2.0 & 0.08 & 0.58 & 0.28 & 0.05 & 2.0 \\
\hline $\mathrm{Ni}$ & 0.01 & 0.78 & 0.16 & - & 1.0 & 0.01 & 1.00 & 0.20 & - & 1.0 \\
\hline $\mathrm{Pb}$ & $<0.007<$ & $<0.007$ & $<0.007$ & - & $0.067^{\mathrm{a}}$ & $<0.009$ & $<0.009$ & $<0.009$ & - & $0.087^{\mathrm{a}}$ \\
\hline $\mathrm{Sb}$ & $<0.0002<0$ & 0.0002 & $<0.0002$ & & $0.27^{\mathrm{b}}$ & $<0.0003<$ & 0.0003 & $<0.0003$ & & $0.35^{\mathrm{b}}$ \\
\hline $\mathrm{Sn}$ & $<0.02$ & $<0.02$ & $<0.02$ & - & $90^{\mathrm{a}}$ & $<0.03$ & $<0.03$ & $<0.03$ & & $116^{\mathrm{a}}$ \\
\hline $\mathrm{U}$ & $<0.00004$ & $0.0006<0$ & 0.00004 & - & $0.03^{\mathrm{a}}$ & $<0.00004$ & $0.0007<0$ & 0.00004 & - & $0.04^{\mathrm{a}}$ \\
\hline
\end{tabular}

${ }^{a}$ calculated from tolerable weekly intake doses issued by the European Food Safety Authority (EFSA, various years) for average Vietnamese female and male; ${ }^{\mathrm{b}}$ calculated from data of van Leeuwen and Aldenberg (2012)

The intake of the critical elements $\mathrm{Sn}, \mathrm{As}, \mathrm{Cd}, \mathrm{U}, \mathrm{Pb}, \mathrm{Co}$, and $\mathrm{Sb}$ is compared with the ULs given by the EFSA (various years) and van Leeuwen and Aldenberg (2012). The UL value of EFSA in $\mu \mathrm{g} \mathrm{kg}^{-1}$ body weight (b.w.) per day is multiplied by the average body weight of a Vietnamese adult of $58 \mathrm{~kg}$ for males and $45 \mathrm{~kg}$ for females and listed in Table 3. The intake of $\mathrm{Pb}, \mathrm{U}, \mathrm{Sb}$, and $\mathrm{Sn}$ by eating rice are at least 10 times lower than the ULs. 


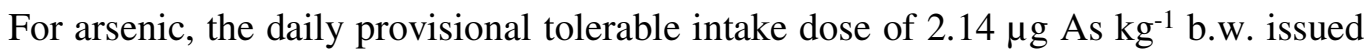
by the Joint FAO/WHO Expert Committee on Food Additives (1989; cited in EFSA 2009b) is used in this analysis. It corresponds to a daily UL of $0.096 \mathrm{mg}$ As for females and $0.124 \mathrm{mg}$ for males. $21 \%$ of the samples exceed these tolerable upper intake values. The daily provisional tolerable intake dose of $2.14 \mu \mathrm{g} \mathrm{As} \mathrm{kg}{ }^{-1}$ b.w. was superseded by EFSA (2009b), which suggests

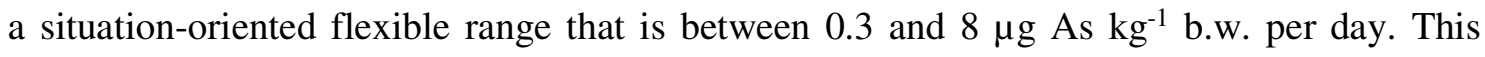
corresponds to a maximum daily uptake of $0.014-0.36 \mathrm{mg}$ As for females and 0.017 - 0.46 $\mathrm{mg}$ for males. In our study, the daily As intake from only rice ranges between 0.04 and 0.12 for women and 0.05 and 0.15 for men. All calculated daily As intakes are within the range recommended by EFSA. However, all values are higher than the lower limit of $0.01 \mathrm{mg}$.

For cadmium, EFSA (2009b) proposed a daily UL of $0.36 \mu \mathrm{g} \mathrm{kg}^{-1}$ b.w., which corresponds to ULs of 0.016 and $0.021 \mathrm{mg}^{-1 a y^{-1}}$ for a Vietnamese female and male respectively. $46 \%$ of the rice samples exceed this limit, and the most contaminated rice sample (HN10) is higher by a factor of 21.

Another approach for the health relevance of the rice grain data is to compare them with the permissible maximum concentration (MC) of $0.2 \mathrm{mg} \mathrm{kg}^{-1}$ for each $\mathrm{Cd}, \mathrm{Pb}$, and inorganic As in rice grains, as proposed by FAO/WHO (2014) and European Union (2006). For young children, the inorganic As concentration should be below $0.1 \mathrm{mg} \mathrm{kg} \mathrm{kg}^{-1}$. According to Suriyagoda et al. (2018), the inorganic As fraction in rice grains is $54 \%$ of total As. Thus the resulting permissible level of total As should be $0.37 \mathrm{mg} \mathrm{kg}^{-1}$ for adults and $0.19 \mathrm{mg} \mathrm{kg}^{-1}$ for children. All samples are within the permissible As level for adults, but $54 \%$ of the samples exceed the level for children. Rahman and Hasegawa (2011) proposed a fraction of 80 to $91 \%$ of inorganic As in rice, which correspond to total permissible levels of 0.22 to $0.25 \mathrm{mg} \mathrm{kg}^{-1}$ for adults and 0.11 to $0.13 \mathrm{mg} \mathrm{kg}^{-1}$ for children. According to that study, $50 \%$ of the grains surpass the As level of $0.22 \mathrm{mg} \mathrm{kg}^{-1}$ for adults, but all grain samples exceed the level of $0.11 \mathrm{mg} \mathrm{kg}^{-1}$ for children.

Twelve percent of the rice samples exceed the MC of Cd of $0.2 \mathrm{mg} \mathrm{kg}^{-1}$ as proposed by the European Union (2006). However, only $4 \%$ of the samples would surpass the MC of Cd of $0.4 \mathrm{mg} \mathrm{kg}^{-1}$, which has been recommended recently by the FAO/WHO (2014). Rice sample $\mathrm{HN} 10$ contains $0.99 \mathrm{mg} \mathrm{Cd} \mathrm{kg}^{-1}$ that is approximately 5 times and 2.5 times higher than the limits proposed by guidelines of the European Union and the FAO/WHO respectively. The rice harvested in this area may cause a risk for human health. Fortunately, all studied samples 
contain $\mathrm{Pb}$ concentrations that is below the detection limit of $0.02 \mathrm{mg} \mathrm{kg}^{-1}$, which is at least 10 times lower than the allowable threshold of $0.2 \mathrm{mg} \mathrm{kg}^{-1}$ as proposed by both organizations.

With the amount of daily consumed rice of Vietnamese people, the MCs of $0.2 \mathrm{mg} \mathrm{kg}$

${ }^{1}$ for $\mathrm{Cd}, \mathrm{Pb}$, and inorganic As in rice correspond to the daily maximum intake level from rice of $0.070 \mathrm{mg}$ for women and $0.089 \mathrm{mg}$ for men for each element. These calculated values are nearly identical with the UL values of $\mathrm{Pb}$, but about $40 \%$ lower than the UL (Table 3.3). The calculated value for $\mathrm{Cd}$ is, however, 4.3 times higher than its UL value for total food and drinking water as proposed by EFSA (Table 3.3). Therefore, countries with rice as the main staple food should adjust the maximum Cd concentration of $0.2 \mathrm{mg} \mathrm{kg}^{-1}$ in rice to a considerably lower level for their respective population, for example from $0.2 \mathrm{mg} \mathrm{kg}^{-1}$ to 0.05 $\mathrm{mg} \mathrm{kg}^{-1}$ or lower.

\subsection{Conclusion}

The parent material of the paddy soils that were collected along Huong River in central Vietnam are alluvial sediments delivered from the Annam Cordillera. The alluvial sediments along the Red River consist of eroded materials from the Yunnan Plateau in China and surrounding highlands. Compared to average shale or outer Earth crust, most of the soil samples are not or only slightly polluted by toxic elements from anthropogenic activities. The concentrations of most of the potentially harmful elements are positively correlated with the concentrations of $\mathrm{Al}$ (an indicator of clay minerals) and $\mathrm{Fe}$ (Fe oxides/hydroxides), which bind most elements by sorption or co-precipitation processes. Strong positive interrelations exist within the following groups: $\mathrm{Co}, \mathrm{Cr}$, and $\mathrm{Ni}$; $\mathrm{As}, \mathrm{Bi}, \mathrm{Cu}$, and $\mathrm{Pb} ; \mathrm{Cd}, \mathrm{Zn}$, and $\mathrm{Sb}$.

$80 \%$ of the soil samples exceed the permissible As limit for Vietnamese agricultural soils. Elevated As and $\mathrm{Bi}$ concentrations presumably stem from natural sources and are regulated by redox mechanisms. In an area $60 \mathrm{~km}$ northwest of Hanoi, one site is polluted by numerous potentially toxic elements and two other sites are contaminated by $\mathrm{Cr}$ and $\mathrm{Fe}$. Pollution sources may be wastewater from a local fertilizer and chemical factory. Also, two paddy soils located $120 \mathrm{~km}$ northwest of Hanoi, that are directly flooded by the Red River, contain elevated contents of $\mathrm{As}, \mathrm{Bi}, \mathrm{Cd}, \mathrm{Ce}, \mathrm{Cu}, \mathrm{La}, \mathrm{Mn}, \mathrm{Pb}, \mathrm{Sb}$, and $\mathrm{Sn}$, probably caused by upstream mining activities.

The element transfer from soil into rice grains depends on soil factors such as $\mathrm{pH}$, Eh, organic matter, Fe-, Mn-, and Al-oxides/hydroxides, and clay minerals. The transfer factors decrease in the following order: $\mathrm{P}, \mathrm{S}>\mathrm{Mo}, \mathrm{Zn}, \mathrm{Mg}, \mathrm{K}, \mathrm{Cd}>\mathrm{Rb}, \mathrm{Cu}, \mathrm{Mn}, \mathrm{Ca}, \mathrm{Sn}, \mathrm{As}>\mathrm{Ni}, \mathrm{Sr}$, 
Cs, Ba, Nb, Co > Cr, Na, Bi, Tl, Fe, Pb, Sb, Sc, Zr, Hf, U, La, Ce, Li, Al, Ti, Th. Some element groups show a slight positive trend of the transfer factors: $\mathrm{As}, \mathrm{Sb}$, and $\mathrm{U} ; \mathrm{Co}, \mathrm{Cu}, \mathrm{Ni}$, and $\mathrm{Zn}$; $\mathrm{Cd}$ and $\mathrm{Mn}$.

With reference to the recommended dietary allowance (RDA), the daily intake by rice consumption is very low for $\mathrm{Ca}$ and $\mathrm{Fe}$ and moderate for $\mathrm{Zn}$ and $\mathrm{Cu}$. The average intake of $\mathrm{Mn}$, $\mathrm{Mo}, \mathrm{P}$, and $\mathrm{Cu}$ is higher than the corresponding RDA-values but lower than the tolerable upper intake levels (UL). The Mg intake by rice consumption is even higher than the UL. The intake of most potentially harmful elements such as $\mathrm{Co}, \mathrm{Cu}, \mathrm{Mo}, \mathrm{Ni}, \mathrm{Pb}, \mathrm{Sb}$, and $\mathrm{U}$ is lower than their ULs. The daily intake of As is within the range of lower and upper UL, but all samples exceed the lower UL. $46 \%$ of the rice samples induce a Cd intake higher than UL. Regarding the permissible maximum concentrations of harmful elements in rice published by the FAO/WHO (2014) and the European Union (2006), Pb concentrations in all rice samples are far below the limit, whereas Cd surpasses the limit in $12 \%$ of the samples and As exceeds the limit for young children in $54 \%$.

Further research activities should focus on the following issues:

- Improvement in the knowledge base, especially for rice grown in areas with anthropogenic contamination and in regions with high As concentrations in irrigation water and soil.

- Careful revision and harmonization of the tolerable upper intake level for As and the maximum concentrations limits for $\mathrm{As}$ and $\mathrm{Cd}$ in rice to prevent contradictory results (Sauve' 2014). Future studies should focus on As speciation, as well as on As and $\mathrm{Cd}$ intake and their health risks.

- Intensification of research on how to decrease the transfer of harmful elements from contaminated soils into the rice plant. For example, to prevent As transfer from Asrich soils into rice grains, Suriyagoda et al. (2018) proposed the cultivation of rice under aerobic, intermittent flooding or alternate wetting or drying conditions. Under such conditions, Fe-oxides/hydroxides precipitate and bind As. Thus, the availability of As plant is lowered. In addition, the presence of Fe-oxides/hydroxides increases the sorption of other critical elements. To reduce the enrichment of $\mathrm{Cd}$ and $\mathrm{As}$ in grains that are grown in acidic soils, soil $\mathrm{pH}$ should be increased to 6.5 in order to improve sorption, and to diminish the uptake of these elements. 


\subsection{Acknowledgements}

The authors thank the Department of Sedimentology \& Environmental Geology, Faculty of Geoscience and Geography, Göttingen University for providing consumables, instruments, and chemicals for the analytical work. Many thanks also to Prof. Dr. Klaus Dittert, Institute of Applied Plant Nutrition at Göttingen University, and Mr. Stephen B. Asabere, Institute of Physical Geography at Göttingen University, who kindly improved this manuscript. The Vietnamese government generously supported the stay of Thuy Phuong Nguyen at Göttingen University with a research grant.

\subsection{Supplementary material}

Supplementary material of this paper can be found in Appendix A1

\subsection{References}

Ahmed, I. A. M., Crout, N. M. J., \& Young, S. D. (2008). Kinetics of Cd sorption, desorption and fixation by calcite: A long-term radiotracer study. Geochimica et Cosmochimica Acta, 72, 1498-1512. https://doi.org/10.1016/j.gca.2008.01.014.

Alloway, B. J. (Ed.). (2013). Sources of heavy metals and metalloids in soils. In Heavy metals in soils: Trace metals and metalloids in soils and their bioavailability. Environmental Pollution (3rd ed., vol. 22, pp. 11-50). Dordrecht: Springer.

Arunakumara, K. K. I. U., Walpola, B. C., \& Yoon, M.-H. (2013). Current status of heavy metal contamination in Asia's rice lands. Reviews in Environmental Science and Bio/Technology, 12, 355-377. https://doi.org/10.1007/s11157-013-9323-1.

Chaney, R. L., Kim, W. I., Kunhikrishnan, A., Yang, J. E.,\&Ok, Y. S. (2016). Integrated management strategies for arsenic and cadmium in rice paddy environments.

Geoderma, 270, 1-2. https://doi.org/10.1016/j.geoderma.2016.03.001.

Chen, M., \& Graedel, T. E. (2015). The potential for mining trace elements from phosphate rock. Journal of Cleaner Production, 91, 337-346. https://doi.org/10.1016/j.jclepro.2014.12.042.

Chu, H. (2011). Survey on heavy metals contaminated soils in Thai Nguyen and Hung Yen provinces in Northern Vietnam. Journal of Vietnamese Environment, 1, 34-39. https://doi.org/10.13141/jve.vol1.no1.pp34-39. 
EFSA. (2005). Opinion of the Scientific Panel on Dietetic products, nutrition and allergies [NDA] related to the tolerable upper intake level of tin. EFSA Journal, 3, 254. https://doi.org/10.2903/j.efsa.2005.254.

EFSA. (2009a). Cadmium in food-Scientific opinion of the Panel on Contaminants in the Food Chain. EFSA Journal, 7, 980. https://doi.org/10.2903/j.efsa.2009.980.

EFSA. (2009b). Scientific opinion on arsenic in food. EFSA Journal, 7, 1351. https://doi.org/10.2903/j.efsa.2009.1351.

EFSA. (2009c). Scientific opinion on the use of cobalt compounds as additives in animal nutrition. EFSA Journal, 7, 1383. https://doi.org/10.2903/j.efsa.2009.1383.

EFSA. (2009d). Uranium in foodstuffs, in particular mineral water. EFSA Journal, 7, 1018. https://doi.org/10.2903/j.efsa.2009.1018.

EFSA. (2010). Scientific opinion on lead in food-EFSA panel on contaminants in the food chain (CONTAM). EFSA Journal, 8, 1570. https://doi.org/10.2903/j.efsa.2010.1570.

European Union (2006). Commission regulation (EC) No 1881/2006 of 19 December 2006 setting the maximum levels for certain contaminants in foodstuffs. Journal of European Union, 32006R1881 (Vol. 1881/2006). European Commision: EUR-Lex.

Fan, Y., Zhu, T., Li, M., He, J., \& Huang, R. (2017). Heavy metal contamination in soil and brown rice and human health risk assessment near three mining areas in central china. Journal of Healthcare Engineering, 2017, 9. https://doi.org/10.1155/2017/4124302.

FAO. (2017). Rice market monitor, Vol XX No. 1. http://www.fao.org/fileadmin/templates/est/COMM_MARKETS_MONITORING/Rice /Images/RMM/RMM_APR17_H.pdf. Accessed 12 January 2018.

FAO/WHO. (2014). Joint FAO/WHO food standards programme codex alimentarius commission. (Vol. REP14/CF). Geneva, Switzerland: FAO/WHO.

Fendorf, S., \& Kocar, B. D. (2009). Biogeochemical processes controlling the fate and transport of arsenic. Advances in Agronomy, 104, 137-164. https://doi.org/10.1016/S0065-2113(09)04003-6.

Gransee, A.,\&Fu“hrs, H. (2013). Magnesium mobility in soils as a challenge for soil and plant analysis, magnesium fertilization and root uptake under adverse growth conditions. Plant and Soil, 368, 5-21. https://doi.org/10.1007/s11104-012-1567-y. 
Greger, M. (2004). Metal availability, uptake, transport and accumulation in plants. In M. N.

V. Prasad (Ed.), Heavy metal stress in plants from biomolecules to ecosystems ( $2^{\text {nd }}$ ed., pp. 1-27). Berlin: Springer.

Gromet, L. P., Dymek, R. F., Haskin, L. A., \& Korotev, R. L. (1984). The “'North American shale composite'": Its compilation, major and trace element characteristics.Geochimica et Cosmochimica Acta, 48, 2469-2482.

Hensawang, S., \& Chanpiwat, P. (2017). Health impact ssessment of arsenic and cadmium intake via rice consumption n Bangkok, Thailand. Environmental Monitoring Assessment, 189, 599. https://doi.org/10.1007/s10661-017-6321-8.

Huong, N. T. L., Ohtsubo, M., Li, L., Higashi, T., Kanayama, M., \& Nakano, A. (2008). Heavy metal contamination of soil and rice in wastewater-irrigated paddy field in a suburban area of Hanoi, vietnam. Clay Science, 13, 205-215. https://doi.org/10.11362/jcssjclayscience1960.13.205.

Institute of Medicine (US) Panel on Micronutrients. (2001). Reference intakes for vitamin A, vitamin $\mathrm{K}$, arsenic, boron, chromium, copper, iodine, iron, manganese, molybdenum, nickel, silicon, vanadium, and zinc. Washington, DC: National Academies Press (US).

Kabata-Pendias, A. (2011). Trace elements in soils and plants (4th ed.). Boca Raton: CRC Press.

Kobayashi, J. (1978). Pollution by cadmium and the itai-itai diseases in Japan. In F. W. Dehme (Ed.), The toxicity of heavy metals in the environment (pp. 199-260). New York: Marcel Dekker.

Kratz, S., Schick, J., \& Schnug, E. (2016). Trace elements in rock phosphates and P containing mineral and organomineral fertilizers sold in Germany. Science of the Total Environment, 542, 1013-1019. https://doi.org/10.1016/j.scitotenv.2015.08.046.

Lair, G. J., Gerzabek, M. H., \& Haberhauer, G. (2007). Sorption of heavy metals on organic and inorganic soil constituents. Environmental Chemistry Letters, 5(1), 23-27. https://doi.org/10.1007/s10311-006-0059-9.

Phuong, N. M., Kang, Y., Sakurai, K., Iwasaki, K., Kien, C. N., Noi, N. V., et al. (2010). Levels and chemical forms of heavy metals in soils from Red River Delta, Vietnam. Water, Air, \& Soil Pollution, 207, 319-332. https://doi.org/10.1007/s11270-009-0139-0. 
Polizzotto, M. L., Kocar, B. D., Benner, S. G., Sampson, M., \& Fendorf, S. (2008). Nearsurface wetland sediments as a source of arsenic release to ground water in Asia. Nature, 454, 505-508. https://doi.org/10.1038/nature07093.

Postma, D., Larsen, F., Thai, N. T., Trang, P. T. K., Jakobsen, R., et al. (2012). Groundwater arsenic concentrations in Vietnam controlled by sediment age. Nature Geoscience, 5 , 656-661. https://doi.org/10.1038/NGEO1540.

Postma, D., Trang, P. T. K., Sø, H. U., Hoang, V. H., Lan, V. M., et al. (2016). A model for the evolution in water chemistry of an arsenic contaminated aquifer over the last 6000 years, Red River floodplain, Vietnam. Geochimica et Cosmochimica Acta, 195, 277292. https://doi.org/10.1016/j.gca.2016.09.014.

QCVN. (2015). National technical regulation on the allowable limits of heavy metals in the soils. In Vietnamese-Government (Ed.), 03-MT:2015/BTNMT. Vietnam: Ministry of Natural Resources and Environment.

Rahman, M. A., \& Hasegawa, H. (2011). High levels of inorganic arsenic in rice in areas where arsenic-contaminated water is used for irrigation and cooking. Science of the Total Environment, 409, 4645-4655. https://doi.org/10.1016/j.scitotenv.2011.07.068.

Reimann, C., Fabian, K., Birke, M., Filzmoser, P., Demetriades, A., Ne'grel, P., et al. (2018). GEMAS: Establishing geochemical background and threshold for 53 chemical elements in European agricultural soil. Applied Geochemistry, 88, 302-318. https://doi.org/10.1016/j.apgeochem.2017.01.021.

Rudnick, R. L., \& Gao, S. (2003). Composition of the continental crust. In H. D. Holland \& K. K. Turekian (Eds.), Treatise on geochemistry (Vol. 3, pp. 1-64). Oxford: Pergamon.

Sauer, B., \& Ruppert, H. (2013). Bioenergy production as an option for polluted soils-A non-phytoremediation approach. In H. Ruppert, M. Kappas, \& J. Ibendorf (Eds.), Sustainable bioenergy production-An integrated approach (pp. 425-444). Dordrecht: Springer.

Sauve', S. (2014). Time to revisit arsenic regulations: Comparing drinking water and rice. BMC Public Health, 14, 465. https://doi.org/10.1186/1471-2458-14-465.

Singh, D. J., \& Kalamdhad, A. (2011). Effects of heavy metals on soil, plants, human health and aquatic life. International Journal of Research in Chemistry and Environment, 1(2), $15-21$. 
Sø, H. U., Postma, D., Hoang, V. H., Mai, L. V., Pham, P. T. K., et al. (2018). Arsenite adsorption controlled by the iron oxide content of Holocene Red River aquifer sediment. Geochimica et Cosmochimica Acta, 239, 61-73. https://doi.org/10.1016/j.gca.2018.07.026.

Suriyagoda, L. D. B., Dittert, K., \& Lambers, H. (2018). Mechanism of arsenic uptake, translocation and plant resistance to accumulate arsenic in rice grains. Agriculture, Ecosystems \& Environment, 253, 23-37. https://doi.org/10.1016/j.agee.2017.10.017.

Turekian, K. K., \& Wedepohl, K. H. (1961). Distribution of the elements in some major units of the Earth's Crust. Geological Society of America Bulletin, 72, 175-192.

van Leeuwen, L. C., \& Aldenberg, T. (2012). Environmental risk limits for antimony. National Institute for Public Health and the Environment, Ministry of Health, Welfare and Sport.

Vinh, N. C., Oborn, I., Ha, P. Q., Minh, N. D., Hough, R. L., Khai, N. M., et al. (2012). Potential environment and public health risk due to contamination of heavy metals from industrial waste water in Lam Thao, Phu Tho, Vietnam. American Journal of Environmental Sciences, 8, 71-78.

Wedepohl, K. H. (2004). The composition of Earth's Upper Crust, Natural Cycles of Elements, Natural, Resources. In E. Merian, M. Anke, M. Ihnat, \& M. Stoeppler (Eds.), Elements and their compounds in the environment: Occurrence, analysis and biological relevance (2nd ed. pp. 1-36). Weinheim: WILEY-VCH Verlag GmbH \& Co.KGaA.

Xie, Y., Hou, Z., Goldfarb, R., Guo, X., \& Wang, L. (2016). Rare earth element deposits in China. In Reviews in economic geology (Vol. 18, pp. 115-136): Society of Economic Geologists.

Yang, Y.-Y., Xu, Y.-S., Shen, S.-L., Yuan, Y., \& Yin, Z.-Y. (2014). Mining-induced geohazards with environmental protection measures in Yunnan, China: An overview. Bulletin of Engineering Geology and the Environment, 74, 141-150. https://doi.org/10.1007/s10064-014-0608-6.

Young, S. D. (2013). Chemistry of heavy metals and metalloids in soils. In B. J. Alloway (Ed.), Heavy metals in soils: Trace metals and metalloids in soils and their bioavailability. Environmental Pollution (3rd ed., vol. 22, pp. 51-96). Dordrecht: Springer 


\section{Chapter 4}

\section{Paddy soil geochemistry, uptake of trace elements by rice grains (Oryza sativa), and resulting in health risks in the Mekong River Delta, Vietnam}

Thuy Phuong Nguyen ${ }^{1,2}$. Hans Ruppert ${ }^{1}$. Benedikt Sauer ${ }^{1}$. Tino Pasold ${ }^{1}$

Submitted in Environmental Geochemistry and Health, manuscript number: EGAH-D-1900210 in a state of minor revision

Nguyen, T. P., Ruppert, H., Sauer, B., \& Pasold, T. (2019). Paddy soil geochemistry, uptake of trace elements by rice grains (Oryza sativa), and resulting in health risks in the Mekong River Delta, Vietnam. Environmental Geochemistry and Health. Submitted manuscript.

\footnotetext{
${ }^{1}$ Department of Sedimentology and Environmental Geology, Faculty of Geoscience and Geography, Georg-August-University Go“ttingen, Goldschmidtstr. 3, 37077 Göttingen, Germany

${ }^{2}$ Department of Environment and Resources Management, Faculty of Land Resources and Agricultural Environment, Hue University of Agriculture and Forestry, 102 Phung Hung Street, Hue City, Vietnam
} 


\begin{abstract}
Soil geochemistry and phytoavailable trace elements were investigated in 80 paddy soil samples and corresponding rice grains from the Mekong River Delta in Vietnam. Soil parameters like Fe-, Al-, and Mn-phases, organic matter, and pH-value determine element concentrations in soil and affect their transfer into rice grains. Arsenic exceeded the allowed limit for Vietnamese agricultural soils in $11 \%$ of the samples, presumably caused by natural processes. Lead surpassed the limit in one soil sample. Other toxic elements were close to their natural concentrations and far below allowable limits for agricultural soil. There was no clear correlation of trace element concentrations in soils with those in corresponding grains, even if the different soil parameters and the large pH-range between 3.7 and 6.8 were considered.

To assess health risks of critical elements in rice, the thresholds of Tolerable Upper Intake Level for total food and drinking water (UL) and of Permissible Maximum Concentration (MC) for rice grains were evaluated. Surprisingly, rice grains grown on non- or low-polluted soils can surpass the upper limits. According to the UL concept, $12 \%$ of the grains exceeded the UL of As, $29 \%$ that of $\mathrm{Cd}$, and $27 \%$ that of $\mathrm{Pb}$ for each gender. According to the MC concept, 5\% of the rice grains exceeded the MC of inorganic As for adults and $38 \%$ that for young children. $24 \%$ of the grains surpassed the $\mathrm{MC}$ of $\mathrm{Pb}$, while $\mathrm{Cd}$ in all grains was below the MC. The differing results of the UL and MC approaches show an urgent need for revision and harmonization concerning $\mathrm{As}, \mathrm{Cd}$, and $\mathrm{Pb}$ limits especially regarding countries with high rice consumption.
\end{abstract}

Keywords $\bullet$ nutrient and toxic elements $\bullet$ paddy soils $\bullet$ rice grains $\bullet$ transfer factors $\bullet$ Mekong River Delta $\bullet$ health assessments 


\subsection{Introduction}

Soil geochemistry provides valuable hints to explain the provenance of trace elements and their enrichment in soils. Natural concentrations and anthropogenic additions determine element concentrations and toxicity in living systems (Singh et al. 2017). Anthropogenic harmful element inputs to soils may come from the atmosphere, application of sewage sludge or industrial and mining waste water as a source for $\mathrm{Cd}, \mathrm{Cu}, \mathrm{Hg}, \mathrm{Ni}, \mathrm{Pb}$, and $\mathrm{Zn}$ (Barakat 2011; Kim et al. 2015; Akpor et al. 2014), phosphate fertilizers for Cd, U, As, Sb, and Bi (Alloway 2013; Stroebel 2008) and biocides for $\mathrm{Cu}$ (in earlier times also for $\mathrm{Hg}, \mathrm{Sn}$, and $\mathrm{Pb}$; GimenoGarcia et al. 1996).

On the other hand, natural processes can also lead to unusually high concentrations of some elements. For example, naturally elevated concentrations of As and Se in sediments or soils can be caused by co-precipitation with sulfidic compounds under anaerobic conditions or by their fixation on Fe-oxides/hydroxides in oxidizing environments (Wenzel 2013; Christophersen et al. 2013; Wang et al. 2012). In the Himalayan mountains sulfidic minerals in some sediments release As during rock weathering, leading to As enrichments in soils, sediment and groundwater in Bangladesh (Hossain 2006; Meharg and Rahman 2003).

Element speciation, fixation, mobility in soils are determined by different soil parameters such as $\mathrm{pH}-\mathrm{Eh}$, the concentrations of ligands in the interstitial solution, by the concentration of organic material, Al-, Fe-, and Mn-oxides/hydroxides, and clay minerals in the soil. These conditions influence the bioavailability of elements in soil and their uptake by plants (Alloway 2013; Kabata-Pendias 2011).

From the health point of view, As and Cd are regarded as the two most important risk elements for rice-consuming people (Bolan et al. 2013; Chaney et al. 2016). Especially, adult people in eastern and southern Asia consume large amounts of rice varying between 200 and $600 \mathrm{~g}$ per day (Suriyagoda et al. 2018). Roychowdhury (2008), for example calculated for the adult population of Bengal Delta in India an average inorganic As exposure of $2.3 \mu \mathrm{g} \mathrm{As} \mathrm{kg}{ }^{-1}$ body weight (b.w.) day ${ }^{-1}$ by eating rice. This exceeds the WHO recommended maximum level of $2.1 \mu \mathrm{g} \mathrm{As} \mathrm{kg}^{-1}$ b.w. day ${ }^{-1}$. Additional As-sources such as drinking water or eating other foods are not included in that study, but would increase the As-intake. In Bangladesh, Hossain (2006) estimated, that more than 25 million people are facing potential As poisoning from water and rice consumption, whereas Rahman et al. (2018) projected that even 35 - 77 million people are health-affected just by water consumption. Sauvé (2014) described the existing arsenic 
guidelines as a cost-benefit compromise and, as such, they should be periodically re-evaluated in favor of health aspects. Consequences of As exposure are skin lesions, cancer of lung, liver, and bladder (EFSA 2009a; Lin et al. 2013; Smith et al. 2006; Tchounwou et al. 2019).

In the 1960s for the first time, the world witnessed severe $\mathrm{Cd}$ poisoning by rice consumption that caused the Itai-Itai disease in Toyama Prefecture, Japan. Nogawa et al. (2017) calculated from $\mathrm{Cd}$ concentrations of thousands of rice samples in this area a threshold limit concentration of $0.27 \mathrm{mg} \mathrm{kg}^{-1}$ to prevent the Itai-Itai disease. For Chinese population, rice is the most important Cd-source compared to other food (Yu et al. 2017). Chronic Cd exposure can cause renal dysfunction, bone demineralization, as well as cancer of lung, endometrium, bladder, and breast (EFSA 2009b).

In addition to $\mathrm{As}$ and $\mathrm{Cd}$, the toxic element $\mathrm{Pb}$ can also be enriched in rice grains (Norton et al. 2014; Shraim 2017). Chronic Pb-exposure causes developmental neurotoxicity in young children, cardiovascular effects and nephrotoxicity in adults and many effects such as headaches, convulsions, tremors, paralysis, and probable cancer (EFSA 2010).

Vietnam is one of the main rice producing and consuming countries. The Mekong River Delta - the largest granary in Vietnam - produces more than $50 \%$ of total national rice (Thuy and Anh 2015). The paddy soils in this delta consist of fertile alluvial material in combination with plentiful water. The Mekong River provides about 160 million tons suspended sediment in 475000 million cubic meters' water per year (Hung 2011). The Mekong River originates in the Tibetan plateau (China) and flows through Burma, Thailand, Laos, Cambodia and finally Vietnam where it disembogues into the South China Sea. Inhabitants of Laos, Cambodia, and Vietnam living along the Mekong River are facing a chronic As exposure consuming naturally As-enriched groundwater and crops grown on soils contaminated by irrigation (Buschmann et al. 2008; Chanpiwat et al. 2011; Huang et al. 2016). More than 17 million people live in the Mekong River Delta area in Vietnam. Most of their income is based on rice cultivation (Huang et al. 2016).

Soil geochemistry combined with data of rice composition are a key to understand the transport of nutrient and harmful elements into the rice grains and resulting health aspects. The main research aims of our study are: (1) distinction of natural and anthropogenic element concentrations in paddy soils in the Mekong River Delta; (2) influence of soil parameters regarding retention and phytoavailability of elements for rice grains; (3) aspects of rice composition and health risks for people. 


\subsection{Material and methods}

\subsubsection{Sampling, sample preparation, analysis, and quality control}

Soils and corresponding rice grains were collected in April 2017 within a 10-day period before rice harvesting at 80 sites in the Mekong River Delta area of Vietnam. The soil samples were taken in the root zone of the rice plants at depths between 0 to $10 \mathrm{~cm}$.

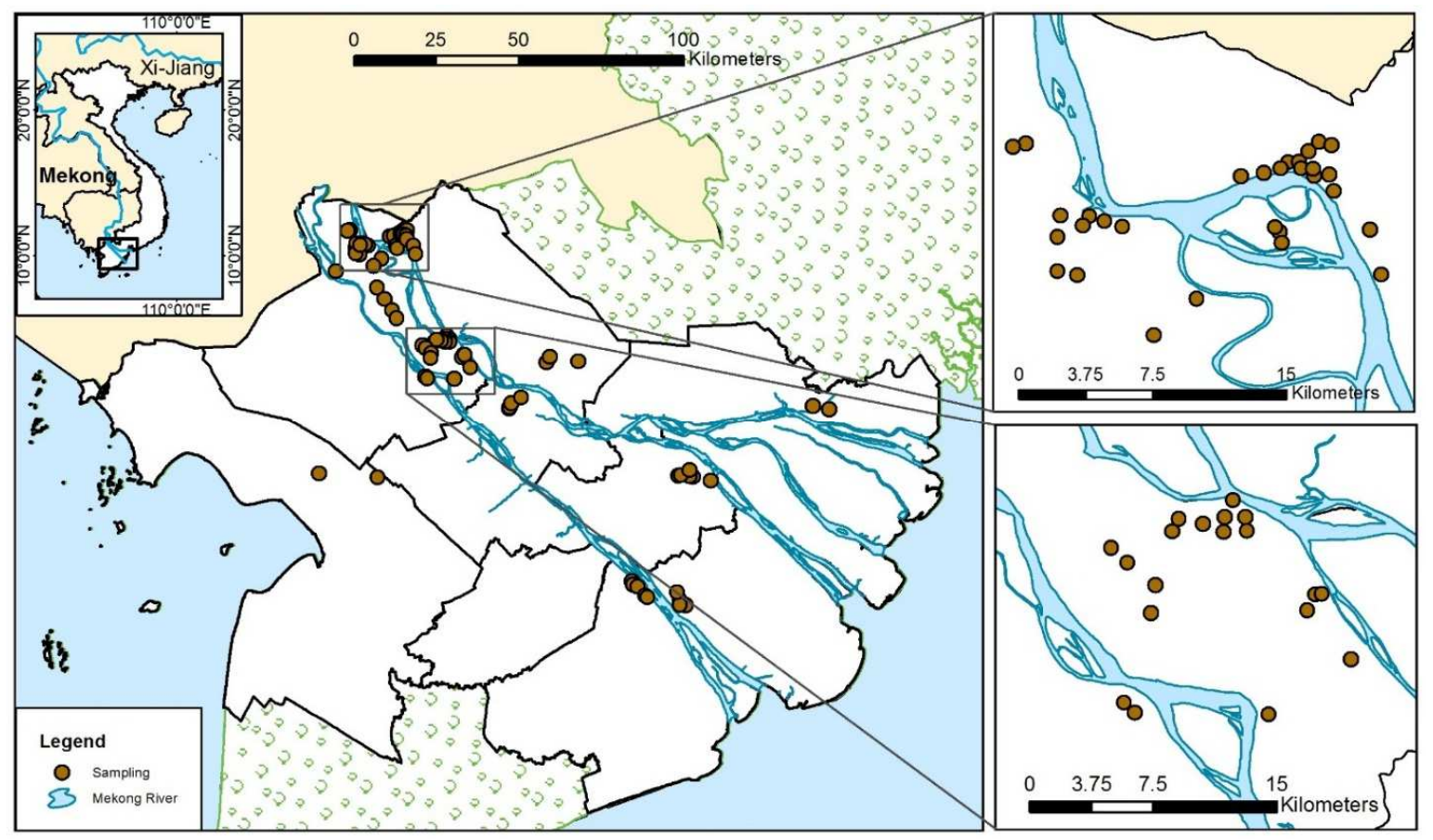

Fig. 4.1 Map of sample locations in the Mekong River Delta area, Vietnam

Before analysis, the soil samples were dried at $105{ }^{\circ} \mathrm{C}$, rice grains at $60{ }^{\circ} \mathrm{C}$, then grounded to a particle size $<63 \mu \mathrm{m}$ by a Fritsch ${ }^{\odot}$ agate ball mill for soils and by an agate hand mortar for the rice grains. The $\mathrm{pH}$-values of air-dried soils were measured in a $0.01 \mathrm{M} \mathrm{CaCl}_{2}$ solution (1:2.5) using the glass electrode ProfiLine $\mathrm{pH} / \mathrm{mV}$-Meter 197. To quantify the total concentration of elements in soil and rice grains, the milled samples were completely digested in a closed ultra-clean PTFE vessel (PicoTrace®, Bovenden, Acid Sample Digestion System DAS 30): about $700 \mathrm{mg}$ of dried milled rice were digested by $4 \mathrm{ml} \mathrm{HNO}_{3}, 0.5 \mathrm{ml} \mathrm{HF}$, and $3 \mathrm{ml} \mathrm{HClO}_{4}$, about $150 \mathrm{mg}$ of dried milled soils by $2 \mathrm{ml}$ $\mathrm{HNO}_{3}, 3 \mathrm{ml} \mathrm{HF}$, and $3 \mathrm{ml} \mathrm{HClO}_{4}$. The reason for the use of $\mathrm{HF}$ to digest the rice grains was to identify if adhering soil or dust material contaminated the samples or if all the elements were taken up by physiological processes. The digestion solutions were measured afterwards by two analytical tools: ICP-OES (Inductively Coupled Plasma - Optical Emission Spectrometry) 5100 VDV (Agilent) and ICP-MS (Inductively Coupled Plasma - Mass Spectrometry) Thermo Scientific iCAP Q (Thermo Fisher 
Scientific). Loss on ignition (LOI) was determined by weight loss after heating the dried soil samples to $530{ }^{\circ} \mathrm{C}$ for 24 hours. The concentration of $\mathrm{SiO}_{2}$ was calculated by the following equation:

$$
\mathrm{SiO}_{2}=[100-(\text { main element oxides }+ \text { minor element oxides }+\mathrm{LOI})] \quad \text { (wt. \%) }
$$

To ensure the accuracy and precision of the element data, the following reference materials were measured (see the compilation of the results in the supplement of the previous paper of Nguyen et al. 2019): GSJ-JA-2 (Andesite), GSJ-JLK-1 (Lake Sediment), NCS-DC73349 (Branches and Leaves of Bush), WEPAL-IPE 126 (Maize plant), and WEPAL-IPE-168 (Sunflower). Deviations from the element concentrations of certified reference materials were smaller than $10 \%$ for most elements, but $\mathrm{Bi}, \mathrm{Mo}$, and $\mathrm{Zr}$ showed deviations of up to $20 \%$.

\subsubsection{Data and statistical analysis}

The software IBM statistics 20 was used to calculate how trace element concentrations depend on soil parameters by using the module Multiple Linear Regression Analysis. The relations between trace element concentration $\mathrm{y}$ and soil parameters $\mathrm{x}_{\mathrm{n}}$ are modeled according to the regression equation:

$$
y=\beta_{0}+\beta_{1} x_{1}+\beta_{2} x_{2}+\beta_{3} x_{3}+\varepsilon
$$

where $\beta_{0}$ is a constant (intercept), $\beta_{\mathrm{n}}$ are slopes (regression coefficients), and $\varepsilon$ is the standard error of the estimate.

For each element, soil parameters were selected according to significance levels below 0.05 for the regression coefficient, coefficient of determination $\mathrm{R}^{2}$, and standard error $\varepsilon$.

To describe the transport of elements from soils into rice grains, transfer factors $(T F)$ were calculated as ratio of element concentration in grain $\left(E l_{\text {grain }}\right)$ to that in corresponding soil $\left(E l_{\text {soil }}\right)$ :

$$
T F=E l_{\text {grain }} / E l_{\text {soil }}
$$

\subsection{Results and discussion}

\subsubsection{Soil geochemistry}

Parent materials of paddy soils within the Mekong River Delta area in Vietnam are composed of alluvial delta sediments delivered from the Tibetan Plateau and lower mountains along the river course. The geochemical data for each soil sample are compiled in Tables S1 and S2 of the supplementary material. The paddy fields contain on average 10.3\% LOI (Table $4.1)$, a representative for organic material $(\mathrm{OM})$ and water in mineral structures like $\mathrm{Al}-$, Fe-, 
and Mn-oxides/hydroxides and clay minerals. The $\mathrm{pH}$-values of the delta soils range from 3.7 to 6.8 with $50 \%$ of the samples between 3.7 and $4.9,34 \%$ between 5.0 and 5.5 , and $16 \%$ between 5.5 and 6.8. Acidification of paddy soils can be due to organic acidic groups and/or the application of ammonium nitrate fertilizers.

Table 4.1 Statistics of main and trace element concentrations in soils of the Mekong River Delta $(n=80)$. For comparison, mean values for soils along the Red River $(n=24)$ in northern Vietnam and Huong River ( $\mathrm{n}=5)$ in central Vietnam, average shale and Earth's crust data as well as allowable limits for agricultural soils are listed.

\begin{tabular}{|c|c|c|c|c|c|c|c|c|c|c|c|c|c|}
\hline \multirow{2}{*}{$\begin{array}{l}\text { Ele- } \\
\text { ment }\end{array}$} & \multirow[b]{2}{*}{ Unit } & \multicolumn{7}{|c|}{ Mekong River } & \multirow{2}{*}{$\begin{array}{l}\text { Huong } \\
\text { River }\end{array}$} & \multirow{2}{*}{$\begin{array}{l}\text { Red } \\
\text { River }\end{array}$} & \multirow[t]{2}{*}{ Shale } & \multirow{2}{*}{$\begin{array}{c}\text { Earth's } \\
\text { crust }\end{array}$} & \multirow{2}{*}{$\begin{array}{c}\text { Allowabl } \\
\text { e limit }\end{array}$} \\
\hline & & Min & Q1 & $\begin{array}{r}\text { Media } \\
n\end{array}$ & Q3 & Max & Mean & Stdev & & & & & \\
\hline$\overline{\mathrm{pH}}$ & - & 3.7 & 4.6 & 4.9 & 5.3 & 6.8 & 5.0 & 0.6 & 4.4 & 6.2 & - & - & - \\
\hline LOI & $\%$ & 4.7 & 8.6 & 10.2 & 11.9 & 18.8 & 10.3 & 2.6 & 6.4 & 6.5 & - & - & - \\
\hline $\mathrm{Al}_{2} \mathrm{O}_{3}$ & $\%$ & 11.9 & 14.8 & 16.5 & 18.4 & 20.9 & 16.5 & 2.2 & 14.1 & 14.3 & $15.1^{\mathrm{a}}$ & $15.4^{\mathrm{c}}$ & - \\
\hline $\mathrm{CaO}$ & $\%$ & 0.30 & 0.44 & 0.49 & 0.55 & 1.27 & 0.52 & 0.14 & 0.31 & 0.80 & $3.3^{\mathrm{b}}$ & $3.6^{\mathrm{c}}$ & - \\
\hline $\mathrm{Fe}_{2} \mathrm{O}_{3}$ & $\%$ & 2.63 & 4.57 & 5.14 & 5.44 & 6.78 & 4.97 & 0.83 & 4.94 & 6.32 & $6.9^{\mathrm{d}}$ & $5.0^{\mathrm{c}}$ & - \\
\hline $\mathrm{K}_{2} \mathrm{O}$ & $\%$ & 1.89 & 2.19 & 2.35 & 2.55 & 2.78 & 2.37 & 0.22 & 2.38 & 2.42 & $3.8^{\mathrm{b}}$ & $2.8^{\mathrm{c}}$ & - \\
\hline $\mathrm{MgO}$ & $\%$ & 0.70 & 0.99 & 1.08 & 1.17 & 1.33 & 1.07 & 0.15 & 0.96 & 1.35 & $2.7^{\mathrm{d}}$ & $2.5^{\mathrm{c}}$ & - \\
\hline $\mathrm{MnO}$ & $\%$ & 0.009 & 0.024 & 0.033 & 0.046 & 0.161 & 0.039 & 0.024 & 0.033 & 0.068 & $0.11^{\mathrm{d}}$ & $0.10^{c}$ & - \\
\hline $\mathrm{Na}_{2} \mathrm{O}$ & $\%$ & 0.40 & 0.56 & 0.61 & 0.69 & 0.86 & 0.62 & 0.10 & 0.40 & 0.71 & $1.0^{\mathrm{b}}$ & $3.3^{\mathrm{c}}$ & - \\
\hline $\mathrm{P}_{2} \mathrm{O}_{5}$ & $\%$ & 0.09 & 0.13 & 0.17 & 0.20 & 0.32 & 0.18 & 0.05 & 0.11 & 0.20 & $0.16^{\mathrm{a}}$ & $0.15^{\mathrm{c}}$ & - \\
\hline $\mathrm{S}$ & $\%$ & 0.015 & 0.047 & 0.072 & 0.113 & 0.431 & 0.093 & 0.072 & 0.052 & 0.065 & $0.24^{\mathrm{a}}$ & $0.056^{\mathrm{c}}$ & - \\
\hline $\mathrm{TiO}_{2}$ & $\%$ & 0.64 & 0.76 & 0.79 & 0.84 & 1.01 & 0.80 & 0.06 & 0.81 & 0.81 & $0.77^{\mathrm{d}}$ & $0.64^{\mathrm{c}}$ & - \\
\hline $\mathrm{SiO}_{2}$ & $\%$ & 54 & 60 & 62 & 66 & 72 & 63 & 4.3 & 70 & 67 & $61^{\mathrm{b}}$ & $67^{c}$ & - \\
\hline As & $\mathrm{mg} \mathrm{kg}^{-1}$ & 8.3 & 10.9 & 12.4 & 13.7 & 28.9 & 12.6 & 3.2 & 13.6 & 22.5 & $10.0^{\mathrm{d}}$ & $4.8^{c}$ & $15^{\mathrm{e}}$ \\
\hline $\mathrm{Ba}$ & $\mathrm{mg} \mathrm{kg}^{-1}$ & 283 & 373 & 399 & 420 & 487 & 394 & 42 & 460 & 417 & $636^{\mathrm{b}}$ & $624^{c}$ & - \\
\hline $\mathrm{Bi}$ & $\mathrm{mg} \mathrm{kg}^{-1}$ & 0.29 & 0.37 & 0.40 & 0.43 & 0.52 & 0.40 & 0.05 & 0.56 & 0.88 & $0.13^{\mathrm{d}}$ & $0.16^{c}$ & - \\
\hline $\mathrm{Cd}$ & $\mathrm{mg} \mathrm{kg}^{-1}$ & 0.16 & 0.22 & 0.29 & 0.32 & 0.43 & 0.27 & 0.06 & 0.25 & 0.37 & $0.13^{\mathrm{d}}$ & $0.09^{c}$ & $1.5^{\mathrm{f}}$ \\
\hline $\mathrm{Ce}$ & $\mathrm{mg} \mathrm{kg}^{-1}$ & 68 & 76 & 81 & 85 & 108 & 81 & 7 & 83 & 90 & $67^{\mathrm{b}}$ & $63^{c}$ & - \\
\hline $\mathrm{Co}$ & $\mathrm{mg} \mathrm{kg}^{-1}$ & 5.6 & 11.8 & 13.7 & 14.9 & 20.6 & 13.2 & 3.0 & 13.3 & 15.7 & $19.0^{\mathrm{d}}$ & $17.3^{c}$ & $20-50^{e}$ \\
\hline $\mathrm{Cs}$ & $\mathrm{mg} \mathrm{kg}^{-1}$ & 7.2 & 9.6 & 11.1 & 12.8 & 15.1 & 11.2 & 2.0 & 6.3 & 8.1 & 5.2 & $4.9^{c}$ & - \\
\hline $\mathrm{Cu}$ & $\mathrm{mg} \mathrm{kg}^{-1}$ & 20.1 & 27.3 & 29.2 & 33.2 & 43.0 & 30.0 & 4.2 & 27.1 & 47.8 & $45^{\mathrm{d}}$ & $28^{c}$ & $100^{\mathrm{f}}$ \\
\hline $\mathrm{Hf}$ & $\mathrm{mg} \mathrm{kg}^{-1}$ & 3.1 & 3.9 & 4.1 & 4.4 & 5.3 & 4.1 & 0.4 & 3.8 & 4.1 & $6.3^{b}$ & $5.3^{\mathrm{c}}$ & - \\
\hline $\mathrm{La}$ & $\mathrm{mg} \mathrm{kg}^{-1}$ & 34 & 38 & 40 & 43 & 53 & 41 & 4 & 41 & 44 & $31^{\mathrm{b}}$ & $31^{\mathrm{c}}$ & - \\
\hline $\mathrm{Li}$ & $\mathrm{mg} \mathrm{kg}^{-1}$ & 35 & 43 & 50 & 58 & 76 & 50 & 9 & 27 & 40 & $66^{\mathrm{a}}$ & $21^{\mathrm{c}}$ & - \\
\hline Mo & $\mathrm{mg} \mathrm{kg}^{-1}$ & 0.49 & 0.68 & 0.86 & 1.07 & 2.63 & 0.94 & 0.36 & 1.07 & 0.98 & $1.3^{\mathrm{d}}$ & $1.1^{\mathrm{c}}$ & $4-10^{e}$ \\
\hline $\mathrm{Ni}$ & $\mathrm{mg} \mathrm{kg}^{-1}$ & 23.2 & 31.8 & 36.3 & 39.2 & 50.4 & 36.3 & 5.8 & 28.5 & 39.9 & $68^{d}$ & $47^{c}$ & $20-60^{e}$ \\
\hline $\mathrm{Pb}$ & $\mathrm{mg} \mathrm{kg}^{-1}$ & 20.9 & 24.9 & 26.6 & 28.6 & 190 & 28.6 & 18.5 & 29.7 & 50.5 & $22^{\mathrm{d}}$ & $17^{\mathrm{c}}$ & $70^{f}$ \\
\hline $\mathrm{Rb}$ & $\mathrm{mg} \mathrm{kg}^{-1}$ & 94 & 111 & 121 & 134 & 154 & 123 & 15 & 117 & 119 & $125^{\mathrm{b}}$ & $84^{\mathrm{c}}$ & - \\
\hline $\mathrm{Sb}$ & $\mathrm{mg} \mathrm{kg}^{-1}$ & 1.07 & 1.82 & 2.02 & 2.28 & 6.45 & 2.06 & 0.62 & 1.58 & 2.01 & $2.1^{\mathrm{b}}$ & $0.4^{\mathrm{c}}$ & $10^{\mathrm{e}}$ \\
\hline $\mathrm{Sn}$ & $\mathrm{mg} \mathrm{kg}^{-1}$ & 3.22 & 3.92 & 4.22 & 4.39 & 5.18 & 4.15 & 0.38 & 4.56 & 4.81 & $2.5^{\mathrm{d}}$ & $2.1^{\mathrm{c}}$ & $50^{e}$ \\
\hline $\mathrm{Sr}$ & $\mathrm{mg} \mathrm{kg}^{-1}$ & 71 & 80 & 83 & 87 & 108 & 84 & 6 & 41 & 82 & $142^{\mathrm{b}}$ & $320^{c}$ & - \\
\hline Th & $\mathrm{mg} \mathrm{kg}^{-1}$ & 12.6 & 14.7 & 15.4 & 16.1 & 17.5 & 15.3 & 1.0 & 19.2 & 17.5 & $12.3^{b}$ & $10.5^{\mathrm{c}}$ & - \\
\hline $\mathrm{Tl}$ & $\mathrm{mg} \mathrm{kg}^{-1}$ & 0.50 & 0.60 & 0.67 & 0.72 & 0.83 & 0.66 & 0.08 & 0.59 & 0.60 & $0.68^{d}$ & $0.90^{c}$ & - \\
\hline $\mathrm{U}$ & $\mathrm{mg} \mathrm{kg}^{-1}$ & 3.59 & 4.18 & 4.41 & 4.71 & 5.66 & 4.45 & 0.41 & 4.53 & 3.74 & $2.7^{\mathrm{b}}$ & $2.7^{\mathrm{c}}$ & - \\
\hline $\mathrm{V}$ & $\mathrm{mg} \mathrm{kg}^{-1}$ & 84 & 100 & 114 & 120 & 139 & 111 & 13 & 97 & 111 & $130^{\mathrm{d}}$ & $97^{\mathrm{c}}$ & - \\
\hline $\mathrm{Zn}$ & $\mathrm{mg} \mathrm{kg}^{-1}$ & 51 & 78 & 90 & 100 & 134 & 90 & 16 & 83 & 110 & $95^{\mathrm{a}}$ & $67^{c}$ & $200^{f}$ \\
\hline $\mathrm{Zr}$ & $\mathrm{mg} \mathrm{kg}^{-1}$ & 115 & 145 & 152 & 163 & 197 & 154 & 15 & 110 & 129 & $160^{\mathrm{a}}$ & $193^{c}$ & - \\
\hline
\end{tabular}

${ }^{\mathrm{a}}$ Turekian and Wedepohl (1961); ${ }^{\mathrm{b}}$ Gromet et al. (1984); ${ }^{\mathrm{c}}$ Rudnick and Gao (2003); ${ }^{\mathrm{d}}$ Wedepohl (2004); ${ }^{\mathrm{e}}$ Kabata-

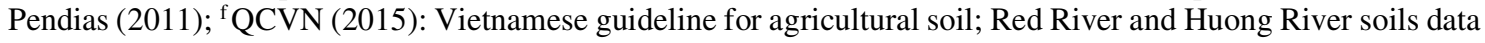
from Nguyen et al. (2019) 
The average concentrations of main and trace elements in the studied soils from the Mekong area were compared to the mean global shale composition (Table 4.1) to point out the depletion or enrichment of elements. The reason for using average shale as background composition is due to the lack of soil data. The ratio of average element concentrations in Mekong soils to those in shale increases as follows:

- Depleted elements (ratio from 0.15 to 0.9): $\mathrm{Ca}, \mathrm{Mn}, \mathrm{S}, \mathrm{Mg}, \mathrm{Ni}, \mathrm{Sr}, \mathrm{Na}, \mathrm{Ba}, \mathrm{K}, \mathrm{Hf}$, $\mathrm{Cu}, \mathrm{Co}, \mathrm{Mo}, \mathrm{Fe}, \mathrm{Li}, \mathrm{V}$

- Elements with little changes (0.9 to 1.1): $\quad \mathrm{Zn}, \mathrm{Zr}, \mathrm{Tl}, \mathrm{Rb}, \mathrm{Sb}, \mathrm{Si}, \mathrm{Ti}, \mathrm{Al}$

- Enriched elements (1.1 to 3.1): $\quad$ P, Ce, Th, As, Pb, La, U, Sn, Cd, Cs, Bi.

The depletion of alkaline, earth-alkaline elements, and S may be explained by the delivery of soil material from pre-weathered landscapes. Furthermore, the decrease of these elements can be additionally promoted by low $\mathrm{pH}$-values in the soil. The dissolution of $\mathrm{Fe}$ - and Mn-oxides/hydroxides under reducing conditions or at low $\mathrm{pH}$-values (84\% of the soils have $\mathrm{pH}<5.5)$ may diminish their soil concentrations. The elements $\mathrm{Zr}, \mathrm{Tl}, \mathrm{Rb}, \mathrm{Si}, \mathrm{Ti}$, and $\mathrm{Al}$ are resistant to weathering and keep ratios around 1. The application of phosphate fertilizer originating from apatite not only increased phosphorus, but also concomitant elements such as Cd and $\mathrm{U}$ in the paddy soils (Chen and Graedel 2015). The soil As- and Bi-enrichment is suggested to be due to natural redox and co-precipitation processes related to $\mathrm{Fe}$ oxides/hydroxides. In contrast, the Pb-enrichments in soils may be caused by anthropogenic emissions from transportation (former $\mathrm{Pb}$-containing gasoline), non-ferrous metal industry and energy production (especially coal), and the sedimentation of contaminated suspended riverine materials.

The element concentrations in Mekong Delta soils were compared with those of the Red River in north and the Huong River in central Vietnam (Nguyen et al. 2019; Table 4.1). Most elements showed similar enrichments or depletions within the three areas. This can be explained by a similar provenance and weathering stage of the suspension in the rivers. However, the concentrations of easily dissolvable elements $\mathrm{Ca}, \mathrm{Mn}, \mathrm{Mg}, \mathrm{Na}, \mathrm{Zn}, \mathrm{P}$ and Fe in Red River were slightly higher than those in the Mekong and Huong River. This is consistent with higher $\mathrm{pH}$-values in the Red River soils (mean $\mathrm{pH}=6.2$ ) than in the Mekong River soils (mean $\mathrm{pH}=5$ ) and Red River soils (mean $\mathrm{pH}=4.4$ ). In addition, the considerably higher concentrations of $\mathrm{As}$ and $\mathrm{Bi}$ in Red River soils may partially result from higher content of $\mathrm{Fe}$ oxides/hydroxides, the most important sorbents of $\mathrm{As}$ and $\mathrm{Bi}$. The enrichment of $\mathrm{Cd}$ and $\mathrm{Pb}$ in 
Red River soils can be caused by anthropogenic influences such as phosphate fertilizer application and emissions from energy production or industrial activities.

Except for $\mathrm{As}$ and $\mathrm{Pb}$, the other critical elements were within the permissible soil levels from the Vietnamese Ministry of Natural Resource and Environment (QCVN 2015) and from other countries. $11 \%$ of Mekong Delta soils exceed the As-threshold of $15 \mathrm{mg} \mathrm{kg}^{-1}$. The increased As-concentrations were probably a consequence of the aforementioned natural causes, even for the samples MK8 and MK9 with 29 and $25 \mathrm{mg} \mathrm{As} \mathrm{kg}^{-1}$ respectively. Consistent with soils, Luu (2019) mentioned that $26 \%$ of groundwater samples from the Mekong River Delta As-values were higher than the limit of $10 \mu \mathrm{g} \mathrm{L}^{-1}$.

Soil sample MK14 shows extreme concentrations of $190 \mathrm{mg} \mathrm{kg}^{-1} \mathrm{~Pb}$ and $6.4 \mathrm{mg} \mathrm{kg}^{-1}$ $\mathrm{Sb}$, corresponding to 7- and 3-times enrichments respectively compared to their mean contents. This site is 200 meters away from a small husking rice factory. Previous use of leaded gasoline may be a source for $\mathrm{Pb}$ and tire abrasion for $\mathrm{Sb}$.

Two highly correlated element groups could be distinguished (Fig. 4.2):

- Highly significant correlations existed between the elements $\mathrm{K}, \mathrm{Al}, \mathrm{Li}, \mathrm{Rb}, \mathrm{Cs}, \mathrm{Tl}$, $\mathrm{V}$, and $\mathrm{Ba}$. These elements are bound in K-rich alumino-silicate minerals such as Kfeldspars, illite/muscovite and clay minerals. The alkaline elements $\mathrm{Li}, \mathrm{Rb}, \mathrm{Cs}$, as well as $\mathrm{Tl}$ and $\mathrm{Ba}$ can substitute $\mathrm{K} ; \mathrm{V}$ may replace $\mathrm{Al}$ in clay mineral structure. A significant positive correlation between $\mathrm{K}, \mathrm{Fe}$, and $\mathrm{Mg}$ suggests the existence of biotite. The highly significant negative correlations of Si with LOI (a proxy for OM and water), $\mathrm{Al}, \mathrm{K}, \mathrm{Li}, \mathrm{Rb}, \mathrm{Cs}, \mathrm{Tl}, \mathrm{V}$, and $\mathrm{Ba}$ could be attributed to the dilution by quartz (nearly pure $\mathrm{SiO}_{2}$ ) or opal $\left(\mathrm{SiO}_{2}\right.$ with some water). It must be considered that this dilution causes spurious positive correlations within this element group. The correlation of LOI with $\mathrm{Al}, \mathrm{K}, \mathrm{Li}, \mathrm{Rb}, \mathrm{Cs}, \mathrm{Tl}, \mathrm{V}$, and $\mathrm{Ba}$ may be due to presence of water in clay minerals. The enrichment of $\mathrm{S}$ in organic material leaded to a positive correlation of $\mathrm{S}$ with LOI. The low Fe-concentration in some S-rich samples suggest that some of the S may exist in elementary form and not as Fe-sulfide. This was evident in sample MK82 containing $0.43 \% \mathrm{~S}$ and only $2.2 \% \mathrm{Fe}$. The increase of Mnconcentration with rising $\mathrm{pH}$ may be caused by the oxidation of $\mathrm{Mn}^{2+}$ ion and formation $\mathrm{Mn}^{\mathrm{IV}}$-oxides/hydroxides. In addition, the negative correlation of $\mathrm{Mn}$ with LOI may indicate less reducing soil environments and less microbial reduction and dissolution of already existing $\mathrm{Mn}^{\mathrm{IV}}$-phases at higher LOI-contents. The negative correlation of LOI and $\mathrm{pH}$ may be caused by a better preservation of OM in acidic 
soils due to lower activities of oxidizing organisms. In addition, weak acidic groups in $\mathrm{OM}$ may decrease the $\mathrm{pH}$ of paddy soils. The low $\mathrm{pH}$-values facilitated the dissolution of Mn- and Fe-oxides/hydroxides (Chen et al. 2003).

- The extremely strong correlation between $\mathrm{Hf}$ and $\mathrm{Zr}(\mathrm{r}=0.99)$ was caused by their usually constant ratio in parent materials and their poor mobility in soil. They are often bound in own, weathering-resistant phases like $\mathrm{Zr}$.

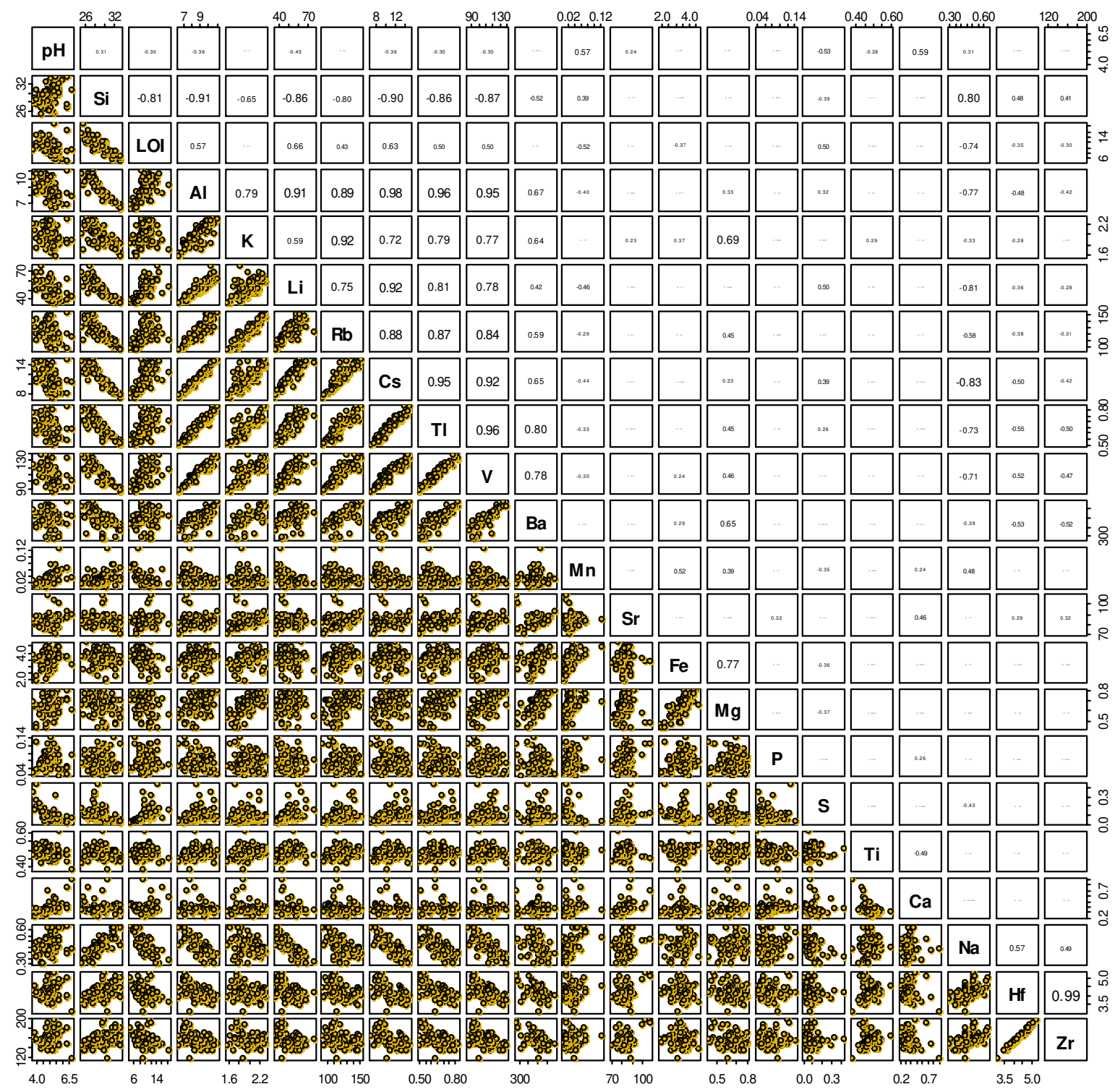

Fig. 4.2 Scattergram and correlation matrix of concentrations of selected main and trace elements, $\mathrm{pH}$, and LOI in soils of the Mekong River area (main and minor elements in wt. $\%$; trace elements $\mathrm{Li}, \mathrm{Sr}, \mathrm{Rb}, \mathrm{Cs}, \mathrm{Tl}, \mathrm{V}, \mathrm{Ba}, \mathrm{Hf}$ and $\mathrm{Zr}$ in $\mathrm{mg} \mathrm{kg}^{-1}$ ) 


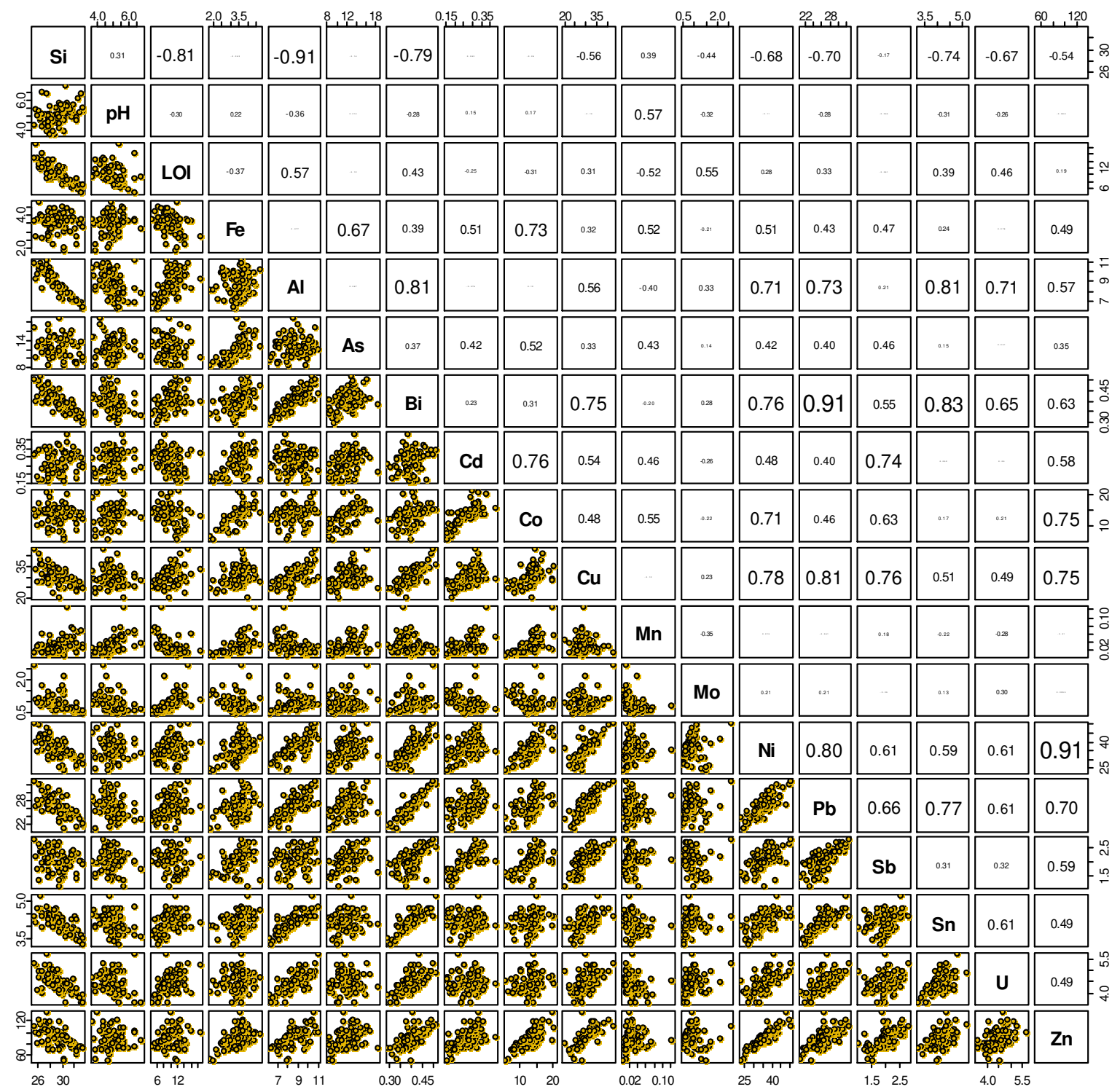

Fig. 4.3 Scattergram and correlation matrix for $\mathrm{pH}$, LOI, selected main elements (in wt. \%), and critical trace elements $\left(\mathrm{mg} \mathrm{kg}^{-1}\right)$ in soils of the Mekong River Delta. Pb $\left(190 \mathrm{mg} \mathrm{kg}^{-1}\right)$ and $\mathrm{Sb}\left(6.5 \mathrm{mg} \mathrm{kg}^{-1}\right)$ in sample MK-14 as well as As in MK-8 (29 mg kg-1) and MK-9 (25 mg kg$\left.{ }^{1}\right)$ are excluded

In addition to parent materials, element concentrations in soils are impacted by soil factors like $\mathrm{pH}$, concentration of $\mathrm{OM}, \mathrm{Al}-, \mathrm{Fe}-, \mathrm{Mn}$-oxides/hydroxides, and clay minerals. These factors play an important role for holding and fixing trace elements in soils and determine their phytoavailability. Oxides/hydroxides, clay minerals and OM act as sorbents binding toxic element ions on their surfaces (Alloway 2013; Kabata-Pendias 2011). Organic material may additionally form soluble complexes with some metals such as $\mathrm{Cu}, \mathrm{Pb}$, and $\mathrm{Mo}$ 
(Greger 2004) or provide electrons for the reduction of Fe- and Mn-oxides/hydroxides and of the oxyanions arsenate, bismutate, molybdate, vanadate, and antimonate. The effect of $\mathrm{pH}$ on release or retention of trace elements in soils has two facets: (1) low soil-pH directly increases the solubility of sorbed trace metal cations thereby increasing their mobility but lowering the mobility of anions; (2) low soil-pH increases the solubility of Fe- and Mn-oxide/hydroxides releasing sorbed metal ions. In contrast, higher $\mathrm{pH}$-values lead to increased sorption of trace element cations and/or co-precipitation with oxides/hydroxides. However, correlations between trace element concentrations and the $\mathrm{pH}$-values in Mekong soils were not significant, except for Mn (Fig. 4.3). Trace element concentrations exhibit positive correlations with Aland $\mathrm{Fe}$-oxide/hydroxide and $\mathrm{OM}$. The increase of concentrations of $\mathrm{As}, \mathrm{Cd}, \mathrm{Co}$, and $\mathrm{Sb}$ can be partially explained by increasing concentrations of $\mathrm{Fe}$-phases, that of $\mathrm{Bi}, \mathrm{Cu}, \mathrm{Mo}, \mathrm{Ni}, \mathrm{Pb}, \mathrm{Sn}$, Tl, U, V, and Zn by rising concentrations of Al-phases (Fig. 4.3). In addition, the positive correlation between Al- and LOI-concentrations induced positive association of the Alcorrelated elements with LOI as well. Molybdenum had a strong positive correlation with LOI caused by the strong sorption of molybdate anions on humic acids in reducing soils (KabataPendias 2011).

The application of multiple regression analysis can give a more reliable estimate for the influence of the main soil components on the trace element concentrations. As master variables, five soil parameters $\mathrm{pH}$, LOI (as a proxy for $\mathrm{OM}$ ), $\mathrm{Fe}, \mathrm{Al}$, and $\mathrm{Mn}$ (as representatives for oxides/hydroxides and clay minerals) were chosen. Table 2 shows multiple regression equations describing the dependency of the trace element concentration on main soil parameters at significance levels of $\leq 0.05$, coefficient of determination $\mathrm{R}^{2}$ at maximum and the standard error of estimate $\varepsilon$ at minimum. These equations were partially suitable to give a calculation and estimate of trace element concentrations in uncontaminated paddy soils of the Mekong Delta. Scattergrams of measured content versus modeled content for selected trace elements are presented in Fig. A2.1 (Appendix A2).

Table 4.2 Regression models to estimate some trace element concentrations ( $\mathrm{mg} \mathrm{kg}^{-1}$ ) in soils in the Mekong River Delta based on soil parameters (wt. \%) and pH. The importance of soil factors is listed in decreasing order.

\begin{tabular}{lccl}
\hline Regression equation & $\begin{array}{c}\text { Std. Error of } \\
\text { Estimate }(\boldsymbol{\varepsilon})\end{array}$ & $\mathbf{R}^{\mathbf{2}}$ & $\begin{array}{l}\text { Importance } \\
\text { of soil factors }\end{array}$ \\
\hline$[\mathrm{As}]=5.98-1.04[\mathrm{pH}]+0.199[\mathrm{LOI}]+2.22[\mathrm{Fe}]+58.9[\mathrm{Mn}]$ & 1.47 & 0.55 & $\mathrm{Fe}, \mathrm{Mn}, \mathrm{pH}$ \\
{$[\mathrm{Bi}]=0.021+0.004[\mathrm{LOI}]+0.033[\mathrm{Fe}]+0.026[\mathrm{Al}]$} & 0.02 & 0.78 & $\mathrm{Al}, \mathrm{Fe}, \mathrm{LOI}$ \\
{$[\mathrm{Cd}]=0.11+0.04[\mathrm{Fe}]+0.9[\mathrm{Mn}]$} & 0.05 & 0.32 & $\mathrm{Fe}, \mathrm{Mn}$ \\
{$[\mathrm{Co}]=-2.7+0.58[\mathrm{Al}]+2.62[\mathrm{Fe}]+58.4[\mathrm{Mn}]$} & 1.89 & 0.61 & $\mathrm{Fe}, \mathrm{Mn}, \mathrm{Al}$
\end{tabular}




$$
\begin{aligned}
& {[\mathrm{Cu}]=6.4+1.91[\mathrm{Al}]+2[\mathrm{Fe}]} \\
& {[\mathrm{Mo}]=0.14+0.077[\mathrm{LOI}]} \\
& {[\mathrm{Ni}]=-9.1+3.331[\mathrm{Al}]+4.571[\mathrm{Fe}]} \\
& {[\mathrm{Pb}]=7.26+1.539[\mathrm{Al}]+1.688[\mathrm{Fe}]} \\
& {[\mathrm{Sb}]=0.78+0.369[\mathrm{Fe}]} \\
& {[\mathrm{Sn}]=1.55+0.114[\mathrm{Fe}]+0.253[\mathrm{Al}]} \\
& {[\mathrm{Tl}]=0.07+0.067[\mathrm{Al}]} \\
& {[\mathrm{U}]=2.28+0.25[\mathrm{Al}]} \\
& {[\mathrm{V}]=8.03+10.34[\mathrm{Al}]+3.7[\mathrm{Fe}]} \\
& {[\mathrm{Zn}]=-15+7.16[\mathrm{Al}]+12.17[\mathrm{Fe}]}
\end{aligned}
$$

$\begin{array}{rll}3.4 & 0.38 & \mathrm{Al}, \mathrm{Fe} \\ 0.3 & 0.30 & \mathrm{LOI} \\ 3.2 & 0.71 & \mathrm{Al}, \mathrm{Fe} \\ 1.5 & 0.68 & \mathrm{Al}, \mathrm{Fe} \\ 0.25 & 0.42 & \mathrm{Fe} \\ 0.21 & 0.68 & \mathrm{Al}, \mathrm{Fe} \\ 0.02 & 0.92 & \mathrm{Al} \\ 0.29 & 0.51 & \mathrm{Al} \\ 3.5 & 0.93 & \mathrm{Al}, \mathrm{Fe} \\ 11 & 0.53 & \mathrm{Al}, \mathrm{Fe}\end{array}$

The results of Table 4.2 confirm the main conclusions from the bivariate plots in Fig. 4.3 , but clarify that usually more than one soil factor was responsible to explain the concentration of trace elements in soil. Al-phases like clay minerals determine the concentrations of $\mathrm{Tl}, \mathrm{V}, \mathrm{Bi}, \mathrm{Sn}, \mathrm{Pb}, \mathrm{U}, \mathrm{Ni}, \mathrm{Zn}$, and $\mathrm{Cu}$ (in decreasing order). Fe-phases such as oxides/hydroxides regulate the concentrations of $\mathrm{Co}, \mathrm{As}, \mathrm{Cd}, \mathrm{Sb}$, and to a lesser extent those of $\mathrm{Bi}, \mathrm{Cu}, \mathrm{Ni}, \mathrm{Pb}, \mathrm{Sn}, \mathrm{V}$, and $\mathrm{Zn}$; organic matter the concentration of Mo. Mn-phases influence slightly the concentrations of $\mathrm{As}, \mathrm{Cd}$, and $\mathrm{Co}, \mathrm{pH}$ that of As.

\subsubsection{Transfer of nutrient and trace elements into rice grains}

Statistical values of element concentrations in unpolished rice grains and transfer factor soil-to-grain are compiled in Table 4.3. Detailed data for grain composition in the Mekong area are compiled in Tables A2.3 and for TFs in Table A2.4 (Appendix A2). The data show a negligible transfer of $\mathrm{Ti}, \mathrm{Ce}, \mathrm{La}, \mathrm{Th}, \mathrm{U}, \mathrm{Zr}, \mathrm{Hf}, \mathrm{Al}, \mathrm{V}, \mathrm{Li}, \mathrm{Tl}, \mathrm{Sb}$, and $\mathrm{Fe}$ into rice grains. Especially the extremely low $\mathrm{Ti}$ concentrations indicate very low, negligible amount of adhering soil or dust material in the rice grains. Most of the concentrations of these elements were below detection limit. The insolubility of these elements in soils causes their low bioavailability and uptake. In contrast, $\mathrm{K}, \mathrm{Mg}, \mathrm{P}$, and $\mathrm{S}$ from fertilizers have high bioavailability because they are much more soluble. That may explain the high correlation of $\mathrm{P}$ with $\mathrm{Mg}(\mathrm{r}=0.92)$ and $\mathrm{K}(\mathrm{r}=0.75)$ in the grain (Fig. A2.2 in Appendix A2). The reduction of Fe- and Mn-oxides/hydroxides in paddy soils and the release of dissolved $\mathrm{Fe}^{2+}$ and $\mathrm{Mn}^{2+}$ ions facilitated the uptake of these elements into grains. There were weak positive correlations between $\mathrm{Ni}, \mathrm{Co}, \mathrm{Cd}$, and $\mathrm{Cu}$ in rice grains (Fig. A2.3 in Appendix A2), whereas As showed slight negative correlations with $\mathrm{Cd}, \mathrm{Cu}$ and $\mathrm{Ni}$. 
Table 4.3 Element concentrations $\left(\mathrm{mg} \mathrm{kg}^{-1}\right)$ in rice grains and transfer factors of the Mekong River area $(\mathrm{n}=78)$ in comparison with mean values of the Huong River area in central Vietnam $(n=4)$ and the Red River area in northern Vietnam $(n=19)$ from Nguyen et al. (2019)

\begin{tabular}{|c|c|c|c|c|c|c|c|c|c|c|c|c|c|c|}
\hline \multirow{3}{*}{ Element } & \multicolumn{7}{|c|}{ Concentration in rice grains } & \multicolumn{7}{|c|}{ Transfer factor } \\
\hline & \multicolumn{5}{|c|}{ Mekong River } & \multirow{2}{*}{$\begin{array}{r}\text { Huong } \\
\text { River }\end{array}$} & \multirow{2}{*}{$\begin{array}{r}\text { Red } \\
\text { River } \\
\end{array}$} & \multicolumn{5}{|c|}{ Mekong River } & \multirow{2}{*}{$\begin{array}{r}\text { Huong } \\
\text { River }\end{array}$} & \multirow{2}{*}{$\begin{array}{r}\text { Red } \\
\text { River }\end{array}$} \\
\hline & Min & Median & Max & Mean & $\overline{\text { Stdev }}$ & & & Min & Median & Max & Mean & $\overline{\text { Stdev }}$ & & \\
\hline$\overline{\mathrm{Al}}$ & $<4$ & $<4$ & 19 & $<4$ & - & $<4$ & $\overline{<4}$ & $<0.00004$ & $<0.00005$ & 0.00019 & $<0.00005$ & & $<0.00009$ & $<0.00007$ \\
\hline $\mathbf{C a}$ & 66 & 86 & 113 & 87 & 11 & 139 & 134 & 0.01 & 0.02 & 0.05 & 0.03 & 0.01 & 0.06 & 0.04 \\
\hline $\mathrm{Fe}$ & 6.6 & 10.1 & 17.4 & 10.3 & 1.81 & 13 & 11 & 0.0002 & 0.0003 & 0.0009 & 0.0003 & 0.0001 & 0.0004 & 0.0003 \\
\hline $\mathbf{K}$ & 1817 & 2580 & 3462 & 2595 & 278 & 2945 & 2910 & 0.10 & 0.13 & 0.18 & 0.13 & 0.02 & 0.15 & 0.16 \\
\hline Mg & 1011 & 1282 & 1562 & 1290 & 119 & 1240 & 1394 & 0.14 & 0.19 & 0.34 & 0.20 & 0.04 & 0.22 & 0.20 \\
\hline Mn & 13 & 21 & 29 & 21 & 4 & 24 & 22 & 0.02 & 0.08 & 0.21 & 0.09 & 0.05 & 0.09 & 0.06 \\
\hline $\mathbf{N a}$ & 3.3 & 6.1 & 29.1 & 7.6 & 4.7 & 5.5 & 4.2 & 0.0006 & 0.0014 & 0.0063 & 0.0017 & 0.0011 & 0.0019 & 0.0012 \\
\hline $\mathbf{S}$ & 624 & 875 & 1113 & 880 & 105 & 1051 & 1098 & 0.2 & 1.2 & 5.3 & 1.4 & 0.9 & 2.6 & 2.9 \\
\hline $\mathbf{T i}$ & $<0.05$ & $<0.05$ & 0.41 & $<0.07$ & - & 0.33 & $<0.07$ & $<0.00001$ & $<0.00001$ & 0.00009 & $<0.00001$ & - & 0.00007 & $<0.00002$ \\
\hline As & 0.08 & 0.16 & 0.56 & 0.18 & 0.09 & 0.27 & 0.13 & 0.006 & 0.013 & 0.044 & 0.015 & 0.008 & 0.020 & 0.009 \\
\hline Ba & 0.05 & 0.43 & 1.59 & 0.51 & 0.33 & 1.51 & 1.24 & 0.0001 & 0.0010 & 0.0036 & 0.0013 & 0.0008 & 0.0033 & 0.0033 \\
\hline $\mathbf{B i}$ & $<0.0002$ & 0.0003 & 0.0019 & $<0.0004$ & - & 0.0017 & $<0.0003$ & $<0.0005$ & 0.0009 & 0.0048 & $<0.0011$ & - & 0.0026 & $<0.0008$ \\
\hline Cd & 0.001 & 0.024 & 0.187 & 0.037 & 0.039 & 0.085 & 0.116 & 0.005 & 0.09 & 0.93 & 0.15 & 0.181 & 0.37 & 0.36 \\
\hline $\mathrm{Ce}$ & $<0.0006$ & $<0.0006$ & 0.0018 & $<0.0007$ & - & 0.0058 & $<0.0009$ & $<0.00001$ & $<0.00001$ & 0.00002 & $<0.00001$ & - & 0.00006 & $<0.00002$ \\
\hline Co & 0.008 & 0.022 & 0.115 & 0.025 & 0.017 & 0.083 & 0.017 & 0.001 & 0.002 & 0.011 & 0.002 & 0.002 & 0.007 & 0.002 \\
\hline Cs & 0.002 & 0.02 & 0.15 & 0.03 & 0.02 & 0.43 & 0.04 & 0.0001 & 0.0022 & 0.0113 & 0.0026 & 0.0021 & 0.0802 & 0.0198 \\
\hline $\mathrm{Cr}$ & $<0.1$ & $<0.1$ & 0.64 & $<0.15$ & - & $<0.1$ & $<0.1$ & - & - & - & - & - & - & 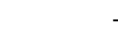 \\
\hline Hf & $<0.0002$ & $<0.0002$ & 0.0007 & $<0.0002$ & - & $<0.0005$ & $<0.0003$ & $<0.00004$ & $<0.00005$ & 0.0002 & $<0.00005$ & - & $<0.00005$ & $<0.00009$ \\
\hline La & $<0.0003$ & $<0.0003$ & 0.0010 & $<0.0004$ & - & 0.0032 & $<0.0005$ & $<0.00001$ & $<0.00001$ & 0.00003 & $<0.00001$ & - & 0.00007 & $<0.00002$ \\
\hline $\mathbf{L i}$ & $<0.006$ & $<0.006$ & 0.028 & $<0.006$ & - & $<0.014$ & $<0.006$ & $<0.0001$ & $<0.0001$ & 0.0005 & $<0.0001$ & - & $<0.0005$ & $<0.0002$ \\
\hline Mo & 0.11 & 0.40 & 1.02 & 0.41 & 0.17 & 0.69 & 0.62 & 0.10 & 0.44 & 1.62 & 0.49 & 0.27 & 0.72 & 0.98 \\
\hline $\mathbf{N i}$ & 0.03 & 0.26 & 0.96 & 0.30 & 0.19 & 0.95 & 0.35 & 0.001 & 0.008 & 0.031 & 0.009 & 0.006 & 0.039 & 0.015 \\
\hline $\mathbf{P b}$ & 0.02 & 0.10 & 0.93 & 0.17 & 0.19 & $<0.02$ & $<0.02$ & 0.001 & 0.004 & 0.034 & 0.006 & 0.007 & $<0.0007$ & $<0.0005$ \\
\hline $\mathbf{R b}$ & 1.1 & 11.3 & 52.1 & 11.5 & 7.7 & 44 & 13 & 0.008 & 0.090 & 0.447 & 0.096 & 0.066 & 0.41 & 0.19 \\
\hline Sb & $<0.0006$ & $<0.0006$ & 0.0026 & $<0.0007$ & - & $<0.0006$ & $<0.0006$ & $<0.0001$ & $<0.0003$ & 0.0012 & $<0.0004$ & - & $<0.0005$ & $<0.0004$ \\
\hline Sn & $<0.06$ & $<0.06$ & 2.57 & $<0.16$ & 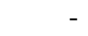 & $<0.06$ & $<0.06$ & $<0.01$ & $<0.01$ & 0.76 & $<0.04$ & - & $<0.014$ & $<0.014$ \\
\hline $\mathrm{Sr}$ & 0.19 & 0.35 & 0.55 & 0.35 & 0.09 & 0.47 & 0.36 & 0.002 & 0.004 & 0.007 & 0.004 & 0.001 & 0.012 & 0.006 \\
\hline Th & $<0.0002$ & $<0.0002$ & 0.0003 & $<0.0002$ & - & 0.0009 & $<0.0002$ & $<0.00001$ & $<0.00001$ & 0.00002 & $<0.00001$ & - & 0.00004 & $<0.00002$ \\
\hline Tl & $<0.0002$ & $<0.0002$ & $<0.0002$ & $<0.0002$ & - & $<0.0003$ & $<0.0002$ & $<0.0002$ & $<0.0003$ & $<0.0004$ & $<0.0003$ & - & $<0.0005$ & $<0.0004$ \\
\hline $\mathbf{U}$ & $<0.0001$ & $<0.0001$ & 0.0002 & $<0.0001$ & - & 0.0006 & $<0.0001$ & $<0.00002$ & $<0.00002$ & 0.00004 & $<0.00002$ & - & 0.00013 & $<0.00005$ \\
\hline $\mathbf{V}$ & $<0.008$ & $<0.008$ & 0.024 & $<0.009$ & - & $<0.046$ & $<0.008$ & $<0.00006$ & $<0.00007$ & 0.00027 & $<0.00008$ & - & $<0.00043$ & $<0.00014$ \\
\hline $\mathbf{Z n}$ & 15 & 19 & 27 & 20 & 2 & 27 & 23 & 0.13 & 0.22 & 0.40 & 0.23 & 0.06 & 0.33 & 0.24 \\
\hline $\mathrm{Zr}$ & $<0.007$ & $<0.007$ & 0.027 & $<0.007$ & - & $<0.02$ & $<0.05$ & $<0.00004$ & $<0.00005$ & 0.0002 & $<0.00005$ & - & $<0.0002$ & $<0.0001$ \\
\hline
\end{tabular}


The transfer factors soil-to-grain of elements (Fig. 4.4) increased in the following order:

- $\mathrm{TF} \leq$ 0.001: $\quad \mathrm{Ti}, \mathrm{Ce}, \mathrm{La}, \mathrm{Th}, \mathrm{U}, \mathrm{Zr}, \mathrm{Hf}, \mathrm{Al}, \mathrm{V}, \mathrm{Li}, \mathrm{Tl}, \mathrm{Sb}, \mathrm{Fe}$

- $0.001<\mathrm{TF} \leq 0.01: \mathrm{Cr}, \mathrm{Bi}, \mathrm{Ba}, \mathrm{Na}, \mathrm{Co}, \mathrm{Cs}, \mathrm{Pb}, \mathrm{Sr}, \mathrm{Ni}, \mathrm{Sn}$

- $0.01<\mathrm{TF} \leq 0.1: \quad$ As, $\mathrm{Ca}, \mathrm{Mn}, \mathrm{Rb}, \mathrm{Cd}$

- $0.1<\mathrm{TF} \leq 1: \quad \mathrm{Cu}, \mathrm{K}, \mathrm{Mg}, \mathrm{Zn}, \mathrm{Mo}$

- $1<\mathrm{TF}<5: \quad \mathrm{S}, \mathrm{P}$

Scattergrams in Fig. A2.4 (Appendix A2) visualize that the element concentrations in rice grains were not correlated with their total concentrations in soils. To better understand the dominant factors, that determine the soil-plant transfer in the Mekong area, ratios of maximum to minimum concentrations for selected elements in rice grains and soils as well as the ratios of TF are compiled in Table 4.4 (based on values in Table 4.1 and Table 4.3). Grain concentrations and TFs of the nutrients such as $\mathrm{K}, \mathrm{Mg}, \mathrm{Zn}, \mathrm{Sr}, \mathrm{P}, \mathrm{Ca}, \mathrm{Fe}, \mathrm{Mn}$ and $\mathrm{S}$ fluctuated only little (except for the TFs of Mn and S vary strongly). The ratios for the nutrients $\mathrm{K}, \mathrm{Mg}$, and $\mathrm{Zn}$ in soils and grains were similar, those of $\mathrm{P}, \mathrm{Ca}$, and $\mathrm{Mn}$ fluctuated more in the soils. In

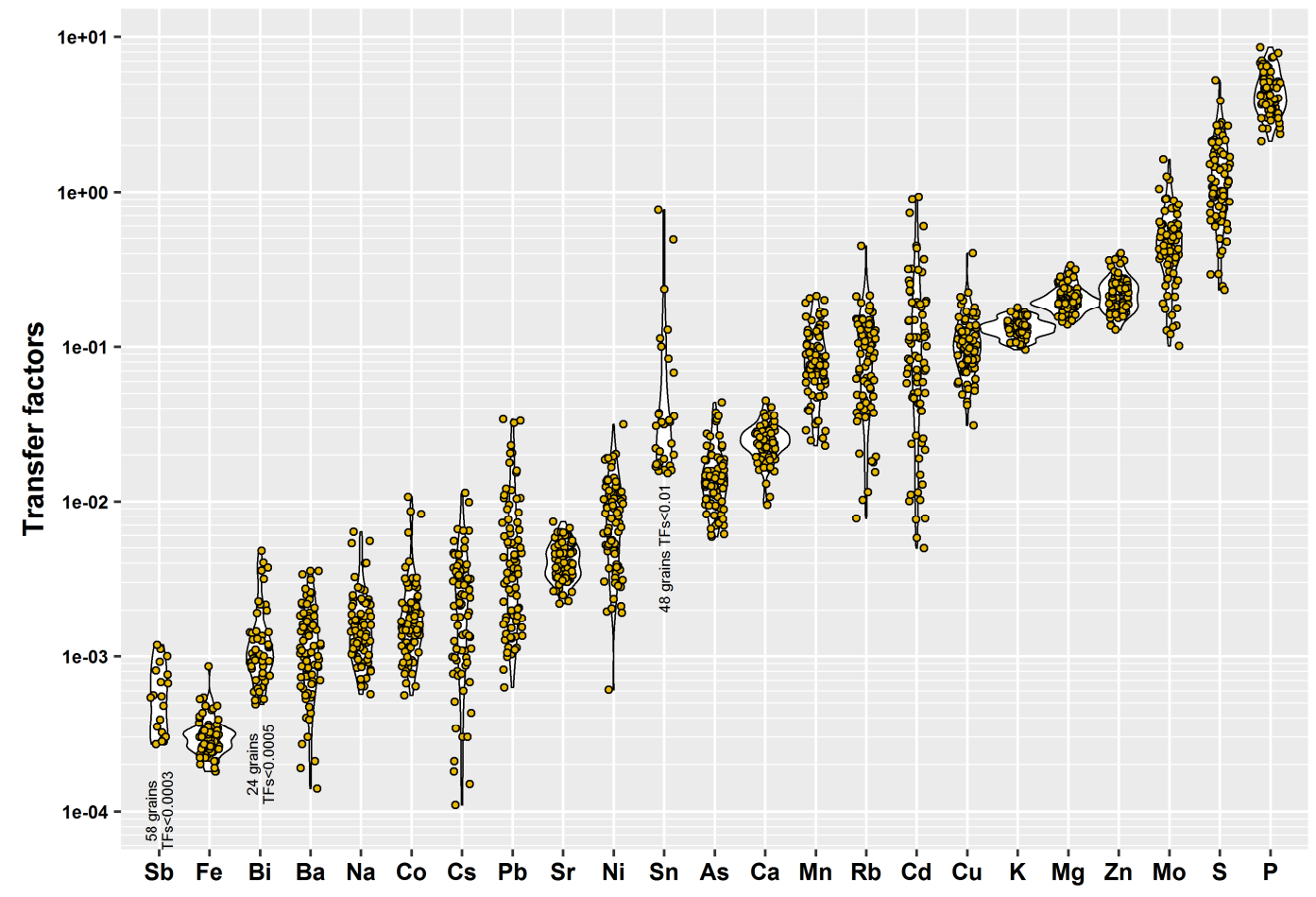

Fig. 4.4 Transfer factors of selected elements from soil to rice grain in the Mekong River area. Elements in rice with concentrations below detection limit such as $\mathrm{Ti}, \mathrm{Ce}, \mathrm{La}, \mathrm{Th}$, $\mathrm{U}, \mathrm{Al}, \mathrm{Hf}, \mathrm{Zr}, \mathrm{V}, \mathrm{Li}$, and $\mathrm{Tl}$ are not plotted 
contrast, these ratios of some other nutrients ( $\mathrm{Na}, \mathrm{Cu}$, and $\mathrm{Mo}$ ) and harmful elements largely fluctuated. With most trace elements the ratios of grain concentrations are up to 50 times higher than those of soils. Uptake and fluctuation of the trace elements in grains cannot be explained only to a limited extent by the measured soil concentrations or combined soil factors such as Eh-pH, element sorption by and release from OM, clay minerals, $\mathrm{Fe}$ - and $\mathrm{Mn}$ oxides/hydroxides. Mechanisms of specific uptake, translocation and fractionation of elements within the plant seem more important. In addition, other factors affect the element uptake such as nutrient demand, variety of rice, genotypes, and weather (Greger 2004). Unfortunately, an evaluation of the different influences on the element uptake was not possible in this study. However, despite lacking correlations between soil-pH (usually a dominant regulative for element uptake) and grain concentrations of $\mathrm{Cd}, \mathrm{Co}, \mathrm{Cu}, \mathrm{Mn}, \mathrm{Ni}, \mathrm{Pb}, \mathrm{Zn}, \mathrm{As}, \mathrm{Bi}$, and $\mathrm{Sb}$ in our investigation, the influence of $\mathrm{pH}$ must be considered in future studies. The relation between soil parameters and trace element concentrations in rice grains would be more evident if the concentration ranges would be larger like in the Red River and Huong River areas (Nguyen et al. 2019).

Table 4.4 Ratios of maximum to minimum element concentrations in unpolished rice grains and soils as well as ratios of TF in Mekong River area (arranged in increasing order of TF)

\begin{tabular}{lrrrrrrrrrrrrrrrrrrrr}
\hline Ratios & $\mathbf{K}$ & $\mathbf{M g}$ & $\mathbf{Z n}$ & $\mathbf{S r}$ & $\mathbf{P}$ & $\mathbf{C a}$ & $\mathbf{F e}$ & $\mathbf{A s}$ & $\mathbf{M n}$ & $\mathbf{N a}$ & $\mathbf{C u}$ & $\mathbf{M o}$ & $\mathbf{C o}$ & $\mathbf{S}$ & $\mathbf{B a}$ & $\mathbf{P b}$ & $\mathbf{R b}$ & $\mathbf{C s}$ & $\mathbf{N i}$ & $\mathbf{C d}$ \\
\hline Grains & 1.9 & 1.5 & 1.8 & 2.9 & 1.6 & 1.7 & 2.6 & 7.5 & 2.2 & 8.8 & 9.3 & 9.5 & 14 & 1.8 & 33 & 46 & 45 & 97 & 32 & 127 \\
Soils & 1.5 & 1.9 & 2.6 & 1.5 & 3.6 & 4.2 & 2.6 & 3.5 & 17 & 2.2 & 2.1 & 5.4 & 3.6 & 29 & 1.6 & 9.1 & 1.6 & 2.1 & 2.2 & 2.8 \\
\hline TF & 1.9 & 2.4 & 3.1 & 3.3 & 4.0 & 4.7 & 4.5 & 7.5 & 9.4 & 11 & 13 & 16 & 19 & 23 & 26 & 54 & 58 & 100 & 31 & 186 \\
\hline
\end{tabular}

Furthermore, it was not possible to detect relations between soil parameters and TFs of trace elements (Fig. 4.5), except for a few elements. The TFs of $\mathrm{Cd}$ showed negative trends with soil Fe- and Mn-concentrations. One explanation can be that increasing Fe- and Mnoxide/hydroxide concentrations in soil competed for dissolved $\mathrm{Cd}$ by sorption, diminishing its concentration in the soil solution and uptake by the plants. The TFs of Mo were dependent on $\mathrm{pH}$ (weak positive correlation), LOI- and Al-concentration in the soils (weak negative correlations). Increasing molybdate sorption on OM and Al-phases towards lower soil pH (Fig. 4.3) may decrease the transfer of Mo into the plant (Smedley and Kinniburgh 2017). The TFs of Mn showed a highly significant negative correlation with Mn-concentration in soil (Fig. 4.5) following the trendline:

$$
\mathrm{TF}_{\mathrm{Mn}}=13.42 *\left[\mathrm{Mn}_{\text {soil }}\right]-0.926 \quad\left(\mathrm{R}^{2}=0.87\right)
$$


Increasing Mn concentrations with rising $\mathrm{pH}$ (Fig. 4.3) in soil led to less $\mathrm{Mn}$ in soil solution lowering the TF. In addition, decreasing OM-concentration at higher $\mathrm{pH}$ declined the Mn-solubility and plant availability. Both trends confirm the positive correlation between TFs of Mn and LOI (Fig. 4.5). The TFs of $\mathrm{Zn}$ increased with decreasing concentrations of Al- and Fe-phases in soils what is explainable with less sorption of dissolved $\mathrm{Zn}^{2+}$, augmenting phytoavailable $\mathrm{Zn}$ in soil solution.

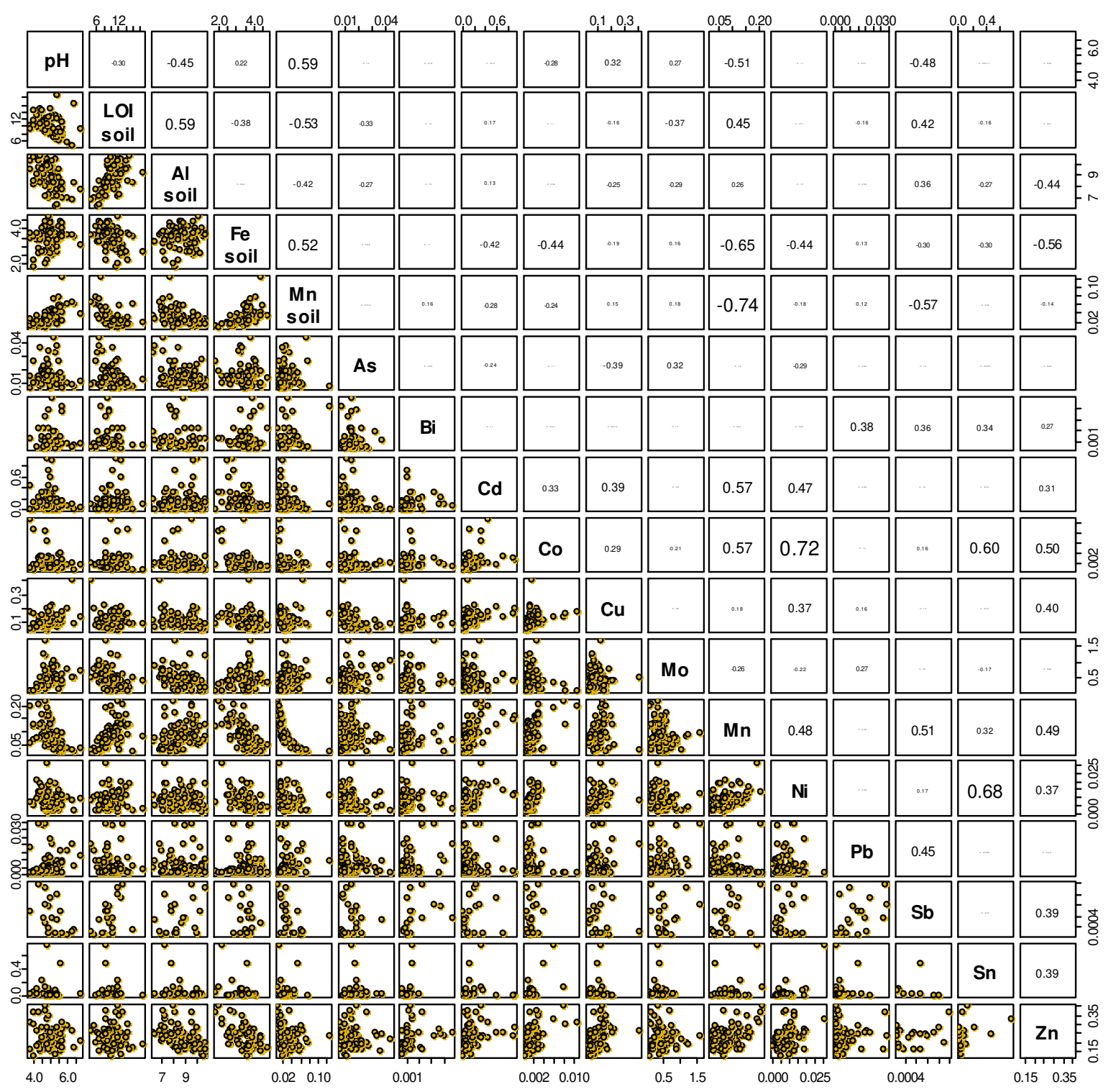

Fig. 4.5 Scattergram and correlation matrix for TFs of trace elements in the Mekong River area including relations between TFs and main element concentrations (wt. \%) and $\mathrm{pH}$ in soils. Samples with grain concentrations below detection limit are not shown. 
Comparing samples from all three river areas, the mean element concentrations in rice grains and transfer factors showed remarkable differences (Table 4.3), which are probably due to diverse soil properties and other factors like agronomic practices (phosphorus fertilizer applications, irrigation water), emissions, and rice cultivars. Huong River soils (mean $\mathrm{pH}=$ 4.4) and Mekong River soils (mean $\mathrm{pH}=5.0$ ) are more acidic than Red River soils (mean $\mathrm{pH}$ $=6.2$ ). The low pH-value in Huong River soils led to remarkably higher grain concentrations of $\mathrm{Ti}, \mathrm{Ce}, \mathrm{Cs}, \mathrm{La}, \mathrm{Li}, \mathrm{Rb}, \mathrm{Sr}$, Th, $\mathrm{U}$, and $\mathrm{V}$. In contrast, $\mathrm{Mg}$-concentrations in grains were lower in more acidic soils, probably caused by less $\mathrm{Mg}$ on soil exchange sites diminishing its uptake. Compared to the Mekong area, the 1.5 times higher Ca-concentrations in rice from Huong and Red River area may be caused by Ca supply through fertilizer or irrigation water, in the Red River area additionally by higher soil Ca-concentration. The substantially higher concentration of $\mathrm{Na}$ in grains from the Mekong area may result from seaspray of the Pacific and Indian Ocean (no data available). Rice samples close to the Pacific Ocean contained twice as much Na than samples apart from the coast. Brackish groundwater and/or tide influences may deliver additional $\mathrm{Na}$. The K-concentrations in soils and grains in the three areas were similar leading to comparable TFs.

Decreasing TFs and grain concentrations of As, Co, and Ni in the order Huong River > Mekong River > Red River area indicate that rising $\mathrm{pH}$ lowers the element uptake. Although As-anions are more soluble at higher $\mathrm{pH}$, rising amounts of Fe-oxides/hydroxides lower the bioavailable As-concentration by sorption. The concentration of OM in Mekong River soils (mean LOI 10.3\%) was much higher than in the other two areas (LOI 6.5\%). More OM may lead to stronger solubilization of $\mathrm{Pb}$ and possibly of $\mathrm{Sn}$ by organic complexation, increasing the transfer into the grains. In contrast, the strong binding of Mo on soil OM may be the reason for lower Mo-concentration in grains from the Mekong area. A similar mechanism could be responsible for low $\mathrm{Zn}$-concentration in Mekong rice grains. In all three river areas, mean $\mathrm{Cd}$ concentrations were rising with mean P-concentrations in soils, indicating P-fertilizer as a Cdsource. The transfer into the grains was the highest in the Red River area where the soils contained the most Cd. The acidic soils of the Huong River area had the lowest Cdconcentration, but two times higher Cd-concentrations in the grains compared to the Mekong River area. This showed the strong impact of soil acidity on the Cd-uptake. The grain concentrations of the essential elements $\mathrm{Fe}$ and $\mathrm{Cu}$ in all three areas seemed not dependent on soil $\mathrm{pH}$-values. The concentration trends described here can be roughly applied also to the TFs listed in Table 4.3. 
The TFs of As for the rice grains from the Mekong River Delta ranged from 0.006 to 0.044 (mean 0.015; Table 4.3). They were similar to those in Yangtze River Delta (China) ranging from 0.002 to 0.053 (mean 0.020; Mao et al. 2019). The TFs of Cd for Mekong rice grains ranged from 0.005 to 0.93 (mean 0.15 ) and were slightly lower than those of Yangtze River with 0.012 to 1.51 (mean 0.224), even though Mekong River soils are more acid (mean $\mathrm{pH}$ 5.0) than Yangtze River soils (mean $\mathrm{pH}$ 6.8).

\subsubsection{Rice composition and implications for health}

As a major food for the Vietnamese population, the daily rice consumption supplies many essential nutrients to the human body. However, enrichment of toxic trace elements in paddy soils and corresponding rice grains may cause health risks for people - besides additions from other foods, drinking water and air. The average amount of rice that a Vietnamese adult consumes is $350 \mathrm{~g}$ for females and $446 \mathrm{~g}$ for males per day. An average Vietnamese woman weights $45 \mathrm{~kg}$ and a Vietnamese man $58 \mathrm{~kg}$. The health risks from daily rice consumption were approached following two concepts: (1) the daily element intake doses from rice compared to Recommended Dietary Allowances (RDAs) and Tolerable Upper Intake Levels (ULs) for total food, drinking water, and supplements; (2) measured grain element concentrations compared to permissible Maximum Concentrations (MCs) in rice grains. The daily element intake (DEI) for a Vietnamese female or male was calculated as follows:

$\mathrm{DEI}\left(\mathrm{mg}\right.$ day $\left.^{-1}\right)=$ Daily amount of rice consumption $\left(\mathrm{kg} \mathrm{day}^{-1}\right) \times E l_{\text {rrain }}\left(\mathrm{mg} \mathrm{kg}^{-1}\right)$

In the first approach, the calculated daily intake amounts of nutrient and harmful elements by eating rice were compared with RDAs and ULs. The UL represents the highest level of daily element intake that is likely to pose no risk of adverse health effects - a definition given by the Food and Nutrient Board (FNB) of U.S. National Academies (Institute of Medicine 2001) and European Food Safety Authority (EFSA) (Table 4.5). RDAs and some ULs for females and males were taken directly from their publications. The ULs of the elements $\mathrm{As}, \mathrm{Cd}, \mathrm{Co}, \mathrm{Pb}, \mathrm{Sb}$, and $\mathrm{U}$ were calculated for a Vietnamese adult as follows:

$\mathrm{UL}\left(\mathrm{mg}\right.$ day $\left.^{-1}\right)=$ body weight $(\mathrm{kg}) \mathrm{x}$ daily tolerable intake level per $\mathrm{kg}$ body weight $\left(\mathrm{mg} \mathrm{day}^{-1} \mathrm{~kg}^{-1}\right)$

Please note that RDAs and ULs are valid for the consumption of all food, water, and supplement, with rice being only one element supplier. 
Chapter 4. Southern paddy soils

Table 4.5 Daily element uptake by eating rice for a Vietnamese adult in $\mathrm{mg} \mathrm{day}^{-1}$ in Mekong River area, in comparison with Red River area, Huong River area, the daily recommended dietary allowances and upper intake levels for total food and drinking water

\begin{tabular}{|c|c|c|c|c|c|c|c|c|c|c|c|c|c|c|}
\hline \multirow[t]{3}{*}{$\overline{\text { Element }}$} & \multicolumn{7}{|c|}{ Intake by Female } & \multicolumn{7}{|c|}{ Intake by Male } \\
\hline & \multicolumn{3}{|c|}{ Mekong area } & \multirow{2}{*}{$\begin{array}{r}\text { Huong } \\
\text { River }\end{array}$} & \multirow{2}{*}{$\begin{array}{r}\text { Red } \\
\text { River }\end{array}$} & \multicolumn{2}{|c|}{ FNB } & \multicolumn{3}{|c|}{ Mekong area } & \multirow{2}{*}{$\begin{array}{r}\text { Huong } \\
\text { River }\end{array}$} & \multirow{2}{*}{$\begin{array}{r}\text { Red } \\
\text { River }\end{array}$} & \multicolumn{2}{|c|}{ FNB } \\
\hline & Min & Max & $\overline{\text { Mean }}$ & & & $\overline{\mathrm{RDA}}$ & $\overline{\mathrm{UL}}$ & Min & $\operatorname{Max}$ & $\overline{\text { Mean }}$ & & & $\overline{\mathrm{RDA}}$ & UL \\
\hline$\overline{\mathrm{Ca}}$ & 23 & 40 & 30 & 49 & 47 & 1000 & 2500 & 30 & 51 & 39 & 62 & 60 & 1000 & 2500 \\
\hline $\mathrm{Fe}$ & 2 & 6 & 4 & 5 & 4 & 18 & 45 & 3 & 8 & 5 & 6 & 5 & 8 & 45 \\
\hline $\mathrm{K}$ & 636 & 1212 & 908 & 1031 & 1019 & - & - & 810 & 1544 & 1157 & 1313 & 1298 & - & \\
\hline $\mathrm{Mg}$ & 354 & 547 & 451 & 434 & 488 & 310 & - & 451 & 697 & 575 & 553 & 622 & 400 & \\
\hline $\mathrm{Na}$ & 1.2 & 10.2 & 2.7 & 1.9 & 1.5 & - & 2300 & 1.5 & 13.0 & 3.4 & 2.5 & 1.9 & - & 2300 \\
\hline $\mathrm{Zn}$ & 5.2 & 9.3 & 6.9 & 9.5 & 8.1 & 8 & 40 & 6.7 & 11.9 & 8.7 & 12.0 & 10.3 & 11 & 40 \\
\hline $\mathrm{P}$ & 864 & 1374 & 1144 & 1132 & 1252 & 700 & 4000 & 1101 & 1751 & 1457 & 1443 & 1595 & 700 & 4000 \\
\hline As & 0.03 & 0.2 & 0.06 & 0.09 & 0.05 & & $0.096^{\mathrm{b}}$ & 0.03 & 0.25 & 0.08 & 0.12 & 0.06 & & $0.124^{b}$ \\
\hline $\mathrm{Cd}$ & 0.001 & 0.065 & 0.013 & 0.030 & 0.041 & & $0.016^{\mathrm{a}}$ & 0.001 & 0.083 & 0.017 & 0.038 & 0.052 & & $0.021^{\mathrm{a}}$ \\
\hline Co & 0.003 & 0.040 & 0.009 & 0.029 & 0.006 & - & $0.072^{\mathrm{a}}$ & 0.004 & 0.051 & 0.011 & 0.037 & 0.008 & - & $0.093^{\mathrm{a}}$ \\
\hline $\mathrm{Cr}$ & $<0.04$ & 0.22 & $<0.11$ & $<0.04$ & $<0.04$ & 0.03 & - & $<0.05$ & 0.29 & $<0.14$ & $<0.05$ & $<0.05$ & 0.0 & \\
\hline $\mathrm{Cu}$ & 0.4 & 3.6 & 1.1 & 1.3 & 1.2 & 0.9 & 10 & 0.5 & 4.6 & 1.5 & 1.6 & 1.5 & 0.9 & 1 \\
\hline $\mathrm{Mn}$ & 4.6 & 10.0 & 7.2 & 8.4 & 7.7 & 1.8 & 11 & 5.9 & 12.7 & 9.2 & 10.7 & 9.8 & 2.3 & 1 \\
\hline Mo & 0.04 & 0.36 & 0.15 & 0.24 & 0.22 & 0.04 & 2.0 & 0.05 & 0.45 & 0.18 & 0.31 & 0.28 & 0.05 & 2.0 \\
\hline $\mathrm{Ni}$ & 0.01 & 0.34 & 0.11 & 0.33 & 0.12 & - & 1.0 & 0.01 & 0.43 & 0.14 & 0.42 & 0.16 & - & 1.0 \\
\hline $\mathrm{Pb}$ & 0.01 & 0.32 & 0.06 & $<0.01$ & $<0.01$ & & $0.067^{\mathrm{a}}$ & 0.01 & 0.41 & 0.08 & $<0.01$ & $<0.01$ & & $0.087^{\mathrm{a}}$ \\
\hline $\mathrm{Sb}$ & $<0.0002$ & 0.001 & $<0.0002$ & $<0.0002$ & $<0.0002$ & - & $0.27^{\mathrm{c}}$ & $<0.0003$ & 0.001 & $<0.0003$ & $<0.0003$ & $<0.0003$ & - & $0.35^{\mathrm{c}}$ \\
\hline $\mathrm{Sn}$ & $<0.02$ & 0.90 & $<0.04$ & $<0.02$ & $<0.02$ & - & 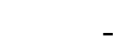 & $<0.03$ & 1.15 & $<0.04$ & $<0.03$ & $<0.03$ & - & \\
\hline $\mathrm{U}$ & $<0.00004$ & 0.0001 & $<0.00004$ & 0.0002 & $<0.00004$ & - & $0.03^{\mathrm{a}}$ & $<0.00004$ & 0.0001 & $<0.00004$ & 0.0003 & $<0.00004$ & - & $0.04^{\mathrm{a}}$ \\
\hline
\end{tabular}

RDA: Recommended Dietary Allowance; UL: Tolerable Upper Intake Level for adults; FNB: Food and Nutrient Board of U.S. National Academies (Institute of Medicine

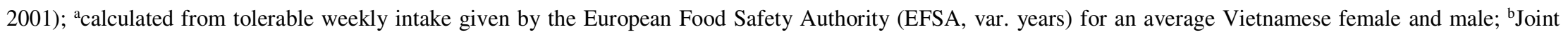
FAO/WHO Expert Committee on Food Additives (1989) mentioned by EFSA (2009a); 'van Leeuwen and Aldenberg (2012); Red River and Huong River areas from Nguyen et al. (2019) 
Looking at the results of the Mekong area in Table 4.5, rice provided only around 3\% of daily needed $\mathrm{Ca}$ and $22 \%$ of needed Fe, although rice is the main nutritional base. Both elements must be supplemented from other foods such as meat, milk and drinking water. Magnesium intake by rice consumption surpassed the RDA. However, exceedance of magnesium intake does not pose risks for healthy individuals (National Institutes of Health 2018). The remaining nutrient elements $\mathrm{Cu}, \mathrm{Zn}, \mathrm{P}, \mathrm{Mn}$, and Mo are sufficiently supplied by rice but are far below the ULs. The Na-uptake has no RDA but is far below UL.

The provisional tolerable intake doses of inorganic As for an average Vietnamese female is $0.096 \mathrm{mg} \mathrm{day}^{-1}$ and $0.124 \mathrm{mg} \mathrm{day}^{-1}$ for a male (calculation based on older limits from of Joint FAO/WHO Expert Committee on Food Additives, cited in EFSA 2009a). Although in the Mekong area the mean As-intake was lower than the tolerable dose, $12 \%$ of the rice samples exceeded the As-doses for both genders causing potential health risks. Other As-sources such as drinking water and foods increase the doses. Compared to the results from Red River and Huong River areas (Nguyen et al. 2019), rice from the Huong River area showed the highest potential health risk. Using the recent tolerable As-doses proposed by EFSA (2009a), the maximum allowed As-intake for a Vietnamese woman would range from 0.014 to $0.360 \mathrm{mg}$ day $^{-1}$ and for a man from 0.017 to $0.464 \mathrm{mg} \mathrm{day}^{-1}$. All As-intake values calculated in this study were within those ranges, but all values are higher than the lowest tolerable limit. There were systematic studies of health risks by drinking water with more than $10 \mu \mathrm{g} / \mathrm{L}$ As in the Mekong area, where more than 0.5 million people are at risk of chronic arsenic poisoning (Berg et al. 2007; Erban et al. 2013; Merola et al. 2015), but Specific symptoms of As poisoning, however, have not been described (Berg et al. 2007; Erban et al. 2013; Merola et al. 2015). A corresponding study about As-related health risks from rice consumption was hitherto lacking as well as a study for the combined effects from both sources.

The ULs for Cd are 0.016 and $0.021 \mathrm{mg} \mathrm{day}^{-1}$ for a Vietnamese female and male respectively. $29 \%$ of studied samples exceeded the Cd-threshold for both female and male; $9 \%$ surpassed twice the threshold. The risk of Cd-toxicity in Mekong River area was remarkably lower than in the other two areas.

The ULs for $\mathrm{Pb}$ are 0.067 and $0.087 \mathrm{mg} \mathrm{day}^{-1}$ for a Vietnamese female and male respectively. $27 \%$ of the rice samples are higher than the ULs for both female and male, whereby $10 \%$ of the samples were more than 2-times higher. It seems, while the $\mathrm{Pb}$ intake from rice grown in Red and Huong River areas is not a problem, it presented a serious issue in the 
Mekong area. Healthwise, the daily intake of $\mathrm{Co}, \mathrm{Cr}, \mathrm{Sb}$, and $\mathrm{U}$ by eating rice seems safe for all three areas since intake amounts were far below tolerable limits.

In the second approach, the measured concentrations of $\mathrm{As}, \mathrm{Cd}$, and $\mathrm{Pb}$ in rice grains, shown as maps in Fig. 6, were compared with the MC-values proposed by FAO/WHO (2014) and European Union (2006). These organizations recommend a $\mathrm{MC}$ of $0.2 \mathrm{mg} \mathrm{kg}^{-1}$ inorganic As for adults and $0.1 \mathrm{mg} \mathrm{kg}^{-1}$ for young children. According to Suriyagoda et al. (2018), the inorganic As-portion in rice grains is $54 \%$ of total As. This corresponds to the MC of $0.37 \mathrm{mg}$ $\mathrm{kg}^{-1}$ total As for adults and $0.19 \mathrm{mg} \mathrm{kg}^{-1}$ for young children. Compared to these limits, $5 \%$ of the Mekong samples would pose a health risk to adults and about $37 \%$ to young children. All Red and Huong River rice samples showed total As-concentrations below the MC for adults, but for children $75 \%$ of Huong River samples and $26 \%$ of Red River samples were above the MC and may cause As-related health risks. It must be considered, that in the compilation of Rahman and Hasegawa (2011) the portion of inorganic As in rice ranged broadly between 31 and $100 \%$ depending on rice species and climate.

$24 \%$ of the Mekong rice samples exceeded the MC of $0.2 \mathrm{mg} \mathrm{Pb} \mathrm{kg}-1,10 \%$ contained more than twice as much. All Pb-concentrations in the Huong and Red River rice were below the MC. All Cd-concentrations of Mekong and Huong River rice samples were lower than the MC of $0.2 \mathrm{mg} \mathrm{kg}^{-1}$, but $16 \%$ of Red River samples surpassed the MC.

The inconsistent results of the MC concept and of the UL concept stress the need to accommodate the MCs of $\mathrm{As}, \mathrm{Cd}$, and $\mathrm{Pb}$ in rice grains and the ULs for total food, water, and supplements. 


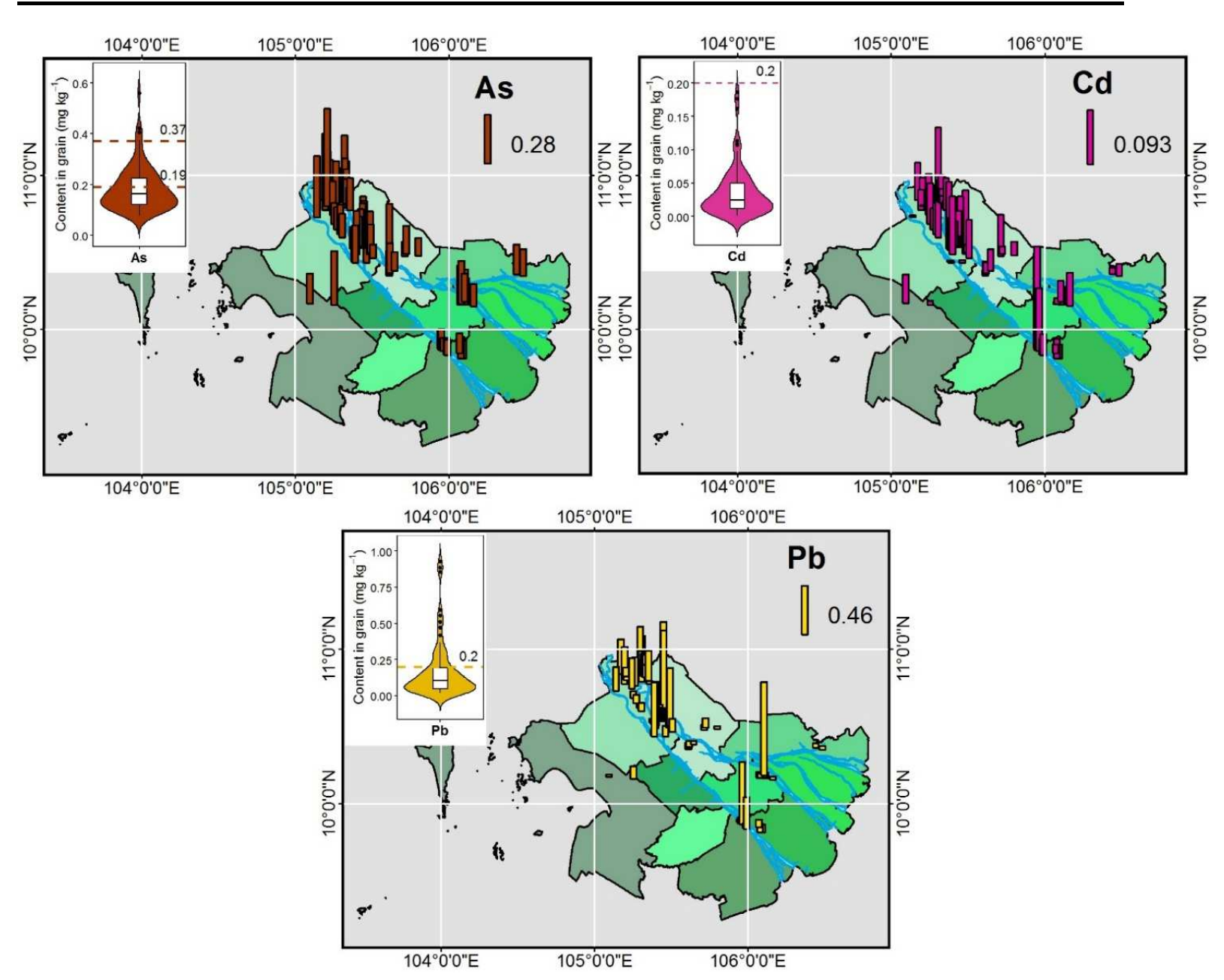

Fig. 4.6 Map of $\mathrm{As}, \mathrm{Cd}$, and $\mathrm{Pb}$ concentrations in rice grain in the Mekong River Delta and their allowable maximum levels (in $\mathrm{mg} \mathrm{kg}^{-1}$ )

\subsection{Conclusions}

The parent material of paddy soils along Mekong River in southern Vietnam consists of alluvial sediments, delivered from Tibetan Plateau and surrounding mountains. Most of the soil samples were not or only slightly contaminated by harmful elements. Compared to average shale, the 80 investigated paddy soils were naturally enriched by Ce, Th, As, La, U, Sn, Cs, and $\mathrm{Bi}$. Fertilizer and emission inputs may cause slight enrichments of $\mathrm{P}, \mathrm{Cd}$, and $\mathrm{Pb}$. Multiple linear regression models can help to reveal the relationship between trace element concentrations and soil phases. The soil parameters with the strongest influence on trace element concentrations were:

- Fe-phases:

$\mathrm{Co}, \mathrm{As}, \mathrm{Cd}, \mathrm{Sb}$

- Al-phases:

Tl, V, Bi, Sn, Pb, U, Ni, Zn, Cu 
- Organic material (LOI): Mo

Strong positive correlations of these elements with the mentioned soil phases point to structural binding, sorption and/or co-precipitation processes.

$11 \%$ of all Mekong soil samples exceeded the permissible As-limits for Vietnamese agricultural soils. One sample had extraordinary high concentrations of $\mathrm{Pb}\left(190 \mathrm{mg} \mathrm{kg}^{-1}\right)$ and of $\mathrm{Sb}\left(6.5 \mathrm{mg} \mathrm{kg}^{-1}\right)$ greatly exceeding their geochemical background values. All other critical elements were far below their permissible soil limits.

Soil parameters are partially responsible for element concentrations in rice grains. However, in the Mekong River area the element TFs showed no correlations with soil parameters, except for the TF of Mn, which correlated strongly with soil Mn-concentrations, following the trendline $\mathrm{TF}_{M n}=13.42 *\left[\mathrm{Mn}_{\text {soil }}\right]^{-0.926}\left(\mathrm{R}^{2}=0.87\right)$. Larger ranges of soil parameters and/or stronger toxic element enrichments would make the transfer of toxic elements into rice grains more obvious.

Based on the Tolerable Upper Intake Levels UL of As for total daily food and drinking water, $12 \%$ of studied rice samples in the Mekong Delta area may cause As-related health risks for adults. $29 \%$ of the rice grain samples surpassed the ULs of Cd. $27 \%$ of the samples exceeded the ULs of $\mathrm{Pb}$. On the basis of maximum concentration $\mathrm{MC}$ for inorganic $\mathrm{As}, \mathrm{Cd}$, and $\mathrm{Pb}$ in rice grain, $5 \%$ of the studied rice grains surpassed the MC of inorganic As for adults and 38\% that for young children. $24 \%$ of studied rice samples exceeded the $\mathrm{MC}$ of $\mathrm{Pb}$. $\mathrm{Cd}$ was below the $\mathrm{MC}$ in all the rice samples.

To sum up, in some parts of lowland river areas in Vietnam, the intense continuous rice consumption may lead to chronic exposure to $\mathrm{As}, \mathrm{Cd}$, and $\mathrm{Pb}$ and potential health risks of the local population.

Considering the importance of rice as the main staple food for billions of people worldwide, four important research priorities result from our investigation:

1. High health risks from $\mathrm{As}, \mathrm{Cd}$, and $\mathrm{Pb}$ exposure by eating rice ask for urgent revision and harmonization of the daily element intake dosis concept (UL) with the maximum element concentration concept (MC). In addition, the combined effects of rice and drinking water on the As-intake should be studied in detail for different areas.

2. Soil concentrations of $\mathrm{As}, \mathrm{Cd}$, and $\mathrm{Pb}$ do not allow to predict the expected concentrations in rice grains, even if soil $\mathrm{pH}$, mineral and organic phases are taken into consideration. 
Surprisingly, rice grains growing in non- or low-polluted paddies may surpass critical health levels of $\mathrm{As}, \mathrm{Cd}$, and $\mathrm{Pb}$. Thus, limits for critical elements in paddy soils cannot be the standard to guarantee uncontaminated rice. Not the soils but the rice grains should be measured in different areas to get information about health relevance.

3. The research on how to minimize the translocation of $\mathrm{As}, \mathrm{Cd}$, and $\mathrm{Pb}$ from the soils into the rice grains should be intensified (see overviews of Rizwan et al. (2016) for Cd, Suriyagoda et al. (2018) for As).

4. Rice cultivars with reasonable yield should be systematically tested for low uptake of critical elements. Such cultivars should be preferentially planted in critical areas.

\subsection{Acknowledgements}

The authors thank the Department Sedimentology/Environmental Geology and Geo-GenderChancenfonds, Faculty of Geoscience and Geography, Göttingen University for providing chemicals and instruments for the analytical work. The Vietnamese government kindly supported the stay of Thuy Phuong Nguyen at Göttingen University with a research grant.

\subsection{Supplementary material}

The supplementary material of this paper are introduced in Appendix A2

\subsection{References}

Akpor, O. B., Ohiobor, G. O., \& Olaolu, T. D. (2014). Heavy metal pollutants in wastewater effluents: Sources, effects and remediation. Advances in Bioscience and Bioengineering, 2:37-43. https://doi.org/10.11648/j.abb.20140204.11.

Alloway, B. J. (2013). Sources of heavy metals and metalloids in soils. In B. J. Alloway (Ed.), Heavy metals in soils: Trace metals and metalloids in soils and their bioavailability. Environmental Pollution (3rd ed., vol. 22, pp. 11-50). Dordrecht: Springer.

Barakat, M. A. (2011). New trends in removing heavy metals from industrial wastewater. Arabian Journal of Chemistry, 4:361-377. https://doi.org/10.1016/j.arabjc.2010.07.019.

Berg, M., Stengel, C., Trang, P. T. K., Hung Viet, P., Sampson, M. L., Leng, M., et al. (2007). Magnitude of arsenic pollution in the Mekong and Red River Deltas Cambodia and Vietnam. Science of the Total Environment, 372:413-425. https://doi.org/10.1016/j.scitotenv.2006.09.010. 
Bolan, N. S., Makino, T., Kunhikrishnan, A., Kim, P.-J., Ishikawa, S., Murakami, M., et al. (2013). Chapter Four - Cadmium Contamination and Its Risk Management in Rice Ecosystems. In D. L. Sparks (Ed.), Advances in Agronomy, 119:183-273. Academic Press.

Buschmann, J., Berg, M., Stengel, C., Winkel, L., Sampson, M. L., Trang, P. T. K., et al. (2008). Contamination of drinking water resources in the Mekong delta floodplains: Arsenic and other trace metals pose serious health risks to population. Environment International, 34:756-764. https://doi.org/10.1016/j.envint.2007.12.025.

Chaney, R. L., Kim, W. 1., Kunhikrishnan, A., Yang, J. E., \& Ok, Y. S. (2016). Integrated management strategies for arsenic and cadmium in rice paddy environments. Geoderma - A Global Journal of Soil Science, 270:1-2. https://doi.org/10.1016/j.geoderma.2016.03.001.

Chanpiwat, P., Sthiannopkao, S., Cho, K. H., Kim, K.-W., San, V., Suvanthong, B., et al. (2011). Contamination by arsenic and other trace elements of tube-well water along the Mekong River in Lao PDR. Environmental Pollution, 159:567-576. https://doi.org/10.1016/j.envpol.2010.10.007.

Chen, J., Gu, B., Royer, R. A., \& Burgos, W. D. (2003). The roles of natural organic matter in chemical and microbial reduction of ferric iron. Science of the Total Environment, 307:167-178. https://doi.org/10.1016/S0048-9697(02)00538-7.

Chen, M., \& Graedel, T. E. (2015). The potential for mining trace elements from phosphate rock. Journal of Cleaner Production, 91:337-346. https://doi.org/10.1016/j.jclepro.2014.12.042

Christophersen, O. A., Lyons, G., Haug, A., \& Steinnes, E. (2013). Selenium. In B. J. Alloway (Ed.), Heavy Metals in Soils: Trace elements and Metalloids and their Bioavailability, 22:428-469. Dordrecht, Heidelberg, New York, London: Springer.

EFSA (2009a). Scientific Opinion on Arsenic in Food - EFSA Panel on Contaminants in the Food Chain (CONTAM). EFSA Journal, 7:1351. https://doi.org/10.2903/j.efsa.2009.1351.

EFSA (2009b). Cadmium in food - Scientific Opinion of the Panel on Contaminants in the Food Chain. The EFSA Journal, 980:1-139. https://doi.org/10.2903/j.efsa.2009.980. 
EFSA (2009c). Uranium in foodstuffs, in particular mineral water - Scientific Opinion of the

Panel on Contaminants in the Food Chain. The EFSA Journal, 1018:1-59.

https://doi.org/10.2903/j.efsa.2009.1018.

EFSA (2010). Scientific Opinion on Lead in Food - EFSA Panel on Contaminants in the

Food Chain (CONTAM). EFSA Journal, 8:1570.

https://doi.org/10.2903/j.efsa.2010.1570.

EFSA (2012). Scientific Opinion on the use of cobalt compounds as additives in animal nutrition. EFSA Journal, 7:2791. https://doi.org/10.2903/j.efsa.2009.1383.

EFSA (2014). Scientific Opinion on the risks to public health related to the presence of chromium in food and drinking water. EFSA Journal, 12. https://doi.org/10.2903/j.efsa.2014.3595.

Erban, L. E., Gorelick, S. M., Zebker, H. A., \& Fendorf, S. (2013). Release of arsenic to deep groundwater in the Mekong Delta, Vietnam, linked to pumping-induced land subsidence. Proceedings of the National Academy of Sciences, 110:13751-13756. https://doi.org/10.1073/pnas.1300503110.

European Union (2006). Commission regulation (EC) No 1881/2006 of 19 December 2006 setting the maximum levels for certain contaminants in foodstuffs. Official Journal of the European Union L 364/5-364/24. European Commision: EUR-Lex. https://eur-lex.europa.eu/legalcontent/EN/TXT/PDF/?uri=CELEX:32006R1881\&from=ES/. Accessed 27 February 2019.

FAO/WHO (2014). Joint FAO/WHO food standards programme codex alimentarius commission. (Vol. REP14/CF). Geneva, Switzerland: FAO/WHO.

Gimeno-Garcia, E., Andreu, V., \& Boluda, R. (1996). Heavy metals incidence in the application of inorganic fertilizers and pesticides to rice farming soils. Environmental Pollution, 92:19-25. https://doi.org/10.1016/0269-7491(95)00090-9.

Greger, M. (2004). Metal Availability, Uptake, Transport and Accumulation in Plants. In M. N. V. Prasad (Ed.). Heavy Metal Stress in Plants from Biomolecules to Ecosystems (pp.1-27). Springer Berlin Heidelberg.

Gromet, L. P., Dymek, R. F., Haskin, L. A., \& Korotev, R. L. (1984). The "North American shale composite": Its compilation, major and trace element characteristics. Geochimica et Cosmochimica Acta, 48:2469-2482. 
Hossain, M. F. (2006). Arsenic contamination in Bangladesh-An overview. Agriculture, Ecosystems and Environment, 113:1-16. https://doi.org/10.1016/j.agee.2005.08.034.

Huang, Y., Miyauchi, K., Endo, G., Don, L. D., Manh, N. C., \& Inoue, C. (2016). Arsenic contamination of groundwater and agricultural soil irrigated with the groundwater in Mekong Delta, Vietnam. Environmental Earth Sciences, 75:757. https://doi.org/10.1007/s12665-016-5535-3.

Hung, N. N. (2011). Sediment dynamics in the floodplain of the Mekong Delta, Vietnam. University of Stuttgart, Germany, The University of Stuttgart, Germany.

Institute of Medicine (2001). Dietary Reference Intakes for Vitamin A, Vitamin K, Arsenic, Boron, Chromium, Copper, Iodine, Iron, Manganese, Molybdenum, Nickel, Silicon, Vanadium, and Zinc. Washington (DC): National Academies Press (US): Institute of Medicine (US) Panel on Micronutrients.

Kabata-Pendias, A. (2011). Trace Elements in Soils and Plants (4th ed.). CRC Press: Taylor \& Francis Group.

Kim, H. K., Jang, T. I., Kim, S. M., \& Park, S. W. (2015). Impact of domestic wastewater irrigation on heavy metal contamination in soil and vegetables. Environmental Earth Sciences, 73:2377-2383. https://doi.org/10.1007/s12665-014-3581-2.

Lin, H.-J., Sung, T.-I., Chen, C.-Y., \& Guo, H.-R. (2013). Arsenic levels in drinking water and mortality of liver cancer in Taiwan. Journal of Hazardous Materials, 262:11321138. https://doi.org/10.1016/j.jhazmat.2012.12.049.

Luu, T. L. (2019). Remarks on the current quality of groundwater in Vietnam. Environmental Science and Pollution Research, 26:1163-1169. https://doi.org/10.1007/s11356-0179631-z.

Mao, C., Song, Y., Chen, L., Ji, J., Li, J., Yuan, X., et al. (2019). Human health risks of heavy metals in paddy rice based on transfer characteristics of heavy metals from soil to rice. Catena, 175:339-348. https://doi.org/10.1016/j.catena.2018.12.029.

Meharg, A. A., \& Rahman, M. M. (2003). Arsenic Contamination of Bangladesh Paddy Field Soils: Implications for Rice Contribution to Arsenic Consumption. Environmental Science \& Technology, 37:229-234. https://doi.org/10.1021/es0259842.

Merola, R. B., Hien, T. T., Quyen, D. T. T., \& Vengosh, A. (2015). Arsenic exposure to drinking water in the Mekong Delta. Science of the Total Environment, 511:544-552. https://doi.org/10.1016/j.scitotenv.2014.12.091. 
National Institutes of Health (2018). Magnesium.

https://ods.od.nih.gov/factsheets/Magnesium-HealthProfessional/. Accessed January 27 2019.

Nguyen, T. P., Ruppert, H., Sauer, B., \& Pasold, T. (2019). Harmful and nutrient elements in paddy soils and their transfer into rice grains (Oryza sativa) along two river systems in northern and central Vietnam. Environmental Geochemistry and Health, 1-17. https://doi.org/10.1007/s10653-019-00333-3.

Nogawa, K., Sakurai, M., Ishizaki, M., Kido, T., Nakagawa, H., \& Suwazono, Y. (2017). Threshold limit values of the cadmium concentration in rice in the development of itaiitai disease using benchmark dose analysis. Journal of Applied Toxicology, 37:962-966. https://doi.org/10.1002/jat.3444.

Norton, G. J., Williams, P. N., Adomako, E. E., Price, A. H., Zhu, Y., Zhao, F.-J., et al. (2014). Lead in rice: Analysis of baseline lead levels in market and field collected rice grains. Science of the Total Environment, 485-486: 428-434. https://doi.org/10.1016/j.scitotenv.2014.03.090.

QCVN (2015). National technical regulation on the allowable limits of heavy metals in the soils. In Vietnamese-Government (Ed.), 03-MT:2015/BTNMT. Vietnam: Ministry of Natural Resources and Environment.

Rahman, M. A., \& Hasegawa, H. (2011). High levels of inorganic arsenic in rice in areas where arsenic-contaminated water is used for irrigation and cooking. Science of the Total Environment, 409:4645-4655. https://doi.org/10.1016/j.scitotenv.2011.07.068.

Rahman, M. A., Rahman, A., Khan, M. Z. K., \& Renzaho, A. M. N. (2018). Human health risks and socio-economic perspectives of arsenic exposure in Bangladesh: A scoping review. Ecotoxicology and Environmental Safety, 150:335-343. https://doi.org/10.1016/j.ecoenv.2017.12.032.

Rizwan, M., Ali, S., Adrees, M., Rizvi, H., Zia-ur-Rehman, M., Hannan, F., et al. (2016). Cadmium stress in rice: toxic effects, tolerance mechanisms, and management: a critical review. Environmental Science and Pollution Research, 23:17859-17879. https://doi.org/10.1007/s11356-016-6436-4.

Roychowdhury, T. (2008). Impact of sedimentary arsenic through irrigated groundwater on soil, plant, crops and human continuum from Bengal delta: Special reference to raw and 
cooked rice. Food and Chemical Toxicology, 46:2856-2864.

https://doi.org/10.1016/j.fct.2008.05.019.

Rudnick, R. L., \& Gao, S. (2003). Composition of the Continental Crust. In H. D. Holland, \& K. K. Turekian (Eds.), Treatise on Geochemistry. 3:1-64. Elsevier.

Sauvé, S. (2014). Time to revisit arsenic regulations: comparing drinking water and rice. BMC Public Health, 14:465. https://doi.org/10.1186/1471-2458-14-465.

Shraim, A. M. (2017). Rice is a potential dietary source of not only arsenic but also other toxic elements like lead and chromium. Arabian Journal of Chemistry, 10:S3434-S3443. https://doi.org/10.1016/j.arabjc.2014.02.004

Singh, N., Gupta, V. K., Kumar, A., \& Sharma, B. (2017). Synergistic Effects of Heavy Metals and Pesticides in Living Systems. Frontiers Chemistry, 5. https://doi.org/10.3389/fchem.2017.00070.

Smedley, P. L., \& Kinniburgh, D. G. (2017). Molybdenum in natural waters: A review of occurrence, distributions and controls. Applied Geochemistry, 84:387-432. https://doi.org/10.1016/j.apgeochem.2017.05.008.

Smith, A. H., Marshall, G., Yuan, Y., Ferreccio, C., Liaw, J., von Ehrenstein, O., et al. (2006). Increased mortality from lung cancer and bronchiectasis in young adults after exposure to arsenic in utero and in early childhood. Environmental health perspectives, 114:1293-1296. https://doi.org/10.1289/ehp.8832.

Stroebel, C. (2008). Screening Evaluation of Heavy Metals in Inorganic Fertilizers. http://www.health.state.mn.us/divs/eh/risk/studies/fertrpt08.pdf. Accessed 3rd December 2018.

Suriyagoda, L. D. B., Dittert, K., \& Lambers, H. (2018). Mechanism of arsenic uptake, translocation and plant resistance to accumulate arsenic in rice grains. Agriculture, Ecosystems \& Environment, 253:23-37. https://doi.org/10.1016/j.agee.2017.10.017.

Tchounwou, P. B., Yedjou, C. G., Udensi, U. K., Pacurari, M., Stevens, J. J., Patlolla, A. K., et al. (2019). State of the science review of the health effects of inorganic arsenic: Perspectives for future research. Environmental Toxicology, 34:188-202. https://doi.org/10.1002/tox.22673.

Thuy, N. N., \& Anh, H. H. (2015). Vulnerability of Rice Production in Mekong River Delta under Impacts from Floods, Salinity and Climate Change. International Journal on 
Advanced Science, Engineering and Information Technology, 5:272-279.

https://doi.org/10.18517/ijaseit.5.4.545.

Turekian, K. K., \& Wedepohl, K. H. (1961). Distribution of the Elements in some major units of the Earth's Crust. Geological Society of America Bulletin, 72:175-192.

van Leeuwen, L. C., \& Aldenberg, T. (2012) Environmental risk limits for antimony. National Institute for Public Health and the Environment, Ministry of Health, Welfare and Sport.

Wang, Y., Jiao, J. J., \& Cherry, J. A. (2012). Occurrence and geochemical behavior of arsenic in a coastal aquifer-aquitard system of the Pearl River Delta, China. Science of the Total Environment, 427-428:286-297. https://doi.org/10.1016/j.scitotenv.2012.04.006.

Wedepohl, K. H. (2004). The composition of Earth's Upper Crust, Natural Cycles of Elements, Natural, Resources. In E. Merian, M. Anke, M. Ihnat, \& M. Stoeppler (Eds.), Elements and Their Compounds in the Environment: Occurrence, Analysis and Biological Relevance (2nd ed., pp. 1-36). Weinheim: WILEY-VCH Verlag GmbH \& Co.KGaA.

Wenzel, W. W. (2013). Arsenic. In B. J. Alloway (Ed.), Heavy Metals in Soils: Trace elements and Metalloids in soil and their Bioavailability (22:241-282). Dordrecht, Heidelberg, New York, London: Springer.

Yu, G., Zheng, W., Wang, W., Dai, F., Zhang, Z., Yuan, Y., et al. (2017). Health risk assessment of Chinese consumers to Cadmium via dietary intake. Journal of Trace Elements in Medicine and Biology, 44:137-145. https://doi.org/10.1016/j.jtemb.2017.07.003. 


\section{Chapter 5}

\section{Transfer of nutrient and toxic elements from paddy soils into rice plant parts (Oryza sativa) in Vietnam and health risk assessments for the population}

Thuy Phuong Nguyen ${ }^{1,2}$. Hans Ruppert ${ }^{1}$. Benedikt Sauer ${ }^{1}$. Tino Pasold ${ }^{1}$

Submitted in Environmental Science and Pollution Research, manuscript number: ESPRD-19-04761

Nguyen, T. P., Ruppert, H., Sauer, B., \& Pasold, T. (2019). Transfer of nutrient and toxic elements from paddy soils into rice plant parts (Oryza sativa) in Vietnam and health risk assessments for the population. Environmental Science and Pollution Research. Submitted manuscript.

\footnotetext{
${ }^{1}$ Department of Sedimentology and Environmental Geology, Faculty of Geoscience and Geography, Georg-August-University Go“ttingen, Goldschmidtstr. 3, 37077 Göttingen, Germany

${ }^{2}$ Department of Environment and Resources Management, Faculty of Land Resources and Agricultural Environment, Hue University of Agriculture and Forestry, 102 Phung Hung Street, Hue City, Vietnam
} 


\section{Abstract}

The uptake of elements from soils into shoot, husk, and unpolished grain of rice plants are investigated in Mekong, Huong and Red River areas in Vietnam. The influence of soil parameters on transfer factors (TF) of elements from soil into plant parts and the whole aboveground plant are evaluated. The TF of most elements decrease in the order shoot $>$ husk > grain. Exceptions are $\mathrm{Mg}, \mathrm{S}, \mathrm{Cd}, \mathrm{Cu}, \mathrm{Zn}$, and Mo, whose TF diminishes in the order shoot > grain > husk, and P whose TF declines in the order grain $>$ shoot $>$ husk. The translocation of health relevant elements like $\mathrm{As}, \mathrm{Cd}$ and $\mathrm{Pb}$ into the different plant parts is described in dependency on the soil parameters $\mathrm{pH}$, contents of organic matter, $\mathrm{Fe}$ - and Mn-phases, and clay minerals. Lead transfer into rice grains increases in soils rich in organic matter. Health risk assessment approaches for the average daily consumption of rice are performed for noncancer risk (Hazard Index $\mathrm{HI}$ ) with the elements $\mathrm{As}, \mathrm{Cd}, \mathrm{Pb}, \mathrm{Co}, \mathrm{Cu}, \mathrm{Mn}, \mathrm{Mo}$ and $\mathrm{Ni}$ as well as for cancer risk with $\mathrm{As}$ and $\mathrm{Pb}$ (Incremental Lifetime Cancer Risk $\sum \mathrm{ILCR}$ ). All rice grains exceed the safe HI-index (below 1). $81 \%$ of the samples are within the level of concern ranging between $1.4<\mathrm{HI}<5.18 \%$ vary between $5<\mathrm{HI}<8.4$, although their soils show only little pollution. One sample from a contaminated site even reaches HI 24. Cadmium, As, Mn, and $\mathrm{Pb}$ are the main elements causing non-cancer risks for rice-consuming people. The cancer-risk values $\sum \mathrm{ILCR}$ of $\mathrm{As}$ and $\mathrm{Pb}$ are between $0.9 \times 10^{-3}$ to $6.4 \times 10^{-3}$ (mean $2.2 \times 10^{-3}$ ) and are considerably higher than the safe threshold of $10^{-4}$ to $10^{-6}$. Arsenic is the dominant factor for cancer risk. People living in Red River and Huong River areas face mainly As- and Cd-related health risks from rice consumption. People in the Mekong River area suffer from additional $\mathrm{Pb}$ exposition.

Keywords rice $\bullet$ paddy soils $\bullet$ element transfer $\bullet$ health risk $\bullet$ Vietnam 


\subsection{Introduction}

Rice is a principal daily energy and protein-supplying source for most of the Asian population. On the other hand, rice can be a prominent source for harmful elements such as $\mathrm{As}, \mathrm{Cd}$, and $\mathrm{Pb}$. Rahman and Hasegawa (2011) stated that rice is the food with highest accumulation of As compared to other agricultural products. High As concentrations in rice and drinking water were recognized as the main reasons for serious chronic diseases of millions inhabitants in Bangladesh and West Bengal, India (Bhattacharya et al. 2010; Abedin et al. 2002; Khan et al. 2009). Due to the easy Cd uptake of rice plants, rice consumption can also cause illnesses (Rizwan et al. 2016). 50\% of rice samples from Cd-polluted paddy soils in Tak Province, Thailand, exceed the concentration of $0.4 \mathrm{mg} \mathrm{Cd} \mathrm{kg}^{-1}$ and up to $90 \%$ surpass the permissible threshold of $0.2 \mathrm{mg} \mathrm{Cd} \mathrm{kg}^{-1}$ (Sriprachote et al. 2012; Simmons et al. 2005). Lead may also have a potential health risk in different rice-producing areas as recognized by Norton et al. (2014), Shraim (2017), and Fakhri et al. (2018). Chronic exposure to these elements causes deleterious health effects resulting in increasing carcinosis, harmful impacts on heart, bones, skin, kidney, and neurological disorders (EFSA 2009, 2010; Smith et al. 2006; Kumarathilaka et al. 2018; Jaishankar et al. 2014).

Soils enriched with potentially toxic elements are often assumed to cause higher accumulation in plants. The element concentration in paddy soils originates from geologic sources, but also from anthropogenic additions like mining and industrial operations, agricultural practices (fertilizer and pesticides), and/or using contaminated wastewater for irrigation. However, the accumulation of an element in a plant depends on the plant species or cultivar, its concentration in solid soil phases, type of bonding and its concentration in interstitial solution. According to Xiao et al. (2017), the soil bioavailable metal concentration of $\mathrm{Cd}, \mathrm{Cr}$, and $\mathrm{Ni}$ and microbial activities have a major impact on their accumulation in rice grains. Environmental effects such as the site, the crop season in combination with the kind of cultivars may explain most of the variation of As and $\mathrm{Cd}$ concentrations in rice grains (Chi et al. 2018). Soil parameters like pH, Eh, CEC (cation exchange capacity), organic matters, Fe-, Al-, Mn-oxides/hydroxides, and clay minerals substantially affect elements' transfer factors (Young 2013; Kabata-Pendias 2011). Iron-rich plaques along rice roots are able to fix the two species As(V) (44 - 66\%) and As(III) (34 - 56\%) (Seyfferth et al. 2011) and can diminish the As uptake into the plant (Suriyagoda et al. 2018). Under reducing conditions mediated by microorganisms, As(V) in Fe-plaques can be reduced to more phytoavailable As(III)-forms 
(Seyfferth et al. 2014; Hu et al. 2015). Depending on rice genotypes, Islam et al. (2016) observed a considerable enhancement of the As transfer into rice under reducing conditions. Simmons et al. (2005) identified in submerged paddy soils downstream of a mineralized area with sulfidic ore deposits in Thailand precipitation of $\mathrm{CdS}$ and $\mathrm{ZnS}$ due to the reduction of sulfate $\left(\mathrm{SO}_{4}{ }^{2-}\right)$ to sulfide $\left(\mathrm{S}^{2-}\right)$. However, these precipitates might be transformed under oxic conditions into phytoavailable $\mathrm{Cd}^{2+}, \mathrm{Zn}^{2+}$, and $\mathrm{SO}_{4}{ }^{2-}$. Together with the resulting soil acidification, this may lead to a considerable uptake into rice grains. Xiao et al. (2017) assumed that the uptake of $\mathrm{Pb}$ by rice grains is not determined by its bioavailability in soils, but rather by multi-metal interactive effects.

Some other external factors such as plant density, temperature, and light may also affect the element uptake but their effects are intricate and only poorly understood (Greger 2004). Interaction with $\mathrm{Zn}, \mathrm{Fe}, \mathrm{Se}, \mathrm{Si}$, and liming limits the uptake and translocation of $\mathrm{Cd}$ from root to shoot (Rizwan et al. 2016; Wan et al. 2018). Also according to Greger (2004), the fluidtransporting process from root to other plant parts are fostered by some factors: transpiration of water, root pressure, cation exchange at cell walls of the xylem vessel, formation of complexes with amino acid $(\mathrm{Cu})$, with histidine and peptide $(\mathrm{Ni})$, and chelates with organic acids ( $\mathrm{Zn}$ ). Due to the powerful binding on cell walls, most elements are mainly located in the roots and only smaller portions are transferred to other parts such as stem, leave, and grain. For the soil-rice system, the concentrations of $\mathrm{Cr}, \mathrm{Fe}, \mathrm{Co}, \mathrm{Ni}, \mathrm{Cu}, \mathrm{Cd}, \mathrm{Zn}, \mathrm{As}, \mathrm{Ba}$, and $\mathrm{Pb}$ generally decrease in the following order: soil > root > shoot > grain (Du et al. 2018; Biswas et al. 2013; Bhattacharya et al. 2010). Satpathy et al. (2014) identified higher $\mathrm{Cd}$ and $\mathrm{Mn}$ concentrations in shoot compared to root. In addition, the kind of cultivar also determines the element distribution in plant parts as shown for Cd and As (Liu et al. 2011; Islam et al. 2016; Duan et al. 2017; Li et al. 2017).

After cropping, roots and stubbles are left in the fields and become a source of organic material (OM) for paddy soils. Depending on the area, rice straw may be taken away for animal bedding, cooking, or soil conditioning materials. Husk, the remaining part after rice peeling, is increasingly applied for many purposes such as the production of heat or electricity, activated carbon, fertilizer, bricks, ceramics or sorbents for heavy metals (Kumar et al. 2013). Often the fields are burned after harvesting. Both, the export and burning of organic material deteriorate the humus balance. 
Vietnam is mainly an agricultural country and one of the world's largest rice producers. The biggest granaries of the country are the Mekong River Delta in the south and the Red River Delta in the north, where abundant water boosts the irrigation. In addition, the annual flooding delivers fertile suspended material that settles in the rice fields. As a result, parent material of paddy soils is mainly alluvial sediment rich in organic matter. Some of the paddy soils in Vietnam are polluted by heavy metal(loid)s such as $\mathrm{As}, \mathrm{Cd}, \mathrm{Cr}, \mathrm{Cu}, \mathrm{Pb}$, and $\mathrm{Zn}$ from industrial and mining activities leading to the contamination of rice grains (Huong et al. 2008; Phuong et al. 2010; Ha 2011; Vinh et al. 2012). However, most of the As contamination in paddy soils and rice grains comes from natural sources influenced strongly by redox processes as described by Seyfferth et al. (2014) and Nguyen et al. (2019a, b). 11\% of Mekong River soils and 92\% of Red River soils exceed the Vietnamese As limit of $15 \mathrm{mg} \mathrm{kg}^{-1}$ for agricultural soils. $5 \%$ of unpolished rice grains in the Mekong River area surpass the permissible maximum inorganic As concentration of $0.2 \mathrm{mg} \mathrm{kg}^{-1}$ for adults while all rice samples from the Red River area are below that limit (Nguyen et al. 2019a, b). 37\% of the Mekong River rice and 26\% of the Red River rice samples exceed the permissible maximum concentration of $0.1 \mathrm{mg} \mathrm{kg}^{-1}$ for children. Even in uncontaminated soils, $\mathrm{Cd}$ and $\mathrm{Pb}$ concentrations in rice grains can be higher than their permissible maximum limits of $0.2 \mathrm{mg} \mathrm{kg}^{-1}$ in rice. $12 \%$ of Red River rice grains exceed the Cd limit but no sample of the Mekong River area surpasses this limit. 24\% of Mekong River rice grains trespass the $\mathrm{Pb}$ limit of $0.2 \mathrm{mg} \mathrm{kg}^{-1}$, but no sample from the Red River area. Different soil conditions among these areas should be a reason for toxic element enrichments within the grains (Nguyen et al. 2019a, b). Most of current studies just focus on the uptake of a few harmful elements, but do not include the transfer of the other elements into rice plants. Understanding of the influence of soil factors on element translocation to and within the rice plant is crucial to mitigate their uptake and to protect human health.

The research purpose of this study is to evaluate a) the translocation of the phytoavailable/bioavailable portion of elements from soil into the aboveground parts of rice plants under the influence of soil parameters such as $\mathrm{pH}$, organic material, Al-, Fe-, and Mnoxides/hydroxides; b) the differing accumulation in shoot, husk, and rice grain; c) health risk assessment of rice consumption for cancer and non-cancer risks. 


\subsection{Materials and methods}

\subsubsection{Sampling, digestion, analysis and quality control}

The rice plant and corresponding soil samples were collected along three river systems in Vietnam including the Red River Delta in the north (19 sites), Huong River in the center (4 sites), and Mekong River Delta in the south (78 sites). The sample locations are shown in Fig. 2.1 (coordinates of the samples are shown in Table A3.1 in Appendix A3). All samples were taken within 10 days before harvesting time. The 23 rice plant samples of the Red River and Huong River areas were separated into shoot (stalk and leaves combined), husk, and unpolished rice grain. Roots and stubbles were left in the fields. 78 rice samples of the Mekong River area were split into husk and grains. The soil samples were taken within the root zone to a depth of $10 \mathrm{~cm}$.

The plant samples were dried at $60^{\circ} \mathrm{C}$, the soil samples at $105^{\circ} \mathrm{C}$. All samples were pulverized into grain sizes $<63 \mu \mathrm{m}$ by a Fritsch ${ }^{\odot}$ agate ball mill before analyzing.

The soil $\mathrm{pH}$-values were determined in a 1:2.5 (w/v) mixture of the air-dried unground soils and $0.01 \mathrm{M} \mathrm{CaCl}_{2}$ solution by using the glass electrode ProfiLine $\mathrm{pH} / \mathrm{mV}$-Meter 197. The Loss on Ignition (LOI), representative for organic matter and structural water in the soil samples, was determined as weight loss after heating the samples to $530^{\circ} \mathrm{C}$ for 24 hours.

The milled samples were completely digested in a mixture of ultrapure concentrated acids $\mathrm{HNO}_{3}(65 \%), \mathrm{HF}(40 \%)$ and $\mathrm{HClO}_{4}(72 \%)$ in closed ultra clean PTFE vessels (PicoTrace®, Göttingen, Acid Sample Digestion System DAS 30). The clear digestion solutions were then measured by ICP-OES (Inductively Coupled Plasma - Optical Emission Spectrometry) Agilent $5100 \mathrm{VDV}$ and by ICP-MS (Inductively Coupled Plasma Mass Spectrometry) Thermo Scientific iCAP Q to get the total element concentrations. For accuracy and precision, the data were validated by in-house and international reference materials: GSJJA-2 (Andesite) and GSJ-JLk-1 (Lake Sediment) for soil concentrations; NCS-DC-73349 (Branches and Leaves of Bush), WEPAL-IPE 126 (Maize plant), WEPAL-IPE-168 (Sunflower) for grain concentrations. Most selected elements have deviations of below 5\% from the recommended values of the reference materials. 


\subsubsection{Correction for adhering particles, calculation of transfer factors}

To evaluate more exactly the element transferability from soil into plant, the physiological or biological concentrations in the different plant parts are calculated. The measured concentration in plant material is composed of the physiological element amount within the plant plus the additional amount caused by adhering soil and dust particles. Because of lacking information about the composition of atmospheric dust at a single sample location, the soil material of the sampling site is used as representative for the correction of adhering material (Pospiech et al. 2017). This correction is important for concentrations in shoot and husk, but can be neglected for the grains because they are protected by husks against adhering dust or soil. Titanium is chosen as indicator element for the adhering soil portion because plants take up Ti in only negligible quantities.

One approach to calculate the portion of adhering soil (x) of a plant part is dividing the measured $\mathrm{Ti}$ concentration in that part $\left(T i_{\text {measured,plant parts }}\right)$ by the $\mathrm{Ti}$ concentration in the corresponding soil $\left(\mathrm{Ti}_{\text {soil }}\right)$ (Pospiech et al. 2017):

$$
x=\frac{T i_{\text {measured }, \text { plant } \text { parts }}}{T i_{\text {soil }}}
$$

The physiological concentration of an element in a plant part $\left(E l_{\text {physiological,plant parts }}\right)$ can be calculated from the measured concentration $\left(E l_{\text {messured,plant parts }}\right)$ and adhering soil portion $(x)$ as follows:

$$
E l_{\text {physiological,plant parts }}=\frac{E l_{\text {measured,plant parts }}-x * E l_{\text {soil }}}{1-x}
$$

Transfer factors $(T F)$ or bioaccumulation factors of elements are the ratio of the physiological element concentration in plant parts $\left(E l_{\text {physiological,plant parts }}\right)$ to its concentration in soil $\left(E l_{\text {soil }}\right)$ :

$$
T F=\frac{E l_{\text {physiological,plant parts }}}{E l_{\text {soil }}}
$$

Transfer factors are calculated for shoot, husk, grain, and the whole aboveground plant without roots and stubbles. The measured and physiological concentrations and transfer factors in plant parts are listed in Tables S2 to S5 in the supplement material of this paper. 


\subsubsection{Exposure and health risk calculations}

Chronic risk exposure from rice consumption for people's health can be evaluated on the basis of indices of lifetime cancer risk and of lifetime non-cancer risk (Järup 2003; Mulware 2013). These indices are based on the Chronic Daily Intake (CDI) ( $\mathrm{mg} \mathrm{kg}^{-1}$ body weight day $\left.{ }^{-1}\right)$ (USEPA 1989) which can be calculated as follows:

$$
C D I=(C F \times I R \times E F \times E D) /(B W \times A T)
$$

where $C F$ is the harmful element concentration in rice $\left(\mathrm{mg} \mathrm{kg}^{-1}\right)$; $I R$ is the average daily rice consumption of $0.398 \mathrm{~kg} \mathrm{day}^{-1}$ for Vietnamese adults (Nguyen et al. 2019a); EF is the exposure frequency (365 days year ${ }^{-1}$ ); $E D$ is the exposure duration (70 years); $B W$ is the Vietnamese average body weight of $52 \mathrm{~kg}$ (Nguyen et al. 2019a); $A T$ is the average period of exposure days to hazardous element intake.

Non-cancer risks

The chronic non-cancer risk approach is used to evaluate non-carcinogenic health effect of harmful elements from different sources. For rice, $\mathrm{As}, \mathrm{Cd}, \mathrm{Pb}, \mathrm{Mn}, \mathrm{Co}, \mathrm{Ni}, \mathrm{Cu}$, and $\mathrm{Mo}$ are considered the most potentially harmful elements causing adverse health effects. The Target Hazard Quotient (THQ) describes the exposure to an element and can be calculated as follows:

$$
T H Q=C D I / R f D
$$

$R f D$ is the chronic reference dose $\left(\mathrm{mg} \mathrm{kg}^{-1} \mathrm{~b} . \mathrm{w}\right.$. day $\left.{ }^{-1}\right)$ of a harmful element and represents the maximum permissible element amount taken up from all sources (food, water, air etc.). The $R f D$ values of elements for this paper were calculated by using data compiled by Nguyen et al. (2019a, b).

The Chronic Hazard Index $(H I)$ for non-cancer factors is the sum of the single $T H Q$ and represents the total non-carcinogenic hazard attributable to exposure:

$$
H I=\sum_{n=1}^{\infty} T H Q
$$

At $\mathrm{HI} \geq 1$, potential health effects must be worried even if the exposure for every single element is below its RfD (USEPA 1989). Nordberg et al. (2015a) notice that the HI-approach is simple but limited in its scope because it may either under- or over-estimate the risk from multiple chemical exposures. 
Cancer risks

Incremental Lifetime Cancer Risk (ILCR) is an index to estimate the incremental probability of an individual cancer progression over a lifetime (USEPA 1989). The ILCR of a harmful substance is computed as follows:

$$
I L C R=C D I x S F
$$

where $S F$ is the Slope Factor. It represents an upper estimate of the probability of an adverse response to the lifetime intake of a carcinogenic substance by ingestion, inhalation or dermal contact (USEPA 1989) (mg/kg-day) ${ }^{-1}$. The three elements As, Cd, and Pb are considered key carcinogenic risk factors for low dose element intakes. However, there is insufficient information about the slope factor of oral Cd intake so Cd is excluded. In this study, the ILCR of $\mathrm{As}$ and $\mathrm{Pb}$ are estimated for eating unpolished rice with slope factors $S F_{A s}=1.5$ and $S F_{P b}=$ $0.0085\left[\mathrm{mg} \mathrm{kg}^{-1} \mathrm{day}^{-1}\right]^{-1}$ (OEHHA 2011).

Cumulative cancer risk $\left(\sum I L C R\right)$ is the sum of single lifetime cancer risks, which are restricted here to the carcinogens $\mathrm{As}$ and $\mathrm{Pb}$ :

$$
\sum I L C R=I L C R_{A s}+I L C R_{P b}
$$

USEPA (1989) proposes a healthy safe level when $\sum$ ILCR is below $10^{-6}$ and acceptable levels at values from $10^{-6}$ to $10^{-4}$.

\subsection{Results and discussion}

\subsubsection{Soil composition}

Main soil parameters such as $\mathrm{pH}-/$ Eh-values, organic matter (OM, LOI as proxy), $\mathrm{Al}$ (clay minerals), and Fe- oxides/hydroxides determine the behavior and availability of elements in soil solution and their uptake by rice plants. Statistical data for paddy soils in three important river areas in northern, central, and southern Vietnam are compiled in Table 5.1 (detailed data are listed in Nguyen et al. 2019a, b). The influence of soil parameters on the element concentration can be summarized as follows:

- Organic matter (OM) has a large, negatively charged surface area. Therefore, OM is able to hold cationic elements by sorption and to lower their plant availability. In addition, some organic ligands can form soluble complexes with trace elements, promoting their plant uptake. In an oxidizing environment, Fe- oxides/hydroxides may sorb or co-precipitate trace elements. During the dissolution of this phase at low 
$\mathrm{pH}$-values, adsorbed elements either may be released and become bioavailable or may be re-adsorbed by the organic material. For example, As-enriched Feoxides/hydroxides are dissolving towards lower $\mathrm{pH}$-values and sorbed arsenate ions are released. These arsenate ions may be reduced to arsenite ions and even to methylated As(III)-compounds (Kumarathilaka et al. 2018).

- In acidic soils, protons may compete with cationic trace elements sorbed on soil phases and release them into solution. Additionally, the dissolution of $\mathrm{Fe}-$ oxides/hydroxides at low $\mathrm{pH}$-value liberates their trace elements. Both mechanisms provide trace elements for an easy uptake by rice plant.

Paddy soils in the Huong and Mekong River areas are mainly acidic with mean $\mathrm{pH}-$ values of 4.4 and 5.0, respectively. Soils in the Red River area show average near-neutral pHvalues at 6.2. The relation between $\mathrm{pH}$ and the concentrations of $\mathrm{OM}, \mathrm{Al}, \mathrm{Fe}$, and $\mathrm{Mn}$ in soils can be described as follows (plotted in Fig. A3.1 in Appendix A3):

- Manganese in soils is positively correlated with $\mathrm{pH}$-values. At lower $\mathrm{pH}$-values, some of the Mn may be dissolved from Mn-containing mineral phases like clay minerals, Fe- and Mn-oxides/hydroxides. At the relatively high $\mathrm{pH}$-value soils in the Red River area, the Mn-containing phases seem to be stable and no Mn has been lost. Mn-oxides/hydroxides in paddy soils are unlikely to exist for the following reasons: First, the Mn concentration in the soils is below $800 \mathrm{mg} \mathrm{kg}^{-1}$ of which most of it is bound in silicates and little in Fe-oxides/hydroxides. Second, the soil $\mathrm{pH}-$ values in all paddy soils are below 7.3 and mostly reducing - conditions under which the Mn-oxides/hydroxides are not stable.

- Iron is not significantly correlated with the $\mathrm{pH}$-value. Some of the $\mathrm{Fe}$ is bound in the framework of silicates, but only the fraction bound in Fe-oxides/hydroxides is sensitive to reductive dissolution or acidification. Suboxic and anoxic sediment samples taken along the Red River contain between 1 and $77 \mu \mathrm{mol} / \mathrm{g}$ Fe that is bound as Fe-oxides/hydroxides (corresponding to 0.008 to 0.61 wt. $\% \mathrm{Fe}_{2} \mathrm{O}_{3}$ ). Their highest concentrations are identified in the most recent sediments (Jessen et al. 2012; Postma et al. 2016; S $\varnothing$ et al. 2018). In the Mekong River Delta, however, the upper meters of sediments contain between 27 to $50 \%$ reducible $\mathrm{Fe}$ (up to $3.4 \% \mathrm{Fe}_{2} \mathrm{O}_{3}$ ), meaning that this Fe-fraction is bound in oxides-hydroxides (Stuckey et al. 2015a; Wang et 
al. 2018). Depending on the reactivity of the Fe-oxides/hydroxides and of the OM, not all of the oxidic iron phases are reducible at low Eh-values (Stuckey et al. 2015a, b).

- The Mekong River soils contain more OM (mean LOI of 10.3\%) than the Red River soils (6.5\%) and Huong River soils (6.4\%). The LOI concentrations tend to increase with decreasing $\mathrm{pH}$-values. Acidic groups in organic matter may cause some of the acidity in soil (McCauley et al. 2017). Lower pH-values conditions are less favorable for the OM oxidation leading to higher OM contents. Another reason for the higher OM content in Mekong River soils may be the shorter time span for its oxidation due to three cropping seasons per year compared to only two cropping seasons further in the north. In addition, three harvestings release more roots and stubbles in the soils increasing the $\mathrm{OM}$ content.

- Soil pH-values negatively correlate with the $\mathrm{Al}$ concentrations similar to OM. Al and $\mathrm{OM}$ are positively correlated with high significance. Reasons are: The finer the suspension in the irrigation water is, the higher the concentrations of Al-rich clay minerals and of $\mathrm{OM}$ are. In addition, clay minerals contain structural water increasing the LOI concentration. 
Table 5.1 Average element concentrations in soils and rice plant parts ( $\mathrm{mg} \mathrm{kg}^{-1}$, except for LOI in wt. \%). Ratio represents the mass ratio of shoot, husk, and unpolished grain to the whole aboveground plant. (Data of soils and grains from Nguyen et al. (2019a, b)

\begin{tabular}{|c|c|c|c|c|c|c|c|c|c|c|c|c|c|c|c|c|c|c|c|c|}
\hline \multirow{2}{*}{$\begin{array}{l}\text { Ele- } \\
\text { ment }\end{array}$} & \multicolumn{4}{|c|}{ Soil $(n=101)$} & \multicolumn{4}{|c|}{ Shoot $(n=23)$} & \multicolumn{4}{|c|}{ Husk $(n=101)$} & \multicolumn{4}{|c|}{ Grain $(n=101)$} & \multicolumn{3}{|c|}{ Plant $(n=23)$} & \multirow[b]{2}{*}{ All } \\
\hline & Red & Huong 1 & Mekong & Mean & Red & Huong & ekor & Mean & Red & Huong & Mekong & Mean & Red & Huong & Mekong & All & Red & Huong & ekong & \\
\hline Ratio & - & - & - & - & 0.41 & 0.47 & - & 0.42 & 0.12 & 0.11 & 0.12 & 0.12 & 0.47 & 0.43 & 0.46 & 0.46 & 1 & 1 & 1 & 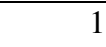 \\
\hline pH & 6.2 & 4.4 & 5.0 & 5.2 & - & - & - & - & - & - & - & - & - & - & - & - & - & - & - & \\
\hline LOI & 6.5 & 6.4 & 10.3 & 9.3 & - & - & - & - & - & - & - & - & - & - & - & . & - & - & - & - \\
\hline Al & 75850 & 74854 & 87130 & 84522 & $<4$ & $<4$ & - & $<4$ & $<4$ & $<4$ & $<4$ & $<6$ & $<4$ & $<4$ & $<4$ & $<4$ & $<4$ & $<4$ & - & $<9$ \\
\hline Ca & 5689 & 2180 & 3725 & 4033 & 5219 & 3915 & - & 4992 & 1099 & 1388 & 749 & 840 & 134 & 139 & 87 & 98 & 2275 & 2079 & - & 2241 \\
\hline $\mathbf{F e}$ & 44221 & 34523 & 34773 & 36541 & 70 & 163 & - & 86 & 23.8 & 28.6 & 20.0 & 21 & 10.8 & 12.9 & 10.3 & 10.5 & 37 & 88 & - & 46 \\
\hline $\mathbf{K}$ & 20081 & 19786 & 19680 & 19760 & 35711 & 22842 & - & 33473 & 3878 & 5184 & 4010 & 4032 & 2897 & 2945 & 2595 & 2666 & 16103 & 12615 & - & 15496 \\
\hline Mg & 8142 & 5772 & 6460 & 6750 & 2671 & 3013 & - & 2731 & 311 & 415 & 324 & 325 & 1384 & 1240 & 1290 & 1305 & 1789 & 1974 & - & 1821 \\
\hline Mn & 526 & 254 & 304 & 344 & 696 & 848 & - & 723 & 256 & 252 & 177 & 195 & 22 & 24 & 21 & 21 & 328 & 434 & - & 347 \\
\hline $\mathbf{N a}$ & 5295 & 2991 & 4587 & 4657 & 346 & 541 & - & 380 & 20.1 & 8.6 & 52.5 & 44.7 & 4.2 & 5.5 & 7.6 & 6.9 & 146 & 238 & - & 162 \\
\hline $\mathbf{P}$ & 865 & 487 & 780 & 785 & 1139 & 1493 & - & 1200 & 1308 & 1104 & 1411 & 1380 & 3545 & 3235 & 3269 & 3319 & 2308 & 2219 & - & 2293 \\
\hline $\mathbf{S}$ & 651 & 516 & 930 & 861 & 1635 & 2352 & - & 1760 & 690 & 554 & 625 & 634 & 1089 & 1051 & 880 & 926 & 1269 & 1620 & - & 1330 \\
\hline $\mathbf{T i}$ & 4854 & 4856 & 4808 & 4819 & 0 & 0 & - & 0 & 0 & 0 & 0 & 0.0 & 0 & 0 & 0 & 0 & 0 & 0 & - & 0 \\
\hline As & 22.5 & 13.6 & 12.6 & 14.8 & 2.7 & 3.2 & - & 2.82 & 0.41 & 0.78 & 0.30 & 0.34 & 0.21 & 0.27 & 0.18 & 0.19 & 1.26 & 1.74 & - & 1.34 \\
\hline Ba & 417 & 460 & 394 & 402 & 93 & 125 & - & 99 & 19.2 & 21.5 & 7.1 & 10.0 & 1.24 & 1.51 & 0.51 & 0.69 & 41 & 61 & - & 45 \\
\hline $\mathbf{B i}$ & 0.88 & 0.56 & 0.40 & 0.51 & 0.010 & 0.008 & - & 0.009 & 0.0058 & 0.0035 & 0.0006 & 0.0017 & $<0.0004$ & 0.0017 & $<0.0004$ & 0.0004 & 0.005 & 0.005 & - & 0.005 \\
\hline Cd & 0.37 & 0.25 & 0.27 & 0.29 & 0.44 & 0.45 & - & 0.44 & 0.103 & 0.155 & 0.028 & 0.047 & 0.120 & 0.085 & 0.037 & 0.055 & 0.254 & 0.255 & - & 0.254 \\
\hline $\mathrm{Ce}$ & 90 & 83 & 81 & 83 & 0.123 & 0.202 & - & 0.137 & 0.0714 & 0.0537 & 0.0230 & 0.0333 & $<0.0009$ & 0.0058 & $<0.0007$ & $<0.001$ & 0.053 & 0.102 & - & 0.061 \\
\hline Co & 15.7 & 13.3 & 13.2 & 13.8 & 0.17 & 0.79 & - & 0.28 & 0.063 & 0.126 & 0.045 & 0.052 & 0.016 & 0.083 & 0.025 & 0.026 & 0.085 & 0.422 & - & 0.144 \\
\hline $\mathrm{Cr}$ & 69 & 39 & 94 & 86 & 0.97 & 0.71 & - & 0.92 & 0.38 & 0.39 & 0.17 & 0.22 & $<0.1$ & $<0.1$ & $<0.1$ & $<0.24$ & 0.46 & 0.40 & - & 0.45 \\
\hline Cs & 8.1 & 6.3 & 11.2 & 10.3 & 0.191 & 1.062 & - & 0.343 & 0.102 & 0.403 & 0.039 & 0.066 & 0.038 & 0.426 & 0.029 & 0.046 & 0.10 & 0.72 & - & 0.21 \\
\hline $\mathbf{C u}$ & 48 & 27 & 30 & 34 & 3.52 & 3.51 & - & 3.52 & 2.23 & 2.21 & 1.99 & 2.04 & 3.35 & 3.58 & 3.26 & 3.29 & 3.3 & 3.4 & - & 3.3 \\
\hline Hf & 4.1 & 3.8 & 4.1 & 4.1 & 0.0068 & 0.0078 & - & 0.007 & .0040 & 0.0020 & 0.0044 & 0.0042 & $<0.0002$ & 0.0005 & $<0.0002$ & $<0.0002$ & 0.0033 & 0.0042 & - & 0.004 \\
\hline La & 44 & 41 & 41 & 41 & 0.092 & 0.102 & - & 0.094 & 0.0415 & 0.0267 & 0.0168 & 0.0218 & $<0.0005$ & 0.0032 & $<0.0004$ & $<0.0005$ & 0.040 & 0.052 & - & 0.042 \\
\hline $\mathbf{L i}$ & 40 & 27 & 50 & 47 & 0.061 & 0.090 & - & 0.066 & 0.0207 & 0.0202 & 0.0240 & 0.0232 & $<0.006$ & $<0.014$ & $<0.006$ & $<0.007$ & 0.034 & 0.050 & - & 0.033 \\
\hline Mo & 0.98 & 1.07 & 0.94 & 0.95 & 0.52 & 0.71 & - & 0.55 & 0.10 & 0.06 & 0.17 & 0.16 & 0.64 & 0.69 & 0.41 & 0.47 & 0.52 & 0.65 & - & 0.54 \\
\hline $\mathbf{N i}$ & 39.9 & 28.5 & 36.3 & 36.4 & 0.37 & 0.85 & - & 0.45 & 0.58 & 0.44 & 0.42 & 0.45 & 0.36 & 0.95 & 0.30 & 0.34 & 0.38 & 0.85 & - & 0.46 \\
\hline $\mathbf{P b}$ & 50.5 & 29.7 & 28.6 & 33.5 & 0.73 & 0.13 & - & 0.63 & 0.90 & 0.74 & 0.44 & 0.54 & $<0.02$ & $<0.02$ & 0.17 & 0.17 & 0.41 & 0.14 & - & 0.36 \\
\hline $\mathbf{R b}$ & 119 & 117 & 123 & 122 & 64.7 & 144.7 & - & 78.6 & 15.9 & 49.1 & 13.6 & 15.5 & 13 & 44 & 12 & 13 & 34 & 91 & - & 44 \\
\hline Sb & 2.01 & 1.58 & 2.06 & 2.03 & 0.033 & 0.008 & - & 0.029 & 0.0234 & 0.0095 & 0.0028 & 0.0070 & $<0.0006$ & $<0.0006$ & $<0.0006$ & $<0.0007$ & 0.016 & 0.005 & - & 0.014 \\
\hline Sn & 4.81 & 4.56 & 4.15 & 4.32 & $<1.16$ & $<0.06$ & - & 0.94 & $<0.69$ & $<0.06$ & $<0.32$ & $<0.38$ & $<0.06$ & $<0.06$ & $<0.16$ & $<0.14$ & $<0.58$ & $<0.06$ & - & $<0.49$ \\
\hline $\mathrm{Sr}$ & 82 & 41 & 84 & 81 & 15.3 & 16.3 & - & 15.5 & 3.97 & 5.15 & 3.21 & 3.43 & 0.35 & 0.47 & 0.35 & 0.35 & 6.8 & 8.4 & - & 7.0 \\
\hline Th & 17.5 & 19.2 & 15.3 & 16.0 & 0.0280 & 0.0008 & - & 0.0233 & .0140 & 0.0008 & 0.0061 & 0.0074 & $<0.0002$ & 0.0009 & $<0.0002$ & $<0.0002$ & 0.013 & 0.001 & - & 0.011 \\
\hline Tl & 0.60 & 0.59 & 0.66 & 0.64 & 0.014 & 0.144 & - & 0.037 & 0.0039 & 0.0029 & 0.0010 & 0.0016 & $<0.0002$ & $<0.0002$ & $<0.0002$ & $<0.0002$ & 0.006 & 0.067 & - & 0.017 \\
\hline $\mathbf{U}$ & 3.74 & 4.53 & 4.45 & 4.30 & 0.0096 & 0.0042 & - & 0.0087 & 0.0062 & 0.0032 & 0.0025 & 0.0032 & $<0.0001$ & 0.0006 & $<0.0001$ & $<0.0001$ & 0.0048 & 0.0026 & - & 0.0044 \\
\hline Zn & 110 & 83 & 90 & 94 & 40.1 & 62.6 & - & 44 & 11.5 & 9.5 & 15.9 & 14.8 & 23.1 & 26.9 & 19.6 & 20.5 & 29 & 41 & - & 31 \\
\hline $\mathbf{Z r}$ & 129 & 110 & 154 & 147 & 0.273 & 0.030 & - & 0.231 & 0.164 & 0.049 & 0.118 & 0.124 & $<0.013$ & $<0.019$ & $<0.007$ & $<0.009$ & 0.15 & 0.03 & - & 0.13 \\
\hline
\end{tabular}




\subsubsection{Element distribution in parts of rice plants}

After being taken up primarily by the root apex and other parts of the root surface, ions are translocated by the xylem sap to the different plant parts. During the transport, many elements are enriched at cell walls (Greger 2004; Meharg and Zhao 2012). In general, the element transferability to plant parts depends on element species, plant genotypes/ cultivars, and external factors. The translocation of elements in the plant takes place by the phloem and/or xylem sap. Essential elements fulfill different biological functions such as osmoregulation and mass flow driven solute movement within the plant, stomata movement, energy transfer, controlling membrane permeability and electrochemical potentials. In addition, some of the elements serve as cell wall and membrane stabilizer and are necessary constituents of amino and nucleic acids, proteins, enzymes, coenzymes, and chlorophyll (Marschner 2012).

Average values for the plant parts and the aboveground plant are listed in Table 5.1. Element concentrations in plant parts and the aboveground rice plant are visualized in Fig. 5.1.

Average ratios of element concentrations of shoot to grain $(\mathrm{Sh} / \mathrm{Gr})$ and of husk to grain $(\mathrm{Hu} / \mathrm{Gr})$ are listed in Table A3.2. These ratios illustrate in which plant part the single elements are enriched or depleted. In decreasing order, the elements $\mathrm{Ba}, \mathrm{Na}, \mathrm{Sr}, \mathrm{Ca}, \mathrm{Mn}, \mathrm{Pb}, \mathrm{Co}, \mathrm{As}, \mathrm{K}$, $\mathrm{Cs}, \mathrm{Cd}, \mathrm{Fe}, \mathrm{Rb}, \mathrm{Ni}, \mathrm{Mg}, \mathrm{Zn}, \mathrm{S}$, and $\mathrm{Cu}$ are more concentrated in the shoot than in unpolished grains (Sh/Gr 84 to 1 ). The elements Mo and $\mathrm{P}$ are easily transported and enriched in grains $(\mathrm{Sh} / \mathrm{Gr}<1)$, $\mathrm{P}$ even by factor 3. Concentrations of most elements (except $\mathrm{Ni}$ and $\mathrm{P}$ ) are higher in shoot than in husk, especially $\mathrm{Na}, \mathrm{Cd}, \mathrm{Mg}$, and $\mathrm{K}$. Preferential transfer of some elements to grains may be explained by ion charges or the formation of organic complexes. Phosphate, molybdate and sulfate anions are repelled by the negatively charged cell walls allowing more distant transport (Marschner 2012). Copper, $\mathrm{Zn}, \mathrm{Mg}$, Ni and presumably some other metals are transported within the plant as soluble organic complexes facilitating their transport (Marschner 2012). The husk to grain ratio $(\mathrm{Hu} / \mathrm{Gr})$ shows no significant difference between the areas. Most elements show higher concentrations in husk compared to grain, except for $\mathrm{Cu}, \mathrm{Cd}, \mathrm{S}, \mathrm{Zn}, \mathrm{P}, \mathrm{Mg}$, and Mo. 

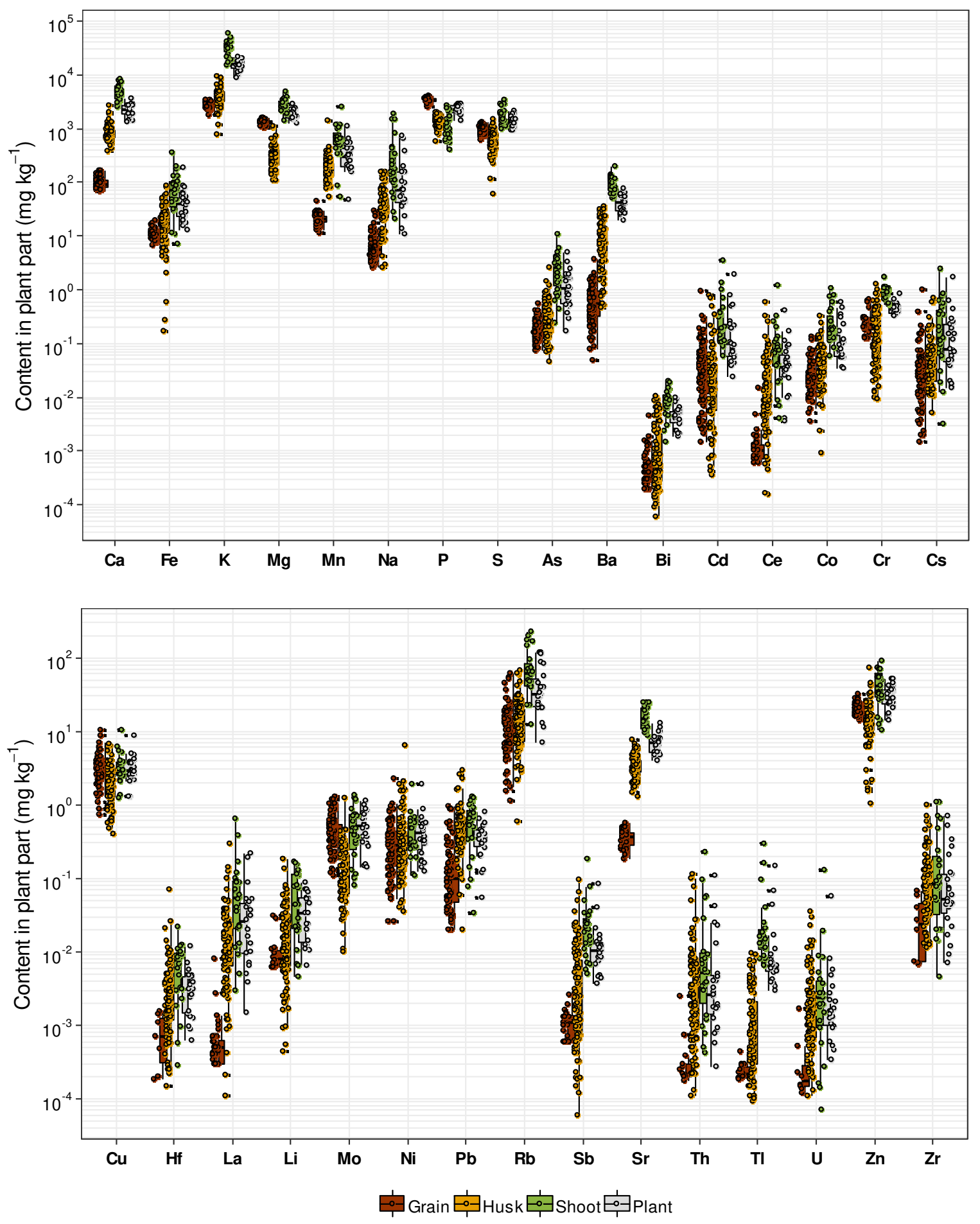

Fig. 5.1 Element concentrations in shoot, husk, grain, and whole aboveground rice plant ( $\mathrm{mg} \mathrm{kg}^{-1}$ ) (shoot and plant: $\mathrm{n}=23$; husk and grain: $\mathrm{n}=101$ ). Concentrations of $\mathrm{Bi}, \mathrm{Ce}$, $\mathrm{Cr}, \mathrm{Hf}, \mathrm{La}, \mathrm{Li}, \mathrm{Pb}, \mathrm{Sb}$, Th, Tl, U, and $\mathrm{Zr}$, whose concentrations are below detection limit in some grain samples limits are not plotted. 
As a general trend, most element concentrations decrease in the order: shoot > husk > grain, while $\mathrm{Cd}, \mathrm{Mg}, \mathrm{Zn}, \mathrm{S}, \mathrm{Cu}$, and Mo concentrations in shoot > grain > husk, and $\mathrm{P}$ concentration in grain $>$ shoot $>$ husk. Meng et al. (2018) found comparable results for the $\mathrm{Cd}$ distribution in rice plant parts.

Table 5.2 Average ratios of element concentrations in rice plant parts for the different areas

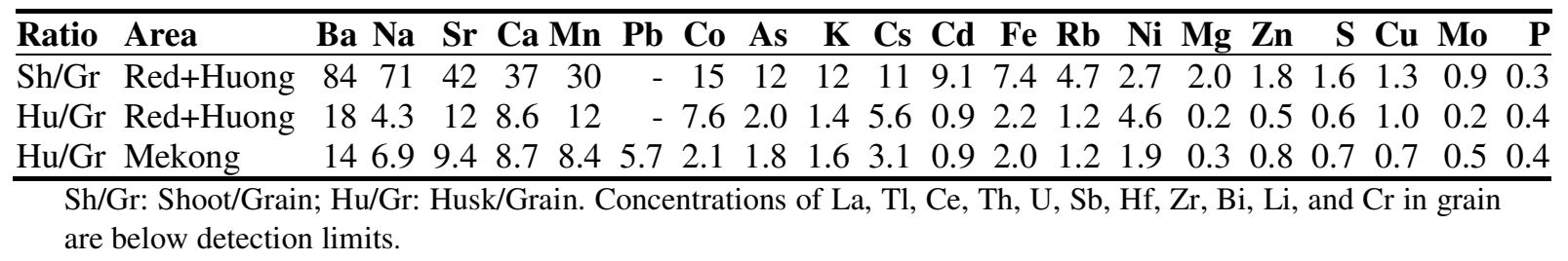

To show the complexity of element transfer from roots to rice grains, some detailed investigations of other authors are summarized in the following. Seyfferth et al. (2011) detected on a root cross-section of a rice plant by using micro-X-ray absorption near-edge spectroscopy ( $\mu$-XANES), that Fe is distributed only along the xylem channel, whereas As, K, and Ca are present in the xylem and inside the cell vacuole. $\mathrm{Zn}$ and Mn are found only in vacuoles localized in the same area as $\mathrm{K}$. The authors observed that mainly inorganic $\mathrm{As}(\mathrm{V})$ is enriched in the xylem and inorganic As(III) adjacent to the xylem channel. In addition, the total As uptake into rice plants is dependent on the extent of Fe plaques which are Fe-oxides/hydroxides coatings at the root surface (Moore et al. 2011), as well as by the type of cultivar and soil conditions (Eh, $\mathrm{pH}$, concentration of As, soil phase composition). Additionally, As in grain can be delivered by phloem transport, where inorganic and organic $\mathrm{As}(\mathrm{V})$ forms are predominant (Ye et al. 2017). However, Ma et al. (2017) and Patel et al. (2016) determined a dominance of As(III) in rice grains. Seyfferth et al. (2011) as well delivered detailed element maps of a rice grain. They identified clear enrichments of Fe, As, K, Zn, Mn, and $\mathrm{Ca}$ in the bran relative to the interior part of the grain (endosperm). Furthermore, K, Ca, Mn, Zn, and Fe are enriched in the germ. Lombi et al. (2009) similarly proved by $\mu$-XANES and PIXE that the bran is strongly enriched in $\mathrm{P}, \mathrm{K}, \mathrm{Cu}, \mathrm{Zn}$, and $\mathrm{S}$. The germ within the grain accumulates more $\mathrm{Zn}, \mathrm{Mn}, \mathrm{Cu}$, and Fe than the endosperm. Si and As are mainly located in the husk. Elevated concentrations of $\mathrm{Mn}, \mathrm{Fe}$, and $\mathrm{Zn}$ are scattered in some regions of the husk. According to Naito et al. (2015) the As concentration in brown rice drops by one third after polishing, confirming the As enrichment in the remaining bran. 


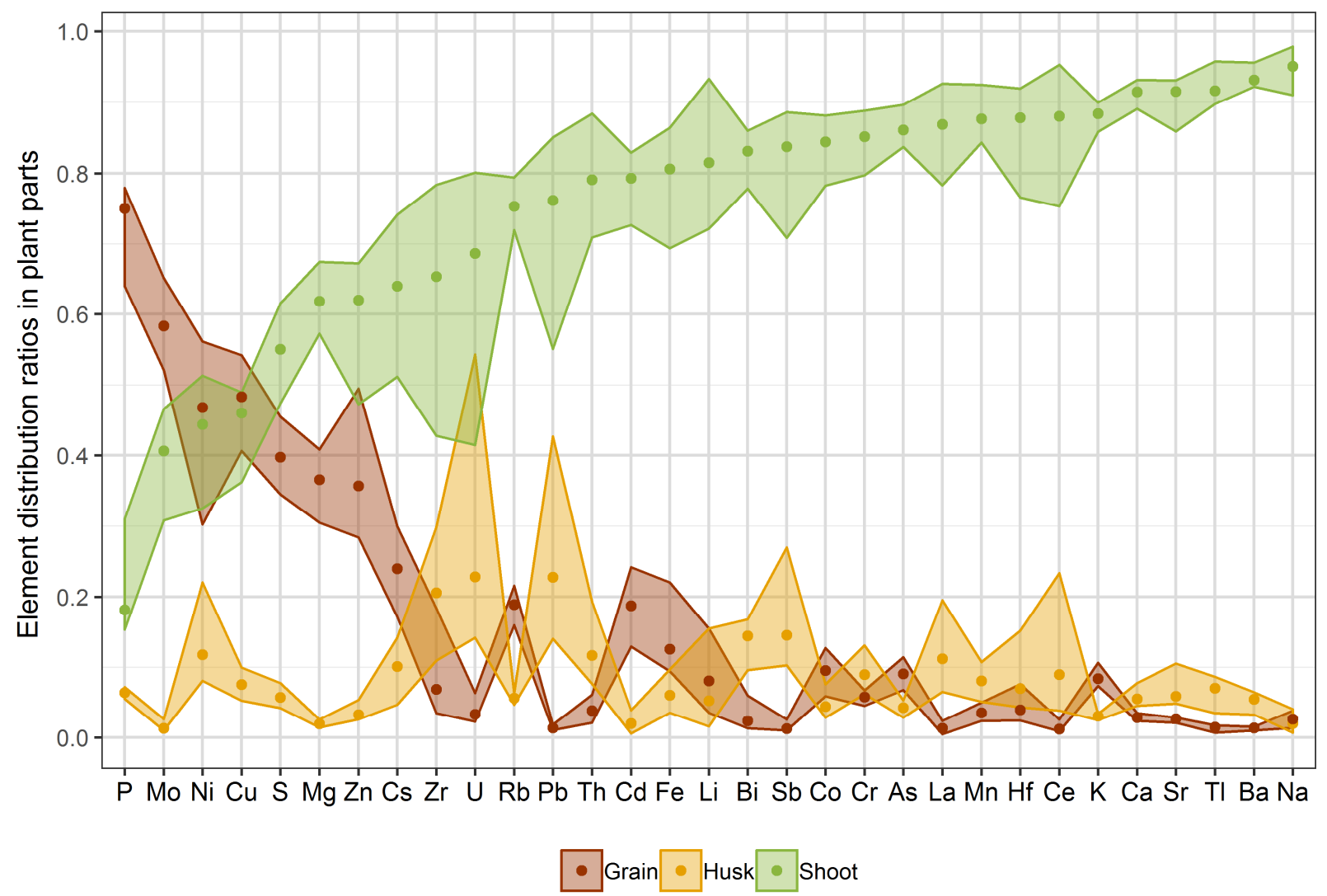

Fig. 5.2 Mass portions of elements in plant parts in relation to the aboveground rice plant. The sum of the portions of each element in grain, husk and shoot equals 1 . Dots represent median values; the colored areas cover the range of the $1^{\text {st }}$ to $3^{\text {rd }}$ quartile portion for each element $(n=23)$

The relative mass portions of elements in different parts of the aboveground rice plants is shown in Fig. 5.2. The mass portions of the plant parts in relation to the whole plant are on average 0.42 for shoot, 0.46 for grain, and 0.12 for husk (Table 5.1, detailed data in Table A3.1 in Appendix A3). More than 50\% of the median amounts of most elements are stored in the shoot. In contrast, $50 \%-80 \%$ of the amount of $\mathrm{P}, \mathrm{Mo}, \mathrm{Ni}$, and $\mathrm{Cu}$ are stored in the grain. The storage of elements in husk is below $10 \%$ except for $\mathrm{U}, \mathrm{Pb}, \mathrm{Zr}, \mathrm{Bi}, \mathrm{Sb}$, and $\mathrm{La}$.

Mean concentrations of potentially harmful elements in soils and related rice plant parts from other regions in Asia are compared with results of this study in Table 5.3. Among the regions there are great differences in element concentrations, which may be attributed to different analytical techniques, especially during the digestion. We used total digestion releasing the elements completely into solution, whereas most of the other authors applied aqua regia or similar methods for soil samples. Arsenic concentrations in Japanese and Vietnamese 
soils are similar, but two times higher than in soils from India, Malaysia, Thailand, and China. However, husk and grain samples from India and Malaysia contain 2 - 3 times more As. This may be explainable by the very high As concentration up to $700 \mu \mathrm{g} \mathrm{L}^{-1}$ in the irrigation water (Biswas et al. 2013). Surprisingly, the As concentrations in shoots from India are about 3 times lower compared to China and Vietnam. The Cd concentrations in soils and grains from China, Japan, and Vietnam are remarkably higher than in other countries. Concentrations of other potentially harmful elements in grains are similar in China, Japan, and Vietnam. Grain samples from India and Malaysia have high contents of $\mathrm{As}, \mathrm{Cr}$ and $\mathrm{Pb}$. Korea shows remarkably low soil element concentrations compared to China, Japan, and Vietnam. Nearly all elements within the different areas show decreasing concentrations in the order soil $>$ shoot $>$ husk $>$ grain.

Table 5.3 Mean concentrations of selected elements in soils and rice plant parts $\left(\mathrm{mg} \mathrm{kg}^{-1}\right)$ in Vietnam compared to other Asian countries

\begin{tabular}{|c|c|c|c|c|c|c|c|c|c|c|c|}
\hline & Country & Area & $\mathbf{n}$ & As & $\mathbf{C d}$ & $\mathrm{Cr}$ & $\mathbf{C u}$ & Mn & $\mathbf{N i}$ & $\mathbf{P b}$ & $\mathbf{Z n}$ \\
\hline \multirow{7}{*}{ Soil } & India & Nadia District, East coast & 94 & 7.3 & - & - & - & - & - & -1 & \\
\hline & Malaysia & Whole country & 16 & 8.0 & 0.07 & 27 & 9 & - & 12 & 28 & 28 \\
\hline & Thailand & Whole country & 108 & 6.4 & 0.04 & 25 & 12 & - & 13 & 20 & 24 \\
\hline & China & Yangtze River Delta & 137 & 7.3 & 0.36 & 73 & 41 & - & - & 32 & 117 \\
\hline & Korea & Whole country & 82 & 4.4 & 0.25 & & 13 & & 14 & 21 & 54 \\
\hline & Japan & North, east, center, south & $10 / 111$ & 14.0 & 0.45 & - & 20 & - & - & - & 96 \\
\hline & Vietnam & This work & 101 & 14.4 & 0.29 & 87 & 33 & 343 & 36 & 33 & 93 \\
\hline \multirow[t]{3}{*}{ Shoot } & India & Nadia District, East coast & $94 / 5$ & 0.91 & 0.25 & 0.65 & 0.2 & 29 & - & 0.75 & 4.2 \\
\hline & China & Yangtze River Delta & 137 & 3.51 & 0.34 & 0.83 & 26 & - & - & 1.97 & 63.8 \\
\hline & Vietnam & This work & 101 & 2.82 & 0.44 & 0.92 & 3.5 & 723 & 0.45 & 0.63 & 44.0 \\
\hline \multirow[t]{3}{*}{ Husk } & India & Nadia District, East coast & 94 & 0.74 & - & - & - & - & - & - & \\
\hline & Japan & North, east, center, south & 10 & 0.24 & - & - & - & - & - & - & \\
\hline & Vietnam & This work & 101 & 0.34 & 0.05 & 0.22 & 2.0 & 195 & 0.45 & 0.54 & 14.8 \\
\hline \multirow[t]{7}{*}{ Grain } & India & Nadia District, East coast & $94 / 5$ & 0.45 & 0.04 & 0.35 & 0.2 & 6.6 & - & 0.51 & 5.2 \\
\hline & Malaysia & Whole country & 16 & 1.27 & 0.01 & 0.37 & 1.9 & - & 1.1 & 0.24 & 42 \\
\hline & Thailand & Whole country & 108 & $<1$ & 0.05 & 0.7 & 2 & - & 1.7 & 0.11 & 22.8 \\
\hline & China & Yangtze River Delta & 137 & 0.13 & 0.06 & 0.19 & 5.2 & - & 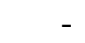 & 0.10 & 22.8 \\
\hline & Korea & Whole country & 82 & 0.15 & 0.02 & & 4.3 & & 0.35 & 0.11 & 22.6 \\
\hline & Japan & North, east, center, south & $10 / 111$ & 0.14 & 0.05 & - & 3.3 & - & - & . & 15.5 \\
\hline & Vietnam & This work & 101 & 0.19 & 0.06 & $<0.24$ & 3.3 & 21 & 0.42 & 0.17 & 20.5 \\
\hline
\end{tabular}

India: Biswas et al. (2013) for $\mathrm{As}(\mathrm{n}=94)$ and Satpathy et al. (2014) for $\mathrm{Cd}, \mathrm{Cr}, \mathrm{Cu}, \mathrm{Mn}, \mathrm{Pb}$, and $\mathrm{Zn}(\mathrm{n}=5)$; Malaysia: Zarcinas et al. 2004a; Thailand: Zarcinas et al. (2004b); China: Mao et al. (2019); Korea: Kunhikrishnan et al. (2015); Japan: Kuramata et al. (2010) for As $(\mathrm{n}=10)$ and Herawati et al. (2000) for Cd, Cu, and $\mathrm{Zn}(\mathrm{n}=111)$

\subsubsection{Transfer factors soil to rice plant}

In this study, transfer factors (TF) from soil to aboveground plant are calculated as ratio of physiological plant concentration to soil concentration for the Red River and Huong River 
areas. The TFs for grains have been discussed in two previous publications (Nguyen et al. 2019a, b). The TFs of shoot and husk are not considered in detail here because their trends are similar to the concentration trends described in the preceding chapter.

According to Table 5.4 and Fig. 5.3, the median TF-values of elements for the aboveground plant decrease in the order:

- Very low transfer (TF <0.001): $\quad$ Ti, Al, Th, U, Ce, Zr, La, Li, Hf, Fe

- Low transfer $(0.001-0.01)$ : $\quad \mathrm{Co}, \mathrm{Sb}, \mathrm{Bi}, \mathrm{Pb}, \mathrm{Ni}, \mathrm{Sn}$

- Intermediate transfer $(0.01-0.1)$ : $\quad \mathrm{Tl}, \mathrm{Na}, \mathrm{Cs}, \mathrm{As}, \mathrm{Cu}, \mathrm{Sr}$

- High transfer $(0.1-1)$ : $\quad \mathrm{Ba}, \mathrm{Mg}, \mathrm{Rb}, \mathrm{Zn}, \mathrm{Cd}, \mathrm{Ca}, \mathrm{Mn}, \mathrm{Mo}, \mathrm{K}$

- Very high transfer $(>1)$ : $\quad$ P, S

The TFs for elements vary by many orders of magnitude. The lowest TF is around 0.00001 for Th and even lower for elements whose concentrations are below detection limit while the highest TF is 7.2 for S. Even the transferability of a single element shows wide variations: For example, the TFs of Th and Cs vary by factor 240, Na by factor 204. Such variations reflect the sensibility of the element phytoavailability under differing soil conditions. Some elements like $\mathrm{Ca}, \mathrm{K}, \mathrm{Mg}, \mathrm{P}, \mathrm{Ba}, \mathrm{Cr}, \mathrm{Pb}, \mathrm{Sr}$, and $\mathrm{Zn}$ have a more stable uptake with TF fluctuating by less than factor 10. Notably, the TF of As and Cd fluctuates 78- and 115-times respectively, showing a potential to govern their uptake by changing the soil conditions such as $\mathrm{pH}$ or Eh. Another reason for such fluctuations may be different uptake patterns of various rice cultivars, as described for Cd and As by Duan et al. (2017), Chi et al. (2018), Islam et al. (2016), Liu et al. (2011), and Li et al. (2017). The rice cultivars of this study, however, were not distinguished during the sample collection. 
Chapter 5. Element transfer to plant

Table 5.4 Average transfer factors for elements in shoot, husk, grain, and in the whole aboveground rice plant in the three different river areas

\begin{tabular}{|c|c|c|c|c|c|c|c|c|c|c|c|c|c|c|c|c|}
\hline \multirow{2}{*}{$\begin{array}{l}\text { Ele- } \\
\text { ment }\end{array}$} & \multicolumn{4}{|c|}{ Shoot $(n=23)$} & \multicolumn{4}{|c|}{ Husk $(\mathrm{n}=101)$} & \multicolumn{4}{|c|}{ Grain $(n=101)$} & \multicolumn{4}{|c|}{ Plant $(n=23)$} \\
\hline & Red & Huong & Mekong & $\overline{\text { Mean }}$ & Red & Huong & Mekong & $\overline{\text { Mean }}$ & Red & Huong & Mekong & $\overline{\text { Mean }}$ & Red & Huong & Mekong & $\overline{\text { Mean }}$ \\
\hline$\overline{\mathrm{Al}}$ & $<0.00005$ & $<0.00005$ & & $-<0.00005$ & $<0.00005$ & $<0.00005$ & $<0.00005$ & 0.00005 & $<0.00005$ & $<0.00005$ & $<0.00005$ & $<0.00005$ & $<0.00005$ & $<0.00005$ & & $<0.00005$ \\
\hline $\mathbf{C a}$ & 1.06 & 1.80 & 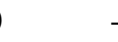 & 1.19 & 0.23 & 0.65 & 0.21 & 0.23 & 0.029 & 0.064 & 0.025 & 0.027 & 0.48 & 0.96 & - & 0.56 \\
\hline $\mathbf{F e}$ & 0.002 & 0.005 & 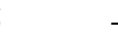 & 0.002 & 0.0006 & 0.0008 & 0.0006 & 0.0006 & 0.0003 & 0.0004 & 0.0003 & 0.0003 & 0.001 & 0.003 & - & 0.0012 \\
\hline $\mathbf{K}$ & 1.92 & 1.16 & 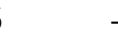 & 1.79 & 0.22 & 0.27 & 0.20 & 0.21 & 0.16 & 0.15 & 0.13 & 0.14 & 0.87 & 0.64 & - & 0.83 \\
\hline Mg & 0.40 & 0.55 & - & 0.42 & 0.04 & 0.07 & 0.05 & 0.05 & 0.20 & 0.22 & 0.20 & 0.20 & 0.26 & 0.36 & - & 0.28 \\
\hline Mn & 1.88 & 3.36 & 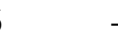 & 2.14 & 0.54 & 1.02 & 0.75 & 0.73 & 0.05 & 0.09 & 0.09 & 0.08 & 0.87 & 1.73 & - & 1.02 \\
\hline $\mathbf{N a}$ & 0.09 & 0.17 & 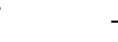 & 0.11 & 0.005 & 0.003 & 0.012 & 0.010 & 0.001 & 0.002 & 0.002 & 0.002 & 0.04 & 0.08 & - & 0.047 \\
\hline $\mathbf{P}$ & 1.46 & 2.97 & 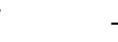 & 1.72 & 1.63 & 2.32 & 1.94 & 1.89 & 4.4 & 6.7 & 4.5 & 4.6 & 2.8 & 4.6 & - & 3.14 \\
\hline $\mathbf{S}$ & 4.10 & 6.31 & 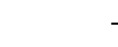 & 4.48 & 1.86 & 1.38 & 0.95 & 1.14 & 2.9 & 2.6 & 1.4 & 1.7 & 3.3 & 4.2 & - & 3.46 \\
\hline $\mathbf{T i}$ & - & - & . & - & - & - & - & - & - & - & - & - & - & - & - & . \\
\hline As & 0.14 & 0.25 & 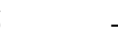 & 0.16 & 0.022 & 0.057 & 0.024 & 0.025 & 0.007 & 0.020 & 0.015 & 0.014 & 0.06 & 0.13 & - & 0.08 \\
\hline Ba & 0.25 & 0.28 & 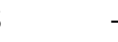 & 0.25 & 0.06 & 0.05 & 0.02 & 0.026 & 0.0033 & 0.0033 & 0.0013 & 0.0017 & 0.11 & 0.14 & - & 0.11 \\
\hline $\mathbf{B i}$ & 0.017 & 0.014 & . & 0.016 & 0.010 & 0.006 & 0.002 & 0.003 & $<0.0005$ & 0.0026 & $<0.001$ & $<0.001$ & 0.008 & 0.008 & - & 0.008 \\
\hline Cd & 1.31 & 1.98 & 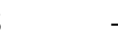 & 1.43 & 0.30 & 0.71 & 0.11 & 0.171 & 0.361 & 0.373 & 0.151 & 0.200 & 0.76 & 1.12 & - & 0.82 \\
\hline $\mathrm{Ce}$ & 0.0015 & 0.0027 & 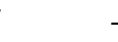 & 0.0017 & .0010 & 0.0006 & 0.0003 & 0.0004 & $<0.00001$ & 0.00006 & $<0.00001$ & $<0.00001$ & 0.0007 & 0.0013 & - & 0.0008 \\
\hline Co & 0.013 & 0.061 & . & 0.021 & 0.0054 & 0.0108 & 0.0037 & 0.004 & 0.0011 & 0.0069 & 0.0021 & 0.0021 & 0.006 & 0.033 & - & 0.011 \\
\hline $\mathrm{Cr}$ & 0.016 & 0.019 & 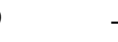 & 0.016 & 0.0058 & 0.0107 & 0.0019 & 0.003 & $<0.001$ & $<0.001$ & $<0.002$ & $<0.003$ & 0.007 & 0.011 & - & 0.008 \\
\hline Cs & 0.03 & 0.20 & 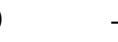 & 0.06 & 0.0187 & 0.0743 & 0.0036 & 0.009 & 0.007 & 0.080 & 0.003 & 0.0065 & 0.018 & 0.136 & - & 0.038 \\
\hline $\mathbf{C u}$ & 0.08 & 0.14 & 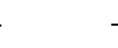 & 0.09 & 0.052 & 0.082 & 0.068 & 0.065 & 0.08 & 0.14 & 0.11 & 0.11 & 0.074 & 0.136 & - & 0.09 \\
\hline Hf & 0.0016 & 0.0022 & ? & 0.0017 & 0.0013 & 0.0006 & 0.0010 & 0.0011 & $<0.00008$ & $<0.00014$ & $<0.00005$ & $<0.00005$ & 0.0008 & 0.0012 & - & 0.0009 \\
\hline La & 0.0023 & 0.0026 & 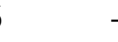 & 0.0024 & 0.0011 & 0.0007 & 0.0004 & 0.0005 & $<0.00001$ & 0.00007 & $<0.00001$ & $<0.00001$ & 0.0010 & 0.0013 & - & 0.0011 \\
\hline $\mathbf{L i}$ & 0.002 & 0.004 & . & 0.0023 & 0.0008 & 0.0008 & 0.0005 & 0.0006 & $<0.0001$ & $<0.0005$ & $<0.0001$ & $<0.0001$ & 0.001 & 0.002 & - & 0.0012 \\
\hline Mo & 0.82 & 0.74 & . & 0.81 & 0.12 & 0.06 & 0.21 & 0.19 & 0.98 & 0.72 & 0.49 & 0.59 & 0.80 & 0.67 & - & 0.78 \\
\hline $\mathbf{N i}$ & 0.010 & 0.035 & 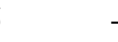 & 0.015 & 0.016 & 0.017 & 0.012 & 0.013 & 0.010 & 0.039 & 0.009 & 0.010 & 0.011 & 0.035 & - & 0.015 \\
\hline $\mathbf{P b}$ & 0.016 & 0.005 & 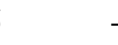 & 0.014 & 0.021 & 0.023 & 0.016 & 0.017 & $<0.0005$ & $<0.0005$ & 0.0063 & $<0.005$ & 0.009 & 0.005 & - & 0.008 \\
\hline $\mathbf{R b}$ & 0.68 & 1.32 & . & 0.79 & 0.176 & 0.452 & 0.114 & 0.139 & 0.15 & 0.41 & 0.10 & 0.12 & 0.36 & 0.84 & - & 0.45 \\
\hline Sb & 0.023 & 0.005 & 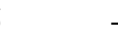 & 0.02 & 0.015 & 0.006 & 0.001 & 0.0042 & $<0.0003$ & $<0.0003$ & $<0.0003$ & $<0.0003$ & 0.011 & 0.003 & - & 0.0095 \\
\hline Sn & $<0.01$ & $<0.23$ & 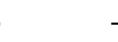 & $<0.19$ & $<0.13$ & $<0.01$ & $<0.08$ & $<0.09$ & $<0.01$ & $<0.01$ & $<0.04$ & $<0.03$ & $<0.12$ & $<0.01$ & - & $<0.097$ \\
\hline $\mathrm{Sr}$ & 0.23 & 0.41 & 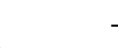 & 0.26 & 0.06 & 0.13 & 0.04 & 0.046 & 0.005 & 0.012 & 0.004 & 0.005 & 0.10238 & 0.21050 & - & 0.12 \\
\hline Th & 0.00151 & 0.00005 & 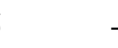 & 0.0013 & 0.00077 & 0.00004 & 0.00040 & 0.0005 & $<0.00001$ & 0.00004 & $<0.00001$ & $<0.00001$ & 0.00069 & 0.00004 & - & 0.0006 \\
\hline Tl & 0.03 & 0.27 & 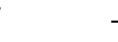 & 0.069 & 0.007 & 0.005 & 0.001 & 0.003 & $<0.0003$ & $<0.0003$ & $<0.0003$ & $<0.0003$ & 0.012 & 0.127 & - & 0.032 \\
\hline $\mathbf{U}$ & 0.003 & 0.001 & . & 0.002 & 0.0017 & 0.0007 & 0.0006 & 0.0008 & $<0.00002$ & 0.00013 & $<0.00002$ & $<0.00002$ & 0.0013 & 0.0006 & - & 0.0011 \\
\hline Zn & 0.39 & 0.75 & T. & 0.45 & 0.12 & 0.12 & 0.19 & 0.17 & 0.22 & 0.33 & 0.23 & 0.23 & 0.28 & 0.50 & - & 0.31 \\
\hline $\mathbf{Z r}$ & 0.0020 & 0.0003 & 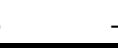 & 0.0017 & 0.0017 & 0.0005 & 0.0008 & 0.0009 & $<0.00005$ & $<0.00018$ & $<0.00005$ & $<0.00004$ & 0.0011 & 0.0003 & - & 0.0010 \\
\hline
\end{tabular}




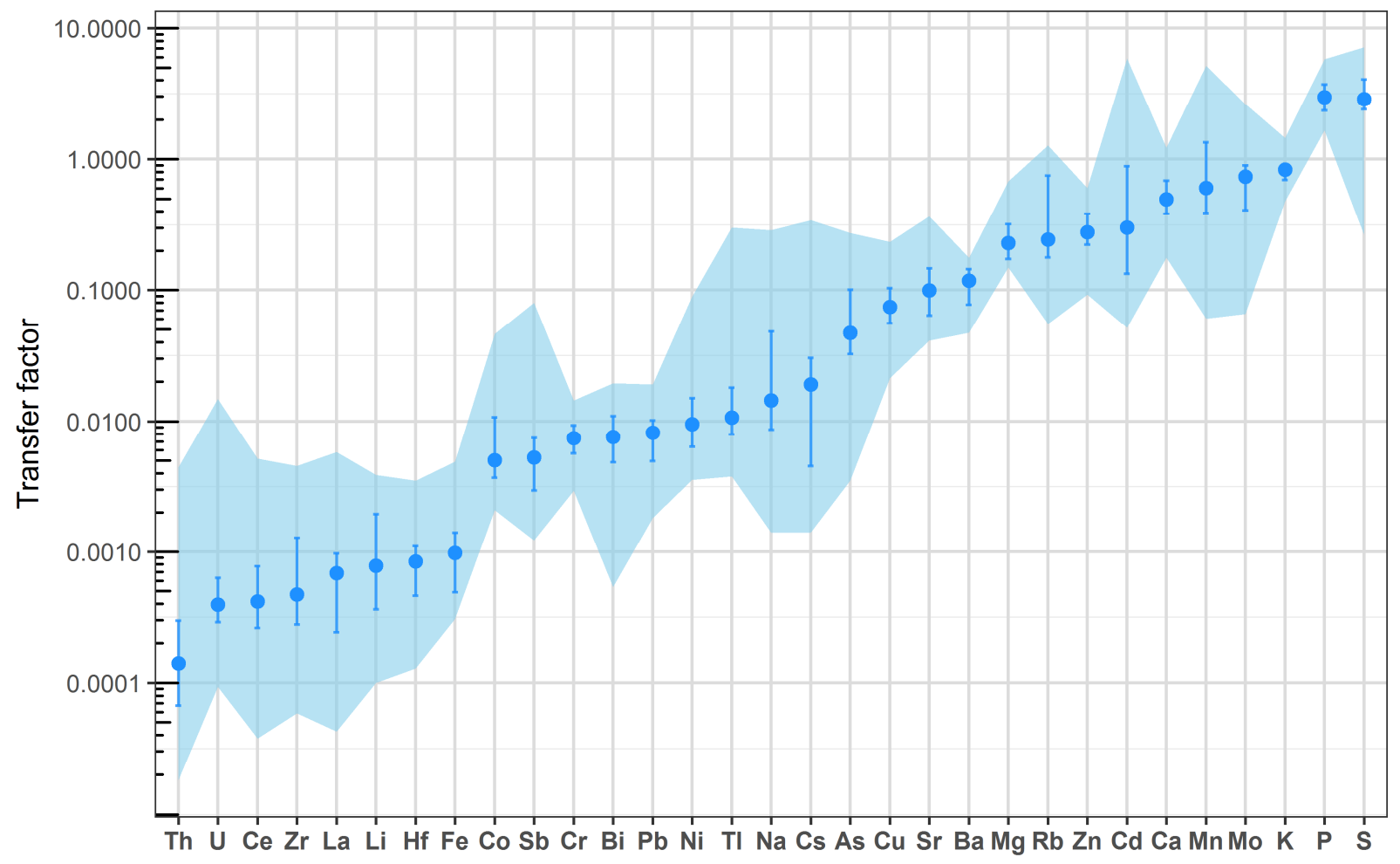

Fig. 5.3 Transfer factors from soil to aboveground plant for the Red River and Huong River area $(n=23)$. Dots are median values. The straight line indicates the $1^{\text {st }}$ to $3^{\text {rd }}$ quartile of the TFs. The colored zone marks the area between minimum and maximum values.

Soil parameters that determine the transferability for each element from soil to the aboveground plant are presented in Table 5.5. The uptake of elements is simultaneously influenced by their concentration and speciation in the soil solution, which depend on redoxand $\mathrm{pH}$-value, the concentration and reactivity of sorbents (Fe and Mn oxides/hydroxides, clay minerals and organic matter), and microbial activities. The influence of the soil concentration of each element and of the soil parameters $\mathrm{pH}, \mathrm{OM}, \mathrm{Al}, \mathrm{Fe}$, and $\mathrm{Mn}$ on the TFs is evaluated on the basis of xy-scatterplots in Fig. A3.2 and Fig. A3.5 (Appendix A3). It was not possible to measure Eh-values and microbial activities in the field.

The TFs of the elements Ca, Mg, Mn, Na, P, S, As, Bi, Cr, Cs, Cu, Mo, Ni, Pb, Rb, Sb, $\mathrm{Sr}$, and $\mathrm{Zn}$ decrease exponentially with their increasing soil concentrations (Table 5.5; Fig. A3.2 in the supplementary material). However, these elements show no significant correlation between soil and plant concentrations. Increasing soil element concentrations systematically lower the TFs demonstrating that the decrease of TF is a spurious effect. 
Table 5.5 Influences of soil parameters and soil element concentrations and $\mathrm{pH}$-value on transfer factors (TF) for aboveground rice plants from the Red River and Huong River areas

\begin{tabular}{lllll}
\hline $\mathrm{TF}$ & Soil factors & & $\mathrm{TF}$ & Soil factors \\
${$\cline { 5 - 5 }$} }$ & $-\mathrm{Ca},-\mathrm{pH}>-\mathrm{Mn}>+\mathrm{Al}$ & & $\mathrm{Cs}$ & $-\mathrm{Cs}$ \\
$\mathrm{Mg}$ & $-\mathrm{Mg},-\mathrm{Fe}>-\mathrm{Mn}$ & & $\mathrm{Cu}$ & $-\mathrm{Cu}>-\mathrm{LOI}>-\mathrm{pH}$ \\
$\mathrm{Mn}$ & $-\mathrm{Mn}>-\mathrm{pH}$ & $\mathrm{Mo}$ & $-\mathrm{Mo}>-\mathrm{Fe},-\mathrm{Al},-\mathrm{LOI},+\mathrm{pH}$ \\
$\mathrm{Na}$ & $-\mathrm{Na},+\mathrm{Fe}>+\mathrm{LOI}>+\mathrm{Al}$ & & $\mathrm{Ni}$ & $-\mathrm{Ni}>-\mathrm{Mn},-\mathrm{pH},-\mathrm{Fe}$ \\
$\mathrm{P}$ & $-\mathrm{P}>-\mathrm{pH}>-\mathrm{Mn}$ & & $\mathrm{Pb}$ & $-\mathrm{Pb}$ \\
$\mathrm{S}$ & $-\mathrm{LOI},-\mathrm{S}>-\mathrm{Al},-\mathrm{Fe}$ & & $\mathrm{Rb}$ & $-\mathrm{Rb}>-\mathrm{Fe},-\mathrm{Al}$ \\
$\mathrm{As}$ & $-\mathrm{As}>+\mathrm{LOI},-\mathrm{Fe}$, & & $\mathrm{Sb}$ & $-\mathrm{Sb}>+\mathrm{pH},-\mathrm{Fe}$ \\
$\mathrm{Bi}$ & $-\mathrm{Bi}>-\mathrm{Fe}$ & $\mathrm{Sr}$ & $-\mathrm{Sr}>-\mathrm{Fe}>-\mathrm{pH}$ \\
$\mathrm{Cd}$ & $-\mathrm{pH}>-\mathrm{Mn}$ & $\mathrm{Tl}$ & $-\mathrm{pH},-\mathrm{Mn}$ \\
$\mathrm{Co}$ & $-\mathrm{pH},-\mathrm{Mn}$ & $\mathrm{Zn}$ & $-\mathrm{Fe},-\mathrm{Zn}$ \\
$\mathrm{Cr}$ & $-\mathrm{Cr},-\mathrm{Fe}>-\mathrm{Al},-\mathrm{LOI}$ & & \\
\hline “+” positive correlation trends (mostly linear); “-” negative correlation trends (mostly exponentially decreasing); \\
$\mathrm{Fe}, \mathrm{K}, \mathrm{Ba}, \mathrm{Li}, \mathrm{Sn}$, and U show no visible correlation with soil factors or their soil concentration.
\end{tabular}

The influence of the soil parameters $\mathrm{pH}, \mathrm{LOI}, \mathrm{Al}, \mathrm{Fe}$, and $\mathrm{Mn}$ on the TF of an element is in general less relevant than its soil concentration (Table 5.5 and Fig. A3.5 in Appendix A). This is easily explainable by the fact that each soil parameter has a different impact on element availability. Thus, the element concentration in the plant reflects the combined effects of all soil parameters as mentioned in literature (Blume et al. 2016). Some effects of soil parameters on the TFs are summarized here:

- The negative correlation trends of the TFs of elements $\mathrm{Ca}, \mathrm{Mn}, \mathrm{P}, \mathrm{Cd}, \mathrm{Co}, \mathrm{Cu}, \mathrm{Ni}$, $\mathrm{Sr}$, and $\mathrm{Tl}$ with soil $\mathrm{pH}$-value may be explained by higher plant-available element concentration in soil solution at lower $\mathrm{pH}$-value. In an acidic environment, $\mathrm{H}^{+}$ions can replace sorbed cations at the surfaces of soil phases and release them into solution. This facilitates the element uptake by the plant. In circum-neutral soils, these elements are much less soluble. Compared to the other elements, $\mathrm{Cd}, \mathrm{Co}$, and Tl show an extremely sharp decrease of their TF at low pH-value. An additional reason for the negative trends between $\mathrm{pH}$-value and $\mathrm{TF}$ for the elements $\mathrm{Ca}, \mathrm{Mn}, \mathrm{P}$, $\mathrm{Cd}, \mathrm{Cu}$, and $\mathrm{Sr}$ is again a spurious effect: Their concentration increase in the soil with rising $\mathrm{pH}$ lowers their TFs.

- Opposite to cations, Mo shows an increased uptake trend towards higher $\mathrm{pH}$-value. Under reducing conditions Mo is able to form complexes with organic matter, presumably with sulphur-groups. Increasing soil $\mathrm{pH}$-values lead to more biological destruction of organic matter releasing Mo into the soil solution. 
- The TFs of $\mathrm{Cr}$ and Mo are negatively correlated with soil Fe and Al. Chromium and Mo are less sorbed at low Fe and Al soil concentrations facilitating their plant uptake.

- The positive correlations between the TFs of $\mathrm{As}, \mathrm{Bi}$, and $\mathrm{Sb}$ suggest their similar solution behavior in the soil and comparable uptake mechanisms by the plant.

- The TFs of Mg, S, As, Bi, Cr, Mo, Ni, Rb, Sb, Sr, and Zn show negative trends with the soil concentrations of $\mathrm{Fe}$ and $\mathrm{Al}$. The sorption of these elements on $\mathrm{Fe}$ oxides/hydroxides or clay minerals leads to their decreased bioavailable concentrations in soil solution and hence in rice plants. In contrast, the TF of $\mathrm{Ca}$ correlates positively with soil concentrations of $\mathrm{Al}$ and Fe. Their phases hold mobile $\mathrm{Ca}$ and $\mathrm{Na}$ cations available to plants.

- The TFs of $\mathrm{Ca}, \mathrm{Mg}, \mathrm{Mn}, \mathrm{P}, \mathrm{Cd}, \mathrm{Co}, \mathrm{Ni}$, and Tl decrease exponentially with increasing Mn-concentrations in the soils. A smart explanation may result from the positive correlation of the soil Mn concentration with increasing soil-pH leading to a spurious negative trend between soil Mn concentration and the TFs of the elements.

- The LOI concentration influences positively the TF of As. The organic matter may form soluble As-organic complexes facilitating the As-transport into the plant. In contrast, increasing LOI concentrations in the soil lead to decreasing TFs of $\mathrm{S}, \mathrm{Cr}$, $\mathrm{Cu}$, and Mo. Sulphur is compound of the OM, the other elements may be sorbed. At oxidizing conditions and/or at higher $\mathrm{pH}$-value, organic compounds are degraded and release these elements into solution facilitating their plant uptake.

\subsubsection{Health risk assessment}

Potentially harmful elements such as $\mathrm{As}, \mathrm{Cd}, \mathrm{Pb}, \mathrm{Co}, \mathrm{Cu}, \mathrm{Mn}, \mathrm{Mo}$, and $\mathrm{Ni}$ are selected to estimate the non-cancer risk by means of Target Hazard Quotients (THQ) for an elements and chronic cumulative Hazard Index (HI) for all selected elements (USEPA 1989; Nordberg et al. 2015a). Elements with implicit carcinogenic risk like $\mathrm{As}$ and $\mathrm{Pb}$ are evaluated by means of Incremental Lifetime Cancer Risk (ILCR) and Cumulative Cancer Risk ( ILCR). Statistics on the exposure risk of single elements and total health risks are compiled in Table 6 for the three river areas (detailed data in Table A3.6 in Appendix A3). The HI and $\sum$ ILCR for the single samples of the three river areas are plotted in Fig. 5.4. 
Table 5.6 Indexes for health risk assessment for potentially harmful elements including noncancer risk and cancer risk

\begin{tabular}{|c|c|c|c|c|c|c|c|c|c|c|c|c|}
\hline Index & Area & Statistics & As & $\mathbf{P b}$ & Cd & Co & $\mathrm{Cu}$ & Mn & Mo & $\mathrm{Ni}$ & HI & $\sum$ ILCR \\
\hline \multicolumn{2}{|c|}{ RfD $\left(\times 10^{-3}\right)$} & & 2 & 1.5 & 1.5 & 0.35 & 200 & 200 & 40 & 20 & & \\
\hline \multirow{7}{*}{$\begin{array}{l}\mathbf{C D I} \\
\left(\times 10^{-3}\right)\end{array}$} & Red & Min-Max & $0.8-2.6$ & $<0.2$ & $0.02-7.4$ & $0.03-0.24$ & $5.5-65$ & $88-348$ & $1.4-9.9$ & $0.2-7.8$ & & \\
\hline & & Mean & 1.6 & $<0.2$ & 0.92 & 0.12 & 26 & 170 & 4.9 & 2.8 & & \\
\hline & Huong & Min-Max & $1.0-2.6$ & $<0.2$ & $0.33-0.96$ & $0.48-1.02$ & $21-36$ & $163-202$ & $3.7-7.0$ & $2.9-17$ & & \\
\hline & & Mean & 2.1 & $<0.2$ & 0.63 & 0.63 & 27 & 181 & 5.3 & 7.3 & & \\
\hline & Mekong & Min-Max & $0.6-4.3$ & $0.02-7.1$ & $0.06-0.88$ & $0.06-0.88$ & 8.4-78 & $101-219$ & $0.8-7.8$ & $0.2-23$ & & \\
\hline & & Mean & 1.4 & 1.3 & 0.19 & 0.19 & 25 & 158 & 3.2 & 3.1 & & \\
\hline & Mean & Mean & 1.5 & 1.0 & 0.42 & 0.20 & 25 & 161 & 3.6 & 3.2 & & \\
\hline \multirow[t]{7}{*}{ THQ } & Red & Min-Max & $0.41-1.3$ & $<0.1$ & $0.05-21$ & $0.02-0.16$ & $0.03-0.33$ & $0.44-1.74$ & $0.03-0.25$ & $0.01-039$ & $1.4-24$ & \\
\hline & & Mean & 0.80 & $<0.1$ & 2.6 & 0.08 & 0.13 & 0.85 & 0.12 & 0.14 & 4.7 & \\
\hline & Huong & Min-Max & $0.5-1.3$ & $<0.1$ & $0.93-2.7$ & $0.32-0.68$ & $0.11-0.18$ & $0.81-1.01$ & $0.09-0.18$ & $0.15-0.86$ & $3.7-6.1$ & \\
\hline & & Mean & 1.04 & $<0.1$ & 1.86 & 0.42 & 0.14 & 0.91 & 0.13 & 0.37 & 4.9 & \\
\hline & Mekong & Min-Max & $0.29-2.1$ & $0.1-4.7$ & $0.03-4.1$ & $0.04-0.59$ & $0.04-0.39$ & $0.50-1.09$ & $0.02-0.20$ & $0.01-1.13$ & $1.6-8.4$ & \\
\hline & & Mean & 0.70 & 0.87 & 0.81 & 0.13 & 0.12 & 0.79 & 0.08 & 0.15 & 3.7 & \\
\hline & Mean & Mean & 0.73 & 0.69 & 1.19 & 0.13 & 0.13 & 0.81 & 0.09 & 0.16 & 3.9 & \\
\hline \multirow{7}{*}{$\begin{array}{l}\text { ILCR } \\
\left(\mathrm{x} 10^{-3}\right)\end{array}$} & Red & Min-Max & $1.2-3.9$ & $<0.001$ & & & & & & & & $1.2-3.9$ \\
\hline & & Mean & 2.4 & $<0.001$ & & & & & & & & 2.4 \\
\hline & Huong & Min-Max & $1.5-3.9$ & $<0.001$ & & & & & & & & $1.5-3.9$ \\
\hline & & Mean & 3.1 & $<0.001$ & & & & & & & & 3.1 \\
\hline & Mekong & Min-Max & $0.9-6.4$ & $0.001-0.06$ & & & & & & & & $0.9-6.4$ \\
\hline & & Mean & 2.1 & 0.01 & & & & & & & & 2.1 \\
\hline & Mean & Mean & 2.2 & 0.009 & & & & & & & & 2.2 \\
\hline \multicolumn{13}{|c|}{$\begin{array}{l}\text { RfD: the reference dose of an element represents its maximum permissible level for daily intake per kg human } \\
\text { body weight in } \mathrm{mg} \mathrm{kg}^{-1} \mathrm{~b} . \mathrm{w} \text {. day }{ }^{-1} \text { (recalculated data from Nguyen et al.2019a); CDI: Chronic Daily Intake of an } \\
\text { element from rice consumption in } \mathrm{mg} \mathrm{kg}^{-1} \text { b.w. day }{ }^{-1} ; T H Q: \text { Target Hazard Quotients; HI: chronic cumulative } \\
\text { Hazard Index for non-cancer risk; ILCR: Incremental Lifetime Cancer Risk; } \sum I L C R \text { : Incremental Cumulative } \\
\text { Cancer Risk }\end{array}$} \\
\hline
\end{tabular}

\section{Non-cancer risks}

Chronic cumulative Hazard Indexes (HI) for the intake of the elements $\mathrm{As}, \mathrm{Cd}, \mathrm{Pb}, \mathrm{Co}$, $\mathrm{Cu}, \mathrm{Mn}, \mathrm{Mo}$, and Ni from rice consumption are calculated. All samples have HI values $\geq 1.4$ surpassing the safe level of 1 as suggested by USEPA (1989). 39\% of the samples show HIvalues between 1.4 and 3, 44\% between 3 and 5, and $18 \%$ between 5 and 8.4. Rice consumption poses health hazards of concern with HI > 5 in $26 \%$ of the Red River samples, in 2 of 4 samples from the Huong River, and 14\% of the Mekong River samples. Cadmium, $\mathrm{As}, \mathrm{Pb}$, and $\mathrm{Mn}$ are the most prominent harmful elements by rice consumption and contribute 64 - 97\% (average $86 \%$ ) to the HI. In some samples, the THQs of $\mathrm{Cd}, \mathrm{Pb}, \mathrm{As}$, and $\mathrm{Mn}$ are very high, reaching 21 , 4.7, 2.1, and 1.7 respectively. The elements $\mathrm{Ni}, \mathrm{Cu}, \mathrm{Co}$, and $\mathrm{Mo}$ are present a much lower risk. Other sources for harmful element intake such as other food, drinking water or air pollution are not considered in this study.

For arsenic, 3 of 4 samples from the Huong River, $26 \%$ of the Red River samples and $14 \%$ of the Mekong River samples have $\mathrm{THQ}_{\mathrm{As}}>1$. Arsenic contributes on the average 22\% to the HI value in the three river areas. For cadmium, 39\% of the Red River and $29 \%$ and 
Mekong River samples show THQ $\mathrm{Cd}>1$. Especially, samples HN10 and HN9, collected close to a brick manufactory, have $\mathrm{THQ}_{\mathrm{Cd}}$ of 21 and 7 respectively. Cadmium contributes on the average $23 \%$ to the total hazard index (HI) in the three river areas. All of the Red River and Huong River grain samples have very low $\mathrm{Pb}$ concentrations $<0.02 \mathrm{mg} \mathrm{kg}^{-1}$ corresponding to $\mathrm{CDI}_{\mathrm{Pb}}<0.2 \mathrm{mg} \mathrm{kg}^{-1}$ b.w. day ${ }^{-1}$ and THQPb $<0.1$. Lead is just responsible for less than $2 \%$ of the HI-value in these two river areas. In contrast, the Mekong River grain samples contain at least 10-times more $\mathrm{Pb}$ than the samples from the other rivers. Lead contributes 3 - 69\% (average 21\%) to the total hazard risk in the Mekong River area. Manganese is usually not considered as a harmful element. In fact, Mn, on the average, holds $24 \%$ of the HI value, being the highest contributor compared to the other harmful elements. Manganese surpasses THQ = 1 in $10 \%$ of the samples, but $99 \%$ of the samples have THQ $>0.5$.

For a better understanding of the HI value, the following aspects should be considered: If the calculation of HI would be performed with the reference doses RfD of the 8 elements listed in Table 5.6, the HI value would be 8. Because of their nutrient character $\mathrm{Ca}, \mathrm{Mg}, \mathrm{P}, \mathrm{Fe}$, and $\mathrm{Zn}$ are not included in our list although their RfD values are available. Magnesium alone would increase the $\mathrm{HI}$ by at least 1 . In so doing, an increasing number of potentially harmful substances in the rice grain boost the values of HI, but also the values $\sum$ ILCR. In case $\mathrm{Mg}$ would be included additionally, many of the samples would be located in the very high risk field of $\mathrm{HI}>5$. In addition, the positive health effects of the beneficial elements $\mathrm{Cu}, \mathrm{Mo}, \mathrm{Mg}$, and $\mathrm{Mn}$ are not considered in the schematic addition assessment applied here. Furthermore, antagonistic and synergistic effects are neglected, because studies of interactions among toxic elements in human body are limited (Nordberg et al. 2015b).

\section{Cancer risk}

The index of Incremental Lifetime Cancer Risk (ILCR) for As and $\mathrm{Pb}$ from rice consumption, as well as the Cumulative Cancer Risk ( $\sum$ ILCR) is calculated and shown in Table 6 and Fig. 5. All samples exceed the threshold of acceptable cancer risk which should be between $10^{-4}$ to $10^{-6}$ according to USEPA (1989). At the $\sum$ ILCR between $10^{-4}$ and $10^{-3}$, health risk management should take action. The $\sum$ ILCR values fluctuate from $0.9 \times 10^{-3}$ to $6.4 \times 10^{-3}$ (average $2.2 \times 10^{-3}$ ) revealing a high level of cancer risk. The mean risk levels $\sum$ ILCR are 2.1 x $10^{-3}$ for the Mekong River rice, 2.4 x $10^{-3}$ for the Red River rice, and $3.1 \times 10^{-3}$ for the Huong River rice. The slightly greater risk of the Huong River samples might be due to the strongly acidic condition there (Nguyen et al. 2019a). Of these two elements, As contributes to $96 \%$ of 
$\sum$ ILCR while $\mathrm{Pb}$ only holds $4 \%$ of the cancer risk. Cadmium is another important cancer risk factor for Red River and Huong River rice. However, the missing reliable data for food intake makes it impossible to consider $\mathrm{Cd}$ in this research.
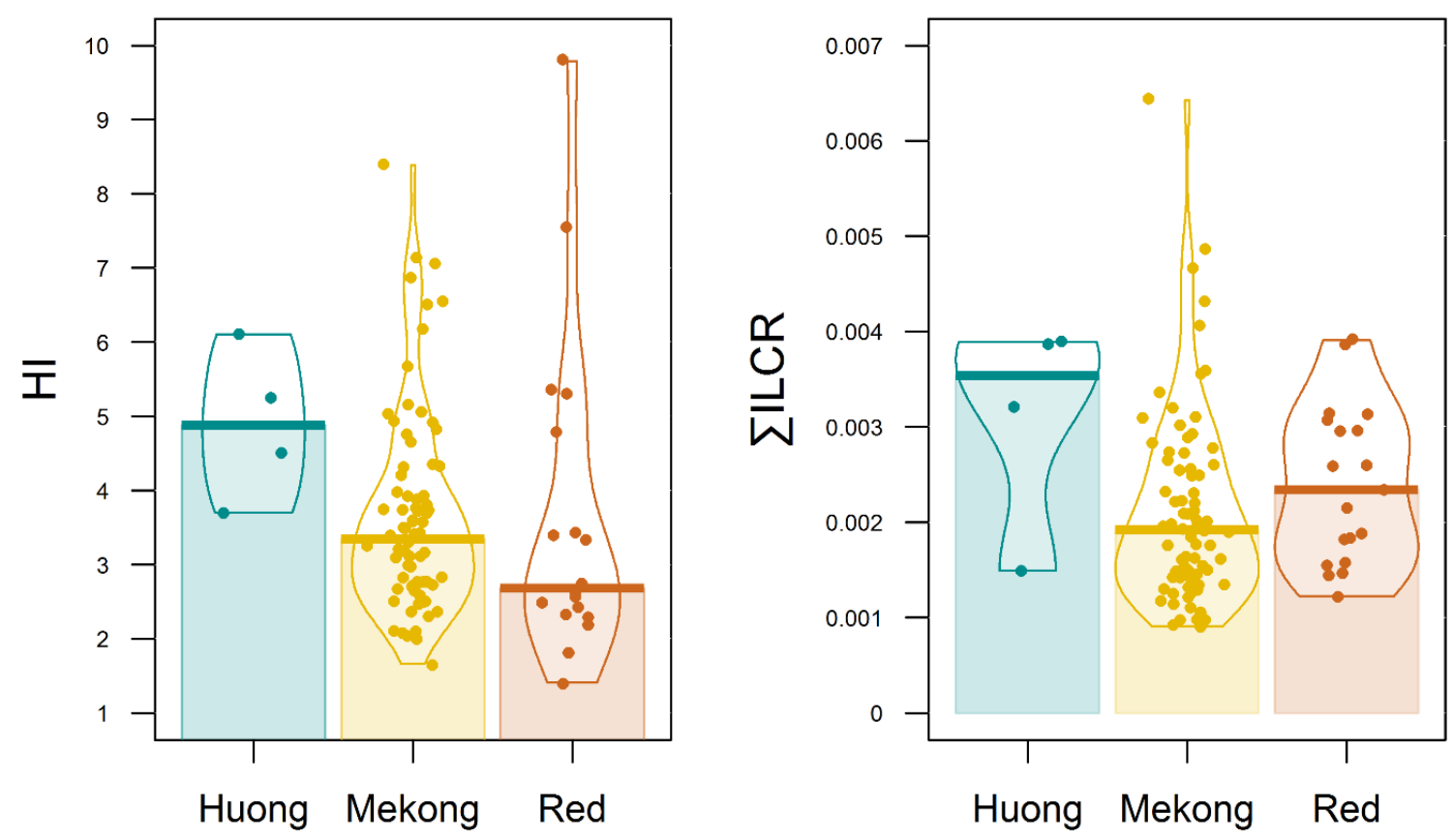

Fig. 5.4 Target hazard index (HI) for non-cancer risk from intake of $\mathrm{As}, \mathrm{Cd}, \mathrm{Pb}, \mathrm{Co}, \mathrm{Cu}$, $\mathrm{Mn}, \mathrm{Mo}$, and Ni by rice consumption and cumulative carcinogenic risk ( $(\mathrm{ILCR})$ from As and $\mathrm{Pb}$ intake. The horizontal lines represent the medians. The extreme HI-value 24 of sample HN10 from the Red River area is not plotted.

Both cancer risks and non-cancer risks from rice consumption are considerably higher than the tolerable health risks. Our results show the urgent need to lower the uptake of potentially harmful elements into rice grains. In addition to the critical comments given above, the indexes may deliver only rough risk estimates for several reasons: The simple addition of single elements quotients to get the health risk seems questionable because of lacking knowledge about the interaction among the elements and other harmful compounds (Nordberg et al. 2015a). In addition, more sources of harmful elements such as other food, drinking water, air pollution, etc. additionally aggravate the situation. All calculations in this paper are done for adult lifetime exposure without considering the special stages of infancy, child, and old age. According to Liao et al. (2018), these sensible age groups may have an elevated cancer risk even with lower rice consumption, because the cancer slope factor for these groups are higher. The evaluation system used here is not appropriate to get an exact risk calculation, because 
some health-relevant elements are not included. However, the system helps to get a relative risk contribution of every harmful substance and allows to compare the risk for different rice samples. Altogether, at least the elements $\mathrm{As}, \mathrm{Cd}, \mathrm{Mn}$, and $\mathrm{Pb}$ should be investigated as basis for risk assessment studies. Especially for these elements further possibilities to lower their uptake by rice grains should be explored.

\subsection{Conclusion}

101 paddy soil and rice plant samples were collected in the Red River Delta in northern, Huong River area in the center, and Mekong River Delta in southern Vietnam. The soils contain comparable alluvial parent materials, verified by similar main, minor and trace element concentrations. However, soil parameters like $\mathrm{Eh} / \mathrm{pH}$-values, concentrations of sorbents such as organic matter, Fe-oxides/hydroxides and clay minerals can lead to great differences of element transferability into rice plants. Huong River soils are acidic $(\mathrm{pH}=4.2-4.7)$, Mekong River soils are acidic to nearly neutral ( $\mathrm{pH}=3.7-6.8)$, and Red River soils are mostly circumneutral ( $\mathrm{pH}=4.8$ - 7.3). Mekong River soils contain a higher concentrations of organic matter (10.3\%) compared to Red River soils (6.5\%) and Huong River soils (6.4\%). Soluble organic complexes are suggested to be responsible for the high $\mathrm{Pb}$ concentration (average $0.17 \mathrm{mg} \mathrm{kg}^{-}$

${ }^{1}$ ), especially in Mekong River grains. The application of large amounts of phosphate fertilizers might be a reason of the high Cd concentration in Red River grains (average $0.116 \mathrm{mg} \mathrm{kg}^{-1}$ ). The As concentrations in Huong River grains (average $0.27 \mathrm{mg} \mathrm{kg}^{-1}$ ) are possibly caused by stronger dissolution of Fe-oxides/hydroxides as the main sorbents for As at low soil $\mathrm{pH}$-values.

Elements are transported within the plant through the xylem and phloem sap. During this process, cations interact with negatively charged cell walls decreasing their transfer rate on their way from root to grain. For this reason, concentrations of most elements gradually decrease with increasing distance from the root in the order: shoot $>$ husk > grain. Exceptions are $\mathrm{Cd}, \mathrm{Mg}, \mathrm{Zn}, \mathrm{S}, \mathrm{Cu}$, and $\mathrm{Mo}$, whose concentrations decrease in the order: shoot > grain > husk. In particular, the $\mathrm{P}$ concentration decreases in the order grain $>$ shoot $>$ husk. The preferential transfer of S, Mo, and $\mathrm{P}$ into the grain is probably due to their anionic character and their electrostatic repulsion at negative loaded cell walls. The transport of $\mathrm{Cu}, \mathrm{Zn}$ and $\mathrm{Ni}$ into the grains may be facilitated by the formation of soluble organic complexes in the sap.

Health risk calculations on basis of the daily intake of $\mathrm{As}, \mathrm{Cd}, \mathrm{Pb}, \mathrm{Cu}, \mathrm{Mn}, \mathrm{Mo}$, and $\mathrm{Ni}$ by rice consumption indicate, that all unpolished rice grains are within unsafe levels of noncancer risk with chronic cumulative Hazard Indexes (HI) between 1.4 and 8.4 (one sample even 
reaching 21). The risk level $\mathrm{HI}=1$ should not be exceeded. $18 \%$ of all samples surpass the high risk level of HI = 5 in Huong River area 2 out of 4, Red River area 26\%, and the Mekong River area $14 \%$. The elements $\mathrm{Cd}, \mathrm{As}, \mathrm{Mn}$, and $\mathrm{Pb}$ are main contributors to the HI-value covering 64 - 97\% of the HI (average 86\%). These elements should be included into any health risk study for rice consumption. Further possibilities to lower their uptake by rice grains should be explored.

The cancer risk index ( $\sum \mathrm{ILCR}$ ) of As and $\mathrm{Pb}$ fluctuates from $0.9 \times 10^{-3}$ to $6.4 \times 10^{-3}$ (mean $2.2 \times 10^{-3}$ ). It is considerably higher than the acceptable cancer risk threshold of $10^{-4}$ and $10^{-6}$. Mean $\sum$ LCR-values are $2.1 \times 10^{-3}$ for Mekong River grain, $2.4 \times 10^{-3}$ for Red River grain, and $3.1 \times 10^{-3}$ for Huong River grain. Arsenic is the most potential carcinogenic risk factor for Vietnam rice.

\subsection{Acknowledgement}

The authors thank the Department Sedimentology \& Environmental Geology, Faculty of Geoscience and Geography, Göttingen University for providing chemicals and instruments for the analytical work. The Vietnamese government kindly supported the stay of Thuy Phuong Nguyen at Göttingen University with a research grant.

\subsection{Supplementary material}

The supplementary material is presented in Appendix A3

\subsection{References}

Abedin MJ, Feldmann J, Meharg AA (2002) Uptake Kinetics of Arsenic Species in Rice Plants. Plant Physiology, 128:1120-1128. https://doi.org/10.1104/pp.010733.

Bhattacharya P, Samal AC, Majumdar J, Santra SC (2010) Arsenic Contamination in Rice, Wheat, Pulses, and Vegetables: A Study in an Arsenic Affected Area of West Bengal, India. Water, Air, \& Soil Pollution, 213:3-13. https://doi.org/10.1007/s11270-010-0361-9.

Biswas A, Biswas S, Santra SC (2013) Arsenic in irrigated water, soil, and rice: perspective of the cropping seasons. Paddy and Water Environment, 12:407-412. https://doi.org/10.1007/s10333-013-0396-9.

Blume HP, Brümmer GW, Fleige H, Horn R, Kandeler E, Kögel-Knabner I et al (2016) Soil Science (16th ed.). Springer, Germany 
Chi Y, Li F, Tam NF, Liu C, Ouyang Y, Qi X et al (2018) Variations in grain cadmium and arsenic concentrations and screening for stable low-accumulating rice cultivars from multi-environment trials. Science of the Total Environment, 643:1314-1324. https://doi.org/10.1016/j.scitotenv.2018.06.288.

Du F., Yang Z, Liu P, Wang L (2018) Accumulation, translocation, and assessment of heavy metals in the soil-rice systems near a mine-impacted region. Environmental Science and Pollution Research, 25:32221-32230. https://doi.org/10.1007/s11356-018-3184-7.

Duan G, Shao G, Tang Z, Chen H, Wang B, Tang Z et al (2017) Genotypic and Environmental Variations in Grain Cadmium and Arsenic Concentrations Among a Panel of High Yielding Rice Cultivars. Rice, 10:9-9. https://doi.org/10.1186/s12284017-0149-2.

EFSA (2009) Cadmium in food - Scientific opinion of the Panel on Contaminants in the Food Chain. EFSA Journal, 7:980. https://doi.org/10.2903/j.efsa.2009.980.

EFSA (2010) Scientific Opinion on Lead in Food - EFSA Panel on Contaminants in the Food Chain (CONTAM). EFSA Journal, 8:1570. https://doi.org/10.2903/j.efsa.2010.1570.

Fakhri Y, Bjørklund G, Bandpei AM, Chirumbolo S, Keramati H, Hosseini PR et al (2018) Concentrations of arsenic and lead in rice (Oryza sativa L.) in Iran: A systematic review and carcinogenic risk assessment. Food and Chemical Toxicology, 113:267-277. https://doi.org/10.1016/j.fct.2018.01.018.

Greger M (2004) Metal Availability, Uptake, Transport and Accumulation in Plants. In M. N. V. Prasad (ed), Heavy Metal Stress in Plants from Biomolecules to Ecosystems (2nd ed), pp 1-27. Springer, Berlin.

Ha CTT (2011) Survey on heavy metals contaminated soils in Thai Nguyen and Hung Yen provinces in Northern Vietnam. Journal of Vietnamese Environment, 1:34-39. https://doi.org/10.13141/jve.vol1.no1.pp34-39.

Herawati N, Suzuki S, Hayashi K, Rivai IF, Koyama H (2000) Cadmium, Copper, and Zinc Levels in Rice and Soil of Japan, Indonesia, and China by Soil Type. Bulletin of Environmental Contamination and Toxicology, 64:33-39. https://doi.org/10.1007/s001289910006.

Hu M, Li F, Liu C, Wu W (2015) The diversity and abundance of As(III) oxidizers on root iron plaque is critical for arsenic bioavailability to rice. Scientific reports 5:1361113611. https://doi.org/10.1038/srep13611. 
Huong NTL, Ohtsubo M, Li L, Higashi T, Kanayama M, Nakano A (2008) Heavy metal contamination of soil and rice in wastewater-irrigated paddy field in a suburban area of Hanoi, Vietnam. Clay Science, 13:205-215. https://doi.org/10.11362/jcssjclayscience1960.13.205.

Islam S, Rahman MM, Islam MR, Naidu R (2016) Arsenic accumulation in rice: Consequences of rice genotypes and management practices to reduce human health risk. Environ Int, 96:139-155. https://doi.org/10.1016/j.envint.2016.09.006.

Jaishankar M, Tseten T, Anbalagan N, Mathew BB, Beeregowda KN (2014) Toxicity, mechanism and health effects of some heavy metals. Interdisciplinary Toxicology, 7:6072. https://doi.org/10.2478/intox-2014-0009.

Järup L (2003) Hazards of heavy metal contamination. British Medical Bulletin, 68:167-182. https://doi.org/10.1093/bmb/ldg032.

Jessen S, Postma D, Larsen F, Nhan PQ, Hoa LQ, Trang PTK et al (2012) Surface complexation modeling of groundwater arsenic mobility: Results of a forced gradient experiment in a Red River flood plain aquifer, Vietnam. Geochimica et Cosmochimica Acta, 98:186-201. https://doi.org/10.1016/j.gca.2012.07.014.

Kabata-Pendias A (2011) Trace Elements in Soils and Plants. CRC Press, Boca Raton, London, New York.

Khan NI, Owens G, Bruce D, Naidu R (2009) Human arsenic exposure and risk assessment at the landscape level: a review. Environ Geochem Health, 31:143-166. https://doi.org/10.1007/s10653-008-9240-3.

Kumar S, Sangwan P, Dhankhar R, Mor V, Bidra S (2013) Utilization of Rice Husk and Their Ash: A Review. Research Journal of Chemical and Environmental Sciences, 1:126-129.

Kumarathilaka P, Seneweera S, Meharg A, Bundschuh J (2018) Arsenic speciation dynamics in paddy rice soil-water environment: sources, physico-chemical, and biological factors - A review. Water Research, 140:403-414. https://doi.org/10.1016/j.watres.2018.04.034.

Kunhikrishnan A, Go WR, Park JH, Kim KR, Kim HS, Kim KH et al (2015) Heavy Metal(loid) Levels in Paddy Soils and Brown Rice in Korea. Korean Journal of Soil Science and Fertilizer, 48. https://doi.org/10.7745/KJSSF.2015.48.5.515. 
Kuramata M, Abe T, Matsumoto S, Ishikawa S (2011) Arsenic accumulation and speciation in Japanese paddy rice cultivars. Soil Science and Plant Nutrition, 57:248-258. https://doi.org/10.1080/00380768.2011.565479.

Li H, Luo N, Li YW, Cai QY, Li HY, Mo CH et al (2017) Cadmium in rice: Transport mechanisms, influencing factors, and minimizing measures. Environ Pollut, 224:622630. https://doi.org/10.1016/j.envpol.2017.01.087.

Liu JG, Mei ZX, Xin WM (2011) Concentration of Cadmium in Different Rice Cultivars. Advanced Materials Research, 356-360:259-262. https://doi.org/10.4028/www.scientific.net/AMR.356-360.259.

Lombi E, Scheckel KG, Pallon J, Carey AM, Zhu YG, Meharg AA (2009) Speciation and distribution of arsenic and localization of nutrients in rice grains. New Phytologist, 184:193-201. https://doi.org/10.1111/j.1469-8137.2009.02912.x.

Ma L, Wang L, Jia Y, Yang Z (2017) Accumulation, translocation and conversion of six arsenic species in rice plants grown near a mine impacted city. Chemosphere, 183:4452. https://doi.org/10.1016/j.chemosphere.2017.05.089.

Mao C, Song Y, Chen L, Ji J, Li J, Yuan X et al (2019) Human health risks of heavy metals in paddy rice based on transfer characteristics of heavy metals from soil to rice. Catena, 175:339-348. https://doi.org/10.1016/j.catena.2018.12.029.

Marschner P (2012) Marschner's Mineral Nutrition of Higher Plants, 3rd edn. Elsevier, UK USA.

McCauley A, Jones C, Olson-Rutz K (2017) Soil pH and organic matter. Nutrient Management 8. http://landresources.montana.edu/nm/documents/NM8.pdf. Accessed 27 March 2019.

Meharg AA, Zhao FJ (2012) Arsenic \& Rice. Springer, Dordrecht Heidelberg London New York.

Meng J, Zhong L, Wang L, Liu X, Tang C, Chen H et al (2018) Contrasting effects of alkaline amendments on the bioavailability and uptake of $\mathrm{Cd}$ in rice plants in a $\mathrm{Cd}$ contaminated acid paddy soil. Environmental Science and Pollution Research, 25:88278835. https://doi.org/10.1007/s11356-017-1148-y.

Moore KL, Schröder, M, Wu Z, Martin BGH, Hawes CR, McGrath SP et al (2011) Highresolution secondary ion mass spectrometry reveals the contrasting subcellular 
distribution of arsenic and silicon in rice roots. Plant Physiology, 156:913-924. https://doi.org/10.1104/pp.111.173088.

Mulware SJ (2013) Trace elements and carcinogenicity: a subject in review. 3 Biotech, 3:8596. https://doi.org/10.1007/s13205-012-0072-6.

Naito S, Matsumoto E, Shindoh K, Nishimura T (2015) Effects of polishing, cooking, and storing on total arsenic and arsenic species concentrations in rice cultivated in Japan. Food Chemistry, 168:294-301. https://doi.org/10.1016/j.foodchem.2014.07.060.

Nguyen TP, Ruppert H, Pasold T, Sauer B (2019a) Harmful and nutrient elements in paddy soils and their transfer into rice grains (Oryza sativa) along two river systems in northern and central Vietnam. Environ Geochem Health, 1-17. https://doi.org/10.1007/s10653-019-00333-3.

Nguyen TP, Ruppert H, Pasold T, Sauer B (2019b) Paddy soil geochemistry, uptake of trace elements by rice grains (Oryza sativa) and resulting health risks in the Mekong River Delta, Vietnam. Environ Geochem Health. Submitted manuscript

Nordberg GF, Fowler BA, Nordberg M (2015a) Toxicology of Metals: Overview, Definitions, Concepts, and Trends. In G. F. Nordberg, B. A. Fowler, M. Nordberg (ed) Handbook on the Toxicology of Metals (pp 3-14). Elsevier, UK.

Nordberg GF, Gerhardsson L, Mumtaz MM, Ruiz P, Fowler BA (2015b) Interactions and Mixtures in Metal Toxicology. In G. F. Nordberg, B. A. Fowler, M. Nordberg (ed) Handbook on the Toxicology of Metals (pp 213-238). Elsevier, UK.

Norton GJ, Williams PN, Adomako EE, Price AH, Zhu Y, Zhao FJ et al (2014) Lead in rice: Analysis of baseline lead levels in market and field collected rice grains. Science of the Total Environment, 485-486:428-434. https://doi.org/10.1016/j.scitotenv.2014.03.090.

OEHHA - Office of Environmental Health Hazard Assessment (2009) Technical Support Document for Cancer Potency Factors: Methodologies for derivation, listing of available values, and adjustments to allow for early life stage exposures. https://oehha.ca.gov/media/downloads/crnr/tsdcancerpotency.pdf. Accessed 1 March 2019.

Patel KS, Sahu B, Ramteke S, Bontempi E (2016) Contamination of Paddy Soil and Rice with Arsenic. Earth \& Environmental Sciences, 07:689-698. https://doi.org/10.4236/jep.2016.75061. 
Peoples Republic of China (2018). China Releases the Standard for Maximum Levels of Contaminants in Foods. Global Agricultural Information Network, GAIN Report CH18025, 17pp. USDA Foreign Agricultural Service.

https://gain.fas.usda.gov/Recent\%20GAIN\%20Publications/China\%20Releases\%20the \%20Standard\%20for\%20Levels\%20of\%20Contaminants\%20in\%20Foods\%20_Beijin g_China\%20-\%20Peoples\%20Republic\%20of_5-9-2018.pdf. Accessed 22 June 2019.

Phuong NM, Kang Y, Sakurai K, Iwasaki K, Kien CN, Noi NV et al (2010) Levels and Chemical Forms of Heavy Metals in Soils from Red River Delta, Vietnam. Water, Air, \& Soil Pollution, 207:319-332. https://doi.org/10.1007/s11270-009-0139-0.

Pospiech S, Fahlbusch W, Sauer B, Pasold T, Ruppert H (2017) Alteration of trace element concentrations in plants by adhering particles - Methods of correction. Chemosphere, 182:501-508. https://doi.org/10.1016/j.chemosphere.2017.05.038.

Postma D, Pham TKT, Sø HU, Hoang VH, Vi ML, Nguyen TT et al (2016) A model for the evolution in water chemistry of an arsenic contaminated aquifer over the last 6000years, Red River floodplain, Vietnam. Geochimica et Cosmochimica Acta, 195:277-292. https://doi.org/10.1016/j.gca.2016.09.014.

Rahman MA, Hasegawa H (2011) High levels of inorganic arsenic in rice in areas where arsenic-contaminated water is used for irrigation and cooking. Science of the Total Environment, 409:4645-4655. https://doi.org/10.1016/j.scitotenv.2011.07.068.

Rizwan M, Ali S, Adrees M, Rizvi H, Zia-ur-Rehman M, Hannan F et al (2016) Cadmium stress in rice: toxic effects, tolerance mechanisms, and management: a critical review. Environmental Science and Pollution Research, 23:17859-17879. https://doi.org/10.1007/s11356-016-6436-4.

Satpathy D, Reddy MV, Dhal SP (2014) Risk assessment of heavy metals contamination in paddy soil, plants, and grains (Oryza sativa L.) at the East Coast of India. BioMed research international, 2014:545473-545473. https://doi.org/10.1155/2014/545473.

Seyfferth AL, McCurdy S, Schaefer MV, Fendorf S (2014) Arsenic Concentrations in Paddy Soil and Rice and Health Implications for Major Rice-Growing Regions of Cambodia. Environmental Science \& Technology, 48:4699-4706. https://doi.org/10.1021/es405016t.

Seyfferth AL, Webb SM, Andrews JC, Fendorf S (2011) Defining the distribution of arsenic species and plant nutrients in rice (Oryza sativa L.) from the root to the grain. 
Geochimica et Cosmochimica Acta, 75:6655-6671.

https://doi.org/10.1016/j.gca.2011.06.029.

Shraim AM (2017) Rice is a potential dietary source of not only arsenic but also other toxic elements like lead and chromium. Arabian Journal of Chemistry, 10:S3434-S3443. https://doi.org/10.1016/j.arabjc.2014.02.004.

Simmons RW, Pongsakul P, Saiyasitpanich D, Klinphoklap S (2005) Elevated Levels of Cadmium and Zinc in Paddy Soils and Elevated Levels of Cadmium in Rice Grain Downstream of a Zinc Mineralized Area in Thailand: Implications for Public Health. Environ Geochem Health, 27:501-511. https://doi.org/10.1007/s10653-005-7857-z.

Smith AH, Marshall G, Yuan Y, Ferreccio C, Liaw J, von Ehrenstein O et al (2006) Increased mortality from lung cancer and bronchiectasis in young adults after exposure to arsenic in utero and in early childhood. Environmental health perspectives, 114:1293-1296. https://doi.org/10.1289/ehp.8832.

Sø, HU, Postma D, Vi ML, Pham TKT, Kazmierczak J, Dao VN et al (2018) Arsenic in Holocene aquifers of the Red River floodplain, Vietnam: Effects of sediment-water interactions, sediment burial age and groundwater residence time. Geochimica et Cosmochimica Acta, 225:192-209. https://doi.org/10.1016/j.gca.2018.01.010.

Sriprachote A, Kanyawongha P, Ochiai K, Matoh T (2012). Current situation of cadmiumpolluted paddy soil, rice and soybean in the Mae Sot District, Tak Province, Thailand. Soil Science and Plant Nutrition, 58:349-359. https://doi.org/10.1080/00380768.2012.686435.

Stuckey JW, Schaefer MV, Benner SG, Fendorf S (2015a) Reactivity and speciation of mineral-associated arsenic in seasonal and permanent wetlands of the Mekong Delta. Geochimica et Cosmochimica Acta, 171:143-155.

https://doi.org/10.1016/j.gca.2015.09.002.

Stuckey JW, Schaefer MV, Kocar BD, Benner SG, Fendorf S (2015b) Arsenic release metabolically limited to permanently water-saturated soil in Mekong Delta. Nature Geoscience. https://doi.org/10.1038/ngeo2589.

Suriyagoda LDB, Dittert K, Lambers H (2018) Mechanism of arsenic uptake, translocation and plant resistance to accumulate arsenic in rice grains. Agriculture, Ecosystems \& Environment, 253:23-37. https://doi.org/10.1016/j.agee.2017.10.017. 
USEPA (1989) Risk Assessment Guide for Superfund (RAGS): volume I, Human Health

Evaluation Manual-Part A, baseline risk assessment.

https://www.epa.gov/sites/production/files/2015-09/documents/rags_a.pdf. Accessed 19 March 2019.

Vinh NC, Oborn I, Ha PQ, Minh ND, Hough RL, Khai NM et al (2012) Potential

Environment and Public Health Risk Due to Contamination of Heavy Metals from Industrial Waste Water in Lam Thao, Phu Tho, Vietnam. American Journal of Environmental Sciences, 8:71-78.

Wan Y, Camara AY, Yu Y, Wang Q, Guo T, Zhu L et al (2018) Cadmium dynamics in soil pore water and uptake by rice: Influences of soil-applied selenite with different water managements. Environ Pollut, 240:523-533. https://doi.org/10.1016/j.envpol.2018.04.044.

Wang H, Xu C, Luo Z, Zhu H, Wang S, Zhu Q et al (2018) Foliar application of Zn can reduce $\mathrm{Cd}$ concentrations in rice (Oryza sativa L.) under field conditions.

Environmental Science and Pollution Research, 25:29287-29294. https://doi.org/10.1007/s11356-018-2938-6.

Xiao L, Guan D, Peart MR, Chen Y, Li Q, Dai J (2017) The influence of bioavailable heavy metals and microbial parameters of soil on the metal accumulation in rice grain. Chemosphere,185:868-878. https://doi.org/10.1016/j.chemosphere.2017.07.096

Ye W, Zhang J, Fan T, Lu H, Chen H, Li X et al (2017) Arsenic speciation in the phloem exudates of rice and its role in arsenic accumulation in rice grains. Ecotoxicology and Environmental Safety, 143:87-91. https://doi.org/10.1016/j.ecoenv.2017.05.006.

Young SD (2013) Chemistry of Heavy Metals and Metalloids in Soils. In B. J. Alloway (ed) Heavy Metals in Soils: Trace Metals and Metalloids in Soils and their Bioavailability, 3rd edn, 22. Springer, UK.

Zarcinas BA, Ishak CF, McLaughlin MJ, Cozens G (2004a) Heavy metals in soils and crops in Southeast Asia 1. Peninsular Malaysia. Environ Geochem Health, 26:343-357. https://doi.org/10.1007/s10653-005-4669-0.

Zarcinas BA, Pongsakul P, McLaughlin MJ, Cozens G (2004b) Heavy metals in soils and crops in Southeast Asia 2. Thailand. Environ Geochem Health, 26:359-371. https://doi.org/10.1007/s10653-005-4670-7. 
Chapter 6

\section{General conclusions and perspectives}




\section{General conclusions and perspectives}

110 soil samples and corresponding rice grain samples in the Mekong River, Red River, and Huong River area in Vietnam were analyzed for main and ultratrace elements to get information about the concentration, the soil-plant transfer of elements, enrichment of potentially harmful element and related health risks for the population. In addition, the husk and the aboveground rice plant collected in the Red River and Huong River area were also analyzed. The translocation of nutrient and harmful elements from soil into rice plants under varying soil conditions were discussed. This knowledge is a basis for understanding and helping limiting the uptake of harmful elements by rice. It is obvious that in some areas in Vietnam with increased burden of toxic elements in rice grains, the large consumption of local rice may cause chronic potential health risks for the population. The goals of this work are to contribute to a better comprehensive and systematic understanding of how the soil compositions determine the transfer of elements into rice.

\subsection{General conclusion}

\section{Soil geochemistry}

The paddy soils in the three river areas consist mainly of alluvial sediments, which consist of eroded materials transported by the rivers. Beside material from the surrounding mountains, the Red River contains suspended load from the Yunnan Plateau, the Mekong from the Tibetan Plateau, the Huong River from the Annamite Range of eastern Indochina Vietnam. Because geochemical data for these suspensions are not available, the main and trace element concentrations of the investigated paddy soils are compared with world-wide average concentration values of the upper earth crust and/or global shale data as proxies for the parent material. This comparison helps to decipher if the soils are contaminated by anthropogenic sources or if elements are lost by weathering. The following depletion or enrichment trends can be stated for the investigated paddy soils in Vietnam $(n=110)$ :

- Depleted element (decreasing depletion):

$\mathrm{Ca}, \mathrm{S}, \mathrm{Mg}, \mathrm{Ni}, \mathrm{Li}, \mathrm{Sr}, \mathrm{Mn}, \mathrm{Na}, \mathrm{K}$, $\mathrm{Mo}, \mathrm{Cr}, \mathrm{Ba}, \mathrm{Hf}, \mathrm{Co}, \mathrm{V}, \mathrm{Zr}, \mathrm{Fe}, \mathrm{Sb}$

- Elements with changes of less than $10 \%$ : $\mathrm{Cu}, \mathrm{Tl}, \mathrm{Sc}, \mathrm{Rb}, \mathrm{Al}, \mathrm{Ga}, \mathrm{Ti}, \mathrm{Si}$

- Enriched elements (increasing enrichment): P, Ce, Cs, Th, U, La, Nb, Sn, Pb, As, Cd, Bi. 
The paddy soils in three river areas have similar compositions, showing that the parent materials are comparable. There are, however, some distinguishable discrepancies in soil $\mathrm{pH}$ and $\mathrm{OM}$ content among the areas. The Huong River soils are acidic (mean $\mathrm{pH}=4.4$ ), the Mekong River soils weakly acidic (mean $\mathrm{pH}=5.0$ ), and Red River soils close to neutral (mean $\mathrm{pH}=6.2$ ). The soils in Mekong River have much higher OM contents (mean LOI 10.3\%) than Red River and Huong River soils (mean LOI 6.5\%).

In comparison with the average shale or upper Earth crust, elements such as $\mathrm{Ce}$, Th, As, La, U, Sn, Cs, and Bi are naturally enriched in the paddy soils. The slight enrichment of P, $\mathrm{Cd}$, and $\mathrm{Pb}$ can be attributed to fertilizer and emission inputs. However, nearly all of the potentially harmful elements are in the allowable levels of Vietnamese agricultural soil, except for As. $92 \%$ of the Red River soils, $20 \%$ of the Huong River soils, and $11 \%$ of the Mekong River soils exceed the Vietnamese permissible As limit of $15 \mathrm{mg} \mathrm{kg}^{-1}$. The average As concentration in the Red River soils is $22.5 \mathrm{mg} \mathrm{kg}^{-1}$, remarkably higher than those in Huong River soils (13.5 mg kg-1) and in Mekong River soils (12.6 mg kg-1). The obviously high As concentrations are probably delivered by the transported-river materials in combination with reducing processes in the rice fields. One possible enrichment mechanism may be: in the deeper reducing soil layer, As may be released in solution and subsequently be diffused into upper parts of the soil profile, where it may be enriched under the intermittent reducing and oxidizing conditions. Only a few of the investigated paddy soils show clear signs of strong anthropogenic contamination. Paddy soils close to a Lam Thao fertilizer and chemical factory in the Red River are polluted by factory effluents, delivering the dangerous elements $\mathrm{As}, \mathrm{Cd}, \mathrm{Cu}, \mathrm{Pb}, \mathrm{Zn}, \mathrm{Co}$, Mo, U, S, Cr, (and Fe). Two sites collected in the Red River bank are enriched in As, Bi, Cd, $\mathrm{Cu}, \mathrm{Mn}, \mathrm{Pb}, \mathrm{Sb}, \mathrm{Sn}, \mathrm{Zn}$, and rare-earth elements such as La and Ce. Reason for their enrichment may be the expoitation of the Adebo monazite $\left(\mathrm{Ce}\left[\mathrm{PO}_{4}\right]\right)$ mine in Jinping, the Yuanjiang Gold Mine, Grjiu Tin Mine, and Laojinshan Gold Mine in Yunnan Province, China.

Mainly highly significant positive correlations between the elements can be observed within the following groups: group $1-\mathrm{Ba}$, Ti, Th, K, Rb, Tl, Ga, V, Al, Sc, Cs, Fe, Mg, Nb, $\mathrm{Ce}$, and $\mathrm{La}$ (elements contained in silicates without quartz); group $2-\mathrm{Hf}$ and $\mathrm{Zr}$ (contained in the mineral zircon; both are immobile elements with identical loading and ionic diameter); group $3-\mathrm{Ca}, \mathrm{P}, \mathrm{Na}$, and $\mathrm{Sr}$ (fertilizer group); group 4 - organic matter (OM) and $\mathrm{S}(\mathrm{OM}$ is the main host for $\mathrm{S}$ as part of the $\mathrm{OM}$ or as sulfide associated with $\mathrm{OM}$ ). The main reason for the mostly highly significant positive correlation coefficients within the four groups is the varying 
amount of quartz and/or bio-opal in the soil samples. Increasing concentrations of these phases dilute the elements within the groups and cause spurious correlations.

The concentrations of trace elements in the paddy soils can be related to the the main soil phases: pH, OM, Al-, Fe-, and Mn-phases, which govern the binding, sorption, and coprecipitation of trace elements in soil and thus impact the trace element phytoavailability. Multiple regression analysis between these main soil factors and trace element concentration shows the visible associations as follows: Fe-phases: Co, As, Cd, and Sb; Al-phases: Tl, V, Bi, $\mathrm{Sn}, \mathrm{Pb}, \mathrm{U}, \mathrm{Ni}, \mathrm{Zn}, \mathrm{Cu}$; and $\mathrm{OM}$ : Mo and $\mathrm{S}$. It must be taken into account that the soil parameters also mutually interact. For example, soil $\mathrm{pH}$ affects the formation or dissolution of Fe-, Al-, and Mn-phases, and the microbial oxidation of OM. The influence of the changing redox conditions could not be included into the calculations, because the Eh values are highly variable during the growing season and could not be measured continuously.

\section{Transferability and distribution of elements into rice plant}

After taken up by root, osmoregulation and mass flux drive the translocation of elements within the rice plant. The flow rate and composition of xylem and phloem sap, element concentration and species, interactions between elements and cell wall (such as selective binding, cation exchange, adsorption and/or desorption processes on cell wall), synergistic and antagonistic effects among elements are the main mechanisms determining the element concentrations in the different plant parts. These interactions are very complicated and difficult to determine.

Due to ion exchange with the negatively charged cell walls in xylem, most cationic element concentrations tend to decrease in rice plants with increasing distance from the root, except for $\mathrm{P}, \mathrm{Mo}, \mathrm{Ni}$, and $\mathrm{Cu}$. Most of elements are dominantly concentrated in shoot (they may accumulate $50-95 \%$ of the total element mass of the aboveground plant). In contrast, P, $\mathrm{Mo}, \mathrm{Ni}$, and $\mathrm{Cu}$ are more stored in the grains than in the shoot. Besides, $\mathrm{S}, \mathrm{Mg}$, and $\mathrm{Zn}$ are also transported quite easily to the grain. This is because $\mathrm{Ni}, \mathrm{Mg}, \mathrm{Zn}$, and $\mathrm{Cu}$ may be transported in xylem sap as soluble organic complexes facilitating their translocation. The elements S, Mo, and $\mathrm{P}$ exist as anions sulfate, molybdate, and phosphate respectively, which are repelled at the negatively charged cell, facilitating their transport within the plant. 
Most elements have higher concentrations in husk than in grain while $\mathrm{Cu}, \mathrm{Cd}, \mathrm{S}, \mathrm{Zn}, \mathrm{P}$, $\mathrm{Mg}$, and Mo accumulate more in grain.

Physiological transfer factors (TF) from soil to the whole aboveground plant cover a very broad range from $<0.00001$ to 7.2 . Elements like Ti, Zr, Hf, and lanthanides have extremely low TF, whereas $\mathrm{P}, \mathrm{S}$, and Mn are taken up by the plant very easily (TF $>1$ ). Harmful elements like $\mathrm{Pb}, \mathrm{As}, \mathrm{Cd}$, and $\mathrm{Mn}$ show a very broad spread of TFs (from average 0.008 to 1.02). Even for one single element, its uptake ability may extremely alter with a spread of transfer factors possibly up to 250 -fold ( $\mathrm{Cs}$ and $\mathrm{Na}$ ). The great discrepancies may be related to the sensibility of the element phytoavailability under varying soil conditions. Particularly, the transfer factors of $\mathrm{As}, \mathrm{Pb}$, and $\mathrm{Cd}$ are easily controlled by the soil parameters. This opens up the possibilities to limit their uptake by altering soil factors.

Many soil parameters have inhibitive roles in the element uptake. Sorption, complexing and/or coprecipitation of trace elements on surface of OM, oxides/hydroxides, and clay minerals lead to a decrease in the trace element bioavailability. With regard to the soil factor $\mathrm{pH}$, most cationic elements are solubilized and released in acidic soils, fostering their transferability to plant, whereas in alkaline soils the precipitation of sorbents (oxides/hydroxides) and increased sorption at higher $\mathrm{pH}$ are responsible for a decreasing transfer factor. Especially, the uptake of the harmful elements $\mathrm{Cd}$, and $\mathrm{Mn}$ in rice grains may be restricted partially by increasing the soil $\mathrm{pH}$.

The dissimilarity of potentially harmful elements in rice grain in three studied regions are summarized as follows:

(1) Mn and As concentrations in Huong River and Mekong River rice grains are similar and higher than in Red River grain, probably relating to differing soil $\mathrm{pH}$-values;

(2) The higher Cd concentrations in rice grains of Red River and Huong River compared to Mekong River's grains is probably due to the amount of used phosphate fertilizer which mostly contains high Cd concentrations;

(3) The average 1.6 times higher content of OM in Mekong River soils is possibly responsible for the visibly higher $\mathrm{Pb}$ concentration in Mekong River rice grain.

\section{Health risks of rice consumption}

The exposure to different harmful elements by eating rice was evaluated for the three studied areas. The permissible Maximum Concentrations (MC) of $\mathrm{iAs}, \mathrm{Cd}$, and $\mathrm{Pb}$ in rice grain 
proposed by the European Union (2006) and FAO/WHO (2014) are used in this study to assess their health risks. Rice grains in Red River and Huong River areas are within the MC of 0.37 $\mathrm{mg}$ iAs kg${ }^{-1}$ (assumption that the portion of iAs is $54 \%$ of the tAs according to Suriyagoda et al. 2008) while $5 \%$ of Mekong River grains exceed this MC. $16 \%$ of the Red River grains surpass the $\mathrm{MC}$ for $\mathrm{Cd}$ of $0.2 \mathrm{mg} \mathrm{kg}^{-1}$ whilst rice grains in Mekong River and Huong River zones are below this limit. $24 \%$ of the Mekong River grains exceed the $\mathrm{MC}$ for $\mathrm{Pb}$ of $0.2 \mathrm{mg}$ $\mathrm{kg}^{-1}$, whereas all grains $\mathrm{Pb}$ in the two other regions contain less than $0.02 \mathrm{mg} \mathrm{kg}^{-1}$.

The tolerable Upper Intake Levels (ULs) for all sources ruled by EFSA are compared with the intake of harmful element by rice consumption. Three of the four rice samples in Huong River, $10 \%$ in Red River, and $12 \%$ in Mekong River exceed the UL of As. Two of four rice grains in Huong River, $40 \%$ in Red River, and $29 \%$ in Mekong River may induce $\mathrm{Cd}$-related health risks. There is no Pb risks for inhabitants in the Red River and Huong River area, but $27 \%$ of the rice grains from the Mekong River area may generate health risks for the people there.

For the cumulative non-cancer risks of the elements $\mathrm{As}, \mathrm{Cd}, \mathrm{Pb}, \mathrm{Co}, \mathrm{Cu}, \mathrm{Mn}, \mathrm{Mo}$, and $\mathrm{Ni}$, all rice grains have a chronic cumulative Hazard Indexes $(\mathrm{HI}) \geq 1.4$, higher than the safe level of 1 as suggested by USEPA (1989). Red River and Huong River rice grains result in more adverse reactions than Mekong River rice grain. The sum of risk indices of $\mathrm{Cd}, \mathrm{As}, \mathrm{Pb}$, and Mn contribute $64-97 \%$ to the HI-value, in which Cd is generally the highest contributor.

For the cumulative oral cancer risks of $\mathrm{As}$ and $\mathrm{Pb}$, all samples overshoot the acceptable cumulative Incremental Lifetime Cancer Risk ( $\sum$ ILCR) of from $10^{-4}$ to $10^{-6}$ according to USEPA (1989). The $\sum$ ILCR values fluctuate from $0.9 \times 10^{-3}$ to $6.4 \times 10^{-3}$ (average $2.2 \times 10^{-3}$ ) corresponding to a high level of cancer risk. Of these two elements, As contributes is the vast majority of up to $96 \%$ of $\sum \mathrm{ILCR}$ while $\mathrm{Pb}$ is a negligible factor with below $4 \%$. Huong River people are facing the higher cancer risk from rice than the others.

All values calculated in this study are derived from unpolished rice grains, which usually contain the larger amount of beneficial compounds to health (vitamins, protein, fibers, beneficial, nutrient elements) than polished rice grains (Reddy et al. 2017). However, unpolished rice also includes the higher concentration of harmful elements (especially As) than polished rice. Therefore, these health risk assessments may be a little bit different depending on kind of used rice. To restrict the As intake in contaminated area, washing carefully rice with 
water that is low As concentration is suggested (eliminate partially As-containing bran) (Sun et al. 2012; Halder et al. 2014).

If permissible MCs are recalculated into Tolerable Upper Intake Levels (UL), even the consumption of rice with harmful elements satisfying the MC guideline may also exceed the ULs for Asian population. A simple calculation for a Vietnamese shows this critical dilemma: if a person eats every day $420 \mathrm{~g}$ rice containing the maximum permitted concentration of 0.2 $\mathrm{mg} \mathrm{kg}^{-1}$ for iAs, $\mathrm{Cd}$, and $\mathrm{Pb}, 0.076 \mathrm{mg}$ of each element would be able to enter the human body. Meanwhile, the ULs calculated for a Vietnamese adult should not surpass $0.110,0.019,0.077$ $\mathrm{mg}$ per day for iAs, $\mathrm{Cd}$, and $\mathrm{Pb}$ respectively. Especially for $\mathrm{Cd}$, its allowable concentration value for rice grains should be nearly 4 time lower to fit the upper intake level. A harmonization of regulations between the ULs and MCs is urgent especially for the health situation of large rice-consuming communities. Thus, the regulation for rice's MCs need be related to the local rice consumption. For example, the MCs ruled in China, a country consuming much larger amount of rice $\left(210 \mathrm{~g} \mathrm{day}^{-1}\right.$ person $\left.^{-1}\right)$ than the European Union $\left(15.6 \mathrm{~g} \mathrm{day}^{-1}\right.$ person $\left.^{-1}\right)$, are the same as these in Europe (Peoples Republic of China 2018). Instead of $0.2 \mathrm{mg} \mathrm{kg}^{-1}$, the MC of Cd should be below $0.1 \mathrm{mg} \mathrm{kg}^{-1}$ for Chinese and $0.5 \mathrm{mg} \mathrm{kg}^{-1}$ for Vietnamese.

\subsection{An outlook}

In view of the importance for paddy soil and rice as the main staple food for billions of people, further research activities should focus on the following issues:

- Improvement in the knowledge base, especially for rice grown in areas with anthropogenic contamination and in regions with high As concentrations in irrigation water and soil.

- Soil concentrations of $\mathrm{As}, \mathrm{Cd}$, and $\mathrm{Pb}$ do not allow to predict the expected concentration in rice grains, even if soil $\mathrm{pH}$, mineral, and organic phases are taken into consideration. Rice grains from non- or low-polluted soils far below allowed soil limits may surpass critical health levels. Not the soils but the rice grains should be investigated in single areas to get information about health relevance.

- Intensification of research on how to decrease the transfer of harmful elements from contaminated soils into the rice plant. For example, to prevent As transfer from As-rich soils into rice grains, Suriyagoda et al. (2018) proposed the cultivation of rice under aerobic, intermittent flooding or alternate wetting or drying conditions. Under such conditions, $\mathrm{Fe}$ oxides/hydroxides precipitate and bind As. Thus, the availability of As plant is lowered. In 
addition, the presence of Fe-oxides/hydroxides increases the sorption of other critical elements. To reduce the enrichment of $\mathrm{Cd}$ and As in grains that are grown in acidic soils, soil $\mathrm{pH}$ should be increased to 6.5 in order to improve sorption and to diminish the uptake of these elements.

- Careful revision and harmonization of the tolerable upper intake level and the maximum concentrations limits for As and $\mathrm{Cd}$ in rice to prevent contradictory results (Sauvé 2014). Future studies should focus on As speciation, as well as on As and Cd intake and their health risks.

- Rice cultivars should be systematically tested for the uptake of critical elements (Islam et al. 2016; Xie et al. 2017; Yang et al. 2018).

In future studies, the combination of interacting parameters must be investigated in much more detail to get a better basis for improving practical cultivation and management measures in order to mitigate the accumulation of potentially toxic elements in rice. These parameters are: AWD, role of soil conditioners, redox conditions, $\mathrm{pH}$-value, pore water geochemistry, the concentration of reactive $\mathrm{Si}$ and phosphate, influence of cultivars, ROL, formation and composition of plaque, the phases in the rhizosphere soil, the kind and role of iron and organic phases for sorption etc. It should be taken in mind, that a measure minimizing the uptake of one critical element such as As into the rice plant may increase the uptake of another critical element such as $\mathrm{Cd}$, as observed for water management (AWD) practices (Seyfferth et al. 2018).

This kind of research should be complemented by systematic physiological, microbiological, biochemical and species investigations, elucidating the mechanisms behind the transfer of toxic elements from the soil into the rice plant and within the plant - as shown by Kumarathilaka et al. (2018), Wang et al. (2019) and Panthri and Gupta (2019) for As, and by Fahad et al. (2019), Pandey and Dubey (2019), and Roychowdhury et al. (2019) for additional critical elements. Further research is needed to understand the interactions between different elements, the role of pore water chemistry, microbial processes, and speciation of the elements, as well as the plant uptake and accumulation mechanisms especially in rice grains. The resulting new knowledge should help to mitigate the impact of harmful elements on the population but also to understand much better their transfer mechanisms in the soil-water-plant system.

For areas with high concentrations of toxic elements in rice grains, it should be surveyed, if other crops with a lower critical element uptake can be alternatively cultivated. 


\subsection{References}

Fahad, S., Rehman, A., Shahzad, B., Tanveer, M., Saud, S., Kamran, M., Ihtisham, M., Khan, S. U., Turan, V., \& ur Rahman, M. H. (2019). Rice responses and tolerance to metal/metalloid toxicity. In Hasanuzzaman, M., Fujita, M., Nahar, K., \& Biswas, J. K. (Eds.), Advances in Rice Research for Abiotic Stress Tolerance (pp. 299-312). Woodhead Publisher, Elsevier. https://doi.org/10.1016/B978-0-12-814332-2.00014-9.

Halder, D., Biswas, A., Šlejkovec, Z., Chatterjee, D., Nriagu, J., Jacks, G., et al. (2014). Arsenic species in raw and cooked rice: Implications for human health in rural Bengal. Science of the Total Environment, 497-498:200-208. https://doi.org/10.1016/j.scitotenv.2014.07.075.

Islam S, Rahman MM, Islam MR, Naidu R (2016) Arsenic accumulation in rice: Consequences of rice genotypes and management practices to reduce human health risk. Environ Int, 96:139-155. https://doi.org/10.1016/j.envint.2016.09.006.

Kumarathilaka, P., Seneweera, S., Meharg, A., \& Bundschuh, J. (2018). Arsenic accumulation in rice (Oryza sativa L.) is influenced by environment and genetic factors. Science of The Total Environment, 642: 485-496. https://doi.org/10.1016/j.scitotenv.2018.06.030.

Pandey, P. \& Dubey, R.S. (2019). Metal toxicity in rice and strategies for improving stress tolerance. In Hasanuzzaman, M., Fujita, M., Nahar, K., \& Biswas, J.K. (Eds.): Advances in Rice Research for Abiotic Stress Tolerance (pp. 313-339). Woodhead Publisher, Elsevier. https://doi.org/10.1016/B978-0-12-814332-2.00015-0.

Panthri, M. \& Gupta, M. (2019). Plausible strategies to reduce arsenic accumulation in rice. In Hasanuzzaman, M., Fujita, M., Nahar, K., \& Biswas, J.K. (Eds.): Advances in Rice Research for Abiotic Stress Tolerance (pp. 371-384). Woodhead Publisher, Elsevier. https://doi.org/10.1016/B978-0-12-814332-2.00017-4.

Peoples Republic of China (2018). China Releases the Standard for Maximum Levels of Contaminants in Foods. Global Agricultural Information Network, GAIN Report CH18025, 17pp. USDA Foreign Agricultural Service.

https://gain.fas.usda.gov/Recent\%20GAIN\%20Publications/China\%20Releases\%20the \%20Standard\%20for\%20Levels\%20of\%20Contaminants\%20in\%20Foods\%20_Beijin g_China\%20-\%20Peoples\%20Republic\%20of_5-9-2018.pdf. Accessed 22 July 2019. 
Reddy, C.K., Kimi, L., Haripriya, S., \& Kang, N. (2017). Effects of Polishing on Proximate Composition, Physico- Chemical Characteristics, Mineral Composition and Antioxidant Properties of Pigmented Rice. Rice Science, 24(5):241-252. https://doi.org/10.1016/j.rsci.2017.05.002.

Roychowdhury, R., Khan, M. H., \& Choudhury, S. (2019). Chapter 16 - Physiological and Molecular Responses for Metalloid Stress in Rice-A Comprehensive Overview. In M. Hasanuzzaman, M. Fujita, K. Nahar, \& J. K. Biswas (Eds.), Advances in Rice Research for Abiotic Stress Tolerance (pp. 341-369): Woodhead Publishing.

Sauve', S. (2014). Time to revisit arsenic regulations: Comparing drinking water and rice. BMC Public Health, 14, 465. https://doi.org/10.1186/1471-2458-14-465.

Seyfferth, A. L., Limmer, M. A., \& Dykes G. E. (2018). Chapter Two - On the Use of Silicon as an Agronomic Mitigation Strategy to Decrease Arsenic Uptake by Rice. Advances in Agronomy, 149:49-91. https://doi.org/10.1016/bs.agron.2018.01.002.

Sun, G.-X., Van de Wiele, T., Alava, P., Tack, F., \& Du Laing, G. (2012). Arsenic in cooked rice: Effect of chemical, enzymatic and microbial processes on bioaccessibility and speciation in the human gastrointestinal tract. Environ Pollut, 162:241-246. https://doi.org/10.1016/j.envpol.2011.11.021.

Suriyagoda, L. D. B., Dittert, K., \& Lambers, H. (2018). Mechanism of arsenic uptake, translocation and plant resistance to accumulate arsenic in rice grains. Agriculture, Ecosystems \& Environment, 253:23-37. http://doi.org/10.1016/j.agee.2017.10.017.

Wang, M., Tang, Z., Chen, X.-P., Wang, X., Zhou, W.-X., Tang, Z., Zhang, J., Zhao, F.-J. (2019). Water management impacts the soil microbial communities and total arsenic and methylated arsenicals in rice grains. Environmental Pollution, 247: 736-744. https://doi.org/10.1016/j.envpol.2019.01.043.

Xie, L. H., Tang, S. Q., Wei, X. J., Shao, G. N., Jiao, G. A., Sheng, Z. H., et al. (2017). The cadmium and lead content of the grain produced by leading Chinese rice cultivars. Food Chemistry, 217:217-224. https://doi.org/10.1016/j.foodchem.2016.08.099.

Yang, Y., Chen, J., Huang, Q., Tang, S., Wang, J., Hu, P., et al. (2018). Can liming reduce cadmium $(\mathrm{Cd})$ accumulation in rice (Oryza sativa) in slightly acidic soils? Can liming reduce cadmium $(\mathrm{Cd})$ accumulation in rice (Oryza sativa) in slightly acidic soils. Chemosphere, 193:547-556. https://doi.org/10.1016/j.chemosphere.2017.11.061. 


\section{$\underline{\text { Appendix }}$}




\section{Appendix A1: Supplementary Material for Chapter 3}

Table A1.1 Compilation of wavelengths used by ICP-OES and masses by ICP-MS for the quantification of single elements in soil and plant samples, as well as percentage deviations of measured element concentrations from certified/recommended values of in-house or international reference samples Wissenbach slate TW45, lake sediment GSJ-JLk-1, bush branches and leaves NCS DC 73349, and maize plant WEPAL-IPE-126

\begin{tabular}{|c|c|c|c|c|c|c|c|c|}
\hline \multirow[t]{3}{*}{ Element } & \multicolumn{4}{|c|}{ For soil } & \multicolumn{4}{|c|}{ For grain } \\
\hline & \multirow{2}{*}{$\begin{array}{l}\text { ICP-OES } \\
\text { (wavelength: } \\
\mathrm{nm} \text { ) }\end{array}$} & \multirow{2}{*}{$\begin{array}{l}\text { ICP-MS } \\
\text { (mass) }\end{array}$} & \multicolumn{2}{|c|}{ Deviation (\%) } & \multirow{2}{*}{$\begin{array}{l}\text { ICP-OES } \\
\text { (wavelength: } \\
\mathrm{nm} \text { ) }\end{array}$} & \multirow{2}{*}{$\begin{array}{l}\text { ICP-MS } \\
\text { (mass) }\end{array}$} & \multicolumn{2}{|c|}{ Deviation (\%) } \\
\hline & & & $\begin{array}{r}\text { TW-45 } \\
(\mathrm{n}=2)\end{array}$ & $\begin{array}{r}\text { GSJ-JLK-1 } \\
(\mathrm{n}=2)\end{array}$ & & & $\begin{array}{r}\text { NCS-DC-73349 } \\
(\mathrm{n}=4)\end{array}$ & $\begin{array}{r}\text { WEPAL-IPE-126 } \\
(\mathrm{n}=2)\end{array}$ \\
\hline$\overline{\mathrm{Al}}$ & 396.152 & & 0.3 & 1.5 & 396.152 & & -0.4 & 2.5 \\
\hline As & & 75 & 5.7 & -6.1 & & 75 & -0.3 & 4.9 \\
\hline $\mathrm{Ba}$ & 455.403 & & -3.2 & -0.7 & & 135 & -1.2 & 9.5 \\
\hline $\mathrm{Bi}$ & & 209 & -4.7 & 1.6 & & 209 & -14.7 & -12.6 \\
\hline $\mathrm{Ca}$ & 422.673.rad & & 2.2 & 1.4 & 317.933.rad & & -3.0 & -4.5 \\
\hline $\mathrm{Cd}$ & & 111 & 14.7 & -2.0 & & 114 & -2.0 & -5.7 \\
\hline $\mathrm{Ce}$ & 413.765 & & -0.5 & -3.2 & & 140 & 6.2 & 9.7 \\
\hline Co & 230.786 & & -3.1 & 1.6 & 230.786 & & -5.6 & -0.6 \\
\hline $\mathrm{Cr}$ & 205.560 & & -12.2 & 2.0 & 205.560 & & 10.0 & -1.9 \\
\hline Cs & & 133 & -7.0 & -7.0 & & 133 & -7.5 & -0.3 \\
\hline $\mathrm{Cu}$ & 327.395 & & 1.1 & 1.8 & & 63 & 1.4 & -0.03 \\
\hline $\mathrm{Fe}$ & 259.940 & & -1.8 & -2.5 & 238.204 & & -15.1 & -5.7 \\
\hline $\mathrm{Ga}$ & 294.363 & & 5 & 8.4 & - & - & - & - \\
\hline $\mathrm{Hf}$ & & 178 & -10 & -14 & & 178 & 8.7 & 13.6 \\
\hline K & 766.491 rad & & 0.5 & 0.9 & 766.491.rad & & 7.4 & -0.2 \\
\hline $\mathrm{La}$ & 408.671 & & 0.7 & -4.3 & & 139 & -12.8 & 12.0 \\
\hline $\mathrm{Li}$ & 670.783 & & 0.9 & -1.6 & & 7 & 14.1 & 4.9 \\
\hline $\mathrm{Mg}$ & $279.078 \mathrm{rad}$ & & -1.3 & 1.8 & 279.553.rad & & -3.0 & -5.8 \\
\hline $\mathrm{Mn}$ & 257.610 & & -4.3 & -3.1 & 260.568 & & 3.3 & 3.0 \\
\hline Mo & & 98 & -2.5 & -16 & 202.032 & & -1.3 & 3.3 \\
\hline $\mathrm{Na}$ & 588.995.rad & & 0.2 & 5.3 & 588.995.rad & & -1.3 & 6.1 \\
\hline $\mathrm{Nb}$ & 309.417 & & 11 & 6.7 & & 93 & -2.3 & 9.0 \\
\hline $\mathrm{Ni}$ & 231.604 & & -0.9 & 4.8 & & 62 & 5.3 & -2.3 \\
\hline $\mathrm{P}$ & 214.914 & & -2.0 & 2.1 & 214.914 & & -5.7 & -0.8 \\
\hline $\mathrm{Pb}$ & 220.353 & & -0.7 & 7.2 & & 208 & -9.4 & 8.9 \\
\hline $\mathrm{Rb}$ & & 85 & -6.0 & -10.0 & & 85 & -8.1 & 2.2 \\
\hline S & 182.562 & & 7.2 & 4.3 & 181.972 & & -2.6 & -7.7 \\
\hline $\mathrm{Sb}$ & & 121 & -3.0 & 2.0 & & 121 & 9.0 & 10.7 \\
\hline $\mathrm{Sc}$ & 361.383 & & 0.8 & -4.3 & 361.383 & & -6.9 & -5.9 \\
\hline Sn & & 120 & 4.4 & -8.5 & & 120 & 17.4 & 23.2 \\
\hline $\mathrm{Sr}$ & 460.733 & & 0.3 & -3.9 & & 85 & -2.2 & 12.0 \\
\hline Th & & 232 & 0.5 & -3.0 & & 232 & 5.4 & 3.3 \\
\hline $\mathrm{Tl}$ & & 205 & -8.5 & -7.0 & & 205 & -2.8 & -6.2 \\
\hline $\mathrm{Ti}$ & 368.520 & & -1.9 & -0.1 & 368.520 & & 8.8 & -12.5 \\
\hline V & 292.401 & & 1.3 & -0.3 & - & - & - & - \\
\hline $\mathrm{U}$ & & 238 & 4.5 & 3.0 & & 238 & 19.3 & 16.3 \\
\hline $\mathrm{Zn}$ & 213.857 & & 0.5 & -5.4 & 213.857 & & -2.1 & -5.1 \\
\hline $\mathrm{Zr}$ & & 90 & -26.0 & -25.0 & & 90 & -1.6 & 22.7 \\
\hline
\end{tabular}


Table A1.2 Concentrations of elements in studied soils along Red River and Huong River in wt. $\%(\mathrm{n}=30)$

\begin{tabular}{|c|c|c|c|c|c|c|c|c|c|c|c|c|c|c|}
\hline Area & Site & pH & LOI & $\overline{\mathrm{Al}}$ & $\mathbf{C a}$ & $\mathrm{Fe}$ & $\bar{K}$ & Mg & Mn & $\mathbf{N a}$ & $\mathbf{P}$ & $\mathbf{S}$ & Ti & $\mathbf{S i}$ \\
\hline Huong & H1 & 4.4 & 8.9 & 9.1 & 0.22 & 3.8 & 2.22 & 0.64 & 0.026 & 0.26 & 0.071 & 0.056 & 0.51 & 29 \\
\hline \multirow[t]{4}{*}{ River } & H5 & 4.7 & 6.5 & 7.9 & 0.21 & 4.0 & 2.08 & 0.63 & 0.028 & 0.32 & 0.050 & 0.048 & 0.50 & 32 \\
\hline & H6 & 4.4 & 4.5 & 5.9 & 0.22 & 2.8 & 1.70 & 0.49 & 0.024 & 0.30 & 0.041 & 0.030 & 0.46 & 35 \\
\hline & H7 & 4.3 & 5.1 & 6.4 & 0.20 & 3.0 & 1.80 & 0.53 & 0.023 & 0.30 & 0.037 & 0.036 & 0.46 & 34 \\
\hline & H8 & 4.2 & 7.0 & 8.0 & 0.23 & 3.7 & 2.10 & 0.60 & 0.026 & 0.32 & 0.044 & 0.088 & 0.50 & 31 \\
\hline Red & HN1 & 7.2 & 6.6 & 7.4 & 0.84 & 3.9 & 2.11 & 0.88 & 0.060 & 0.54 & 0.084 & 0.062 & 0.49 & 31 \\
\hline \multirow[t]{24}{*}{ River } & HN2 & 7.1 & 4.0 & 6.2 & 0.70 & 3.3 & 1.80 & 0.75 & 0.072 & 0.53 & 0.077 & 0.016 & 0.46 & 34 \\
\hline & HN3 & 7.1 & 5.4 & 6.2 & 0.64 & 3.3 & 1.83 & 0.78 & 0.050 & 0.54 & 0.078 & 0.032 & 0.44 & 34 \\
\hline & HN4 & 4.8 & 7.0 & 9.7 & 0.34 & 5.0 & 2.66 & 1.08 & 0.051 & 0.46 & 0.082 & 0.055 & 0.53 & 28 \\
\hline & HN5 & 6.7 & 6.4 & 7.1 & 0.51 & 3.9 & 1.95 & 0.85 & 0.052 & 0.54 & 0.085 & 0.043 & 0.50 & 32 \\
\hline & HN6 & 6.3 & 5.7 & 7.7 & 0.40 & 4.3 & 2.16 & 0.92 & 0.081 & 0.52 & 0.069 & 0.028 & 0.54 & 31 \\
\hline & HN7 & 5.6 & 6.8 & 8.6 & 0.32 & 4.4 & 2.38 & 0.97 & 0.034 & 0.48 & 0.059 & 0.033 & 0.54 & 30 \\
\hline & HN8 & 5.2 & 6.3 & 8.6 & 0.30 & 4.4 & 2.32 & 0.97 & 0.034 & 0.50 & 0.060 & 0.036 & 0.55 & 30 \\
\hline & HN9 & 5.5 & 6.5 & 8.6 & 0.35 & 4.3 & 2.32 & 0.99 & 0.033 & 0.50 & 0.097 & 0.040 & 0.55 & 30 \\
\hline & HN10 & 4.8 & 10.0 & 8.8 & 0.25 & 5.5 & 2.05 & 0.47 & 0.021 & 0.31 & 0.073 & 0.100 & 0.48 & 28 \\
\hline & HN11 & 6.0 & 5.0 & 8.1 & 0.45 & 4.3 & 2.35 & 0.97 & 0.064 & 0.54 & 0.126 & 0.025 & 0.51 & 31 \\
\hline & PT1 & 5.9 & 3.5 & 3.9 & 0.46 & 2.3 & 1.16 & 0.43 & 0.033 & 0.58 & 0.094 & 0.018 & 0.43 & 38 \\
\hline & PT2 & 7.0 & 4.8 & 8.0 & 1.16 & 4.6 & 2.54 & 1.16 & 0.090 & 1.12 & 0.081 & 0.016 & 0.55 & 30 \\
\hline & PT3 & 6.9 & 6.4 & 6.6 & 0.80 & 3.7 & 1.92 & 0.90 & 0.056 & 0.76 & 0.106 & 0.046 & 0.48 & 32 \\
\hline & PT4 & 7.3 & 4.9 & 7.2 & 1.07 & 4.1 & 2.07 & 1.01 & 0.077 & 0.75 & 0.089 & 0.018 & 0.49 & 32 \\
\hline & PT5 & 5.1 & 11.1 & 8.9 & 0.61 & 6.4 & 1.81 & 0.71 & 0.072 & 0.35 & 0.205 & 0.869 & 0.45 & 26 \\
\hline & PT6 & 6.2 & 7.1 & 8.0 & 0.30 & 9.2 & 1.11 & 0.44 & 0.043 & 0.23 & 0.059 & 0.066 & 0.41 & 29 \\
\hline & PT7 & 6.6 & 7.9 & 8.5 & 0.33 & 8.0 & 0.83 & 0.34 & 0.029 & 0.20 & 0.061 & 0.066 & 0.41 & 29 \\
\hline & PT8 & 6.4 & 6.5 & 6.6 & 0.71 & 3.6 & 1.86 & 0.77 & 0.052 & 0.68 & 0.106 & 0.054 & 0.45 & 32 \\
\hline & РT9 & 7.1 & 6.3 & 6.2 & 1.48 & 3.6 & 1.84 & 0.92 & 0.072 & 0.64 & 0.134 & 0.046 & 0.43 & 32 \\
\hline & PT10 & 5.4 & 10.1 & 9.4 & 0.52 & 5.0 & 2.49 & 1.01 & 0.066 & 0.44 & 0.083 & 0.558 & 0.51 & 27 \\
\hline & PT11 & 6.7 & 8.1 & 8.5 & 0.55 & 4.3 & 2.11 & 0.64 & 0.058 & 0.32 & 0.085 & 0.058 & 0.53 & 30 \\
\hline & ND1 & 6.2 & 3.7 & 4.3 & 0.38 & 2.0 & 1.51 & 0.33 & 0.045 & 0.59 & 0.088 & 0.024 & 0.33 & 38 \\
\hline & ND2 & 5.6 & 9.2 & 8.7 & 0.39 & 4.5 & 2.35 & 0.92 & 0.042 & 0.46 & 0.105 & 0.082 & 0.52 & 29 \\
\hline & ND3 & 5.7 & 7.2 & 9.1 & 0.41 & 4.7 & 2.46 & 1.03 & 0.046 & 0.48 & 0.096 & 0.040 & 0.54 & 29 \\
\hline
\end{tabular}


Table A1.2 (cont.) Concentrations of elements in studied soils along Red River and Huong River in $\mathrm{mg} \mathrm{kg}^{-1}(\mathrm{n}=30)$

\begin{tabular}{|c|c|c|c|c|c|c|c|c|c|c|c|c|c|c|c|}
\hline$\overline{\text { Area }}$ & Site & As & $\mathbf{B a}$ & $\mathbf{B i}$ & Cd & $\mathrm{Ce}$ & Co & $\mathrm{Cr}$ & Cs & $\mathbf{C u}$ & Ga & Hf & La & $\mathbf{L i}$ & Mo \\
\hline Huong & $\mathrm{H} 1$ & 12.5 & 493 & 0.79 & 0.34 & 103 & 17 & 47 & 7.8 & 35 & 22 & 3.4 & 47 & 30 & 1.11 \\
\hline & H6 & 11.2 & 404 & 0.40 & 0.19 & 63 & 10 & 30 & 4.9 & 20 & 14 & 4.1 & 34 & 21 & 0.82 \\
\hline & $\mathrm{H} 8$ & 15.0 & 481 & 0.57 & 0.27 & 90 & 14 & 43 & 6.8 & 28 & 19 & 4.0 & 45 & 29 & 1.28 \\
\hline Red River & $\mathrm{HN} 1$ & 17.8 & 399 & 0.51 & 0.34 & 81 & 17 & 58 & 8.8 & 38 & 19 & 4.8 & 42 & 44 & 0.70 \\
\hline & HN2 & 15.6 & 381 & 0.43 & 0.30 & 79 & 14 & 48 & 6.8 & 33 & 16 & 5.0 & 39 & 36 & 0.41 \\
\hline & HN5 & 17.9 & 395 & 0.40 & 0.37 & 79 & 17 & 63 & 8.0 & 39 & 18 & 4.5 & 39 & 43 & 0.53 \\
\hline & HN6 & 23.7 & 427 & 0.40 & 0.37 & 88 & 19 & 66 & 9.1 & 38 & 19 & 4.8 & 43 & 46 & 0.67 \\
\hline & HN7 & 19.7 & 442 & 0.48 & 0.32 & 93 & 19 & 77 & 10.7 & 41 & 22 & 4.5 & 45 & 52 & 0.63 \\
\hline & HN8 & 19.8 & 439 & 0.49 & 0.31 & 95 & 19 & 80 & 10.6 & 43 & 22 & 4.8 & 46 & 52 & 0.61 \\
\hline & HN9 & 16.7 & 449 & 0.56 & 0.37 & 95 & 20 & 93 & 10.5 & 45 & 22 & 4.8 & 47 & 52 & 0.53 \\
\hline & HN10 & 30.9 & 354 & 0.53 & 0.32 & 93 & 13 & 78 & 10.7 & 38 & 23 & 4.5 & 45 & 43 & 1.35 \\
\hline & PT5 & 49.7 & 376 & 1.06 & 6.46 & 157 & 50 & 72 & 8.6 & 885 & 23 & 3.5 & 56 & 41 & 2.50 \\
\hline & PT6 & 26.3 & 209 & 0.62 & 0.38 & 61 & 11 & 128 & 4.7 & 59 & 27 & 1.9 & 33 & 23 & 2.21 \\
\hline & PT7 & 18.1 & 159 & 0.60 & 0.20 & 77 & 8 & 125 & 3.7 & 41 & 26 & 1.6 & 37 & 19 & 2.41 \\
\hline & PT8 & 24.6 & 439 & 1.25 & 0.46 & 79 & 15 & 58 & 6.2 & 56 & 17 & 3.5 & 38 & 32 & 0.87 \\
\hline & PT9 & 28.5 & 423 & 1.43 & 0.49 & 80 & 14 & 59 & 6.5 & 61 & 16 & 3.4 & 39 & 34 & 0.78 \\
\hline & PT10 & 21.9 & 455 & 0.72 & 0.46 & 98 & 21 & 90 & 11.3 & 52 & 24 & 4.5 & 47 & 55 & 1.27 \\
\hline & PT11 & 18.5 & 376 & 0.65 & 0.49 & 104 & 16 & 61 & 10.2 & 37 & 22 & 3.7 & 45 & 35 & 1.02 \\
\hline & ND1 & 10.7 & 342 & 0.22 & 0.17 & 55 & 8 & 40 & 4.5 & 41 & 10 & 2.8 & 27 & 28 & 0.85 \\
\hline & ND2 & 20.2 & 428 & 0.63 & 0.34 & 92 & 19 & 85 & 10.9 & 46 & 22 & 4.5 & 45 & 56 & 1.18 \\
\hline & ND3 & 23.9 & 467 & 1.02 & 0.40 & 100 & 20 & 83 & 11.1 & 55 & 23 & 4.7 & 47 & 54 & 0.77 \\
\hline
\end{tabular}


Table A1.2 (cont.) Concentrations of elements in studied soils along Red River and Huong River in $\mathrm{mg} \mathrm{kg}^{-1}(\mathrm{n}=30)$

\begin{tabular}{|c|c|c|c|c|c|c|c|c|c|c|c|c|c|c|c|}
\hline Area & Site & $\mathbf{N b}$ & $\mathbf{N i}$ & $\mathbf{P b}$ & $\mathbf{R b}$ & Sb & Sc & Sn & $\mathrm{Sr}$ & Th & Tl & $\mathbf{U}$ & $\mathbf{V}$ & $\mathbf{Z n}$ & $\mathbf{Z r}$ \\
\hline$\overline{\text { Huong }}$ & $\mathrm{H} 1$ & 19 & 36 & 38 & 133 & 1.77 & 16 & 5.7 & 39 & 23 & 0.70 & 5.2 & 115 & 114 & 96 \\
\hline River & H6 & 14 & 22 & 23 & 98 & 1.32 & 11 & 3.6 & 40 & 16 & 0.49 & 3.9 & 78 & 64 & 119 \\
\hline \multirow{19}{*}{ Red River } & $\mathrm{HN} 1$ & 20 & 43 & 35 & 128 & 1.88 & 13 & 4.0 & 81 & 17 & 0.62 & 3.8 & 105 & 96 & 147 \\
\hline & HN2 & 17 & 35 & 31 & 108 & 1.60 & 10 & 3.5 & 76 & 16 & 0.53 & 3.4 & 88 & 85 & 154 \\
\hline & HN3 & 17 & 35 & 33 & 112 & 1.62 & 10 & 3.4 & 80 & 14 & 0.54 & 3.1 & 87 & 100 & 132 \\
\hline & HN6 & 21 & 45 & 38 & 128 & 2.03 & 14 & 3.9 & 75 & 17 & 0.62 & 3.7 & 113 & 98 & 152 \\
\hline & HN7 & 22 & 49 & 41 & 143 & 1.91 & 15 & 4.8 & 78 & 18 & 0.71 & 3.8 & 123 & 107 & 144 \\
\hline & HN8 & 22 & 48 & 44 & 141 & 1.96 & 15 & 4.4 & 78 & 18 & 0.71 & 3.9 & 122 & 107 & 152 \\
\hline & HN9 & 23 & 50 & 45 & 140 & 2.08 & 15 & 4.5 & 82 & 18 & 0.71 & 4.0 & 122 & 111 & 149 \\
\hline & HN10 & 23 & 35 & 39 & 134 & 3.48 & 14 & 4.8 & 81 & 19 & 0.71 & 4.2 & 128 & 89 & 149 \\
\hline & HN11 & 21 & 46 & 42 & 143 & 1.89 & 14 & 5.2 & 79 & 17 & 0.70 & 3.7 & 116 & 132 & 142 \\
\hline & PT1 & 21 & 19 & 40 & 64 & 1.04 & 6 & 3.8 & 78 & 13 & 0.32 & 2.9 & 57 & 70 & 143 \\
\hline & PT6 & 21 & 27 & 55 & 65 & 1.35 & 19 & 3.3 & 35 & 24 & 0.38 & 3.8 & 165 & 139 & 61 \\
\hline & PT7 & 20 & 23 & 52 & 49 & 1.16 & 17 & 3.7 & 30 & 30 & 0.31 & 4.2 & 152 & 83 & 47 \\
\hline & PT8 & 18 & 34 & 75 & 104 & 2.22 & 11 & 4.8 & 100 & 15 & 0.54 & 3.3 & 92 & 113 & 113 \\
\hline & PT9 & 17 & 35 & 86 & 108 & 2.09 & 10 & 5.2 & 102 & 15 & 0.53 & 3.1 & 89 & 127 & 108 \\
\hline & PT10 & 23 & 54 & 49 & 151 & 1.72 & 17 & 5.3 & 79 & 18 & 0.78 & 4.2 & 139 & 152 & 142 \\
\hline & PT11 & 22 & 38 & 50 & 133 & 2.85 & 15 & 6.7 & 43 & 18 & 0.71 & 4.2 & 119 & 124 & 118 \\
\hline & ND1 & 13 & 19 & 27 & 86 & 1.13 & 7 & 3.9 & 87 & 9 & 0.41 & 2.8 & 55 & 65 & 93 \\
\hline & ND2 & 23 & 54 & 51 & 143 & 2.01 & 15 & 4.9 & 81 & 17 & 0.71 & 4.2 & 129 & 119 & 140 \\
\hline & ND3 & 24 & 53 & 66 & 146 & 2.54 & 16 & 5.8 & 84 & 19 & 0.76 & 4.2 & 129 & 130 & 153 \\
\hline
\end{tabular}


Table A1.3 Concentrations of elements in unpolished rice in $\mathrm{mg} \mathrm{kg}^{-1}$ dry matter $(\mathrm{n}=24)$

\begin{tabular}{lcrrrrrrrrrr}
\hline Area & Site & Al & Ca & Fe & K & Mg & Mn & Na & P & S & Ti \\
\hline Huong & H1 & 15 & 161 & 19.3 & 3348 & 1262 & 21 & 6.4 & 3680 & 1205 & 0.86 \\
River & H5 & $<4$ & 132 & 14.1 & 2983 & 1347 & 24 & 8.4 & 3407 & 927 & 0.27 \\
& H6 & $<4$ & 118 & 9.1 & 2453 & 1104 & 26 & 3.3 & 2656 & 1004 & 0.09 \\
& H7 & $<4$ & 143 & 9.1 & 2995 & 1247 & 23 & 3.9 & 3198 & 1069 & 0.09 \\
\hline Red & HN1 & $<4$ & 145 & 11.7 & 3103 & 1511 & 18 & 6.0 & 3820 & 1262 & 0.13 \\
River & HN2 & $<4$ & 146 & 13.2 & 2988 & 1468 & 23 & 5.2 & 3833 & 1069 & 0.09 \\
& HN3 & $<4$ & 134 & 12.5 & 2942 & 1441 & 20 & 5.3 & 3738 & 1127 & 0.11 \\
& HN5 & $<4$ & 139 & 11.5 & 2689 & 1386 & 23 & 3.2 & 3515 & 1122 & $<0.05$ \\
& HN6 & $<4$ & 125 & 9.9 & 2720 & 1241 & 29 & 3.9 & 3145 & 934 & $<0.05$ \\
& HN7 & $<4$ & 128 & 10.0 & 2826 & 1236 & 23 & 4.1 & 3216 & 986 & $<0.05$ \\
& HN8 & $<4$ & 114 & 8.3 & 2356 & 1205 & 20 & 3.5 & 2859 & 884 & $<0.05$ \\
& HN9 & $<4$ & 150 & 12.2 & 2761 & 1376 & 29 & 2.8 & 3527 & 969 & 0.08 \\
& HN10 & $<4$ & 139 & 9.1 & 2978 & 1352 & 45 & 3.6 & 3590 & 1066 & 0.06 \\
& HN11 & $<4$ & 137 & 12.5 & 3168 & 1447 & 26 & 4.3 & 3800 & 1119 & 0.06 \\
& PT1 & $<4$ & 122 & 10.1 & 2870 & 1369 & 24 & 3.3 & 3462 & 1054 & $<0.05$ \\
& PT3 & 13 & 106 & 9.0 & 3021 & 1502 & 17 & 2.8 & 3637 & 890 & 0.06 \\
& PT4 & $<4$ & 139 & 13.5 & 2512 & 1126 & 12 & 2.7 & 2815 & 1148 & 0.09 \\
& PT5 & $<4$ & 145 & 13.3 & 3157 & 1591 & 20 & 4.7 & 4167 & 1256 & 0.10 \\
& PT6 & $<4$ & 145 & 11.2 & 2866 & 1468 & 17 & 6.7 & 3794 & 1067 & $<0.05$ \\
& PT7 & $<4$ & 163 & 10.8 & 2955 & 1422 & 18 & 6.3 & 3709 & 1330 & $<0.05$ \\
& PT8 & $<4$ & 133 & 11.2 & 3099 & 1584 & 24 & 3.9 & 4024 & 1149 & $<0.05$ \\
& PT9 & $<4$ & 122 & 10.4 & 3215 & 1432 & 18 & 3.6 & 3682 & 1104 & $<0.05$ \\
& PT10 & $<4$ & 124 & 9.8 & 3352 & 1475 & 16 & 5.6 & 3912 & 1226 & 0.06 \\
& PT11 & $<4$ & 131 & 9.0 & 2620 & 1248 & 21 & 3.2 & 3273 & 1191 & $<0.05$ \\
\hline
\end{tabular}


Table A1.3 (cont.) Concentrations of elements in unpolished rice in $\mathrm{mg} \mathrm{kg}^{-1}$ dry matter $(\mathrm{n}=24)$

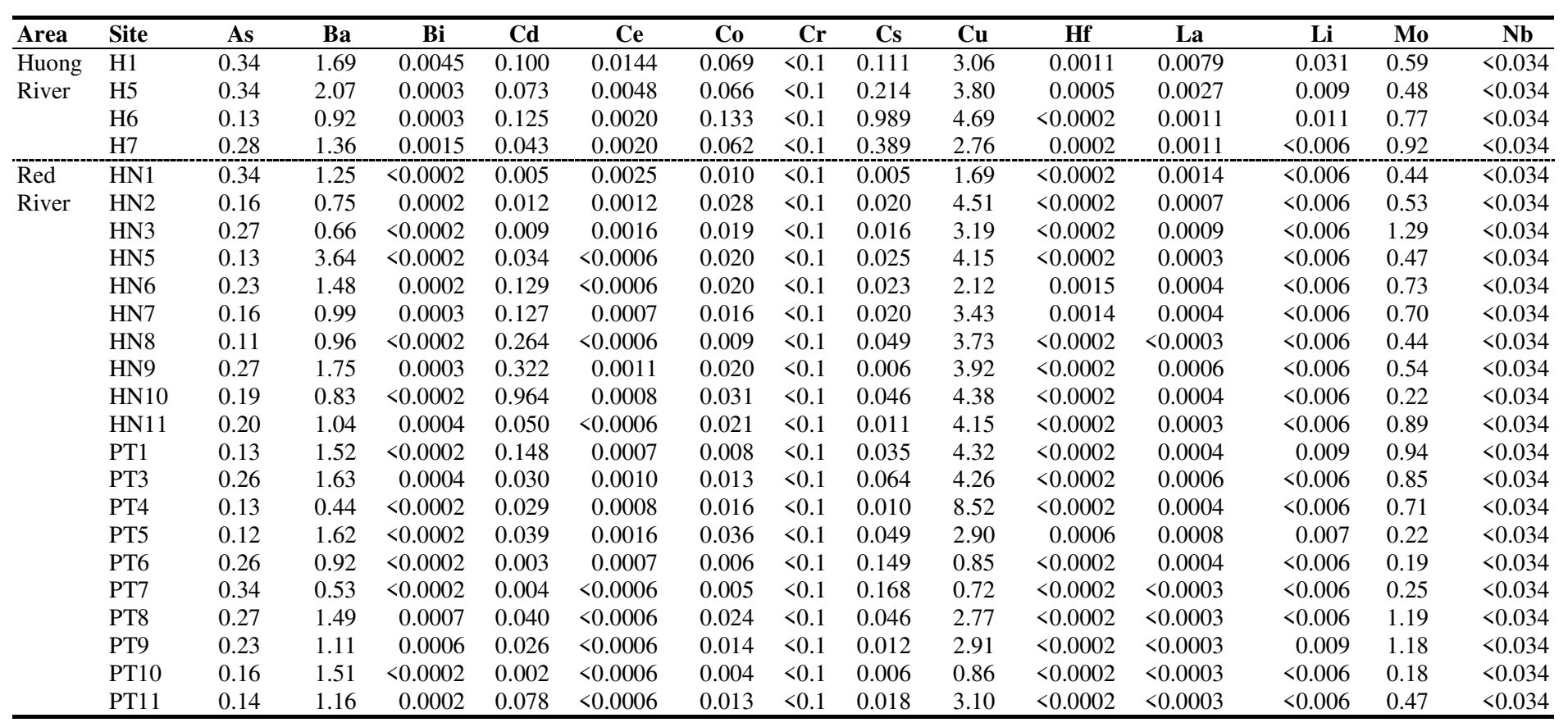


Table A1.3 (cont.) Concentrations of elements in unpolished rice in $\mathrm{mg} \mathrm{kg}^{-1}$ dry matter $(\mathrm{n}=24)$

\begin{tabular}{|c|c|c|c|c|c|c|c|c|c|c|c|c|c|}
\hline Area & Site & $\mathbf{N i}$ & $\mathbf{P b}$ & $\mathbf{R b}$ & $\mathbf{S b}$ & Sc & Sn & $\mathbf{S r}$ & Th & $\mathrm{Tl}$ & $\mathbf{U}$ & Zn & $\mathbf{Z r}$ \\
\hline Huong & H1 & 0.67 & 0.02 & 19.3 & 0.0011 & 0.005 & $<0.06$ & 0.44 & 0.0025 & $<0.0002$ & 0.0017 & 32 & 0.040 \\
\hline \multirow[t]{3}{*}{ River } & H5 & 0.38 & $<0.02$ & 44.5 & $<0.0006$ & $<0.003$ & $<0.06$ & 0.53 & 0.0007 & $<0.0002$ & 0.0005 & 27 & 0.020 \\
\hline & H6 & 2.24 & $<0.02$ & 60.2 & $<0.0006$ & $<0.003$ & $<0.06$ & 0.44 & 0.0002 & 0.0004 & 0.0002 & 24 & $<0.007$ \\
\hline & $\mathrm{H} 7$ & 0.53 & $<0.02$ & 53.5 & $<0.0006$ & $<0.003$ & $<0.06$ & 0.46 & 0.0002 & $<0.0002$ & 0.0001 & 25 & 0.007 \\
\hline Red & HN1 & 0.06 & $<0.02$ & 2.6 & 0.0006 & $<0.003$ & $<0.06$ & 0.37 & 0.0004 & $<0.0002$ & 0.0002 & 17 & $<0.007$ \\
\hline \multirow[t]{19}{*}{ River } & HN2 & 0.36 & $<0.02$ & 11.8 & $<0.0006$ & $<0.003$ & $<0.06$ & 0.39 & 0.0002 & $<0.0002$ & 0.0001 & 28 & $<0.007$ \\
\hline & HN3 & 0.11 & $<0.02$ & 9.1 & $<0.0006$ & $<0.003$ & $<0.06$ & 0.41 & 0.0003 & 0.0003 & 0.0001 & 21 & $<0.007$ \\
\hline & HN5 & 0.34 & $<0.02$ & 8.6 & $<0.0006$ & $<0.003$ & $<0.06$ & 0.37 & $<0.0002$ & 0.0002 & $<0.0001$ & 25 & 0.066 \\
\hline & HN6 & 0.44 & $<0.02$ & 11.3 & $<0.0006$ & $<0.003$ & $<0.06$ & 0.30 & $<0.0002$ & 0.0002 & $<0.0001$ & 21 & 0.060 \\
\hline & HN7 & 0.43 & $<0.02$ & 10.2 & $<0.0006$ & $<0.003$ & $<0.06$ & 0.25 & $<0.0002$ & 0.0002 & $<0.0001$ & 24 & $<0.007$ \\
\hline & HN8 & 0.89 & $<0.02$ & 13.1 & $<0.0006$ & $<0.003$ & $<0.06$ & 0.25 & $<0.0002$ & $<0.0002$ & $<0.0001$ & 26 & $<0.007$ \\
\hline & HN9 & 0.62 & $<0.02$ & 4.0 & $<0.0006$ & $<0.003$ & $<0.06$ & 0.43 & 0.0002 & 0.0003 & $<0.0001$ & 26 & $<0.007$ \\
\hline & HN10 & 1.02 & $<0.02$ & 11.5 & $<0.0006$ & $<0.003$ & $<0.06$ & 0.29 & $<0.0002$ & $<0.0002$ & $<0.0001$ & 28 & $<0.007$ \\
\hline & HN11 & 0.31 & $<0.02$ & 7.3 & $<0.0006$ & $<0.003$ & $<0.06$ & 0.28 & $<0.0002$ & 0.0002 & $<0.0001$ & 25 & $<0.007$ \\
\hline & PT1 & 0.84 & $<0.02$ & 27.3 & $<0.0006$ & $<0.003$ & $<0.06$ & 0.42 & $<0.0002$ & $<0.0002$ & $<0.0001$ & 25 & $<0.007$ \\
\hline & PT3 & 0.14 & $<0.02$ & 35.6 & 0.0009 & $<0.003$ & $<0.06$ & 0.37 & $<0.0002$ & 0.0003 & $<0.0001$ & 19 & $<0.007$ \\
\hline & PT4 & 0.84 & $<0.02$ & 6.5 & $<0.0006$ & $<0.003$ & $<0.06$ & 0.18 & $<0.0002$ & 0.0003 & $<0.0001$ & 25 & $<0.007$ \\
\hline & PT5 & 0.08 & $<0.02$ & 11.0 & $<0.0006$ & $<0.003$ & $<0.06$ & 0.49 & 0.0003 & 0.0002 & 0.0001 & 28 & 0.021 \\
\hline & PT6 & 0.03 & $<0.02$ & 26.8 & $<0.0006$ & $<0.003$ & $<0.06$ & 0.45 & $<0.0002$ & 0.0002 & $<0.0001$ & 20 & $<0.007$ \\
\hline & PT7 & 0.05 & $<0.02$ & 20.6 & $<0.0006$ & $<0.003$ & $<0.06$ & 0.44 & $<0.0002$ & 0.0002 & $<0.0001$ & 19 & $<0.007$ \\
\hline & PT8 & 0.08 & $<0.02$ & 22.3 & $<0.0006$ & $<0.003$ & $<0.06$ & 0.37 & $<0.0002$ & 0.0002 & $<0.0001$ & 28 & $<0.007$ \\
\hline & PT9 & 0.07 & $<0.02$ & 11.4 & $<0.0006$ & $<0.003$ & $<0.06$ & 0.34 & $<0.0002$ & 0.0002 & $<0.0001$ & 24 & $<0.007$ \\
\hline & PT10 & 0.08 & $<0.02$ & 4.1 & $<0.0006$ & $<0.003$ & $<0.06$ & 0.45 & $<0.0002$ & $<0.0002$ & $<0.0001$ & 14 & $<0.007$ \\
\hline & PT11 & 0.20 & $<0.02$ & 9.2 & $<0.0006$ & $<0.003$ & $<0.06$ & 0.28 & $<0.0002$ & 0.0002 & $<0.0001$ & 24 & $<0.007$ \\
\hline
\end{tabular}


Table A1.4 Transfer factors of selected elements from soil to unpolished rice $(n=24)$

\begin{tabular}{llrllllllllr}
\hline Area & Site & Al & Ca & Fe & K & Mg & Mn & Na & P & S & Ti \\
\hline Huong & H1 & 0.00017 & 0.073 & 0.00050 & 0.15 & 0.20 & 0.081 & 0.0024 & 5.2 & 2.2 & 0.00017 \\
River & H5 & $<0.00005$ & 0.062 & 0.00036 & 0.14 & 0.21 & 0.085 & 0.0026 & 6.8 & 1.9 & 0.00005 \\
& H6 & $<0.00005$ & 0.052 & 0.00033 & 0.14 & 0.22 & 0.111 & 0.0011 & 6.4 & 3.4 & 0.00002 \\
& H7 & $<0.00005$ & 0.070 & 0.00030 & 0.17 & 0.23 & 0.100 & 0.0013 & 8.5 & 3.0 & 0.00002 \\
\hline Red & HN1 & $<0.00005$ & 0.017 & 0.00030 & 0.15 & 0.17 & 0.030 & 0.0011 & 4.5 & 2.0 & 0.00003 \\
River & HN2 & $<0.00005$ & 0.021 & 0.00040 & 0.17 & 0.20 & 0.031 & 0.0010 & 5.0 & 6.5 & 0.00002 \\
& HN3 & $<0.00005$ & 0.021 & 0.00038 & 0.16 & 0.19 & 0.039 & 0.0010 & 4.8 & 3.5 & 0.00002 \\
& HN5 & $<0.00005$ & 0.027 & 0.00029 & 0.14 & 0.16 & 0.044 & 0.0006 & 4.1 & 2.6 & $<0.00001$ \\
& HN6 & $<0.00005$ & 0.031 & 0.00023 & 0.13 & 0.14 & 0.036 & 0.0007 & 4.6 & 3.3 & $<0.00001$ \\
& HN7 & $<0.00005$ & 0.040 & 0.00023 & 0.12 & 0.13 & 0.067 & 0.0009 & 5.4 & 3.0 & $<0.00001$ \\
& HN8 & $<0.00005$ & 0.039 & 0.00019 & 0.10 & 0.12 & 0.058 & 0.0007 & 4.8 & 2.5 & $<0.00001$ \\
& HN9 & $<0.00005$ & 0.043 & 0.00028 & 0.12 & 0.14 & 0.089 & 0.0006 & 3.7 & 2.4 & 0.00001 \\
& HN10 & $<0.00005$ & 0.056 & 0.00017 & 0.15 & 0.28 & 0.219 & 0.0011 & 4.9 & 1.1 & 0.00001 \\
& HN11 & $<0.00005$ & 0.030 & 0.00029 & 0.13 & 0.15 & 0.041 & 0.0008 & 3.0 & 4.5 & 0.00001 \\
& PT1 & $<0.00005$ & 0.026 & 0.00043 & 0.25 & 0.32 & 0.074 & 0.0006 & 3.7 & 5.8 & $<0.00001$ \\
& PT3 & 0.00020 & 0.013 & 0.00024 & 0.16 & 0.17 & 0.031 & 0.0004 & 3.4 & 1.9 & 0.00001 \\
& PT4 & $<0.00005$ & 0.013 & 0.00033 & 0.12 & 0.11 & 0.015 & 0.0004 & 3.2 & 6.4 & 0.00002 \\
& PT5 & $<0.00005$ & 0.024 & 0.00025 & 0.17 & 0.22 & 0.028 & 0.0013 & 2.0 & 0.1 & 0.00002 \\
& PT6 & $<0.00005$ & 0.048 & 0.00012 & 0.26 & 0.34 & 0.039 & 0.0029 & 6.4 & 1.6 & $<0.00001$ \\
& PT7 & $<0.00005$ & 0.049 & 0.00014 & 0.36 & 0.42 & 0.062 & 0.0032 & 6.1 & 2.0 & $<0.00001$ \\
& PT8 & $<0.00005$ & 0.019 & 0.00031 & 0.17 & 0.21 & 0.046 & 0.0006 & 3.8 & 2.1 & $<0.00001$ \\
& PT9 & $<0.00005$ & 0.008 & 0.00029 & 0.17 & 0.15 & 0.025 & 0.0006 & 2.7 & 2.4 & $<0.00001$ \\
& PT10 & $<0.00005$ & 0.024 & 0.00019 & 0.13 & 0.15 & 0.024 & 0.0013 & 4.7 & 0.2 & 0.00001 \\
& PT11 & $<0.00005$ & 0.024 & 0.00021 & 0.12 & 0.19 & 0.036 & 0.0010 & 3.8 & 2.1 & $<0.00001$ \\
\hline
\end{tabular}


Table A1.4 (cont.) Transfer factors of elements from soil to unpolished rice ( $\mathrm{n}=24)$

\begin{tabular}{|c|c|c|c|c|c|c|c|c|c|c|c|c|c|c|c|}
\hline Area & Site & As & $\mathbf{B a}$ & $\mathbf{B i}$ & Cd & $\mathrm{Ce}$ & Co & $\mathrm{Cr}$ & Cs & $\mathbf{C u}$ & Hf & La & $\mathbf{L i}$ & Mo & $\mathrm{Nb}$ \\
\hline Huong & H1 & 0.027 & 0.003 & 0.0057 & 0.291 & 0.00014 & 0.0040 & $<0.001$ & 0.0143 & 0.088 & 0.00032 & 0.00017 & 0.0010 & 0.54 & $<0.002$ \\
\hline \multirow[t]{3}{*}{ River } & H5 & 0.020 & 0.004 & 0.0005 & 0.333 & 0.00005 & 0.0045 & $<0.001$ & 0.0324 & 0.130 & 0.00013 & 0.00006 & 0.0003 & 0.40 & $<0.002$ \\
\hline & H6 & 0.012 & 0.002 & 0.0008 & 0.658 & 0.00003 & 0.0134 & $<0.001$ & 0.2021 & 0.232 & $<0.00005$ & 0.00003 & 0.0005 & 0.94 & $<0.002$ \\
\hline & $\mathrm{H} 7$ & 0.023 & 0.003 & 0.0034 & 0.209 & 0.00003 & 0.0057 & $<0.001$ & 0.0717 & 0.120 & 0.00005 & 0.00003 & $<0.0001$ & 1.00 & $<0.002$ \\
\hline Red & $\mathrm{HN} 1$ & 0.019 & 0.003 & $<0.0003$ & 0.014 & 0.00003 & 0.0006 & $<0.001$ & 0.0006 & 0.044 & $<0.00005$ & 0.00003 & $<0.0001$ & 0.62 & $<0.002$ \\
\hline \multirow[t]{19}{*}{ River } & HN2 & 0.010 & 0.002 & 0.0006 & 0.038 & 0.00002 & 0.0020 & $<0.001$ & 0.0029 & 0.135 & $<0.00005$ & 0.00002 & $<0.0001$ & 1.30 & $<0.002$ \\
\hline & HN3 & 0.018 & 0.002 & $<0.0003$ & 0.028 & 0.00002 & 0.0014 & $<0.001$ & 0.0023 & 0.083 & $<0.00005$ & 0.00002 & $<0.0001$ & 3.06 & $<0.002$ \\
\hline & HN5 & 0.008 & 0.009 & $<0.0003$ & 0.091 & $<0.00001$ & 0.0012 & $<0.001$ & 0.0031 & 0.106 & $<0.00005$ & 0.00001 & $<0.0001$ & 0.89 & $<0.002$ \\
\hline & HN6 & 0.010 & 0.003 & 0.0006 & 0.347 & $<0.00001$ & 0.0010 & $<0.001$ & 0.0026 & 0.056 & 0.00034 & 0.00001 & $<0.0001$ & 1.08 & $<0.002$ \\
\hline & HN7 & 0.008 & 0.002 & 0.0006 & 0.392 & 0.00001 & 0.0009 & $<0.001$ & 0.0019 & 0.085 & 0.00030 & 0.00001 & $<0.0001$ & 1.11 & $<0.002$ \\
\hline & HN8 & 0.005 & 0.002 & $<0.0003$ & 0.857 & $<0.00001$ & 0.0005 & $<0.001$ & 0.0046 & 0.087 & $<0.00005$ & $<0.00001$ & $<0.0001$ & 0.73 & $<0.002$ \\
\hline & HN9 & 0.016 & 0.004 & 0.0005 & 0.873 & 0.00001 & 0.0010 & $<0.001$ & 0.0005 & 0.088 & $<0.00005$ & 0.00001 & $<0.0001$ & 1.03 & $<0.002$ \\
\hline & HN10 & 0.006 & 0.002 & $<0.0003$ & 2.992 & 0.00001 & 0.0024 & $<0.001$ & 0.0042 & 0.116 & $<0.00005$ & 0.00001 & $<0.0001$ & 0.16 & $<0.002$ \\
\hline & HN11 & 0.009 & 0.002 & 0.0007 & 0.158 & $<0.00001$ & 0.0012 & $<0.001$ & 0.0011 & 0.096 & $<0.00005$ & 0.00001 & $<0.0001$ & 1.28 & $<0.002$ \\
\hline & PT1 & 0.013 & 0.005 & $<0.0003$ & 0.621 & 0.00001 & 0.0011 & $<0.001$ & 0.0110 & 0.155 & $<0.00005$ & 0.00001 & 0.0005 & 2.02 & $<0.002$ \\
\hline & PT3 & 0.012 & 0.004 & 0.0005 & 0.064 & 0.00001 & 0.0009 & 0.003 & 0.0108 & 0.082 & $<0.00005$ & 0.00001 & $<0.0001$ & 1.09 & $<0.002$ \\
\hline & PT4 & 0.003 & 0.001 & $<0.0003$ & 0.051 & 0.00001 & 0.0010 & $<0.001$ & 0.0015 & 0.101 & $<0.00005$ & 0.00001 & $<0.0001$ & 0.53 & $<0.002$ \\
\hline & PT5 & 0.002 & 0.004 & $<0.0003$ & 0.006 & 0.00001 & 0.0007 & $<0.001$ & 0.0057 & 0.003 & 0.000158 & 0.00001 & 0.0002 & 0.09 & $<0.002$ \\
\hline & PT6 & 0.010 & 0.004 & $<0.0003$ & 0.007 & 0.00001 & 0.0005 & $<0.001$ & 0.0315 & 0.014 & $<0.00005$ & 0.00001 & $<0.0001$ & 0.09 & $<0.002$ \\
\hline & PT7 & 0.019 & 0.003 & $<0.0003$ & 0.019 & $<0.00001$ & 0.0007 & $<0.001$ & 0.0455 & 0.018 & $<0.00005$ & $<0.00001$ & $<0.0001$ & 0.11 & $<0.002$ \\
\hline & PT8 & 0.011 & 0.003 & 0.0005 & 0.088 & $<0.00001$ & 0.0017 & $<0.001$ & 0.0073 & 0.050 & $<0.00005$ & $<0.00001$ & $<0.0001$ & 1.36 & $<0.002$ \\
\hline & PT9 & 0.008 & 0.003 & 0.0004 & 0.053 & $<0.00001$ & 0.0010 & $<0.001$ & 0.0019 & 0.048 & $<0.00005$ & $<0.00001$ & 0.0005 & 1.51 & $<0.002$ \\
\hline & PT10 & 0.007 & 0.003 & $<0.0003$ & 0.005 & $<0.00001$ & 0.0002 & 0.001 & 0.0005 & 0.017 & $<0.00005$ & $<0.00001$ & $<0.0001$ & 0.14 & $<0.002$ \\
\hline & PT11 & 0.007 & 0.003 & 0.0004 & 0.160 & $<0.00001$ & 0.0008 & $<0.001$ & 0.0018 & 0.083 & $<0.00005$ & $<0.00001$ & $<0.0001$ & 0.46 & $<0.002$ \\
\hline
\end{tabular}


Table A1.4 (cont.) Transfer factors of elements from soil to unpolished rice $(\mathrm{n}=24)$

\begin{tabular}{|c|c|c|c|c|c|c|c|c|c|c|c|c|c|}
\hline Area & Site & $\mathbf{N i}$ & $\mathbf{P b}$ & $\mathbf{R b}$ & Sb & Sc & Sn & $\mathrm{Sr}$ & Th & Tl & $\mathbf{U}$ & Zn & $\mathbf{Z r}$ \\
\hline Huong & H1 & 0.019 & 0.0005 & 0.14 & 0.0006 & 0.0003 & $<0.02$ & 0.011 & 0.00011 & $<0.0003$ & 0.00032 & 0.28 & 0.00042 \\
\hline \multirow[t]{3}{*}{ River } & H5 & 0.012 & $<0.0005$ & 0.36 & $<0.0003$ & $<0.0003$ & $<0.02$ & 0.013 & 0.00004 & $<0.0003$ & 0.00011 & 0.32 & 0.00018 \\
\hline & H6 & 0.104 & $<0.0005$ & 0.62 & $<0.0003$ & $<0.0003$ & $<0.02$ & 0.011 & 0.00002 & 0.0009 & 0.00004 & 0.37 & $<0.00006$ \\
\hline & H7 & 0.022 & $<0.0005$ & 0.51 & $<0.0003$ & $<0.0003$ & $<0.02$ & 0.012 & 0.00001 & $<0.0003$ & 0.00004 & 0.36 & 0.00006 \\
\hline Red & HN1 & 0.001 & $<0.0005$ & 0.02 & 0.0003 & $<0.0003$ & $<0.02$ & 0.005 & 0.00002 & $<0.0003$ & 0.00006 & 0.18 & $<0.00006$ \\
\hline \multirow[t]{19}{*}{ River } & HN2 & 0.010 & $<0.0005$ & 0.11 & $<0.0003$ & $<0.0003$ & $<0.02$ & 0.005 & 0.00001 & $<0.0003$ & 0.00003 & 0.34 & $<0.00006$ \\
\hline & HN3 & 0.003 & $<0.0005$ & 0.08 & $<0.0003$ & $<0.0003$ & $<0.02$ & 0.005 & 0.00002 & 0.0005 & 0.00004 & 0.21 & $<0.00006$ \\
\hline & HN5 & 0.008 & $<0.0005$ & 0.08 & $<0.0003$ & $<0.0003$ & $<0.02$ & 0.005 & $<0.00001$ & 0.0003 & $<0.00002$ & 0.25 & 0.00046 \\
\hline & HN6 & 0.010 & $<0.0005$ & 0.09 & $<0.0003$ & $<0.0003$ & $<0.02$ & 0.004 & $<0.00001$ & 0.0004 & $<0.00002$ & 0.21 & 0.00039 \\
\hline & HN7 & 0.009 & $<0.0005$ & 0.07 & $<0.0003$ & $<0.0003$ & $<0.02$ & 0.003 & $<0.00001$ & 0.0003 & $<0.00002$ & 0.22 & $<0.00006$ \\
\hline & HN8 & 0.018 & $<0.0005$ & 0.09 & $<0.0003$ & $<0.0003$ & $<0.02$ & 0.003 & $<0.00001$ & $<0.0003$ & $<0.00002$ & 0.24 & $<0.00006$ \\
\hline & HN9 & 0.013 & $<0.0005$ & 0.03 & $<0.0003$ & $<0.0003$ & $<0.02$ & 0.005 & 0.00001 & 0.0004 & $<0.00002$ & 0.24 & $<0.00006$ \\
\hline & HN10 & 0.029 & $<0.0005$ & 0.09 & $<0.0003$ & $<0.0003$ & $<0.02$ & 0.004 & $<0.00001$ & $<0.0003$ & $<0.00002$ & 0.32 & $<0.00006$ \\
\hline & HN11 & 0.007 & $<0.0005$ & 0.05 & $<0.0003$ & $<0.0003$ & $<0.02$ & 0.004 & $<0.00001$ & 0.0003 & $<0.00002$ & 0.19 & $<0.00006$ \\
\hline & PT1 & 0.045 & $<0.0005$ & 0.42 & $<0.0003$ & $<0.0003$ & $<0.02$ & 0.005 & $<0.00001$ & $<0.0003$ & $<0.00002$ & 0.35 & $<0.00006$ \\
\hline & PT3 & 0.004 & $<0.0005$ & 0.34 & 0.0005 & $<0.0003$ & $<0.02$ & 0.004 & $<0.00001$ & 0.0006 & $<0.00002$ & 0.18 & $<0.00006$ \\
\hline & PT4 & 0.022 & $<0.0005$ & 0.06 & $<0.0003$ & $<0.0003$ & $<0.02$ & 0.002 & $<0.00001$ & 0.0005 & $<0.00002$ & 0.19 & $<0.00006$ \\
\hline & PT5 & 0.002 & $<0.0005$ & 0.10 & $<0.0003$ & $<0.0003$ & $<0.02$ & 0.007 & 0.00001 & 0.0003 & 0.00002 & 0.02 & 0.00019 \\
\hline & PT6 & 0.001 & $<0.0005$ & 0.41 & $<0.0003$ & $<0.0003$ & $<0.02$ & 0.013 & $<0.00001$ & 0.0006 & $<0.00002$ & 0.14 & $<0.00006$ \\
\hline & PT7 & 0.002 & $<0.0005$ & 0.42 & $<0.0003$ & $<0.0003$ & $<0.02$ & 0.015 & $<0.00001$ & 0.0006 & $<0.00002$ & 0.23 & $<0.00006$ \\
\hline & PT8 & 0.002 & $<0.0005$ & 0.22 & $<0.0003$ & $<0.0003$ & $<0.02$ & 0.004 & $<0.00001$ & 0.0003 & $<0.00002$ & 0.25 & $<0.00006$ \\
\hline & PT9 & 0.002 & $<0.0005$ & 0.11 & $<0.0003$ & $<0.0003$ & $<0.02$ & 0.003 & $<0.00001$ & 0.0004 & $<0.00002$ & 0.19 & $<0.00006$ \\
\hline & PT10 & 0.001 & $<0.0005$ & 0.03 & $<0.0003$ & $<0.0003$ & $<0.02$ & 0.006 & $<0.00001$ & $<0.0003$ & $<0.00002$ & 0.09 & $<0.00006$ \\
\hline & PT11 & 0.005 & $<0.0005$ & 0.07 & $<0.0003$ & $<0.0003$ & $<0.02$ & 0.007 & $<0.00001$ & 0.0003 & $<0.00002$ & 0.19 & $<0.00006$ \\
\hline
\end{tabular}




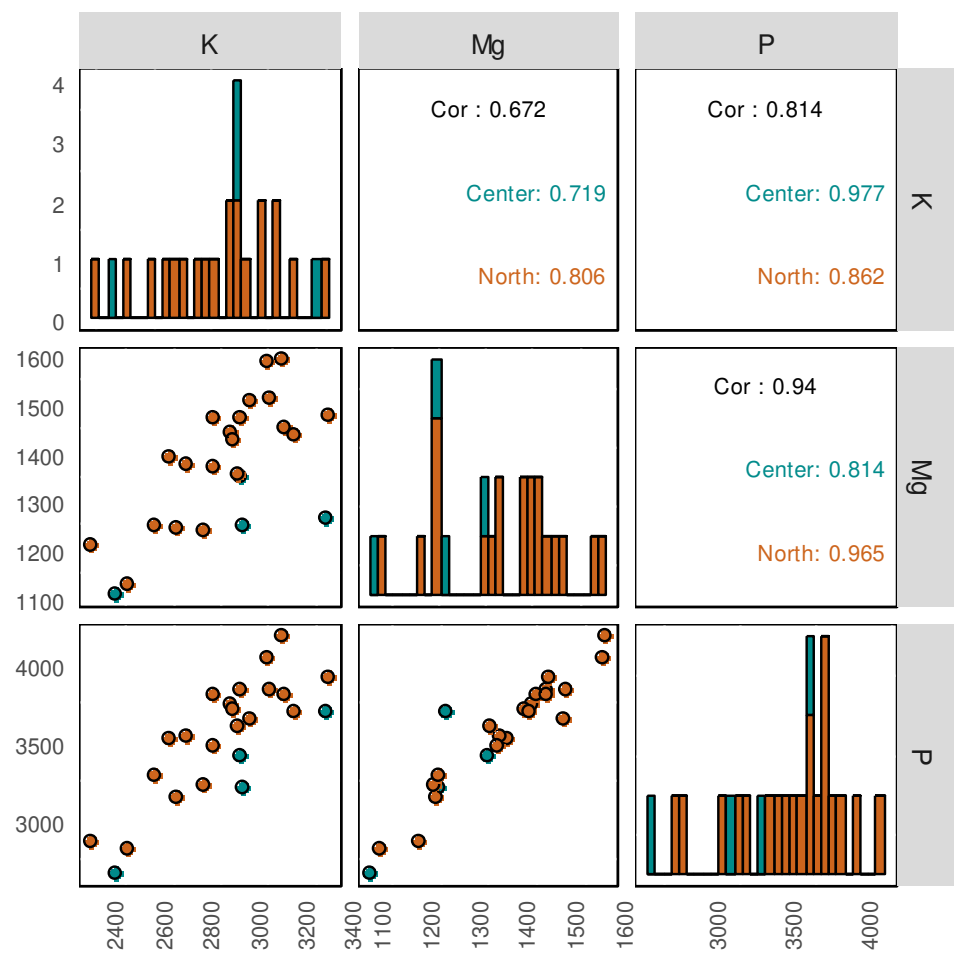

Fig. A1.1 Correlation matrix of $\mathrm{K}, \mathrm{Mg}$, and $\mathrm{P}$ concentrations in unpolished rice grains $\left(\mathrm{mg} \mathrm{kg}^{-1}\right)$ 


\section{Appendix A2: Supplementary Material for Chapter 4}

Table A2.1 Coordinates of sampling locations in the Mekong River Delta area, $\mathrm{pH}$-values and concentrations of main elements and LOI in paddy soils in wt. \% $(\mathrm{n}=78)$

\begin{tabular}{|c|c|c|c|c|c|c|c|c|c|c|c|c|c|c|c|}
\hline \multirow{2}{*}{ Sites } & \multicolumn{2}{|c|}{ Coordinate } & \multirow{2}{*}{ pH } & \multirow{2}{*}{ LOI } & \multirow{2}{*}{$\mathbf{A l}_{2} \mathbf{O}_{3}$} & \multirow{2}{*}{$\mathrm{CaO}$} & \multirow{2}{*}{$\mathrm{Fe}_{2} \mathrm{O}_{3}$} & \multirow{2}{*}{$\mathbf{K}_{2} \mathbf{O}$} & \multirow{2}{*}{ MgO } & \multirow{2}{*}{ MnO } & \multirow{2}{*}{$\mathrm{Na}_{2} \mathrm{O}$} & \multirow{2}{*}{$\mathbf{P}_{2} \mathbf{O}_{5}$} & & & \\
\hline & $\mathbf{E}$ & $\mathbf{N}$ & & & & & & & & & & & $S$ & & \\
\hline$\overline{\mathrm{K}-1}$ & 105.1789 & 0.84005 & 6.4 & 10 & 15.6 & 1.0 & 5.11 & .20 & 1.19 & 0.079 & 56 & & 007 & 0.72 & ש.0 \\
\hline & & & 7 & & & & & & & & & & & & \\
\hline IK-3 & 10 & 348 & 5.1 & & 6.2 & 55 & 58 & .51 & 0 & & & & & & 3.1 \\
\hline $\mathrm{K}-4$ & 105 & & 6.0 & 5 & 13.1 & 6 & 5.2 & 2.25 & 1.17 & & & & & & 0.3 \\
\hline & & & 56 & 6. & 6.1 & & & 2.59 & 1.33 & & & & & & \\
\hline & & & 6.4 & 4.7 & & & & & & & & & & & \\
\hline & 10 & & 51 & 8 & & & 5 & 226 & 99 & & & & & & \\
\hline & 10 & & 57 & 74 & & 048 & & 225 & 4 & & & & & & \\
\hline & & & 50 & 8 & & & & 65 & & & & & & & \\
\hline 10 & 07 & & 10 & 1 & .8 & & & 78 & & & & & & & \\
\hline & & & & & & & & 1.98 & & & & & & & \\
\hline & 52 & & & & & & & 2.38 & & & & & & & \\
\hline & & & 4.7 & & & & & & & & & & & & \\
\hline & 39 & & 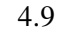 & & & & & & & & & & & & \\
\hline & 78 & & 4 & & & & & & & & & & & & \\
\hline & & & & & & & & & & & & & & & \\
\hline & & & 51 & & & & & & & & & & & & \\
\hline & & & 4.6 & & & & & & & & & & & & \\
\hline & & & & & & & & & & & & & & & \\
\hline & & & & & & & & & & & & & & & \\
\hline & & & & & & & & & & & & & & & \\
\hline & & & & & & & & & & & & & & & \\
\hline & & & 5 & & & & & & & & & & & & \\
\hline & & & 5. & & & & & & & & & & & & \\
\hline & & & & & & & & & & & & & & & \\
\hline & & & & & & & & & & & & & & & 5.3 \\
\hline & & & & & & & & & & & & & & & \\
\hline & & & & & & & & & & & & & & & 0.5 \\
\hline & & & 5 & & & & & & & & & & & & \\
\hline & & & & & & & & & & & & & & & 1.3 \\
\hline & & & & & & & & & & & & & & & 0.6 \\
\hline & & & 4 & & & & & & & & & & & & 3.0 \\
\hline & & & 5 & & & & & & & & & & & & 2.3 \\
\hline & & & 5. & & & & & & & & & & & & 8.5 \\
\hline & & & 4 & & & & & & & & & & & & 5.1 \\
\hline & & & 5 & & & & & & & & & & & & 2.3 \\
\hline & & & 4. & & & & & & & & & & & & 9.7 \\
\hline & & & 4. & & & & & & & & & & & & 8.5 \\
\hline & & & 4. & & & & & & & & & & & & 2.6 \\
\hline-43 & & & 4. & & & & & 9 & & & & & & & 9.6 \\
\hline $\mathrm{K}-44$ & & & 4. & & & & & & & & & & & & 59.7 \\
\hline $\mathrm{K}-45$ & & & 4. & & & & & & & & & & & & 62.7 \\
\hline-46 & & & 4. & & & & & & & & & & & & 5.1 \\
\hline K-47 & & & 4. & & & & & 2 & & & & & & & 63.5 \\
\hline K-48 & & & 4. & & & & & & & & & & & & 64.9 \\
\hline $\mathrm{K}-49$ & & & 4. & & & & & & & & & & & & 59.2 \\
\hline & & & 5 . & & & & & & & & & & & & 71.8 \\
\hline & & & 5. & & & & & 2.42 & & & & & 30 & 76 & 59.8 \\
\hline & & & 4. & & & & & & & & & & & & 60.1 \\
\hline & & & 4. & & & & & & & & & & & 75 & 61.2 \\
\hline & & & 4. & & & & & & & & & & & 78 & 59.3 \\
\hline & & & 5 . & & & & & & & & & & & 76 & 55.7 \\
\hline & 53 & & 5 . & & & & & 2.26 & & & & & & 78 & 65.5 \\
\hline & 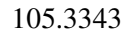 & & 5 . & 9 & & & & 2.31 & 1 & & & & & 0.76 & 63.1 \\
\hline & 5 & 79633 & 6. & 9 & & 1. & & 2.2 & 1. & & & & & 0.64 & 65.6 \\
\hline MK-60 & 105.3582 & 10.77364 & 5.2 & 9.1 & 15.8 & 0.53 & 5.10 & 2.40 & 1.13 & 0.058 & 0.60 & 0.20 & 0.05 & 0.72 & 64.3 \\
\hline
\end{tabular}


Table A2.1 (cont.) Coordinates of sampling locations in the Mekong River Delta area, $\mathrm{pH}$ values and concentrations of main elements and LOI in paddy soils in wt. \% ( $\mathrm{n}=78)$

\begin{tabular}{|c|c|c|c|c|c|c|c|c|c|c|c|c|c|c|c|}
\hline \multirow[b]{2}{*}{ Sites } & \multicolumn{2}{|c|}{ Coordinate } & \multirow[b]{2}{*}{ pH } & \multirow[b]{2}{*}{ LOI } & \multirow[b]{2}{*}{$\mathbf{A l}_{2} \mathbf{O}_{3}$} & \multirow[b]{2}{*}{$\mathrm{CaO}$} & \multirow[b]{2}{*}{$\mathrm{Fe}_{2} \mathrm{O}_{3}$} & \multirow[b]{2}{*}{$\mathbf{K}_{2} \mathrm{O}$} & \multirow[b]{2}{*}{ MgO } & \multirow[b]{2}{*}{ MnO } & \multirow[b]{2}{*}{$\mathrm{Na}_{2} \mathrm{O}$} & \multirow[b]{2}{*}{$\mathbf{P}_{2} \mathbf{O}_{5}$} & \multirow[b]{2}{*}{$\mathbf{S}$} & \multirow[b]{2}{*}{$\mathrm{TiO}_{2}$} & \multirow[b]{2}{*}{$\mathrm{SiO}_{2}$} \\
\hline & $\mathbf{E}$ & $\mathbf{N}$ & & & & & & & & & & & & & \\
\hline MK-61 & 105.3770 & 10.52436 & 5.3 & 7.7 & 14.0 & 0.50 & 5.15 & 2.19 & 1.05 & 0.058 & 0.70 & 0.18 & 0.03 & 0.78 & 67.7 \\
\hline $\mathrm{K}-62$ & 105.3861 & 10.51619 & 5.4 & 8.4 & 14.6 & 0.52 & 4.29 & 2.08 & 0.92 & 0.037 & 0.58 & 0.21 & 0.04 & .74 & 7.5 \\
\hline MK-63 & 105.4013 & 10.50378 & 5.6 & 8.4 & 14.8 & 0.59 & 5.18 & 2.26 & 1.06 & 0.068 & 0.60 & 0.26 & 0.04 & .74 & 6.0 \\
\hline IK-64 & 105.3988 & 10.48869 & 3.8 & 9.9 & 18.1 & 0.30 & 4.93 & 2.48 & 1.05 & 0.016 & 0.58 & 0.12 & 0.16 & 0.82 & 61.6 \\
\hline K-65 & 105.3840 & 10.43972 & 4.0 & 10.2 & 20.1 & 0.40 & 5.14 & 2.63 & 1.09 & 0.027 & 0.49 & 0.12 & 0.26 & 0.77 & 58.8 \\
\hline K-66 & 105.3900 & 10.43422 & 3.7 & 9.2 & 19.5 & 0.53 & 5.38 & 2.65 & 1.13 & 0.034 & 0.52 & 0.10 & 0.34 & 0.79 & 59.9 \\
\hline K-67 & 105.9468 & 9.877722 & 4.8 & 11.4 & 18.9 & 0.43 & 4.02 & 2.76 & 1.07 & 0.020 & 0.59 & 0.17 & 0.08 & 0.86 & 59.7 \\
\hline MK-68 & 105.9506 & 9.868500 & 5.1 & 12.9 & 18.5 & 0.46 & 3.52 & 2.71 & 1.05 & 0.024 & 0.60 & 0.19 & 0.09 & 0.86 & 59.1 \\
\hline MK-69 & 105.9633 & 9.862083 & 5.0 & 12.6 & 18.5 & 0.43 & 3.67 & 2.70 & 1.05 & 0.022 & 0.58 & 0.20 & 0.08 & .85 & 59.2 \\
\hline MK-70 & 105.9845 & 9.837694 & 5.1 & 12.0 & 19.3 & 0.47 & 5.57 & 2.73 & 1.18 & 0.042 & 0.55 & 0.19 & 0.08 & .83 & 57.1 \\
\hline MK-71 & 105.9907 & 9.832972 & 5.0 & 14.7 & 18.3 & 0.70 & 5.32 & 2.59 & 1.15 & 0.040 & 0.56 & 0.24 & 0.12 & .80 & 55.5 \\
\hline MK-72 & 106.0933 & 9.811639 & 5.4 & 11.8 & 13.6 & 0.65 & 4.78 & 2.13 & 0.79 & 0.021 & 0.69 & 0.28 & 0.09 & 0.76 & 64.4 \\
\hline MK-73 & 106.0785 & 9.825667 & 5.7 & 11.0 & 14.7 & 0.50 & 5.07 & 2.29 & 0.94 & 0.030 & 0.68 & 0.21 & 0.10 & 0.76 & 63.7 \\
\hline MK-74 & 106.0783 & 9.812667 & 4.9 & 12.3 & 13.7 & 0.96 & 4.80 & 2.15 & 0.80 & 0.021 & 0.70 & 0.29 & 0.12 & 0.74 & 63.4 \\
\hline MK-75 & 106.0711 & 9.846556 & 4.7 & 8.6 & 13.4 & 0.35 & 3.81 & 2.02 & 0.76 & 0.046 & 0.69 & 0.13 & 0.10 & 0.81 & 69.3 \\
\hline MK-76 & 105.6119 & 10.35236 & 4.3 & 14.4 & 19.5 & 0.49 & 3.64 & 2.19 & 0.89 & 0.016 & 0.43 & 0.18 & 0.16 & 0.78 & 57.3 \\
\hline MK-77 & 105.6144 & 10.35535 & 4.4 & 10.5 & 15.9 & 0.48 & 4.78 & 2.26 & 1.02 & 0.025 & 0.61 & 0.16 & 0.11 & 0.78 & 63.4 \\
\hline MK-78 & 105.6179 & 10.36672 & 4.8 & 10.8 & 18.7 & 0.48 & 4.57 & 2.44 & 1.04 & 0.026 & 0.51 & 0.18 & 0.08 & 0.81 & 60.4 \\
\hline MK-79 & 105.6466 & 10.38142 & 4.4 & 15.0 & 20.2 & 0.46 & 5.24 & 2.40 & 1.08 & 0.018 & 0.40 & 0.16 & 0.18 & 0.69 & 54.1 \\
\hline MK-80 & 105.7149 & 10.47660 & 4.5 & 14.2 & 17.8 & 0.44 & 3.82 & 2.16 & 0.87 & 0.020 & 0.41 & 0.12 & 0.13 & 0.79 & 59.2 \\
\hline MK-81 & 105.7232 & 10.49193 & 4.2 & 12.8 & 17.1 & 0.45 & 5.37 & 2.23 & 0.91 & 0.029 & 0.50 & 0.16 & 0.22 & 0.79 & 59.5 \\
\hline MK-82 & 105.8007 & 10.48096 & 4.0 & 14.5 & 15.9 & 0.50 & 3.15 & 2.08 & 0.70 & 0.019 & 0.49 & 0.30 & 0.43 & 0.84 & 61.1 \\
\hline
\end{tabular}


Table A2.2 Concentrations of trace elements in paddy soils in the Mekong River Delta area in $\mathrm{mg} \mathrm{kg}^{-1}(\mathrm{n}=78)$

\begin{tabular}{|c|c|c|c|c|c|c|c|c|c|c|c|c|c|c|c|c|c|c|c|c|c|c|c|c|}
\hline Sites & As & $\mathbf{B a}$ & $\mathbf{B i}$ & Cd & $\mathrm{Ce}$ & Co & Cs & $\mathbf{C u}$ & Hf & La & $\mathbf{L i}$ & Мo & $\mathbf{N i}$ & $\mathbf{P b}$ & $\mathbf{R b}$ & Sb & Sn & $\mathrm{Sr}$ & Th & Tl & $\mathbf{U}$ & $\mathbf{V}$ & Zn & $\mathbf{Z r}$ \\
\hline MK-1 & 13.4 & 416 & .39 & 0.33 & 73 & 13.9 & 10.6 & 31 & 3.89 & 37 & 45 & 0.77 & 39 & 25 & 120 & 1.94 & 3.9 & 88 & 14.4 & 0.64 & 4.0 & 107 & 103 & 145 \\
\hline $\mathrm{K}-2$ & 13.1 & 3 & 18 & 4 & 85 & 1.0 & 14.3 & 38 & 4.09 & 43 & 58 & 15 & 44 & 31 & 143 & .33 & 47 & 87 & 17.5 & 81 & 4.9 & 138 & 98 & 51 \\
\hline K-3 & 12.3 & 11 & 46 & .36 & 86 & 5.4 & 10.2 & 33 & 4.55 & 42 & 47 & 0.67 & 37 & 30 & 120 & .69 & 4.5 & 87 & 16.6 & .66 & 4.6 & 114 & 93 & 167 \\
\hline K-4 & 12.5 & 370 & 36 & 0.33 & 74 & 3.8 & 8.0 & 26 & 4.84 & 37 & 37 & 0.57 & 30 & 24 & 103 & 2.26 & 3.8 & 84 & 14.7 & 0.55 & 3.8 & 92 & 73 & 174 \\
\hline K-5 & 15.8 & 419 & 0.42 & 0.33 & 85 & 17.2 & 10.3 & 30 & 4.65 & 41 & 47 & 0.77 & 38 & 29 & 123 & 2.35 & 4.3 & 89 & 16.1 & 0.66 & 4.2 & 113 & 98 & 170 \\
\hline K-6 & 13.6 & 366 & 0.34 & 0.29 & 74 & 14.0 & 8.1 & 25 & 4.95 & 37 & 38 & 0.60 & 32 & 23 & 99 & 1.98 & 3.6 & 87 & 14.3 & 0.54 & 3.6 & 91 & 74 & 180 \\
\hline K-7 & 12.8 & 390 & 0.36 & 0.33 & 76 & 13.4 & 9.4 & 33 & 4.70 & 38 & 43 & 0.66 & 34 & 26 & 109 & 2.01 & 3.8 & 85 & 14.8 & 0.60 & 4.3 & 106 & 95 & 171 \\
\hline $\mathrm{K}-8$ & 28.9 & 417 & 0.37 & 0.38 & 85 & 19.9 & 9.2 & 29 & 4.51 & 39 & 42 & 0.82 & 35 & 29 & 110 & 2.05 & 4.0 & & 14.5 & 0.58 & 4.5 & 107 & 87 & 165 \\
\hline K-9 & 25.2 & 465 & 0.44 & 0.31 & 82 & 15.4 & 12.7 & 34 & 4.00 & 41 & 53 & 0.77 & 41 & 29 & 137 & 2.07 & 4.6 & & 16.0 & 0.74 & 4.8 & 126 & 98 & 149 \\
\hline-10 & 13.0 & 57 & 0.52 & 0.3 & 83 & 15.1 & 14.2 & 36 & 3.93 & 42 & 58 & 0.78 & 43 & 2 & 145 & 2.54 & 5.2 & & 17.3 & 83 & 4.9 & 131 & 112 & 146 \\
\hline-11 & 9.5 & 6 & 0.29 & 0.26 & 69 & 12 & 7.2 & 24 & 4.47 & 3 & 35 & 0.49 & 27 & 22 & 9 & 1.92 & 3.5 & & 13.0 & 0 & 3.9 & 84 & 73 & 165 \\
\hline-12 & 6.0 & 403 & 0.40 & 0.32 & 81 & 5.6 & 9.0 & 28 & 4.40 & 40 & 41 & 0.71 & 34 & 25 & 113 & 2.33 & 4.2 & & 15.5 & 60 & 3.9 & 101 & 79 & 163 \\
\hline-13 & 14.5 & 420 & 0.45 & 0.3 & 86 & 16.5 & 11.2 & 33 & 4.54 & 4 & 48 & 0.69 & 39 & 30 & 131 & 2.37 & 4.5 & & 16.7 & .70 & 4.9 & 117 & 100 & 167 \\
\hline K-14 & 9.1 & 353 & 0.34 & 0.29 & 72 & 12.0 & 8.5 & 29 & 5.09 & 36 & 39 & 0.51 & 29 & 190 & 109 & 6.45 & 4.4 & 78 & 14.2 & 0.55 & 4.0 & 92 & 81 & 188 \\
\hline K-15 & 13.5 & 371 & 0.34 & 0.30 & 75 & 14.3 & 8.0 & 26 & 4.81 & 37 & 39 & 0.60 & 31 & 24 & 101 & 2.04 & 3.6 & 8 & 14.3 & 0.55 & 4.2 & 94 & 73 & 175 \\
\hline-16 & 13.6 & 375 & 0.35 & 0.29 & 77 & 14.8 & 8.1 & 27 & 4.02 & 38 & 39 & 0.52 & 31 & 24 & 104 & 2.14 & 36 & 90 & 14.1 & 0.55 & 4.1 & 95 & 76 & 147 \\
\hline-17 & 15.3 & 368 & 0.38 & 0.28 & 74 & 14.0 & 8.4 & 27 & 3.97 & 36 & 39 & 0.64 & 31 & & 103 & 2.11 & 3.8 & & 14.3 & 0.56 & 4.1 & 5 & 77 & 145 \\
\hline & 15.7 & 423 & 0.49 & 0.33 & 86 & 15.4 & 12.0 & 35 & 3.90 & 43 & 50 & 0.82 & 41 & & 136 & 2.67 & 4.7 & & 16.8 & 0.74 & 4.8 & 121 & 104 & 144 \\
\hline & 12.8 & 0 & 0.38 & 0 & 78 & 14.9 & 8.5 & 28 & 4.15 & 38 & 38 & 0.58 & 33 & & 10 & 2.41 & 3.9 & & 14.8 & .58 & 4.6 & 94 & 82 & 152 \\
\hline 20 & 13.1 & 398 & 0.39 & 0. & 81 & 16.4 & 9.4 & 30 & 4.14 & 4 & 43 & 2. & 42 & 26 & 1 & 2.17 & 3 & & 14.9 & 0.62 & 4.4 & 107 & 89 & 154 \\
\hline-21 & 10.7 & 371 & 0.38 & 0.3 & 76 & 12 & 9.6 & 29 & 4. & 3 & 43 & 0. & 32 & 2. & 10 & 2.05 & 3 & & 14.8 & 51 & 4.3 & 102 & 85 & 152 \\
\hline $\mathrm{K}-22$ & 11.2 & 406 & 0.41 & 0.2 & 81 & 12.6 & 12.4 & 31 & 4.05 & 4 & 52 & 0.99 & 38 & 26 & 12 & 2.14 & 4.2 & 80 & 15.8 & 0.72 & 5.2 & 118 & 90 & 148 \\
\hline $\mathrm{K}-23$ & 10.2 & 405 & 0.40 & 0.32 & 73 & 12.9 & 12.4 & 33 & 3.61 & 3 & 53 & 1.08 & 39 & 27 & 111 & 2.15 & 4.1 & 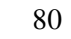 & 14.8 & 0.70 & 5.2 & 117 & 100 & 131 \\
\hline $\mathrm{K}-24$ & 11.8 & 42 & 0.41 & 0.36 & 79 & 13.4 & .8 & 34 & 3.80 & 4( & 53 & 0.98 & 38 & 26 & 12 & 2.03 & 4.2 & 8 & 15.9 & 0.72 & 5.0 & 12 & 99 & 141 \\
\hline-25 & 8.5 & 3 & 0.37 & 0.26 & 74 & 11.8 & 10.4 & 28 & 3.92 & 37 & 45 & 0.67 & 33 & 24 & 10 & 1.99 & 3.9 & & 14.3 & 0.63 & 4.4 & 10 & 92 & 142 \\
\hline-26 & 12.5 & 311 & 0.47 & 0.17 & 79 & 14.1 & 12.1 & 27 & 3.63 & 39 & 63 & 1.15 & 42 & 27 & 136 & 1.30 & 4.6 & & 16.4 & .67 & 4.7 & 119 & 98 & 136 \\
\hline-27 & 10.5 & 313 & 0.38 & 0.1 & 81 & 13.8 & 9.4 & 20 & 4.57 & 40 & 4 & 0.98 & 36 & 3 & 116 & 1.07 & 3.9 & & 15.4 & .58 & 4.9 & 0 & 81 & 164 \\
\hline & 12.0 & & 0.44 & 0. & 80 & 13.6 & 13.0 & 30 & 3.87 & 40 & 6 & 0.85 & 39 & & 1. & 2.22 & 4.4 & & 15.9 & 0.77 & 4.5 & 5 & 96 & 145 \\
\hline & 14 & & 0. & 0. & 8 & 15 & & 3. & 3. & 4( & 46 & 0. & 38 & & 12 & 2.34 & 4.2 & & 15.5 & 67 & 4.2 & & 97 & 145 \\
\hline & 11 & & 0. & & $8 c$ & 13.9 & & 32 & 4. & 42 & 47 & 0. & 3 & & 13 & 2.47 & 4 & & 16.0 & 8 & 5.0 & & 98 & 148 \\
\hline-33 & 10.4 & 4 & 0.44 & 0. & 86 & 13.1 & 11.9 & 34 & 3.96 & 4 & 50 & 0.72 & 38 & 28 & 13 & 2.24 & 4.6 & 8 & 16.1 & 0.69 & 4.8 & 125 & 102 & 147 \\
\hline K-34 & 11.5 & 4 & 0.38 & 0.2 & 78 & 13.2 & 10.8 & 31 & 4.15 & 40 & 46 & 0.75 & 36 & 26 & 12 & 1.94 & 3.9 & 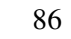 & 15.1 & 0.64 & 4.3 & 114 & 91 & 151 \\
\hline K-35 & 18 & 4 & 0.40 & 0 & 0 & 14 & 11.2 & 29 & 4.30 & 43 & 48 & 0. & 37 & 27 & 12 & 1.90 & 4.7 & & 16.0 & 0.67 & 4.6 & 115 & 92 & 158 \\
\hline-36 & 13.0 & 4 & 0.44 & 0.2 & 108 & 14.2 & 12.8 & 34 & 3.90 & 5 & 62 & 1. & 44 & 29 & 12 & 2.12 & 4.4 & 81 & 15.9 & 0.72 & 5.2 & 126 & 118 & 145 \\
\hline-37 & 11.4 & 3 & 0.37 & 0.29 & 81 & 1 & 9.8 & 30 & 4.36 & 40 & 43 & 0.63 & 3 & 2 & 11 & 1.88 & 3.8 & & 14.9 & 0.60 & 4.3 & 108 & 87 & 161 \\
\hline-38 & 11.6 & 434 & 0.39 & 0.23 & 76 & 13.0 & 12.7 & 29 & 3.89 & 39 & 52 & 0.85 & 37 & 26 & 132 & 1.96 & 4.7 & 84 & 15.4 & 0.72 & 4.9 & 120 & 90 & 143 \\
\hline-40 & 10.9 & 432 & 0.43 & 0.32 & 79 & 13.7 & 13.2 & 36 & 3.89 & 41 & 54 & 0.84 & 41 & 28 & 13 & 2.13 & 4.1 & 86 & 15.7 & 0.74 & 4.7 & 126 & 102 & 147 \\
\hline K-41 & 13.3 & 433 & 0.47 & 0.3 & 8. & 14. & 12.5 & 35 & 3.80 & 42 & 52 & 0.8 & 41 & $x$ & 13 & 2.49 & 4.4 & $\delta$ & 16.2 & 0.74 & 4.5 & 124 & 106 & 142 \\
\hline MK-42 & 14.0 & 386 & 0.42 & 0.37 & 77 & 13.4 & 10.3 & 32 & 4.13 & 39 & 43 & 0.90 & 37 & 28 & 119 & 2.57 & 4.3 & 79 & 15.1 & 0.64 & 4.2 & 107 & 94 & 152 \\
\hline
\end{tabular}


Table A2.2 (Cont.) Concentrations of trace elements in paddy soils in the Mekong River Delta area in $\mathrm{mg} \mathrm{kg}^{-1}(\mathrm{n}=78)$

\begin{tabular}{|c|c|c|c|c|c|c|c|c|c|c|c|c|c|c|c|c|c|c|c|c|c|c|c|c|}
\hline Sites & As & $\mathbf{B a}$ & $\mathbf{B i}$ & Cd & $\mathrm{Ce}$ & Co & $\mathrm{Cs}$ & $\mathbf{C u}$ & Hf & La & $\mathbf{L i}$ & Mo & $\mathbf{N i}$ & $\mathbf{P b}$ & $\mathbf{R b}$ & Sb & Sn & $\mathbf{S r}$ & Th & Tl & $\mathbf{U}$ & $\mathrm{V}$ & $\mathbf{Z n}$ & $\mathbf{Z r}$ \\
\hline MK-43 & 9.0 & 378 & .32 & 0.18 & 75 & 8.7 & 8.5 & 24 & 4.42 & 38 & 43 & 0.93 & 26 & 22 & 102 & 1.55 & 3.4 & 82 & 13.9 & 0.54 & 4.0 & 92 & 62 & 162 \\
\hline K-44 & 0.4 & 409 & 41 & 0.16 & 82 & 8.8 & 12.9 & 27 & 4.08 & 42 & 59 & 01 & 32 & 28 & 129 & .70 & 4.3 & 87 & 16.1 & 71 & 4.6 & 122 & 74 & 152 \\
\hline K-45 & 11.0 & 3 & 0.38 & 0. & 87 & 10.5 & 10.7 & 27 & 4.30 & 43 & 51 & 0.81 & 31 & 5 & 114 & & 4.1 & 87 & 16.1 & 62 & 5.0 & 0 & 79 & 158 \\
\hline-46 & 8.4 & 50 & 34 & & 4 & 6.7 & 10.4 & 25 & 4.29 & 50 & 0 & .31 & 24 & 1 & 120 & & & & & 59 & 4.1 & 8 & 53 & 157 \\
\hline K-47 & 18.6 & 32 & 38 & 0.21 & f & 11.7 & 10.8 & 25 & 4.21 & 39 & 52 & 07 & 31 & 5 & 121 & .61 & 4.0 & & 15.2 & 62 & 4.3 & 107 & 72 & 154 \\
\hline K-48 & 9.2 & 357 & 0.40 & 0.16 & 73 & 5.6 & 10.2 & 28 & 4.09 & 37 & 46 & 1.53 & 23 & 24 & 115 & 1.58 & 4.0 & & 14.7 & .60 & 4.6 & 104 & 51 & 149 \\
\hline $\mathrm{K}-49$ & 11.0 & 395 & 0.39 & 0.16 & 78 & 7.7 & 12.7 & 27 & 3.67 & 40 & 60 & 1.20 & 30 & 27 & 129 & 1.64 & 4.3 & 79 & 14.9 & 0.69 & 4.6 & 116 & 69 & 137 \\
\hline K-51 & 10.0 & 325 & 0.31 & 0.24 & 70 & 12.1 & 7.8 & 24 & 3.88 & 35 & 36 & 0.60 & 27 & 22 & 95 & 1.86 & 3.2 & 71 & 12.6 & 0.50 & 3.6 & 86 & 72 & 144 \\
\hline-52 & 13.1 & 407 & 0.42 & 0.30 & 82 & 20.6 & 12.2 & 35 & 3.76 & 42 & 49 & 1.07 & 44 & 27 & 136 & 2.35 & 4.4 & 88 & 15.3 & 0.69 & 4.4 & 116 & 109 & 141 \\
\hline-53 & 12.7 & 415 & 0.44 & 0.29 & 81 & 13.4 & 12.2 & 35 & 3.81 & 41 & 50 & 1.11 & 39 & 29 & 135 & 2.32 & 4.3 & 8 & 15.8 & 0.72 & 4.5 & 119 & 99 & 141 \\
\hline & 11.0 & 402 & 0.45 & 0.30 & 83 & 14.0 & 12.2 & 36 & 3.83 & 42 & 51 & 0.92 & 40 & 9 & 134 & 2.37 & 4.3 & 79 & 15.6 & 0.72 & 4.4 & 16 & 104 & 143 \\
\hline & 13.7 & 447 & 0.48 & 0.31 & 0 & 16.7 & 13.5 & 38 & 3.50 & 46 & 57 & 1.12 & 47 & 1 & 14 & 2.58 & 4 & & 16.4 & 76 & 4.7 & 9 & 5 & 133 \\
\hline K-56 & 13.4 & 56 & 0.49 & 0 & 95 & 17.1 & 14.3 & 41 & 3.45 & 47 & 61 & 1. & 50 & 32 & 14 & 2.62 & $T$ & & 16.4 & 80 & 4.9 & 4 & 20 & 132 \\
\hline K-57 & 15.0 & 396 & 0.39 & 0.32 & 90 & 6.7 & 10.7 & 32 & 3.75 & 44 & 46 & 0.93 & 39 & 27 & 120 & 2.07 & 3.9 & & 14.9 & 63 & 4.4 & 0 & 07 & 142 \\
\hline-5 & 14.2 & 400 & 0.41 & 0.2 & 0 & 5.1 & 11.5 & 34 & 3.72 & 45 & 49 & 0.98 & 40 & 28 & 121 & 2.22 & 4.0 & & 15.2 & 67 & 4.5 & 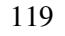 & 101 & 139 \\
\hline-59 & 10.4 & 406 & 0.33 & 0.2 & 68 & 12.4 & 10.4 & 28 & 3.09 & 35 & 43 & 0.68 & 34 & 24 & 116 & 1.73 & 3.5 & 8 & 12.8 & 0.63 & 3.6 & 100 & 86 & 115 \\
\hline-60 & 12.6 & 414 & 0.38 & 0.28 & 76 & 14.1 & 11.2 & 32 & 3.48 & 39 & 46 & 0.67 & 37 & 26 & 128 & 1.98 & 4.2 & o. & 14.4 & 0.67 & 3.9 & 108 & 93 & 131 \\
\hline-61 & 13.5 & 378 & 0.37 & 0.31 & 78 & 13.9 & 8.8 & 29 & 4.10 & 39 & 38 & 0.63 & 32 & 26 & 110 & 2.20 & 3.9 & 7 & 14.7 & 0.57 & 4.2 & & 84 & 153 \\
\hline-62 & 10.6 & 377 & 0.34 & 0.28 & $r$ & 13.0 & 9.9 & 25 & 4.70 & 38 & 43 & 0.63 & 32 & & 110 & 1.83 & 5.0 & & 14.2 & .59 & 4.3 & & 86 & 179 \\
\hline 3 & 13.9 & 393 & 0.39 & 0.4 & 78 & 15.4 & 9.7 & 29 & 4.42 & 39 & 42 & 0.67 & 34 & & 113 & 2.00 & 4.0 & & 15.0 & 61 & 4.4 & 00 & 91 & 168 \\
\hline & 14.5 & 406 & 0.43 & 0.2 & 79 & 10.8 & 13.0 & 29 & 4.50 & 41 & 57 & 0.99 & 34 & 8 & 129 & 1.93 & 4.7 & & 14.3 & .71 & 4.3 & 8 & 87 & 171 \\
\hline & 11.5 & 6 & 0.40 & 0. & 103 & 20.1 & 14.5 & 28 & 4.02 & 51 & 69 & 0 & 48 & & 1 & 1.92 & 4.3 & & 15.4 & 78 & 4.7 & & 34 & 153 \\
\hline $\mathrm{K}-66$ & 14.4 & 443 & 0.42 & 0. & 9 & 19.0 & 14.1 & 3 & 4.25 & $4 c$ & 64 & 0.8 & 4. & 29 & 14 & 1.99 & 4.4 & & 15.9 & 78 & 4.6 & 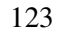 & 118 & 161 \\
\hline K-67 & 9.8 & 383 & 0.42 & 0.1 & & 9.1 & 13.3 & 27 & 4.43 & 43 & 60 & 0.96 & 32 & 26 & 14 & 1.43 & 4 & & 16.6 & .72 & 4.3 & 115 & 78 & 166 \\
\hline-6 & 8.3 & 378 & 0.41 & 0.2 & 8 & 8.8 & 13.3 & 28 & 4.31 & 44 & 59 & 1.01 & 32 & 26 & 150 & 1.41 & 4.3 & 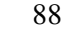 & 16.6 & 0.70 & 4.4 & 1 & 80 & 161 \\
\hline-6 & 8. & 373 & 0.41 & 0.1 & & 8.5 & 13.3 & 2 & 4.27 & 4 & 61 & 0. & 32 & 26 & 15 & 1.43 & 4. & 8 & 16.3 & 0.71 & 4.4 & 114 & 77 & 163 \\
\hline-7 & 13.8 & 4 & 0.43 & 0.1 & & 10.5 & 13.8 & 28 & 4.15 & 43 & 66 & 0.9 & 35 & 28 & 14 & 1.71 & 4.5 & 8 & 16.2 & .74 & 4.2 & 12 & 79 & 158 \\
\hline-7 & 12.5 & 3 & 0.42 & 0.1 & & 10.1 & 13.2 & 28 & 4.10 & 42 & 61 & 0.92 & 34 & & 14 & 1.73 & 4.7 & & 15.6 & 70 & 4.1 & 11 & 79 & 154 \\
\hline-72 & 12.8 & 290 & 0.38 & 0.21 & 75 & 8.3 & 9.3 & 29 & 5.26 & 38 & 43 & 1.69 & 27 & 5 & 113 & 1.34 & 3.9 & 104 & 15.6 & .54 & 4.1 & 94 & 74 & 197 \\
\hline & 14.0 & 296 & 0.38 & 0.2 & 7 & 10.4 & 10.2 & 25 & 4.93 & 38 & 47 & & 31 & & 120 & 1.32 & 3.9 & & 15.4 & 55 & 4.0 & 98 & 73 & 188 \\
\hline & 12.0 & & 0.36 & 0.2 & & 7.9 & 9. & 26 & 5.10 & 3. & 43 & & 26 & & 11 & 1.29 & 3.7 & 10 & 14.5 & 52 & 4.0 & & 70 & 192 \\
\hline M & 8. & & 0. & 0.2 & & 0.7 & 8. & $2 ?$ & 4.84 & 4( & T. & 0. & 2 & & 10 & 1.3 & & & 15.0 & 53 & 4.2 & & 0 & 179 \\
\hline 7 & 11.2 & & 0.4 & & & 1 & 14.5 & 36 & 4.15 & 45 & 76 & 1.7 & 38 & & 12 & 2.35 & 4. & & 16.2 & .75 & 4.9 & 125 & 83 & 157 \\
\hline 7 & 114 & & 0 & & & 15 & 11.2 & 34 & 3.96 & 40 & 50 & 0. & 3 & & 11 & 1.94 & 4. & & 14.6 & 64 & 4.1 & 106 & 118 & 148 \\
\hline 7 & 12 & 430 & 0 & 02 & & 13.6 & 13.2 & 32 & 3.91 & 42 & 5 & 1. & 38 & & 12 & 2.1 & 4.3 & 8 & 15.7 & 0.72 & 4.7 & 121 & 103 & 147 \\
\hline K-79 & 16 & 460 & 50 & 0.3 & & 148 & 18 & 43 & 3.68 & 46 & 69 & 2. & 5( & & 13 & 2.8 & 4.4 & & 16.1 & 0.79 & 5.3 & 139 & 110 & 141 \\
\hline 0 & 1 & 384 & 0.39 & 0.2 & 8 & 15 & 33 & 30 & 3.83 & 43 & 60 & 1. & 36 & 27 & 12 & 1.93 & 4.2 & 75 & 15.1 & .71 & 4.6 & 5 & 85 & 145 \\
\hline K-81 & 17.1 & 355 & 0.41 & 0.29 & 95 & 14.9 & 12.1 & 29 & 4.06 & 46 & 58 & 1.44 & 41 & 27 & 116 & 2.13 & 4.1 & 76 & 16.2 & 0.66 & 4.8 & 118 & 101 & 154 \\
\hline MK-82 & 10.2 & 345 & 0.34 & 0.20 & 91 & 8.4 & 11.1 & 22 & 4.19 & 45 & 59 & 1.31 & 31 & 25 & 111 & 1.52 & 3.9 & 89 & 14.2 & 0.62 & 4.3 & 99 & 69 & 157 \\
\hline
\end{tabular}


Appendix A2

Table A2.3 Concentrations of elements in rice grains in the Mekong River Delta area in $\mathrm{mg} \mathrm{kg}^{-1}(\mathrm{n}=78)$

\begin{tabular}{|c|c|c|c|c|c|c|c|c|c|c|c|c|c|c|c|c|c|c|c|}
\hline Sites & Al & $\mathbf{C a}$ & $\mathbf{F e}$ & $\mathbf{K}$ & Mg & Mn & $\mathrm{Na}$ & $\mathbf{P}$ & $S$ & $\mathbf{T i}$ & $\overline{A s}$ & $\mathbf{B a}$ & $\mathbf{B i}$ & Cd & $\mathrm{Ce}$ & Co & $\mathrm{Cr}$ & Cs & $\mathrm{Cu}$ \\
\hline MK-1 & $<0.8$ & 73 & 8.5 & 1817 & 1128 & 15.1 & 4.1 & 2598 & 770 & $<0.05$ & 0.10 & 0.40 & 0.0003 & 0.003 & $<0.0006$ & 0.009 & $<0.1$ & 0.032 & 2.74 \\
\hline MK-2 & $<0.8$ & 87 & 11.2 & 2415 & 1488 & 2.1 & 9.0 & 3570 & 1024 & $<0.05$ & 0.15 & 0.45 & 0.0006 & 0.064 & 0.0006 & .012 & 0.1 & 047 & 2.72 \\
\hline MK-3 & $<0.8$ & 78 & 8.8 & 2257 & 1323 & 21.1 & 5.8 & 3210 & 814 & $<0.05$ & 0.11 & 0.71 & 0.0004 & 0.021 & $<0.0006$ & 0.014 & $<0.1$ & 022 & 3.09 \\
\hline MK-4 & 1.4 & 72 & 9.6 & 2595 & 1342 & 24.7 & 5.6 & 3546 & 866 & $<0.05$ & 0.11 & 0.54 & 0.0003 & 0.026 & 0.0006 & 0.022 & $<0.1$ & 0.030 & 4.96 \\
\hline MK-5 & $<0.8$ & 71 & 8.4 & 2483 & 1362 & 18.6 & 5.1 & 3348 & 782 & $<0.05$ & 0.13 & 0.56 & 0.0004 & 0.020 & $<0.0006$ & 0.021 & $<0.1$ & 0.022 & 3.19 \\
\hline MK-6 & 2.2 & 68 & 8.7 & 2629 & 1336 & 22.1 & 5.8 & 3310 & 793 & 0.07 & 0.11 & 0.60 & 0.0002 & 0.026 & 0.0013 & 0.027 & $<0.1$ & 0.022 & 10.21 \\
\hline MK-7 & $<0.8$ & 79 & 10.1 & 2690 & 1473 & 18.7 & 12.4 & 3576 & 879 & 0.09 & 0.18 & 0.62 & 0.0004 & 0.005 & 0.0007 & 0.011 & $<0.1$ & 0.015 & 3.42 \\
\hline MK-8 & $<0.8$ & 85 & 11.6 & 2666 & 1382 & 28.6 & 12.1 & 3511 & 938 & 0.06 & 0.20 & 1.48 & 0.0015 & 0.038 & 0.0010 & 0.031 & .1 & 013 & 4.57 \\
\hline MK-9 & $<0.8$ & 66 & 9.3 & 2264 & 1167 & 23.1 & 4.4 & 2857 & 812 & 0.10 & 0.23 & 0.29 & $<0.0002$ & 0.007 & $<0.0006$ & 0.014 & .1 & 004 & 3.99 \\
\hline MK-10 & $<0.8$ & 86 & 9.5 & 2336 & 1121 & 14.0 & 4.4 & 2967 & 737 & 0.17 & 0.35 & 0.25 & 0.0003 & 0.003 & 0.0006 & 0.012 & .1 & 13 & 1.09 \\
\hline MK-11 & $<0.8$ & 82 & 7.8 & 2320 & 1149 & 22.2 & 4.0 & 2925 & 770 & 0.41 & 0.31 & 0.29 & 0.0006 & 0.047 & $<0.0006$ & 0.019 & $<0.1$ & 19 & 2.72 \\
\hline MK-12 & $<0.8$ & 73 & 7.3 & 2140 & 1145 & 19.4 & 3.4 & 2758 & 624 & $<0.05$ & 0.42 & 0.42 & 0.0003 & 0.003 & $<0.0006$ & 0.023 & $<0.1$ & 0.028 & 2.06 \\
\hline MK-13 & $<0.8$ & 92 & 11.0 & 2574 & 1251 & 20.9 & 4.8 & 3114 & 746 & $<0.05$ & 0.27 & 0.31 & 0.0004 & 0.008 & $<0.0006$ & 0.023 & $<0.1$ & 0.040 & 1.47 \\
\hline MK-14 & $<0.8$ & 81 & 8.6 & 2398 & 1226 & 20.2 & 3.3 & 3118 & 882 & $<0.05$ & 0.31 & 0.37 & $<0.0002$ & 0.007 & $<0.0006$ & 0.018 & $<0.1$ & 0.007 & 1.67 \\
\hline MK-15 & $<0.8$ & 72 & 7.8 & 2226 & 1084 & 18.6 & 5.3 & 2721 & 831 & $<0.05$ & 0.27 & 0.34 & 0.0005 & 0.021 & $<0.0006$ & 0.023 & $<0.1$ & 0.017 & 2.59 \\
\hline MK-16 & 2.2 & 76 & 6.6 & 2082 & 1011 & 14.7 & 4.4 & 2469 & 784 & $<0.05$ & 0.17 & 0.72 & 0.0003 & 0.025 & $<0.0006$ & 0.020 & $<0.1$ & 0.045 & 2.76 \\
\hline MK-17 & $<0.8$ & 88 & 8.9 & 2551 & 1223 & 24.9 & 4.6 & 3116 & 959 & $<0.05$ & 0.19 & 0.38 & 0.0004 & 0.055 & $<0.0006$ & 0.021 & 0.1 & 1.042 & 6.06 \\
\hline MK-18 & $<0.8$ & 89 & 8.3 & 2334 & 1251 & 21.1 & 3.3 & 3 & 895 & $<0.05$ & 0.24 & 0.24 & 0.0002 & 0.035 & $<0.0006$ & 0.017 & .1 & 17 & 2.37 \\
\hline 19 & $<0.8$ & 103 & 8.4 & 2374 & 1141 & 20 & 4.7 & 3002 & 806 & $<0.05$ & 0.56 & 0.26 & $<0.0002$ & 0.002 & $<0.0006$ & 0.031 & 1 & & 2.36 \\
\hline MK-20 & $<0.8$ & 90 & 10.8 & 2561 & 1278 & 19 & 4.4 & 3278 & 961 & $<0.05$ & 0.29 & 0.56 & 0.0004 & 0.009 & $<0.0006$ & 0.015 & $<0.1$ & 06 & 1.67 \\
\hline MK-21 & $<0.8$ & 110 & 9.9 & 2874 & 1275 & 23 & 4.8 & 3521 & 956 & $<0.05$ & 0.19 & 0.56 & 0.0014 & 0.070 & 0.0012 & 0.025 & $<0.1$ & 39 & 2.15 \\
\hline MK-22 & $<0.8$ & 113 & 10.5 & 2998 & 1198 & 26.0 & 6.4 & 3356 & 996 & $<0.05$ & 0.12 & 1.01 & $<0.0002$ & 0.070 & $<0.0006$ & 0.015 & $<0.1$ & 0.030 & 3.26 \\
\hline MK-23 & $<0.8$ & 102 & 9.9 & 2694 & 1198 & 14.6 & 4.8 & 3197 & 950 & $<0.05$ & 0.13 & 0.88 & 0.0003 & 0.036 & $<0.00062$ & 0.008 & $<0.1$ & 0.042 & 2.60 \\
\hline MK-24 & $<0.8$ & 104 & 9.9 & 2786 & 1417 & 20.5 & 5.5 & 3686 & 1033 & $<0.05$ & 0.17 & 0.77 & 0.0006 & 0.053 & $<0.0006$ & 0.016 & $<0.1$ & 0.059 & 3.27 \\
\hline MK-25 & 2.2 & 113 & 10.5 & 3016 & 1282 & 24.9 & 5.7 & 3518 & 1044 & 0.08 & 0.13 & 0.73 & 0.0004 & 0.187 & $<0.0006$ & 0.038 & $<0.1$ & 0.038 & 3.79 \\
\hline MK-26 & 3.4 & 81 & 8.9 & 2241 & 1184 & 15.9 & 5.6 & 2872 & 695 & $<0.05$ & 0.17 & 0.39 & 0.0010 & 0.011 & $<0.0006$ & 0.016 & .1 & 0.014 & 1.88 \\
\hline MK-27 & $<0.8$ & 90 & 10.2 & 2584 & 1381 & 28.1 & 5.5 & 3345 & 921 & $<0.05$ & 0.15 & 0.73 & 0.0013 & 0.021 & $<0.00062$ & 0.026 & .1 & 0.007 & 2.61 \\
\hline & $<0.8$ & 100 & 10.8 & 3026 & 1510 & 20 & 5. & 3926 & 1113 & $<0.05$ & 0.23 & 1.59 & & 0.005 & $<0.0006$ & 0.011 & .1 & & 3.46 \\
\hline 31 & $<0.8$ & 76 & 9.4 & 2355 & 13 & 22 & 5. & 3299 & 898 & $<0.05$ & 0.28 & 0.68 & 04 & 0.012 & $<0.0006$ & 0.021 & .1 & 08 & 3.36 \\
\hline MK-32 & 2.2 & 8 & 11.6 & 2543 & 1361 & 18 & 5.3 & 3419 & 962 & 0.08 & 0.26 & 0.92 & 0.0010 & 0.004 & 0.0012 & 0.024 & $<0.1$ & 0.021 & 2.60 \\
\hline MK-33 & 2.4 & 9 & 10.4 & 2656 & 1438 & 18 & 4.9 & 3419 & 1002 & $<0.05$ & 0.24 & 0.63 & 0.0003 & 0.014 & 0.0010 & 0.021 & $<0.1$ & 0.022 & 2.08 \\
\hline MK-34 & $<0.8$ & 8 & 10.9 & 2152 & 1084 & 25. & 4.7 & 2669 & 948 & $<0.05$ & 0.11 & 0.73 & $<0.0002$ & 0.109 & $<0.0006$ & 0.025 & $<0.1$ & .019 & 4.07 \\
\hline MK-35 & 1.1 & 78 & 12.1 & 2458 & 1310 & 20.9 & 29.1 & 3242 & 980 & 0.09 & 0.16 & 0.30 & 0.0019 & 0.014 & 0.0013 & 0.017 & $<0.1$ & 0.024 & 2.49 \\
\hline MK-36 & $<0.8$ & 97 & 11.0 & 2523 & 1266 & 24.1 & 6.1 & 3174 & 1102 & $<0.05$ & 0.08 & 0.26 & $<0.0002$ & 0.065 & $<0.0006$ & 0.029 & $<0.1$ & 0.040 & 5.75 \\
\hline MK-37 & 1.4 & 90 & 12.3 & 2750 & 1362 & 23.7 & 4.0 & 3347 & 990 & 0.07 & 0.14 & 1.21 & 0.0012 & 0.087 & 0.0015 & 0.039 & $<0.1$ & 0.013 & 3.72 \\
\hline MK-38 & $<0.8$ & 74 & 8.3 & 2123 & 1012 & 13.1 & 4.2 & 2587 & 740 & $<0.05$ & 0.18 & 0.33 & 0.0003 & 0.019 & $<0.0006$ & 0.012 & $<0.1$ & 0.005 & 2.56 \\
\hline MK-40 & 1.3 & 93 & 8.3 & 2567 & 1232 & 23.2 & 4.6 & 3130 & 709 & 0.13 & 0.25 & 0.49 & 0.0005 & 0.062 & 0.0007 & 0.020 & 0.16 & 0.029 & 2.48 \\
\hline MK-41 & 4.0 & 85 & 13.0 & 2584 & 1477 & 21. & 6.5 & 3691 & 875 & 0.13 & 0.22 & 0.38 & 0.0007 & 0.018 & $<0.0006$ & 0.032 & NA & 0.012 & 1.86 \\
\hline MK-42 & 1.7 & 80 & 9.0 & 2334 & 1245 & 21.3 & 6.2 & 3056 & 717 & $<0.05$ & 0.17 & 0.34 & 0.0004 & 0.042 & $<0.0006$ & 0.025 & 0.28 & 0.011 & 3.61 \\
\hline
\end{tabular}


Appendix A2

Table A2.3 (cont.) Concentrations of elements in rice grains in the Mekong River Delta area in $\mathrm{mg} \mathrm{kg}^{-1}(\mathrm{n}=78)$

\begin{tabular}{|c|c|c|c|c|c|c|c|c|c|c|c|c|c|c|c|c|c|c|c|}
\hline$\overline{\text { Sites }}$ & Al & Ca & $\mathrm{Fe}$ & $\mathbf{K}$ & $\mathrm{Mg}$ & Mn & $\mathrm{Na}$ & $\overline{\mathbf{P}}$ & $\mathbf{S}$ & $\mathbf{T i}$ & As & $\mathbf{B a}$ & $\overline{\mathbf{B i}}$ & $\overline{C d}$ & $\mathrm{Ce}$ & Co & $\mathbf{C r}$ & Cs & $\mathbf{C u}$ \\
\hline MK-43 & 1.3 & 87 & 10.1 & 2793 & 1274 & 24.3 & 7.1 & 3351 & 821 & $<0.05$ & 0.13 & 0.60 & 0.0004 & 0.057 & $<0.0006$ & 0.054 & 0.64 & 0.056 & 3.11 \\
\hline MK-44 & 1.6 & 92 & 10.9 & 2202 & 1115 & 14.1 & 9.3 & 2850 & 791 & $<0.05$ & 0.15 & 0.48 & $<0.0002$ & 0.030 & $<0.0006$ & 0.021 & .23 & 0.071 & 2.60 \\
\hline MK-45 & 1.2 & 97 & 11.5 & 2871 & 1436 & 17.8 & 8.9 & 3761 & 931 & $<0.05$ & 0.20 & 0.21 & $<0.0002$ & 0.025 & $<0.0006$ & 0.012 & 0.46 & 0.031 & 2.96 \\
\hline MK-46 & $<0.8$ & 113 & 9.9 & 2714 & 1388 & 14.5 & 9.0 & 3608 & 954 & $<0.05$ & 0.22 & 0.19 & $<0.0002$ & 0.003 & $<0.0006$ & 0.010 & $<0.1$ & 0.037 & 1.95 \\
\hline MK-47 & 5.2 & 82 & 16.1 & 2615 & 1306 & 24.7 & 6.3 & 3427 & 796 & $<0.05$ & 0.25 & 0.32 & 0.0002 & 0.010 & $<0.0006$ & 0.019 & NA & 0.039 & 1.28 \\
\hline MK-48 & 6.3 & 101 & 17.4 & 2383 & 1234 & 15.7 & 9.0 & 3147 & 873 & $<0.05$ & 0.17 & 0.21 & 0.0005 & 0.049 & $<0.0006$ & 0.046 & NA & 0.116 & 3.87 \\
\hline MK-49 & 3.4 & 96 & 15.4 & 2482 & 1428 & 19.7 & 6.9 & 3621 & 907 & 0.13 & 0.16 & 0.26 & 0.0009 & 0.036 & 0.0014 & 0.023 & $<0.1$ & 0.032 & 3.77 \\
\hline MK-51 & $<0.8$ & 108 & 10.7 & 2505 & 1337 & 19.8 & 10.1 & 3276 & 790 & 0.30 & 0.37 & 0.67 & 0.0004 & 0.003 & 0.0006 & 0.023 & 0.18 & 0.036 & 1.41 \\
\hline MK-52 & 1.2 & 89 & 11.7 & 2798 & 1270 & 18.4 & 9.4 & 3249 & 900 & 0.06 & 0.12 & 0.08 & 0.0003 & 0.014 & $<0.0006$ & 0.077 & 0.1 & 0.004 & 2.88 \\
\hline MK-53 & $<0.8$ & 83 & 8.9 & 2546 & 1202 & 17.1 & 9.2 & 3116 & 789 & $<0.05$ & 0.22 & 0.12 & 0.0002 & 0.042 & $<0.0006$ & 0.024 & $<0.1$ & 0.012 & 3.80 \\
\hline MK-54 & 0.9 & 89 & 9.9 & 2557 & 1294 & 23.0 & 6.7 & 3149 & 758 & $<0.05$ & 0.18 & 0.77 & 0.0003 & 0.038 & 0.0010 & 0.031 & 0.29 & 0.055 & 3.41 \\
\hline MK-55 & 19.4 & 92 & 12.3 & 2851 & 1406 & 21.9 & 7.3 & 3552 & 864 & $<0.05$ & 0.25 & 0.82 & 0.0004 & 0.003 & 0.0008 & 0.028 & 0.18 & 0.018 & 6.92 \\
\hline MK-56 & 1.5 & 81 & 13.2 & 2376 & 1239 & 18.1 & 6.5 & 3052 & 827 & $<0.05$ & 0.14 & 0.47 & 0.0003 & 0.046 & $<0.0006$ & 0.023 & 0.64 & 0.012 & 3.14 \\
\hline MK-57 & $<0.8$ & 86 & 11.7 & 2520 & 1316 & 20.9 & 12.1 & 3274 & 754 & 0.09 & 0.19 & 1.02 & 0.0004 & 0.023 & 0.0007 & 0.018 & $<0.1$ & 0.010 & 3.17 \\
\hline MK-58 & $<0.8$ & 86 & 11.1 & 2762 & 1418 & 24.6 & 6.5 & 3500 & 928 & $<0.05$ & 0.14 & 1.35 & 0.0004 & 0.013 & $<0.0006$ & 0.019 & $<0.1$ & 0.013 & 3.89 \\
\hline MK-59 & $<0.8$ & 97 & 9.8 & 2339 & 1169 & 14.6 & 4.4 & 2979 & 832 & 0.09 & 0.11 & 0.16 & 0.0003 & 0.010 & $<0.0006$ & 0.018 & $<0.1$ & 0.010 & 3.62 \\
\hline MK-60 & $<0.8$ & 90 & 10.9 & 2830 & 1340 & 23.2 & 6.4 & 3511 & 845 & $<0.05$ & 0.18 & 0.69 & 0.0008 & 0.055 & $<0.0006$ & 0.020 & 0.57 & 0.020 & 2.95 \\
\hline MK-61 & $<0.8$ & 101 & 11.4 & 2937 & 1191 & 26.3 & 6.0 & 3316 & 883 & $<0.05$ & 0.13 & 0.98 & $<0.0002$ & 0.114 & $<0.0006$ & 028 & .30 & 033 & 3.68 \\
\hline MK-62 & 6.5 & 101 & 10.5 & 2910 & 1282 & 23.4 & 5.3 & 3490 & 857 & $<0.05$ & 0.13 & 0.83 & 0.0003 & 0.054 & $<0.0006$ & 0.013 & 0.23 & 0.029 & 2.61 \\
\hline MK-63 & 4.6 & 92 & NA & 2655 & 1294 & 20.3 & 5.0 & 3369 & 874 & $<0.05$ & 0.24 & 0.34 & 0.0006 & 0.049 & 0.0007 & 0.063 & NA & 0.044 & 3.11 \\
\hline MK-64 & $<0.8$ & 96 & 10.8 & 2776 & 1475 & 24.5 & 6.3 & 3809 & 1074 & $<0.05$ & 0.09 & 0.09 & $<0.0002$ & 0.098 & 0.0007 & 0.115 & 0.13 & 0.051 & 4.94 \\
\hline MK-65 & 0.8 & 77 & 9.3 & 2577 & 1226 & 15.0 & 6.1 & 3198 & 775 & $<0.05$ & 0.13 & 0.47 & $<0.0002$ & 0.003 & 0.0009 & 0.011 & 0.22 & 0.046 & 1.39 \\
\hline MK-66 & 1.9 & 84 & 11.9 & 2956 & 1306 & 15.5 & 8.6 & 3470 & 844 & 0.06 & 0.21 & 0.68 & 0.0005 & 0.001 & 0.0008 & 0.015 & 0.31 & 0.050 & 1.38 \\
\hline MK-67 & $<0.8$ & 81 & 10.1 & 2833 & 1212 & 25.7 & 14.3 & 3127 & 881 & $<0.05$ & 0.11 & 0.27 & $<0.0002$ & 0.162 & $<0.0006$ & 0.025 & 0.20 & 0.002 & 5.34 \\
\hline MK-68 & $<0.8$ & 85 & 9.6 & 2862 & 1215 & 27.0 & 12.1 & 3104 & 851 & $<0.05$ & 0.12 & 0.44 & $<0.0002$ & 0.177 & $<0.0006$ & 0.025 & 0.28 & 0.002 & 4.36 \\
\hline MK-69 & 1.0 & 77 & 11.0 & 2784 & 1188 & 21.5 & 17.2 & 3007 & 795 & $<0.05$ & 0.08 & 0.50 & 0.0004 & 0.107 & 0.0012 & 0.013 & 0.20 & 0.002 & 5.62 \\
\hline MK-70 & 0.9 & 74 & 9.9 & 3068 & 1385 & 23.5 & 25.9 & 3339 & 760 & $<0.05$ & 0.10 & 0.34 & $<0.0002$ & 0.027 & 0.0018 & 0.010 & $<0.1$ & 0.009 & 2.28 \\
\hline-71 & 1.3 & 78 & 11.5 & 3462 & 1562 & 26.9 & 22.8 & 3915 & 905 & 0.07 & 0.09 & 0.42 & $<0.0002$ & 0.036 & 0.0010 & 0.011 & $<0.1$ & 0.010 & 2.58 \\
\hline MK-72 & 1.0 & 77 & 10.9 & 2784 & 1275 & 16.6 & 12.7 & 3150 & 843 & $<0.05$ & 0.10 & 0.08 & $<0.0002$ & 0.024 & 0.0006 & 0.017 & $<0.1$ & 0.002 & 4.19 \\
\hline MK-73 & $<0.8$ & 78 & 9.7 & 2800 & 1285 & 22.5 & 11.1 & 3334 & 786 & $<0.05$ & 0.08 & 0.13 & $<0.0002$ & 0.030 & $<0.0006$ & 0.026 & $<0.1$ & 0.005 & 4.13 \\
\hline MK-74 & $<0.8$ & 89 & 10.6 & 2874 & 1379 & 25.4 & 14.6 & 3612 & 840 & 0.22 & 0.12 & 0.11 & 0.0005 & 0.016 & 0.0010 & 0.024 & $<0.1$ & 0.003 & 4.34 \\
\hline MK-75 & $<0.8$ & 90 & 12.2 & 2694 & 1541 & 24.3 & 6.2 & 3813 & 1021 & $<0.05$ & 0.12 & 0.25 & 0.0004 & 0.015 & $<0.0006$ & 0.030 & $<0.1$ & 0.011 & 3.01 \\
\hline MK-76 & $<0.8$ & 82 & 8.4 & 2450 & 1282 & 15.6 & 7.5 & 3188 & 1029 & $<0.05$ & 0.14 & 0.42 & $<0.0002$ & 0.009 & $<0.0006$ & 0.019 & $<0.1$ & 0.036 & 3.50 \\
\hline MK-77 & 6.0 & 78 & 10.3 & 2668 & 1461 & 14.8 & 6.3 & 3625 & 1060 & $<0.05$ & 0.41 & 0.22 & $<0.0002$ & 0.023 & $<0.0006$ & 0.034 & $<0.1$ & 0.072 & 2.31 \\
\hline MK-78 & $<0.8$ & 85 & 8.8 & 2802 & 1395 & 16.4 & 6.4 & 3610 & 1017 & $<0.05$ & 0.17 & 1.17 & 0.0003 & 0.018 & $<0.0006$ & 0.041 & $<0.1$ & 0.032 & 4.00 \\
\hline MK-79 & 1.1 & 85 & 9.8 & 2420 & 1248 & 18.4 & 11.8 & 3051 & 1006 & 0.05 & 0.11 & 0.43 & $<0.0002$ & 0.037 & $<0.0006$ & 0.047 & $<0.1$ & 0.146 & 3.55 \\
\hline MK-80 & $<0.8$ & 74 & 8.2 & 2318 & 1132 & 25.1 & 5.5 & 2768 & 956 & $<0.05$ & 0.08 & 0.46 & $<0.0002$ & 0.070 & $<0.0006$ & 0.037 & $<0.1$ & 0.044 & 4.47 \\
\hline MK-81 & $<0.8$ & 71 & 9.7 & 2550 & 1319 & 16.9 & 5.2 & 3283 & 897 & 0.09 & 0.16 & 0.17 & $<0.0002$ & 0.013 & 0.0007 & 0.022 & $<0.1$ & 0.038 & 1.74 \\
\hline MK-82 & 6.8 & 98 & 10.5 & 3108 & 1339 & 18.5 & 4.9 & 3343 & 1009 & $<0.05$ & 0.10 & 0.05 & $<0.0002$ & 0.023 & $<0.0006$ & 0.072 & $<0.1$ & 0.012 & 3.48 \\
\hline
\end{tabular}

$<$ lower than detection limits, NA: not analyzed 
Table A2.3 (cont.) Concentrations of elements in rice grains in the Mekong River Delta area in $\mathrm{mg} \mathrm{kg}^{-1}(\mathrm{n}=78)$

\begin{tabular}{|c|c|c|c|c|c|c|c|c|c|c|c|c|c|c|c|c|}
\hline Sites & Hf & La & $\mathbf{L i}$ & Mo & $\mathbf{N i}$ & $\mathbf{P b}$ & $\mathbf{R b}$ & Sb & Sn & $\mathrm{Sr}$ & Th & Tl & $\mathbf{U}$ & V & Zn & $\mathbf{Z r}$ \\
\hline$\overline{\mathrm{MK}}-1$ & $<0.0002$ & $<0.0003$ & $<0.006$ & 0.41 & 0.09 & 0.16 & 16.1 & 0.0007 & $<0.06$ & 0.23 & $<0.0002$ & $<0.0002$ & $<0.0001$ & $<0.008$ & 17.4 & $<0.007$ \\
\hline MK-2 & $<0.0002$ & 0.0003 & $<0.006$ & 1.02 & 0.15 & 0.33 & 21.1 & 0.0026 & $<0.06$ & 0.30 & $<0.0002$ & $<0.0002$ & $<0.0001$ & $<0.008$ & 19.5 & $<0.007$ \\
\hline MK-3 & $<0.0002$ & $<0.0003$ & $<0.006$ & 0.32 & 0.21 & 0.12 & 11.9 & $<0.0006$ & 0.07 & 0.33 & $<0.0002$ & $<0.0002$ & $<0.0001$ & $<0.008$ & 15.8 & $<0.007$ \\
\hline MK-4 & $<0.0002$ & 0.0003 & $<0.006$ & 0.44 & 0.32 & 0.37 & 15.5 & 0.0006 & $<0.06$ & 0.27 & $<0.0002$ & $<0.0002$ & $<0.0001$ & 0.024 & 21.1 & $<0.007$ \\
\hline MK-5 & $<0.0002$ & $<0.0003$ & $<0.006$ & 0.30 & 0.18 & 0.15 & 12.8 & $<0.0006$ & $<0.06$ & 0.28 & $<0.0002$ & $<0.0002$ & $<0.0001$ & $<0.008$ & 15.0 & $<0.007$ \\
\hline MK-6 & $<0.0002$ & 0.0010 & $<0.006$ & 0.32 & 0.26 & 0.47 & 13.6 & 0.0006 & $<0.06$ & 0.27 & $<0.0002$ & $<0.0002$ & $<0.0001$ & 0.013 & 19.8 & 0.007 \\
\hline MK-7 & $<0.0002$ & 0.0003 & $<0.006$ & 0.60 & 0.07 & 0.17 & 9.7 & $<0.0006$ & $<0.06$ & 0.28 & 0.0002 & $<0.0002$ & $<0.0001$ & 0.019 & 17.4 & $<0.007$ \\
\hline MK-8 & $<0.0002$ & 0.0005 & 0.006 & 0.35 & 0.39 & 0.28 & 6.9 & $<0.0006$ & $<0.06$ & 0.38 & $<0.0002$ & $<0.0002$ & $<0.0001$ & $<0.008$ & 20.5 & $<0.007$ \\
\hline MK-9 & 0.0007 & $<0.0003$ & $<0.006$ & 0.48 & 0.13 & 0.11 & 2.7 & $<0.0006$ & $<0.06$ & 0.22 & $<0.0002$ & $<0.0002$ & $<0.0001$ & 0.013 & 15.0 & 0.027 \\
\hline MK-10 & $<0.0002$ & 0.0003 & $<0.006$ & 0.29 & 0.03 & 0.23 & 5.6 & $<0.0006$ & $<0.06$ & 0.23 & $<0.0002$ & $<0.0002$ & $<0.0001$ & 0.012 & 20.5 & $<0.007$ \\
\hline MK-11 & $<0.0002$ & $<0.0003$ & $<0.006$ & 0.44 & 0.30 & 0.09 & 9.6 & $<0.0006$ & $<0.06$ & 0.26 & $<0.0002$ & $<0.0002$ & $<0.0001$ & $<0.008$ & 18.4 & $<0.007$ \\
\hline MK-12 & $<0.0002$ & $<0.0003$ & $<0.006$ & 0.42 & 0.07 & 0.21 & 11.9 & $<0.0006$ & 0.07 & 0.25 & $<0.0002$ & $<0.0002$ & $<0.0001$ & $<0.008$ & 16.1 & $<0.007$ \\
\hline MK-13 & $<0.0002$ & $<0.0003$ & $<0.006$ & 0.40 & 0.08 & 0.31 & 19.2 & 0.0011 & $<0.06$ & 0.31 & $<0.0002$ & $<0.0002$ & $<0.0001$ & $<0.008$ & 22.6 & $<0.007$ \\
\hline MK-14 & $<0.0002$ & $<0.0003$ & $<0.006$ & 0.40 & 0.11 & 0.12 & 5.2 & $<0.0006$ & 0.08 & 0.28 & $<0.0002$ & $<0.0002$ & $<0.0001$ & $<0.008$ & 19.0 & $<0.007$ \\
\hline MK-15 & $<0.0002$ & $<0.0003$ & $<0.006$ & 0.35 & 0.15 & 0.12 & 6.6 & $<0.0006$ & $<0.06$ & 0.24 & $<0.0002$ & $<0.0002$ & $<0.0001$ & $<0.008$ & 17.4 & $<0.007$ \\
\hline MK-16 & $<0.0002$ & $<0.0003$ & $<0.006$ & 0.32 & 0.26 & 0.03 & 14.6 & $<0.0006$ & $<0.06$ & 0.32 & $<0.0002$ & $<0.0002$ & $<0.0001$ & $<0.008$ & 15.9 & $<0.007$ \\
\hline MK-17 & $<0.0002$ & $<0.0003$ & $<0.006$ & 0.28 & 0.59 & 0.16 & 17.2 & $<0.0006$ & $<0.06$ & 0.31 & $<0.0002$ & $<0.0002$ & $<0.0001$ & 0.015 & 21.3 & $<0.007$ \\
\hline MK-18 & $<0.0002$ & $<0.0003$ & $<0.006$ & 0.39 & 0.21 & 0.06 & 6.0 & $<0.0006$ & $<0.06$ & 0.28 & $<0.0002$ & $<0.0002$ & $<0.0001$ & $<0.008$ & 21.1 & $<0.007$ \\
\hline MK-19 & $<0.0002$ & $<0.0003$ & 0.006 & 0.60 & 0.06 & 0.04 & 18.5 & $<0.0006$ & $<0.06$ & 0.38 & $<0.0002$ & $<0.0002$ & $<0.0001$ & $<0.008$ & 17.6 & $<0.007$ \\
\hline MK-20 & $<0.0002$ & 0.0004 & $<0.006$ & 0.38 & 0.12 & 0.27 & 4.3 & $<0.0006$ & 0.07 & 0.38 & $<0.0002$ & $<0.0002$ & $<0.0001$ & $<0.008$ & 18.8 & $<0.007$ \\
\hline MK-21 & $<0.0002$ & 0.0007 & $<0.006$ & 0.41 & 0.20 & 0.29 & 16.1 & 0.0016 & $<0.06$ & 0.44 & $<0.0002$ & $<0.0002$ & $<0.0001$ & $<0.008$ & 20.8 & $<0.007$ \\
\hline MK-22 & $<0.0002$ & $<0.0003$ & $<0.006$ & 0.60 & 0.23 & 0.07 & 17.3 & $<0.0006$ & $<0.06$ & 0.53 & $<0.0002$ & $<0.0002$ & $<0.0001$ & $<0.008$ & 21.1 & $<0.007$ \\
\hline MK-23 & $<0.0002$ & $<0.0003$ & $<0.006$ & 0.47 & 0.12 & 0.08 & 19.1 & $<0.0006$ & 0.06 & 0.49 & $<0.0002$ & $<0.0002$ & $<0.0001$ & $<0.008$ & 18.9 & $<0.007$ \\
\hline MK-24 & $<0.0002$ & $<0.0003$ & $<0.006$ & 0.50 & 0.34 & 0.03 & 18.4 & $<0.0006$ & $<0.06$ & 0.39 & $<0.0002$ & $<0.0002$ & $<0.0001$ & $<0.008$ & 20.7 & $<0.007$ \\
\hline MK-25 & $<0.0002$ & $<0.0003$ & $<0.006$ & 0.41 & 0.47 & 0.08 & 12.0 & 0.0006 & $<0.06$ & 0.47 & $<0.0002$ & $<0.0002$ & $<0.0001$ & $<0.008$ & 23.3 & $<0.007$ \\
\hline MK-26 & $<0.0002$ & $<0.0003$ & $<0.006$ & 0.41 & 0.16 & 0.05 & 8.3 & $<0.0006$ & $<0.06$ & 0.48 & $<0.0002$ & $<0.0002$ & $<0.0001$ & $<0.008$ & 17.2 & $<0.007$ \\
\hline MK-27 & $<0.0002$ & $<0.0003$ & 0.006 & 0.33 & 0.32 & 0.03 & 5.7 & $<0.0006$ & $<0.06$ & 0.48 & $<0.0002$ & $<0.0002$ & $<0.0001$ & 0.013 & 22.2 & $<0.007$ \\
\hline MK-30 & $<0.0002$ & $<0.0003$ & $<0.006$ & 0.33 & 0.28 & 0.10 & 16.1 & $<0.0006$ & 0.10 & 0.35 & $<0.0002$ & $<0.0002$ & $<0.0001$ & $<0.008$ & 20.3 & $<0.007$ \\
\hline MK-31 & $<0.0002$ & $<0.0003$ & $<0.006$ & 0.47 & 0.15 & 0.04 & 5.9 & $<0.0006$ & $<0.06$ & 0.31 & $<0.0002$ & $<0.0002$ & $<0.0001$ & $<0.008$ & 18.6 & $<0.007$ \\
\hline MK-32 & $<0.0002$ & 0.0006 & $<0.006$ & 0.56 & 0.11 & 0.93 & 11.8 & 014 & $<0.06$ & 0.42 & $<0$. & $<0.0002$ & 0.0002 & $<0.008$ & 16.2 & $<0.007$ \\
\hline MK-33 & $<0.0002$ & 0.0005 & $<0.006$ & 0.91 & 0.14 & 0.15 & 11.9 & $<0.0006$ & $<0.06$ & 0.41 & $<0.0002$ & $<0.0002$ & $<0.0001$ & $<0.008$ & 19.7 & $<0.007$ \\
\hline MK-34 & $<0.0002$ & $<0.0003$ & $<0.006$ & 0.19 & 0.64 & 0.14 & 7.4 & $<0.0006$ & $<0.06$ & 0.34 & $<0.0002$ & $<0.0002$ & $<0.0001$ & $<0.008$ & 20.4 & $<0.007$ \\
\hline MK-35 & $<0.0002$ & 0.0006 & $<0.006$ & 0.24 & 0.11 & 0.55 & 6.7 & 0.0011 & $<0.06$ & 0.28 & 0.0003 & $<0.0002$ & $<0.0001$ & 0.010 & 23.3 & $<0.007$ \\
\hline MK-36 & $<0.0002$ & $<0.0003$ & $<0.006$ & 0.51 & 0.46 & 0.12 & 12.9 & $<0.0006$ & $<0.06$ & 0.34 & $<0.0002$ & $<0.0002$ & $<0.0001$ & $<0.008$ & 21.4 & $<0.007$ \\
\hline MK-37 & 0.0002 & 0.0007 & $<0.006$ & 1.02 & 0.42 & 0.86 & 6.8 & 0.0015 & $<0.06$ & 0.37 & 0.0002 & $<0.0002$ & $<0.0001$ & $<0.008$ & 20.3 & 0.007 \\
\hline MK-38 & $<0.0002$ & $<0.0003$ & $<0.006$ & 0.41 & 0.18 & 0.03 & 2.0 & $<0.0006$ & $<0.06$ & 0.22 & $<0.0002$ & $<0.0002$ & $<0.0001$ & $<0.008$ & 16.5 & $<0.007$ \\
\hline MK-40 & $<0.0002$ & 0.0005 & $<0.006$ & 0.44 & 0.19 & 0.13 & 11.2 & 0.0006 & 0.47 & 0.35 & $<0.0002$ & $<0.0002$ & $<0.0001$ & $<0.008$ & 19.3 & $<0.007$ \\
\hline MK-41 & $<0.0002$ & $<0.0003$ & $<0.006$ & 0.45 & NA & 0.15 & 5.9 & $<0.0006$ & 0.16 & 0.28 & $<0.0002$ & $<0.0002$ & $<0.0001$ & $<0.008$ & 18.2 & $<0.007$ \\
\hline MK-42 & $<0.0002$ & $<0.0003$ & $<0.006$ & 0.37 & 0.37 & 0.12 & 4.8 & $<0.0006$ & 0.07 & 0.29 & $<0.0002$ & $<0.0002$ & $<0.0001$ & $<0.008$ & 16.3 & $<0.007$ \\
\hline MK-43 & $<0.0002$ & $<0.0003$ & 0.006 & 0.33 & 0.80 & 0.03 & 18.9 & $<0.0006$ & 2.57 & 0.41 & $<0.0002$ & $<0.0002$ & $<0.0001$ & $<0.008$ & 20.6 & $<0.007$ \\
\hline
\end{tabular}


Table A2.3 (cont.) Concentrations of elements in rice grains in the Mekong River Delta area in $\mathrm{mg} \mathrm{kg}^{-1}(\mathrm{n}=78)$

\begin{tabular}{|c|c|c|c|c|c|c|c|c|c|c|c|c|c|c|c|c|}
\hline ites & Hf & La & $\mathbf{L i}$ & Mo & $\mathbf{N i}$ & $\mathbf{P b}$ & $\mathbf{R b}$ & $\mathbf{S b}$ & Sn & $\mathbf{S r}$ & Th & Tl & $\mathbf{U}$ & $\mathbf{V}$ & $\mathbf{Z n}$ & $\mathbf{Z r}$ \\
\hline $1 \mathrm{~K}-44$ & .0002 & 0.0003 & .006 & 0.56 & 0.31 & .05 & & 0.0006 & $<0.06$ & 0.36 & 0.0002 & .0002 & 0.0001 & $<0.0$ & 20.1 & 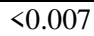 \\
\hline & & & & & & & & & & & & & & & 2.3 & \\
\hline & & & & & & & & & & & & & & & 19.3 & .007 \\
\hline [K-47 & .0002 & 0.0003 & $<0.006$ & & 0.63 & .04 & 15.8 & 006 & 0.40 & 0.30 & K0.0002 & 002 & 0.0001 & & 19.0 & 0.007 \\
\hline K-48 & .0002 & $<0.0003$ & $<0.006$ & 0.52 & NA & .02 & 24.6 & $<0.0006$ & 0.51 & 0.37 & 0.0002 & 0.0002 & 0.0001 & $<0.008$ & 20.6 & 0.007 \\
\hline K-49 & .0002 & 0.0007 & $<0.006$ & 0.2 & 0.40 & 88 & 9.6 & 0.0019 & $<0.06$ & 0.26 & $<0.0002$ & 0.0002 & 0.0001 & $<0.008$ & 24.9 & 0.007 \\
\hline IK-51 & .0002 & 0.0003 & $<0.006$ & & 0.14 & 20 & 13.5 & 0.0010 & .08 & & 0.0002 & .0002 & 0.0001 & 0.008 & 17.9 & 0.007 \\
\hline$K-52$ & .0002 & $<0.0003$ & $<0.006$ & & .61 & 20 & 2.8 & $<00006$ & 0.06 & & 0.0002 & .0002 & 0.0001 & .008 & 19.3 & 0.007 \\
\hline & 02 & $<0.0$ & 006 & & & 07 & 6.6 & & 06 & & & & & & 17.4 & 0.007 \\
\hline & & & & & & & .9 & & & & & & & & 16.8 & 0.007 \\
\hline & & & & & & & 1 & & & & & & & & 9.0 & 0.007 \\
\hline & 02 & 3 & & & & & & $<0$. & & & & & & & 6.5 & 0.007 \\
\hline $2-7$ & 02 & 03 & 06 & & 0. & 20 & 0.0 & & $<0.06$ & & 02 & 02 & 01 & & 18.3 & 007 \\
\hline & .0002 & .0003 & $<0.006$ & 0. & 0.27 & 0.12 & 8.7 & $<0.0006$ & 0.13 & 0. & $<0.0002$ & 02 & $<0.0001$ & 008 & 20.6 & $<0.007$ \\
\hline & .0002 & 0003 & $<0.006$ & 0 & & 0.28 & 4.1 & 06 & 0.07 & & $<0.0002$ & & & & 18.1 & 0.007 \\
\hline & .0002 & .0003 & $<0.006$ & 0.5 & & 0.03 & 10.2 & $<0$. & .14 & & & & & & 23.7 & $<0.007$ \\
\hline & & .0003 & $<0.006$ & & & 0.03 & 6 & & 0.32 & & & & & 016 & 19.9 & 0.007 \\
\hline & & & & & & 0.04 & & & & & & & & 13 & 21.6 & .007 \\
\hline & & & & & & & & & & & & & & 11 & 2.0 & .007 \\
\hline & & & & & & & & & & & & & & & 6.6 & 007 \\
\hline & & & 06 & & & & & & & & & & & & 7.3 & 007 \\
\hline & 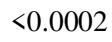 & 04 & & & & 0. & 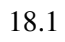 & & & & 02 & & $<0$. & & 19.2 & $<0.007$ \\
\hline & 0002 & .0003 & $<0.006$ & 0. & & 0.0 & & 00 & & & $<0.0002$ & 02 & $<0$. & $<0$ & 21.8 & $<0.007$ \\
\hline & 0002 & .0003 & 06 & 0 & & 0. & & 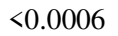 & & & 02 & & 01 & $<0$ & 19.3 & $<0.007$ \\
\hline-6 & & & 06 & & & & 1 & & & & & & & & 19.6 & $<0.007$ \\
\hline & 0002 & 07 & $<0.006$ & & & 0. & 5 & $<0.0006$ & 0.00 & & & & $<0$. & $<0.008$ & 17.6 & $<0.007$ \\
\hline & & & $<0.006$ & & & 0.30 & 5.6 & & 0.06 & & & & & & 20.4 & $<0.007$ \\
\hline & & & & & & & 2.0 & & & & & & & & 21.1 & 0.007 \\
\hline & & & & & & & & & & & & & & & 2.4 & 007 \\
\hline & & & & & & & & & & & & & & & .1 & \\
\hline & & & & & & 0 & & & & & & & & & 4.4 & $<0.007$ \\
\hline & & & & & & 0. & & & & & & & & & 15.8 & $<0.007$ \\
\hline & & & & & & & & & & & & & & & 18.5 & $<0.007$ \\
\hline & & & & & & & & & & & & & & & 19.3 & 0.007 \\
\hline & 02 & 3 & 06 & & & & 28 & & & & 02 & & $<0$ & & 17.9 & $<0.007$ \\
\hline & .0002 & $<0.0003$ & $<0.006$ & $\mathrm{c}$ & 0 & 0.05 & 10. & 06 & $<0.06$ & & $<0.0002$ & & $<00$ & $<0.008$ & 19.5 & $<0.007$ \\
\hline & .0002 & 2 & 0.007 & 0. & 0.38 & 0.09 & 14.3 & 06 & 0.12 & & & & $<0$. & $<0.008$ & 18.4 & $<0.007$ \\
\hline MK-82 & $<0.0002$ & $<0.0003$ & 0.006 & 0.18 & NA & 0.03 & 4.6 & $<0.0006$ & $<0.06$ & 0.20 & $<0.0002$ & $<0.0002$ & $<0.0001$ & 0.012 & 20.7 & $<0.007$ \\
\hline
\end{tabular}

"<": lower than detection limit, NA: not analyzed 
Appendix A2

Table A2.4 Transfer factors of elements from soils into rice grains in the Mekong River Delta area $(\mathrm{n}=78)$

\begin{tabular}{|c|c|c|c|c|c|c|c|c|c|c|c|c|c|c|c|c|c|}
\hline Sites & Al & $\mathbf{C a}$ & $\mathbf{F e}$ & $\mathbf{K}$ & $\mathbf{M g}$ & Mn & $\mathbf{N a}$ & $\mathbf{P}$ & $\mathbf{S}$ & $\mathbf{T i}$ & As & $\mathbf{B a}$ & $\mathbf{B i}$ & $\overline{C d}$ & $\mathrm{Ce}$ & Co & $\mathrm{Cr}$ \\
\hline MK-1 & .00005 & 0 & 00 & 10 & 0.16 & 0.02 & 1 & .0 & 1.1 & .00001 & 07 & 0.0010 & 0007 & .008 & 0.00001 & .0007 & 0.001 \\
\hline$M V ?$ & & O & 0002 & & & 77 & & .7 & 1.8 & & & & & & & & \\
\hline & & & & & & & & 2 & 2.6 & 0.0 & & & & & 01 & & \\
\hline & & 16 & & & 9 & & & & 5.3 & & & & & & & & \\
\hline & & .020 & & & 0.23 & 0.06 & & 5.4 & 2.1 & & & & & & & & 001 \\
\hline MK-8 & & .024 & 003 & 14 & 0.20 & 0.02 & 02 & 4.3 & 3.9 & 0.00001 & .007 & & & 0.101 & 0.00001 & 0.0016 & $<0.001$ \\
\hline K-11 & & .023 & & 14 & 0.19 & 0.07 & & 2.4 & 1.5 & & & & & 81 & 001 & 0.0016 & $<0.002$ \\
\hline & & & & & 0.15 & & & 7 & 2.4 & & & & & & & 015 & 0.001 \\
\hline & & & & & & & & .5 & 1.8 & & & & & & & & .001 \\
\hline & & & & & & & & 4 & 1.5 & & & & & & & & 001 \\
\hline & & & & & & & & & 1.6 & & & & & & & & 001 \\
\hline & & & & & 4 & 0. & & & 2.4 & & & & & & & & 002 \\
\hline-17 & & & & & 0.19 & 0. & & .0 & 2.3 & & 13 & & & 99 & & & 002 \\
\hline & & & & & 0.21 & & & 3.9 & 1.4 & & & & & & & & 001 \\
\hline & & & & & 0.21 & & & 8 & 0.6 & & & & & & & & 001 \\
\hline & & & & & & & & & 1.4 & & & & & & & & 001 \\
\hline & & & & & & & & & 1.5 & & & & & & & & \\
\hline-26 & & & & & 0.18 & & & & 1.1 & & & & & 0.067 & & & $<0.001$ \\
\hline & & & & & 0.2 & 0. & & & 1.4 & & 15 & & & 0.110 & $<0$. & 19 & $<0.001$ \\
\hline 315 & & & & & 0.20 & 0. & & & 1.8 & & 19 & & & 0.021 & 001 & 08 & $<0.001$ \\
\hline & & & & & & & & & 1.8 & & & & & & & & $<0.001$ \\
\hline-32 & & & 03 & 0.12 & 0.18 & 0.08 & & 4.5 & 1.7 & & & & & & 001 & 0.0017 & $<0.001$ \\
\hline & & & & & & & & 3.8 & 1.4 & & & & & & & 016 & $<0.001$ \\
\hline & & & & & & & & 3.4 & 1.7 & & & & & & & 019 & 0.001 \\
\hline & & & & & & & & & 0.8 & & & & & & & & 001 \\
\hline & & & & & & & & & 1.2 & & & & & & & & \\
\hline
\end{tabular}


Table A2.4 (cont.) Transfer factors of elements from soils into rice grains in the Mekong River Delta area $(\mathrm{n}=78)$

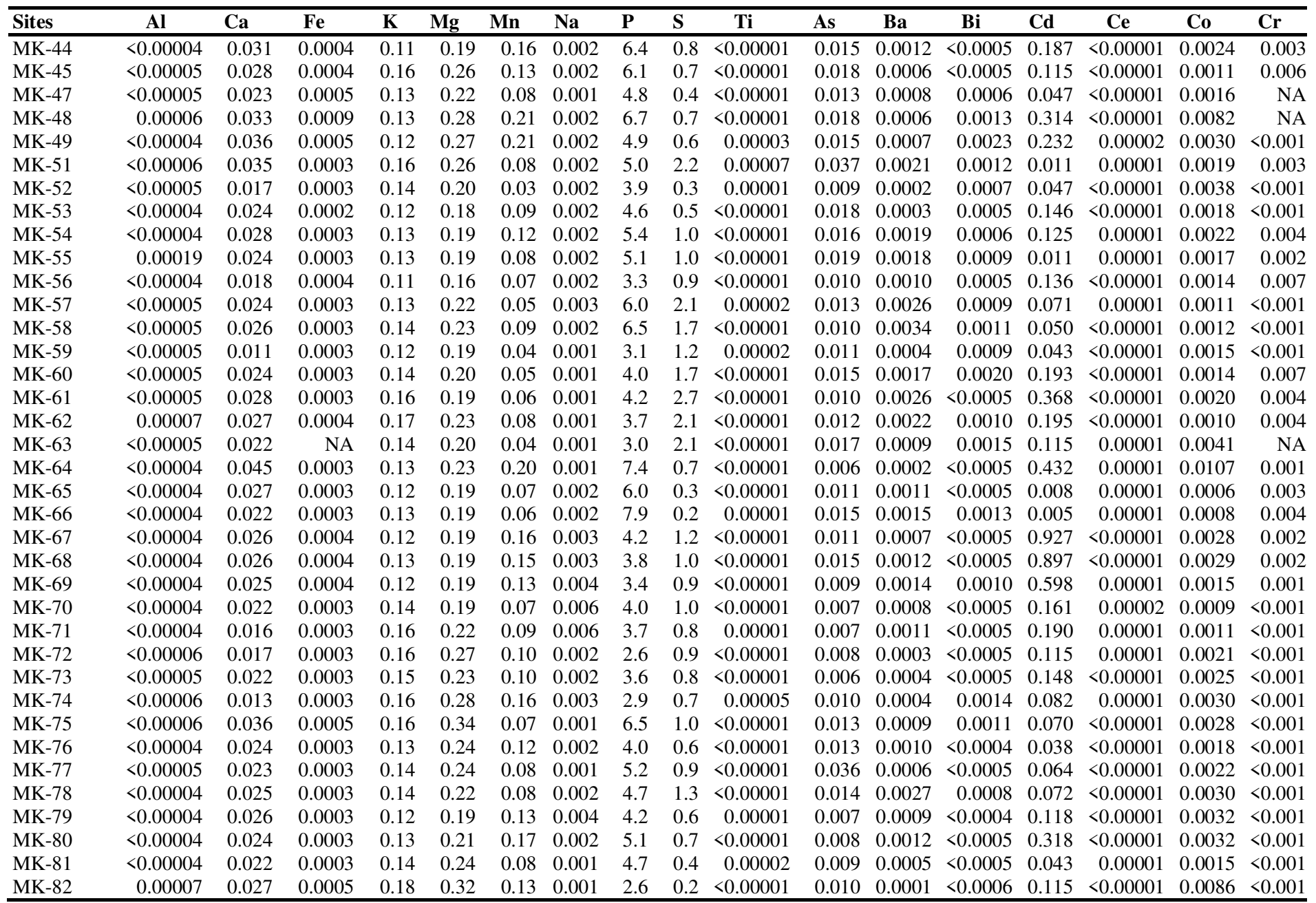


Table A2.4 (cont.) Transfer factors of elements from soils into rice grains in the Mekong River Delta area $(\mathrm{n}=78)$

\begin{tabular}{|c|c|c|c|c|c|c|c|c|c|c|c|c|c|c|c|c|c|c|}
\hline Sites & Cs & $\mathbf{C u}$ & Hf & La & $\mathbf{L i}$ & Mo & $\mathbf{N i}$ & $\mathbf{P b}$ & $\mathbf{R b}$ & $\mathbf{S b}$ & Sn & $\mathrm{Sr}$ & Th & Tl & $\mathbf{U}$ & V & $\mathrm{Zn}$ & $\mathbf{Z r}$ \\
\hline MK-1 & 0.0031 & 0.09 & .00005 & $<0.00001$ & $<0.0001$ & 0.52 & 0.002 & 0.0062 & 0.13 & 0.0004 & $<0.015$ & 0.003 & 0.00001 & 0.0003 & 0.00003 & 0.0001 & 0.17 & $\overline{0.00005}$ \\
\hline MK-2 & 032 & 07 & 00005 & 01 & 0001 & & 0.003 & 0105 & & 11 & & 0.003 & 01 & 02 & 00002 & 1 & 20 & 00005 \\
\hline $\mathrm{K}-3$ & 021 & 09 & .00004 & $<0.000$ & 1 & 19 & 0.006 & 0040 & 0.10 & $<0.0002$ & & 0.004 & .00001 & .0003 & $<0.00002$ & .0001 & 17 & 0.00004 \\
\hline K-4 & 037 & 19 & $<0.00004$ & 0.00001 & 0.0002 & 78 & 0.011 & .0154 & 0.15 & 0.0003 & $<0.016$ & 0.003 & 0001 & 0.0004 & 0.00003 & 0.0003 & .29 & 0.00004 \\
\hline MK-5 & 0022 & 10 & $<0.00004$ & $<0.00001$ & $<0.0001$ & 0.39 & 0.005 & 0.0052 & 0.10 & $<0.0003$ & $<0.014$ & 0.003 & $<0.00001$ & $<0.0003$ & $<0.00002$ & $<0.0001$ & 0.15 & $<0.00004$ \\
\hline MK-6 & 0.0027 & 0.40 & $<0.00004$ & 0.00003 & $<0.0002$ & 0.53 & 0.008 & 0.0205 & 0.14 & 0.0003 & $<0.017$ & 0.003 & $<0.00001$ & $<0.0004$ & $<0.00003$ & 0.0001 & 0.27 & 0.00004 \\
\hline MK-7 & 0.0016 & 0.10 & $<0.00004$ & 0.00001 & $<0.0001$ & 0.91 & 0.002 & 0.0066 & 0.09 & $<0.0003$ & $<0.016$ & 0.003 & 0.00001 & $<0.0003$ & $<0.00002$ & 0.0002 & 0.18 & $<0.00004$ \\
\hline MK-8 & 0.0014 & 0.16 & $<0.00004$ & 0.00001 & 0.0001 & 0.43 & 0.011 & 0.0095 & 0.06 & $<0.0003$ & $<0.015$ & 0.004 & $<0.00001$ & $<0.0003$ & $<0.00002$ & $<0.0001$ & 0.24 & $<0.00004$ \\
\hline MK-9 & 0.0003 & 0.12 & 0.00017 & $<0.00001$ & $<0.0001$ & 0.62 & 0.003 & 0.0037 & 0.02 & 0.0003 & $<0.013$ & 0.002 & $<0.00001$ & $<0.0003$ & $<0.00002$ & 0.0001 & 0.15 & 0.00018 \\
\hline MK-10 & 0.0009 & 0.03 & $<0.00005$ & 0.00001 & $<0.0001$ & 0.37 & 0.001 & 0.0072 & 0.04 & 0.0002 & $<0.012$ & 0.003 & $<0.00001$ & $<0.0002$ & $<0.00002$ & 0.0001 & 0.18 & $<0.00005$ \\
\hline MK-11 & 027 & 0.11 & $<0.00004$ & $<0.00001$ & $<0.0002$ & 0.90 & 0.011 & 0.0041 & 0.10 & $<0$ & $<0.017$ & 0.003 & 0002 & 004 & $<0.00003$ & $<0.0001$ & .25 & .00004 \\
\hline $\mathrm{K}-12$ & 30 & .07 & 005 & $<0.0$ & $<0.0$ & 0.59 & 0.002 & 0.0 & 0.11 & 03 & 0. & 0.003 & $<0$ & 03 & $<0.00003$ & 01 & 20 & $<0.00004$ \\
\hline-13 & 36 & 04 & 004 & $<0$ & $<0.0$ & 0.58 & 0.002 & 05 & 0.15 & 05 & $<0$. & 0.004 & 01 & 03 & 0002 & 01 & 3 & 0004 \\
\hline MK-14 & 08 & .06 & $<0.00004$ & $<0.0$ & $<0.0002$ & 0.79 & 0.004 & 0.0006 & 0.05 & 01 & 0. & 0.004 & $<0$. & $<0$. & $<0.00002$ & 01 & 3 & $<0.00004$ \\
\hline MK-15 & 21 & .10 & $<0.00004$ & $<0.00001$ & $<0.0002$ & 0.59 & 0.005 & 0.0052 & 0.06 & 03 & $<0$. & 0.003 & $<0$. & $<0$. & $<0.00002$ & $<0$. & 24 & $<0.00004$ \\
\hline MK-16 & 0.0055 & 0.10 & $<0.00005$ & $<0.00001$ & $<0.0002$ & 0.61 & 0.008 & 0.0013 & 0.14 & $<0.0003$ & $<0.017$ & 0.004 & 001 & $<0.0004$ & $<0.00002$ & $<0.0001$ & 0.21 & $<0.00005$ \\
\hline MK-17 & 0050 & 0.22 & $<0.00005$ & $<0.0$ & $<0.0002$ & 0.43 & 0.019 & 0.0065 & 0.17 & 03 & $<0.016$ & 0.004 & 001 & $<0$. & 002 & 0.0002 & 0.28 & $<0.00005$ \\
\hline MK-18 & 0.0014 & 0.07 & $<0.00005$ & $<0.00001$ & $<0.0001$ & 0.48 & 0.005 & 0.0018 & 0.04 & $<0.0002$ & $<0.013$ & 0.003 & $<0.00001$ & $<0.0003$ & $<0.00002$ & $<0.0001$ & 0.20 & $<0.00005$ \\
\hline K-19 & 0.0064 & 0.08 & $<0.00005$ & $<0.00001$ & 0.0002 & 1.05 & 0.002 & 0.0015 & 0.18 & & & 05 & & & 002 & $<0.0001$ & .21 & 0005 \\
\hline-20 & & 0.06 & & & $<0$. & 0.18 & 0.003 & & 0.04 & & & 05 & & & $<0.00002$ & 01 & 21 & 00005 \\
\hline-21 & & .07 & & & & 0.55 & 0.006 & & 0.15 & & $<0$. & 06 & & 03 & 002 & & 25 & 0005 \\
\hline-22 & & 11 & $<0$ & $<0.0$ & $<0.0$ & 0.61 & 0.006 & 0.0 & 0.14 & $<0.0$ & & 0.007 & & & 02 & 01 & 23 & 005 \\
\hline-23 & 34 & 08 & 06 & $<0.0$ & $<0.0$ & 0.44 & 0.003 & 0.0 & 0.17 & $<0$. & & 0.006 & $<0$ & $<0$ & $<0$. & $<0$ & 9 & $<0.0$ \\
\hline MK-24 & 46 & 0.10 & $<0.00005$ & $<0.00001$ & $<0.0001$ & 0.51 & 0.009 & 0.0013 & 0.15 & $<0.0003$ & $<0.014$ & 0.005 & $<0.00001$ & $<0.0003$ & $<0.00002$ & $<0.0001$ & 0.21 & $<0.00005$ \\
\hline MK-25 & 0.0037 & 0.14 & $<0.00005$ & $<0.00001$ & $<0.0001$ & 0.61 & 0.014 & 0.0033 & 0.11 & 0.0003 & $<0.015$ & 0.006 & $<0.00001$ & $<0.0003$ & $<0.00002$ & $<0.0001$ & 0.25 & $<0.00005$ \\
\hline MK-26 & 0.0011 & 0.07 & $<0.00006$ & $<0.00001$ & $<0.0001$ & 0.35 & 0.004 & 0.0017 & 0.06 & $<0.0005$ & $<0.013$ & 0.006 & $<0.00001$ & $<0.0003$ & $<0.00002$ & $<0.0001$ & 0.18 & $<0.00005$ \\
\hline MK-27 & 0.0008 & 0.13 & $<0.00004$ & $<0.00001$ & 0.0001 & 0.33 & 0.009 & 0.0014 & 0.05 & $<0.0006$ & $<0.015$ & 0.006 & $<0.00001$ & $<0.0003$ & $<0.00002$ & 0.0001 & 0.27 & $<0.00004$ \\
\hline MK-30 & 0.0034 & 12 & $<0.00005$ & $<0.00001$ & 0.0001 & 0.39 & 0.007 & 0.0036 & 0.12 & $<0.0003$ & 0.022 & 0.004 & $<0.0$ & $<0.0003$ & $<0.00002$ & $<0.0001$ & 0.21 & $<0.00005$ \\
\hline MK-31 & 0.0008 & 0.10 & $<0.00005$ & $<0.00001$ & $<0.0001$ & 0.64 & 0.004 & 0.0013 & 0.05 & $<0.0003$ & $<0.014$ & 0.004 & $<0.00001$ & $<0.0003$ & $<0.00002$ & $<0.0001$ & 0.19 & $<0.00005$ \\
\hline-32 & 0.0019 & 0.08 & $<0.00005$ & & & 0.90 & 0.003 & 0.0320 & 0.09 & & & 05 & 01 & 03 & 0004 & $<0.0001$ & 17 & .00005 \\
\hline-33 & & 06 & & & & 1.25 & 0.004 & & 0.09 & & & & & & & & 9 & 0005 \\
\hline-34 & & .13 & & $<0.00$ & & 0.25 & 0.018 & & 0.06 & $<0$. & & 0.004 & $<0$. & & $<0.0$ & $<0$ & 3 & $<0.00005$ \\
\hline MK-35 & & $0 \mathrm{c}_{\mathrm{S}}$ & $<0.00005$ & & & 0.39 & 0.003 & 0.0204 & 0.05 & & $<0$. & 0.003 & 02 & $<0$. & $<0.00002$ & 0.0001 & 0.25 & $<0.00004$ \\
\hline MK-36 & & 17 & $<0.00005$ & $<0.00001$ & $<0.0001$ & 047 & 0.010 & 0.0042 & 0.10 & $<0.0$ & $<0$. & 0.004 & $<0.0$ & $<0$. & $<0.00002$ & $<0.0001$ & 0.18 & $<0.00005$ \\
\hline MK-37 & 13 & 0.12 & 0.00004 & 0.00002 & $<0.0001$ & 1.62 & 0.012 & 0.0339 & 0.06 & 0.0008 & $<0$. & 0.005 & 0.0 & $<0$ & $<0.00002$ & $<0.0001$ & 0.23 & 0.00005 \\
\hline MK-38 & 0.0004 & 09 & $<0.00005$ & $<0.00001$ & $<0.0001$ & 0.49 & 0.005 & 0.0013 & 0.02 & $<0.0003$ & $<0.013$ & 0.003 & $<0.0$ & $<0$. & $<0.00002$ & $<0.0001$ & 0.18 & $<0.00005$ \\
\hline MK-40 & 0022 & 07 & $<0.00005$ & 0.00001 & $<0.0001$ & 0.52 & 0.005 & 0.0046 & 0.0 & 0.0003 & 0 & 0.004 & 01 & 03 & $<0.00002$ & 01 & 0.19 & 0.00005 \\
\hline MK-41 & 0.0010 & 05 & $<0.00005$ & $<0.00001$ & $<0.0001$ & 0.54 & NA & 0.0050 & 0.04 & 0.0002 & 0 & 0.003 & $<0.00001$ & $<0.0003$ & $<0.00002$ & $<0.0001$ & .17 & 0.00005 \\
\hline MK-42 & 0.0011 & 0.11 & $<0.00005$ & $<0.00001$ & $<0.0001$ & 0.41 & 0.010 & 0.0044 & 0.04 & $<0.0002$ & 0.016 & 0.004 & $<0.00001$ & $<0.0003$ & $<0.00002$ & $<0.0001$ & 0.17 & $<0.00005$ \\
\hline MK-43 & 0.0066 & 0.13 & $<0.00005$ & $<0.00001$ & 0.0001 & 0.35 & 0.031 & 0.0015 & 0.19 & $<0.0004$ & 0.762 & 0.005 & $<0.00001$ & $<0.0004$ & $<0.00003$ & $<0.0001$ & 0.33 & $<0.00004$ \\
\hline
\end{tabular}


Table A2.4 (cont.) Transfer factors of elements from soils into rice grains in the Mekong River Delta area $(\mathrm{n}=78)$

\begin{tabular}{|c|c|c|c|c|c|c|c|c|c|c|c|c|c|c|c|c|c|c|}
\hline Sites & Cs & $\mathbf{C u}$ & Hf & La & $\mathbf{L i}$ & Mo & $\mathbf{N i}$ & $\mathbf{P b}$ & $\mathbf{R b}$ & $\mathbf{S b}$ & Sn & $\mathrm{Sr}$ & Th & Tl & $\mathbf{U}$ & $\mathbf{V}$ & $\mathbf{Z n}$ & $\mathbf{Z r}$ \\
\hline$\overline{\mathrm{MK}-44}$ & 0.0056 & 0.10 & 0.00005 & $<0.00001$ & 00001 & 0.55 & 0.010 & 0.0019 & 0.15 & .0004 & $<0.014$ & 0.004 & 0.00001 & 0.0003 & 0.00002 & 0.0001 & 0.27 & 0.00005 \\
\hline & & & 05 & $<1$ & & & & & & & & & 01 & 0.0003 & 0.00002 & & 0.28 & 0.00004 \\
\hline-46 & 036 & 08 & & 001 & 0001 & 10 & .007 & 0028 & 3 & 0004 & 68 & 05 & & 0.0003 & 0.00002 & & 36 & \\
\hline MK-47 & 0.0036 & 0.05 & $<0.00005$ & $<0.00001$ & 0.0001 & 31 & 0.020 & .0016 & 13 & 0.0004 & 0.100 & 0.003 & 0.00001 & $<0.0003$ & 0.00002 & $<0.0001$ & 0.26 & 0.00005 \\
\hline MK-48 & 0.0113 & 0.14 & $<0.00005$ & $<0.00001$ & $<0.0001$ & 0.34 & NA & 0.0010 & 0.21 & $<0.0004$ & 0.129 & 0.005 & $<0.00001$ & $<0.0003$ & $<0.00002$ & $<0.0001$ & 0.40 & $<0.00005$ \\
\hline ИK-49 & 0.0025 & 0.14 & $<0.00005$ & 0.00002 & $<0.0001$ & 0.18 & 0.013 & 0.0332 & 0.07 & 0.0012 & $<0.014$ & 0.003 & $<0.00001$ & $<0.0003$ & $<0.00002$ & $<0.0001$ & 0.36 & $<0.00005$ \\
\hline $1 \mathrm{~K}-51$ & 0.0046 & 0.06 & $<0.00005$ & 0.00001 & $<0.0002$ & 0.88 & 0.005 & .0089 & 0.14 & 0.0005 & 0.024 & 0.006 & $<0.00002$ & $<0.0004$ & $<0.00003$ & $<0.0001$ & 0.25 & $<0.00005$ \\
\hline IK-52 & 0.0003 & 0.08 & $<0.00005$ & $<0.00001$ & $<0.0001$ & 0.16 & 0.014 & .0072 & .02 & $<0.0003$ & $<0.014$ & 0.002 & 0.00001 & $<0.0003$ & $<0.00002$ & $<0.0001$ & 0.18 & $<0.00005$ \\
\hline IK-53 & 0.0010 & 0.11 & $<0.00005$ & $<0.00001$ & $<0.0001$ & 0.25 & 0.006 & .0025 & 05 & $<0.0003$ & $<0.014$ & 0.003 & 0001 & 0.0003 & 0.00002 & $<0.0001$ & 0.18 & $<0.00005$ \\
\hline K-54 & 0.0045 & 0.10 & 05 & 0.00001 & $<$ & 0.52 & 0.011 & 54 & 19 & 0003 & 0.037 & 0.005 & 01 & 0.0003 & .00002 & 001 & .16 & 0.00005 \\
\hline-55 & 0.0014 & 0.18 & & & & 0 & 0. & & 77 & & 36 & 0.004 & & & 02 & 01 & 17 & 0.00005 \\
\hline-56 & 0.0009 & 0.08 & 06 & $<0.00$ & $<0.0$ & 42 & 0.010 & 59 & 0.04 & 02 & 0.031 & 0.003 & 01 & 03 & 02 & 01 & 14 & 0005 \\
\hline-57 & 0.0009 & 0.10 & $<0.0$ & 0.00001 & 01 & 43 & 0.005 & 0076 & 0.05 & 03 & $<0.016$ & 0.005 & $<0$ & $<0.0003$ & $<0.00002$ & $<0$ & 0.17 & $<0.00005$ \\
\hline MK-58 & 0.0011 & 0.11 & $<0.00005$ & $<0.00001$ & $<0.0001$ & .34 & 0.007 & .0045 & .07 & 03 & 0.033 & 0.005 & 01 & $<0$. & 002 & $<0$ & 0.20 & 005 \\
\hline K-59 & 0.0010 & 0.13 & $<0.00006$ & 0.00001 & $<0.0001$ & 0.75 & 0.009 & 0.0120 & 0.04 & $<0.0003$ & 0.021 & 0.003 & $<0.00002$ & $<0.0003$ & $<0.00003$ & $<0.0001$ & 0.21 & $<0.00006$ \\
\hline-60 & 0.0018 & 0.09 & $<0.00006$ & $<0.00001$ & $<0.0001$ & 0.83 & 0.009 & 0.0011 & 0.08 & $<0.0003$ & 0.033 & 0.005 & $<0.00001$ & $<0.0003$ & $<0.00003$ & $<0.0001$ & 0.25 & $<0.00005$ \\
\hline-61 & 0.0038 & 0.13 & $<0.00005$ & $<0.00001$ & $<0.0002$ & 0.61 & 0.019 & 0.0014 & 15 & & 0.084 & 0.005 & $<0$. & $<0.0004$ & $<0.00002$ & 0.0002 & 0.24 & $<0.00005$ \\
\hline-62 & 0.0029 & 0.10 & $<0.0$ & $<0.0$ & & 0.58 & 0.006 & & 14 & & & 0.005 & & & & & .25 & 004 \\
\hline-63 & & 0.11 & & & & 0.41 & NA & & 10 & & & 0.004 & & & & & 24 & \\
\hline & & 0.17 & & & & & & & & & 13 & 03 & & & & & 30 & \\
\hline & 32 & 0.05 & & & $\leq C$ & 2 & 0.006 & & & & $<0$ & 3 & & $<0$ & $<0$ & $<0$ & 3 & $<0$ \\
\hline-66 & 0.0035 & 0.04 & $<0.0$ & 01 & $<0$ & 0 & 0.007 & 0. & 0.13 & 07 & 0. & 0.003 & $<0$ & $<0$. & $<0$. & 01 & 0.16 & $<0$. \\
\hline MK-67 & 0.0001 & 0.20 & $<0.00005$ & $<0.00001$ & $<0.0001$ & 0.44 & 0.012 & 0.0011 & 01 & 0.0004 & 0.017 & 0.004 & $<0$. & $<0.0003$ & $<0.00002$ & $<0.0001$ & 0.28 & $<0.00004$ \\
\hline MK-68 & 0.0002 & 0.16 & $<0.00005$ & $<0.00001$ & $<0.0001$ & 0.41 & 0.011 & 0.0023 & .01 & $<0.0004$ & 0.017 & 0.004 & $<0.00001$ & $<0.0003$ & $<0.00002$ & $<0.0001$ & 0.24 & $<0.00004$ \\
\hline MK-69 & 0.0002 & 0.21 & $<0.00005$ & 0.00001 & $<0.0001$ & 0.43 & 0.019 & 0.0230 & .01 & 0.0009 & 0.015 & 0.005 & $<0.00001$ & $<0.0003$ & $<0.00002$ & 0.0001 & 0.25 & $<0.00004$ \\
\hline MK-70 & 0.0007 & 0.08 & $<0.00005$ & .00002 & $<0.0001$ & 0.30 & 0.003 & 0.0019 & .03 & 0.0004 & $<0.013$ & 0.005 & $<0.00001$ & $<0.0003$ & $<0.00002$ & $<0.0001$ & 0.22 & $<0.00004$ \\
\hline K-71 & 0.0008 & 0.09 & $<0.00005$ & .00001 & $<0.0001$ & 0.38 & 0.004 & 0.0109 & 0.04 & $<0.0003$ & $<0.013$ & 0.005 & $<0$ & $<0.0003$ & $<0.00002$ & 0.0001 & 0.26 & $<0.00005$ \\
\hline-72 & 0.0002 & .15 & 04 & 0.00001 & & 0.49 & 0.010 & 031 & .02 & & 7 & 0.004 & & $<0$ & 02 & $<0$. & 0.29 & $<0.00004$ \\
\hline-73 & 0.0005 & 0.17 & $<0.00004$ & $<0.00001$ & & 0.41 & 0.012 & & 03 & 005 & 0.016 & 0.005 & & 004 & 03 & 001 & 0.31 & $<0.00004$ \\
\hline MK-74 & 0.0003 & 0.17 & & & & 0.27 & 0.014 & & 02 & & & 0.004 & & $<0.0$ & & $<0$ & 0.35 & $<0.00004$ \\
\hline & 0.0013 & 0.13 & & $<0.000$ & $\leq 00$ & 0.71 & 0.008 & & & & & 0.007 & & $<0.0$ & $<0.0$ & $<0$. & 0.37 & $<0.00004$ \\
\hline-76 & 0.0025 & 0.10 & $<0.00005$ & & & 0.19 & 0.012 & & 0 & & $<0.014$ & 0.005 & & $<0.0$ & $<0.00002$ & & 0.19 & $<0.00004$ \\
\hline 877 & & 0.07 & $<0.00005$ & $<0.00001$ & & & 0.014 & 0.0018 & 0.45 & 03 & $<0.015$ & 0.006 & $<0$. & $<0.0003$ & $<0.00002$ & 0.0001 & 0.16 & $<0.00005$ \\
\hline-78 & 0.0024 & 0.13 & $<0.00005$ & 0.00001 & 0 & 0.45 & 0.010 & 0.0020 & 10 & 0003 & $<0.014$ & 0.006 & $<0.0$ & $<0.0003$ & $<0.00002$ & $<0.0001$ & 0.19 & $<0.00005$ \\
\hline MK-79 & 0099 & 0.08 & $<0.00005$ & 00001 & (OO & 1 & 0.019 & 11 & 0.21 & 02 & $<0.014$ & 0.005 & 01 & $<0$ & $<0.00002$ & $<0$ & 0.16 & $<0.00005$ \\
\hline MK-80 & 0034 & 015 & $<0.00005$ & $<0.00001$ & $<0.0001$ & 0.28 & .017 & .0018 & 08 & 0.0003 & $<0.014$ & 0.006 & $<0.00001$ & $<0.0003$ & $<0.00002$ & $<0.0001$ & 0.23 & $<0.00005$ \\
\hline MK-81 & 0.0032 & 0.06 & $<0.00005$ & 0.00001 & 0.0001 & 0.21 & 0.009 & 0.0032 & 0.12 & $<0.0003$ & 0.031 & 0.003 & 0.00001 & $<0.0003$ & $<0.00002$ & $<0.0001$ & 0.18 & $<0.00005$ \\
\hline MK-82 & 0.0011 & 0.16 & $<0.00005$ & $<0.00001$ & 0.0001 & 0.13 & NA & 0.0011 & 0.04 & $<0.0004$ & $<0.015$ & 0.002 & $<0.00001$ & $<0.0003$ & $<0.00002$ & 0.0001 & 0.30 & $<0.00004$ \\
\hline
\end{tabular}



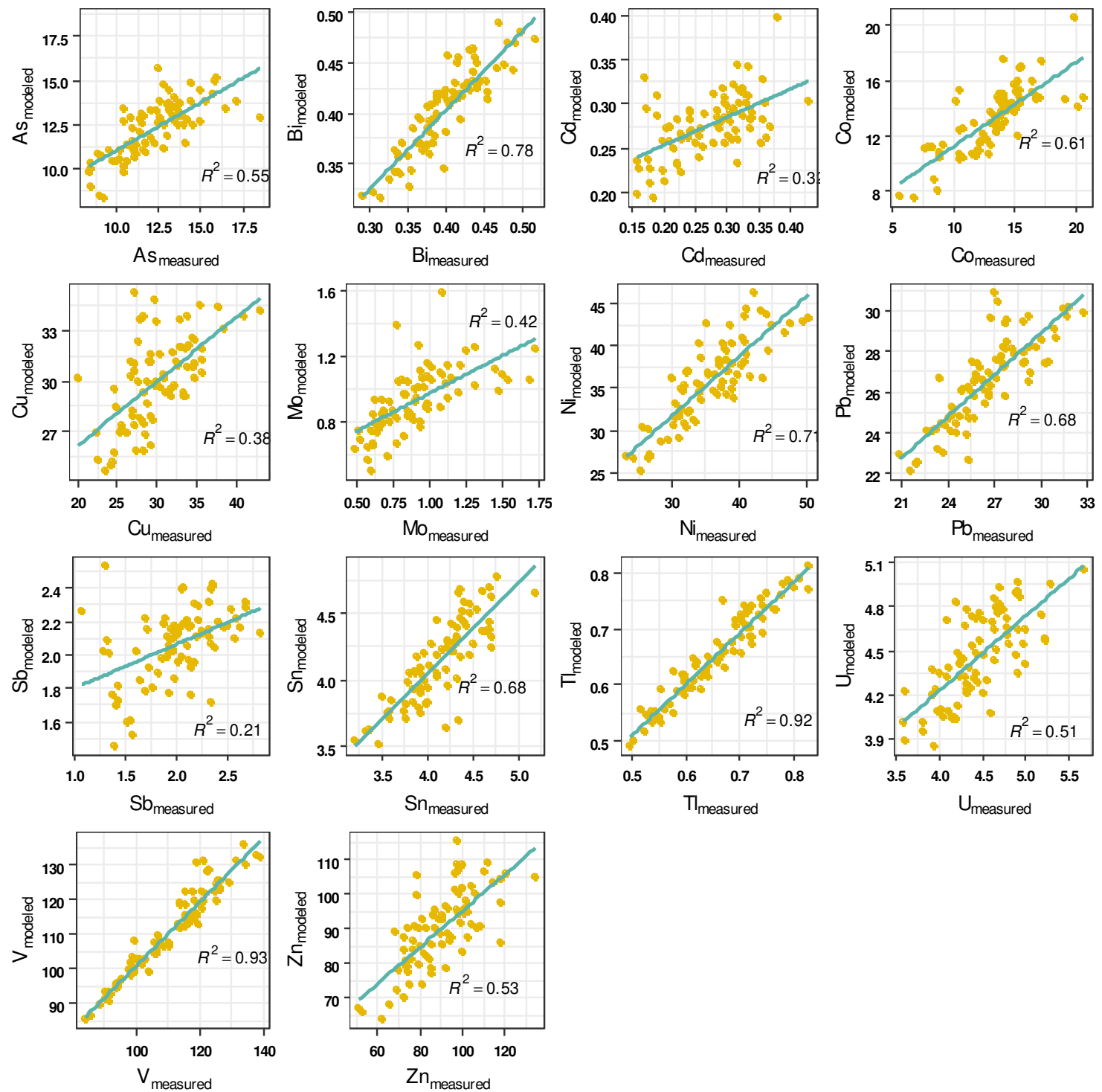

Fig. A2.1 Scattergram of measured contents versus modeled contents of selected trace elements in soils in the Mekong River (in $\mathrm{mg} \mathrm{kg}^{-1}$ ). The modeled values are obtained by using regression models based on soil parameters according to Table 4.2 in the main text. 


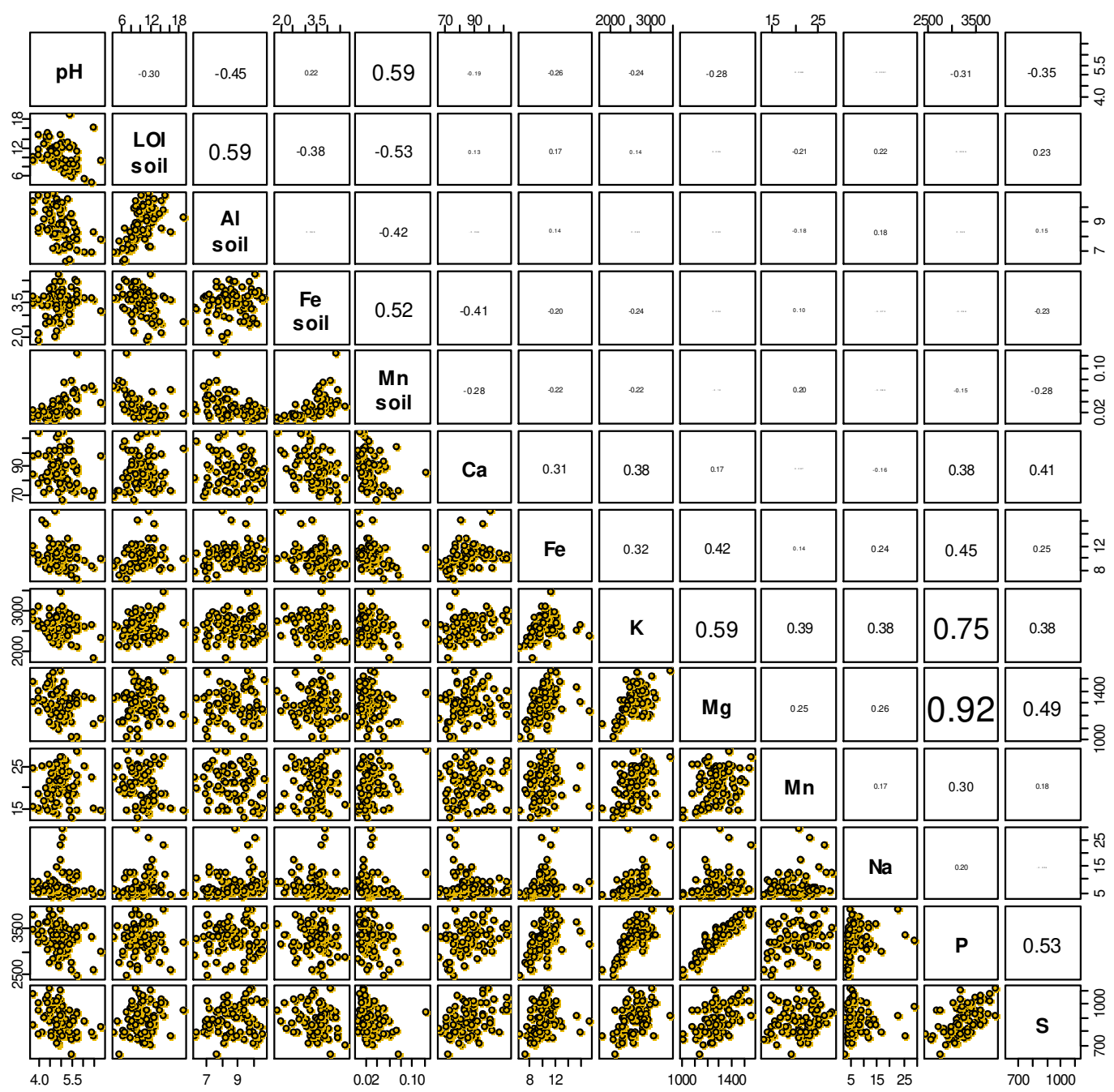

Fig. A2.2 Scattergram and correlation matrix for nutrient concentrations in rice grains in the Mekong River Delta area including relations between grain concentrations and soil parameters (soil concentrations in wt. \%, grain concentrations in $\mathrm{mg} \mathrm{kg}^{-1}$ ) 


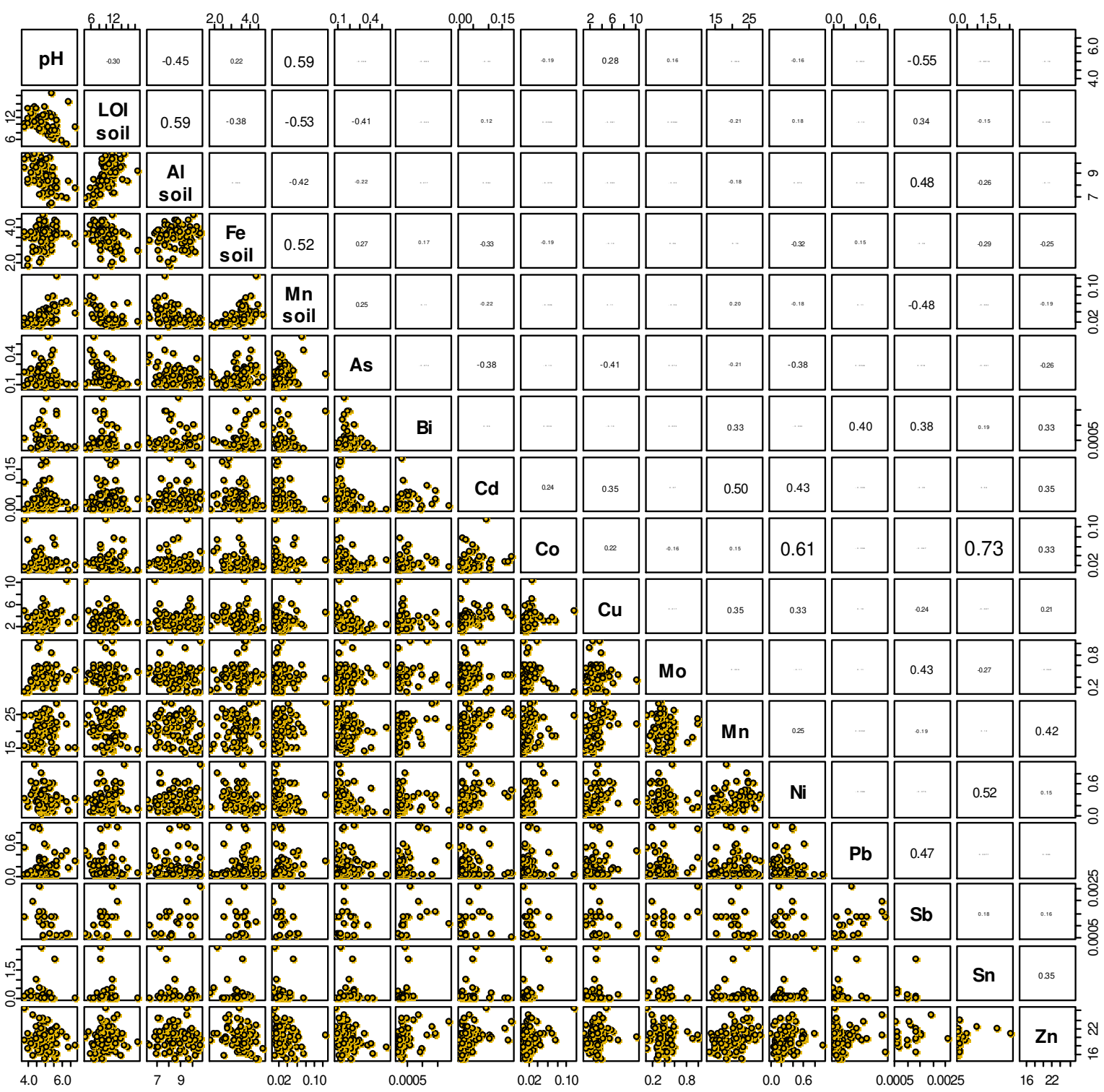

Fig. A2.3 Scattergram and correlation matrix of trace element concentrations in rice grains of the Mekong River Delta area including relations between grain concentrations and soil parameters (soil concentrations in wt. \%, grain concentrations in $\mathrm{mg} \mathrm{kg}^{-1}$ ) 

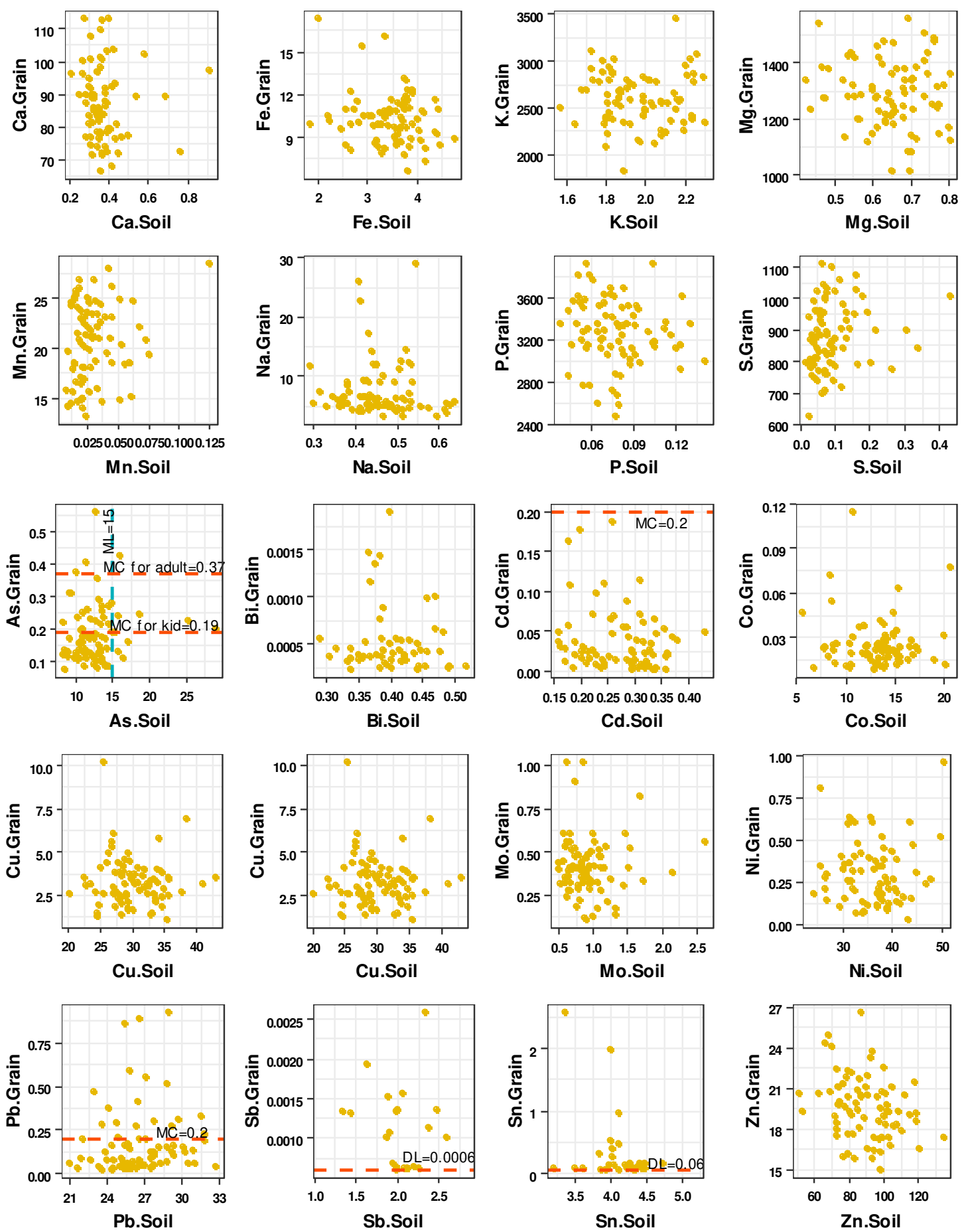

Fig. A2.4 Scattergrams of element concentrations in soils versus concentrations in corresponding grains in the Mekong River Delta area (main elements in soils in \%, trace elements in soils and grains in $\mathrm{mg} \mathrm{kg}^{-1}$ ). For $\mathrm{As}, \mathrm{Cd}$, and $\mathrm{Pb}$ plots, red lines indicate the maximum level (ML) for Vietnamese agricultural soil. blue lines represent the maximum concentration (MC) of elements in rice grain for adults and children. The green lines in the plots of Sb and Sn represent their detection limit (DL). 


\section{Appendix A3: Supplementary Material for Chapter 5}

Table A3.1 Coordinates of sample positions and mass ratios of plant parts to the aboveground plant

\begin{tabular}{|c|c|c|c|c|c|c|c|c|c|c|}
\hline \multirow{2}{*}{ Area } & \multirow{2}{*}{ Site } & \multirow{2}{*}{$\mathbf{E}$} & \multirow{2}{*}{$\mathbf{N}$} & \multicolumn{3}{|c|}{ Mass ratio } & \multirow{2}{*}{ Area } & \multirow{2}{*}{ Site } & \multirow[b]{2}{*}{$\mathbf{E}$} & \multirow{2}{*}{$\mathbf{N}$} \\
\hline & & & & Shoot & Husk & Grain & & & & \\
\hline Huong & H1 & 107.5372 & 16.44096 & 0.52 & 0.10 & 0.38 & Mekong & MK31 & 105.4434 & 10.55026 \\
\hline \multirow[t]{3}{*}{ River } & $\mathrm{H} 5$ & 107.5875 & 16.54479 & 0.42 & 0.11 & 0.47 & River & MK32 & 105.4503 & 10.5412 \\
\hline & H6 & 107.5945 & 16.55145 & 0.49 & 0.10 & 0.41 & & MK33 & 105.4884 & 10.49884 \\
\hline & $\mathrm{H7}$ & 107.5947 & 16.55188 & 0.45 & 0.11 & 0.44 & & MK34 & 105.4842 & 10.49025 \\
\hline Red & HN1 & 105.9115 & 20.85542 & 0.44 & 0.10 & 0.46 & & MK35 & 105.4921 & 10.49890 \\
\hline \multirow{18}{*}{ River } & HN2 & 105.9049 & 20.8294 & 0.31 & 0.15 & 0.54 & & MK36 & 105.5078 & 10.46332 \\
\hline & HN3 & 105.9071 & 20.80671 & 0.35 & 0.13 & 0.52 & & MK37 & 105.4510 & 10.53349 \\
\hline & HN5 & 105.4479 & 21.18195 & 0.36 & 0.13 & 0.51 & & MK38 & 105.4103 & 10.53300 \\
\hline & HN6 & 105.4500 & 21.18146 & 0.47 & 0.13 & 0.40 & & MK40 & 105.4384 & 10.53296 \\
\hline & HN7 & 105.4522 & 21.18124 & 0.45 & 0.10 & 0.45 & & MK41 & 105.4269 & 10.53729 \\
\hline & HN8 & 105.4515 & 21.18280 & 0.62 & 0.15 & 0.23 & & MK42 & 105.4139 & 10.54031 \\
\hline & HN9 & 105.4506 & 21.18461 & 0.47 & 0.08 & 0.45 & & MK43 & 106.1629 & 10.15198 \\
\hline & HN10 & 105.3556 & 21.23928 & 0.40 & 0.11 & 0.49 & & MK44 & 106.1141 & 10.16194 \\
\hline & HN11 & 105.5521 & 21.17566 & 0.33 & 0.11 & 0.56 & & MK45 & 106.1052 & 10.16381 \\
\hline & PT1 & 105.0707 & 21.48281 & 0.39 & 0.12 & 0.49 & & MK46 & 106.0737 & 10.16444 \\
\hline & PT3 & 105.0672 & 21.49603 & 0.39 & 0.13 & 0.48 & & MK47 & 106.0812 & 10.16661 \\
\hline & PT4 & 105.1323 & 21.43983 & 0.40 & 0.12 & 0.48 & & MK48 & 105.0946 & 10.17084 \\
\hline & PT6 & 105.2812 & 21.34621 & 0.44 & 0.13 & 0.43 & & MK49 & 106.1047 & 10.18074 \\
\hline & PT7 & 105.2802 & 21.34854 & 0.43 & 0.08 & 0.49 & & MK51 & 105.3216 & 10.83619 \\
\hline & PT8 & 105.2794 & 21.35039 & 0.40 & 0.10 & 0.50 & & MK52 & 105.3270 & 10.84106 \\
\hline & PT9 & 105.2804 & 21.35107 & 0.35 & 0.12 & 0.53 & & MK53 & 105.3333 & 10.83933 \\
\hline & PT10 & 105.3543 & 21.31105 & 0.38 & 0.13 & 0.49 & & MK54 & 105.3181 & 10.82736 \\
\hline & PT11 & 105.4452 & 21.29736 & 0.43 & 0.11 & 0.46 & & MK55 & 105.3244 & 10.82386 \\
\hline Mekong & MK1 & 105.1789 & 10.84005 & & & & & MK56 & 105.3239 & 10.82708 \\
\hline \multirow[t]{27}{*}{ River } & MK2 & 105.1726 & 10.83846 & & & & & MK57 & 105.3321 & 10.82444 \\
\hline & MK3 & 105.2876 & 10.82348 & & & & & MK58 & 105.3343 & 10.81592 \\
\hline & MK4 & 105.3117 & 10.83041 & & & & & MK59 & 105.3526 & 10.79633 \\
\hline & MK5 & 105.3077 & 10.82734 & & & & & MK60 & 105.3582 & 10.77364 \\
\hline & MK6 & 105.2991 & 10.82513 & & & & & MK61 & 105.3770 & 10.52436 \\
\hline & MK7 & 105.3071 & 10.7954 & & & & & MK62 & 105.3861 & 10.51619 \\
\hline & MK8 & 105.3047 & 10.79752 & & & & & MK63 & 105.4013 & 10.50378 \\
\hline & MK9 & 105.3082 & 10.78972 & & & & & MK64 & 105.3988 & 10.48869 \\
\hline & MK10 & 105.1407 & 10.7277 & & & & & MK65 & 105.3840 & 10.43972 \\
\hline & MK11 & 105.2111 & 10.80318 & & & & & MK66 & 105.3900 & 10.43422 \\
\hline & MK12 & 105.1952 & 10.79276 & & & & & MK67 & 105.9468 & 9.877722 \\
\hline & MK13 & 105.1966 & 10.80347 & & & & & MK68 & 105.9506 & 9.868500 \\
\hline & MK14 & 105.2539 & 10.16000 & & & & & MK69 & 105.9633 & 9.862083 \\
\hline & MK15 & 105.2278 & 10.79780 & & & & & MK70 & 105.9845 & 9.837694 \\
\hline & MK16 & 105.2187 & 10.80072 & & & & & MK71 & 105.9907 & 9.832972 \\
\hline & MK17 & 105.2050 & 10.77340 & & & & & MK72 & 106.0933 & 9.811639 \\
\hline & MK18 & 105.1952 & 10.77515 & & & & & MK73 & 106.0785 & 9.825667 \\
\hline & MK19 & 105.2079 & 10.79831 & & & & & MK74 & 106.0783 & 9.812667 \\
\hline & MK20 & 105.2653 & 10.76141 & & & & & MK75 & 106.0711 & 9.846556 \\
\hline & MK21 & 105.2436 & 10.74276 & & & & & MK76 & 105.6119 & 10.35236 \\
\hline & MK22 & 105.2535 & 10.68282 & & & & & MK77 & 105.6144 & 10.35535 \\
\hline & MK23 & 105.2726 & 10.65025 & & & & & MK78 & 105.6179 & 10.36672 \\
\hline & MK24 & 105.2934 & 10.62049 & & & & & MK79 & 105.6466 & 10.38142 \\
\hline & MK25 & 105.3058 & 10.59924 & & & & & MK80 & 105.7149 & 10.47660 \\
\hline & MK26 & 106.4413 & 10.35912 & & & & & MK81 & 105.7232 & 10.49193 \\
\hline & MK27 & 106.4850 & 10.34935 & & & & & MK82 & 105.8007 & 10.48096 \\
\hline & MK30 & 105.4629 & 10.43315 & & & & & & & \\
\hline
\end{tabular}


Appendix A3

Table A3.2 Measured element concentrations in husk and shoot $\left(\mathrm{mg} \mathrm{kg}^{-1} ; \mathrm{n}=23\right)$

\begin{tabular}{|c|c|c|c|c|c|c|c|c|c|c|c|c|c|c|c|c|c|c|c|c|c|c|}
\hline & \multirow{2}{*}{\multicolumn{2}{|c|}{$\frac{\text { Al }}{\text { Husk Shoot }}$}} & \multirow{2}{*}{\multicolumn{2}{|c|}{$\frac{\text { Ca }}{\text { Husk Shoot }}$}} & \multirow{2}{*}{\multicolumn{2}{|c|}{$\frac{\mathbf{F e}}{\text { Husk Shoot }}$}} & \multicolumn{2}{|c|}{$\mathbf{K}$} & \multicolumn{2}{|c|}{$\mathrm{Mg}$} & \multirow{2}{*}{\multicolumn{2}{|c|}{$\frac{\text { Mn }}{\text { Husk Sh }}$}} & \multicolumn{2}{|c|}{$\mathrm{Na}$} & \multicolumn{2}{|c|}{$\mathbf{P}$} & \multicolumn{2}{|c|}{$S$} & \multicolumn{2}{|c|}{ As } & \multicolumn{2}{|c|}{ Ba } \\
\hline & & & & & & & Husk & Shoot & Husk & Shoot & & & Husk & Shoot & Husk & Shoot & Husk & Shoot & Husk & Shoot & Husk & hoot \\
\hline H1 & 32 & 246 & 730 & 4921 & 28 & 476 & 4777 & 32125 & 214 & 1411 & 152 & 684 & 3.7 & 146 & 1149 & 2660 & 688 & 2074 & 0.75 & 5.95 & 21.6 & 125 \\
\hline H5 & 32 & 29 & 2739 & 3106 & 60 & 132 & 5072 & 19173 & 1027 & 3626 & 198 & 966 & 11.8 & 1498 & 1222 & 537 & 407 & 1111 & 1.20 & 3.08 & 9.4 & 123 \\
\hline H6 & 32 & 41 & 790 & 4914 & 30 & 105 & 5228 & 15288 & 194 & 4931 & 379 & 1184 & 9.5 & 87 & 987 & 1312 & 596 & 3328 & 0.26 & 0.86 & 20.3 & 119 \\
\hline H7 & 46 & 56 & 1296 & 2709 & 45 & 158 & 5680 & 24764 & 234 & 2107 & 278 & 556 & 13.4 & 448 & 1057 & 1456 & 524 & 2884 & 0.92 & 3.14 & 35.4 & 135 \\
\hline HN1 & 93 & 924 & 1296 & 6038 & 98 & 612 & 9512 & 37541 & 584 & 3435 & 129 & 1185 & 43.2 & 874 & 1544 & 2264 & 689 & 1849 & 1.45 & 10.53 & 22.4 & 92 \\
\hline HN2 & 149 & 571 & 1018 & 7872 & 107 & 396 & 3227 & 42715 & 174 & 2735 & 140 & 574 & 25.0 & 178 & 1608 & 1147 & 562 & 1163 & 0.24 & 2.85 & 9.8 & 86 \\
\hline HN3 & 74 & 731 & 927 & 6478 & 68 & 475 & 3796 & 37939 & 242 & 3088 & 109 & 484 & 17.4 & 478 & 1526 & 1482 & 695 & 1068 & 0.43 & 4.20 & 9.2 & 55 \\
\hline HN5 & 62 & 105 & 991 & 7428 & 57 & 107 & 3202 & 31271 & 230 & 3407 & 169 & 667 & 13.7 & 42 & 985 & 979 & 791 & 1619 & 0.19 & 1.49 & 0.7 & 104 \\
\hline HN6 & 258 & 116 & 1495 & 3311 & 176 & 104 & 1230 & 39644 & 491 & 1895 & 317 & 610 & 36.6 & 103 & 1065 & 575 & 658 & 981 & 0.64 & 2.08 & 30.5 & 82 \\
\hline HN7 & 152 & 181 & 16 & 4016 & 99 & 161 & 2998 & 32866 & 244 & 2472 & 181 & 613 & 30.8 & 221 & 1259 & 619 & 412 & 1402 & 0.24 & 1.41 & 11.2 & 61 \\
\hline HN8 & 35 & 74 & 683 & 3087 & 39 & 77 & 3358 & 17291 & 210 & 2165 & 257 & 623 & 37.2 & 115 & 873 & 768 & 432 & 1341 & 0.17 & 0.78 & 17.2 & 96 \\
\hline HN9 & 62 & 199 & 812 & 4517 & 55 & 193 & 3723 & 31571 & 345 & 263 & 257 & 1050 & 34.9 & 79 & 1009 & 1258 & 222 & 1385 & 0.18 & 3.86 & 19.8 & 123 \\
\hline HN10 & 79 & 63 & 956 & 4351 & 71 & 108 & 3635 & 40087 & 323 & 248 & 217 & 2580 & 22.8 & 54 & 1235 & 1055 & 751 & 2625 & 0.12 & 1.79 & 31.1 & 62 \\
\hline HN11 & 42 & 182 & 956 & 4997 & 112 & 129 & 4916 & 57709 & 450 & 2179 & 193 & 637 & 29.0 & 161 & 1674 & 645 & 933 & 1483 & 0.68 & 3.69 & 14.3 & 72 \\
\hline PT1 & 29 & 44 & 1023 & 4835 & 59 & 64 & 5113 & 38050 & 516 & 2758 & 287 & 1158 & 18.3 & 145 & 1101 & 971 & 570 & 1835 & 0.58 & 0.43 & 28.1 & 133 \\
\hline PT3 & 23 & 14 & 1027 & 3131 & 33 & 38 & 2310 & 42162 & 275 & 2390 & 142 & 337 & 7.5 & 245 & 1135 & 588 & 708 & 1092 & 0.33 & 1.73 & 30.4 & 132 \\
\hline PT4 & 104 & 187 & 1089 & 5264 & 108 & 241 & 5238 & 39074 & 279 & 2703 & 54 & 89 & 26.0 & 40 & 989 & 821 & 959 & 1244 & 0.15 & 0.37 & 7.7 & 60 \\
\hline PT6 & 43 & 503 & 1837 & 2534 & 161 & 637 & 4159 & 21335 & 227 & 3687 & 156 & 617 & 53.2 & 1497 & 1567 & 2058 & 673 & 1736 & 0.62 & 3.95 & 24.3 & 71 \\
\hline PT7 & 21 & 122 & 811 & 8269 & 57 & 249 & 3049 & 21795 & 264 & 3786 & 242 & 336 & 37.6 & 347 & 1790 & 2318 & 709 & 2827 & 0.47 & 5.14 & 30.7 & 52 \\
\hline PT8 & 41 & 142 & 1187 & 4109 & 53 & 160 & 2511 & 33990 & 373 & 2587 & 259 & 547 & 11.9 & 186 & 1098 & 1644 & 777 & 1693 & 0.76 & 4.26 & 25.1 & 120 \\
\hline PT9 & 17 & 80 & 946 & 7037 & 38 & 98 & 2962 & 34367 & 287 & 1897 & 139 & 415 & 10.3 & 113 & 1272 & 397 & 732 & 1804 & 0.40 & 2.57 & 16.7 & 82 \\
\hline ?T10 & 91 & 419 & 1948 & 6088 & 79 & 431 & 4587 & 48168 & 478 & 1866 & 1412 & 55 & 26.6 & 1846 & 1672 & 1209 & 884 & 1970 & 0.39 & 0.74 & 22.1 & 194 \\
\hline PT11 & 133 & 163 & 1187 & 5878 & 112 & 176 & 4555 & 30039 & 118 & 2974 & 214 & 650 & 29.8 & 166 & 1445 & 791 & 946 & 1906 & 0.26 & 1.09 & 23.4 & 118 \\
\hline
\end{tabular}


Appendix A3

Table A3.2 (cont.) Measured element concentrations in husk and shoot ( $\mathrm{mg} \mathrm{kg}^{-1} ; \mathrm{n}=23$ )

\begin{tabular}{|c|c|c|c|c|c|c|c|c|c|c|c|c|c|c|c|c|c|c|c|c|c|c|}
\hline \multirow{2}{*}{ Site } & \multicolumn{2}{|c|}{ Bi } & \multicolumn{2}{|c|}{ Cd } & \multicolumn{2}{|c|}{$\mathrm{Ce}$} & \multicolumn{2}{|c|}{ Co } & \multicolumn{2}{|c|}{$\mathrm{Cr}$} & \multicolumn{2}{|c|}{ Cs } & \multicolumn{2}{|c|}{$\mathbf{C u}$} & \multicolumn{2}{|c|}{ Hf } & \multicolumn{2}{|c|}{ La } & \multicolumn{2}{|c|}{$\mathbf{L i}$} & \multicolumn{2}{|c|}{ Mo } \\
\hline & Husk & Shoot & Husk & Shoot & Husk & Shoot & Husk & Shoot & Husk 5 & Shoot & Husk & Shoot & Husk & Shoot & Husk & Shoot & Husk & Shoot & Husk & Shoot & Husk S & Shoot \\
\hline$\overline{\mathrm{H} 1}$ & 0.003 & 0.016 & 0.029 & 0.319 & 0.15 & 0.49 & 0.10 & 1.11 & 0.37 & 0.94 & 0.18 & 0.20 & 3.01 & 2.88 & 0.005 & 0.033 & 0.066 & 0.229 & 0.04 & 0.18 & 0.07 & 1.13 \\
\hline H5 & 0.009 & 003 & 489 & 0.978 & 05 & 0.33 & 0.09 & 0.73 & 0.47 & 0.69 & 13 & 0.77 & 2.70 & 3.55 & .002 & 0.010 & .029 & 0.158 & 0.03 & .07 & 0.07 & 0.13 \\
\hline H6 & 0.001 & 0.005 & 0.082 & 0.313 & 0.09 & 0.38 & 0.25 & 0.78 & 0.45 & 0.67 & 0.71 & 2.46 & 2.23 & 5.26 & 0.002 & 0.006 & 0.047 & 0.201 & 0.03 & 0.15 & 0.06 & 0.86 \\
\hline H7 & 0.002 & 0.010 & 0.021 & 0.183 & 0.04 & 0.17 & 0.09 & 0.61 & 0.34 & 0.79 & 0.60 & 0.86 & 0.92 & 2.50 & 0.004 & 0.005 & 0.023 & 0.090 & 0.01 & 0.14 & 0.04 & 0.73 \\
\hline HN1 & 0.010 & 0.026 & 0.002 & 0.168 & 0.14 & 1.10 & 0.07 & 0.37 & 0.57 & 2.37 & 0.21 & 0.55 & 2.60 & 3.00 & 0.010 & 0.054 & 0.073 & 0.550 & 0.07 & 0.64 & 0.08 & 0.74 \\
\hline $\mathrm{HN} 2$ & 008 & 0.019 & 0.020 & 0.105 & 0.47 & 2.02 & 0.06 & 0.31 & 0.29 & 2.25 & 0.05 & 0.62 & 1.47 & 4.11 & 0.019 & 0.061 & 0.231 & 1.057 & 0.12 & 0.40 & 0.04 & 0.69 \\
\hline $\mathrm{H}$ & 010 & 0.024 & 003 & 0.111 & .14 & 0.8 & .04 & 0.3 & 0.33 & 1.6 & 0.04 & 0.7 & 1.21 & 2.61 & 0.010 & 0.063 & 0.073 & 0.447 & 0.07 & 0.60 & 0.03 & 1.22 \\
\hline $\mathrm{HN}$ & 05 & 0. & 016 & 0.14 & 99 & 0.2 & 04 & 0 . & 0.22 & 1.0 & 0.05 & 0. & 1.94 & 3. & 0.003 & 0. & 0.045 & 0. & 0.02 & 0.11 & 0.07 & 0.32 \\
\hline HN & 08 & 0 & 776 & 0.1 & 7 & 0. & 8 & 0. & 0.50 & $1 .($ & 4 & $0 .($ & 1.64 & 2. & 0.025 & 0. & 0.189 & 0. & .17 & 0.09 & 0.09 & 0.37 \\
\hline $\mathrm{HN}$ & 005 & 0.00 & 020 & 0.3 & 0.19 & 0.2 & 0.05 & 0 & 0.25 & 1. & 0.05 & 0. & 1.40 & 3. & 0.009 & 0. & 0.101 & 0. & 0.09 & 0 . & 0.03 & 0.43 \\
\hline $\mathrm{HN}$ & 003 & 0.005 & 103 & 0.72 & .07 & 0.1 & . 03 & 0 . & .19 & 1.0 & 0.07 & 0 . & 3.05 & 3.0 & 0.006 & 0.016 & 0.035 & $0 .($ & 0.04 & 0.13 & 0.05 & 0.21 \\
\hline $\mathrm{HN}$ & 0.006 & 0.012 & 215 & 1.332 & 0.09 & 0.34 & 0.05 & 0.2 & 0.84 & 0.7 & 0.12 & 0.03 & 1.80 & 3.80 & 0.004 & 0.016 & 0.049 & 0.170 & 0.04 & 0.16 & 0.32 & 0.08 \\
\hline HN1 & 003 & 0.005 & 680 & 3.395 & 0.12 & 0.22 & 0.06 & 0.2 & 0.49 & 0.9 & 0.04 & 0.1 & 2.70 & 6.07 & 0.006 & 0.016 & 0.059 & 0.084 & 0.05 & 0.14 & 0.06 & 0.10 \\
\hline HN1 & 005 & 0.010 & 0.036 & 0.195 & 0.13 & 0.32 & .14 & 0.20 & 1.03 & 1.09 & 0.03 & 0.0 & .95 & 4.10 & 0.010 & 0.017 & 0.061 & 0.156 & 0.04 & 0.14 & 0.06 & 1.19 \\
\hline PT1 & 007 & 0.007 & 0.012 & 0.461 & 0.11 & 0.06 & .10 & 0.06 & 0.24 & 0.8 & 0.08 & 0.1 & 2.97 & 3.76 & 0.009 & 0.009 & 0.051 & 0.026 & 0.07 & 0.12 & 0.10 & 1.34 \\
\hline PT3 & 008 & 0.003 & 019 & 0.114 & 07 & 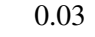 & 02 & 0. & 0.44 & 0.8 & 0.08 & 0. & 2.90 & 3.0 & 0.005 & 0.010 & 0.038 & 0.020 & 0.06 & 0.05 & 0.05 & 0.58 \\
\hline PT4 & 18 & 0.011 & 0.015 & 0.120 & 33 & 0.38 & 05 & 0. & .63 & 0.81 & 03 & 7 & 2.53 & 10.54 & 0. & & 0.210 & & .08 & 6 & 0.13 & 0.70 \\
\hline PT6 & 111 & 0.014 & 0.002 & 0.08 & 70 & 0. & & 0.2 & 0.61 & 1.8 & 0.31 & 0. & 3.15 & & 0. & & 0.347 & & 0.22 & 0 & 0.10 & 0.12 \\
\hline PT7 & 001 & 0.016 & 0.003 & 0.1 & 0.06 & 0.2 & & 0. & 0.42 & 0.9 & 0.58 & 0. & 4.05 & 1.2 & 0.002 & 0.005 & 0.035 & & 0.02 & 0 . & 0.34 & 0.48 \\
\hline & 007 & 0.011 & 0.005 & $0.1 \mathrm{C}$ & 7 & 0.1 & & 0. & 0.37 & 1.0 & 0.05 & 0. & 0.43 & 3.0 & 0.004 & 0.015 & 0.040 & & 0.03 & 0.11 & 0.07 & 0.48 \\
\hline PT9 & 005 & 014 & 002 & 0.1 & 08 & 0 . & & 0. & 0.54 & 1.1 & 0.02 & 0. & 1.04 & 2.5 & 0.004 & 0.007 & 0.052 & 0.092 & 0.04 & 0.06 & 0.07 & 0.30 \\
\hline $\mathrm{P}^{\prime}$ & 005 & 0.013 & 001 & 0.06 & 0.16 & 0. & 0.19 & 0.2 & 0.26 & 1.4 & 0.23 & 0.1 & 2.62 & 5.6 & 0.008 & 0.032 & 0.085 & 0.233 & 0.08 & 0.26 & 0.09 & 0.12 \\
\hline PT11 & 0.007 & 0.011 & 0.037 & 0.361 & 0.19 & 0.47 & 0.06 & 0.18 & 0.72 & 0.78 & 0.05 & 0.05 & 2.02 & 2.68 & 0.011 & 0.024 & 0.094 & 0.243 & 0.07 & 0.15 & 0.05 & 0.39 \\
\hline
\end{tabular}


Appendix A3

Table A3.2 (cont.) Measured element concentrations in husk and shoot $\left(\mathrm{mg} \mathrm{kg}^{-1} ; \mathrm{n}=23\right)$

\begin{tabular}{|c|c|c|c|c|c|c|c|c|c|c|c|c|c|c|c|c|c|c|c|c|c|c|c|c|}
\hline \multirow{2}{*}{ Site } & \multicolumn{2}{|c|}{$\mathbf{N i}$} & \multicolumn{2}{|c|}{$\mathbf{P b}$} & \multicolumn{2}{|c|}{$\mathbf{R b}$} & \multicolumn{2}{|c|}{ Sb } & \multicolumn{2}{|c|}{ Sn } & \multicolumn{2}{|c|}{$\mathrm{Sr}$} & \multicolumn{2}{|c|}{ Th } & \multicolumn{2}{|c|}{ Tl } & \multicolumn{2}{|c|}{$\mathbf{T i}$} & \multicolumn{2}{|c|}{$\mathbf{U}$} & \multicolumn{2}{|c|}{ Zn } & \multicolumn{2}{|c|}{$\mathrm{Zr}$} \\
\hline & Husk & Shoot & Husk & Shoot & Husk & Shoot & Husk & Shoot & Husk & Shoot & Husk & Shoot & Husk & Shoot & Husk & Shoot & Husk & Shoot & Husk & Shoot & Husk & Shoot & Husk & Shoot \\
\hline$\overline{\mathrm{H} 1}$ & 0.49 & 0.65 & 1.61 & 0.21 & 24 & 68 & 0.015 & 0.017 & $<0.06$ & $<0.06$ & 2.3 & 13.3 & 0.008 & 0.078 & 1.7 & 17.5 & 0.001 & 0.023 & 0.010 & 0.026 & 10.0 & 74 & 0.08 & 0.38 \\
\hline H5 & 0.37 & 0.50 & 0.66 & 0.12 & 48 & 145 & 0.021 & 0.007 & $<0.06$ & $<0.06$ & 7.6 & 15.5 & 0.008 & 0.018 & 1.8 & 4.3 & 0.007 & 0.163 & 0.004 & 0.006 & 9.3 & 90 & 0.05 & 0.11 \\
\hline H6 & 0.59 & 1.95 & 0.41 & 0.35 & 67 & 170 & 0.002 & 0.008 & $<0.06$ & $<0.06$ & 4.6 & 24.4 & 0.007 & 0.016 & 1.6 & 4.2 & 0.004 & 0.298 & 0.002 & 0.005 & 8.6 & 35 & 0.07 & 0.12 \\
\hline H7 & 0.35 & 0.51 & 0.32 & 0.06 & 58 & 195 & 0.002 & 0.010 & $<0.06$ & $<0.06$ & 6.2 & 12.0 & 0.007 & 0.018 & 1.7 & 4.7 & 0.001 & 0.097 & 0.004 & 0.009 & 10.2 & 52 & 0.14 & 0.16 \\
\hline HN1 & 0.47 & 1.14 & 1.72 & 1.12 & 5 & 14 & 0.052 & 0.097 & $<0.06$ & $<0.06$ & 4.6 & 21.4 & 0.029 & 0.198 & 7.1 & 54.2 & 0.007 & 0.020 & 0.011 & 0.166 & 13.0 & 28 & 0.38 & 1.71 \\
\hline HN2 & 0.42 & 0.64 & 0.58 & 1.09 & 16 & 68 & 0.024 & 0.051 & $<0.06$ & $<0.06$ & 3.2 & 23.8 & 0.093 & 0.223 & 12.9 & 49.3 & 0.005 & 0.022 & 0.012 & 0.038 & 6.5 & 49 & 0.71 & 1.81 \\
\hline HN3 & 0.19 & 0.69 & 0.96 & 1.47 & 11 & 48 & 0.025 & 0.068 & $<0.06$ & $<0.06$ & 3.4 & 21.4 & 0.032 & 0.176 & 7.8 & 52.0 & 0.005 & 0.030 & 0.007 & 0.039 & 6.4 & 34 & 0.38 & 1.71 \\
\hline HN5 & 0.18 & 0.37 & 0.39 & 0.67 & 12 & 42 & 0.025 & 0.019 & $<0.06$ & $<0.06$ & 3.3 & 19.0 & 0.014 & 0.047 & 1.9 & 12.4 & 0.003 & 0.009 & 0.007 & 0.009 & 2.0 & 32 & 0.12 & 0.43 \\
\hline HN6 & 0.97 & 0.17 & 0.53 & 0.77 & 13 & 72 & 0.019 & 0.027 & $<0.06$ & $<0.06$ & 6.3 & 8.6 & 0.061 & 0.030 & 17.5 & 7.9 & 0.006 & 0.014 & 0.020 & 0.008 & 22.7 & 51 & 0.56 & 1.28 \\
\hline HN7 & 0.31 & 0.33 & 0.31 & 0.72 & 11 & 59 & 0.010 & 0.024 & $<0.06$ & $<0.06$ & 2.7 & 9.4 & 0.033 & 0.035 & 9.4 & 9.6 & 0.004 & 0.014 & 0.009 & 0.009 & 6.8 & 54 & 0.33 & 0.28 \\
\hline HN8 & 0.36 & 0.36 & 0.27 & 0.71 & 15 & 40 & 0.009 & 0.015 & $<0.06$ & $<0.06$ & 3.0 & 9.5 & 0.011 & 0.020 & 3.1 & 5.7 & 0.003 & 0.011 & 0.003 & 0.005 & 10.4 & 31 & 0.25 & 1.25 \\
\hline HN9 & 1.25 & 0.47 & 0.40 & 1.41 & 5 & 23 & 0.016 & 0.028 & 5.18 & 7.82 & 2.6 & 13.8 & 0.016 & 0.053 & 4.1 & 15.4 & 0.003 & 0.010 & 0.006 & 0.015 & 12.4 & 69 & 0.15 & 1.11 \\
\hline HN10 & 0.89 & 0.69 & 0.77 & 0.56 & 13 & 64 & 0.021 & 0.010 & 1.58 & 3.31 & 5.8 & 11.1 & 0.022 & 0.030 & 5.3 & 6.7 & 0.003 & 0.010 & 0.007 & 0.009 & 16.5 & 12 & 0.24 & 0.30 \\
\hline HN11 & 1.04 & 0.93 & 2.96 & 1.33 & 9 & 47 & 0.011 & 0.029 & 0.53 & 1.83 & 3.0 & 10.7 & 0.039 & 0.075 & 3.9 & 14.4 & 0.004 & 0.018 & 0.017 & 0.019 & 6.3 & 69 & 0.43 & 0.88 \\
\hline PT1 & 0.34 & 0.59 & 2.58 & 0.17 & 32 & 165 & 0.098 & 0.184 & $<0.06$ & $<0.06$ & 4.6 & 17.4 & 0.034 & 0.064 & 6.4 & 3.0 & 0.005 & 0.019 & 0.017 & 0.002 & 18.0 & 71 & 0.37 & 0.33 \\
\hline PT3 & 0.25 & 0.12 & 0.40 & 0.21 & 41 & 221 & 0.014 & 0.007 & $<0.06$ & $<0.06$ & 4.5 & 11.3 & 0.019 & 0.014 & 3.1 & 1.1 & 0.005 & 0.040 & 0.003 & 0.003 & 10.2 & 33 & 0.12 & 0.06 \\
\hline PT4 & 0.29 & 0.37 & 0.83 & 0.72 & 7 & 42 & 0.018 & 0.020 & $<0.06$ & $<0.06$ & 2.5 & 10.7 & 0.062 & 0.137 & 10.6 & 12.9 & 0.007 & 0.009 & 0.010 & 0.010 & 11.4 & 28 & 0.36 & 0.41 \\
\hline PT6 & 0.55 & 0.43 & 2.35 & 0.68 & 28 & 93 & 0.066 & 0.033 & $<0.06$ & $<0.06$ & 6.7 & 10.1 & 0.140 & 0.374 & 6.6 & 25.2 & 0.008 & 0.017 & 0.036 & 0.025 & 7.6 & 15 & 1.08 & 0.44 \\
\hline PT7 & 1.60 & 0.60 & 0.67 & 0.99 & 31 & 61 & 0.001 & 0.037 & $<0.06$ & $<0.06$ & 4.5 & 24.2 & 0.018 & 0.060 & 2.2 & 7.4 & 0.001 & 0.012 & 0.013 & 0.009 & 40.6 & 10 & 0.09 & 0.19 \\
\hline PT8 & 0.17 & 0.33 & 0.53 & 0.79 & 26 & 64 & 0.017 & 0.028 & $<0.06$ & $<0.06$ & 4.2 & 13.8 & 0.011 & 0.035 & 2.9 & 8.5 & 0.004 & 0.015 & 0.005 & 0.008 & 1.8 & 68 & 0.16 & 0.30 \\
\hline PT9 & 0.18 & 0.22 & 0.48 & 1.07 & 12 & 49 & 0.011 & 0.033 & $<0.06$ & $<0.06$ & 3.6 & 21.2 & 0.014 & 0.016 & 4.1 & 4.5 & 0.004 & 0.015 & 0.003 & 0.007 & 2.3 & 42 & 0.12 & 0.13 \\
\hline PT10 & 2.11 & 0.84 & 0.80 & 1.00 & 7 & 23 & 0.038 & 0.027 & 2.12 & 5.01 & 4.5 & 24.4 & 0.027 & 0.090 & 7.2 & 24.0 & 0.005 & 0.010 & 0.011 & 0.039 & 10.8 & 16 & 0.32 & 1.32 \\
\hline PT11 & 0.41 & 0.34 & 0.80 & 1.32 & 12 & 40 & 0.019 & 0.027 & 2.86 & 3.11 & 4.2 & 13.7 & 0.033 & 0.076 & 9.3 & 20.4 & 0.005 & 0.014 & 0.011 & 0.016 & 15.1 & 55 & 0.38 & 0.48 \\
\hline
\end{tabular}


Appendix A3

Table A3.3 Physiological element concentrations (Con) in shoot $\left(\mathrm{mg} \mathrm{kg}^{-1}\right)$ and their transfer factors (TF) $(\mathrm{n}=23)$

\begin{tabular}{|c|c|c|c|c|c|c|c|c|c|c|c|c|c|c|c|c|c|c|c|c|c|c|}
\hline \multirow{2}{*}{ Site } & \multicolumn{2}{|r|}{ Al } & \multicolumn{2}{|c|}{$\mathbf{C a}$} & \multicolumn{2}{|c|}{$\mathbf{F e}$} & \multicolumn{2}{|l|}{$\mathbf{K}$} & \multicolumn{2}{|c|}{ Mg } & \multicolumn{2}{|c|}{ Mn } & \multicolumn{2}{|c|}{$\mathbf{N a}$} & \multicolumn{2}{|c|}{$\mathbf{P}$} & \multicolumn{2}{|c|}{$\mathbf{S}$} & \multicolumn{2}{|c|}{ As } & \multicolumn{2}{|c|}{ Ba } \\
\hline & Con & $\mathrm{TF}$ & Con & $\mathrm{TF}$ & Con & $\mathrm{TF}$ & Con & $\mathrm{TF}$ & Con & $\mathrm{TF}$ & Con & $\mathrm{TF}$ & Con & $\mathrm{TF}$ & Con & $\mathrm{TF}$ & Con & $\mathrm{TF}$ & Con & $\mathrm{TF}$ & Con & $\mathrm{TF}$ \\
\hline H1 & $<4$ & $<0.00005$ & 4929 & 2.24 & 346 & 0.0090 & 32145 & 1.45 & 1393 & 0.22 & 685 & 2.62 & 137 & 0.053 & 2666 & 3.73 & 2079 & 3.72 & 5.9 & 0.474 & 123 & 0.25 \\
\hline H5 & $<4$ & $<0.00005$ & 107 & 1.45 & & 0.0025 & 19171 & 0.92 & 3623 & 0.58 & 967 & 3.46 & 1496 & 0.464 & 537 & 1.08 & 1112 & 2.32 & 3.1 & 0.182 & 123 & 0.25 \\
\hline H6 & $<4$ & $<0.00005$ & 4916 & 2.19 & & 0.0028 & 15286 & 0.90 & 4930 & 1.00 & 1185 & 4.99 & 84 & 0.028 & 1313 & 3.17 & 3331 & 11.2 & 0.8 & 0.076 & 118 & 0.29 \\
\hline $\mathrm{H} 7$ & $<4$ & $<0.00005$ & 2710 & 1.33 & 128 & 0.0043 & 24768 & 1.37 & 2103 & 0.39 & 557 & 2.39 & 445 & 0.150 & 1457 & 3.89 & 2886 & 8.03 & 3.1 & 0.254 & 134 & 0.31 \\
\hline HN1 & 99 & 0.00133 & 5002 & 0.71 & 178 & 0.0045 & 37672 & 1.79 & 3370 & 0.38 & 1190 & 2.00 & 822 & 0.154 & 2279 & 2.70 & 1861 & 3.02 & 10.4 & 0.58 & 85 & 0.22 \\
\hline $\mathrm{HN}$ & $<4$ & $<0.00005$ & 864 & 1.12 & 46 & 0.0014 & 42879 & 2.38 & 2677 & 0.36 & 571 & 0.79 & 123 & 0.0 & 1153 & 1.51 & 1172 & 7.17 & 2.7 & 0.17 & 82 & 0.22 \\
\hline $\mathrm{HN}$ & $<4$ & 0.00005 & 6464 & 1.02 & & 0.00 & 38081 & 2.08 & 3025 & 0.3 & 483 & 0.97 & 418 & 0.0 & 1491 & 1.9 & 1076 & 3. & .1 & 0.2 & 51 & 0.14 \\
\hline$H_{3}$ & $<4$ & 0.000 & 30 & 1.4 & & 0.00 & 1284 & 1.6 & 3392 & 0.4 & 667 & 1.2 & 28 & 0.0 & 979 & 1. & 1622 & 3. & .4 & 0. & 103 & 0.26 \\
\hline Ne & $<4$ & $<0.00005$ & 3310 & 0.83 & & 0.00 & 39683 & 1.84 & 1885 & 0.2 & 610 & 0.7 & 95 & 0.01 & 575 & 0.8 & 982 & 3. & .1 & 0.0 & 82 & 0.19 \\
\hline $\mathrm{HN}^{2}$ & 26 & 0.00031 & 4017 & 1.26 & & 0.0019 & 32882 & 1.38 & 2459 & 0.25 & 613 & 1.81 & 213 & 0.044 & 619 & 1.05 & 1404 & 4.20 & .4 & 0.070 & 60 & 0.14 \\
\hline $\mathrm{HN}$ & $<4$ & $<0.00005$ & 3087 & 1.05 & & 0.0007 & 17284 & 0.74 & 2157 & 0.22 & 623 & 1.83 & 110 & 0.022 & 768 & 1.28 & 1342 & 3.77 & 0.8 & 0.039 & 95 & 0.22 \\
\hline NS & $<4$ & $<0.00005$ & 4519 & 1.29 & & 0.0017 & 31584 & 1.36 & 2612 & 0.26 & 1052 & 3.20 & 65 & 0.013 & 1258 & 1.30 & 1387 & 3.50 & 3.8 & 0.229 & 123 & 0.27 \\
\hline $\mathrm{HN}$ & $<4$ & $<0.00005$ & 4353 & 1.77 & 31 & 0.0006 & 40112 & 1.95 & 2476 & 0.52 & 2583 & 12.5 & 50 & 0.016 & 1056 & 1.44 & 2627 & 2.64 & 1.7 & 0.057 & 61 & 0.17 \\
\hline HN11 & $<4$ & $<0.00005$ & 996 & 1.10 & & 0.0002 & 57774 & 2.45 & 2156 & 0.22 & 637 & 0.99 & 145 & 0.027 & 644 & 0.51 & 1486 & 5.92 & 3.6 & 0.165 & 71 & 0.16 \\
\hline PT1 & $<4$ & .00005 & 4835 & 1.04 & & 0.0021 & 38074 & 3.28 & 2757 & 0.65 & 1159 & 3.56 & 141 & 0.0 & 971 & 1.03 & 1837 & 10.1 & 0.4 & 0.045 & 133 & 0.42 \\
\hline $\mathrm{P}$ & $<4$ & 5 & 30 & 0.39 & & 0.0 & 71 & 2.20 & 2389 & 0.26 & 337 & 0.60 & 243 & $0 .($ & 588 & 0.5 & 1092 & 2. & .7 & 0 & 132 & 0.30 \\
\hline PT4 & $<4$ & .06 & 5249 & 0.49 & 132 & 0.0 & 39119 & 1.89 & 2683 & 0.26 & 88 & 0.11 & 20 & 0.003 & 821 & 0.92 & 1247 & 6.92 & .2 & 0.005 & $5 \mathrm{c}$ & 0.11 \\
\hline T6 & $<4$ & 0.00005 & 2531 & 0.84 & & 0.0 & 21386 & 1.93 & 3680 & 0.84 & 618 & 1.44 & 1491 & 0.645 & 2067 & 3.4 & 1742 & 2.6 & 3.8 & 0. & 70 & 0.33 \\
\hline$\Gamma 7$ & $<4$ & $<0.00005$ & 8277 & 2.49 & 103 & 0.0013 & 21815 & 2.63 & 3786 & 1.11 & 336 & 1.15 & 344 & 0.175 & 2321 & 3.80 & 2830 & 4.26 & 5.1 & 0.282 & 52 & 0.33 \\
\hline PT8 & 15 & 0023 & 4102 & 0.58 & ) & 0.0025 & 34011 & 1.82 & 2577 & 0.34 & 547 & 1.04 & 173 & 0.025 & 1645 & 1.55 & 1695 & 3.12 & 4.2 & 0.172 & $11 \mathrm{C}$ & 0.27 \\
\hline $\mathrm{P}^{\prime}$ & $<4$ & $<0.00005$ & 7029 & 0.47 & 2 & 0.0017 & 34383 & 1.87 & 1889 & 0.20 & 415 & 0.57 & 107 & 0.017 & 396 & 0.30 & 1805 & 3.94 & 2.5 & 0.089 & 81 & 0.19 \\
\hline PT 1 & $<4$ & 0.00005 & 6090 & 1.17 & 195 & 0.0039 & 48246 & 1.94 & 1826 & 0.18 & 53 & 0.08 & 1832 & 0.414 & 1212 & 1.47 & 1952 & 0.35 & 0.6 & 0.029 & 192 & 0.42 \\
\hline PT11 & $<4$ & $<0.00005$ & 5878 & 1.08 & 12 & 0.0003 & 30063 & 1.42 & 2959 & 0.46 & 650 & 1.12 & 155 & 0.048 & 791 & 0.93 & 1910 & 3.29 & 1.0 & 0.055 & 117 & 0.31 \\
\hline
\end{tabular}


Table A3.3 (cont.) Physiological element concentrations (Con) in shoot ( $\left.\mathrm{mg} \mathrm{kg}^{-1}\right)$ and their transfer factors $(\mathrm{TF})(\mathrm{n}=23)$

\begin{tabular}{|c|c|c|c|c|c|c|c|c|c|c|c|c|c|c|c|c|c|c|c|}
\hline \multirow{2}{*}{ Site } & \multicolumn{2}{|c|}{ Bi } & Cd & \multicolumn{2}{|c|}{$\mathrm{Ce}$} & \multicolumn{2}{|c|}{ Co } & $\mathrm{Cr}$ & Cs & \multicolumn{2}{|c|}{$\mathbf{C u}$} & \multicolumn{2}{|c|}{ Hf } & \multicolumn{2}{|c|}{$\mathbf{L a}$} & \multicolumn{2}{|c|}{$\mathbf{L i}$} & \multicolumn{2}{|c|}{ Mo } \\
\hline & Con & TF & Con TF & Con & TF & Con & TF & Con TF & Con & Con & TF & Con & TF & Con & TF & Con & TF & Con & TF \\
\hline H1 & 0.014 & 0.017 & 0.320 .93 & 0.135 & 0.0013 & 1.05 & 0.061 & 0.780 .017 & 0.1720 .0221 & 2.77 & 0.08 & 0.021 & 0.0063 & 0.068 & 0.0014 & 0.077 & 0.0026 & 1.13 & 1.02 \\
\hline H5 & 0.003 & 0.005 & 0.984 .47 & 0.252 & 0.0028 & 0.72 & 0.050 & 0.660 .015 & .764 0.1159 & 3.53 & 0.12 & 0.007 & 0.0018 & 0.119 & 0.0027 & 0.041 & 0.0014 & 0.13 & 0.11 \\
\hline H6 & 0.004 & 0.011 & .31 1.65 & .319 & 0.0051 & 0.77 & 0.078 & 640.021 & .4610 .5031 & 5.24 & 0.26 & 0.002 & 0.0005 & 0.169 & 0.0049 & 0.129 & 0.0060 & 0.86 & 1.06 \\
\hline H7 & 0.009 & 0.021 & 0.180 .90 & 0.102 & 0.0015 & 0.60 & 0.055 & 0.760 .023 & 0.8510 .1570 & 2.48 & 0.11 & 0.001 & 0.0003 & 0.053 & 0.0015 & 0.114 & 0.0049 & 0.73 & 0.79 \\
\hline HN1 & 0.020 & 0.040 & 0.170 .48 & 0.205 & 0.0025 & 0.18 & 0.011 & 1.740 .030 & 0.4540 .0519 & 2.61 & 0.07 & 0.001 & 0.0001 & 0.087 & 0.0021 & 0.154 & 0.0035 & 0.74 & 1.06 \\
\hline HN2 & 0.014 & 0.033 & 0.100 .34 & 1.196 & 0.0152 & 0.17 & 0.012 & 1.760 .037 & 0.5540 .0808 & 3.79 & 0.11 & 0.008 & 0.0015 & 0.643 & 0.0163 & 0.022 & 0.0006 & 0.69 & 1.69 \\
\hline HN3 & 0.019 & 0.041 & 0.110 .32 & 0.062 & 0.0009 & 0.17 & 0.012 & 1.100 .022 & 0.6320 .0901 & 2.18 & 0.06 & 0.012 & 0.0029 & 0.022 & 0.0006 & 0.170 & 0.0047 & 1.22 & 2.91 \\
\hline HN5 & 0.008 & 0.021 & 0.140 .39 & 0.071 & 0.0009 & 0.11 & 0.007 & 0.920 .015 & 0.0540 .0067 & 3.42 & 0.09 & 0.010 & 0.0021 & 0.091 & 0.0023 & 0.007 & 0.0002 & 0.32 & 0.60 \\
\hline HN6 & 0.009 & 0.022 & 0.180 .47 & 0.004 & 0.0001 & 0.19 & 0.010 & 0.920 .014 & 0.0780 .0085 & 2.06 & 0.05 & 0.008 & 0.0018 & 0.088 & 0.0021 & 0.022 & 0.0005 & 0.37 & 0.55 \\
\hline HN7 & 0.007 & 0.016 & 0.391 .19 & 0.037 & 0.0004 & 0.13 & 0.007 & 0.980 .013 & 0.0660 .0061 & 3.06 & 0.08 & 0.009 & 0.0021 & 0.021 & 0.0005 & 0.020 & 0.0004 & 0.43 & 0.68 \\
\hline HN8 & 0.005 & 0.010 & 0.722 .34 & 0.069 & 0.0007 & 0.08 & 0.004 & 0.990 .012 & 0.0930 .0087 & 2.95 & 0.07 & 0.011 & 0.0023 & 0.005 & 0.0001 & 0.072 & 0.0014 & 0.21 & 0.34 \\
\hline HN9 & 0.011 & 0.019 & 1.333 .61 & 0.073 & 0.0008 & 0.18 & 0.009 & $\begin{array}{lll}0.51 & 0.005\end{array}$ & 0.0030 .0003 & 3.69 & 0.08 & 0.003 & 0.0007 & 0.040 & 0.0008 & 0.019 & 0.0004 & 0.08 & 0.15 \\
\hline HN10 & 0.004 & 0.008 & 3.4010 .6 & 0.085 & 0.0009 & 0.25 & 0.020 & 0.830 .011 & 0.1130 .0106 & 6.02 & 0.16 & 0.009 & 0.0020 & 0.021 & 0.0005 & 0.080 & 0.0019 & 0.10 & 0.07 \\
\hline HN11 & 0.009 & 0.014 & 0.190 .61 & 0.073 & 0.0008 & 0.15 & 0.008 & 0.900 .013 & 0.0180 .0018 & 3.99 & 0.09 & 0.005 & 0.0011 & 0.036 & 0.0008 & 0.007 & 0.0001 & 1.19 & 1.72 \\
\hline PT1 & 0.007 & 0.015 & 0.461 .93 & 0.009 & 0.0001 & 0.06 & 0.008 & 0.820 .026 & 0.1240 .0390 & 3.75 & 0.13 & 0.006 & 0.0013 & 0.003 & 0.0001 & 0.109 & 0.0059 & 1.34 & 2.89 \\
\hline PT3 & 0.002 & 0.003 & 0.110 .24 & 0.007 & 0.0001 & 0.12 & 0.008 & 0.820 .016 & 0.1990 .0332 & 3.02 & 0.06 & 0.009 & 0.0019 & 0.009 & 0.0002 & 0.044 & 0.0013 & 0.58 & 0.74 \\
\hline PT4 & 0.001 & 0.000 & 0.120 .21 & 0.088 & 0.0008 & 0.06 & 0.004 & 0.670 .012 & 0.3520 .0540 & 10.4 & 0.12 & 0.003 & 0.0008 & 0.097 & 0.0019 & 0.077 & 0.0024 & 0.70 & 0.52 \\
\hline PT6 & 0.010 & 0.016 & 0.090 .23 & 0.041 & 0.0007 & 0.20 & 0.018 & 1.100 .009 & 0.3760 .0799 & 1.35 & 0.02 & 0.000 & 0.0001 & 0.376 & 0.0115 & 0.161 & 0.0072 & 0.10 & 0.05 \\
\hline PT7 & 0.015 & 0.024 & 0.100 .51 & 0.121 & 0.0016 & 0.44 & 0.055 & 0.720 .006 & 0.3460 .0937 & 1.21 & 0.03 & 0.002 & 0.0012 & 0.060 & 0.0016 & 0.115 & 0.0061 & 0.47 & 0.20 \\
\hline PT8 & 0.009 & 0.007 & 0.200 .43 & 0.019 & 0.0003 & 0.39 & 0.027 & 0.910 .016 & 0.0710 .0114 & 2.91 & 0.05 & 0.008 & 0.0024 & 0.013 & 0.0003 & 0.044 & 0.0013 & 0.48 & 0.55 \\
\hline PT9 & 0.012 & 0.008 & 0.110 .23 & 0.096 & 0.0012 & 0.13 & 0.009 & 1.050 .018 & 0.0310 .0047 & 2.52 & 0.04 & 0.003 & 0.0009 & 0.052 & 0.0013 & 0.029 & 0.0008 & 0.30 & 0.38 \\
\hline PT10 & 0.010 & 0.013 & 0.060 .13 & 0.018 & 0.0002 & 0.15 & 0.007 & 1.060 .012 & 0.0570 .0051 & 5.45 & 0.11 & 0.012 & 0.0027 & 0.011 & 0.0002 & 0.005 & 0.0001 & 0.11 & 0.09 \\
\hline PT11 & 0.009 & 0.014 & 0.360 .74 & 0.067 & 0.0006 & 0.12 & 0.008 & 0.550 .009 & 0.0130 .0012 & 2.54 & 0.07 & 0.010 & 0.0026 & 0.069 & 0.0015 & 0.010 & 0.0003 & 0.38 & 0.37 \\
\hline
\end{tabular}


Table A3.3 (cont.) Physiological element concentrations (Con) in shoot $\left(\mathrm{mg} \mathrm{kg}^{-1}\right)$ and their transfer factors $(\mathrm{TF})(\mathrm{n}=23)$

\begin{tabular}{|c|c|c|c|c|c|c|c|c|c|c|c|c|c|c|c|c|c|c|c|c|c|}
\hline \multirow{2}{*}{ Site } & \multicolumn{2}{|c|}{$\mathbf{N i}$} & \multicolumn{2}{|c|}{$\overline{P b}$} & \multicolumn{2}{|c|}{$\overline{\mathbf{R b}}$} & \multicolumn{2}{|c|}{$\mathbf{S b}$} & \multicolumn{2}{|c|}{ Sn } & \multicolumn{2}{|c|}{$\mathrm{Sr}$} & \multicolumn{2}{|c|}{ Th } & \multicolumn{2}{|c|}{ Tl } & \multicolumn{2}{|c|}{$\overline{\mathbf{U}}$} & $\overline{Z n}$ & \multicolumn{2}{|r|}{$\overline{Z r}$} \\
\hline & $\overline{\text { Con }}$ & $\mathrm{TF}$ & $\overline{\text { Con }}$ & $\mathrm{TF}$ & $\overline{\text { Con }}$ & $\mathrm{TF}$ & Con & $\mathrm{TF}$ & Con & $\mathrm{TF}$ & $\overline{\text { Con }}$ & TF & Con & $\mathrm{TF}$ & Con & $\overline{\mathrm{TF}}$ & Con & $\overline{\mathrm{TF}}$ & $\overline{\text { Con } \quad \mathrm{TF}}$ & Con & $\mathrm{TF}$ \\
\hline$\overline{\mathrm{H} 1}$ & $\overline{0.52}$ & 0.015 & 0.07 & 0.002 & 68 & 0.51 & 0.011 & 0.006 & $<0.06$ & $<0.01$ & 13.2 & 0.34 & 0.0004 & 0.00002 & 0.021 & 0.030 & 0.0082 & 0.00159 & 740.64 & 0.049 & 0.00051 \\
\hline H5 & 0.47 & 0.015 & 0.10 & 0.003 & 145 & 1.18 & 0.006 & 0.003 & $<0.06$ & $<0.01$ & 15.5 & 0.37 & 0.0010 & 0.00005 & 0.162 & 0.258 & 0.0024 & 0.00051 & 901.06 & 0.014 & 0.00013 \\
\hline H6 & 1.93 & 0.090 & 0.33 & 0.014 & 170 & 1.74 & 0.007 & 0.005 & $<0.06$ & $<0.01$ & 24.4 & 0.61 & 0.0008 & 0.00005 & 0.298 & 0.611 & 0.0009 & 0.00023 & 350.55 & 0.005 & 0.00004 \\
\hline $\mathrm{H} 7$ & 0.48 & 0.020 & 0.03 & 0.001 & 196 & 1.86 & 0.009 & 0.006 & $<0.06$ & $<0.01$ & 12.0 & 0.30 & 0.0012 & 0.00007 & 0.097 & 0.182 & 0.0052 & 0.00132 & 520.75 & 0.054 & 0.00051 \\
\hline HN1 & 0.67 & 0.015 & 0.74 & 0.021 & 12 & 0.10 & 0.077 & 0.041 & $<0.06$ & $<0.01$ & 20.7 & 0.25 & 0.0077 & 0.00045 & 0.013 & 0.021 & 0.1258 & 0.03333 & 270.28 & 0.088 & 0.00060 \\
\hline $\mathrm{HN} 2$ & 0.27 & 0.008 & 0.77 & 0.025 & 67 & 0.62 & 0.034 & 0.021 & $<0.06$ & $<0.01$ & 23.2 & 0.31 & 0.0560 & 0.00355 & 0.016 & 0.031 & 0.0018 & 0.00052 & 80.57 & 0.173 & 0.00112 \\
\hline HN3 & 0.27 & 0.008 & 1.09 & 0.033 & 47 & 0.42 & 0.049 & 0.031 & 0.14 & 0.04 & 20.7 & 0.26 & 0.0081 & 0.00057 & 0.024 & 0.045 & 0.0027 & 0.00089 & 340.33 & 0.147 & 0.00111 \\
\hline HN5 & 0.27 & 0.006 & 0.59 & 0.017 & 42 & 0.36 & 0.014 & 0.008 & $<0.06$ & $<0.01$ & 18.9 & 0.26 & 0.0093 & 0.00061 & 0.008 & 0.014 & 0.0003 & 0.00008 & 320.33 & 0.075 & 0.00053 \\
\hline HN6 & 0.11 & 0.002 & 0.71 & 0.019 & 72 & 0.56 & 0.024 & 0.012 & $<0.06$ & $<0.01$ & 8.5 & 0.11 & 0.0051 & 0.00031 & 0.013 & 0.021 & 0.0028 & 0.00075 & 510.52 & 1.059 & 0.00695 \\
\hline HN7 & 0.24 & 0.005 & 0.64 & 0.016 & 59 & 0.41 & 0.020 & 0.011 & $<0.06$ & $<0.01$ & 9.2 & 0.12 & 0.0033 & 0.00019 & 0.013 & 0.018 & 0.0019 & 0.00051 & 540.51 & 0.020 & 0.00014 \\
\hline HN8 & 0.31 & 0.006 & 0.67 & 0.015 & 39 & 0.28 & 0.013 & 0.007 & $<0.06$ & $<0.01$ & 9.5 & 0.12 & 0.0013 & 0.00007 & 0.011 & 0.015 & 0.0006 & 0.00015 & 300.28 & 1.090 & 0.00716 \\
\hline HN9 & 0.33 & 0.007 & 1.29 & 0.029 & 22 & 0.16 & 0.022 & 0.011 & 7.83 & 1.76 & 13.6 & 0.17 & 0.0029 & 0.00016 & 0.008 & 0.011 & 0.0037 & 0.00093 & 680.62 & 0.691 & 0.00463 \\
\hline HN10 & 0.65 & 0.019 & 0.51 & 0.013 & 64 & 0.48 & 0.005 & 0.001 & 3.31 & 0.69 & 11.0 & 0.14 & 0.0037 & 0.00020 & 0.009 & 0.012 & 0.0027 & 0.00064 & 120.14 & 0.090 & 0.00060 \\
\hline HN11 & 0.81 & 0.018 & 1.22 & 0.029 & 47 & 0.33 & 0.024 & 0.013 & 1.82 & 0.35 & 10.5 & 0.13 & 0.0282 & 0.00169 & 0.016 & 0.023 & 0088 & 0.00240 & 0.52 & 0.480 & 0.00339 \\
\hline PT1 & 0.57 & 0.031 & 0 & 0.003 & 165 & 2.57 & 0.183 & 0.177 & $<0.06$ & $<0.01$ & 17.4 & 0.22 & 0 & 0.0 & 0.018 & 0.056 & 0.0 & 002 & 1.02 & 0.232 & 0.00163 \\
\hline PT3 & 0.11 & 0.003 & 9 & 0.003 & 221 & 2.09 & 0.007 & 0.004 & $<0.06$ & $<0.01$ & 11.3 & 0.12 & 0.0100 & 0.00060 & 0.040 & 0.075 & 0.0 & 0.00078 & 0.32 & 0.020 & 0.00013 \\
\hline PT4 & 0.27 & 0.007 & 0.50 & 0.006 & 42 & 0.35 & 0.013 & 0.005 & $<0.06$ & $<0.01$ & 10.4 & 0.09 & 0.0941 & 0.00578 & 0.007 & 0.013 & 0.0002 & 0.00004 & 280.21 & 0.082 & 0.00064 \\
\hline PT6 & 0.26 & 0.010 & 0.34 & 0.006 & 93 & 1.43 & 0.025 & 0.018 & $<0.06$ & $<0.01$ & 10.0 & 0.28 & 0.2261 & 0.00930 & 0.015 & 0.039 & 0.0019 & 0.00051 & 140.10 & 0.072 & 0.00119 \\
\hline PT7 & 0.56 & 0.025 & 0.89 & 0.017 & 61 & 1.25 & 0.034 & 0.030 & $<0.06$ & $<0.01$ & 24.2 & 0.81 & 0.0052 & 0.00017 & 0.012 & 0.038 & 0.0011 & 0.00027 & 100.12 & 0.104 & 0.00223 \\
\hline PT8 & 0.27 & 0.008 & 0.65 & 0.009 & 64 & 0.62 & 0.024 & 0.011 & $<0.06$ & $<0.01$ & 13.7 & 0.14 & 0.0066 & 0.00044 & 0.014 & 0.025 & 0.0014 & 0.00043 & 680.60 & 0.079 & 0.00070 \\
\hline PT9 & 0.19 & 0.005 & 0.98 & 0.011 & 49 & 0.45 & 0.031 & 0.015 & $<0.06$ & $<0.01$ & 21.2 & 0.21 & 0.0005 & 0.00003 & 0.015 & 0.028 & 0.0042 & 0.00135 & 420.33 & 0.014 & 0.00013 \\
\hline PT10 & 0.59 & 0.011 & 0.77 & 0.016 & 22 & 0.15 & 0.019 & 0.011 & 5.00 & 0.95 & 24.2 & 0.30 & 0.0039 & 0.00021 & 0.006 & 0.008 & 0.0194 & 0.00458 & 150.10 & 0.650 & 0.00457 \\
\hline PT11 & 0.19 & 0.005 & 1.14 & 0.023 & 40 & 0.30 & 0.016 & 0.006 & 3.10 & 0.46 & 13.6 & 0.32 & 0.0056 & 0.00031 & 0.011 & 0.016 & 0.0001 & 0.00003 & 540.44 & 0.020 & 0.00017 \\
\hline
\end{tabular}


Table A3.4 Physiological element concentrations (Con) in husk $\left(\mathrm{mg} \mathrm{kg}^{-1}\right)$ and their transfer factors (TF) $(\mathrm{n}=101)$

\begin{tabular}{|c|c|c|c|c|c|c|c|c|c|c|c|c|c|c|c|c|c|c|c|c|c|c|}
\hline \multirow{2}{*}{ Site } & \multicolumn{2}{|r|}{ Al } & \multicolumn{2}{|c|}{$\mathbf{C a}$} & \multicolumn{2}{|c|}{$\mathbf{F e}$} & \multicolumn{2}{|c|}{$\mathbf{K}$} & \multicolumn{2}{|c|}{$\mathrm{Mg}$} & \multicolumn{2}{|c|}{ Mn } & \multicolumn{2}{|c|}{$\mathbf{N a}$} & \multicolumn{2}{|l|}{$\mathbf{P}$} & \multicolumn{2}{|c|}{$\mathbf{S}$} & \multicolumn{2}{|c|}{ As } & \multicolumn{2}{|c|}{ Ba } \\
\hline & Con & $\mathrm{TF}$ & Con & $\mathrm{TF}$ & Con & $\mathrm{TF}$ & Con & $\mathrm{TF}$ & Con & $\mathrm{TF}$ & Con & $\mathrm{TF}$ & Con & $\mathrm{TF}$ & Con & $\mathrm{TF}$ & Con & $\mathrm{TF}$ & Con & $\mathrm{TF}$ & Con & $\mathrm{TF}$ \\
\hline $\mathrm{H} 1$ & $<4$ & $<0.00005$ & 729 & 0.33 & 15 & 0.0004 & 4772 & 0.22 & 212 & 0.03 & 152 & 0.58 & 3 & 0.0011 & 1149 & 1.61 & 688 & 1.23 & 0.75 & 0.060 & 21.4 & 0.044 \\
\hline H5 & $<4$ & $<0.00005$ & 2739 & 1.27 & 45 & 0.0011 & 5066 & 0.24 & 1026 & 0.16 & 198 & 0.71 & 11 & 0.0033 & 1222 & 2.45 & 407 & 0.85 & 1.20 & 0.071 & 9.3 & 0.019 \\
\hline 16 & 11 & 0.00018 & 789 & 0.35 & 20 & $0.000 /$ & 224 & 0.31 & 192 & 0. & 379 & 1.60 & 8 & 0.0028 & 987 & 2.38 & 596 & 2.00 & $?$ & 0.023 & 0.1 & 0.050 \\
\hline $\mathrm{H} 7$ & 22 & 0.00035 & 1295 & 0.64 & 34 & 0.0011 & 676 & 0.31 & 232 & 0.04 & 278 & 1.19 & 12 & 0.0042 & 1057 & 2.82 & 524 & 1.46 & 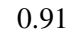 & 0.074 & 35.3 & 0.082 \\
\hline HN1 & $<4$ & $<0.00005$ & 286 & 0.15 & 41 & 0.0010 & 495 & 0.45 & 572 & 0.07 & 128 & 0.22 & 36 & 0.0066 & 1545 & 1.83 & 689 & 1.12 & 1.43 & 0.080 & 21.8 & 0.055 \\
\hline $\mathrm{HN} 2$ & $<4$ & $<0.00005$ & 1001 & 0.14 & 16 & 0.0005 & 3186 & 0.18 & 154 & 0.02 & 138 & 0.19 & 10 & 0.0019 & 1610 & 2.10 & 563 & 3.45 & 0.20 & 0.013 & 8.7 & 0.023 \\
\hline $\mathrm{HN} 3$ & $<4$ & $<0.00005$ & 917 & 0.14 & 11 & 0.0003 & 771 & 0.21 & 229 & 0.03 & 108 & 0.22 & 8 & 0.0015 & 1527 & 1.96 & 695 & 2.18 & 0.40 & 0.027 & 8.6 & 0.023 \\
\hline HN5 & 36 & 0.0005 & 989 & 0.19 & 43 & 0.0011 & 196 & 0.16 & 227 & 0.03 & 169 & 0.32 & 12 & 0.0022 & 985 & 1.16 & 791 & 1.83 & 0.18 & 0.010 & 0.5 & 0.001 \\
\hline IN7 & $<4$ & $<0.00005$ & 812 & 0.26 & 23 & 0.0005 & 961 & 0.12 & 227 & 0.02 & 180 & 0.5 & 22 & 0.0047 & 1260 & 2.13 & 412 & 1.24 & 0.21 & 0.010 & 10.5 & 0.024 \\
\hline N8 & $<4$ & $<0.00005$ & 682 & 0.23 & 14 & 0.00 & 347 & 0.14 & 205 & 0.0 & 257 & 0.7 & 34 & 0.0 & 873 & 1.46 & 432 & 1.21 & .15 & 0.008 & 16.9 & 0.039 \\
\hline HN9 & $<4$ & $<0.00$ & 810 & 0.23 & 23 & 0.00 & 708 & 0.1 & 38 & 0 & 257 & 0. & 31 & 0.0 & 1009 & 1.05 & 222 & 0.56 & 0.17 & 0.010 & 19.4 & 0.043 \\
\hline $\mathrm{HN} 10$ & $<4$ & $<0.00$ & 954 & 0.39 & 10 & 0.0002 & 616 & 0.1 & 18 & 0 . & 217 & 1. & 19 & 0.0062 & 1236 & 1.69 & 751 & 0.75 & 0.09 & 03 & 30.7 & 0.087 \\
\hline NI & $<4$ & $<0.00005$ & 953 & 0.21 & 79 & 0.0018 & 901 & 0.21 & 443 & 0. & 193 & 0. & 25 & 0.0046 & 1674 & 1.33 & 933 & 3.72 & 0.66 & 30 & 13.9 & 0.031 \\
\hline T1 & $<4$ & $<0.00005$ & 1017 & 0.22 & 24 & 0.0010 & 103 & 0.44 & 511 & 0.1 & 287 & 0.8 & 10 & 0.0017 & 1101 & 1.17 & 571 & 3.14 & 0.56 & 0.059 & 27.7 & 0.08 \\
\hline 13 & $<4$ & $<0.00005$ & 1022 & 0.13 & 9 & 0.0002 & 299 & 0.12 & 270 & 0.0 & 142 & 0.2 & 3 & 0.0003 & 1135 & 1.07 & 708 & 1.55 & 0.32 & 0.014 & 30.1 & 0.069 \\
\hline P14 & $<4$ & $<0.00005$ & 1068 & 0.10 & 19 & 0.0004 & 5204 & 0.25 & 257 & 0.03 & 52 & 0.0 & 10 & 0.0013 & 989 & 1.11 & 961 & 5.33 & 0.05 & 0.001 & 6.6 & 0.013 \\
\hline PТ6 & $<4$ & $<0.00005$ & 1835 & 0.61 & 13 & 0.0001 & 4148 & 0.37 & 220 & 0.0 & 156 & 0.3 & 50 & 0.0214 & 1569 & 2.64 & 673 & 1.02 & 0.58 & 0.022 & 24.0 & 0.115 \\
\hline T7 & $<4$ & $<0.00005$ & 810 & 0.24 & 14 & 0.0002 & 046 & 0.37 & 262 & 0.08 & 242 & 0.8 & 37 & 0.0186 & 1791 & 2.93 & 709 & 1.07 & 0.46 & 0.026 & 30.6 & 0.192 \\
\hline Т9 & $<4$ & $<0.00005$ & 933 & 0.0 & 4 & & 17 & 0.1 & 278 & 0 & 138 & 0. & 4 & & 1272 & 0.95 & 732 & 1.60 & 7 & 13 & 16.3 & 0.038 \\
\hline 10 & $<4$ & $<0.00$ & 1944 & 0.37 & 8 & 0.00 & 58 & 0.18 & 464 & $0 .($ & 1413 & 2. & 20 & 0.0 & 1673 & 2.03 & 877 & 0.16 & 0.36 & 016 & 21.5 & 0.047 \\
\hline T11 & $<4$ & $<0.00005$ & 1180 & 0.22 & 37 & 0.0009 & 4526 & 0.2 & 107 & $0 .($ & 213 & 0. & 24 & 0.0076 & 1446 & 1.69 & 946 & 1.63 & 0.23 & 0.012 & 22.8 & 0.061 \\
\hline IK1 & $<4$ & $<0.00005$ & 386 & 0.05 & 7 & .0002 & 3128 & 0.17 & 211 & 0.0 & 93 & 0. & 42 & 0.0101 & 789 & 1.21 & 409 & 0.57 & 0.09 & 0.007 & 2.6 & 0.006 \\
\hline MK2 & $<4$ & $<0.00005$ & 825 & 0.21 & 8 & 0.0002 & 5298 & 0.24 & 246 & 0.0 & 190 & 0. & 86 & 0.0225 & 1562 & 3.23 & 960 & 2.03 & 0.43 & 0.033 & 8.1 & 0.018 \\
\hline MK3 & $<4$ & $<0.00005$ & 607 & 0.15 & 13 & 0.0003 & 3483 & 0.17 & 225 & 0.0 & 153 & 0.5 & 51 & 0.0095 & 1360 & 1.97 & 426 & 0.95 & 0.13 & 0.011 & 9.2 & 0.022 \\
\hline MK4 & $<4$ & $<0.00005$ & 508 & 0.11 & 6 & 0.0002 & 4090 & 0.22 & 149 & 0.0 & 167 & 0.2 & 35 & 0.0056 & 1388 & 2.62 & 367 & 1.19 & 0.10 & 0.008 & 5.5 & 0.015 \\
\hline MK & $<4$ & $<0.00005$ & 540 & 0.15 & 6 & 0.0001 & 5792 & 0.27 & 302 & 0.0 & 133 & 0.2 & 31 & 0.0055 & 1144 & 1.77 & 565 & 1.89 & 0.15 & 0.010 & 6.6 & 0.016 \\
\hline MK6 & $<4$ & $<0.00005$ & 717 & 0.17 & 6 & 0.0002 & 8342 & 0.46 & 245 & 0.03 & 214 & 0.3 & 59 & 0.0093 & 1246 & 2.14 & 586 & 3.89 & 0.09 & 0.006 & 7.5 & 0.021 \\
\hline MK & $<4$ & $<0.00005$ & 829 & 0.21 & 17 & 0.0 & 4822 & 0.26 & 444 & 0.0 & 158 & 0.5 & 157 & 0.0298 & 1674 & 3.02 & 391 & 0.94 & 0.35 & 0.027 & 8.2 & 0.021 \\
\hline MK & $<4$ & $<0.00005$ & 623 & 0.18 & 21 & & 4065 & 0.22 & 302 & 0.0 & 208 & 0.1 & 72 & & 1261 & 1.53 & 633 & 2.63 & 0.15 & 0.005 & 17.1 & 0.041 \\
\hline MK & $<4$ & $<0.00005$ & 433 & 0.12 & 4 & & 3583 & 0.16 & 171 & 0.0 & 197 & 0. & 25 & & 1267 & 1.56 & 325 & 0.69 & 0.3 & 0.016 & 2.5 & 0.005 \\
\hline MK & $<4$ & $<0.00005$ & 656 & 0.17 & 28 & & 2732 & 0.12 & 148 & 0.0 & 104 & 0.4 & 26 & 0.0065 & 1856 & 2.10 & 536 & 0.57 & 0.53 & 0.041 & 2.3 & 0.00 \\
\hline & 17 & 0.000272 & 677 & 0.19 & 30 & & 2840 & 0.17 & 304 & $0 .($ & 253 & 0.7 & 27 & 0.0043 & 1311 & 1.06 & 476 & 0.90 & 0.46 & 0.049 & 3.9 & 0.011 \\
\hline & $<4$ & $<0.00005$ & 654 & 0.17 & 16 & 04 & 4441 & 0.2 & 456 & 0 . & 220 & 0.2 & 27 & 0.0045 & 1400 & 2.38 & 805 & 3.14 & 0.67 & 0.042 & 5.7 & 0.01 \\
\hline MK & $<4$ & $<0.00005$ & 752 & 0.24 & 13 & .0003 & 3337 & 0.16 & 208 & $0 .($ & 156 & 0. & 22 & 0.0047 & 1723 & 1.94 & 593 & 1.44 & 0.31 & 0.022 & 3.2 & 0.00 \\
\hline MK14 & $<4$ & $<0.00005$ & 654 & 0.20 & 20 & 0.0006 & 4085 & 0.23 & 161 & 0.03 & 157 & 0.69 & 23 & 0.0044 & 1466 & 2.56 & 115 & 0.20 & 0.47 & 0.051 & 4.8 & 0.01 \\
\hline
\end{tabular}


Appendix A3

Table A3.4 (cont.) Physiological element concentrations (Con) in husk $\left(\mathrm{mg} \mathrm{kg}^{-1}\right)$ and their transfer factors $(\mathrm{TF})(\mathrm{n}=101)$

\begin{tabular}{|c|c|c|c|c|c|c|c|c|c|c|c|c|c|c|c|c|c|c|c|c|c|c|}
\hline \multirow{2}{*}{ Site } & \multicolumn{2}{|r|}{ Al } & \multicolumn{2}{|c|}{$\mathbf{C a}$} & \multicolumn{2}{|c|}{$\mathbf{F e}$} & \multicolumn{2}{|c|}{$\mathbf{K}$} & \multicolumn{2}{|c|}{ Mg } & \multicolumn{2}{|c|}{ Mn } & \multicolumn{2}{|c|}{$\mathrm{Na}$} & \multicolumn{2}{|c|}{$\mathbf{P}$} & \multicolumn{2}{|c|}{$\mathbf{S}$} & \multicolumn{2}{|c|}{ As } & \multicolumn{2}{|c|}{ Ba } \\
\hline & Con & $\mathrm{TF}$ & Con & TF & Con & TF & Con & TF & Con & $\mathrm{TF}$ & Con & $\mathrm{TF}$ & Con & $\mathrm{TF}$ & Con & $\mathrm{TF}$ & Con & $\mathrm{TF}$ & Con & $\mathrm{TF}$ & Con & $\mathrm{TF}$ \\
\hline MK15 & $<4$ & $<0.00005$ & 798 & 0.22 & 10 & 0.0003 & 6406 & 0.35 & 727 & 0.10 & 260 & 0.58 & 60 & 0.0096 & 941 & 1.25 & 500 & 0.97 & 0.53 & 0.039 & 4.8 & 0.013 \\
\hline MK16 & $<4$ & $<0.00005$ & 763 & 0.18 & 18 & 0.0005 & 5827 & 0.32 & 661 & 0.09 & 166 & 0.32 & 27 & 0.0044 & 884 & 1.13 & 285 & 0.89 & 1 & 0.015 & 10.9 & 0.029 \\
\hline IK17 & $<4$ & 0.00005 & 735 & 0.19 & 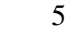 & .0001 & 735 & 0.1 & 127 & 0.02 & 246 & $0 .{ }^{2}$ & 21 & 0.0039 & 1434 & 1.19 & 282 & 0.68 & 0.26 & .017 & 6 & 0.013 \\
\hline 1K19 & 17 & 0.000241 & 876 & 0.22 & 56 & 0.0015 & 625 & 0.47 & 1111 & 0.16 & 199 & 0.27 & 57 & 0.0100 & 1688 & 1.19 & 778 & 2.62 & 0.17 & 0.013 & 4.5 & 0.012 \\
\hline 4K20 & $<4$ & $<0.00005$ & 654 & 0.20 & 18 & 0.0004 & 3703 & 0.19 & 264 & 0.04 & 191 & 0.46 & 36 & 0.0070 & 1316 & 1.30 & 468 & 0.96 & 0.54 & 0.041 & 8.9 & 0.022 \\
\hline IK21 & $<4$ & $<0.00005$ & 861 & 0.24 & 15 & 0.0005 & 301 & 0.18 & 357 & 0.06 & 208 & 1.05 & 22 & 0.0044 & 1642 & 1.78 & 588 & 0.90 & 0.35 & 0.033 & 9.1 & 0.025 \\
\hline 1K22 & $<4$ & $<0.00005$ & 692 & 0.17 & 13 & 0.0004 & 891 & 0.16 & 143 & 0.03 & 309 & 1.64 & 28 & 0.0075 & 1881 & 2.20 & 1029 & 1.48 & 0.14 & 0.013 & 19.1 & 0.047 \\
\hline IK24 & $<4$ & $<0.00005$ & 848 & 0.20 & 19 & 0.0006 & 3720 & 0.20 & 36 & 0.06 & 152 & 0.77 & 27 & 0.0071 & 1483 & 1.99 & 1055 & 1.42 & 0.25 & 0.021 & 13.8 & 0.0 \\
\hline IK25 & $<4$ & .00005 & 748 & 0.20 & 17 & 0.0006 & 2551 & 0.14 & 33 & 0.03 & 04 & 1.3 & 23 & 0.0048 & 283 & 1.95 & 839 & 1.22 & 7 & 0.020 & 12.0 & 0.03 \\
\hline K26 & $<4$ & .00005 & 739 & 0.24 & 16 & 0.0 & 285 & 0.2 & +1 & 0. & 56 & 0.4 & 42 & 0.0 & 1364 & 1.74 & 583 & 0.94 & 2 & 0.026 & 4.9 & 0.016 \\
\hline & $<4$ & 000 & 961 & 0.31 & 23 & 0.0006 & 401 & 0.3 & 38 & 0. & 55 & $1 .($ & 44 & 0.0 & 448 & 3.71 & 573 & 0.90 & 0.21 & 20 & 11.6 & 0.037 \\
\hline IK30 & $<4$ & .00005 & 928 & 0.35 & 37 & 0.0009 & 372 & 0.1 & 165 & 0.0 & 120 & 0.6 & 33 & 0.0075 & 116 & 1.95 & 966 & 1.52 & 0.37 & 31 & 23.8 & 0.053 \\
\hline IK31 & $<4$ & 0.00005 & 757 & 0.22 & 19 & 0.0004 & 4601 & 0.22 & 365 & 0.0 & 190 & 0.5 & 41 & 0.0084 & 1575 & 1.40 & 556 & 1.13 & 0.48 & 0.032 & 12.5 & 0.030 \\
\hline 1K32 & $<4$ & $<0.00005$ & 675 & 0.23 & 10 & 0.0003 & 3128 & 0.15 & 399 & 0.05 & 109 & 0.4 & 32 & 0.0068 & 1328 & 1.75 & 426 & 0.76 & 0.58 & 0.050 & 11.7 & 0.028 \\
\hline IK33 & $<4$ & 0.00005 & 945 & 0.32 & 40 & 0.0011 & 2789 & 0.13 & 402 & 0.05 & 136 & 0.6 & 34 & 0.0074 & 1089 & 1.21 & 419 & 0.58 & .42 & 0.040 & 10.7 & 0.025 \\
\hline IK34 & $<4$ & $<0.00005$ & 710 & 0.21 & 12 & 0.0003 & 4389 & 0.22 & 308 & 0.04 & 244 & 0.9 & 27 & 0.0056 & 1094 & 1.38 & 316 & 0.57 & 0.08 & 0.007 & 9.1 & 0.02 \\
\hline IK35 & $<4$ & .00005 & 849 & 0.23 & 13 & 0.0003 & 3481 & 0.17 & 483 & 0.07 & 216 & 0.7 & 117 & 0.0215 & 977 & 0.84 & 445 & 0.37 & 5 & 0.023 & 2.4 & 0.0 \\
\hline & $<4$ & 5 & 7 & 0.26 & 6 & & 51 & 0.1 & 59 & 0. & 212 & 0 & 31 & 0.0 & 1601 & 2.04 & 250 & 0.68 & .18 & 16 & 15.8 & 0.04 \\
\hline 8 & $<4$ & .00005 & 601 & 0.16 & 8 & 0003 & 4169 & 0.2 & 473 & 0.0 & 84 & 0.3 & 24 & 0.0060 & 572 & 0.71 & 575 & 1.25 & 0.20 & 18 & 3.5 & 0.008 \\
\hline IK40 & $<4$ & $<0.00005$ & 971 & 0.22 & 29 & .0009 & 3748 & 0.1 & 459 & 0.0 & 254 & 1.1 & 8 & 0.0020 & 857 & 0.82 & 860 & 1.24 & 0.51 & 0.046 & 6.5 & 0.015 \\
\hline IK41 & 9 & 0.00009 & 590 & 0.18 & 5 & .0001 & 1869 & 0.0 & 541 & 0.0 & 110 & 0.4 & 28 & 0.0066 & 1693 & 2.02 & 620 & 0.61 & 0.24 & 0.018 & 4.2 & 0.010 \\
\hline IK42 & 70 & 0.00085 & 752 & 0.18 & 39 & .0011 & 5725 & 0.3 & 357 & 0.0 & 198 & 0.8 & 39 & 0.0078 & 1764 & 2.12 & 938 & 0.78 & 0.21 & 0.015 & 5.9 & 0.015 \\
\hline MK43 & $<4$ & $<0.00005$ & 701 & 0.24 & 25 & .0011 & 3232 & 0.1 & 248 & 0.0 & 203 & 1.6 & 31 & 0.0058 & 1249 & 2.48 & 499 & 0.64 & 0.23 & 0.025 & 9.9 & 0.026 \\
\hline 1K44 & $<4$ & $<0.00005$ & 872 & 0.29 & 34 & 0.0013 & 3212 & 0.15 & 110 & 0.0 & 103 & 1.1 & 74 & 0.0176 & 840 & 1.88 & 775 & 0.81 & 0.50 & 0.048 & 6.5 & 0.016 \\
\hline IK45 & $<4$ & $<0.00005$ & 1112 & 0.32 & 38 & 0.0014 & 3770 & 0.21 & 164 & 0.03 & 197 & 1.46 & 64 & 0.0140 & 1692 & 2.75 & 487 & 0.37 & 0.53 & 0.049 & 4.2 & 0.01 \\
\hline MK46 & $<4$ & $<0.00005$ & 934 & 0.34 & 27 & 0.0015 & 2663 & 0.14 & 244 & 0.05 & 80 & 0.65 & 44 & 0.0088 & 1369 & 2.67 & 818 & 0.43 & 0.36 & 0.043 & 3.3 & 0.00 \\
\hline MK47 & $<4$ & $<0.00005$ & 748 & 0.21 & 0 & 0.0003 & 4087 & 0.21 & 304 & 0.05 & 237 & 0.74 & 42 & 0.0084 & 1299 & 1.84 & 473 & 0.23 & 95 & 0.051 & 4.9 & 0.013 \\
\hline IK48 & $<4$ & $<0.00005$ & 1300 & 0.42 & 16 & & 3516 & 0.2 & 127 & 0.0 & 163 & 2.2 & 140 & 0.0261 & 1459 & 3.12 & 1053 & 0.81 & & 0.078 & 5.2 & 0.01 \\
\hline $1 K 40$ & 52 & 0.00054 & & 0.24 & 28 & & 3317 & 0.1 & 286 & 0.0 & 103 & 1.0 & 38 & 0.0087 & 1729 & 2.32 & 1522 & 1.07 & 0.2 & 0.024 & 2.1 & 0.005 \\
\hline IK51 & 6 & 0.00009 & & 0.26 & 35 & & 2656 & 0.1 & 332 & 0.0 & 108 & 0.4 & 44 & 0.0094 & 1511 & 2.33 & 526 & 1.44 & 0.40 & 0.040 & 9.4 & 0.02 \\
\hline & $<4$ & $<0.00005$ & 761 & 0.14 & 19 & 05 & 5220 & 0.2 & 232 & 0. & 121 & 0.2 & 71 & 0.0165 & 1530 & 1.86 & 540 & 0.18 & 0.0 & 0.006 & 0.5 & 0.001 \\
\hline & $<4$ & .00005 & & 0.17 & 15 & 0004 & 3607 & 0.1 & 212 & 0. & 115 & 0. & 54 & 0.0125 & 1479 & 2.20 & 652 & 0.39 & 0.16 & 0.013 & 1.6 & 0.00 \\
\hline MK54 & $<4$ & $<0.00005$ & 760 & 0.24 & 17 & 0.0005 & 3173 & 0.16 & 252 & 0.04 & 197 & 0.99 & 22 & 0.0053 & 1418 & 2.44 & 545 & 0.75 & 0.18 & 0.016 & 8.9 & 0.022 \\
\hline MK55 & $<4$ & $<0.00005$ & 910 & 0.24 & 21 & 0.0005 & 5420 & 0.24 & 538 & 0.07 & 142 & 0.51 & 49 & 0.0128 & 1678 & 2.39 & 498 & 0.56 & 0.29 & 0.021 & 1.6 & 0.002 \\
\hline
\end{tabular}


Appendix A3

Table A3.4 (cont.) Physiological element concentrations (Con) in husk $\left(\mathrm{mg} \mathrm{kg}^{-1}\right)$ and their transfer factors $(\mathrm{TF})(\mathrm{n}=101)$

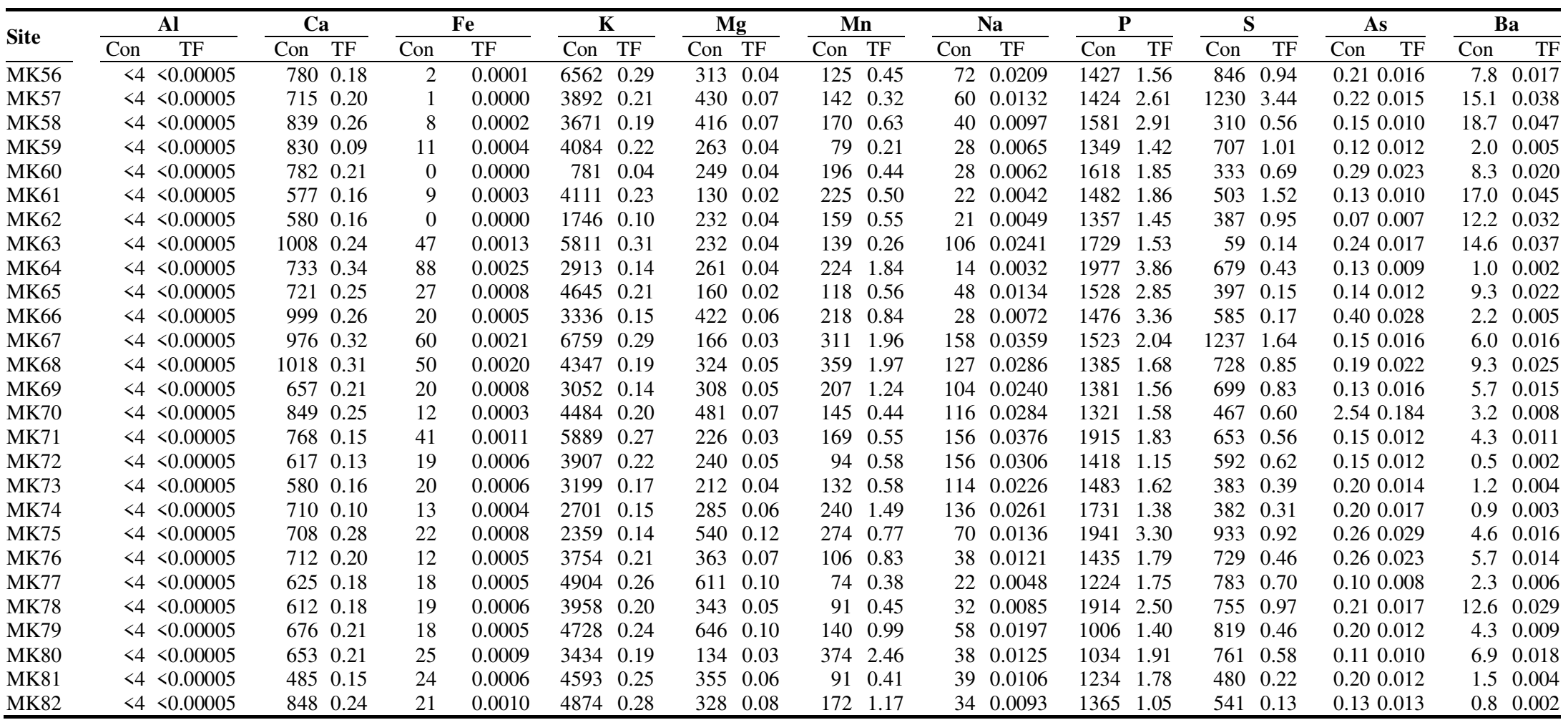


Table A3.4 (cont.) Physiological element concentrations (Con) in husk $\left(\mathrm{mg} \mathrm{kg}^{-1}\right)$ and their transfer factors $(\mathrm{TF})(\mathrm{n}=101)$

\begin{tabular}{|c|c|c|c|c|c|c|c|c|c|c|c|c|c|c|c|c|c|c|c|c|c|c|}
\hline \multirow{2}{*}{ Site } & \multicolumn{2}{|c|}{$\overline{B i}$} & \multicolumn{2}{|c|}{$\overline{C d}$} & \multicolumn{2}{|c|}{$\mathrm{Ce}$} & \multicolumn{2}{|c|}{ Co } & \multicolumn{2}{|c|}{$\mathrm{Cr}$} & \multicolumn{2}{|c|}{ Cs } & \multicolumn{2}{|c|}{$\mathbf{C u}$} & \multicolumn{2}{|c|}{ Hf } & \multicolumn{2}{|c|}{ La } & \multicolumn{2}{|c|}{$\mathbf{L i}$} & \multicolumn{2}{|c|}{ Mo } \\
\hline & Con & TF & Con & TF & Con & TF & Con & TF & on & TF & Con & $\mathrm{TF}$ & Con & TF & Con & $\mathrm{TF}$ & Con & $\mathrm{TF}$ & Con & $\mathrm{TF}$ & Con & $\mathrm{TF}$ \\
\hline 11 & 0.0024 & 0030 & .029 & .083 & 1132 & 0.001098 & 0.091 & 0.00 & .35 & 0.0076 & 176 & 0.0227 & 3.00 & 0.087 & .0038 & 0.00112 & .0498 & 0.001053 & .0299 & 00100 & .07 & 0.06 \\
\hline 5 & 0085 & 141 & 489 & 232 & & 0.000248 & & & & 00107 & & 0.0192 & 2.69 & & 0006 & 0016 & 0125 & 0278 & .0220 & 0076 & .07 & 0.06 \\
\hline 6 & 008 & D10 & & 120 & & 0.001003 & 7 & & & & & & & & & & & & & & 06 & 0.07 \\
\hline 7 & 3 & $\pi$ & & ( & & 0.00 & & ( & & 0.0 & & & & & & & 66 & & & & 04 & 04 \\
\hline & 092 & 181 & 02 & & & 0.00 & 9 & 0.0029 & & 0.0084 & & & & & 31 & & 122 & 290 & & & & 0.11 \\
\hline & 69 & 62 & 20 & & & 0.003 & & 15 & & 33 & & & & & & & & 86 & & & & 0.09 \\
\hline & & & 02 & .006 & & & & & & & & & & & & & & & & & 03 & 008 \\
\hline & 0048 & 0120 & 016 & .044 & 591 & 0.000745 & 8 & 0.0022 & 20 & 0.0031 & 8 & 0.0 & & & .0014 & 0.00032 & .0305 & 782 & .0057 & 013 & .07 & 0.12 \\
\hline & 0063 & 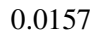 & 777 & 2.086 & & & & & 28 & & & & & & & & & & & & .09 & 0.13 \\
\hline & 0044 & 0007 & 019 & 0.060 & & 0.00 & & & & 0.0015 & & & & & & & & & & & .03 & 0.05 \\
\hline & & & & & & & & & & & & & & & & & & & & & 05 & 0.08 \\
\hline & & & & & & & & & & & & & & & & & & & & & 32 & 0.61 \\
\hline & & & & & & & & & & & & & & & & & & & & & 06 & 0.05 \\
\hline & & & & & & & & & & & & & & & & & & & & & 6 & 0.09 \\
\hline & 99 & ( & & & & & & & & & & & & & & & & & & & 10 & 0.21 \\
\hline & 071 & 08 & 19 & 340 & & 0.0 & & 0 . & 1 & 0.0 & & & & & 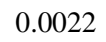 & & 35 & & & 21 & 05 & 0.07 \\
\hline & & & & & & & & & & & & & & & & & & & & & 13 & 0.09 \\
\hline 6 & & & & & & 0.0 & & & & & & & & & & & & & & & 09 & 0.04 \\
\hline$\Gamma 7$ & 009 & - & & 0.014 & & 0.0 & & & & & & & & & & & & & & & 34 & 0.14 \\
\hline & & & & & & & & & & & & & & & & & & & & & .07 & 0.08 \\
\hline & & & & & & & & & & & & & & & & & & & & & 07 & .09 \\
\hline & & & & & & & & & & & & & & & & & & & & & 09 & 07 \\
\hline & & & & & & & & & & & & & & & & & & & & & 05 & 05 \\
\hline & 05 & 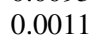 & & .001 & & 0.0 & & & & & & & & & & & & & & & 11 & 0.14 \\
\hline & 002 & ( & & & & & & & & & & & & & 36 & & & & & 04 & .06 & 0.08 \\
\hline & & & & & & & & & & & & & & & & & & & & & 07 & 0.11 \\
\hline MK & 002 & 0007 & 26 & 0.07 & & 0.00 & & 0.0 & & 0.0 & & & & & & & & & & & .19 & 0.34 \\
\hline 1K5 & 0003 & 0007 & .009 & 0.028 & & 0.0000 & 0.011 & 0.00 & 06 & 0.0004 & & & & & & & & & & & .20 & 0.26 \\
\hline$x_{2}$ & 003 & 0008 & 16 & 0.0 & & 0.00 & & & & & & & & & & & & & & & .28 & 0.46 \\
\hline & 054 & 151 & & 0.018 & & & & & & & & & & & & & & & & & 20 & 0.30 \\
\hline & & & & & & & & & & & & & & & & & & & & & 15 & 0.18 \\
\hline & & & & & & & & & & & & & & & & & & & & & 03 & 0.04 \\
\hline & & & & & & & & & & & & & & & & & & & & & .21 & 0.27 \\
\hline & & & & & & & & & & & & & & & & & & & & & .13 & 0.27 \\
\hline & & & & & & & & & & & & & & & & & & & & & .25 & 0.35 \\
\hline & 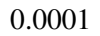 & ( & & 0.0 & & 0.000 & & 0.0 & & 0.0 & & & & & $0 \Omega$ & & 00062 & & & 44 & 0.15 & 0.22 \\
\hline MK14 & 0.0006 & 0.0016 & 0.005 & 0.018 & 0.0029 & 0.000041 & 0.032 & 0.0026 & 0.19 & 0.0027 & 0.011 & 0.0013 & 2.13 & 0.073 & 0.0014 & 0.00028 & 0.0009 & 0.000026 & 0.0021 & 0.00005 & 0.24 & 0.48 \\
\hline
\end{tabular}


Table A3.4 (cont.) Physiological element concentrations (Con) in husk ( $\left.\mathrm{mg} \mathrm{kg}^{-1}\right)$ and their transfer factors $(\mathrm{TF})(\mathrm{n}=101)$

\begin{tabular}{|c|c|c|c|c|c|c|c|c|c|c|c|c|c|c|c|c|c|c|c|c|c|c|}
\hline \multirow{2}{*}{ Site } & \multicolumn{2}{|c|}{$\overline{\mathrm{Bi}}$} & \multicolumn{2}{|c|}{$\overline{C d}$} & \multicolumn{2}{|c|}{$\mathrm{Ce}$} & \multicolumn{2}{|c|}{$\mathrm{Co}$} & \multicolumn{2}{|c|}{$\mathrm{Cr}$} & \multicolumn{2}{|c|}{ Cs } & \multicolumn{2}{|c|}{$\mathbf{C u}$} & \multicolumn{2}{|c|}{ Hf } & \multicolumn{2}{|c|}{ La } & \multicolumn{2}{|c|}{$\mathbf{L i}$} & \multicolumn{2}{|c|}{ Mo } \\
\hline & Con & TF & Con & TF & Con & TF & Con & TF & on & TF & Con & TF & Con & TF & Con & $\overline{\mathrm{TF}}$ & Con & $\overline{\mathrm{TF}}$ & Con & $\overline{\mathrm{TF}}$ & Con & $\mathrm{TF}$ \\
\hline$\overline{\mathrm{K} 1}$ & 0007 & 0.0021 & 020 & .069 & 290 & 0.0003 & 059 & 0.0041 & 09 & 0010 & 0.028 & 0.0035 & 1.95 & 0.076 & 0.0030 & 0.00063 & 0151 & 0.000409 & .0282 & 0.00073 & 28 & $\overline{0.47}$ \\
\hline$V=$ & 003 & (O) & & 053 & & 00054 & & & 03 & 0005 & & & & & & 108 & 0032 & 0083 & 0030 & 0008 & 35 & 0.68 \\
\hline & 010 & 1077 & & 120 & & 0 & & & & & & & & & & & & & & & 11 & .16 \\
\hline & & c & & 001 & & 0.000 & & 0 . & & 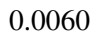 & & 0.0 & & 0.03 & & & & & & & & 24 \\
\hline & & & & 004 & & 0.000 & & 0 & & 0010 & & & & 0. & & & & & & & & 7 \\
\hline & & 08 & & 028 & & & & & & & & & & & & & & & & & & 0.17 \\
\hline & & & & 118 & & & & & & & & & & 0.021 & & & & & & & & 26 \\
\hline & 023 & 0.0056 & 001 & .005 & 007 & 0.000008 & 3 & 42 & 03 & 0.0004 & 29 & 0.0024 & & 0.128 & 0002 & 0.00005 & 001 & 003 & 49 & 009 & 15 & 0.15 \\
\hline & & 0012 & 033 & 104 & & 0.000 & & & 08 & & & & 40 & & & & & & & & 26 & 0.24 \\
\hline & & 00016 & 36 & 102 & & 0.000 & & & & & & & & & & & & & & 117 & 41 & 0.42 \\
\hline & & & & 364 & & & & & & & & & & & & & & & & & 36 & 54 \\
\hline & & & & 1 & & & & & & & & & & & & & & & & & 66 & .05 \\
\hline & & & & & & & & & & & & & & & & & & & & & & 0.28 \\
\hline & & & & & & & & & & & & & & & & & & & & & & 0.13 \\
\hline & 9 & ( & & & & & & & & & & & & & & & & & & 87 & & 0.29 \\
\hline & 005 & $\pi$ & 05 & 01 & & 0 & & & & 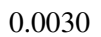 & & & & & & & & & & 02 & .22 & 0.35 \\
\hline & & & & & & & & & & & & & & & & & & & & & & 08 \\
\hline & & & & & & & & & & & & & & & & & & & & & 06 & 0.08 \\
\hline & & 0.001 & 024 & 0.100 & & & & & & & & & & & & & & & & & 27 & 0.44 \\
\hline & & & & 035 & & & & & & & & & & & & & & & & & 97 & .07 \\
\hline & & & & & & & & & & & & & & & & & & & & & & 0.29 \\
\hline & & & & & & & & & & & & & & & & & & & & & & 18 \\
\hline & & & & 7 & & & & & & & & & & & & & & & & & & 22,12 \\
\hline & & 0 & & 7 & & & & & & & & & & & & & & & & & & 0.19 \\
\hline & & 0.00 & 51 & 8 & & & & & & & & & & & & & & 97 & & 775 & & 0.17 \\
\hline & & & & & & & & & & & & & & & & & & & & & & 0.07 \\
\hline & 1 & 0.00 & 21 & 151 & & 0.00 & & & & & & 0.0 & & & & & & & & & 31 & 0.31 \\
\hline & 003 & 0.0008 & 092 & 0.416 & & 0.000 & & 0.00 & & 0.00 & & 0.0031 & & & & & & & & & 01 & 0.01 \\
\hline & 004 & 0.0012 & 001 & 0.005 & & & & & & & & & & & & & & & & & 88 & 0.06 \\
\hline & & 0.0002 & & 0.150 & & & & & & & & & & & & & & & & & 03 & 0.02 \\
\hline & & & & & & & & & & & & & & & & & & & & & 3 & .02 \\
\hline & & & & & & & & & & & & & & & & & & & & & & .15 \\
\hline & & & & & & & & & & & & & & & & & & & & & 08 & 0.13 \\
\hline & & & & & & & & & & & & & & & & & & & & & 06 & 0.03 \\
\hline & & & & & & & & & & & & & & & & & & & & & & \\
\hline & 1 & 0.00 & 272 & 07 & & 0.000 & & & & & & 0.0 & 0 & & & & & & & & 06 & 0.07 \\
\hline MK55 & 0.0007 & 0.0015 & 0.003 & 0.008 & 0.0086 & 0.000093 & 0.039 & 0.0023 & 0.04 & 0.0005 & 0.018 & 0.0014 & 2.05 & 0.053 & 0.0041 & 0.00116 & 0.0014 & 0.000030 & 0.0126 & 0.00022 & 0.03 & 0.03 \\
\hline
\end{tabular}


Appendix A3

Table A3.4 (cont.) Physiological element concentrations (Con) in husk ( $\left.\mathrm{mg} \mathrm{kg}^{-1}\right)$ and their transfer factors $(\mathrm{TF})(\mathrm{n}=101)$

\begin{tabular}{|c|c|c|c|c|c|c|c|c|c|c|c|c|c|c|c|c|c|c|c|c|c|c|}
\hline \multirow{2}{*}{ Site } & \multicolumn{2}{|c|}{ Bi } & \multicolumn{2}{|c|}{ Cd } & \multicolumn{2}{|r|}{$\mathrm{Ce}$} & \multicolumn{2}{|c|}{ Co } & \multicolumn{2}{|c|}{$\mathrm{Cr}$} & \multicolumn{2}{|c|}{ Cs } & \multicolumn{2}{|c|}{$\mathbf{C u}$} & \multicolumn{2}{|c|}{ Hf } & \multicolumn{2}{|c|}{ La } & \multicolumn{2}{|c|}{$\mathbf{L i}$} & \multicolumn{2}{|c|}{ Mo } \\
\hline & Con & $\mathrm{TF}$ & Con & $\mathrm{TF}$ & Con & $\mathrm{TF}$ & Con & $\mathrm{TF}$ & on & $\mathrm{TF}$ & Con & $\mathrm{TF}$ & Con & $\mathrm{TF}$ & Con & $\mathrm{TF}$ & Con & $\mathrm{TF}$ & Con & $\overline{\mathrm{TF}}$ & Con & $\mathrm{TF}$ \\
\hline K56 & 0002 & 0.0004 & 029 & 0.087 & 574 & 0.000709 & 021 & 0.0012 & & 0019 & 0.012 & 0.00 & 1.41 & 0.034 & 0.0003 & 0.00007 & .0221 & 0.000468 & 0182 & 030 & 12 & 0.10 \\
\hline & & & 25 & 7 & & & & & & & & & & & & & 072 & & & & 06 & 0.06 \\
\hline & 002 & 0.0004 & 009 & 035 & & 0.000078 & 28 & 18 & 3 & 0004 & 3 & 0.0 & 33 & & 0008 & 0.00023 & 0043 & 0094 & 116 & 024 & 07 & 0.07 \\
\hline & 0002 & 0006 & 001 & 003 & 045 & 0.000066 & 024 & 0.0019 & 83 & .0120 & 15 & 0.00 & 1.62 & 0.057 & 0035 & 0.00112 & .0236 & 0.000677 & 0161 & 0038 & 0.07 & 0.10 \\
\hline & 0003 & 0007 & 019 & .065 & 169 & 000221 & 007 & 0.00 & 07 & .000 & 011 & 0.00 & .87 & 0.0 & 0048 & 138 & 0081 & 0210 & 81 & 18 & .05 & 0.07 \\
\hline & 002 & 0005 & 35 & 114 & 30 & 00016 & 38 & 0.0 & 9 & 00 & 25 & 00 & 69 & 0.0 & 0048 & 18 & 82 & 12 & 384 & 02 & .18 & 0.29 \\
\hline & 006 & 17 & 52 & 34 & & 0004 & & 0.0 & & 08 & & & 8 & & & & & & 080 & & 08 & 0.13 \\
\hline & & & & & & & & & & & & & & & & & & & & & 33 & 0.49 \\
\hline & & 0 & & & & & & & & & & & & & & & & & & & 02 & 0.02 \\
\hline & 21 & 00 & & 0 & & & & & & .0 & & & & & & & & & & & 08 & 0.09 \\
\hline & 003 & 0007 & 167 & 0 & & 0 & 0 & & & 0.00 & & & 47 & & & & & 46 & & 24 & 46 & 0.53 \\
\hline $6 /$ & 036 & 0087 & 16 & 094 & 57 & 0.000546 & 20 & 0. & 2 & 0.00 & 5 & 0.0 & 58 & 0. & 6 & & & 98 & & 25 & .09 & 0.09 \\
\hline 68 & 004 & 0010 & $\int 28$ & .140 & 303 & 0.00 & 082 & & 62 & 0.00 & 19 & & 27 & 0. & 0031 & 71 & & 32 & 00 & 36 & .11 & 0.11 \\
\hline & 0004 & 0010 & 60 & 339 & & 0.00 & 41 & & & .00 & & & 45 & 0 . & & & & & & & .12 & 0.13 \\
\hline & 04 & 98 & 01 & 005 & & 0 & 2 & 0.0 & & 0 & & & 89 & & & & & & & & .22 & 1.29 \\
\hline & & & & & & & & & & & & & & & & & & & & & 03 & 0.04 \\
\hline & & & & & & & & & & & & & & & & & & & & & 04 & 02 \\
\hline & & & & 0 & & & & & & & & & & & & & & & & & 03 & 02 \\
\hline & & 8 & & 0 & & & & & & & & & & & & & & & & & 30 & 20 \\
\hline & & 0004 & & 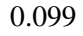 & & & & & & & & & J & & & & & & & & 15 & 0.20 \\
\hline & 002 & 0.0004 & 03 & 011 & & 0.000020 & 3 & 0.0 & & 0.00 & 12 & 0.0 & 0.83 & & 03 & & 25 & 56 & & 003 & 0.20 & 0.12 \\
\hline & 004 & 0010 & 26 & 07 & 22 & 0.00 & 75 & & & 0.00 & 63 & 0.0 & 17 & & 02 & & 12 & 30 & & 20 & 0.26 & 0.29 \\
\hline & 0008 & 0020 & 019 & 07 & 064 & 0.000 & 64 & 0.0 & & 00 & 1 & 0.0 & 26 & 0 & 10 & & 0.0075 & 79 & 10 & 02 & .21 & 0.18 \\
\hline & 002 & 00 & 28 & 08 & 1 & 0.0000 & 3 & 0.0 & 9 & 1 & 0 & 0.0 & 5.41 & 0. & 37 & & 4 & 06 & 98 & 14 & 44 & 0.17 \\
\hline$K 80$ & 002 & 00 & ? & 0 & 77 & 0 & 2 & & & 0 - & & & & & & & & & & & 10 & 0.0 \\
\hline & & 0.0010 & 0.007 & 0.023 & 037 & 0.00 & 044 & 0.00 & & 0.00 & & 0.0 & 2.09 & & & & 0.0032 & 69 & 0.0456 & & 0.07 & 0.05 \\
\hline MK82 & 0002 & 0.0006 & 0.008 & 0.038 & 0.0004 & 0.000005 & 0.082 & 0.0098 & 0.28 & 0.0041 & 0.063 & 0.0056 & 3.39 & 0.152 & 0.0021 & 0.00049 & 0.0041 & 0.000092 & 0.0276 & 0.00047 & 0.11 & 0.0 \\
\hline
\end{tabular}


Table A3.4 (cont.) Physiological element concentrations (Con) in husk $\left(\mathrm{mg} \mathrm{kg}^{-1}\right)$ and their transfer factors $(\mathrm{TF})(\mathrm{n}=101)$

\begin{tabular}{|c|c|c|c|c|c|c|c|c|c|c|c|c|c|c|c|c|c|c|c|c|c|c|}
\hline \multirow{2}{*}{ Site } & \multicolumn{2}{|c|}{$\mathbf{N i}$} & \multicolumn{2}{|c|}{$\mathbf{P b}$} & \multicolumn{2}{|c|}{$\mathbf{R b}$} & \multicolumn{2}{|c|}{$\mathbf{S b}$} & \multicolumn{2}{|c|}{ Sn } & \multicolumn{2}{|c|}{$\mathrm{Sr}$} & \multicolumn{2}{|c|}{ Th } & \multicolumn{2}{|c|}{ Tl } & \multicolumn{2}{|c|}{$\mathbf{U}$} & \multicolumn{2}{|c|}{ Zn } & \multicolumn{2}{|c|}{$\mathbf{Z r}$} \\
\hline & Con & $\mathrm{TF}$ & Con & $\mathrm{TF}$ & Con & $\mathrm{TF}$ & Con & $\mathrm{TF}$ & Con & TF & Con & $\overline{\mathrm{TF}}$ & Con & $\mathrm{TF}$ & Con & $\mathrm{TF}$ & Con & $\mathrm{TF}$ & Con & $\mathrm{TF}$ & Con & $\mathrm{TF}$ \\
\hline H1 & 0.48 & 0.013 & 1.59 & 0.042 & 24.0 & 0.180 & 0.0146 & 0.00824 & 0.06 & $<0.0$ & 2.25 & 0.06 & 0.0003 & 0.00001 & 0.0006 & 0.0009 & 0.0081 & .00156 & 10.0 & 0.09 & .044 & 0005 \\
\hline H5 & 0.36 & 0.012 & 0.65 & 0.021 & 47.8 & 0.390 & 0207 & 0.012 & & $<0$ & .58 & 0.18 & 0007 & 0.00003 & 0065 & 0.0103 & 0019 & 0.00041 & .3 & 11 & .014 & 0001 \\
\hline H6 & & 0.027 & 40 & 0.018 & 9 & 0.686 & 0011 & 0.000 & & $<0$. & .60 & 0. & 0010 & 0.00006 & .0039 & 0.0080 & .0009 & 0.00023 & 8.6 & 0.13 & .032 & 0.0003 \\
\hline H7 & 5 & 0.014 & 31 & 0.013 & & 0.551 & 0015 & 0.00100 & .06 & $<0.01$ & 17 & 0.16 & 0012 & 0.00007 & .0008 & 0.0015 & .0021 & 0.00053 & 10.2 & 0.15 & .104 & 0.0010 \\
\hline HN1 & 1 & 0.009 & 67 & 0.048 & 4.3 & 0.034 & 0491 & 0.02607 & 0.06 & $<0.01$ & .46 & 0.05 & 0043 & 0.00025 & .0057 & 0.0092 & .0060 & 0.00160 & 12.9 & 0.13 & .167 & 0.0011 \\
\hline IN2 & 32 & 0.009 & 0.49 & 0.016 & 15.3 & 0.142 & .0194 & 0.01213 & 0.06 & $<0.01$ & .01 & 0.04 & 0.0491 & 0.00311 & 0.0037 & 0.0070 & 0.0027 & 0.00080 & 6.3 & 0.07 & 0.279 & 0.0018 \\
\hline iN3 & 0.13 & 0.004 & 0.90 & 0.027 & 11.0 & 0.099 & .0221 & 0.01365 & 0.06 & $<0.01$ & 3.25 & 0.04 & 0.0072 & 0.00051 & 0.0040 & 0.0073 & 0.0015 & 0.00048 & 6.3 & 0.06 & 0.150 & 0.0011 \\
\hline IN5 & 0.17 & 0.004 & 0.38 & 0.011 & 12.1 & 0.105 & .0240 & 0.01294 & 0.06 & $<0.01$ & 32 & 0.05 & 0.0085 & 0.00056 & 0.0033 & 0.0057 & 0.0063 & 0.00178 & 2.0 & 0.02 & 0.071 & 0.0005 \\
\hline HN6 & 0.82 & 0.018 & 0.41 & 0.011 & 12.6 & 0.098 & .0129 & 0.00635 & 0.06 & $<0.01$ & .04 & 0.08 & 0.0072 & 0.00043 & 0.0042 & 0.0068 & .0085 & 0.00232 & 22.4 & 0.23 & 0.069 & 0.0005 \\
\hline N7 & 22 & 0.005 & .24 & 0.006 & 11.2 & 0.078 & 0065 & 0.00343 & & $<0.01$ & .53 & 0.03 & 0.0022 & 0.00012 & .0028 & 0.0040 & .0025 & 0.00066 & 6.6 & 0.06 & .078 & 0.0005 \\
\hline N8 & & 0.007 & 24 & 0.006 & 14.8 & 0.1 & 99 & 0.00 & 6 & $<0$. & 96 & 0.04 & 0008 & 0 & 0027 & 38 & .0010 & 0.00027 & 10.3 & 0.10 & 164 & 0.0011 \\
\hline IN9 & & 0.024 & 37 & 0.0 & 5.2 & 0.0 & 5 & 0.00 & & 1. & 56 & 0. & 27 & 0.0 & 028 & 39 & .0034 & 84 & 12.3 & 0.1 & .041 & 0.0003 \\
\hline N1 & ( & 0.0 & 73 & 0.01 & 12.8 & 0.0 & 0 & 0.0 & & 0.3 & 71 & 0. & 16 & 0.1 & 021 & 30 & 26 & 063 & 16.4 & 0.1 & .078 & 0.0005 \\
\hline N1 & 1 & 0.022 & 93 & 0.069 & 8.6 & 0.060 & 0099 & 0.00 & 0.52 & 0.1 & 98 & 0. & 264 & 0.0 & .0036 & 0.0052 & .0139 & 379 & 6.2 & 0.05 & 0.321 & 0.0023 \\
\hline PT1 & 0.31 & 0.017 & 53 & 0.064 & 31.6 & 0.491 & .0968 & 0.09336 & 0.06 & $<0.01$ & 4.48 & 0.06 & 0147 & 0.0 & .0043 & 0.0133 & .0124 & 433 & 17.9 & 0.26 & 0.162 & 0.0011 \\
\hline PT3 & 0.23 & 0.006 & 0.35 & 0.005 & 40.5 & 0.382 & .0127 & 0.00721 & $<0.06$ & $<0.01$ & 4.47 & 0.05 & .0085 & 0.00051 & .0049 & 0.0092 & 0.0011 & 0.00031 & 10.1 & 0.10 & 0.018 & 0.0001 \\
\hline T4 & 0.21 & 0.005 & 0.65 & 0.008 & 6.9 & 0.059 & 0121 & 0.00440 & 0.06 & $<0.01$ & .25 & 0.02 & 268 & & 058 & & .0022 & 060 & 11.1 & 0.08 & .084 & .0007 \\
\hline T6 & 1 & 0.019 & .27 & 0.041 & 28.0 & 0.432 & 6640 & 0.047 & 0.06 & $<0.01$ & 6.61 & 0.19 & 0.1011 & 0.00 & .0075 & 0.0199 & 0.0298 & 0.00782 & 7.4 & 0.05 & 0.981 & 0.0162 \\
\hline PT7 & 1 & 0.070 & 64 & 0.013 & 30.9 & 0.635 & & 0.00 & & $<0.01$ & 47 & 0.15 & & & 010 & & & 265 & 40.5 & 0.49 & 065 & 0.0014 \\
\hline PT8 & & 0.004 & 48 & 0.006 & 25.4 & 0.2 & & 0.00 & & $<0.01$ & & 0.04 & & & 041 & & & 88 & 1.7 & 0.01 & 085 & 0008 \\
\hline T9 & & 0. & & $0.0 c$ & 1 & 0 . & & & & & & 0 . & & & & & & & 2.1 & 0.0 & 18 & 0.0002 \\
\hline $\mathrm{T} 10$ & & 0.037 & 3 & 0.015 & 7 & $0 .($ & 4 & 0.02 & & 0.4 & 40 & 0. & 13 & & 0.0039 & 49 & 0.0 & 24 & 10.6 & 0.07 & 0.122 & 0.0009 \\
\hline PT11 & 0 & 0.009 & 22 & 0.014 & 11 & 0.088 & 8 & 0.00 & 2. & 0.4 & 4.13 & 0. & 011 & 0.0 & .0036 & 0.0051 & 0.0042 & 100 & 14.9 & 0.12 & 0.172 & 0.0015 \\
\hline IK1 & 0.08 & 0.002 & 84 & 0.033 & 17.9 & 0.150 & 0111 & 0.00572 & $<0.06$ & $<0.01$ & 1.30 & 0. & 0008 & 0.00006 & 0.0005 & 0.0008 & 0.0005 & 0.00013 & 9.4 & 0.09 & 0.350 & 0.0024 \\
\hline 1K2 & 0.10 & 0.002 & 0.27 & 0.009 & 23.4 & 0.164 & 0143 & 0.00613 & 60.06 & $<0.01$ & .12 & 0. & 0010 & 0.00006 & 0.0005 & 0.0006 & 0.0001 & 0.00003 & 9.1 & 0.09 & 0.117 & 0.0008 \\
\hline ИK3 & 0.15 & 0.004 & 0.27 & 0.009 & 13.6 & 0.113 & 0012 & 0.00044 & 6 & $<0$. & .83 & 0. & 0089 & 0.0 & .0001 & 0.0002 & 0.0012 & 0.00026 & 9.7 & 0.10 & 0.070 & 0.0004 \\
\hline MK4 & 0.49 & 0.016 & 0.76 & 0.031 & 15.8 & 0.154 & .0002 & 0.00008 & $<0.06$ & $<0.0$ & 2.02 & 0.02 & .0052 & 0.00036 & 0.0001 & 0.0003 & 0.0018 & 0.00047 & 72.0 & 0.98 & 0.306 & 0.0018 \\
\hline MK5 & 1.57 & 0.041 & 0.51 & 0.018 & 16.4 & 0.133 & 0017 & 0.00070 & 0.21 & 0.048 & 2.11 & 0.02 & 0.0057 & 0.00035 & 0.0002 & 0.0003 & 0.0005 & 0.00011 & 14.9 & 0.15 & 0.071 & 0.0004 \\
\hline MK6 & 0.19 & 0.006 & 0.69 & 0.030 & 15.4 & 0.156 & 0.0018 & 0.00092 & $<0.06$ & $<0.01$ & 2.81 & 0.03 & 0.0068 & 0.00047 & 0.0003 & 0.0006 & 0.0002 & 0.00007 & 1.0 & 0.01 & 0.116 & 0.0006 \\
\hline MK7 & 0.23 & 0.007 & 0.40 & 0.016 & 12.5 & 0.1 & & 0.00 & 0.28 & $0 .($ & 3.44 & 0.04 & & 0.0 & 0.0004 & & & 006 & 13.2 & 0.14 & 0.103 & 0.0006 \\
\hline $1 \mathrm{~K} 8$ & & 0.017 & 0.68 & 0.023 & & 0. & & & & & & 0. & & & 002 & & & & 11.2 & 0.13 & 0.446 & 0.0027 \\
\hline $1 \mathrm{~K} 9$ & & 0.003 & & 0.018 & 2 & 0.0 & & 0.00 & & $0 .($ & 1.99 & 0.02 & & & 0.0002 & 0.0002 & 0.0002 & 004 & 1.5 & 0.02 & 0.092 & 0.0006 \\
\hline K1 & & 0.006 & & 0.023 & 6.6 & 0.0 & 0019 & 0.000 & $<0.06$ & $<0$. & 201 & 0. & 018 & & .0095 & & & 0.00036 & 16.0 & 0.14 & 0.039 & 0.0003 \\
\hline & & 0.004 & & 0.016 & 10. & & 0061 & 0.00 & 0.80 & & 261 & 0. & 35 & 0.0 & 0.0002 & & 0.0031 & 080 & 10.3 & 0.14 & 0.045 & 0.0003 \\
\hline & & 0.012 & & 0.014 & & 0.1 & 0023 & 0.00 & 0 & 0.2 & 90 & 0. & 006 & 0.00 & .0008 & & .0007 & 018 & 14.0 & 0.18 & .091 & 0.0006 \\
\hline$V 1$ & & 0.023 & 0.60 & 0.020 & 23.7 & 0.181 & .0009 & 0.00038 & $<0.06$ & $<0.01$ & 2.88 & 0.03 & 0.0006 & 0.00004 & 0.0007 & 0.0010 & 0.0025 & 0.00050 & 11.4 & 0.11 & 0.034 & 0.0002 \\
\hline MK14 & 0.19 & 0.006 & 0.79 & 0.004 & 7.8 & 0.072 & 0.0005 & 0.00007 & 2.74 & 0.630 & 2.53 & 0.03 & 0.0001 & 0.00001 & 0.0014 & 0.0026 & 0.0002 & 0.00005 & 10.0 & 0.12 & 0.105 & 0.0006 \\
\hline
\end{tabular}


Table A3.4 (cont.) Physiological element concentrations (Con) in husk $\left(\mathrm{mg} \mathrm{kg}^{-1}\right)$ and their transfer factors $(\mathrm{TF})(\mathrm{n}=101)$

\begin{tabular}{|c|c|c|c|c|c|c|c|c|c|c|c|c|c|c|c|c|c|c|c|c|c|c|}
\hline \multirow{2}{*}{ Site } & \multicolumn{2}{|c|}{$\mathbf{N i}$} & \multicolumn{2}{|c|}{$\mathbf{P b}$} & \multicolumn{2}{|c|}{$\mathbf{R b}$} & \multicolumn{2}{|c|}{$\mathbf{S b}$} & \multicolumn{2}{|c|}{ Sn } & \multicolumn{2}{|c|}{$\mathrm{Sr}$} & \multicolumn{2}{|c|}{ Th } & \multicolumn{2}{|c|}{ Tl } & \multicolumn{2}{|c|}{$\mathbf{U}$} & \multicolumn{2}{|c|}{ Zn } & \multicolumn{2}{|c|}{$\mathbf{Z r}$} \\
\hline & Con & $\mathrm{TF}$ & Con & $\mathrm{TF}$ & Con & $\mathrm{TF}$ & Con & $\mathrm{TF}$ & Con & $\mathrm{TF}$ & Con & $\overline{\mathrm{TF}}$ & Con & $\mathrm{TF}$ & Con & $\mathrm{TF}$ & Con & $\mathrm{TF}$ & Con & $\mathrm{TF}$ & Con & $\mathrm{TF}$ \\
\hline K15 & 0.14 & 0.005 & 0.29 & 0.012 & 7.5 & 0.074 & 0.0025 & 0.00121 & 0.06 & $<0 .($ & 80 & 0.03 & 0.0075 & 0.00052 & 0.0002 & 0.0003 & 0.0016 & 00039 & 20.3 & 0.28 & 136 & 0008 \\
\hline K16 & 0.16 & 0.005 & 34 & 0.014 & 16.4 & 0.157 & 0027 & 0.00124 & & & & 0.04 & 014 & 0 & 0021 & 0.0038 & 0005 & 0.00011 & 3.4 & 0.18 & 052 & 0004 \\
\hline K17 & & 0.007 & 37 & 0.01 & & 0.22 & 0004 & 0.00020 & & $<0.0$ & & 0. & 0110 & (1) & .0010 & 0.0018 & .0038 & 0.00092 & 3.9 & 0.18 & 173 & 0.0012 \\
\hline K18 & & 0.004 & 36 & 0.012 & & 0.056 & 0002 & 0.00009 & .06 & $<0.01$ & 80 & 0.02 & 0004 & 0.00002 & .0002 & 0.0003 & .0004 & 0.00008 & 0.0 & 0.10 & .014 & 0.0001 \\
\hline K19 & 6 & 0.011 & 02 & 0.001 & 19.9 & 0.187 & 0090 & 0.00372 & 0.06 & $<0.01$ & .34 & 0.05 & 0096 & 0.00065 & 0010 & 0.0017 & .0017 & 0.00038 & 7.3 & 0.21 & .084 & 0.0006 \\
\hline $\mathrm{K} 20$ & 15 & 0.004 & 66 & 0.025 & 5.6 & 0.048 & .0008 & 0.00038 & 0.06 & $<0.01$ & 3.07 & 0.04 & 0.0012 & 0.00008 & 0.0004 & 0.0006 & .0010 & 0.00023 & 24.7 & 0.28 & 0.017 & 0.0001 \\
\hline K21 & 0.05 & 0.001 & 0.69 & 0.028 & 21.5 & 0.198 & .0041 & 0.00198 & 0.16 & 0.042 & 3.86 & 0.05 & 0.0014 & 0.00010 & 0.0001 & 0.0002 & 0.0016 & 0.00037 & 24.0 & 0.28 & 0.114 & 0.0008 \\
\hline K22 & 0.38 & 0.010 & .49 & 0.019 & 18.8 & 0.152 & .0003 & 0.00015 & $<0.06$ & $<0.01$ & 62 & 0.05 & 0.0068 & 0.00043 & 0.0033 & 0.0045 & .0010 & 0.00019 & 29.1 & 0.32 & 0.302 & 0.0020 \\
\hline K23 & 0.20 & 0.005 & 40 & 0.015 & 24.4 & 0.220 & .0002 & 0.00008 & 0.06 & $<0.0$ & .03 & 0.05 & 0.0083 & 0.00056 & .0044 & 0.0062 & .0002 & 0.00004 & 15.5 & 0.16 & .080 & 0.0006 \\
\hline K24 & 0.19 & 0.005 & & 0.013 & 9.8 & 0.163 & 0005 & 0.00024 & & $<0 .($ & 57 & 0.04 & 0.0005 & 0.00003 & 0005 & 0.0007 & .0020 & 0.00040 & 25.6 & 0.26 & .094 & 0.0007 \\
\hline K25 & & 0.004 & & 0.014 & 13.5 & 0.1 & 0035 & ( & & $<0$ & & 0.0 & & 0 & 0015 & 24 & 017 & 39 & 9.3 & 0.21 & 035 & .0002 \\
\hline K26 & 0 & 0.010 & 4 & 0.0 & 10.8 & $0 .($ & 7 & 0.00 & & $<0$ & 2 & 0. & 19 & 0.0 & 06 & 09 & 26 & 56 & 20.3 & 0.21 & 012 & 0.0001 \\
\hline 27 & & 0.003 & & 0.0 & 6.7 & 0.0 & 1 & 0.0 & 6 & $<0$ & & 0. & 24 & & 006 & 11 & 05 & 10 & 2.1 & 0.15 & 103 & 0.0006 \\
\hline K30 & ( & 0.003 & 7 & 0.006 & 17.6 & 0.1 & 245 & 0.01 & 6 & $<0$ & 2 & 0. & 0064 & 0.0 & .0002 & 0.0002 & .0041 & 091 & 0.8 & 0.11 & 0.060 & 0.0004 \\
\hline K31 & 21 & 0.006 & 26 & 0.009 & 6.5 & 0.05 & 0025 & 0.001 & 0.06 & $<0.01$ & 34 & 0. & .0002 & 0.00 & .0008 & 0.0012 & .0022 & 051 & $4.8 \quad$ & 0.46 & 0.021 & 0.0001 \\
\hline K32 & 0.16 & 0.004 & 0.13 & 0.004 & 11.8 & 0.091 & .0008 & 0.00033 & 0.06 & $<0.01$ & 4.03 & 0.05 & .0031 & 0.00020 & .0014 & 0.0020 & .0027 & 0.00054 & 11.8 & 0.12 & 0.077 & 0.0005 \\
\hline K33 & 0.09 & 0.002 & 10 & 0.003 & 12.2 & 0.092 & 0078 & 0.00 & 6 & $<0$. & 4.70 & 0.06 & & & 008 & & 138 & & 17.7 & 0.17 & .257 & .0018 \\
\hline K34 & 2 & 0.012 & & 0.015 & 7.7 & 0.06 & 0055 & 0.00285 & 6 & $<0.0$ & .13 & 0.04 & 0059 & 0.00039 & .0077 & 0.0120 & 0.0008 & 0.00019 & 14.2 & 0.16 & 0.068 & 0.0005 \\
\hline K35 & 4 & 0.006 & & 0.004 & 6.3 & $0 .($ & & 0.00 & & $<0$ & & 0.04 & & & & & & & 32.2 & 0.35 & .164 & 0.0010 \\
\hline 36 & & 0.001 & & 0.002 & 14.5 & 0. & & 0 & & $<0$ & & 0.05 & & & 90 & & & 52 & 8.5 & 0.07 & 048 & 0003 \\
\hline & & 0. & & 0.0 & & & & & & & & 0. & & & & & & & 8.8 & 0.10 & 97 & 0.0006 \\
\hline 38 & & 0.001 & & 0.012 & 2 & 0. & 5 & 0.0 & 6 & $<0$. & & 0. & 81 & & 02 & 02 & 0.0 & 007 & 4.6 & 0.16 & 0.098 & 0.0007 \\
\hline K40 & & 0.004 & 3 & 0.00 & 11.7 & 0.08 & 0037 & 0.00 & & 0. & 56 & 0 . & 0093 & 0.0 & .0007 & 0.0009 & 0.0075 & 158 & 16.7 & 0.16 & 0.160 & 0.0011 \\
\hline K41 & 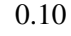 & 0.002 & 5 & 0.008 & 6.8 & 0.05 & 0.0009 & 0.00035 & 1.65 & 0.3 & 39 & 0. & 0007 & 0.00 & 0.0003 & 0.0004 & 0.0009 & 0.00019 & 8.9 & 0.08 & 0.106 & 0.0007 \\
\hline K42 & 9 & 0.005 & 0 & 0.033 & 6.8 & 0.057 & 0016 & 0.00060 & 0.45 & 0.1 & 11 & 0. & 0145 & 0.00096 & 0.0002 & 0.0003 & 0.0068 & 0.00160 & 16.2 & 0.17 & 0.265 & 0.0017 \\
\hline K43 & 0.48 & 0.019 & 1 & 0.024 & 21.5 & 0.211 & 0007 & 0.000 & 3.45 & 1.0 & 94 & 0. & 0009 & 0.0 & .0010 & 0.0018 & .0006 & 016 & 14.7 & 0.24 & 0.508 & 0.0031 \\
\hline K44 & 0.16 & 0.005 & 1 & 0.015 & 8 & 0.161 & .0011 & 0.00065 & $<0.06$ & $<0.0$ & 3.92 & 0.0 & 0020 & 0.00013 & 0.0005 & 0.0006 & 0.0225 & 0.00485 & 33.3 & 0.45 & 0.071 & 0.0005 \\
\hline K45 & 4 & 0.005 & 28 & 0.011 & 15.7 & 0.137 & 0002 & 0.00011 & & 0.38 & 4.38 & 0.0 & 0.0004 & 0.00 & 0.0007 & 0.0011 & 0.0014 & 0.00028 & 14.2 & 0.18 & 0.592 & 0.0037 \\
\hline IK46 & 0.11 & 0.005 & 0.21 & 0.010 & 19.5 & 0.162 & 0.0009 & 0.00062 & & 0.14 & 4.44 & 0.05 & 0.0024 & 0.0 & 0.0003 & 0.0006 & 0.0002 & 0.00006 & 12.9 & 0.24 & 0.443 & 0.0028 \\
\hline IK47 & 0.16 & 0.005 & 0.27 & 0.011 & 18.5 & & & & & 0.1 & 3.39 & 0.04 & & & 005 & & & & 15.2 & 0.21 & .090 & 0.0006 \\
\hline & & 0.012 & & 0.013 & & 0.2 & & & & 0. & & 0. & & & 004 & & & & 7.5 & 0.34 & .076 & 0.0005 \\
\hline & & 0.007 & & 0.016 & & 0.1 & & 0.00 & $<0.06$ & $<0.01$ & 2.18 & 0.03 & & & 0.0002 & & 0.0012 & 27 & 13.7 & 0.20 & .051 & 0.0004 \\
\hline & & 0.002 & & 0.03 & 15.7 & 0.1 & 0028 & 0.00 & & $0 .($ & 3.62 & 0. & & & .0011 & & & 0.00050 & 8.7 & 0.12 & 0.026 & 0.0002 \\
\hline & & 0.006 & & 0.014 & & & 0010 & 0.00 & 0.06 & $<0$. & & 0. & 05 & 0.0 & 0.0005 & & & 029 & 15.9 & 0.15 & 0.013 & 0.0001 \\
\hline & & 0.002 & & 0.01 & & 0.0 & 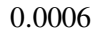 & 0.00 & 6 & $<0$. & 36 & 0. & 177 & & .0001 & & 01 & 0.00002 & 2.1 & 0.12 & .095 & 0.0007 \\
\hline & & 0.008 & 0.36 & 0.012 & 30.0 & 0.224 & .0020 & 0.00085 & 0.48 & 0.11 & 3.54 & 0.04 & 0.0035 & 0.00022 & 0.0007 & 0.0010 & 0.0063 & 0.00145 & 12.0 & 0.11 & 0.097 & 0.0007 \\
\hline MK55 & 1.72 & 0.037 & 0.41 & 0.013 & 14.4 & 0.100 & 0.0001 & 0.00003 & 0.25 & 0.06 & 3.04 & 0.04 & 0.0067 & 0.00041 & 0.0007 & 0.0010 & 0.0013 & 0.00029 & 6.1 & 0.05 & 0.015 & 0.000 \\
\hline
\end{tabular}


Table A3.4 (cont.) Physiological element concentrations (Con) in husk ( $\left.\mathrm{mg} \mathrm{kg}^{-1}\right)$ and their transfer factors (TF) $(\mathrm{n}=101)$

\begin{tabular}{|c|c|c|c|c|c|c|c|c|c|c|c|c|c|c|c|c|c|c|c|c|c|c|}
\hline \multirow{2}{*}{ Site } & \multicolumn{2}{|c|}{$\mathbf{N i}$} & \multicolumn{2}{|c|}{$\mathbf{P b}$} & \multicolumn{2}{|c|}{$\mathbf{R b}$} & \multicolumn{2}{|c|}{ Sb } & \multicolumn{2}{|c|}{ Sn } & \multicolumn{2}{|c|}{$\mathrm{Sr}$} & \multicolumn{2}{|c|}{ Th } & \multicolumn{2}{|c|}{ Tl } & \multicolumn{2}{|c|}{$\mathbf{U}$} & \multicolumn{2}{|c|}{$\mathbf{Z n}$} & \multicolumn{2}{|c|}{$\mathbf{Z r}$} \\
\hline & Con & $\mathrm{TF}$ & Con & $\mathrm{TF}$ & Con & $\mathrm{TF}$ & Con & $\mathrm{TF}$ & Con & $\mathrm{TF}$ & Con & $\mathrm{TF}$ & Con & $\mathrm{TF}$ & Con & $\mathrm{TF}$ & Con & $\mathrm{TF}$ & Con & $\mathrm{TF}$ & Con & $\mathrm{TF}$ \\
\hline K56 & 0.20 & 0.004 & 0.94 & 0.030 & 7.2 & 0.049 & 0.0017 & 0.00064 & 0.18 & 0.04 & 3.21 & 0.04 & 0.0017 & 0.00010 & 0.0001 & 0.0001 & 0.0015 & 0.00031 & 11.5 & 0.10 & 0.028 & 0.0002 \\
\hline K57 & 0.25 & 0.006 & 53 & 0.020 & 7.6 & 0.063 & 0013 & 0.00062 & $<0.06$ & $<0.0$ & .80 & 0. & 0005 & 00003 & 0003 & 0.0005 & 0020 & 0.00045 & 10.5 & 0. & 0.130 & .0009 \\
\hline K58 & 0.25 & 0.006 & 0.29 & 0.011 & 10.4 & 0.086 & .0010 & 0.00044 & 0.54 & 0.14 & 4.70 & 0.06 & .0022 & 0.00015 & 0.0009 & 0.0013 & .0014 & 0.00031 & 4.0 & 0.04 & 0.043 & 0.0003 \\
\hline K59 & 0.34 & 0.010 & 0.69 & 0.029 & 6.5 & 0.056 & 0.0016 & 0.00090 & 0.28 & 0.08 & 2.76 & 0.03 & 0.0030 & 0.00023 & 0.0016 & 0.0025 & 0.0010 & 0.00029 & 12.7 & 0.15 & 0.143 & 0.0012 \\
\hline K60 & 0.09 & 0.002 & 0.45 & 0.017 & 15.3 & 0.120 & .0002 & 0.00008 & 0.66 & 0.16 & 3.23 & 0.04 & 0.0035 & 0.00024 & 0.0001 & 0.0002 & .0008 & 0.00020 & 10.1 & 0.11 & 0.046 & .0004 \\
\hline K61 & 35 & 0.011 & 44 & 0.017 & 20.7 & 0.188 & 0059 & 0.00268 & 0.78 & 0.20 & 3.21 & 0.04 & .0014 & 0.00010 & .0005 & 0.0008 & .0007 & 0.00016 & 21.4 & 0.26 & .024 & .0002 \\
\hline K62 & 04 & 0.001 & 31 & 0.013 & 18.2 & 0.166 & 0006 & .00035 & 0.34 & 0.09 & 2.63 & 0.04 & .0038 & 0.00 & 0004 & 0.0007 & . 0011 & 0.00024 & 17.7 & 0.21 & .037 & 0.0002 \\
\hline K63 & 0 & 0.032 & 66 & 0.025 & 15.2 & 0.1 & & 0.000 & 0.98 & 0.2 & 18 & 0.0 & & & 013 & & 11 & 25 & 3.0 & 0.03 & .030 & 0.0002 \\
\hline K64 & & 0.04 & 0.54 & 0.02 & .2 & 0.1 & 3 & 0.00 & 44 & 0. & 00 & 0.0 & 52 & 0.0 & 030 & & 44 & 01 & 5.3 & 0.18 & 139 & 0.0008 \\
\hline K65 & & 0.0 & 32 & 0.012 & 1 & 0.1 & 6 & 0.00 & 0.08 & $0 .($ & 07 & 0. & 02 & 0.6 & .0001 & 01 & 15 & 31 & 3.9 & 0.1 & .014 & 0.0001 \\
\hline К & 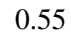 & 0.012 & .30 & 0.010 & 21.0 & 0.1 & 007 & 0.00037 & 0.43 & 0 & 3.45 & 0. & 050 & 0.0 & .0004 & 005 & 039 & 0.00084 & 15.8 & 0.13 & .212 & 0.0013 \\
\hline К67 & 23 & 0.007 & 0.21 & 0.008 & 0.6 & 0.004 & 0088 & 0.00618 & 0.29 & 0.07 & 4.80 & 0.06 & .0749 & 0.00 & .0002 & 0.0002 & 0.0121 & 0.00279 & 20.8 & 0.27 & 0.702 & 0.0042 \\
\hline К 68 & 0.18 & 0.006 & 0.30 & 0.012 & 2.2 & 0.014 & .0006 & 0.00043 & 0.08 & 0.02 & 5.02 & 0.06 & .0013 & 0.00008 & 0.0021 & 0.0029 & 0.0008 & 0.00019 & 17.1 & 0.21 & 0.102 & 0.0006 \\
\hline K69 & 0.45 & 0.014 & 0.23 & 0.009 & 3.2 & 0.021 & .0044 & 0.00304 & 0.08 & 0.02 & 3.27 & 0.04 & .0032 & 0.00019 & .0004 & 05 & 0.0010 & 0.00022 & 16.8 & 0.22 & .011 & 0.0001 \\
\hline K70 & 0.05 & 0.001 & 0.24 & 0.009 & 5.6 & 0.038 & 0023 & 0.00137 & $<0.06$ & $<0.01$ & 2.79 & 0.03 & 0017 & 0.00 & .0003 & 04 & 0.0014 & 034 & 10.4 & 0.13 & .130 & 0.0008 \\
\hline 71 & 6 & 0. & 3 & 0.012 & 5.9 & 0. & & & 13 & 0. & 16 & 0. & & & 02 & & & & 2.1 & 0.15 & 89 & 06 \\
\hline 72 & 5 & 0.025 & & 0.092 & 3.3 & 0. & & 0. & 0.58 & 0.15 & 11 & 0.0 & & & 02 & & & & .1 & 0.33 & 98 & 0.0005 \\
\hline 73 & & 0.0 & 3 & 0.0 & 6.3 & 0. & & & .06 & $<0.01$ & 54 & 0. & & & 03 & & & & 6.5 & 0.23 & 30 & 0.0002 \\
\hline 74 & & 0.01 & 2 & 0.01 & 3.2 & 0.0 & 99 & 0.0 & .06 & $<0$ & 96 & 0. & 14 & & 005 & & & 13 & 9.4 & 0.28 & .055 & 0.0003 \\
\hline K75 & 9 & 0.0 & 8 & 0.027 & 8.8 & 0.082 & 3 & 0.00 & .06 & $<0$ & 3.75 & 0. & 26 & 0.0 & 005 & 09 & $0 .($ & 16 & 16.6 & 0.25 & .107 & 0.0006 \\
\hline K76 & 0.32 & 0.008 & 26 & 0.008 & 15.5 & 0.127 & .0004 & 0.00018 & $<0.06$ & $<0.01$ & 2.46 & 0.03 & .0172 & 0.00106 & 0.0002 & 0.0003 & 0.0013 & 0.00026 & 15.6 & 0.19 & 0.027 & 0.0002 \\
\hline K77 & 6.48 & 0.170 & .54 & 0.021 & 60.9 & 0.522 & .0024 & 0.00122 & 60.06 & $<0.01$ & 1.45 & 0.02 & 0001 & 0.00001 & 0.0003 & 0.0005 & 0.0003 & 0.00007 & 16.6 & 0.14 & 0.012 & 0.0001 \\
\hline K78 & 0.29 & 0.007 & 44 & 0.016 & 15.8 & 0.126 & 0006 & 0.00028 & $<0.06$ & $<0$. & 2.98 & 0.0 & .0009 & 0.00 & 0.0003 & 04 & 0.0002 & 0.00005 & 18.6 & 0.18 & 0.187 & 0.0013 \\
\hline K79 & 0.64 & 0.013 & .86 & 0.026 & 30.7 & 0.235 & .0007 & 0.00024 & 0.06 & $<0.01$ & .93 & 0.04 & .0020 & 0.00 & 0.0006 & 0.0007 & 0.0007 & 0.00012 & 21.4 & 0.19 & 0.016 & 0.0001 \\
\hline K80 & 23 & 0.006 & .33 & 0.012 & 10.9 & 0.091 & 0059 & 0.00306 & .06 & $<0.01$ & .53 & 0. & 0018 & 0.00 & 0001 & 01 & . 0009 & 0.00019 & 17.2 & 0.20 & .032 & 0.0002 \\
\hline 81 & ( & 0.004 & 4 & 0.038 & 17.3 & 0.149 & .0001 & 0.00006 & 0.06 & $<0.01$ & 1.63 & 0.02 & 0.0010 & 0.00006 & 0.0005 & 0.0007 & 0.0002 & 0.00005 & 15.9 & 0.16 & 0.034 & 0.0002 \\
\hline MK82 & 0.21 & 0.007 & 0.30 & 0.012 & 6.5 & 0.059 & 0.0012 & 0.00078 & $<0.06$ & $<0.01$ & 1.72 & 0.02 & 0.0010 & 0.00007 & 0.0011 & 0.0017 & 0.0004 & 0.00009 & 13.8 & 0.20 & 0.036 & 0.0002 \\
\hline
\end{tabular}


Appendix A3

Table A3.5 Physiological element concentrations (Con) in whole aboveground plants $\left(\mathrm{mg} \mathrm{kg}^{-1}\right)$ and their transfer factors $(\mathrm{TF})(\mathrm{n}=23)$

\begin{tabular}{|c|c|c|c|c|c|c|c|c|c|c|c|c|c|c|c|c|c|c|c|c|c|}
\hline \multirow{2}{*}{ Site } & \multicolumn{2}{|r|}{ Al } & \multicolumn{2}{|c|}{$\mathbf{C a}$} & $\mathbf{F e}$ & \multicolumn{2}{|l|}{$\mathbf{K}$} & \multicolumn{2}{|c|}{$\mathbf{M g}$} & \multicolumn{2}{|c|}{ Mn } & \multicolumn{2}{|c|}{$\mathrm{Na}$} & \multicolumn{2}{|c|}{$\mathbf{P}$} & \multicolumn{2}{|l|}{$\bar{S}$} & \multicolumn{2}{|c|}{$\overline{\text { As }}$} & \multicolumn{2}{|c|}{$\mathbf{B a}$} \\
\hline & Con & $\mathrm{TF}$ & Con & $\mathrm{TF}$ & Con & Con & $\mathrm{TF}$ & Con & $\mathrm{TF}$ & Con & $\mathrm{TF}$ & Con & $\mathrm{TF}$ & Con & $\mathrm{TF}$ & Con & $\mathrm{TF}$ & Con & $\mathrm{TF}$ & Con & $\mathrm{TF}$ \\
\hline$\overline{\mathrm{H} 1}$ & 7 & 0.00008 & 2685 & 1.22 & 1880.0049 & 18401 & 0.83 & 1229 & 0.19 & 378 & 1.44 & 74 & 0.028 & 2911 & 4.08 & 1608 & 2.87 & 3.27 & 0.26 & 67 & 0.14 \\
\hline H5 & $<4$ & $<0.00005$ & 1667 & 0.78 & 530.0013 & 9980 & 0.48 & 2262 & 0.36 & 437 & 1.56 & 630 & 0.195 & 1963 & 3.94 & 946 & 1.97 & 1.57 & 0.09 & 53 & 0.11 \\
\hline H6 & $<4$ & $<0.00005$ & 2539 & 1.13 & 440.0016 & 9028 & 0.53 & 2888 & 0.59 & 630 & 2.65 & 43 & 0.015 & 1828 & 4.42 & 2104 & 7.06 & 0.49 & 0.04 & 61 & 0.15 \\
\hline $\mathrm{H} 7$ & $<4$ & $<0.00005$ & 1424 & 0.70 & 650.0022 & 13053 & 0.72 & 1515 & 0.28 & 291 & 1.25 & 202 & 0.068 & 2175 & 5.81 & 1821 & 5.07 & 1.63 & 0.13 & 65 & 0.15 \\
\hline HN1 & 45 & 0.00060 & 2838 & 0.34 & 880.0022 & 18963 & 0.90 & 2230 & 0.25 & 544 & 0.91 & 368 & 0.069 & 2905 & 3.44 & 1465 & 2.38 & 4.89 & 0.27 & 42 & 0.10 \\
\hline $\mathrm{HN} 2$ & $<4$ & $<0.00005$ & 2669 & 0.38 & 240.0007 & 15408 & 0.86 & 1650 & 0.22 & 210 & 0.29 & 43 & 0.008 & 2673 & 3.49 & 1026 & 6.28 & 0.96 & 0.06 & 27 & 0.07 \\
\hline $\mathrm{H}$ & $<4$ & $<0.00005$ & 2478 & 0.39 & 410.0013 & 15504 & 0.85 & 1847 & 0.24 & 195 & 0.39 & 152 & 0.028 & 2657 & 3.42 & 1054 & 3.31 & 1.63 & 0.11 & 19 & 0.05 \\
\hline $\mathrm{H}$ & $<4$ & $<0.00005$ & 2839 & 0.56 & 150.0004 & 12915 & 0.66 & 1950 & 0.23 & 271 & 0.52 & 13 & 0.002 & 2288 & 2.69 & 1257 & 2.91 & 0.61 & 0.03 & 39 & 0.10 \\
\hline HN6 & $<4$ & .00005 & 1750 & 0.44 & 270.0006 & 19756 & 0.91 & 1459 & 0.16 & 330 & 0.41 & 48 & 0.009 & 1731 & 2.52 & 928 & 3.28 & .11 & 0.05 & 42 & 0.10 \\
\hline $\mathrm{HN}^{\prime}$ & $<4$ & .00005 & 1993 & 0.63 & 450.0010 & 16476 & 0.69 & 1641 & 0.17 & 314 & 0.93 & 102 & 0.021 & 1748 & 2.96 & 1090 & 3.27 & 0.72 & 0.04 & 29 & 0.07 \\
\hline $\mathrm{HN} \varepsilon$ & $<4$ & $<0.00005$ & 2007 & 0.68 & 230.0005 & 11709 & 0.50 & 1717 & 0.18 & 413 & 1.21 & 72 & 0.014 & 1402 & 2.34 & 1133 & 3.18 & 0.52 & 0.03 & 51 & 0.14 \\
\hline HN9 & $<4$ & $<0.00005$ & 2263 & 0.64 & 420.0010 & 16344 & 0.70 & 1845 & 0.19 & 532 & 1.62 & 35 & 0.007 & 2200 & 2.28 & 1086 & 2.74 & 1.92 & 0.12 & 60 & 0.13 \\
\hline N10 & $<4$ & $<0.00005$ & 1909 & 0.77 & 180.0003 & 17758 & 0.87 & 1667 & 0.35 & 1072 & 5.16 & 24 & 0.008 & 2291 & 3.13 & 1644 & 1.65 & 0.79 & 0.03 & 29 & 0.08 \\
\hline HN11 & $<4$ & $<0.00005$ & 1850 & 0.41 & 200.0005 & 21401 & 0.91 & 1543 & 0.16 & 250 & 0.39 & 54 & 0.010 & 2468 & 1.96 & 1215 & 4.84 & 1.40 & 0.06 & 26 & 0.06 \\
\hline PT1 & $<4$ & $<0.00005$ & 2066 & 0.44 & 270.0011 & 16857 & 1.45 & 1808 & 0.42 & 498 & 1.53 & 58 & 0.010 & 2210 & 2.35 & 1301 & 7.17 & 0.30 & 0.03 & 56 & 0.18 \\
\hline 10 & 7 & 0.000112 & 1416 & 0.18 & 170.0005 & 18384 & 0.96 & 1696 & 0.19 & 159 & 0.29 & 98 & 0.013 & 2117 & 2.00 & 947 & 2.07 & 0.84 & 0.04 & 57 & 0.13 \\
\hline PT4 & $<4$ & $<0.00005$ & 2288 & 0.21 & 610.0015 & 17444 & 0.84 & 1647 & 0.16 & 47 & 0.06 & 11 & 0.001 & 1806 & 2.02 & 1166 & 6.47 & 0.16 & 0.00 & 25 & 0.05 \\
\hline PT6 & $<4$ & .00005 & 1336 & 0.45 & 380.0 & 113 & 1.00 & 2335 & 0.53 & 293 & 0.68 & 663 & 0.286 & 2848 & 4.79 & 1330 & 2.02 & 1.84 & 0.07 & 33 & 0.16 \\
\hline$P 1$ & $<4$ & $<0.00005$ & 3681 & 1.11 & 510.0 & 985 & 1.33 & 2307 & 0.68 & 177 & 0.61 & 153 & 0.078 & 2920 & 4.77 & 1904 & 2.87 & 2.38 & 0.13 & 6 & 0.16 \\
\hline P1 & 7 & 0.000111 & 1855 & 0.26 & 450.0 & 15498 & 0.83 & 1845 & 0.24 & 262 & 0.50 & 73 & 0.011 & 2728 & 2.58 & 1326 & 2.44 & 1.92 & 0.08 & 52 & 0.12 \\
\hline & $<4$ & .00005 & 2668 & 0.18 & 280.0008 & 14197 & 0.77 & 1445 & 0.16 & 174 & 0.24 & 40 & 0.006 & 2211 & 1.65 & 1304 & 2.85 & 1.06 & 0.04 & 31 & 0.07 \\
\hline $\mathrm{P}$ & $<4$ & .00005 & 2603 & 0.50 & 800.0016 & 20642 & 0.83 & 1499 & 0.15 & 184 & 0.28 & 705 & 0.159 & 2634 & 3.19 & 1465 & 0.26 & 0.36 & 0.02 & 77 & 0.17 \\
\hline PT11 & $<4$ & $<0.00005$ & 2707 & 0.50 & 130.0003 & 14594 & 0.69 & 1862 & 0.29 & 311 & 0.54 & 70 & 0.022 & 2016 & 2.36 & 1474 & 2.54 & 0.53 & 0.03 & 53 & 0.14 \\
\hline
\end{tabular}


Appendix A3

Table A3.5 (cont.) Physiological element concentrations (Con) in whole aboveground plants $\left(\mathrm{mg} \mathrm{kg}^{-1}\right)$ and their transfer factors $(\mathrm{TF})(\mathrm{n}=23)$

\begin{tabular}{|c|c|c|c|c|c|c|c|c|c|c|c|c|c|c|c|c|c|c|c|c|c|c|}
\hline \multirow{2}{*}{ Site } & \multicolumn{2}{|c|}{$\mathbf{B i}$} & \multicolumn{2}{|c|}{ Cd } & \multicolumn{2}{|c|}{$\mathrm{Ce}$} & \multicolumn{2}{|c|}{ Co } & \multicolumn{2}{|c|}{$\mathrm{Cr}$} & \multicolumn{2}{|c|}{ Cs } & \multicolumn{2}{|c|}{$\mathrm{Cu}$} & \multicolumn{2}{|c|}{ Hf } & \multicolumn{2}{|c|}{ La } & \multicolumn{2}{|c|}{$\mathbf{L i}$} & \multicolumn{2}{|c|}{ Mo } \\
\hline & Con & TF & Con & TF & Con & TF & Con & TF & Con & TF & Con & TF & Con & $\mathrm{TF}$ & Con & $\mathrm{TF}$ & Con & $\mathrm{TF}$ & Con & $\mathrm{TF}$ & Con & TF \\
\hline H1 & 0.009 & 0.012 & 0.206 & 0.60 & 0.087 & 0.00084 & 0.581 & 0.033 & 0.46 & 0.010 & 0.15 & 0.019 & 2.91 & 0.08 & 0.012 & 0.0035 & 0.043 & 0.0009 & 0.055 & 0.0018 & 0.82 & 0.74 \\
\hline H5 & 0.002 & 0.004 & 0.498 & 2.27 & 0.110 & 0.00123 & .342 & 0.024 & 0.35 & 0.008 & 0.43 & 0.066 & 56 & 0.12 & 0.003 & 0.0008 & 0.053 & 0.0012 & 0.024 & 0.0008 & .29 & 0.24 \\
\hline H6 & 0.002 & 0.006 & 0.213 & 1.12 & .164 & 0.00260 & 8 & 0.046 & .38 & 0.012 & 1.68 & 0.344 & 71 & 0.2 & 0.001 & 0.0003 & .087 & 0.0025 & 0.070 & 0.0033 & 0.74 & 0.91 \\
\hline $\mathrm{H} 7$ & 0.005 & 0.011 & 103 & 0.51 & 0.048 & 0.00071 & .306 & 0.028 & 0.40 & 0.012 & 0.62 & 0.114 & 2 & 0.1 & 0.001 & 0.0002 & 0.025 & 0.0007 & .053 & 0.0023 & 0.73 & 0.80 \\
\hline HN1 & 0.010 & 0.020 & 0.075 & 0.22 & 0.094 & 0.00116 & 0.091 & 0.005 & 0.84 & 0.014 & 0.22 & 0.025 & 8 & 0.06 & 0.001 & 0.0001 & 0.040 & 0.0010 & 0.069 & 0.0016 & 0.53 & 0.76 \\
\hline HN2 & 0.006 & 0.013 & 0.041 & 0.14 & 0.409 & 0.00518 & 0.070 & 0.005 & 0.60 & 0.012 & 0.19 & 0.027 & 3.82 & 0.11 & 0.003 & 0.0006 & 0.218 & 0.0055 & 0.012 & 0.0003 & 0.51 & 1.24 \\
\hline $\mathrm{HN} 3$ & 0.008 & 0.017 & 0.043 & 0.13 & 0.025 & 0.00036 & 0.072 & 0.005 & 0.45 & 0.009 & 0.24 & 0.034 & 2.57 & 0.07 & 0.005 & 0.0011 & 0.010 & 0.0003 & 0.063 & 0.0017 & 1.11 & 2.62 \\
\hline HN5 & 0.004 & 0.009 & 0.071 & 0.19 & 0.033 & 0.00042 & 0.056 & 0.003 & 0.38 & 0.006 & 0.04 & 0.005 & 3.61 & 0.09 & 0.004 & 0.0010 & 0.037 & 0.0009 & $<0.006<$ & $<0.0001$ & 0.36 & 0.69 \\
\hline HN6 & 0.005 & 0.012 & 0.219 & 0.59 & 0.011 & 0.00012 & 0.098 & 0.005 & 0.48 & 0.007 & 0.05 & 0.005 & 2.03 & 0.05 & 0.006 & 0.0012 & 0.047 & 0.0011 & 0.014 & 0.0003 & .49 & 0.73 \\
\hline HN7 & 0.004 & 0.009 & 0.228 & 0.70 & 0.022 & 0.00024 & 0.068 & 0.004 & 0.48 & 0.006 & 0.04 & 0.004 & 2. & 0.07 & 0.005 & 0.0010 & 0.013 & 0.0003 & 0.010 & 0.0002 & .48 & 0.76 \\
\hline HN8 & 0.003 & 0.007 & 0.535 & 1.74 & 0.044 & 0.00046 & 0.056 & 0.003 & 0.64 & 0.008 & & 0.007 & & 0.07 & 0.007 & 0.0015 & 0.004 & 0.0001 & 0.046 & 0.0009 & .26 & 0.44 \\
\hline HN9 & 0.006 & 0.010 & 0.785 & 2.12 & 0.037 & 0.00039 & 0.0 & 0.005 & 0.34 & 0.004 & 0.02 & 0.001 & 3.59 & 0.0 & 0.002 & 0.0003 & 0.020 & 0.0004 & 0.011 & 0.0002 & 0.30 & 0.57 \\
\hline IN1C & 0.002 & 0.004 & 1.892 & 5.87 & 0.036 & 0.00 & 0. & 0.0 & 0.40 & 0.00 & 0.07 & 0.0 & 4.82 & 0. & 0.004 & 0.0008 & 0.010 & 0.0002 & 0.033 & 0.0008 & .15 & 0.11 \\
\hline HN11 & 0.004 & 0.006 & 0.096 & 0.30 & 0.032 & 0.00037 & 0.078 & 0.004 & 0.46 & 0.007 & 0.01 & 0.001 & 4.07 & 0.0 & 0.003 & 0.0006 & 0.016 & 0.0004 & $<0.006<$ & $<0.0001$ & 0.88 & 1.27 \\
\hline PT1 & 0.003 & 0.008 & 0.254 & 1.06 & 0.004 & 0.00006 & 0.037 & 0.005 & 0.37 & 0.012 & 0.07 & 0.023 & 3.93 & 0.1 & 0.003 & 0.0006 & 0.001 & 0.0000 & 0.052 & 0.0028 & 0.99 & 2.14 \\
\hline PT3 & 0.002 & 0.002 & 0.062 & 0.13 & 0.004 & 0.00004 & 0.054 & 0.004 & 0.44 & 0.009 & 0.12 & 0.020 & 3.60 & 0.07 & 0.004 & 0.0008 & 0.005 & 0.0001 & 0.024 & 0.0007 & 0.64 & 0.83 \\
\hline PT4 & 0.002 & 0.001 & 0.063 & 0.11 & 0.047 & 0.00043 & 0.033 & 0.002 & 0.35 & 0.006 & 0.15 & 0.023 & 8.53 & 0.10 & 0.001 & 0.0004 & 0.051 & 0.0010 & 0.034 & 0.0010 & 0.64 & 0.47 \\
\hline PT6 & 0.005 & 0.009 & 0.039 & 0.10 & 0.069 & 0.00114 & 0.103 & 0.009 & 0.54 & 0.004 & 0.26 & 0.055 & 1.25 & 0.02 & 0.002 & 0.0012 & 0.190 & 0.0058 & 0.088 & 0.0039 & 0.15 & 0.07 \\
\hline PT7 & 0.006 & 0.011 & 0.047 & 0.23 & 0.054 & 0.00070 & 0.222 & 0.028 & 0.37 & 0.003 & 0.29 & 0.077 & 1.27 & 0.03 & 0.001 & 0.0006 & 0.027 & 0.0007 & 0.051 & 0.0027 & 0.36 & 0.15 \\
\hline PT8 & 0.005 & 0.004 & 0.100 & 0.22 & 0.010 & 0.00013 & 0.173 & 0.012 & 0.43 & 0.007 & 0.06 & 0.009 & 2.55 & 0.05 & 0.004 & 0.0010 & 0.007 & 0.0002 & 0.020 & 0.0006 & 0.77 & 0.89 \\
\hline PT9 & 0.005 & 0.004 & 0.054 & 0.11 & 0.035 & 0.00043 & 0.054 & 0.004 & 0.46 & 0.008 & 0.02 & 0.003 & 2.53 & 0.0 & 0.001 & 0.0004 & 0.020 & 0.0005 & 0.013 & 0.0004 & 0.73 & 0.93 \\
\hline PT10 & 0.004 & 0.006 & 0.024 & 0.05 & 0.010 & 0.00010 & 0.07 & 0.004 & 0.48 & 0.005 & 0.0 & 0.004 & 2.80 & 0.0 & 0.005 & 0.0011 & 0.006 & 0.0001 & $<0.006$ & $<0.0001$ & 0.14 & 0.11 \\
\hline PT11 & 0.005 & 0.007 & 0.195 & 0.40 & 0.030 & 0.00029 & 0.063 & 0.004 & 0.32 & 0.005 & 0.02 & 0.002 & 2.74 & 0.07 & 0.005 & 0.0013 & 0.031 & 0.0007 & 0.006 & 0.0002 & 0.39 & 0.38 \\
\hline
\end{tabular}


Appendix A3

Table A3.5 (cont.) Physiological element concentrations (Con) in whole aboveground plants $\left(\mathrm{mg} \mathrm{kg}^{-1}\right)$ and their transfer factors $(\mathrm{TF})(\mathrm{n}=23)$

\begin{tabular}{|c|c|c|c|c|c|c|c|c|c|c|c|c|c|c|c|c|c|c|c|c|c|c|}
\hline \multirow{2}{*}{ Site } & \multicolumn{2}{|c|}{$\mathbf{N i}$} & \multicolumn{2}{|c|}{$\mathbf{P b}$} & \multicolumn{2}{|c|}{$\mathbf{R b}$} & \multicolumn{2}{|c|}{ Sb } & \multicolumn{2}{|c|}{ Sn } & \multicolumn{2}{|c|}{$\mathrm{Sr}$} & \multicolumn{2}{|c|}{ Th } & \multicolumn{2}{|c|}{ Tl } & \multicolumn{2}{|c|}{$\mathbf{U}$} & \multicolumn{2}{|c|}{ Zn } & \multicolumn{2}{|c|}{$\mathrm{Zr}$} \\
\hline & Con & $\mathrm{TF}$ & Con & $\mathrm{TF}$ & Con & $\mathrm{TF}$ & Con & $\mathrm{TF}$ & Con & $\mathrm{TF}$ & Con & $\mathrm{TF}$ & Con & $\mathrm{TF}$ & Con & $\mathrm{TF}$ & Con & $\mathrm{TF}$ & Con & $\mathrm{TF}$ & Con & $\mathrm{TF}$ \\
\hline H1 & 0.58 & 0.016 & 0.20 & 0.005 & 45 & 0.34 & 0.007 & 0.004 & $<0.06$ & $<0.01$ & 7.2 & 0.18 & 0.001 & 0.00005 & 0.011 & 0.016 & 0.0057 & 0.0011 & 51 & 0.45 & 0.05 & 0.0005 \\
\hline $\mathrm{H} 5$ & 0.42 & 0.013 & 0.12 & 0.004 & 87 & 0.71 & 0.005 & 0.003 & $<0.06$ & $<0.01$ & 7.6 & 0.18 & 0.001 & 0.00004 & 0.069 & 0.109 & 0.0015 & 0.0003 & 51 & 0.60 & 0.02 & 0.0002 \\
\hline H6 & 1.92 & 0.089 & 0.21 & 0.009 & 115 & 1.18 & 0.004 & 0.003 & $<0.06$ & $<0.01$ & 12.6 & 0.32 & 0.001 & 0.00004 & 0.147 & 0.301 & 0.0006 & 0.0002 & 28 & 0.43 & 0.01 & 0.0001 \\
\hline $\mathrm{H} 7$ & .49 & 0.020 & 0.05 & 0.002 & 118 & 1.12 & 0.004 & 0.003 & $<0.06$ & $<0.01$ & 6.3 & 0.16 & 0.001 & 0.00005 & 0.043 & 0.082 & 0.0026 & 0.0007 & 36 & 0.51 & 0.04 & 0.0004 \\
\hline N1 & 36 & 0.008 & 0.51 & 0.014 & 7 & 0.06 & 0.039 & 0.021 & $<0.06$ & $<0.01$ & 9.7 & 0.12 & 0.004 & 0.00023 & 0.006 & 0.010 & .0560 & 0.0148 & 21 & 0.22 & 0.06 & 0.0004 \\
\hline $\mathrm{H} 2$ & 33 & 009 & 0.32 & 0.010 & 30 & 0.27 & 014 & 0.008 & $<0.06$ & $<0.01$ & 7.9 & 0.10 & 025 & 0.00157 & 0.006 & 0.011 & 0.0010 & 0.0003 & 31 & 0.37 & 0.10 & 0.0006 \\
\hline 3 & 17 & 005 & 0.51 & 0.015 & 23 & 0.20 & .021 & 0.013 & 0.07 & 0.02 & 8.0 & 0.10 & .004 & 0.00028 & 0.009 & 0.017 & 0.0012 & 0.0004 & 23 & 0.23 & 0.07 & 0.0006 \\
\hline $\mathrm{HN}$ & 29 & 007 & 26 & 0.008 & 21 & 0.18 & 008 & 0.004 & $<0.06$ & $<0.01$ & 3 & 0.1 & .004 & 0.00029 & 0.003 & 0.006 & 0.0009 & 0.0003 & 25 & 0.25 & 0.07 & 0.0005 \\
\hline N6 & 33 & 0.007 & 0.38 & 0.010 & 40 & 0.31 & .013 & 0.006 & 0.06 & $<0$. & .7 & 0.0 & .003 & 0.00019 & 0.006 & 0.011 & 0.0022 & 0.0006 & 35 & 0.36 & 0.53 & 0.0035 \\
\hline HN7 & 32 & 0.006 & 0.33 & 0.008 & 32 & 0.23 & 0.010 & 0.005 & $<0.06$ & $<0.01$ & 4.7 & 0.06 & 0.002 & 0.00011 & 0.006 & 0.009 & 0.0013 & 0.0003 & 35 & 0.33 & 0.02 & 0.0002 \\
\hline IN8 & 48 & 0.010 & 0.44 & 0.010 & 30 & 0.21 & 0.009 & 0.004 & $<0.06$ & $<0.01$ & 6.2 & 0.08 & 0.001 & 0.00005 & 0.007 & 0.010 & 0.0005 & 0.0001 & 27 & 0.26 & 0.69 & 0.0045 \\
\hline HN9 & 55 & 0.011 & 0.65 & 0.014 & 13 & 0.09 & 0.012 & 0.006 & 4.22 & 0.95 & 6.8 & 0.08 & .002 & 0.00010 & 0.004 & 0.006 & 0.0021 & 0.0005 & 45 & 0.40 & 0.33 & 0.0022 \\
\hline HN10 & 0.85 & 0.024 & 0.30 & 0.008 & 33 & 0.24 & 0.004 & 0.001 & 1.52 & 0.32 & 5.2 & 0.06 & 0.002 & 0.00009 & 0.004 & 0.005 & 0.0014 & 0.0003 & 20 & 0.23 & 0.05 & 0.0003 \\
\hline IN11 & 57 & 0.012 & 0.81 & 0.019 & 20 & 0.14 & 0.009 & 0.005 & 0.69 & 0.13 & 4.0 & 0.05 & .013 & 0.00078 & 0.006 & 0.008 & 0048 & 0.0013 & 37 & 0.28 & 0.20 & 0.0014 \\
\hline $\mathrm{T} 1$ & 67 & 0.036 & 0.36 & 0.009 & 82 & 1.27 & 083 & 0.080 & .06 & $<0.01$ & 7.5 & 0. & 023 & 0.0 & 0.008 & 0.024 & .0015 & 0.0005 & 42 & 0.60 & 0.11 & 0.0008 \\
\hline 1. & 14 & .004 & 0.13 & 0.002 & 109 & 1.03 & 0.005 & 0.003 & .06 & $<0.01$ & 5.2 & 0.06 & 05 & 0.0 & 0.016 & 0.031 & 12 & 04 & 24 & 0.23 & 0.01 & 0.0001 \\
\hline T4 4 & 54 & 0.014 & 0.28 & 0.003 & 21 & 0.18 & 0.007 & 0.002 & $<0.06$ & $<0$. & 4.5 & 0.04 & 41 & 0.0 & 0.004 & 0.007 & 003 & 01 & 25 & 0.19 & 0.04 & 0.0003 \\
\hline РТ6 & 17 & 0.006 & 0.35 & 0.006 & 56 & 0.86 & 0.016 & 0.012 & $<0.06$ & $<0.01$ & 5.1 & 0.15 & 0.108 & 0.0 & 0.007 & 0.019 & .0034 & 0.0009 & 16 & 0.12 & 0.12 & 0.0019 \\
\hline РT7 & 43 & 0.019 & 0.45 & 0.009 & 39 & 0.80 & 0.015 & 0.013 & $<0.06$ & $<0.01$ & 11.0 & 0.37 & 0.002 & 0.0 & 0.005 & 0.017 & 0017 & 0.0004 & 18 & 0.21 & 0.05 & 0.0011 \\
\hline РТ8 & 16 & 005 & 0.32 & 0.004 & 40 & 0.38 & 0.012 & 0.005 & $<0.06$ & $<0.01$ & 6.2 & 0.06 & 0.003 & 0.00019 & 0.006 & 0.011 & 0.0009 & 0.0003 & 41 & 0.37 & 0.04 & 0.0004 \\
\hline PT9 & 12 & 004 & 0.40 & 0.005 & 25 & 0.23 & 0.012 & 0.006 & $<0.06$ & $<0.01$ & 8.1 & 0.08 & 0.000 & 0.00002 & 0.006 & 0.011 & 0.0016 & 0.0005 & 28 & 0.22 & 0.01 & 0.0001 \\
\hline PT1 & 49 & 0.009 & 0.38 & 0.008 & 11 & 0.08 & 0.011 & 0.006 & 2.16 & 0.41 & 10.0 & 0.13 & 0.002 & 0.00009 & 0.003 & 0.004 & 0.0080 & 0.0019 & 14 & 0.09 & 0.26 & 0.0019 \\
\hline PT11 & 0.21 & 0.006 & 0.57 & 0.011 & 23 & 0.17 & 0.008 & 0.003 & 1.64 & 0.24 & 6.4 & 0.15 & 0.003 & 0.00014 & 0.005 & 0.008 & 0.0005 & 0.0001 & 36 & 0.29 & 0.03 & 0.0002 \\
\hline
\end{tabular}


Table A3.6 Indexes of non-cancer risk (HI) and cancer risk ( $\left.\sum \mathrm{ILCR}\right)$ assessment in the river areas $(\mathrm{n}=101)$

\begin{tabular}{|c|c|c|c|c|c|c|c|c|c|c|c|c|c|c|c|c|c|c|c|c|c|}
\hline \multirow{2}{*}{ Site } & \multirow{2}{*}{ Area } & \multicolumn{3}{|c|}{ As } & \multicolumn{2}{|l|}{ Cd } & \multicolumn{2}{|c|}{ Co } & \multicolumn{2}{|c|}{$\mathbf{C u}$} & \multicolumn{2}{|c|}{ Mn } & \multicolumn{2}{|l|}{ Mo } & \multicolumn{2}{|l|}{$\mathrm{Ni}$} & \multicolumn{3}{|c|}{$\mathbf{P b}$} & \multirow{2}{*}{ HI } & \multirow{2}{*}{$\sum$ ILCR } \\
\hline & & CDI & THQ & ILCR & CDI & THQ & CDI & THQ & CDI & THQ & CDI 1 & $\overline{\Gamma \mathrm{HQ}}$ & CDI & THQ & $\begin{array}{ll}\text { CDI } \\
\end{array}$ & THQ & CDI & THQ & ILCR & & \\
\hline 11 & Huong & 0.0026 & 1.30 & 0.0039 & 0.00077 & 2.19 & 0.0005 & 0.35 & 0.023 & 0.12 & 0.16 & 0.81 & 0.0046 & 0.11 & 0.0051 & 0.26 & 0.0002 & 0.10 & 0.000001 & 5.2 & 0.00 \\
\hline 5 & Huong & .0026 & 1.29 & 0.0039 & 00056 & 1.59 & 0005 & 0.33 & 029 & 0.15 & 18 & 90 & 0037 & 0.09 & 0029 & 0.15 & .0002 & $<0.1$ & 000001 & $J$ & 39 \\
\hline 6 & Huong & 0010 & 0.50 & 0.0015 & 0096 & 2.73 & 0010 & 0.68 & 036 & 0.18 & 0.20 & 1.01 & 0059 & 0.15 & 0171 & 0.86 & 0.0002 & $<0$. & 000 & 1 & \\
\hline 7 & Huong & 0021 & 1.07 & 0.0032 & 00033 & 0.93 & 0.0005 & 0.32 & .021 & 0.11 & 0.18 & 0.89 & 0.0070 & 0.18 & 0.0040 & 0.20 & $<0.0002$ & $<0.1$ & 0.000001 & 3.7 & 0.0032 \\
\hline IN1 & Red & 0026 & 1.31 & 0.0039 & 0.00004 & 0.10 & 0.0001 & 0.05 & .013 & 0.06 & 0.14 & 0.69 & .0033 & 0.08 & 0.0004 & 0.02 & $<0.0002$ & $<0.1$ & 0.000001 & 2.3 & 0.003 \\
\hline IN2 & Red & 0012 & 0.61 & 0.0018 & 00009 & 0.25 & 0002 & 0.14 & 035 & 0.17 & 0.17 & 0.87 & 0040 & 0.10 & 0.0028 & 0.14 & $<0.0002$ & $<0.1$ & 0.000001 & .3 & 0.001 \\
\hline N3 & $\operatorname{Rec}$ & 020 & 1.02 & 0.0031 & 0007 & 0.20 & 0001 & 0.10 & 024 & 0.12 & 0.15 & 0.75 & 0099 & 0.25 & .0009 & 0.04 & 0.0002 & $<0.1$ & 0.000001 & .5 & .0031 \\
\hline N5 & $\mathrm{Re}$ & 010 & 0.52 & 0.0015 & 0026 & 0.74 & 02 & 0.10 & 32 & 0. & 0.18 & 0.88 & 0036 & 0.09 & 0026 & 0.13 & 0002 & $<0.1<$ & .00000 & .6 & 5 \\
\hline N6 & $\operatorname{Re}$ & & 0.86 & 0.0026 & 9 & 2.82 & 002 & 0.10 & 016 & 0. & 0.22 & 1.12 & 056 & 0. & .0034 & 0.17 & 0.0002 & $<0.1<$ & 0.000001 & 3 & 0026 \\
\hline N7 & R & 3 & 0.63 & 00 & 97 & 2.78 & 01 & 0.08 & 26 & 0.13 & 17 & 0.86 & 154 & 0. & 33 & 0.17 & 002 & $<0.1$ & 0.000 & 8 & 01 \\
\hline N8 & $\mathrm{R}$ & 08 & 0.41 & 0.00 & 202 & 5.77 & 001 & 0.04 & 29 & 0. & 15 & 0.16 & 034 & 0.09 & 0.0068 & 0.34 & 0.0002 & $<0.1$ & 0.00000 & 5 & .0012 \\
\hline N9 & $\mathrm{Re}$ & 021 & 1.04 & 0.0031 & 0247 & 7.05 & 002 & 0.10 & 30 & 0.1 & 0.22 & 1.12 & 042 & 0.10 & 0.0048 & 0.24 & $<0.0002$ & $<0$. & 00000 & 9.8 & 003 \\
\hline N10 & $\mathrm{R}$ & 014 & 0.72 & 0.0021 & 0738 & 21.1 & 0002 & 0.16 & 034 & 0.1 & 0.35 & 1.74 & 0017 & 0.04 & 0.0078 & 0.39 & $<0.0002$ & $<0.1<$ & 00001 & 24.3 & 0.0021 \\
\hline N11 & $\operatorname{Rec}$ & 0016 & 0.78 & 0.0023 & 0038 & 1.09 & 0.0002 & 0.11 & .032 & 0.16 & 0.20 & 1.00 & .0068 & 0.17 & 0.0024 & 0.12 & $<0.0002$ & $<0.1<$ & 0.000001 & 3.4 & 0.0023 \\
\hline $\mathrm{T} 1$ & $\operatorname{Re}$ & 0010 & 0.49 & 0.0015 & 00113 & 3.24 & 0.0001 & 0.04 & 033 & 0.1 & 0.18 & 0.92 & .0072 & 0.18 & 0.0064 & 0.32 & 0.0002 & $<0.1<$ & 0.0000 & .4 & 0015 \\
\hline$\Gamma 3$ & Re & & 0.99 & 0.0030 & 0023 & 0.66 & 0001 & 0.06 & 033 & 0.16 & 0.13 & 0.66 & 065 & 0.16 & 10 & 0.05 & & $<0.1<$ & .000001 & .7 & 0030 \\
\hline$[4$ & $\mathrm{Re}$ & & 0.48 & 0 & & 0.64 & & 0.08 & & & & 0.44 & & 14 & & 0.32 & & $<0.1<$ & & 4 & \\
\hline Г6 & Re & & 0.99 & 0.00 & & 0.06 & & 0.03 & & & & 0.65 & 5 & 0.04 & & 0.01 & & $.1<$ & & 8 & \\
\hline$\Gamma 7$ & $\mathrm{R}$ & & 1.29 & 0.0 & & 0.0 & & 0.03 & & & 14 & 0.69 & 19 & 0. & 04 & 0.02 & 02 & $<0.1<$ & & 2 & 003 \\
\hline Г8 & $\mathrm{R}$ & 1 & 1.05 & .00 & 31 & 0.8 & 02 & 0.1 & 1 & 0. & 18 & 0.9 & 91 & 0.2 & 0.0006 & 0.03 & $<0.0002$ & $<0.1$ & 0.0000 & 3 & .003 \\
\hline T9 & $\mathrm{R}$ & 17 & 0.87 & 0.0026 & 020 & 0.5 & 0001 & 0.07 & 022 & 0. & 0.14 & 0.6 & 0090 & 0.2 & 0.0006 & 0.03 & $<0.0002$ & $<0.1<<$ & 0000 & .6 & 002 \\
\hline T10 & $\mathrm{Re}$ & 012 & 0.61 & 0.0018 & 0.00002 & 0.05 & 0.0000 & 0.02 & .007 & 0.0 & 0.12 & 0.61 & .0014 & 0.0 & 0.0006 & 0.03 & $<0.0002$ & $<0.1<$ & 0.00000 & .4 & 0.0018 \\
\hline PT11 & $\operatorname{Re}$ & 0010 & 0.52 & 0.0016 & 0060 & 1.71 & 0001 & 0.07 & 024 & 0.1 & 0.16 & 0.8 & 0036 & 0.0 & 0.0016 & 0.08 & $<0.0002$ & $<0.1<$ & 0.000001 & .4 & 0.0016 \\
\hline MK-1 & Mekor & 0008 & 0.38 & 0.0011 & 0002 & 0.06 & 0.0001 & 0.05 & 021 & 0.1 & 0.12 & 0.58 & 0031 & 0.0 & 0.0007 & 0.04 & 0.0012 & 0.80 & 0.000 & .1 & 0.0011 \\
\hline IK-2 & Mekong & 0012 & 0.58 & 0.0017 & 0049 & 1.41 & 0001 & 0.06 & 021 & 0.1 & 17 & 0.8 & 0078 & 0.2 & .0012 & 0.06 & .0025 & 1.69 & 0.0000 & .9 & 0.0018 \\
\hline $4 \mathrm{~K}$ & & 009 & 0.44 & 0013 & & 0.4 & 01 & 0.07 & 24 & & 16 & 0. & 25 & 0. & 16 & 0.08 & 09 & 0.61 & 0 & .6 & 013 \\
\hline IK-4 & & & 0.44 & 0.0013 & & 0.57 & & 0.11 & & 0.1 & 0.19 & 0.95 & 34 & 0.08 & 25 & 0.12 & 28 & 1.89 & 24 & .4 & 0.0013 \\
\hline$[V$ & & & 0.50 & & & 0.4 & & 0.11 & & 0. & 0.14 & 0.71 & & 0.0 & & 0.07 & & 0.77 & & 8 & \\
\hline & & & 0.42 & 0.00 & & 0.5 & & 0.1 & & 0.3 & 0.17 & 0.8 & & 0.0 & & 0.10 & & 2.40 & & 9 & \\
\hline IK-7 & & & 0.69 & 0.00 & & 0.1 & & 0.0 & 0.026 & 0.1 & 0.14 & 0.72 & & 0. & & 0.03 & & 0.87 & 0.000 & .7 & \\
\hline $\mathrm{K} 8$ & & & 0.76 & 0.0023 & 0029 & 0.8 & 02 & 0.16 & 035 & & 0.22 & 1.0 & & 0.0 & 0.0030 & 0.15 & 0.0021 & 1.41 & 0.000 & .7 & 0.0023 \\
\hline IK_-9 & Mekong & 017 & 0.86 & 0.0026 & 0006 & 0.1 & 001 & 0.07 & 031 & 0. & 0.18 & 0.88 & 037 & 0.0 & 0.0010 & 0.05 & 0.0008 & 0.55 & 0.0000 & .8 & 0.0026 \\
\hline $\mathrm{IK} 10$ & Mekong & 0027 & 1.35 & 0.0040 & 00003 & 0.08 & 0001 & 0.06 & 0.008 & 0.0 & 0.11 & 0.54 & 0.0022 & 0.0 & 0.0002 & 0.01 & 0.0018 & 1.17 & 0.0000 & .3 & 0.0041 \\
\hline & Mekong & 0024 & 1.19 & 0.0036 & 00036 & 1.02 & .0001 & 0.10 & .021 & 0.1 & 0.17 & 0.85 & 0.0034 & 0.0 & 0.0023 & 0.11 & 0.0007 & 0.45 & 0.000006 & .9 & 0.0036 \\
\hline He & M & 0032 & 1.62 & 0.0049 & 00002 & 0.07 & .0002 & 0.12 & .016 & 0.0 & 0.15 & 0.74 & 0.0032 & 0.08 & 0.0005 & 0.03 & 0.0016 & 1.07 & 0.000014 & 3.8 & 0.0049 \\
\hline MK13 & Mekong & 0.0021 & 1.03 & 0.0031 & 0.00006 & 0.18 & 0.0002 & 0.12 & 0.011 & 0.06 & 0.16 & 0.80 & 0.0031 & 0.08 & 0.0006 & 0.03 & 0.0024 & 1.58 & 0.000020 & 3.9 & 0.0031 \\
\hline
\end{tabular}

CDI: Chronic Daily Intake (mg kg ${ }^{-1}$ b.w. day ${ }^{-1}$ ); THQ: Target Hazard Quotient; and HI: Chronic Hazard Index; ILCR: Incremental Lifetime Cancer Risk; $\sum$ ILCR: Cumulative Cancer Risk 
Table A3.6 (cont.) Indexes of non-cancer risk $(\mathrm{HI})$ and cancer risk $\left(\sum \mathrm{ILCR}\right)$ assessment in the river areas $(\mathrm{n}=101)$

\begin{tabular}{|c|c|c|c|c|c|c|c|c|c|c|c|c|c|c|c|c|c|c|c|c|}
\hline \multirow{2}{*}{ Area } & \multicolumn{3}{|c|}{ As } & \multicolumn{2}{|l|}{ Cd } & \multicolumn{2}{|c|}{ Co } & \multicolumn{2}{|c|}{$\mathbf{C u}$} & \multicolumn{2}{|c|}{ Mn } & \multicolumn{2}{|c|}{ Mo } & \multicolumn{2}{|c|}{$\mathbf{N i}$} & \multicolumn{3}{|c|}{$\mathbf{P b}$} & \multirow{2}{*}{ HI } & \multirow{2}{*}{$\sum$ ILCR } \\
\hline & CDI & THQ & ILCR & CDI & THQ & CDI & THQ & CDI & THQ & CDI & THQ & CDI & THQ & CDI & THQ & CDI & THQ & ILCR & & \\
\hline MK14 Mekong & 0.0024 & 1.18 & 0.0036 & 0.00005 & 0.15 & 0.0001 & 0.09 & 0.013 & 0.06 & 0.15 & 0.77 & 0.0031 & 0.08 & 0.0008 & 0.04 & 0.0009 & 0.61 & 0.000008 & 3.0 & 0.003 \\
\hline MK15 Mekong & 0.0021 & 1.03 & 0.0031 & 00016 & 0.47 & 0.0002 & 0.12 & 0.020 & 0.10 & 0.14 & 0.71 & .0027 & 0.07 & .0012 & 0.06 & 0.0009 & 0.63 & 0.000008 & 3.2 & 0.0031 \\
\hline 6 Mekong & 0013 & 0.67 & 0.0020 & 00019 & 0.54 & 0002 & 0.10 & 0.021 & 0.11 & 11 & 0.56 & .0024 & 0.06 & .0020 & 0.10 & 0.0002 & 0.16 & 0.000002 & 2.3 & .0020 \\
\hline MK17 Mekong & 0.0015 & 0.73 & 0.0022 & .00042 & 1.21 & 0.0002 & 0.11 & 0.046 & 0.23 & 0.19 & 0.95 & 0.0021 & 0.05 & 0.0045 & 0.23 & 0.0012 & 0.81 & 0.000010 & 4.3 & 0.0022 \\
\hline MK18 Mekong & 0.0019 & 0.93 & 0.0028 & 0.00026 & 0.76 & 0.0001 & 0.09 & 0.018 & 0.09 & 0.16 & 0.81 & 0.0030 & 0.08 & 0.0016 & 0.08 & 0.0004 & 0.29 & 0.000004 & 3.1 & 0.0028 \\
\hline MK19 Mekong & 0.0043 & 2.14 & 0.0064 & 0.00002 & 0.05 & 0.0002 & 0.16 & 0.018 & 0.09 & 0.16 & 0.80 & 0.0046 & 0.12 & 0.0005 & 0.02 & 0.0003 & 0.20 & 0.000003 & 3.6 & 0.0064 \\
\hline MK20 Mekong & 0.0022 & 1.11 & 0.0033 & 0.00007 & 0.19 & 0.0001 & 0.08 & 0.013 & 0.06 & 0.15 & 0.75 & 0.0029 & 0.07 & 0.0009 & 0.04 & 0.0021 & 1.39 & 0.000018 & 3.7 & 0.0034 \\
\hline MK21 Mekong & 0.0015 & 0.74 & 0.0022 & 0.00054 & 1.54 & 0.0002 & 0.13 & 0.016 & 0.08 & 0.18 & 0.91 & 0.0032 & 0.08 & 0.0015 & 0.08 & 0.0022 & 1.49 & 0.000019 & 5.0 & .0022 \\
\hline MK22 Mekong & 0.0009 & 0.47 & 0.0014 & .00053 & 1.53 & 0.0001 & 0.08 & 0.025 & 0.12 & 0.20 & 0.99 & 0.0046 & 0.12 & .0018 & 0.09 & 0.0005 & 0.34 & 0.000004 & 3.7 & .0014 \\
\hline MK23 Mekong & 0.0010 & 0.48 & 0.0014 & 0.00027 & 0.78 & 0.0001 & 0.04 & 0.020 & 0.10 & 0.11 & 0.56 & 0.0036 & 0.09 & .0009 & 0.04 & 0.0006 & 0.40 & 0.000005 & 2.5 & 0015 \\
\hline $24 \mathrm{M}$ & 0.0013 & 0.64 & 0.0019 & 0040 & 1.15 & 0.0001 & 0.08 & 0.025 & 0.13 & 0.16 & 0.79 & 0.0038 & 0.10 & 0.0026 & 0.13 & 0.0003 & 0.18 & 0.000 & 3.2 & .0019 \\
\hline ong & 0.0010 & 0.51 & .0015 & 00143 & 4.08 & 0.0003 & 0.19 & 0.029 & 0.15 & 0.19 & 0.95 & 0.0031 & 0.08 & 0.0036 & 0.18 & 0.0006 & 0.40 & 0.00 & 6.5 & .0015 \\
\hline ong & 0.0013 & 0.65 & .0020 & 0009 & 0.25 & 0.0001 & 0.08 & 0.014 & 0.07 & 0.12 & 0.61 & 0.0031 & 0.08 & .0012 & 0.06 & 0.0004 & 0.23 & 0.00 & 2.0 & .0020 \\
\hline MK27 Mekong & 0.0012 & 0.59 & 0.0018 & 0.00016 & 0.45 & 0.0002 & 0.13 & 0.020 & 0.10 & 0.22 & 1.08 & 0.0025 & 0.06 & 0.0025 & 0.12 & 0.0002 & 0.17 & 0.000002 & 2.7 & 0.0018 \\
\hline MK30 Mekong & 0.0018 & 0.88 & 0.0026 & 0.00004 & 0.11 & 0.0001 & 0.06 & 0.026 & 0.13 & 0.16 & 0.80 & 0.0025 & 0.06 & 0.0021 & 0.11 & 0.0008 & 0.52 & 0.000007 & 2.7 & 0.0027 \\
\hline 1 Mekong & 0.0021 & 1.06 & 0.0032 & 0.00009 & 0.27 & 0.0002 & 0.10 & 0.026 & 0.13 & 0.17 & 0.87 & 0.0036 & 0.09 & 0.0011 & 0.06 & 0.0003 & 0.18 & 0.000002 & 2.8 & 0.0032 \\
\hline MK32 Mekong & 0.0020 & 0.99 & 0.0030 & 0.00003 & 0.09 & 0.0002 & 0.12 & 0.020 & 0.10 & 0.14 & 0.69 & 0.0043 & 0.11 & 0.0009 & 0.04 & 0.0071 & 4.73 & 0.000060 & 6.9 & 0.0030 \\
\hline 3 Mekong & 0.0018 & 0.90 & 0.0027 & 0.00011 & 0.31 & 0.0002 & 0.11 & 0.016 & 0.08 & 0.14 & 0.69 & 0.0070 & 0.17 & .0011 & 0.05 & 0.0012 & 0.77 & 0.000010 & 3.1 & 0027 \\
\hline Mekong & 0.0009 & 0.43 & 0.0013 & 0.00083 & 2.38 & 0.0002 & 0.13 & 0.031 & 0.16 & 0.19 & 0.96 & 0.0014 & 0.04 & .0049 & 0.24 & 0.0011 & 0.73 & 0.000009 & 5.1 & .0013 \\
\hline ong & 0.0012 & 0.62 & 0.0019 & 0011 & 0.31 & 0.0001 & 0.08 & 0.019 & 0.10 & 0.16 & 0.80 & 0.0018 & 0.05 & .0008 & 0.04 & 0.0042 & 2.82 & 0.00 & 4.8 & 0.0019 \\
\hline ong & 0.0006 & 0.30 & 0.0009 & 0050 & 1.43 & 0.0002 & 0.15 & 0.044 & 0.22 & 0.18 & 0.92 & 0.0039 & 0.1 & 0.0036 & 0.18 & 0.0009 & 0.63 & 0.0 & 3.9 & .0009 \\
\hline 37 Mekong & 0.0010 & 0.52 & 0.0016 & 00066 & 1.90 & 0.0003 & 0.20 & 0.028 & 0.14 & 0.18 & 0.91 & 0.0078 & 0.19 & 0.0032 & 0.16 & 0.0066 & 4.38 & 0.000056 & 8.4 & 0.0016 \\
\hline MK38 Mekong & 0.0014 & 0.70 & 0.0021 & .00015 & 0.42 & 0.0001 & 0.06 & 0.020 & 0.10 & 0.10 & 0.50 & 0.0032 & 0.08 & 0.0014 & 0.07 & 0.0003 & 0.17 & 0.000002 & 2.1 & 0.0021 \\
\hline MK40 Mekong & 0.0019 & 0.96 & 0.0029 & 0.00047 & 1.35 & 0.0002 & 0.10 & 0.019 & 0.09 & 0.18 & 0.89 & 0.0034 & 0.08 & 0.0014 & 0.07 & 0.0010 & 0.65 & 0.000008 & 4.2 & 0.0029 \\
\hline MK41 Mekong & 0.0017 & 0.83 & 0.0025 & .00014 & 0.40 & 0.0002 & 0.16 & 0.014 & 0.07 & 0.16 & 0.82 & 0.0035 & 0.09 & 0.0127 & 0.63 & 0.0011 & 0.77 & 0.000010 & 3.8 & 0.0025 \\
\hline MK42 Mekong & 0.0013 & 0.65 & 0.0019 & 0.00032 & 0.93 & 0.0002 & 0.13 & 0.028 & 0.14 & 0.16 & 0.81 & 0.0028 & 0.07 & 0.0028 & 0.14 & 0.0009 & 0.62 & 0.000008 & 3.5 & 0.0020 \\
\hline MK43 Mekong & 0.0010 & 0.49 & 0.0015 & 0.00043 & 1.24 & 0.0004 & 0.28 & 0.024 & 0.12 & 0.19 & 0.93 & 0.0025 & 0.06 & 0.0061 & 0.31 & 0.0003 & 0.17 & 0.000002 & 3.6 & 0.0015 \\
\hline MK44 Mekong & 0.0012 & 0.58 & 0.0018 & 0.00023 & 0.66 & 0.0002 & 0.11 & 0.020 & 0.10 & 0.11 & 0.54 & 0.0043 & 0.11 & 0.0024 & 0.12 & 0.0004 & 0.27 & 0.000003 & 2.5 & 0.0018 \\
\hline 45 Mekong & 0.0015 & 0.77 & 0.0023 & 0019 & 0.55 & 0.0001 & 0.06 & 0.023 & 0.11 & 0.14 & 0.68 & 0.0017 & 0.04 & 0.0020 & 0.10 & 0.0007 & 0.45 & 0.000 & 2.8 & 0.0023 \\
\hline kong & 0.0017 & 0.85 & 0.0025 & .00003 & 0.08 & 0.0001 & 0.05 & 0.015 & 0.0 & 0.11 & 0.56 & 0.0010 & 0.0 & 0.0013 & 0.07 & 0.0004 & 0.30 & 0.00 & 2.0 & .0025 \\
\hline 47 Mekong & 0.0019 & 0.94 & 0.0028 & .00008 & 0.22 & 0.0001 & 0.10 & 0.010 & 0.0 & 0.19 & 0.95 & 0.0025 & 0.0 & 0.0048 & 0.24 & 0.0003 & 0.21 & 0.000003 & 2.8 & 0.0028 \\
\hline MK48 Mekong & 0.0013 & 0.65 & 0.0020 & 00038 & 1.08 & 0.0004 & 0.24 & 0.030 & 0.15 & 0.12 & 0.60 & 0.0040 & 0.10 & 0.0111 & 0.55 & 0.0002 & 0.12 & 0.000002 & 3.5 & 0.0020 \\
\hline 49 Mekong & 0.0012 & 0.62 & 0.0019 & 00028 & 0.79 & 0.0002 & 0.12 & 0.029 & 0.14 & 0.15 & 0.75 & 0.0016 & 0.04 & 0.0031 & 0.15 & 0.0068 & 4.51 & 0.000058 & 7.1 & 0.0019 \\
\hline 51 Mekong & 0.0029 & 1.43 & 0.0043 & .00002 & 0.06 & 0.0002 & 0.12 & 0.011 & 0.05 & 0.15 & 0.76 & 0.0041 & 0.10 & 0.0011 & 0.05 & 0.0015 & 1.00 & 0.000013 & 3.6 & 0.0043 \\
\hline MK52 M & 0.0009 & 0.47 & 0.0014 & 0.00011 & 0.31 & 0.0006 & 0.39 & 0.022 & 0.11 & 0.14 & 0.71 & 0.0013 & 0.03 & 0.0046 & 0.23 & 0.0015 & 1.00 & 0.000013 & 3.3 & 0.0014 \\
\hline MK53 Mekong & 0.0017 & 0.85 & 0.0026 & 0.00032 & 0.92 & 0.0002 & 0.12 & 0.029 & 0.15 & 0.13 & 0.66 & 0.0021 & 0.05 & 0.0019 & 0.09 & 0.0005 & 0.36 & 0.000005 & 3.2 & 0.0026 \\
\hline
\end{tabular}

CDI: Chronic Daily Intake (mg kg ${ }^{-1}$ b.w. day ${ }^{-1}$ ); THQ: Target Hazard Quotient; and HI: Chronic Hazard Index; ILCR: Incremental Lifetime Cancer Risk; $\sum$ ILCR: Cumulative Cancer Risk 
Appendix A3

Table A3.6 Indexes of non-cancer risk (HI) and cancer risk ( $\left.\sum \mathrm{ILCR}\right)$ assessment in the river areas $(\mathrm{n}=101)$

\begin{tabular}{|c|c|c|c|c|c|c|c|c|c|c|c|c|c|c|c|c|c|c|c|c|c|}
\hline & \multirow{2}{*}{ Area } & \multicolumn{3}{|c|}{ As } & \multicolumn{2}{|l|}{ Cd } & \multicolumn{2}{|c|}{ Co } & \multicolumn{2}{|c|}{$\mathbf{C u}$} & \multicolumn{2}{|c|}{ Mn } & \multicolumn{2}{|c|}{ Mo } & \multicolumn{2}{|c|}{$\mathbf{N i}$} & \multicolumn{3}{|c|}{$\mathbf{P b}$} & \multirow{2}{*}{ HI } & \multirow{2}{*}{$\sum$ ILCR } \\
\hline & & CDI & THQ & ILCR & CDI & THQ & CDI & THQ & CDI & THQ & CDI & THQ & $\mathrm{CDI}$ & THQ & $\mathrm{CDI}$ & THQ & CDI & THQ & ILCR & & \\
\hline MK5 & Mekong & 0.0013 & 0.67 & 0.0020 & 0.00029 & 0.83 & 0.0002 & 0.16 & 0.026 & 0.13 & 0.18 & 0.88 & 0.0037 & 0.09 & 0.0033 & 0.17 & 0.0012 & 0.81 & 0.000010 & 3.7 & 0.0020 \\
\hline $\mathrm{M}$ & Mekong & 0.0019 & 0.97 & 0.0029 & 0.00003 & 0.07 & 0.0002 & 0.14 & 0.053 & 0.26 & 0.17 & 0.84 & 0031 & 0.08 & 0.0018 & 0.09 & 0.0010 & 0.70 & 0.000009 & 3.2 & 0.0029 \\
\hline & Mekong & 0011 & 0.53 & 0.0016 & .00035 & 1.01 & 0002 & 0.12 & 0.024 & 0.12 & 0.14 & 0.69 & .0036 & 0.09 & .0039 & 0.20 & 0.0014 & 0.96 & 0.000012 & 3.7 & 0.0016 \\
\hline MK & Mekong & 0015 & 0.73 & 0.0022 & 0.00017 & 0.50 & .0001 & 0.09 & 0.024 & 0.12 & 0.16 & 0.80 & 0.0031 & 0.08 & 0.0016 & 0.08 & 0.0015 & 1.03 & 0.000013 & 3.4 & 0.0022 \\
\hline MK & Mekong & 0.0011 & 0.54 & 0.0016 & 0.00010 & 0.29 & 0.0001 & 0.09 & 0.030 & 0.15 & 0.19 & 0.94 & 0.0025 & 0.06 & 0.0021 & 0.10 & 0.0010 & 0.63 & 0.000008 & 2.8 & 0.0016 \\
\hline MK & Mekong & 0.0009 & 0.43 & 0.0013 & 0.00008 & 0.23 & 0.0001 & 0.09 & 0.028 & 0.14 & 0.11 & 0.56 & 0.0039 & 0.10 & 0.0024 & 0.12 & 0.0022 & 1.45 & 0.000018 & 3.1 & 0.0013 \\
\hline MK6C & Mekong & 0.0014 & 0.71 & 0.0021 & 0.00042 & 1.20 & 0.0002 & 0.10 & 0.023 & 0.11 & 0.18 & 0.89 & 0.0042 & 0.11 & 0.0026 & 0.13 & 0.0002 & 0.15 & 0.000002 & 3.4 & 0.0021 \\
\hline MK6 & Mekong & 0.0010 & 0.49 & 0.0015 & 0.00087 & 2.49 & 0.0002 & 0.15 & 0.028 & 0.14 & 0.20 & 1.01 & 0.0029 & 0.07 & 0.0046 & 0.23 & 0.0003 & 0.18 & 0.000002 & 4.8 & 0.0015 \\
\hline MK62 & Mekong & 0.0010 & 0.51 & 0.0015 & 0.00042 & 1.19 & 0.0001 & 0.07 & 0.020 & 0.10 & 0.18 & 0.89 & 0.0028 & 0.07 & 0.0016 & 0.08 & 0.0003 & 0.20 & 0.000003 & 3.1 & 0.0015 \\
\hline MK6. & Mekong & 0.0018 & 0.90 & 0.0027 & 0.00038 & 1.08 & 0.0005 & 0.32 & 0.024 & 0.12 & 0.16 & 0.78 & 0.0021 & 0.05 & 0.0226 & 1.13 & 0.0032 & 2.12 & 0.000027 & 6.5 & 0.0027 \\
\hline MK & Mekong & 0007 & 0.33 & 0.0010 & 0.00075 & 2.15 & 0.0009 & 0.59 & 0.038 & 0.19 & 0.19 & 0.94 & 0.0010 & 0.02 & 0.0160 & 0.80 & 0.0002 & 0.14 & 0.000002 & 5.2 & 0.0010 \\
\hline $\mathrm{MK}$ & Mekong & 0010 & 0.50 & 0.0015 & 0.00002 & 0.06 & 0.0001 & 0.06 & 0.011 & 0.05 & 0.11 & 0.57 & 0.0008 & 0.02 & 0.0020 & 0.10 & 0.0004 & 0.28 & 0.000004 & 1.6 & 0.0015 \\
\hline $\mathrm{MK}$ & Mekong & 0016 & 0.82 & 0.0025 & .00001 & 0.03 & 0001 & 0.07 & 0.011 & 0.05 & 0.12 & 0.59 & 0.0009 & 0.02 & 0.0023 & 0.12 & 0.0039 & 2.60 & 0.000033 & 4.3 & 0.0025 \\
\hline MK & Mekong & 0.0008 & 0.42 & 0.0013 & 0.00124 & 3.54 & 0.0002 & 0.13 & 0.041 & 0.20 & 0.20 & 0.98 & 0.0032 & 0.08 & 0.0031 & 0.15 & 0.0002 & 0.15 & 0.000002 & 5.7 & 0.0013 \\
\hline МК68 & Mekong & .0009 & 0.47 & 0.0014 & 0.00135 & 3.87 & 0.0002 & 0.13 & 0.033 & 0.17 & 0.21 & 1.03 & 0.0032 & 0.08 & 0.0027 & 0.14 & 0.0004 & 0.30 & 0.000004 & 6.2 & 0.0014 \\
\hline MK & Mekong & 0.0006 & 0.29 & 0.0009 & 0.00082 & 2.33 & 0.0001 & 0.07 & 0.043 & 0.22 & 0.16 & 0.82 & 0.0030 & 0.08 & 0.0047 & 0.24 & 0.0045 & 3.02 & 0.000039 & 7.1 & 0.0009 \\
\hline MK7C & Mekong & 0.0007 & 0.37 & 0.0011 & 0.00021 & 0.60 & 0.0001 & 0.05 & 0.017 & 0.09 & 0.18 & 0.90 & 0.0022 & 0.05 & 0.0008 & 0.04 & 0.0004 & 0.26 & 0.000003 & 2.4 & 0.0011 \\
\hline MK7 & Mekong & 0.0007 & 0.34 & 0.0010 & 0.00027 & 0.78 & 0.0001 & 0.05 & 0.020 & 0.10 & 0.21 & 1.03 & 0.0027 & 0.07 & 0.0010 & 0.05 & 0.0023 & 1.55 & 0.000020 & 4.0 & 0.0011 \\
\hline MK & Mekong & 0.0008 & 0.40 & 0.0012 & 0.00019 & 0.53 & 0.0001 & 0.09 & 0.032 & 0.16 & 0.13 & 0.64 & 0.0063 & 0.16 & 0.0021 & 0.11 & 0.0006 & 0.39 & 0.000005 & 2.5 & 0.0012 \\
\hline $\mathrm{Ml}$ & Mekong & 0.0006 & 0.32 & 0.0010 & 0.00023 & 0.66 & 0.0002 & 0.13 & 0.032 & 0.16 & 0.17 & 0.86 & .0046 & 0.12 & 0.0027 & 0.14 & 0.0002 & 0.10 & 0.000001 & 2.5 & 0010 \\
\hline & ong & 0010 & 0.48 & 0.0014 & 0.00012 & 0.36 & 0.0002 & 0.12 & 0.033 & 0.17 & 0.19 & 0.97 & 0.0031 & 0.08 & 0.0026 & 0.13 & 0.0006 & 0.39 & 05 & 2.7 & 014 \\
\hline MK & Mekong & 0009 & 0.45 & 0.0013 & .00012 & 0.33 & 0.0002 & 0.15 & 0.023 & 0.12 & 0.19 & 0.93 & 0.0040 & 0.10 & 0.0016 & 0.08 & 0.0005 & 0.35 & 0.000004 & 2.5 & 0.0013 \\
\hline $\mathrm{MK}^{\prime}$ & Mekong & 0011 & 0.54 & 0.0016 & 0.00007 & 0.19 & 0.0001 & 0.10 & 0.027 & 0.13 & 0.12 & 0.60 & 0.0025 & 0.06 & 0.0034 & 0.17 & 0.0005 & 0.31 & 0.000004 & 2.1 & 0.0016 \\
\hline MK7 & Mekong & 0.0031 & 1.55 & 0.0047 & 0.00018 & 0.50 & 0.0003 & 0.17 & 0.018 & 0.09 & 0.11 & 0.57 & 0.0035 & 0.09 & 0.0040 & 0.20 & 0.0004 & 0.24 & 0.000003 & 3.4 & 0.0047 \\
\hline MK 7 & Mekong & 0.0013 & 0.66 & 0.0020 & 0.00014 & 0.40 & 0.0003 & 0.21 & 0.031 & 0.15 & 0.13 & 0.63 & 0.0041 & 0.10 & 0.0029 & 0.15 & 0.0004 & 0.29 & 0.000004 & 2.6 & 0.0020 \\
\hline $\mathrm{MK}^{\prime}$ & Mekong & 0.0008 & 0.42 & 0.0012 & 0.00029 & 0.81 & 0.0004 & 0.24 & 0.027 & 0.14 & 0.14 & 0.70 & 0.0042 & 0.11 & 0.0073 & 0.37 & 0.0003 & 0.18 & 0.000002 & 3.0 & 0.0013 \\
\hline MK8( & Mekong & 0.0006 & 0.32 & 0.0010 & 0.00054 & 1.54 & 0.0003 & 0.19 & 0.034 & 0.17 & 0.19 & 0.96 & 0.0027 & 0.07 & 0.0046 & 0.23 & 0.0004 & 0.25 & 0.000003 & 3.7 & 0.0010 \\
\hline MK8 & Mekong & 0.0012 & 0.61 & 0.0018 & 0.00010 & 0.28 & 0.0002 & 0.11 & 0.013 & 0.07 & 0.13 & 0.65 & 0.0024 & 0.06 & 0.0029 & 0.15 & 0.0007 & 0.44 & 0.000006 & 2.4 & 0.0018 \\
\hline MK8 & Mekong & 0.0008 & 0.39 & 0.0012 & 0.00018 & 0.51 & 0.0006 & 0.37 & 0.027 & 0.13 & 0.14 & 0.71 & 0.0013 & 0.03 & 0.0090 & 0.45 & 0.0002 & 0.14 & 0.000002 & 2.7 & 0.0012 \\
\hline
\end{tabular}

CDI: Chronic Daily Intake (mg kg-1 b.w. day $\left.{ }^{-1}\right)$; THQ: Target Hazard Quotient; and HI: Chronic Hazard Index; ILCR: Incremental Lifetime Cancer Risk; $\sum$ ILCR: Cumulative Cancer Risk 


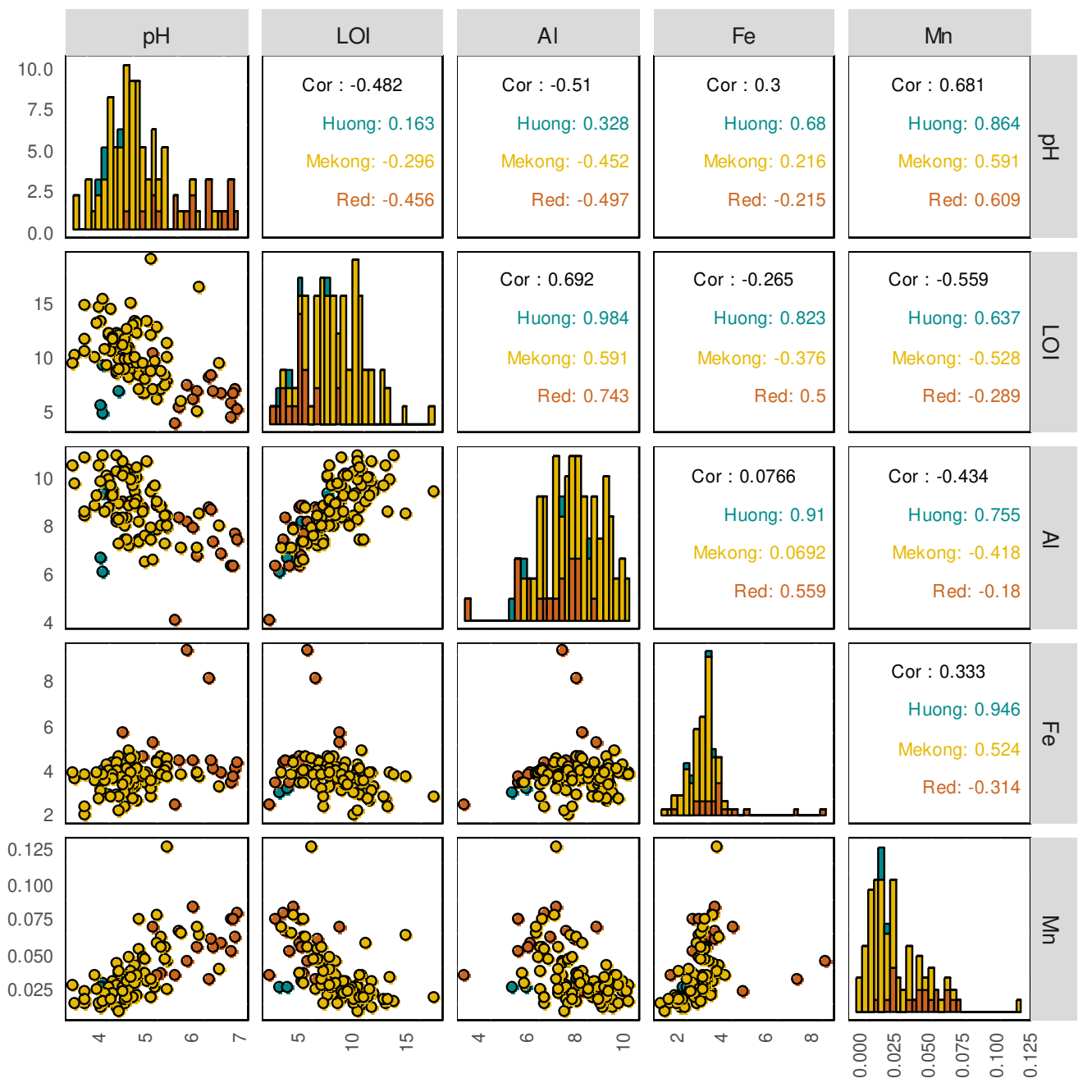

Fig. A3.1 Correlation matrix of the soil parameters $\mathrm{pH}, \mathrm{LOI}, \mathrm{Al}, \mathrm{Fe}$, and $\mathrm{Mn}$ (wt. \%) in the different river area 

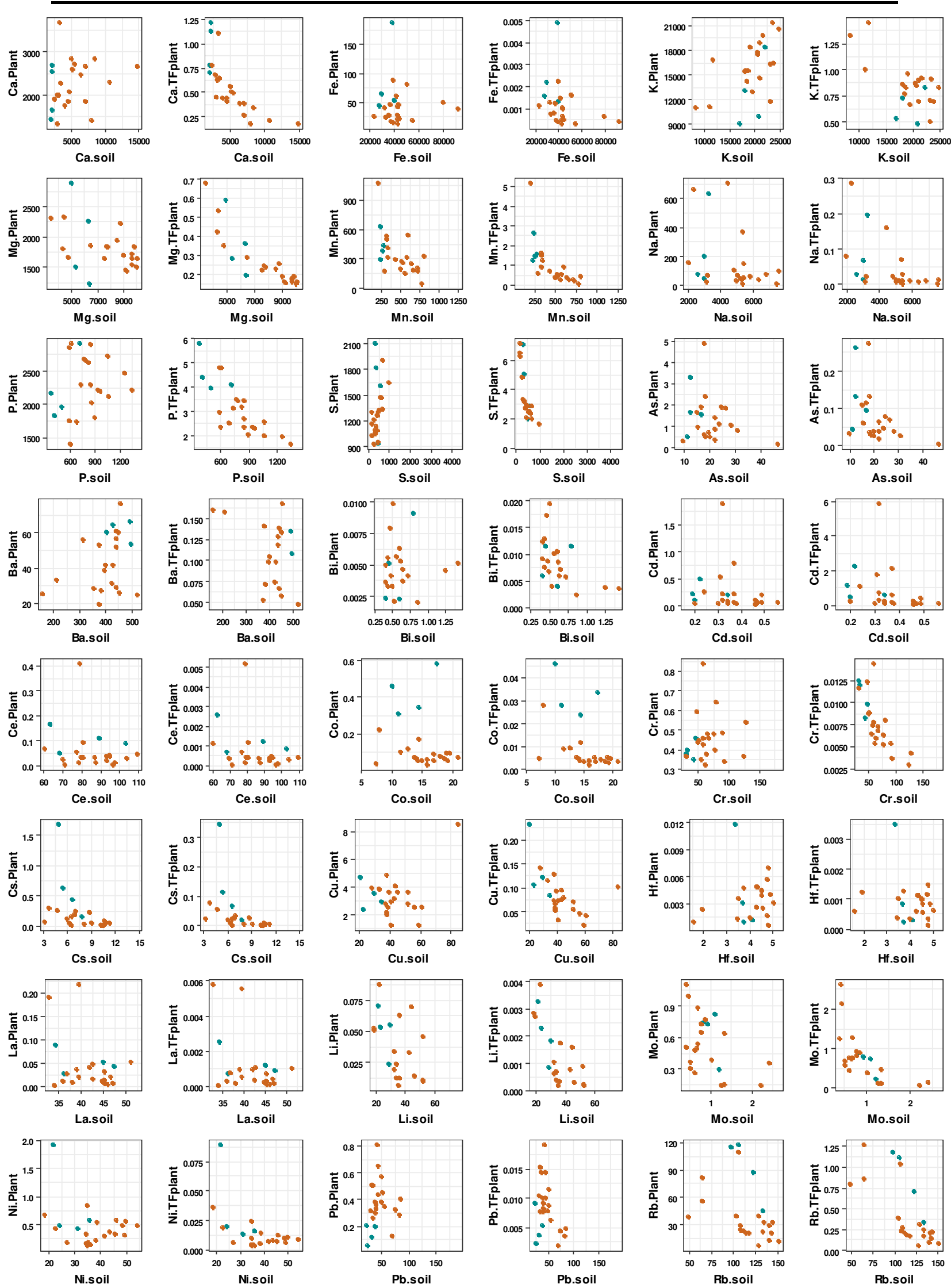

Fig. A3.2 Correlation plots of plant element concentrations $\left(\mathrm{mg} \mathrm{kg}^{-1}\right)$ and plant transfer factors versus their soil concentrations ( $\mathrm{mg} \mathrm{kg}^{-1}$ ). The red dots represent the Red River samples, the blue dots the Huong River samples 

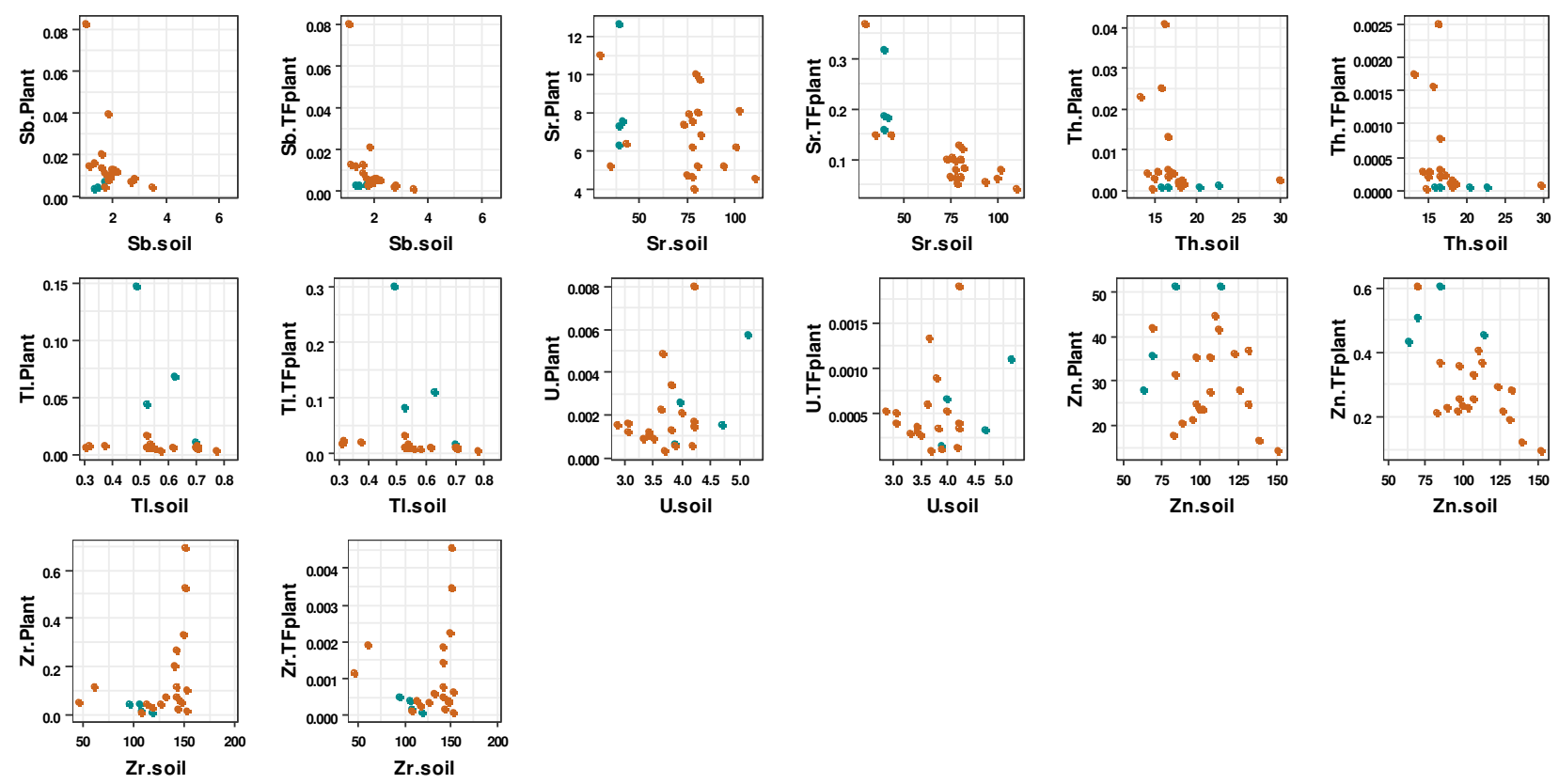

Fig. A3.2 (cont.) Correlation plots of plant element concentrations $\left(\mathrm{mg} \mathrm{kg}^{-1}\right)$ and plant transfer factors versus their soil concentrations $\left(\mathrm{mg} \mathrm{kg}^{-1}\right)$. The red dots represent the Red River samples, the blue dots the Huong River samples 

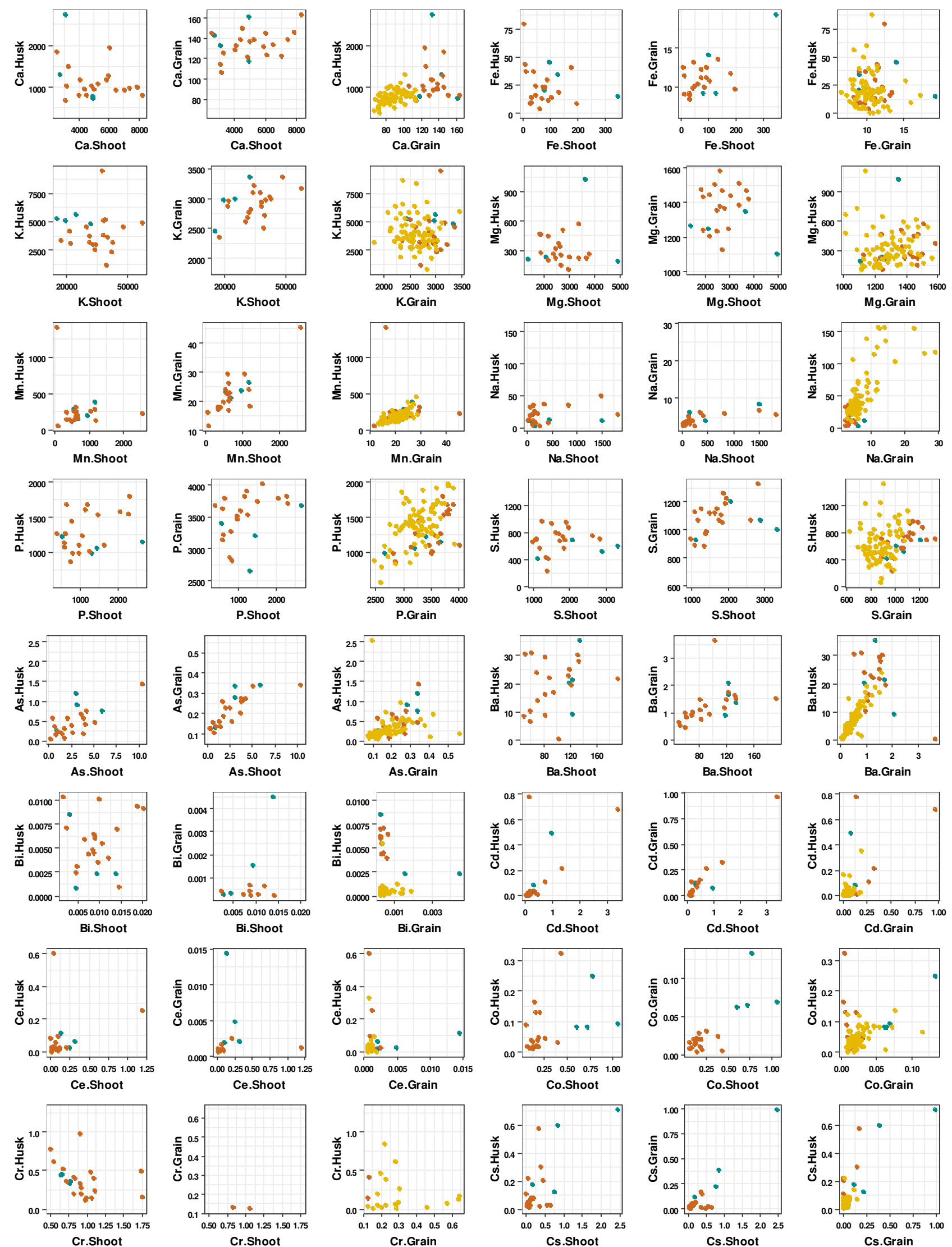

Fig. A3.3 Correlation plots between element concentrations in grain, husk and shoot ( $\left.\mathrm{mg} \mathrm{kg}^{-1}\right)$. The red dots represent Red River samples, the blue dots the Huong River samples, and the yellow dots the Mekong samples 

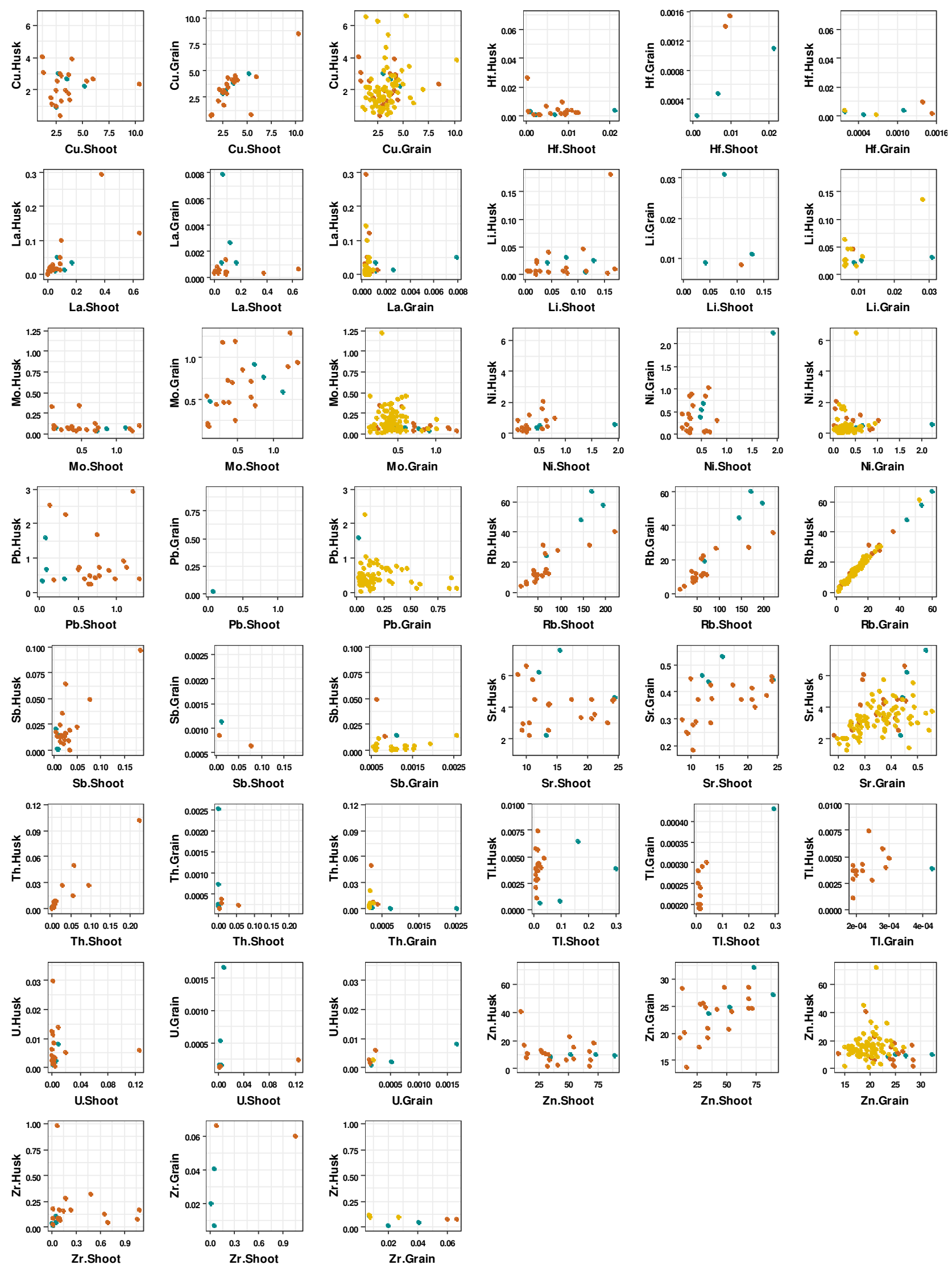

Fig. A3.3 (cont.) Correlation plots between element concentrations in grain, husk and shoot (mg kg${ }^{1}$ ). The red dots represent Red River samples, the blue dots the Huong River samples, and the yellow dots the Mekong samples 

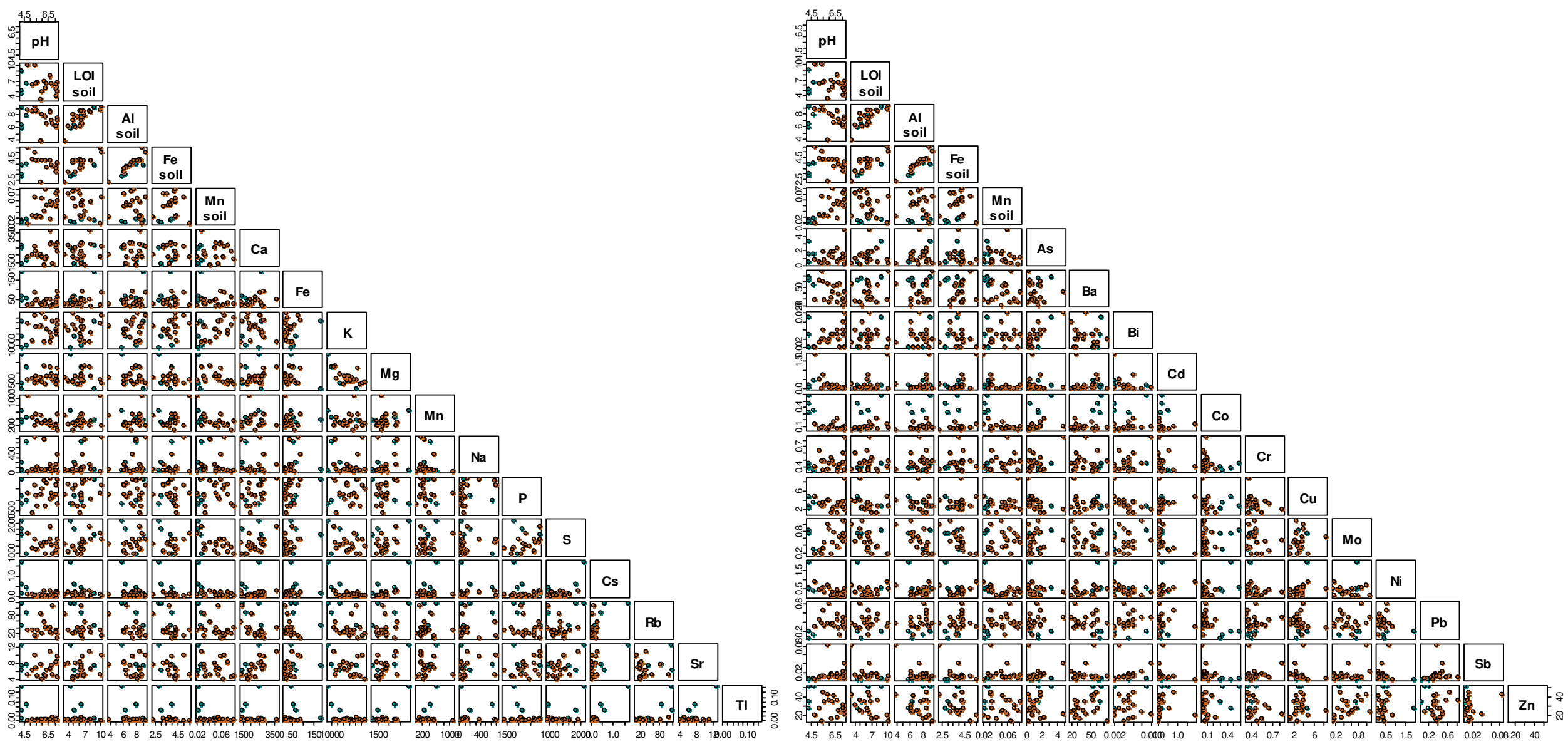

Fig. A3.4 Correlation plot matrix between plant element concentrations $\left(\mathrm{mg} \mathrm{kg}^{-1}\right)$ and soil parameters (pH, LOI, $\mathrm{Al}, \mathrm{Fe}$, and $\mathrm{Mn}$ in wt. \%) 

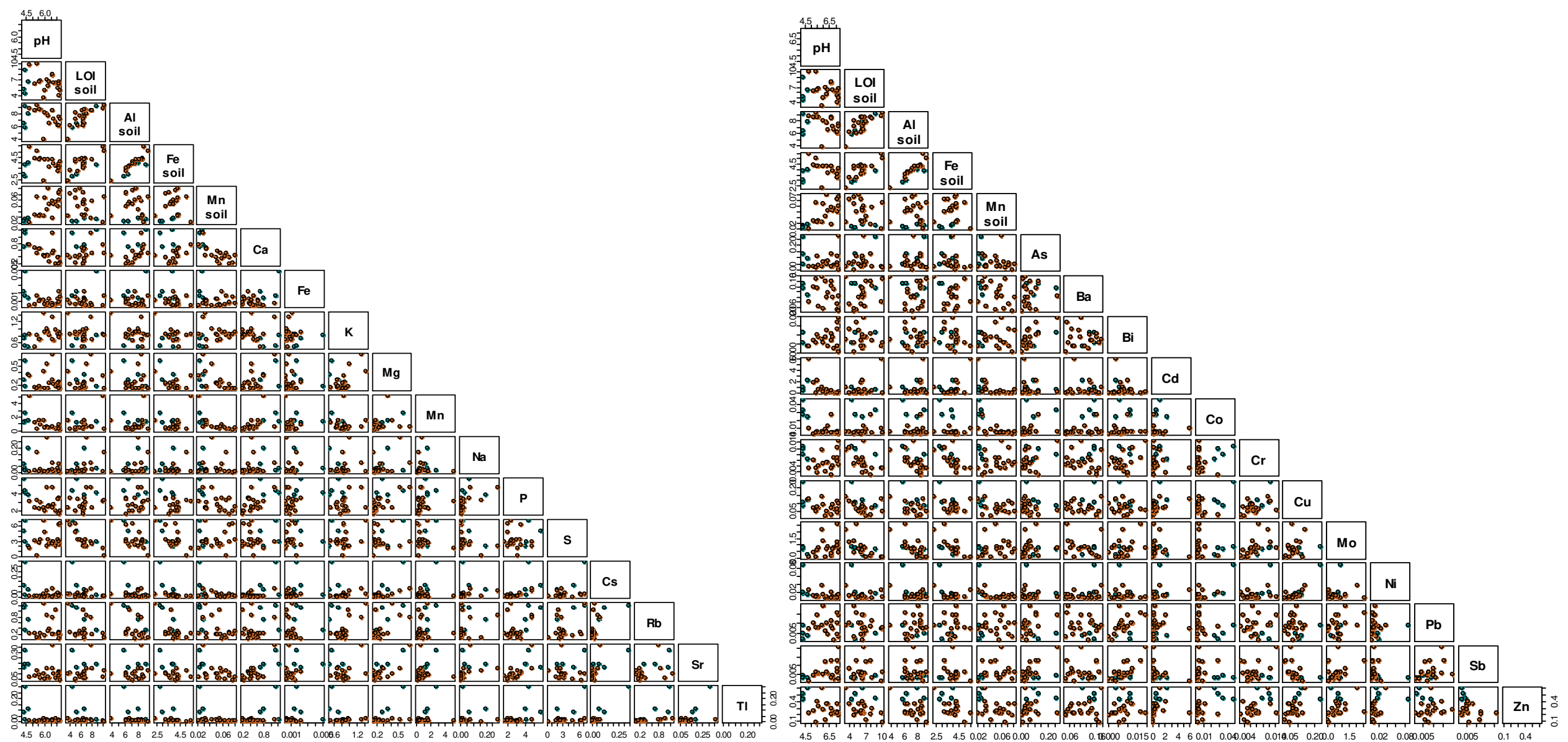

Fig. A3.5 Correlation plot matrix between plant transfer factors and soil parameters (pH, LOI, $\mathrm{Al}, \mathrm{Fe}$, and $\mathrm{Mn}$ in wt. \%) 


\section{Curriculum Vitae}

\section{Personal information}

Full Name:

NGUYEN, THUY PHUONG

Gender:

Female

Date of birth:

12.02.1985

Nationality: $\quad$ Vietnamese

E-mail: $\quad$ nguyenthuyphuong@ @ huaf.edu.vn

thuyphuong.nguyen@geo.uni-goettingen.de

\section{Academic background}

2004 - 2008: $\quad$ Bachelor of Organic Chemistry, Hue University of Sciences, Viet Nam

2009 - 2011: $\quad$ Master of Physical Chemistry, Hue University of Sciences, Viet Nam

2015 - now: $\quad$ PhD student in Sedimentology/Encvironmental Geoscience, Geoscience and Geography, Georg-August Göttingen University, Germany

\section{International conference contributions}

Poster presentation

Nguyen, T. P., Ruppert, H., Sauer, B. (2016). A review of a status of heavy metal contamination in Paddy Field in Vietnam. In: Book of Abstracts of the 9th GeoSymposium of Young Researchers Silesia 2016, Kroczyce, Poland, p. 92 (ISBN 978-83-934005-9-1).

Nguyen, T. P., Ruppert, H., Pasold, T., Fahlbusch, W., Sauer, B., (2018). The transfer of critical elements from soils to rice grains in the Mekong River delta area, Vietnam”. EGU General Assembly 2018, Vienna, Austria. EGU2018-4709.

\section{Working experience}

2009 - now: $\quad$ Lecturer at Faculty of Land Resources and Agricultural Environment, Hue University of Agriculture and Forestry 


\section{Publication}

Nguyen, T. P., Ruppert, H., Sauer, B., \& Pasold, T. (2019). Harmful and nutrient elements in paddy soils and their transfer into rice grains (Oryza sativa) along two river systems in northern and central Vietnam. Environmental Geochemistry and Health, pp. 1-17. https://doi.org/10.1007/s10653-019-00333-32012.

Nguyen, T. P., Ruppert, H., Sauer, B., \& Pasold, T. (2019). Paddy soil geochemistry, uptake of trace elements by rice grains (Oryza sativa), and resulting in health risks in the Mekong River Delta, Vietnam. Environmental Geochemistry and Health. Submitted manuscript in a state of "minor revision".

Nguyen, T. P., Ruppert, H., Sauer, B., \& Pasold, T. (2019). Transfer of nutrient and toxic elements from paddy soils into rice plant parts (Oryza sativa) in Vietnam and health risk assessments for the population. Environmental Science and Pollution Research. Submitted manuscript in a state of "under reviewing".

\section{Scholarship awarded}

- Vietnamese Overseas Scholarship Program

- Geo-Gender-Chancenfonds of Faculty Geoscience and Geography: Conference and Research

- Support of University Federation (Unibund) of Georg-August-University Göttingen (German education). 